Universidade de São Paulo

Escola de Engenharia de São Carlos

Departamento de Engenharia Elétrica

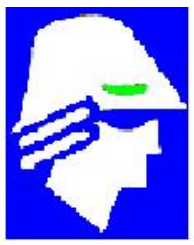

\title{
Avaliação DA LoCOMOÇÃo DO ParapléGico SOB Estimulação Elétrica Neuromuscular
}

Autor: Juracy Emanuel Magalhães da Franca

Orientador: Alberto Cliquet Jr.

Dissertação apresentada à Escola de Engenharia de São Carlos da Universidade de São Paulo, como parte dos requisitos para a obtenção do título de Mestre em Engenharia Elétrica.

São Carlos

Novembro de 2003 
Ficha Catalográfica - Biblioteca 
Folha de Aprovação - Biblioteca 
Dedico tudo o que sou e tenho à minha família. 
"Que os vossos esforços desafiem as impossibilidades. Lembrai-vos de que as grandes proezas da história foram conquistadas do que parecia impossível."

(Charlie Chaplin) 


\section{Resumo}

Este trabalho apresentará um projeto cujo propósito foi definir um protocolo de avaliação para pacientes paraplégicos sob terapia, através do uso de estimulação elétrica neuromuscular, no Ambulatório de Ortopedia do Hospital das Clínicas da Universidade de Campinas. A análise proposta servirá tanto para o acompanhamento da evolução dos pacientes, quanto, principalmente, para avaliação dos sistemas de reabilitação desenvolvidos pelo Laboratório de Biocibernética e Engenharia de Reabilitação na Escola de Engenharia de São Carlos. Neste trabalho o protocolo foi aplicado especificamente para descrever a locomoção do paraplégico usando a estimulação padrão de 4 canais, que realiza a ativação dos quadríceps para extensão das pernas, necessária para o suporte do corpo, e a ativação do reflexo de retirada através da estimulação do nervo fibular para a flexão necessária para a fase de balanço. A análise usou como referência o conhecimento relacionado à descrição das fases e estratégias usadas pela locomoção do ser humano intacto. O protocolo de avaliação usou recursos do Laboratório de Biomecânica e Reabilitação do Aparelho Locomotor, situado no hospital citado acima, que permitiram a descrição da cinemática dos membros superiores e inferiores, da atividade muscular realizada pelos membros superiores, e das forças de reação do solo.

Palavras-chave: Locomoção, paraplegia, biomecânica, EENM, FES. 


\section{Abstract}

This work present a case study on the use of the motion analysis laboratory resources (three-dimensional motion capture system, EMG, and force plate) with the purpose of improve the use of surface electrical stimulation to enable the locomotion in paraplegic subjects. Five trials for each of the five patients (thoracic complete spinal cord lesion) using a four channel electrical stimulator was done for synchronously acquisition of: 3D coordinates of 30 markers distributed on the whole body (to evaluate the stride's characteristics and three-dimensional measurements of angles of whole-body); EMG signal, on both sides, of triceps brachii long head, pectoralis major, middle deltoideus, extensor carpi radialis; and the vertical component of the ground reaction force. All data were normalized on the right gait cycle. The analysis was done braking the cycle in 11 events related with the swing phase in both sides, because it was focused firstly in the actions related with the swing limb and upper body advance, that represents a critical factor in locomotion aided by electrical stimulation. These events divided the gait cycle in 10 phases, which was used for associate the data evaluated with specifics tasks. The results showed temporal parameters similar to that reported by other authors, specific characteristics of the patient, the mechanism used by the patient for advance the body, and the periods of high activity of the muscles on the cycle.

Key Words: Locomotion, biomechanics, SCI, NMES, FES. 


\section{Sumário}

Resumo vii

Abstract viii

1 Introdução 1

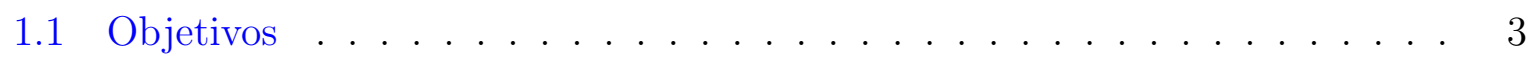

1.1 .1 Objetivo geral . . . . . . . . . . . . . . . 3

1.1 .2 Objetivo específico . . . . . . . . . . . . 3

2 Locomoção do Paraplégico $\quad 4$

2.1 Perspectivas . . . . . . . . . . . . . . . . . . 4

2.2 Requerimentos fundamentais da marcha . . . . . . . . . . . . . 5

2.3 Órteses híbridas . . . . . . . . . . . . . . . . . . . . 6

2.4 Marcha usando apenas a estimulação elétrica . . . . . . . . . . . . . . . 8

2.5 Exemplo: Parastep . . . . . . . . . . . . . . . . . . . . . . . . 9 9

2.6 Sistemas implantáveis . . . . . . . . . . . . . . . . . . . . . . . . . . . . . . . . . . . . .

2.7 Conclusão . . . . . . . . . . . . . . . . . . . . . . . . . . 14

3 Locomoção Normal $\quad 15$

3.1 Determinantes fundamentais da marcha . . . . . . . . . . . . . . . 15

3.2 Terminologia genérica para as fases funcionais da marcha . . . . . . . . . . 19

3.3 Características da passada . . . . . . . . . . . . . . . . . 20

3.4 Processamento da locomoção e suas variáveis . . . . . . . . . . . . . . . . . 21

3.5 Conclusão . . . . . . . . . . . . . . . . . . . . . . 27

4 Materiais e Métodos 29

4.1 Metodologia adotada para a descrição da locomoção . . . . . . . . . . . . . 29

4.2 Pacientes . . . . . . . . . . . . . . . . . . . . . 31

4.3 Estimulador elétrico . . . . . . . . . . . . . . . . . . 31

4.4 Cinemática . . . . . . . . . . . . . . . . . . . 32

4.5 Eletromiografia . . . . . . . . . . . . . . . . 44

4.6 Plataforma de força . . . . . . . . . . . . . . . . . . 50 
4.7 Montagem do laboratório . . . . . . . . . . . . . . . . . 51

4.8 Preparação do paciente . . . . . . . . . . . . . . . . . . . . . . 52

5 Resultados $\quad 53$

5.1 Características das passadas dos pacientes . . . . . . . . . . . 53

5.2 Descrição da locomoção do paciente A . . . . . . . . . . . . . . . 54

5.3 Descrição da locomoção do paciente B . . . . . . . . . . . . . . . . . . 62

5.4 Descrição da locomoção do paciente $\mathbf{C} \ldots \ldots$. . . . . . . . . . . 71

5.5 Descrição da locomoção do paciente $\mathbf{D}$. . . . . . . . . . . . . . . . 79

5.6 Descrição da locomoção do paciente $\mathbf{E} \ldots \ldots$. . . . . . . . . 87

6 Discussão $\quad 95$

6.1 Comparação com referências . . . . . . . . . . . . . . . . . 95

6.2 Comentários gerais sobre os resultados obtidos . . . . . . . . . . . . . . . 99

7 Conclusão $\quad 101$

$\begin{array}{ll}\text { Referências Bibliográficas } & 102\end{array}$

$\begin{array}{ll}\text { A Paciente A } & 108\end{array}$

A.1 Características do paciente . . . . . . . . . . . . . . 108

A.2 Características da passada . . . . . . . . . . . . . . . . . . . 109

A.3 Variações angulares: tronco e membros inferiores . . . . . . . . . . . . . . . 110

A.4 Variações angulares: ombros e cotovelos . . . . . . . . . . . . . . 118

A.5 Eletromiografia . . . . . . . . . . . . . . . . . . . . 122

A.6 Componente vertical da força de reação do solo . . . . . . . . . . . . . 126

$\begin{array}{lr}\text { B Paciente B } & 127\end{array}$

B.1 Características do paciente . . . . . . . . . . . . . . . . . 127

B.2 Características da passada . . . . . . . . . . . . . . . . . . . 128

B.3 Variações angulares: tronco e membros inferiores . . . . . . . . . . . . . . 129

B.4 Variações angulares: ombros e cotovelos . . . . . . . . . . . . . . . . 137

B.5 Eletromiografia . . . . . . . . . . . . . . . . . . . . . 141

B.6 Componente vertical da força de reação do solo . . . . . . . . . . . . . . 145

$\begin{array}{lr}\text { C Paciente C } & 146\end{array}$

C.1 Características do paciente . . . . . . . . . . . . . . . 146

C.2 Características da passada . . . . . . . . . . . . . . . . . 147

C.3 Variações angulares: tronco e membros inferiores . . . . . . . . . . . . . . . 148

C.4 Variações angulares: ombros e cotovelos . . . . . . . . . . . . . . . . 156

C.5 Eletromiografia . . . . . . . . . . . . . . . . . 160 
C.6 Componente vertical da força de reação do solo . . . . . . . . . . . . . . . 164

D Paciente D

D.1 Características do paciente . . . . . . . . . . . . . . . 165

D.2 Características da passada . . . . . . . . . . . . . . 166

D.3 Variações angulares: tronco e membros inferiores . . . . . . . . . . . . . 167

D.4 Variações angulares: ombros e cotovelos . . . . . . . . . . . . . . . . . 175

D.5 Eletromiografia . . . . . . . . . . . . . . . . . . . 179

D.6 Componente vertical da força de reação do solo . . . . . . . . . . . . . . 183

$\begin{array}{lr}\text { E Paciente E } & 184\end{array}$

E.1 Características do paciente . . . . . . . . . . . . . . . . . . . . . . 184

E.2 Características da passada . . . . . . . . . . . . . . . . . . . . 185

E.3 Variações angulares: tronco e membros inferiores . . . . . . . . . . . . . 186

E.4 Variações angulares: ombros e cotovelos . . . . . . . . . . . . . . . . . 194

E.5 Eletromiografia . . . . . . . . . . . . . . . . . . . . . . . 198

E.6 Componente vertical da força de reação do solo . . . . . . . . . . . . . . . 202

$\begin{array}{ll}\text { Índice Remissivo } & 203\end{array}$ 


\section{Capítulo 1}

\section{Introdução}

Aproximadamente $65 \%$ de todas as pessoas com lesão medular tinham menos de 30 anos na época da lesão, e 45\% das causas da lesão nessa faixa etária são atribuídas a acidentes em veículos (Triolo, Kobetic \& Betz 1996). Outras causas freqüentes de lesão são acidentes com armas de fogo, em mergulhos, e no trabalho. Portanto, é um problema social importante, que afeta profundamente a vida de pessoas numa faixa etária produtiva, e cujas causas estão presentes intensamente no dia-a-dia da vida em nossa época, exigindo investimento no intuito de sanar tal problema, ou amenizar suas conseqüências.

Embora a paraplegia resultante da lesão da medula espinal fosse do conhecimento dos médicos egípcios há 5000 anos, durante a Primeira Guerra Mundial aproximadamente $80 \%$ de todos os soldados norte-americanos acometidos pela lesão medular faleceram antes de retornar para seus lares. No final da década de 30, do século XX, as causas mais comuns das mortes dos lesados medulares eram as infecções urinárias, e as escaras. Somente após a Segunda Guerra Mundial o tratamento de tais pacientes alcançou maior eficácia devido a melhores métodos de evacuação, transporte, avanços nas técnicas cirúrgicas e disponibilidade de terapia antimicrobial (Nene, Hermens \& Zilvold 1996). Atualmente a expectativa de vida destes pacientes está próxima daquela para a população normal. No entanto, no início do estabelecimento de centros de reabilitação para lesados medulares, na segunda metade do século XX, a deambulação não era, freqüentemente, considerada como uma alternativa viável (Mikelberg \& Reid 1981).

Garantida a sobrevivência de tais pacientes, estes enfrentam graves problemas psicológicos e físicos, devido à impossibilidade de levantarem-se e andarem. A mobilidade é realizada através de cadeiras de rodas que apresentam eficiência na relação entre a energia gasta e o deslocamento obtido, no entanto, impõem uma série de limitações como na locomoção sobre escadas e em áreas acidentadas. No tratamento clássico o uso de órteses mecânicas tem possibilitado ao paciente ficar em pé e andar, no entanto, poucos indivíduos utilizam tais órteses além do fim terapêutico, pois até as órteses mais avançadas impõem um alto esforço físico, limitações do movimento, dificuldades para vestimenta e 
retirada, além de apresentarem um alto custo. Do ponto de vista da evolução do paciente isto não permite uma visão otimista, ou seja, o paciente deverá cooperar, ser forte, e não esperar muito, tenderá a assumir uma postura de que sua vida dali para frente será sobre a cadeira de rodas.

Embora muitos grupos de pesquisa estejam em busca da cura da lesão medular, o uso da eletricidade para a realização da contração muscular está sendo intensivamente investigado na comunidade internacional no intuito de desenvolver sistemas que possam produzir movimentos funcionais como a locomoção. Recentemente, a mídia tem apresentado continuamente este tema, dando ênfase sempre aos testes com sistemas de estimulação implantados no corpo do paciente, como ocorre com o marca-passo. No entanto, ainda é necessário desenvolver muita pesquisa para que tais sistemas tornem-se viáveis e realmente funcionais. Há problemas relacionados com a interface entre o usuário e o equipamento, na otimização do controle do movimento e na segurança do paciente (pois os condutores internos estão sujeitos à fadiga mecânica e conseqüentemente a ser causa de infecção).

Porém, sistemas que utilizam eletrodos de superfície apresentam uma excelente opção para fins terapêuticos, embora possuam sérias limitações quanto ao seu uso. O uso de eletrodos de superfície acarreta no recrutamento de uma grande quantidade de fibras musculares para a realização de uma função, como flexão/extensão, em uma articulação. Além disso, não possibilitam usufruir a seletividade inata que a redundância e complexidade do sistema músculo-esquelético requer para seu perfeito funcionamento. Isso implica que tais sistemas possibilitam apenas um padrão rudimentar de movimentação, não somente a respeito de sua estética quanto também de sua duração, que é seriamente limitada devido à fadiga muscular acelerada conseqüente do intenso recrutamento das fibras.

No entanto, sistemas de estimulação elétrica neuromuscular (EENM) usando eletrodos de superfície, apresentam grandes benefícios aos lesados medulares, pois em relação aos implantados, que requerem um sofisticado procedimento cirúrgico, são muito mais acessíveis devido à sua simplicidade e ao custo envolvido. Em relação às órteses mecânicas, sua principal vantagem é que possibilita a ativação do metabolismo, e a utilização da estrutura músculo-esquelética da região do corpo que perdeu a conexão com o comando cerebral. Isto por sua vez apresenta benefícios que não estão restritos à área aplicada, mas a todo o corpo. Além disso, possui uma aparência melhor que o uso da órtese mecânica e maior facilidade para vestimenta.

Sistemas de EENM de superfície ainda estão em processo de amadurecimento. O mais famoso, chamado Parastep, funciona basicamente seguindo os mesmos princípios dos primeiros sistemas desenvolvidos para possibilitar a marcha recíproca através da EENM. Este sistema usa 4 canais de estimulação (quadríceps e nervo fibular, bilateralmente), podendo ser acrescentado 2 canais aos músculos glúteos. Ou seja, realiza a flexão das três articulações da perna, necessária para possibilitar seu balanço, através da ativação 
do reflexo de retirada, que representa o marco inicial do uso da estimulação elétrica para um fim funcional (possibilitando ao hemiplégico realizar a dorsiflexão durante a fase de balanço). Isto por sua vez representa uma séria limitação no sistema sob o ponto de vista de desempenho, pois está associado há uma movimentação irregular da perna de balanço, e aos problemas conseqüentes da habituação nervosa. Mas, possui a vantagem de estimular os circuitos primitivos de geração de padrões associados à marcha presentes na medula.

Para obter um desempenho melhor da marcha obtida por EENM de superfície, usam-se mais canais de estimulação para ativar os grupos musculares responsáveis pela flexão/extensão das articulações da perna (quadris, joelhos e tornozelos). Associado a esse propósito está a necessidade de definir estratégias de controle que garantam a mobilidade eficiente de cada segmento ao longo das fases da marcha.

Tanto para sistemas de EENM de superfície, quanto implantáveis, há a necessidade da avaliação dos seus desempenhos com o intuito de possibilitar seus aperfeiçoamentos.

Este trabalho pretende gerar uma contribuição para o desenvolvimento de sistemas de EENM através da definição de um procedimento para a avaliação dos seus desempenhos. Partindo do princípio que para entender a locomoção do lesado medular é necessário entender as estratégias associadas à locomoção natural.

\section{$1.1 \quad$ Objetivos}

\subsubsection{Objetivo geral}

- Descrever a locomoção, com auxílio de estimulação elétrica neuromuscular de superfície (4 canais) e andador, de 5 pacientes paraplégicos, com lesão torácica, usando os equipamentos disponíveis no Laboratório de Biomecânica e Reabilitação do Aparelho Locomotor : sistema de captura tridimensional do movimento, eletromiógrafo e plataforma de força;

\subsubsection{Objetivo específico}

- A descrição da locomoção de cada paciente consistiu em apresentar bilateralmente: as características da passada, variações angulares tridimensionais nos membros superiores (ombros, cotovelos, e tronco) e inferiores (pélvis, quadris, joelhos e tornozelos), componente vertical da força de reação do solo, eletromiografia de músculos dos membros superiores ( peitoral maior, deltóide médio, cabeça longa do tríceps, extensor radial do carpo). 


\section{Capítulo 2}

\section{Locomoção do Paraplégico}

Este capítulo apresentará o efeito da locomoção no paraplégico, em particular quando esta é conseguida usando a estimulação elétrica neuromuscular (EENM).

\subsection{Perspectivas}

Atualmente há uma grande perspectiva para os lesados medulares, 200.000 somente nos Estados Unidos, direcionada para a regeneração da área afetada. Experiências de implantes de células tronco de embriões na medula tem estimulado investimentos nesta direção. Por exemplo, após um mês da realização de implantes de células tronco em animais que tiveram a medula secionada, observou-se mobilidade nos seus membros inferiores, o que sugere que aquelas células se diferenciaram em outras que possibilitaram a reconexão da medula lesada. Outro fato observado tem sido a plasticidade do circuito da marcha na medula, a idéia é que o treinamento pode restaurar a capacidade de deambulação. Isto ocorre porque a medula pode realizar muitas funções necessárias para a marcha independentemente do cérebro, e esta sua capacidade pode ser ativada quando exposta a sensações associadas à marcha (Wickelgren 1998a, Wickelgren 1998b, Wickelgren 1999). Recursos tecnológicos para auxiliar o treinamento da marcha, como sistemas para o suporte parcial do peso, e a geração da marcha através de um sistema de estimulação elétrica neuromuscular (Field-Fote 2001) (Fig. 2.1(a)), ou órteses robóticas (Jezernik, Colombo, Morari \& Dietz 2001) (Fig. 2.1(b)) poderão acelerar o processo de recuperação. 


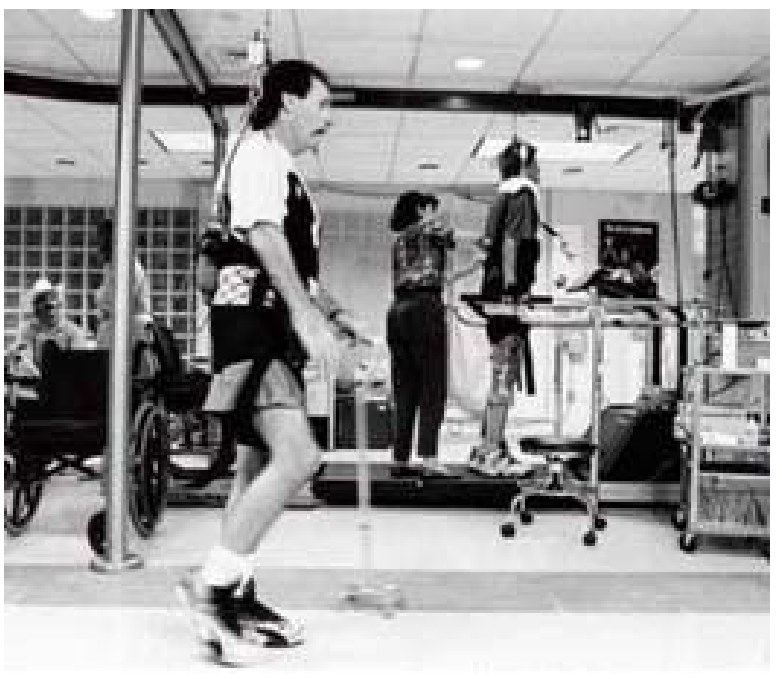

(a) Marcha produzida por EENM (Field-Fote 2001)

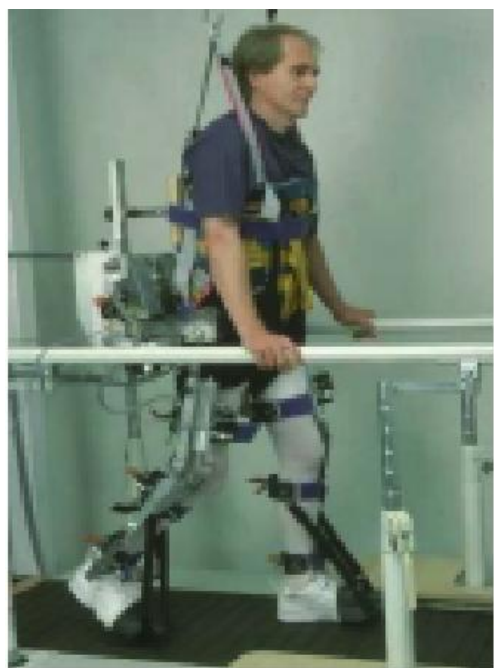

(b) Marcha produzida por órtese robótica (Jezernik, Colombo, Morari \& Dietz 2001)

Figura 2.1: Treinamento da marcha usando sistema de suporte parcial do peso.

No entanto, o sonho da regeneração da lesão medular ainda está muito distante, consequentemente é necessário o desenvolvimento de sistemas que permitam ao paciente ficar em pé e deambular, pois a realização destas atividades apresenta inúmeros benefícios para o mesmo, como prevenção da osteoporose, redução da incidência de calcificação urinária, redução da espasticidade, melhoria da digestão, prevenção da úlcera de decúbito, manutenção da faixa de movimentação da articulação, prevenindo contraturas. Principalmente, a possibilidade de interagir com outros, pois estando na postura ereta melhora o bem estar psicológico.

\subsection{Requerimentos fundamentais da marcha}

Os requerimentos fundamentais da marcha são (Stallard, Major \& Patrick 1989):

1. que a estrutura multi-segmentar do corpo esteja estabilizada para evitar que desmorone, ou tombe;

2. a aplicação e controle das forças que proverão estabilidade e propulsão.

Considerando que o paciente paraplégico não possui o controle voluntário de seus membros inferiores, para satisfazer os requerimentos acima ele precisará da estabilização mecânica através de três pontos de fixação das articulações (tornozelo, joelho, quadril), ou da estimulação elétrica de músculos que possam cumprir o mesmo papel (a estimulação do quadríceps trava o joelho, uma AFO pode ser usada para travar o tornozelo). As forças 
de propulsão são obtidas pela ação dos membros superiores e o auxílio de andador, ou muletas.

Isto representa um problema, pois viver sobre uma cadeira de rodas onde há a necessidade do uso dos braços para a movimentação, o repetitivo levantamento do peso do corpo para realização da transferência, e a elevação dos ombros para realizar tarefas exigem muito dos ossos, articulações e tecidos das extremidades superiores. Como o uso em longo prazo da cadeira de rodas está associado à dor e degeneração dos membros superiores, a ponto de interferir nas atividades da vida diária, é importante verificar o comprometimento durante a locomoção (Pentland \& Twomey 1994a, Pentland \& Twomey 1994b, Sie, Waters, Adkins \& Gellman 1992).

A estimulação elétrica neuromuscular (EENM) pode ser usada para realizar a contração de grupos musculares que facilitem o balanço da perna, possibilitando a redução da carga no ombro.

\section{3 Órteses híbridas}

Tomovic, Vukobratovic \& Vodovnik (1973) propuseram o uso combinado da órtese mecânica com a EENM, o que ele denominou de órtese híbrida. Desta forma o apoio mecânico proporciona suporte para o peso, e a EENM a propulsão durante a fase de balanço. Vários trabalhos analisaram a aplicação desta idéia nas órteses mecânicas mais avançadas do mercado, principalmente a Parawalker e a Louisiana State University reciprocating gait orthosis (LSU-RGO), que são do tipo HKAFO (hip-knee-ankle-foot) permitindo a flexão do quadril (numa faixa pré-estabelecida), mas restringindo o movimento das articulações do joelho e do tornozelo (Fig. 2.2). A Parawalker, também conhecida como órtese com guia de quadril (HGO), foi desenvolvida por Gordon Rose e seus colegas na Unidade de Avaliação Locomotora e Pesquisa Ortótica em Oswestry (Inglaterra) (Rose 1979), ela permite a flexão e extensão dos quadris entre paradas na marcha. A órtese para marcha recíproca (RGO) foi desenvolvida por Roy Douglas e colegas na Universidade do Estado de Louisiana (Douglas, Larson, D'Ambrosia \& McCall 1983), tendo como contribuição mais importante em relação às órteses anteriores o uso de cabos conectando os quadris de tal forma que a flexão em um lado causava a extensão no outro, possibilitando desta for a marcha recíproca. É interessante notar que este conceito já havia sido implementado no início dos anos setenta (Scruton 1971). 


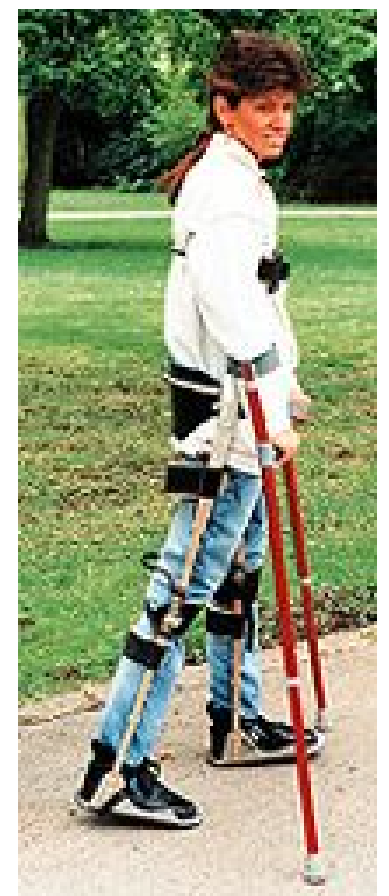

(a) Parawalker

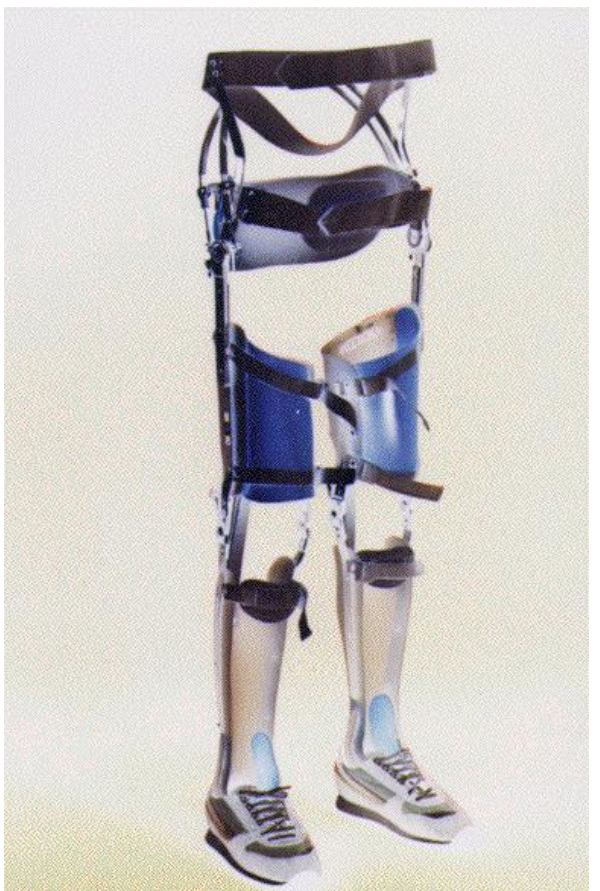

(b) RGO

Figura 2.2: Órteses mecânicas.

Cliquet, Baxendale \& Andrews (1989) indicaram que sistemas baseados em órteses do tipo HKAFO apresentaram um desempenho melhor que a aplicação apenas da EENM devido ao consumo de oxigênio muito alto relacionado à flexão/extensão das articulações do joelho e compensação da oscilação postural ocorridos no último caso. Como a HKAFO suporta o tronco e o quadril do paciente adequadamente, não há necessidade para gastar tanta energia estabilizando o corpo. Eles aplicaram a EENM no nervo fibular para realizar a flexão do quadril, e nos músculos glúteos da perna de apoio para prover hiperextensão do quadril e conseqüentemente empurrar a pélvis para frente, para ajudar a perna de balanço. Também foram indicados inconvenientes relacionados ao uso da estimulação dos músculos glúteos como deslocamento dos eletrodos pela roupa, dificuldade para o posicionamento dos eletrodos no paciente, dificuldade para adesão dos eletrodos devido à sudorese, e a dificuldade para obtenção de uma contração forte devido à presença de uma camada de gordura espessa (Cliquet, Nene, Barnett \& Andrews 1986).

A Parawalker requer esforço físico do paciente adulto para ficar em pé e sentar, além disso apresenta deformação na articulação do quadril da órtese no lado de apoio em adultos pesados. A estimulação elétrica dos abdutores do quadril do lado de apoio durante a deambulação pode ser usada para evitar esta deformação. Usando esta estratégia Nene \& Andrews (1986), McClelland, Andrews, Patrick, Freeman \& ElMasri (1987) mostraram que a estimulação do glúteo em pacientes deambulando com a Parawalker resulta em melhoria no desempenho que pode ser mensurado objetivamente como um 
aumento significante na velocidade da marcha, e o decréscimo no trabalho realizado pelos músculos do ombro, evidenciado pela redução no impulso da muleta usada para auxiliar a marcha (Nene \& Andrews 1986, McClelland et al. 1987).

Phillips (1989) associou o uso de 6 estimuladores comerciais (2 canais cada) com uma órtese RGO para possibilitar a deambulação em um paciente com lesão no nível C-7. Desta forma foram usados 3 estimuladores para cada lado, sendo 2 para estimulação do quadríceps, e um para a estimulação do glúteo e dos músculos isquiotibiais. A ativação do quadríceps era realizada para auxiliar o levantar, e a ativação do glúteo e dos isquiotibiais auxiliava o balanço durante a marcha através da extensão do quadril da perna de apoio.

Solomonow, Baratta, Hirokawa, Rightor, Walker, Beaudette \& (et al.) (1989) usaram a estimulação do reto femural e dos isquiotibiais para melhorar o uso da RGO. Para ficar em pé sem assistência o paciente estimulava os quadríceps e os isquiotibiais das duas pernas simultaneamente. Os quadríceps estendiam os joelhos e os isquiotibiais estendiam os quadris empurrando o paciente para a postura ereta. Durante a marcha o paciente estimulava simultaneamente o quadríceps direito para o balanço da perna direita e os isquiotibiais do lado esquerdo para impulsionar para frente.

Enquanto as órteses híbridas proporcionam segurança e estabilidade devido ao suporte mecânico, e um gasto energético menor que o uso apenas da EENM, esta última quando usada com o devido cuidado apresenta algumas vantagens em relação à primeira, como propiciar a participação ativa do metabolismo dos membros no decorrer da marcha, o uso funcional dos músculos, ossos e articulações dos pacientes para a realização da mesma, ativação dos reflexos neuromusculares preservados, melhor aparência, e facilidade da vestimenta da órtese (isto não ocorre quando são estimulados os glúteos).

\subsection{Marcha usando apenas a estimulação elétrica}

A primeira marcha bípede recíproca de um paciente paraplégico usando apenas a EENM foi descrita por Kralj, Bajd \& Turk (1980). A característica mais importante foi o uso do reflexo de retirada para realizar a fase de balanço. Durante a fase de apoio os extensores do joelho foram estimulados. Como conseqüência deste trabalho, em 1987 aproximadamente 70 pacientes lesados medulares usavam a EENM diariamente nos membros inferiores. Entre eles, 10 pacientes estavam aptos para caminhar com o auxílio de muletas fora de casa, outros 10 estavam usando a EENM e andador para caminhar regularmente em suas casas (Kralj \& Bajd 1989).

Após este trabalho, foram estimulados outros grupos musculares dos membros inferiores como extensores e abdutores do quadril, e flexores plantares do tornozelo com o propósito de melhorar a marcha. Seguindo este caminho Mizrahi, Braun, Najenson \& Graupe (1985) apresentaram um trabalho onde foram utilizados dois canais além daqueles 
usados inicialmente pelo grupo de Kralj. Neste trabalho, durante a marcha, os músculos quadríceps e glúteo máximo foram estimulados simultaneamente na perna de apoio (auxiliando o balanço da perna contralateral, e a passagem da posição sentada para a posição ereta), e o reflexo de retirada foi disparado para obter o balanço da outra perna.

\subsection{Exemplo: Parastep}

Estes princípios são os mesmos adotados pelo sistema Parastep (Fig. 2.3). Um dos autores do artigo citado no parágrafo anterior, Daniel Graupe, participou no seu desenvolvimento (Kantor, Andrews, Marsolais, Solomonow, Lew \& Ragnarsson 1993). Em 1994, o Parastep tornou-se o primeiro sistema de EENM usado para a deambulação aprovado pelo FDA (Food and Drug Administration) norte-americano (Klose, Jacobs, Broton, Guest, Needham-Shropshire, Lebwohl, Nash \& Green 1997), tendo sido enfatizado que o sistema tem como meta a mobilidade em posição ereta, sendo oferecido como uma alternativa e não um substituto para a cadeira de rodas. O sistema (estimulador, andador, eletrodos, etc...) pode ser vendido com um estimulador de 4 canais $(\$ 11.790,00)$, ou de 6 canais $(\$ 12.780,00)$, e há um custo adicional com 32 sessões de fisioterapia (2 ou 3 por semana), incluindo instruções sobre o sistema e treinamento da marcha (SIGMEDICS 2003). Nem sempre é possível a estimulação dos glúteos (uso dos 6 canais), pois em alguns pacientes ocorrem fortes contrações dos músculos do abdômen (Mizrahi et al. 1985, Nene \& Andrews 1986). Graupe, divulgou que o Parastep já foi aplicado com sucesso em mais de 600 pacientes (Popovic, Curt, Keller \& Dietz 2001). No entanto, Kralj, Bajd, Munih \& Turk (1993) e colegas têm apontado alguns problemas com os sistemas que usam a ativação do reflexo de retirada usando eletrodos de superfície para realizar o balanço, como : a necessidade de precisão no posicionamento dos eletrodos; e as conseqüências da habituação nervosa (variação nos movimentos de flexão, dependência da amplitude e do tempo de aplicação da estimulação). 


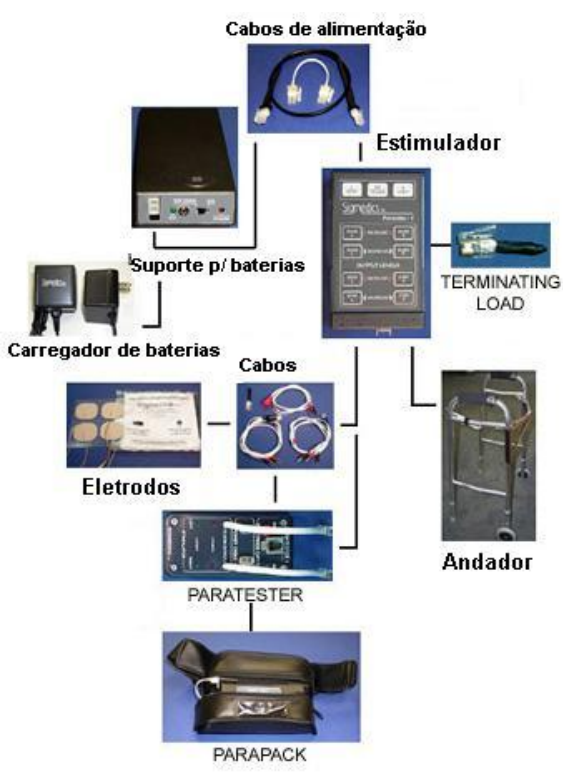

(a) Estimulador

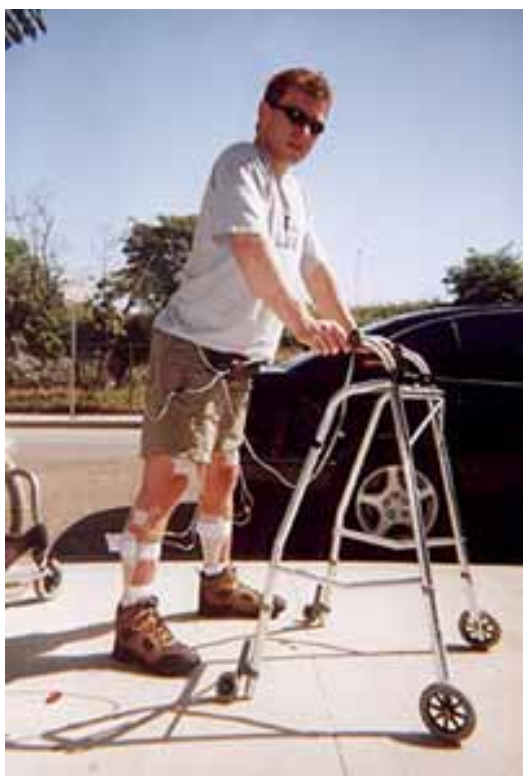

(b) Paciente

Figura 2.3: Parastep (SIGMEDICS 2003).

Um conjunto de 5 artigos publicados em Agosto de 1997, na Archives on Physical Medicine and Rehabilitation, resume uma avaliação dos efeitos de um programa de deambulação usando EENM sobre a saúde física e mental dos pacientes paraplégicos, usando para isso o Parastep 1 (Klose et al. 1997, Jacobs, Nash, Klose, Guest, NeedhamShropshire \& Green 1997, Needham-Shropshire, Broton, Klose, Lebwohl, Guest \& Jacobs 1997, Guest, Klose, Needham-Shropshire \& Jacobs 1997, Nash, Jacobs, Montalvo, Klose, Guest \& Needham-Shropshire 1997). As pesquisas foram realizadas pelo Projeto Miami para Cura da Paralisia, desenvolvido na Faculdade de Medicina da Universidade de Miami.

Os exames foram realizados em 16 pacientes (13 homens e 3 mulheres) com lesões completas entre T4 e T11. Antes de iniciar o treinamento da marcha os pacientes precisavam ficar em pé por no mínimo 3 minutos, aqueles que não possuíssem força adequada nos quadríceps para realizar esta tarefa usavam uma unidade de estimulação para fazer exercícios de extensão do joelho na posição sentada contra uma resistência progressivamente maior até que fossem capazes de satisfazer este critério. Quando os pacientes alcançavam a força necessária, iniciavam o treinamento da marcha 3 vezes por semana até completar 32 sessões. As sessões iniciais enfatizavam o posicionamento dos eletrodos, o controle dos parâmetros de estimulação, a posição correta para ficar em pé, e a técnica para deslocamento do peso à medida que o passo era realizado. A distância e duração de cada caminhada era determinada pelo paciente, que era encorajado a caminhar tanto quanto possível (enquanto estivesse confortável). Os pacientes descansavam de 15 a 20 minutos entre cada caminhada e completavam acima de 3 caminhadas por sessão (Klose 
et al. 1997). Como foi dito as avaliações foram apresentadas em 5 artigos, cada um abordando um tema específico, cujas conclusões serão resumidas a seguir :

Parte I : Entre as sessões 24 e 26 as melhorias no desempenho começavam a parar e os progressos futuros eram modestos. Havia um alto grau de variabilidade de desempenho entre os pacientes. As distâncias máximas variaram de 12 a 1.707 metros, sendo que 6 pacientes excederam 300 metros e que 4 não passaram de 100 metros. As mudanças antropométricas, como o aumento nas medidas das coxas e panturrilhas, estavam de acordo com o uso convencional da EENM em músculos paralisados (Klose et al. 1997).

Parte II : Paraplégicos sofrem com a desregulação hemodinâmica imposta pela imobilidade da extremidade inferior, e disfunção vasomotora. Em exercícios com os braços, os paraplégicos apresentam picos de potência e de consumo de oxigênio inferiores àqueles obtidos em pessoas sem paralisia. E quando são submetidos a cargas inferiores às cargas máximas, os paraplégicos apresentam batimentos cardíacos exagerados, o que não acontece com as pessoas sem paralisia. O treinamento da marcha resultou em um aumento no pico de capacidade de trabalho com os membros superiores, e uma taxa menor de batimentos cardíacos em cargas de trabalho abaixo do pico. Portanto, as adaptações conseqüentes do treinamento da marcha podem reduzir a carga cardiovascular e metabólica em pessoas com paraplegia durante atividades genéricas usando as extremidades superiores (Jacobs et al. 1997).

Parte III : Foi realizada a densitometria óssea antes da primeira sessão e após a última $\left(32^{\circ}\right)$, tendo ocorrido um intervalo de aproximadamente 12 semanas entre os exames. Após analisarem os exames os autores concluíram que os efeitos do programa de treinamento de marcha usando a EENM (carga axial, estimulação dos músculos, exercício resistivo) não resultaram em mudanças significativas na densidade mineral óssea, ou seja, não resultou na reversão da osteoporose (Needham-Shropshire et al. 1997).

Parte IV : Os autores avaliaram o estado psicológico dos pacientes usando dois protocolos : A sub-escala relativa ao estado físico do paciente da Escala de Conceito Próprio Tennessee (TSCS - Tennessee Self-Concept Scale) desenvolvida em 1965; e o Inventário de Depressão de Beck (BDI - Beck Depression Inventory), também desenvolvido na década de 1960. Houve uma melhoria significativa nos resultados das avaliações após o tratamento com a EENM. Isto era esperado, pois o tratamento requer um esforço físico intenso, e isto está associado ao bem estar físico e mental nas pessoas. Mesmo com uma mobilidade muito precária, a possibilidade de ficarem em pé, andarem, e interagirem na posição ereta com outras pessoas gera a sensação de que a conexão perdida pode ser superada, e de que se pode voltar aos hábitos normais. Além disso as alterações na musculatura do corpo os fazem sentirem-se melhores (Guest et al. 1997).

Parte V : Neste trabalho foi observado que o fluxo sangüíneo e a resposta hiperêmica a oclusão na extremidade inferior foram aumentados após a terapia. Isto ocorre porque a força resultante da contração muscular gerada pela EENM está diretamente relacionada 
ao aumento do fluxo sangüíneo no membro. Com o tempo, a contração muscular resultante da EENM aumenta a densidade e comprimento capilar do músculo, e a taxa capilar por fibra (Nash et al. 1997).

Embora a terceira parte da pesquisa (Needham-Shropshire et al. 1997) tenha indicado que não há reversão da osteoporose com este tipo de terapia, outros trabalhos nos quais a aplicação da EENM ocorreu com maior freqüência, e onde a avaliação foi realizada após um período de tempo maior, apresentaram indícios de redução da osteoporose (Bélanger, Stein, Wheeler, Gordon \& Leduc 2000) (Triolo et al. 1996). Por exemplo, Bélanger et al. (2000) observaram reversão substancial da perda de densidade óssea após avaliarem a densidade mineral óssea obtida usando a técnica 'dual energy x-ray absorptiometry' em 14 pacientes com lesão medular de C5 a T5 antes e após um período de treinamento constituído pela aplicação diária (exceto nos finais de semana) da EENM nos quadríceps (aplicações com 5 segundos de duração, intercaladas por intervalos de 5 segundos de repouso) por uma hora, durante 24 semanas, ou seja, 120 sessões.

\subsection{Sistemas implantáveis}

Sistemas como o Parastep apresentam um resultado muito modesto em relação à sua utilização para realização das atividades diárias, devido ao grande esforço físico exigido conseqüente da precária coordenação do movimento, e devido à fadiga precipitada conseqüente da ativação desnecessária de um grande número de fibras musculares.

Para superar tais problemas alguns grupos de pesquisa investem na EENM realizada através de eletrodos implantados no corpo do paciente, permitindo desta forma a seleção precisa dos músculos a serem acionados, e até mesmo de grupos de fibras diferentes em um mesmo músculo (Peckham 1988). Com tais sistemas procura-se habilitar os pacientes para realização de atividades diárias, inclusive no ambiente de trabalho. Isto pode ser uma alternativa para os casos nos quais a lesão na medula seja extensa, dificultando a possibilidade de regeneração no futuro, como ocorre quando a mesma é atingida por um projétil de arma de fogo (Triolo et al. 1996).

O grupo da Case Western Reserve University, associada ao Cleveland Veterans Administration Medical Center, iniciou a aplicação de eletrodos implantáveis em membros inferiores em 1980. Naquele ano, Marsolais \& Kobetic (1988) iniciaram o implante de eletrodos em membros inferiores seguindo as técnicas desenvolvidas anteriormente para os membros superiores.

Há dois tipos de eletrodos que podem ser implantados : o eletrodo intramuscular, que é inserido através de uma agulha hipodérmica; e o eletrodo físico, que é fixado na superfície do músculo através de uma cirurgia. A vantagem dos eletrodos intramusculares é que eles possibilitam seletividade no acionamento dos músculos, e respostas confiáveis 
ao longo do tempo, sem a necessidade da realização de uma cirurgia. Desta forma o pesquisador poderá desenvolver e testar a viabilidade de sistemas de EENM que acionem vários músculos sem os gastos, complexidade e riscos envolvidos no implante cirúrgico de eletrodos e estimuladores. Com as informações obtidas na etapa de desenvolvimento e teste, o pesquisador terá material suficiente para gerar especificações precisas de hardware necessárias para produzir o sistema implantável definitivo. Quanto ao paciente poderá avaliar o sistema e decidir se é viável submeter-se à cirurgia para o implante definitivo do sistema, ou não (Peckham 1988).

Usando eletrodos intramusculares (percutâneos), o grupo de Cleveland já implementou sistemas de 48 canais para o controle individual de músculos do tronco, quadris, joelhos e tornozelos, para possibilitar aos pacientes : ficar em pé, subir escadas, realizar passos laterais, andar de costas, locomoção com uma aparência mais próxima da normal, entre outras atividades (Triolo et al. 1996). A Fig. 2.4(a) é um exemplo do uso de eletrodos intramusculares. Os eletrodos foram inseridos nos seguintes músculos : (vista anterior) vastus lateralis, vastus medialis, vastus intermedius, sartorius, gracilis, tibialis anterior, e peronei; (vista lateral) gluteus maximus, gluteus medius, e tensor fasciae latae; (vista posterior) porção posterior do adductor magnus, o semimembranosus, e soleus (Marsolais \& Kobetic 1987).

Em 1996, Kobetic, Triolo, Uhlir, Bieri, Wibowo, Polando, Marsolais, Davis, Ferguson \& Sharma (1999) realizaram o implante, em um paciente de 41 anos com lesão T10, de um sistema de EENM de 16 canais constituído por dois estimuladores IRS-8 CWRU/VA de 8 canais controlados por ondas de rádio emitidas pela unidade de controle externa (Fig. 2.4(b)). Os músculos selecionados para serem ativados pelo sistema foram definidos por um estudo anterior utilizando um sistema percutâneo de 48 canais, cujo propósito era definir um conjunto mínimo de músculos que produziriam um desempenho da marcha que viabilizaria o implante do sistema de estimulação disponível naquele momento, o IRS-8 CWRU/VA (Kobetic, Triolo \& Marsolais 1997). Os eletrodos foram implantados para ativação dos seguintes músculos : eretor da espinha, gluteus maximus, porção posterior do adductor magnus, semimembranosus, tibialis anterior, tensor fasciae latae, quadriceps e sartorius (Kobetic et al. 1999). 


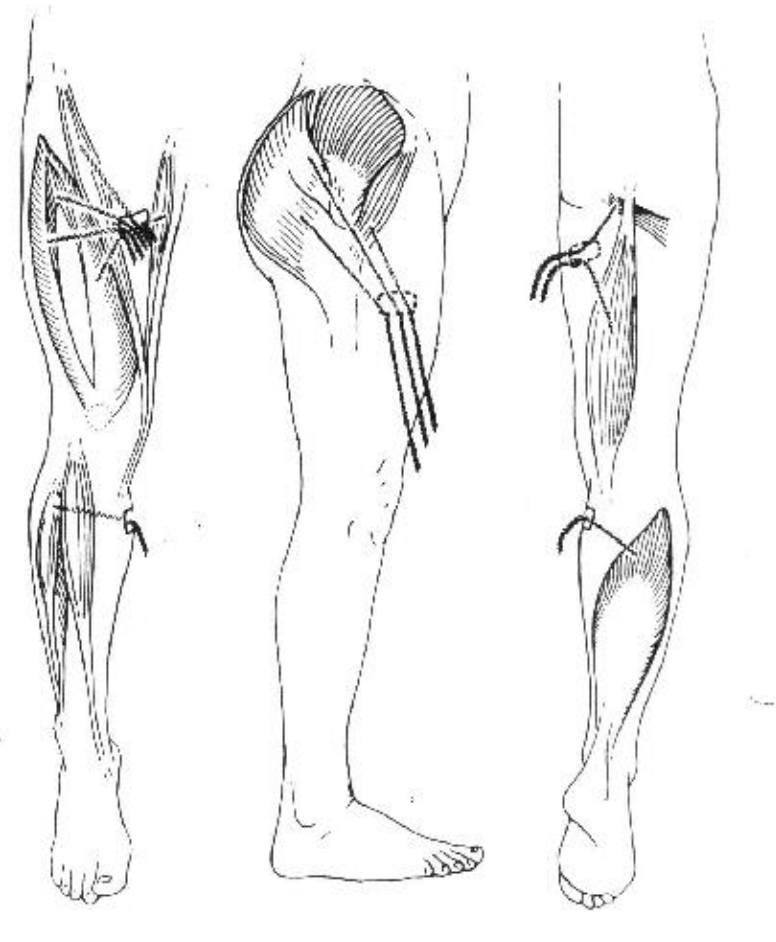

(a) Sistema de EENM percutâneo (Marsolais \& Kobetic 1987)

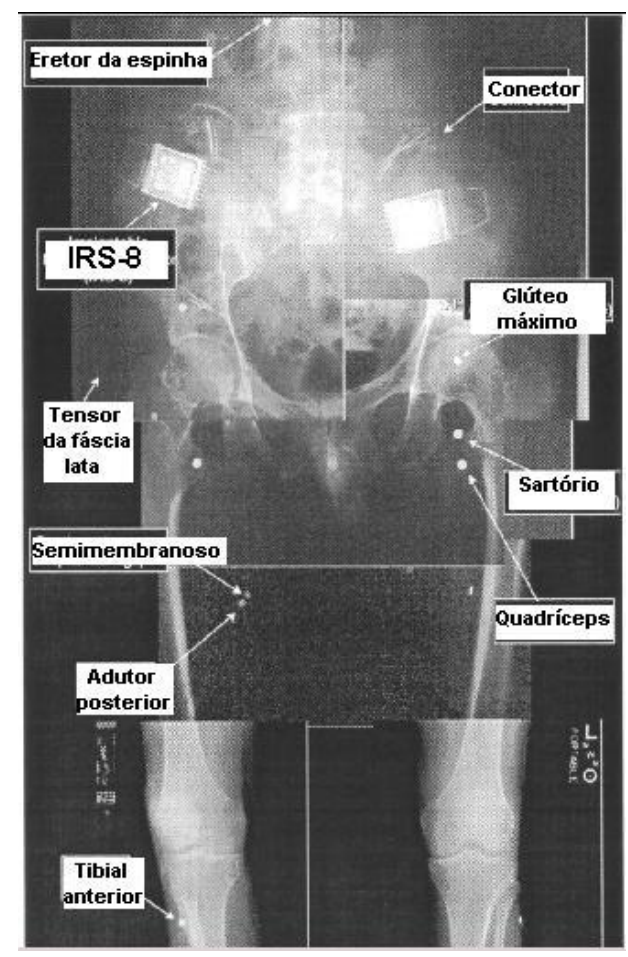

(b) Sistema de EENM implantado (Kobetic et al. 1999)

Figura 2.4: Sistemas implantáveis.

\subsection{Conclusão}

A ausência de uma solução definitiva para a lesão medular implica na necessidade do desenvolvimento de sistemas que possibilitem ao paraplégico ficar em pé e andar.

Sistemas baseados na estimulação elétrica proporcionam vantagens adicionais por realizar tais tarefas através da ativação do metabolismo e da estrutura músculo-esquelética do próprio paciente.

A propulsão do corpo na locomoção assistida depende principalmente da ação dos membros superiores. Isto resulta em sobrecarga que pode gerar uma possível lesão em tais membros. Além disto, torna a locomoção mais cansativa.

O acréscimo de canais de estimulação sobre músculos específicos possibilitará a redução do uso dos membros superiores e melhoraria do desempenho da locomoção.

Para otimizar o controle do sistema de estimulação visando este propósito fazse necessário avaliar o uso dos membros superiores e os parâmetros que possibilitam a descrição quantitativa da locomoção. 


\section{Capítulo 3}

\section{Locomoção Normal}

Neste capítulo serão apresentadas as principais características da locomoção humana.

\subsection{Determinantes fundamentais da marcha}

Inman (1993), em um texto publicado em 1966, descreveu de forma excelente a locomoção humana. Neste texto ele mostrou que embora os movimentos realizados pelos diversos segmentos do corpo possam parecer desnecessários, são de fato importantes para possibilitar transferências de energias que resultem numa marcha relativamente eficiente. Especificamente, os movimentos são realizados para minimizar o gasto de energia através do controle do deslocamento vertical do centro de massa do corpo, e da combinação da desaceleração e aceleração do corpo, ao longo do movimento, para possibilitar o aproveitamento da energia potencial ocorrido durante as elevações em energia cinética necessária para a progressão do corpo, como um pêndulo.

O centro de massa do corpo oscila durante a locomoção seguindo um percurso semelhante àquele apresentado na Fig. 3.1(a). As amplitudes tanto do deslocamento vertical, quanto do lateral, estão na faixa entre 4 e $5 \mathrm{~cm}$, como pode ser visto nas Fig. 3.1(c) e 3.1(d) (Whittle 1997).

A variação vertical do centro de massa é conseqüente da estrutura segmentar dos membros inferiores, que é necessária para a locomoção em terrenos desnivelados. A forma senoidal e a pequena amplitude deste deslocamento são conseqüentes da ação combinada da pélvis, quadris, joelhos e tornozelos. A pélvis, quadris e joelhos apresentam uma contribuição maior para a redução da amplitude do movimento, enquanto os joelhos e tornozelos trabalham conjuntamente principalmente para suavizar o deslocamento, formando a curva senoidal.

A amplitude do movimento depende principalmente de três fatores : rotação pélvica horizontal, inclinação pélvica lateral, e de uma leve flexão do joelho.

Tanto a rotação pélvica quanto a inclinação pélvica variam entre $6^{\circ}$ e $8^{\circ}$, e 


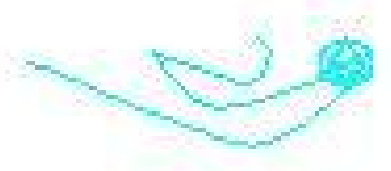

(a) Trajetória de um marcador posicionado na altura do sacro.

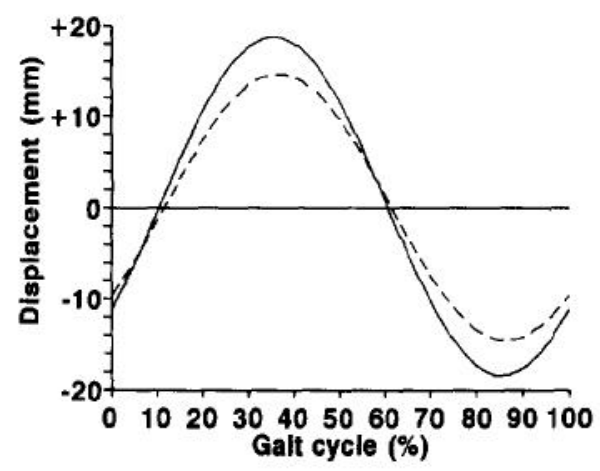

(c) Médio-lateral (positivo para a esquerda).

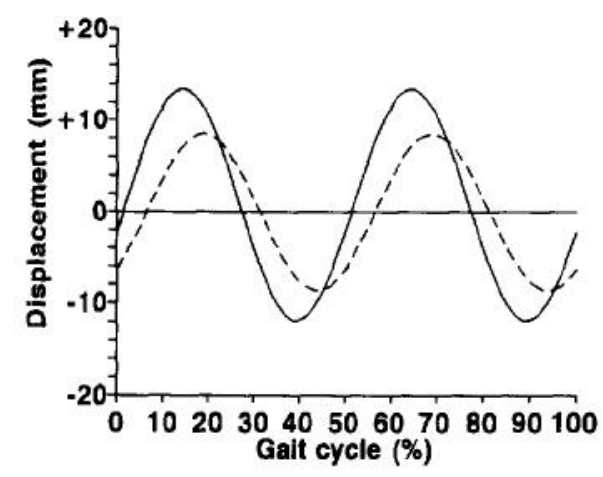

(b) Ântero-posterior (positivo para frente).

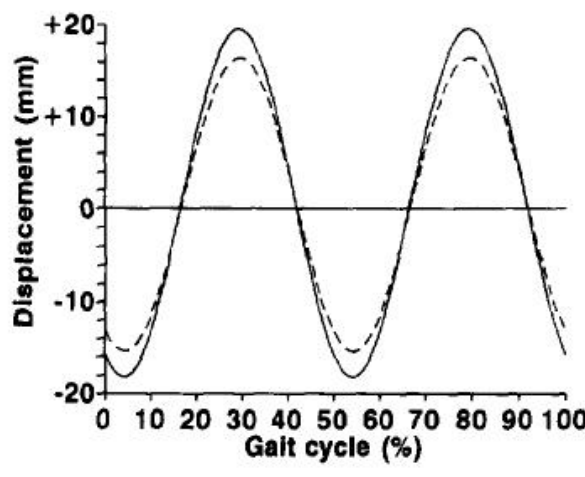

(d) Vertical (positivo para cima).

Figura 3.1: Aproximação senoidal do movimento do centro da pélvis (em linha sólida) e do centro de massa (em linha tracejada) durante o ciclo da marcha (Whittle 1997).

ocorrem no lado da perna de balanço. No momento da perda de contato do pé com o solo a pélvis no lado da perna de balanço começa a girar para frente e a inclinar para baixo, como pode ser visto na Fig. 3.2. O processo é reduzido abruptamente no momento do contato do calcanhar com o solo e é revertido à medida que todo o peso do corpo é posto sobre o pé.

Enquanto a rotação e inclinação pélvica atuam na perna de balanço, uma leve flexão do joelho ocorre na perna de apoio após o contato do calcanhar com o solo (no contato inicial a extensão do joelho é máxima) à medida que o peso do corpo é transferido para a perna. Com o corpo movendo-se sobre a perna "encurtada" o caminho do seu centro de massa terá uma alteração menor no seu deslocamento vertical. Durante este processo, a flexão plantar do pé apresenta um papel importante, principalmente no momento do contato com o solo, e quando o corpo passa sobre a perna quando terá um efeito contrário ao indicado acima, ou seja, causará o levantamento do calcanhar que resultará 


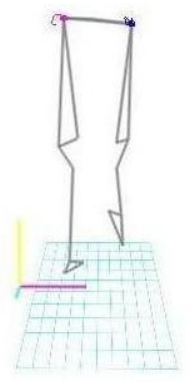

(a) Vista frontal - Balanço esquerdo.

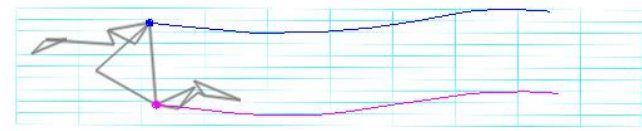

(c) Vista superior - Balanço esquerdo.

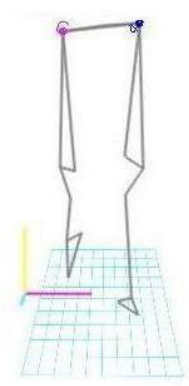

(b) Vista frontal - Balanço direito.

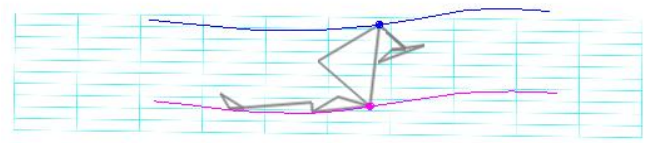

(d) Vista superior - Balanço direito.

Figura 3.2: Início da fase de balanço. A vista frontal apresenta a inclinação para baixo da pélvis, e a vista superior apresenta a rotação que ocorre na mesma.

no alongamento relativo da perna, facilitando a transferência do corpo para o outro pé.

Como as várias partes do corpo possuem dependência entre si, os movimentos citados anteriormente implicam em outros movimentos compensatórios: o movimento lateral do centro de massa do corpo; rotação dos segmentos das pernas na mesma direção e em fase com a rotação pélvica; e rotações de ombros e braços contrárias à da pélvis. A movimentação dos ombros e braços auxilia o amortecimento da rotação pélvica, que muda de orientação após o contato do pé com o solo.

Embora ocorra uma série de movimentos dos segmentos do corpo para minimizar a variação do deslocamento vertical do seu centro de massa, a natureza otimizou a locomoção de tal forma que a energia potencial adquirida quando o peso do corpo é transferido para a perna de apoio, momento no qual o centro de massa alcança a altura máxima, é utilizada para auxiliar a propulsão do corpo para frente, no momento em que este for transferido para a outra perna. Este processo segue o mesmo princípio de conversão de energia potencial para energia cinética que rege o deslocamento de um pêndulo (Fig. 3.3(a)). No entanto, na locomoção o corpo está na forma de um pêndulo invertido cujo ponto de apoio é deslocado na direção da progressão do movimento, neste momento também ocorre uma mudança na direção da velocidade do centro de massa (Fig. 3.3(b)) (Kralj \& Bajd 1989).

Este processo possibilita reduzir o gasto com energia necessário para impulsionar o corpo para frente, no entanto, a transferência do corpo de uma perna para outra requer uma quantidade adicional de energia que é provida pelos músculos durante o balanço da perna que será deslocada para frente. Inicialmente ocorre um empurrão propiciado pela 
flexão plantar quando ocorre o contato com o solo do pé contralateral, logo após os flexores do quadril possibilitam um ganho ainda maior de energia cinética, e finalmente esta energia é transmitida para a parte superior do corpo à medida que a perna é desacelerada através da ação dos músculos isquiotibiais.

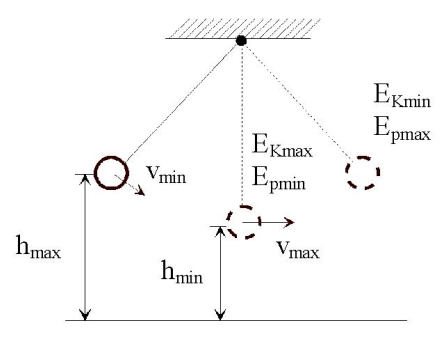

(a) Balanço em um pêndulo.

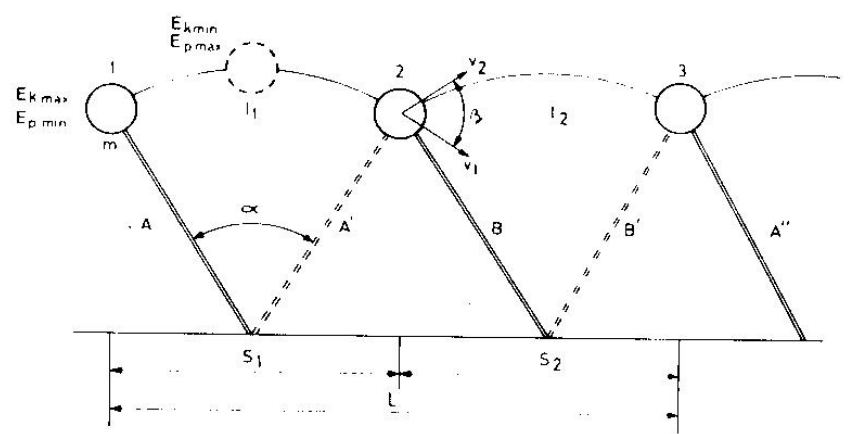

(b) Descrição da marcha através de um pêndulo invertido (Kralj \& Bajd 1989).

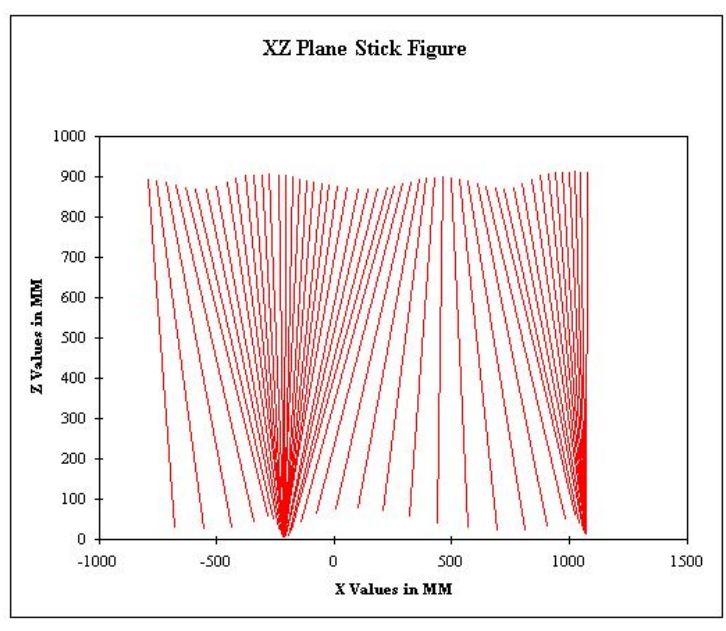

(c) Deslocamento da perna direita no plano sagital (segmento retilíneo liga ponto posicionado próximo à cabeça do $2^{\circ}$ metatarso a um ponto posicionado na espinha ilíaca ântero-superior)

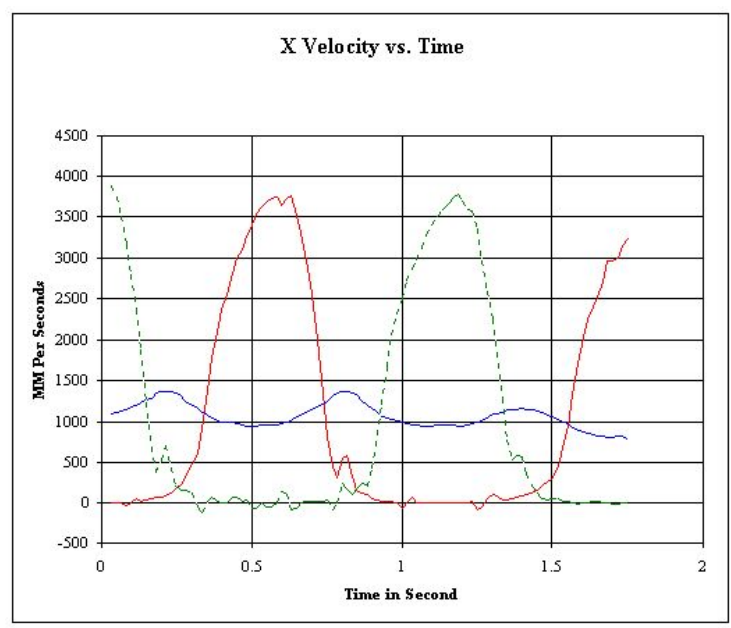

(d) Velocidade da projeção dos pontos no eixo da progressão do movimento(verdemetatarso direito, vermelho-metatarso esquerdo, azul-espinha ilíaca ântero-superior direita).

Figura 3.3: Representação da conversão de energia potencial para energia cinética que ocorre no decorrer da marcha.

Na Fig. 3.3(c) pode-se observar a variação na velocidade no decorrer da locomoção pela proximidade dos segmentos, que no caso representam a perna direita. Na Fig. 3.3(d) pode-se observar que a velocidade de um ponto do quadril começa a aumentar um pouco antes do contato do pé da perna de balanço com o solo, e começa a reduzir um pouco antes da retirada do pé da perna contralateral do solo. 


\subsection{Terminologia genérica para as fases funcionais da marcha}

A estratégia desenvolvida no ser humano para produzir a locomoção com a máxima eficiência possível resulta em um padrão repetitivo de deslocamento de seus segmentos que apresenta fases bem definidas. A representação de um ciclo da marcha (passada) através de uma seqüência de padrões funcionais auxilia a sua análise. Por exemplo, possibilita a associação de um conjunto de dados obtidos para cada articulação com a ação realizada pela perna em um momento específico da passada. A Fig. 3.4 apresenta uma terminologia genérica para as fases funcionais da marcha desenvolvida pelo comitê de análise da marcha do Centro Médico Rancho Los Amigos (Perry 1992).

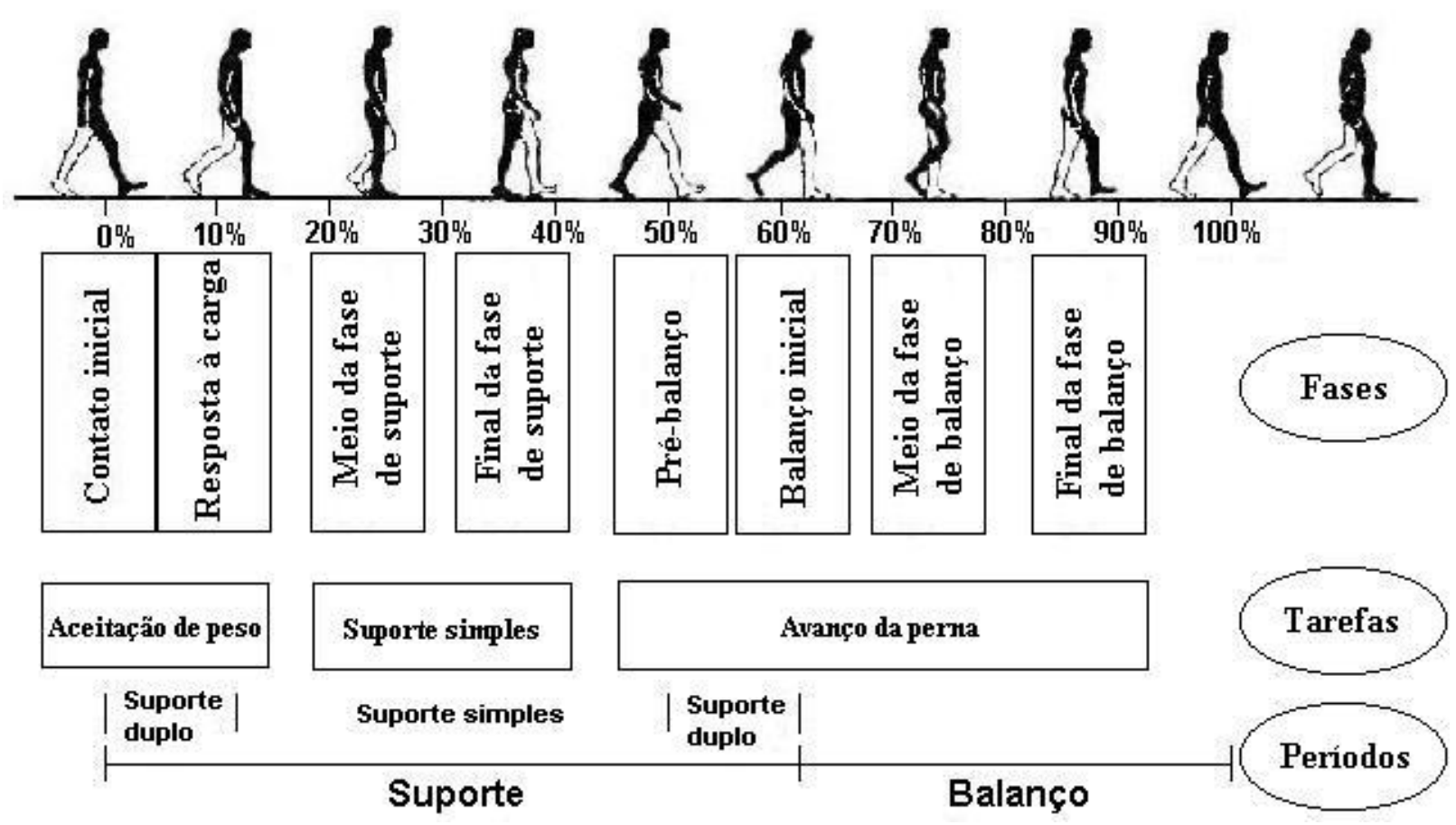

Figura 3.4: Terminologia genérica para as fases funcionais da marcha desenvolvida pelo comitê de análise da marcha do Centro Médico Rancho Los Amigos.

O ciclo da marcha está dividido em 8 fases que realizam 3 tarefas básicas : a aceitação de peso, o suporte simples, e o avanço da perna.

A aceitação de peso é a tarefa mais exigente do ciclo da marcha. Possui como desafio a transferência abrupta de peso do corpo para um membro que acabou de finalizar seu balanço para frente e possui um alinhamento instável. A aceitação de peso ocorre durante as fases de contato inicial e resposta à carga.

O contato inicial ocorre no intervalo de 0 a $2 \%$ do ciclo da marcha, com o contato do pé com o solo que iniciará o período de apoio. Logo após ocorre a resposta à carga (de 0 a 10\% do ciclo da marcha) que findará quando o pé contralateral for levantado para 
o balanço. Esta fase será responsável pela absorção do impacto do corpo com o solo, deverá prover estabilidade para a sustentação do corpo, e manutenção da progressão do movimento.

A tarefa de suporte simples iniciará quando o pé contralateral for liberado para o balanço. Neste momento uma perna terá toda a responsabilidade de sustentar o peso durante a progressão do corpo, tanto no plano sagital como no coronal, até que o pé contralateral entre em contato novamente com o solo. O suporte simples envolve o meio e o final da fase de suporte.

O meio da fase de suporte ocorre no intervalo de 10 a $30 \%$ do ciclo da marcha. Inicia quando o pé contralateral é levantado e continua até o peso do corpo ficar alinhado com a parte anterior do pé de apoio. Neste momento ocorre progressão do corpo sobre o pé de apoio.

O final da fase de suporte (intervalo de 30 a $50 \%$ do ciclo da marcha) inicia quando o calcanhar começa a levantar e continua até o pé contralateral tocar o solo. Durante esta fase o peso do corpo move-se para frente do pé de apoio.

A última tarefa é o avanço da perna, que inicia desde o final do período de suporte. O avanço da perna envolve 4 fases da marcha : pré-balanço, balanço inicial, meio da fase de balanço, final da fase de balanço.

O pré-balanço ocorre no intervalo de 50 a $60 \%$ do ciclo da marcha. Ele inicia com o contato inicial do pé contralateral e finaliza com a retirada do pé ipsilateral do solo. Neste momento, como ocorre o início da transferência do peso para a perna de apoio, há a liberação e posicionamento da perna de balanço para iniciar a fase de balanço.

O balanço inicial ocorre no intervalo de 60 a $73 \%$ do ciclo da marcha, iniciando com o desprendimento do pé do solo, e finalizando quando este alcançar o pé de apoio. Tem como propósito levantar o pé e avançar o membro para frente.

O meio da fase de balanço ocorre no intervalo de 73 a $87 \%$ do ciclo de marcha, quando o pé da perna de balanço está rente ao pé de apoio e continua até que a tíbia esteja na posição vertical. Esta fase dá continuidade à fase anterior com o avanço do membro, e o distanciamento do pé da perna de balanço em relação ao solo.

O final da fase de balanço ocorre no intervalo de 87 a 100\% do ciclo de marcha. Esta fase inicia quando a tíbia está na posição vertical e termina quando o pé toca o solo, fechando o ciclo. Nesta fase ocorre o avanço total do membro, e a preparação do membro para reiniciar o período de suporte.

\subsection{Características da passada}

Medidas simples de comprimento e tempo são as variáveis mais acessíveis e usadas para a descrição da marcha de uma pessoa. Elas representam a síntese de todo o processamento 
realizado para gerar a locomoção. A velocidade da marcha, o comprimento da passada, a taxa de passos (Cadência), o período da passada (tempo do ciclo), e os tempos dos períodos de balanço e apoio, constituem as características da passada de uma pessoa (Perry 1992).

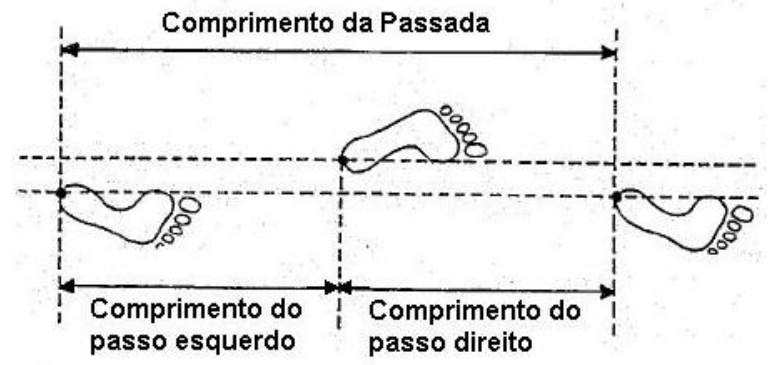

Figura 3.5: Passada

Fórmula relacionando a velocidade em função da cadência:

$$
\text { Velocidade }(\mathrm{m} / \mathrm{s})=\frac{\text { Comprimento da Passada }(\mathrm{m}) \times \text { Cadência }(\text { passos } / \mathrm{min})}{120}
$$

A velocidade da marcha livre normal, sobre uma superfície lisa, é em média $82 \mathrm{~m} / \mathrm{min}$ para adultos. Os homens são $5 \%$ mais rápidos $(86 \mathrm{~m} / \mathrm{min})$ que a média do grupo. A velocidade da marcha da mulher $(77 \mathrm{~m} / \mathrm{min})$ é $6 \%$ mais lenta.

O comprimento da passada para pessoas normais é em média 1,41 m. Homens têm um comprimento de passada $14 \%$ maior que as mulheres. A média para homens é de $1,46 \mathrm{~m}$ e para mulheres $1,28 \mathrm{~m}$.

A cadência da mulher (117 passos/min) é mais rápida que a do homem (111 passos/min). A cadência média de adultos (homens e mulheres) é de 113 passos $/ \mathrm{min}$.

$\mathrm{Na}$ marcha normal o período de apoio dura aproximadamente $60 \%$ do período do ciclo, e o período de balanço aproximadamente $40 \%$ do ciclo.

\subsection{Processamento da locomoção e suas variáveis}

Foram apresentadas as características mais importantes da locomoção nas seções anteriores. Embora tais características sejam comuns a todas as pessoas com um corpo sadio, cada pessoa possui uma forma peculiar de locomoção. Isto ocorre porque a locomoção é definida por um processo de aprendizagem desenvolvida durante a infância (o padrão encontrado nos adultos não aparece antes dos 7 anos) que é ajustado às alterações do corpo devido ao crescimento (Inman 1993).

A Fig. 3.6 resume a cadeia de eventos que culmina na locomoção. Ressalta em particular as variáveis envolvidas no processo que são monitoradas com o propósito de realizar a avaliação tanto da locomoção quanto do aparelho locomotor. 


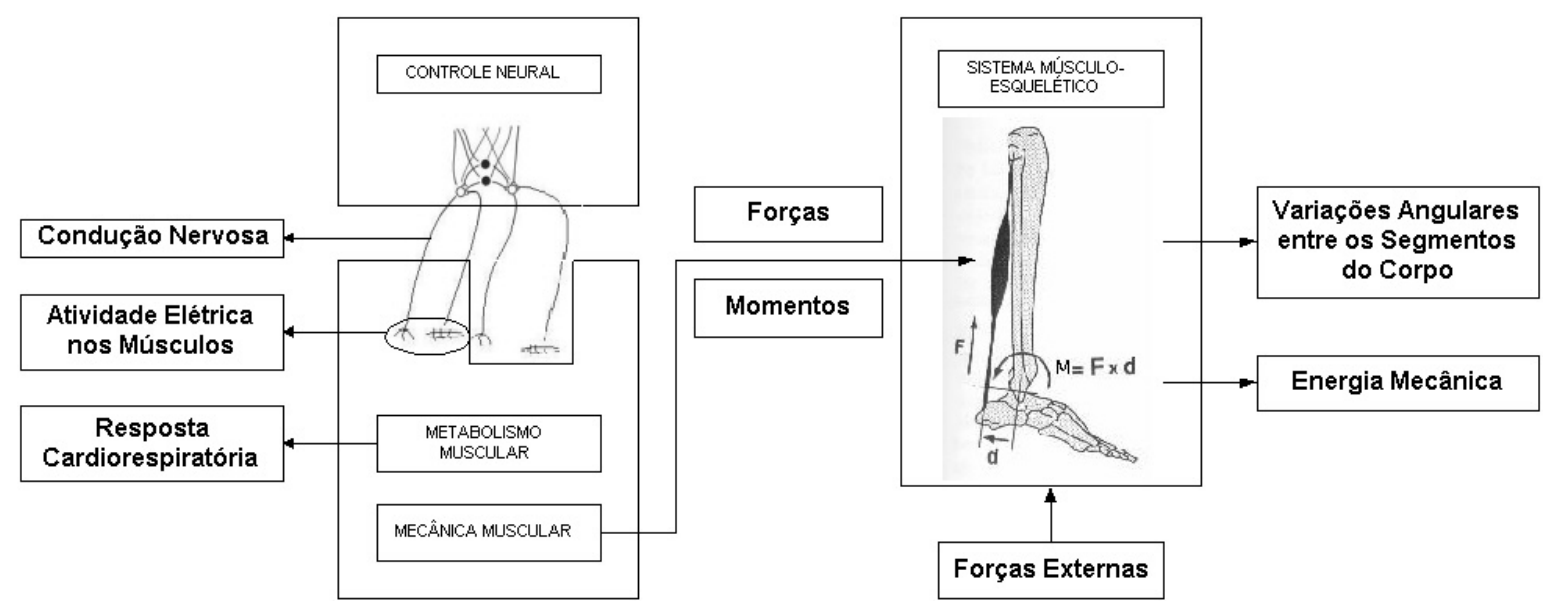

Figura 3.6: Esboço do processamento realizado no ser humano para a realização da locomoção. Também são apresentadas as variáveis utilizadas para avaliação do aparelho locomotor e das características da locomoção (figura inspirada por Winter 1990).

Todas as regiões do sistema nervoso estão envolvidas na locomoção. Porém, estando o corpo em equilíbrio, a locomoção passa a depender apenas de movimentos rítmicos dos membros, atribuídos aos geradores centrais de padrões (GCP). Há uma suposição de que um GCP envolve três tipos de células. Células de dois tipos atuam entre si, alternando as atividades entre os dois grupos de forma cíclica, e provêm saídas para motoneurônios (inferiores) dos músculos envolvidos na locomoção. O terceiro tipo de célula seria responsável por entradas que pudessem suprimir, ou excitar, as células dos outros grupos e também modificar as relações entre eles, podendo desta forma controlar o funcionamento de todo o sistema (Latash 1998).

Os motoneurônios inferiores são células que inervam diretamente as fibras musculares esqueléticas. Seus corpos celulares ficam no corno ventral da medula espinhal. Seus axônios saem da medula espinhal pela raiz ventral, seguindo pelo nervo espinhal correspondente e em seguida pelo nervo periférico até atingir um músculo esquelético. Há dois tipos de motoneurônios inferiores : os motoneurônios alfa e os motoneurônios gama. Os axônios dos motoneurônios alfa induzem a contração das fibras extrafusais do músculo, e os motoneuronios gama inervam as fibras intrafusais, que fazem parte do órgão sensorial do músculo, o fuso muscular (Lundy-Ekman 2000).

Os axônios dos motoneurônios alfa se ramificam em muitas terminações conforme se aproximam do músculo. Cada terminação finda na junção neuromuscular (sinapse entre o nervo e o músculo) de uma única fibra. Um motoneurônio alfa e todas as fibras musculares que ele inerva são chamados de unidade motora. Sempre que um motoneurônio alfa entra em atividade, um neurotransmissor é liberado em todas as junções neuromusculares e todas as fibras musculares inervadas por este neurônio se contraem.

Tanto o motoneurônio alfa quanto a fibra muscular esquelética realizam suas ações, transmissão de informação e contração respectivamente, através da propagação 
de potenciais elétricos, denominados potenciais de ação. O processo através do qual ocorre a geração e a condução dos potenciais de ação é comum aos dois tipos de célula (Guyton 1988).

O potencial de ação ocorre devido a uma dependência entre a permeabilidade da membrana da célula aos ions sódio (abundantes no meio externo) em relação a uma diferença de potencial entre a membrana e os íons externos. O potencial de ação segue a lei do tudo-ou-nada, ou seja, a propagação da despolarização nas células dependerá de que um estímulo externo alcance o limiar mínimo necessário para a deflagração do sinal. Caso o estímulo externo seja maior que o necessário o sinal propagado terá as mesmas características daquele obtido através do valor de limiar. Logo após o potencial de repouso da membrana é restabelecido pela ação da bomba de sódio-potássio (que é disparada quando a quantidade de sódio na célula é aumentada) e pela difusão de íons.

Na fibra muscular esquelética, ao longo de sua propagação, o potencial de ação atinge os túbulos transversos e possibilita a liberação de ions cálcio do retículo sarcoplasmático. Os ions cálcio são difundidos rapidamente para os filamentos contráteis (miofibrilas) de actina e miosina, onde o ATP (adenosina trifosfato) é hidrolisado para produzir : ADP + calor + energia mecânica (tensão) (Winter 1990). Enquanto isso, a bomba de cálcio, continuamente ativa e localizada nas paredes do retículo sarcoplasmático, fazem com que os íons de cálcio retornem para o retículo sarcoplasmático.

Desta forma, o músculo esquelético pode ser visto como um motor que transforma energia química em mecânica, e pode-se considerar o ATP como seu combustível. No entanto, a quantidade de ATP armazenada no organismo é pequena, por isso ele deve ser continuamente ressintetizado com a mesma velocidade em que é desintegrado. Para unir o ADP com a molécula de fosfato é necessário realizar reações químicas que requerem carboidratos, gorduras, e oxigênio em alguns casos. Um dos subprodutos resultantes das reações é o dióxido de carbono (Waters 1992).

Os músculos esqueléticos são constituídos por fibras musculares esqueléticas envolvidas por várias camadas de tecido conectivo que sustentam extensas redes de vasos sanguíneos e nervos (Watkins 1999). Próximo às extremidades do músculo, as células contráteis desaparecem ficando apenas o seu revestimento de tecido conectivo, que fixa os músculos nos ossos. A união pode ocorrer em um ponto localizado, sendo chamado tendão, ou em uma região ampla, neste caso o feixe de tecido conectivo passa a ser aponeurose. Como um tendão reúne e transmite forças de muitas fibras musculares para uma pequena área do osso, o local normalmente é marcado por um tubérculo áspero. Já a aponeurose da origem a uma linha ou crista na região na qual está fixada (Gregor 1991).

A quantidade de força gerada pelo conjunto músculo-tendão depende de seu comprimento no momento da estimulação e da velocidade com a qual varia seu comprimento no decorrer da contração. A faixa de comprimento na qual a unidade músculo-tendão produz tensão está entre $75 \%$ e $175 \%$ de seu comprimento de repouso, aumentando a tensão 
com a sua extensão. Para um comprimento em particular, quanto maior for a velocidade de encurtamento menor será a tensão e quanto maior for a velocidade de alongamento maior será a tensão. A força gerada tem uma relação proporcional com a área da seção transversal de suas fibras musculares (Watkins 1999).

A maioria dos movimentos do corpo envolve a atividade simultânea de vários músculos, cada um desempenhando um papel específico (Fig. 3.7). Tais músculos possuem formatos diversos, e em muitos casos atuam em mais de uma articulação. Portanto, em um dado movimento, a magnitude e a direção da força resultante produzida por um músculo depende das componentes de força produzidas em várias partes do músculo. Isto ocorre devido ao controle seletivo das unidades motoras, que são recrutadas para atender a tarefas específicas.

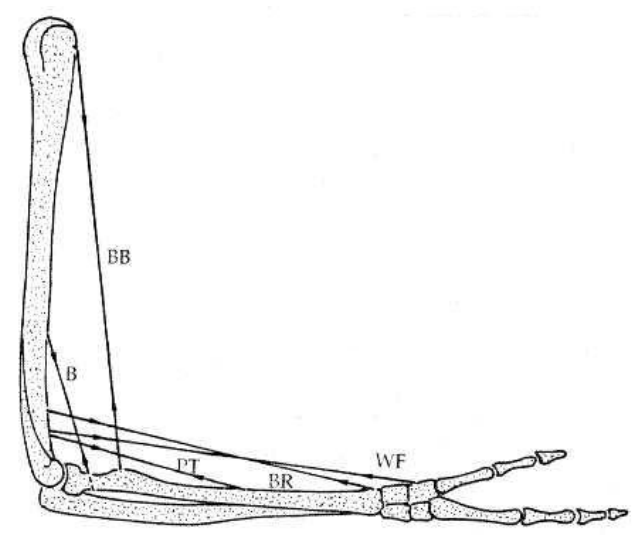

Figura 3.7: Linhas de ação dos músculos que contribuem para a flexão do cotovelo (figura extraída de Watkins 1999).

Os músculos possuem suas origens (conexão proximal entre o músculo e o osso) e inserções (conexão distal) arranjados de tal forma que o sistema musculo-esquelético funciona como um conjunto de alavancas. Os segmentos do corpo são os braços das alavancas, os centros das articulações são os fulcros, e as inserções dos músculos são os pontos de aplicação das forças. A maior parte dos músculos do corpo faz parte de sistemas de alavancas de primeira ou terceira classes (Fig. 3.8) (Watkins 1999, Garhammer 1991).

O fato dos músculos terem suas inserções próximas dos centros das articulações torna a estrutura do corpo compacta, e possui uma vantagem mecânica em relação à geração do movimento, pois uma pequena contração do músculo possibilitará um amplo movimento do final da alavanca (segmento do corpo). No entanto, precisará exercer grandes forças quando for necessário atuar sobre forças externas (Soutas-Little 1998).

A ação sobre os sistemas de alavancas tenderá a produzir movimentos que aproximarão, ou afastarão, segmentos adjacentes (braços das alavancas), movendo-os em torno de suas articulações (Fig. 3.9). O momento de força total sobre uma articulação será igual à taxa de variação em relação ao tempo do momento da quantidade de movimento sobre a articulação . Este momento de força total representará o somatório dos momentos de 


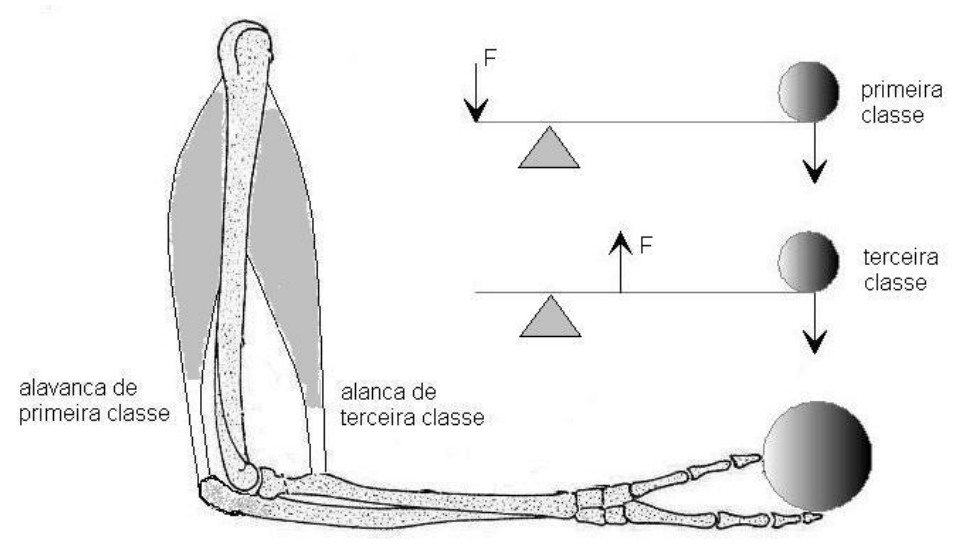

Figura 3.8: Alavancas de primeira e terceira classes (figura baseada em Garhammer 1991).

força resultantes da ação de todos os músculos envolvidos no movimento. Desta forma ele reflete o resultado da aplicação de todas as forças controladas pelo sistema nervoso central (Winter 1990). Na avaliação biomecânica do movimento, as curvas dos momentos de força possibilitam a análise do comportamento dos grupos musculares no decorrer do movimento (por exemplo, no movimento realizado na Fig. 3.9 poderia ser identificada a participação do grupo flexor, ou extensor).

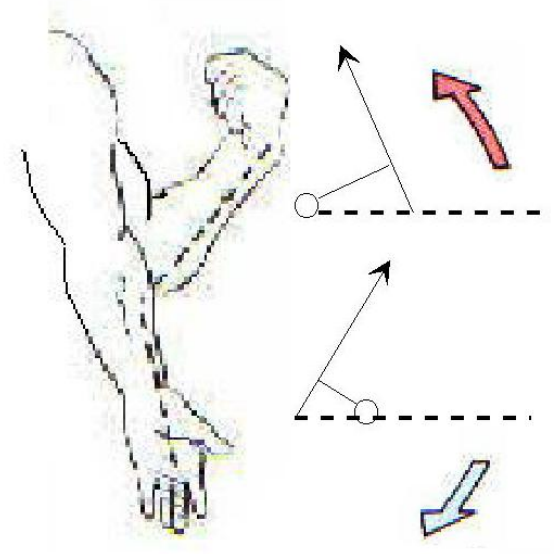

Figura 3.9: Variação angular entre os segmentos do corpo resultante do momento de força.

O produto do momento de força total da articulação pela velocidade angular desta articulação resulta na medida da potência. A potência é uma medida da taxa em relação ao tempo com que um sistema pode realizar trabalho, ou fornecer energia. Quando o músculo é contraído ou alongado ele poderá atuar para gerar ou absorver a energia mecânica necessária para a realização de um certo movimento. Portanto, a potência é uma medida importante para determinar a função de um músculo em um determinado instante do movimento. Especificamente, a potência terá um valor positivo quando a contração que gera o movimento for concêntrica (o músculo encurta com a tensão), ou seja, o momento de força atua na mesma direção que a velocidade angular da articulação 
(Fig. 3.10(a) e 3.10(b)). Caso contrário, a potência terá um valor negativo, e indicará uma contração excêntrica (o músculo alonga com a tensão), neste caso o momento de força atua em uma direção contrária à direção da velocidade angular da articulação (Fig. 3.10(c) e 3.10(d)) (Winter 1990).

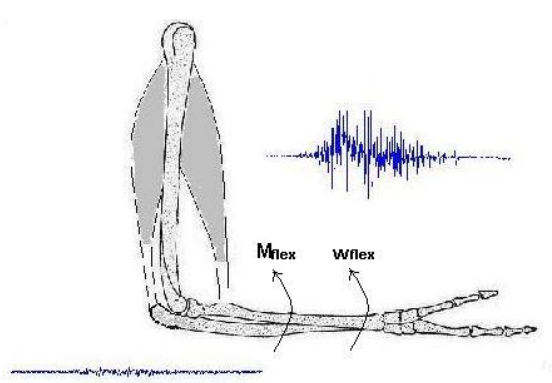

(a) Potência positiva.

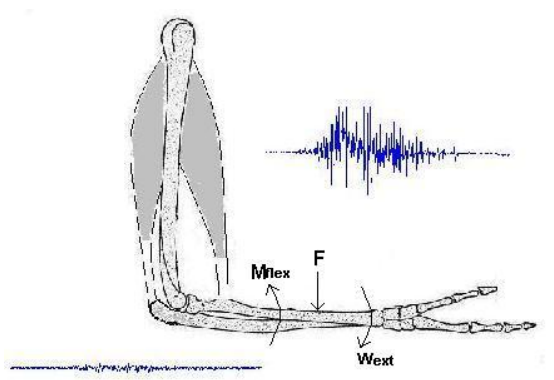

(c) Potência negativa

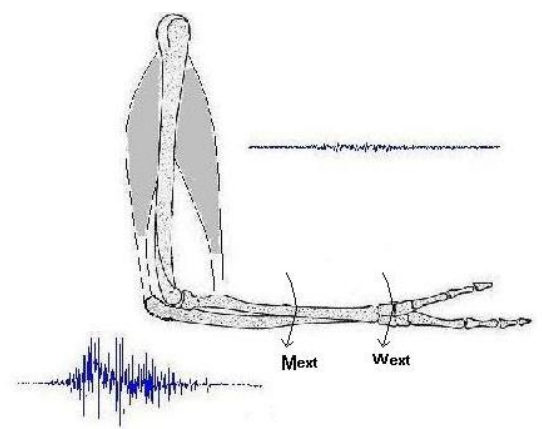

(b) Potência positiva.

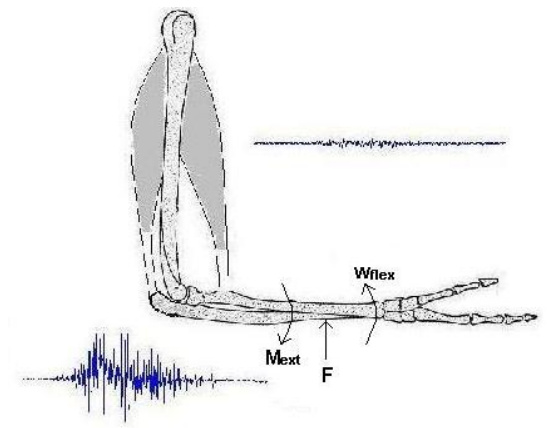

(d) Potência negativa

Figura 3.10: Potência positiva e potência negativa (figura baseada emWinter 1990).

É importante observar que os músculos esqueléticos estão arranjados de tal forma que só podem produzir movimentos rotatórios de segmentos do corpo ao redor dos eixos das articulações do esqueleto. Para ocorrer o deslocamento do corpo através do espaço, é necessário que o corpo exerça forças contra algum ponto externo, no caso da locomoção normal este ponto é o solo (Inman 1993).

Para realizar a descrição destes movimentos há uma padronização que define um conjunto de 3 planos e eixos de referência no ser humano (Fig. 3.11). Tais planos e eixos são definidos em relação à posição anatômica, que coloca o corpo ereto em uma superfície horizontal com os pés unidos e membros superiores pendentes ao lado do corpo com as palmas das mãos voltadas para frente (Rasch 1991).

Os 3 planos são perpendiculares entre si. O plano sagital (Fig. 3.11(c)) é posicionado na direção antero-posterior e divide o corpo em duas metades simétricas, uma à esquerda, e outra à direita. O plano transversal (Fig. 3.11(b)) é um plano horizontal 
que passa através do corpo dividindo-o em uma parte superior (cranial) e uma inferior (caudal). O plano coronal, ou frontal (Fig. 3.11(a)), divide o corpo nas partes anterior (ventral) e posterior (dorsal). Os 3 eixos formados pela interseção dos planos são : anteroposterior (interseção dos planos sagital e transversal), longitudinal (interseção dos planos sagital e frontal), e lateral-medial, ou frontal (interseção dos planos frontal e transversal).

No plano sagital ocorrem os movimentos de flexão e extensão, no plano coronal ocorrem os movimentos de abdução e adução, e no plano transversal ocorrem os movimentos em torno do eixo longitudinal do osso, como a rotação médio-lateral.

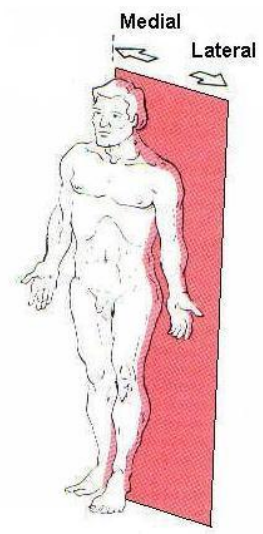

(a) Plano coronal.

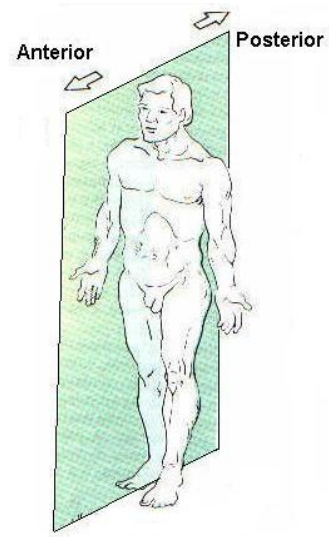

(c) Plano sagital.

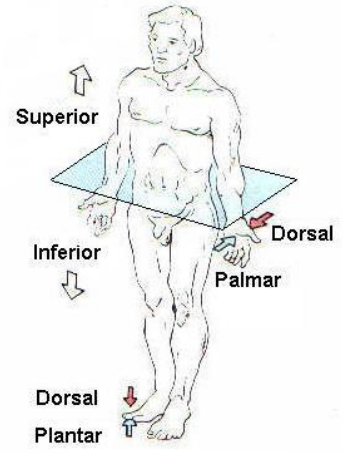

(b) Plano transversal.

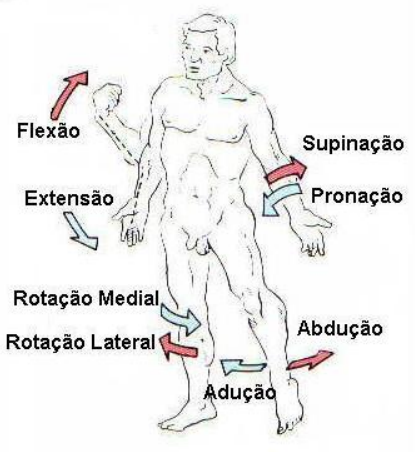

(d) Movimentos.

Figura 3.11: Descrição dos movimentos (baseado em Rasch 1991).

\subsection{Conclusão}

O movimento dos membros do corpo durante a locomoção é realizado com o intuito de minimizar o gasto energético. Seja minimizando a oscilação do centro de massa, ou convertendo a energia potencial obtida com sua elevação em energia cinética para o avanço 
do corpo. Este processo é conseqüente da movimentação dos diversos segmentos do corpo no espaço (plano coronal, sagital e transversal).

A marcha apresenta um padrão cíclico que pode ser dividido em fases. A avaliação da marcha pode ser realizada observando as funções específicas de cada fase.

Os parâmetros mais acessíveis para a descrição do desempenho da marcha são os parâmetros temporais e espaciais, cujo conjunto é denominado por características da passada.

No entanto, a avaliação completa da locomoção envolve as variáveis associadas à condução nervosa, atividade elétrica nos músculos, resposta cardiorespiratória, forças e momentos gerados pelos músculos, energia mecânica gerada ou absorvida, forças externas aplicados ao sistema músculo-esquelético, variações angulares no espaço entre os segmentos do corpo. 


\section{Capítulo 4}

\section{Materiais e Métodos}

Este capítulo apresentará o procedimento adotado para descrição da locomoção, as principais características dos pacientes examinados, os equipamentos usados, o processamento dos dados coletados, o procedimento para montagem do laboratório, e a preparação do paciente para o exame.

\subsection{Metodologia adotada para a descrição da loco- moção}

Foram selecionados 5 pacientes com lesão torácica, habituados ao uso do estimulador elétrico de 4 canais para deambulação, que fazem parte do programa de reabilitação do Ambulatório de Ortopedia do Hospital de Clínicas da Unicamp.

Cada paciente participou de um exame que envolveu várias coletas de dados, realizadas no mesmo dia. Do conjunto de amostras obtidas foram selecionadas 5 para gerar curvas e calcular médias.

Os exames envolveram coleta síncrona de dados de cinemática, eletromiografia e da componente vertical da força de reação do solo (Fig. 4.1).

Um sistema de captura do movimento (Qualisys) constituído por 5 câmeras foi usado para obter dados da cinemática da locomoção dos pacientes. Com tal sistema pode-se obter as características da passada, mensuração tridimensional dos ângulos nas articulações dos tornozelos, joelhos, quadris, ombros e cotovelos. Também foram obtidas as variações angulares para a pélvis e o tronco.

Oito canais de um eletromiógrafo de 16 canais (Noraxon) foram usados para obter sinais mioelétricos de músculos que são importantes para a sustentação do corpo no andador e a propulsão do corpo durante o balanço. Os músculos monitorados, bilateralmente, foram: peitoral maior (porção esternal), deltóide médio, cabeça longa do tríceps e extensor radial do carpo. Os sinais foram processados após a coleta com o intuito de apresentar com maior clareza seu conteúdo. 


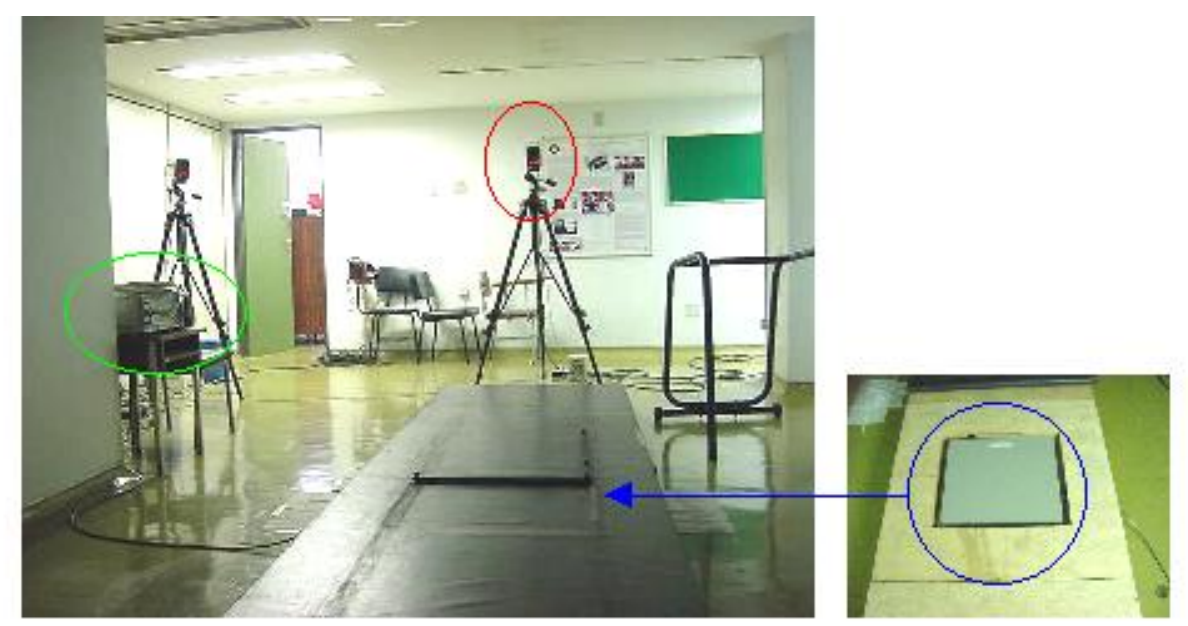

Figura 4.1: Equipamentos usados, da esquerda para a direita: eletromiógrafo (círculo verde), unidade de captura do movimento (círculo vermelho) e plataforma de força (círculo azul).

A componente vertical da força de reação do solo foi obtida usando uma plataforma de força AMTI. A plataforma foi posicionada no centro de uma passarela de madeira sobre a qual o paciente deambulava. Como o passo realizado pelo paciente nas circunstâncias deste exame era muito curto, ele ficava em alguns momentos com os dois pés sobre a plataforma. Isto impossibilitou o cálculo dos momentos nas articulações dos membros inferiores. No entanto, sabendo o peso do paciente e a componente vertical de reação do solo, seja com um pé sobre a plataforma durante o suporte simples, ou os dois pés durante o suporte duplo, a componente vertical da força de reação do solo foi usada para avaliar a parcela de peso sustentado pelos membros superiores.

O conjunto de dados resultante foi relacionado dentro de subdivisões do ciclo baseadas naquelas apresentadas na Sec. 3.2, no entanto adaptadas para as condições dos exames deste projeto (Tab. 4.1). O ciclo foi dividido em 10 fases, definidos por 11 eventos. Os dados para todos os pacientes foram apresentados no ciclo direito. Como as informações sobre a atividade de contração muscular nos membros superiores e a distribuição do peso do paciente entre os membros superiores e inferiores, possuem uma relação direta com os eventos do balanço, tanto esquerdo quanto direito, ao invés de definir no início do ciclo eventos relacionados ao membro de apoio os eventos foram relacionados ao balanço contralateral. Além disto foram acrescentados eventos relacionados ao uso do andador.

O ciclo foi dividido através da seguinte seqüência de eventos: contato inicial direito (CID), início do avanço do andador (IAA), início do balanço esquerdo (IBE), desprendimento do pé esquerdo (DPE), meio do balanço esquerdo (MBE), contato inicial esquerdo (CIE), início do avanço do andador (IAA), início do balanço direito (IBD), desprendimento do pé direito (DPD), meio do balanço direito (MBD), contato inicial 
Tabela 4.1: Divisão adotada para análise do ciclo direito.

\begin{tabular}{|c|c|c|c|c|c|c|c|c|c|c|}
\hline$\frac{\text { Fases }}{\text { Periodos }}$ & $\begin{array}{l}\text { Aceitação de } \\
\text { Peso - Direita } \\
\text { (1) }\end{array}$ & $\begin{array}{l}\text { Avanço do } \\
\text { Andador } \\
\text { (2) }\end{array}$ & $\begin{array}{l}\text { Pré-Balanço } \\
\text { Esquerdo } \\
\text { (3) }\end{array}$ & $\begin{array}{l}\text { Balanço Inicial } \\
\text { Esquerdo } \\
\text { (4) }\end{array}$ & $\begin{array}{l}\text { Balanço Final } \\
\text { Esquerdo } \\
\text { (5) }\end{array}$ & $\begin{array}{c}\text { Aceitacão de } \\
\text { Peso - Esquerda } \\
\text { (6) }\end{array}$ & $\begin{array}{c}\text { Avanco do } \\
\text { Andador } \\
(7)\end{array}$ & $\begin{array}{l}\text { Pré-Balanço } \\
\text { Direito } \\
\text { (8) }\end{array}$ & $\begin{array}{l}\text { Balanço Inicial } \\
\text { Direito } \\
\text { (9) }\end{array}$ & $\begin{array}{c}\text { Balanço Final } \\
\text { Direito } \\
\text { (10) }\end{array}$ \\
\hline $\begin{array}{l}\text { Primeiro Suporte } \\
\text { Duplo }\end{array}$ & $C I D \rightarrow \mid A A_{-} 1$ & IAA_1 $>$ IBE & $\mathrm{IBE} \rightarrow \mathrm{DPE}$ & & & & & & & \\
\hline $\begin{array}{c}\text { Suporte Simples } \\
\text { Direito }\end{array}$ & & & & $\mathrm{DPE} \rightarrow \mathrm{MBE}$ & $\mathrm{MBE} \rightarrow \mathrm{CIE}$ & & & & & \\
\hline $\begin{array}{c}\text { Segundo Suporte } \\
\text { Duplo }\end{array}$ & & & & & & $C I E \rightarrow \mid A A_{-} \_2$ & IAA_2 $\rightarrow$ IBD & $\mathrm{IBD}>\mathrm{DPD}$ & & \\
\hline $\begin{array}{c}\text { Suporte Simples } \\
\text { Esquerdo }\end{array}$ & & & & & & & & & $\mathrm{DPD} \rightarrow \mathrm{MBD}$ & $\mathrm{MDB} \rightarrow \mathrm{CID} \_2$ \\
\hline
\end{tabular}

direito (CID). Resultando em 10 fases.

Do CID ao IAA, e do CIE ao IAA, temos fases correspondentes à aceitação do peso. Do IAA ao IBE, e do IAA ao IBD, temos as fases de avanço do andador. Do IBE ao DPE, temos o pré-balanço esquerdo, e do IBD ao DPD temos o pré-balanço direito. Do DPE ao MBE temos os balanço esquerdo inicial, e do DPD ao MBD temos o balanço direito inicial. Finalmente, do MBE ao CIE temos os balanço esquerdo final, e do MBD ao CID temos o balanço direito final.

\subsection{Pacientes}

Tabela 4.2: Dados dos pacientes

\begin{tabular}{ccccccc}
\hline Nome & Idade & Nível da lesão & Causa & $\begin{array}{c}\text { Tempo da lesão } \\
(\text { anos })\end{array}$ & $\begin{array}{c}\text { Peso } \\
(\mathrm{Kg})\end{array}$ & $\begin{array}{c}\text { Altura } \\
(\mathrm{m})\end{array}$ \\
\hline \hline $\mathrm{A}$ & 29 & $\mathrm{~T} 10$ & Acidente autom & 6 & 51 & 1,69 \\
$\mathrm{~B}$ & 28 & $\mathrm{~T} 4$ & Acidente autom & 5 & 55 & 1,69 \\
$\mathrm{C}$ & 33 & $\mathrm{~T} 11$ & Acidente autom & 14 & 83 & 1,76 \\
$\mathrm{D}$ & 32 & $\mathrm{~T} 2$ & Arma de fogo & 13 & 70 & 1,75 \\
$\mathrm{E}$ & 35 & $\mathrm{~T} 11$ & Cirurgia & 3 & 80 & 1,80 \\
\hline \hline
\end{tabular}

\subsection{Estimulador elétrico}

O estimulador usado foi projetado por um estagiário para atender os requerimentos necessários para possibilitar a excitação controlada de fibras nervosas, e seu princípio de funcionamento é o mesmo do estimulador apresentado na Sec. 2.5. O sinal aplicado é uma série de pulsos elétricos retangulares monofásicos, cujos parâmetros (amplitude, freqüência, duração de um único pulso, e duração de um trem de pulsos) são baseados em pesquisas empíricas da neurofisiologia. Os parâmetros do sinal provido pelo estimulador são: 
- Amplitude $\rightarrow$ até $200 \mathrm{~V}$ (para uma impedância de $1 \mathrm{k} \Omega$ );

- Freqüência $\rightarrow 25 \mathrm{~Hz}$;

- Duração de um único pulso (on/off) $\rightarrow 100 \mu$ s;

- Duração de um trem de pulsos (3 pulsos) $\rightarrow 300 \mu$ s.

O estimulador ficava em uma posição fixa durante a realização do exame, sendo o sinal enviado através de um cabo conectado a um terminal anexado ao andador, do qual saiam os fios para os eletrodos posicionados no paciente como pode ser visto na Fig. 4.2.

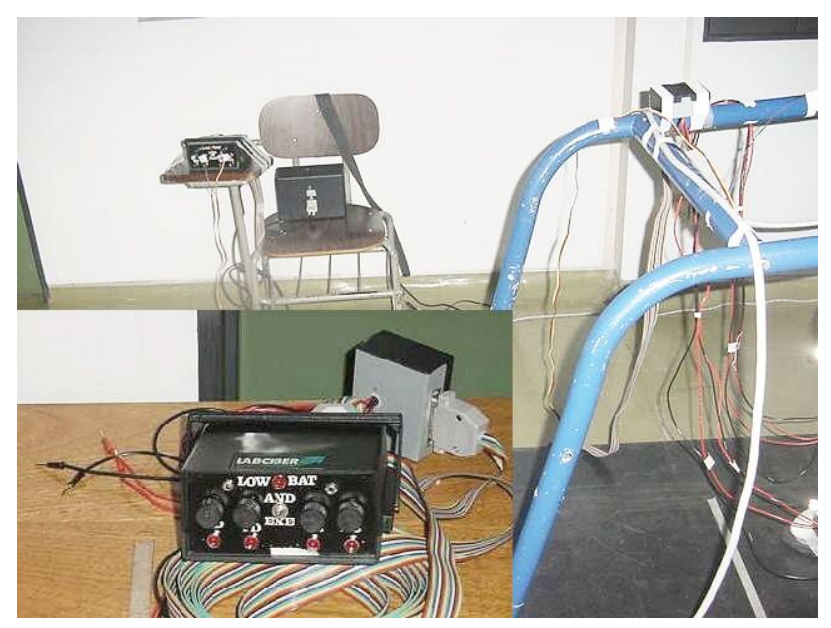

Figura 4.2: Estimulador elétrico

\subsection{Cinemática}

Os ângulos formados pelos segmentos superiores e inferiores foram avaliados através de modelos biomecânicos definidos por marcadores posicionados em pontos anatômicos (normalmente protuberâncias ósseas) escolhidos por apresentarem facilidade de localização, variação em relação à estrutura óssea interna menor que a encontrada na superfície da musculatura, facilitação para avaliação dos centros das articulações e para identificação dos eixos longitudinais dos ossos.

Os modelos biomecânicos avaliam os ângulos formados entre os vetores obtidos a partir das coordenadas tridimensionais dos marcadores. Estas coordenadas são resultantes de um processo de reconstrução tridimensional que usa as coordenadas bidimensionais dos marcadores obtidas por cada câmara. Tais câmaras operam na faixa do infravermelho para facilitar o processamento das imagens necessário para obter as coordenadas dos marcadores.

Os marcadores foram feitos com esferas de polietileno, de aproximadamente $20 \mathrm{~mm}$, revestidas com material refletivo. As esferas foram lixadas para formar uma 
base necessária para possibilitar a aderência do marcador na superfície do corpo do paciente. Os marcadores foram fixados à bases de plástico, através de botões de pressão, para aumentar a área de aderência. A fixação do marcador sobre o paciente foi realizada passando micropore sobre a base plástica. A Fig. 4.3 apresenta um marcador.

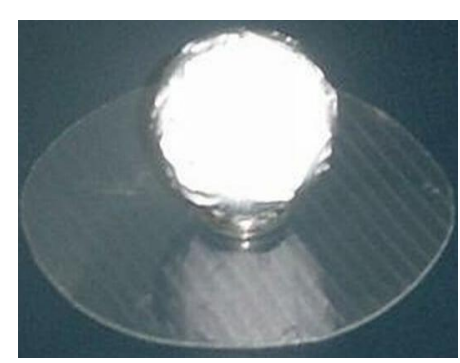

(a) Marcador montado.

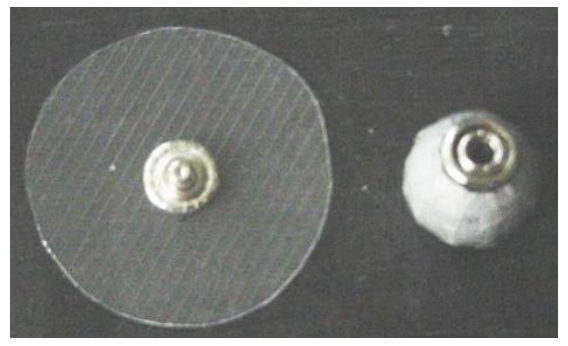

(b) Marcador separado da base.

Figura 4.3: Marcador refletivo.

Embora o laboratório disponha de 6 câmaras (ProReflex 240), foram usadas apenas 5 devido à restrição imposta pela área usada para a montagem. O fabricante do sistema de captura do movimento (Qualisys) indica a necessidade de uma área de 10 metros de comprimento por 6 metros de largura, indicada na Fig. 4.4 pela região em cinza, para a captura bilateral da marcha. Neste caso, há espaço suficiente para distribuir as 6 câmaras de tal forma que os ângulos formados entre elas não sejam pequenos, que implicaria em erro na mensuração. Como a área disponível (região quadriculada) é muito menor, foi necessário reduzir o número de câmeras para garantir a angulação mínima indicada $\left(30^{\circ}\right)$ com o intuito de evitar os erros na mensuração (Nester 2000). O critério usado para determinar as posições das 5 câmeras em torno do tablado (sobre o qual os pacientes deambulam) foi obter um arranjo onde houvesse simetria nessa distribuição, e cobertura adequada do volume de mensuração necessário para a realização dos exames.

Os equipamentos eram posicionados nos dias de realização dos exames e guardados após o final dos mesmos, por isso, houve a necessidade de estabelecer referências para garantir a reprodutibilidade das características dos exames. Aproveitando que o piso do laboratório é revestido por peças quadradas $(30 \mathrm{~cm}$ x $30 \mathrm{~cm})$ foi estabelecido que cada peça corresponde a uma unidade de medida, e a origem como sendo a extremidade superior esquerda na Fig. 4.4 (indicado pela seta vermelha), formando um sistema de coordenadas. Desta forma o posicionamento dos tripés (quadrados amarelos), tablados (onde os pacientes deambulam - região verde), e da plataforma de força (região azul) foram obtidos contando os "quadrados", ou através de marcas fixadas nos pontos pré-estabelecidos.

Os ângulos de orientação das câmaras, e as alturas dos tripés, foram determinados por experimentação, com o propósito de cobrir adequadamente o volume de mensuração. Para isto foram posicionadas hastes com marcadores nas extremidades do volume 


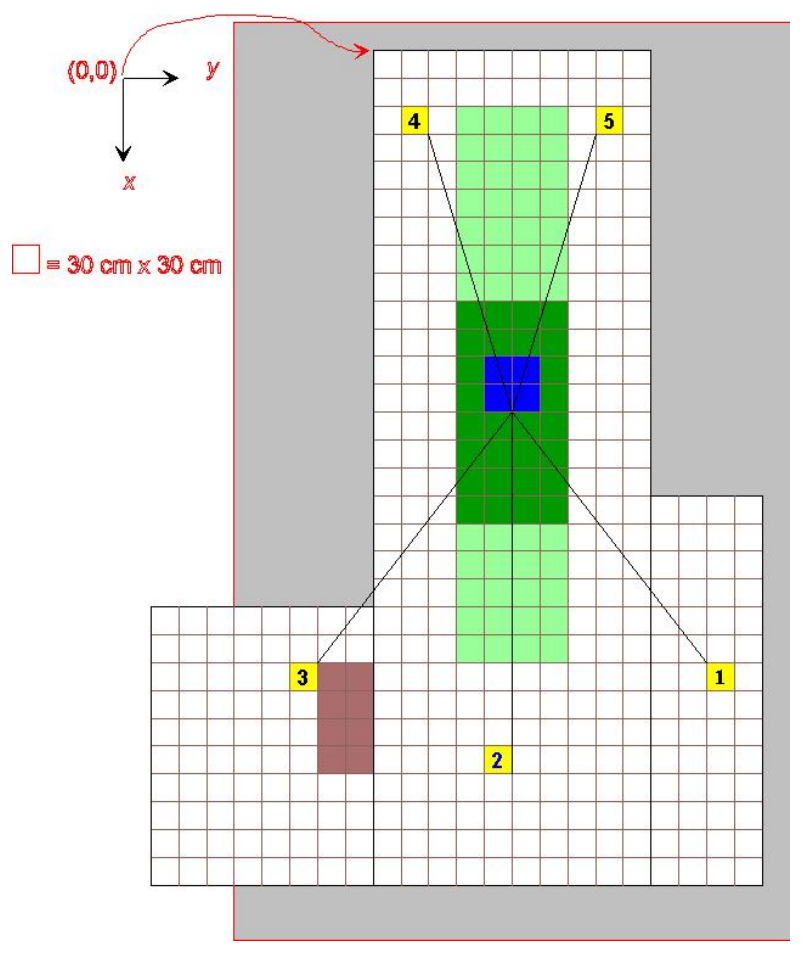

Figura 4.4: Esboço da distribuição das unidades de captura do movimento (quadrados amarelos numerados de 1 a 5), do posicionamento do tablado sobre o qual os pacientes deambulam (região verde), e da plataforma de força (região azul). A região marrom corresponde a área de uma coluna presente no local. A região em cinza representa a área indicada para o uso do sistema neste tipo de aplicação.

(Fig. 4.5(a)). As hastes foram construídas com madeira, tendo ao longo delas perfurações que possibilitaram o ajuste dos suportes dos marcadores, usados como referência. Os suportes de marcadores foram posicionados nas alturas relativas aos tornozelos, quadris e ombros. A orientação da câmera tornava-se adequada quando o volume de mensuração estava centralizado no plano de cada câmera, e quando todos os marcadores das hastes estavam presentes no mesmo, como pode ser visto na Fig. 4.5(b). Os marcadores usados como referências foram os mesmos aplicados nos pacientes. Após o ajuste inicial, as alturas dos tripés (Fig. 4.6(a)) e os ângulos aproximados de orientação das câmaras (3 ângulos definidos por transferidores do suporte da câmera como pode ser visto na Fig. 4.6(b)) foram registrados, e estão descritos na Tab. 4.3. Nas montagens para a realização de cada exame, estes valores eram usados para uma orientação inicial, e as hastes utilizadas para o ajuste final. 


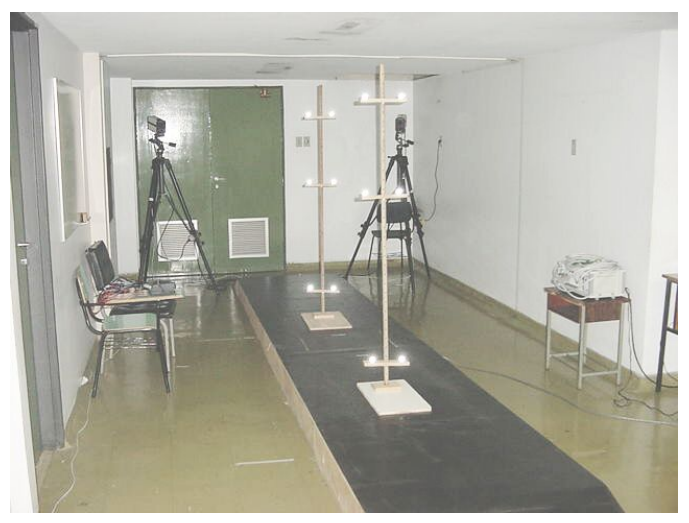

(a) Posicionamento das hastes.

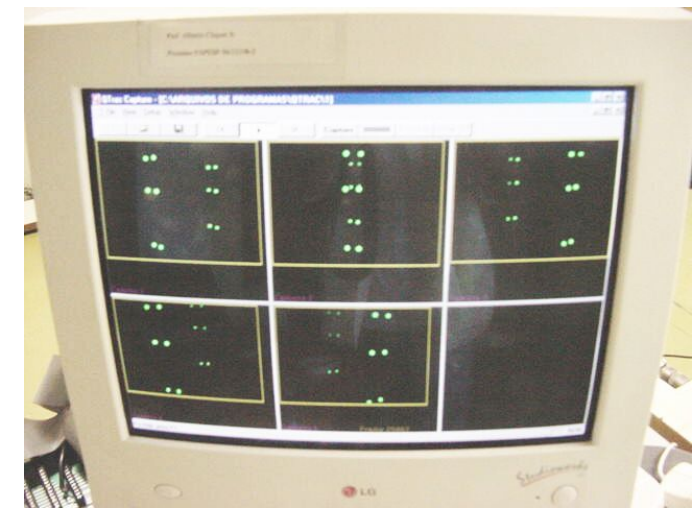

(b) Ajuste da orientação das cameras usando as hastes.

Figura 4.5: Hastes.

Tabela 4.3: Posicionamento e orientação das cameras

\begin{tabular}{cccccc}
\hline Camera & Posição & Altura do tripé & "Yaw" & "Pitch" & "Roll" \\
\hline \hline 1 & $(23,13)$ & $124 \mathrm{~cm}$ & $45^{\circ}$ & $5^{\circ}$ & $0^{\circ}$ \\
2 & $(26,5)$ & $122 \mathrm{~cm}$ & $90^{\circ}$ & $10^{\circ}$ & $0^{\circ}$ \\
3 & $(23,-3)$ & $140,5 \mathrm{~cm}$ & $120^{\circ}$ & $15^{\circ}$ & $0^{\circ}$ \\
4 & $(3,1)$ & $146 \mathrm{~cm}$ & $-120^{\circ}$ & $15^{\circ}$ & $0^{\circ}$ \\
5 & $(3,9)$ & $145 \mathrm{~cm}$ & $-70^{\circ}$ & $15^{\circ}$ & $0^{\circ}$ \\
\hline \hline
\end{tabular}

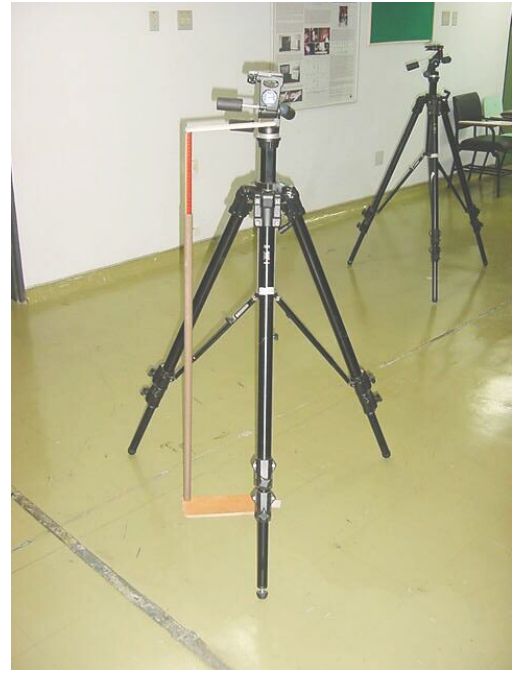

(a) Ajuste da altura do tripé

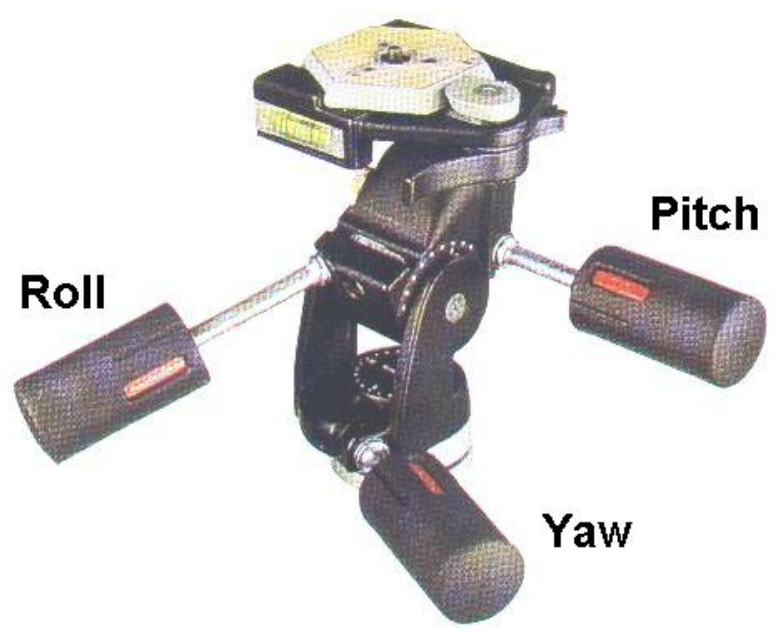

(b) Suporte da câmera

Figura 4.6: Ajuste da altura do tripé e da orientação do suporte da câmera.

Após orientar as câmeras, a abertura foi ajustada para otimizar a identificação dos marcadores. A abertura permite controlar a quantidade de luz transmitida para 
os sensores da câmera. Desta forma, quando a abertura aumenta a quantidade de luz transmitida para os sensores aumenta. O efeito conseqüente é um aumento no grupo de pixels que representa um dado marcador. Dependendo da proximidade de marcadores isto poderá implicar na interpretação de dois grupos de pixels como apenas um, ou seja, dois marcadores próximos podem ser reconhecidos como apenas um.

O parâmetro de referência usado para controlar o ajuste da abertura foi o tamanho relativo. Os tamanhos dos marcadores detectados são expressos como percentuais das dimensões dos diâmetros dos marcadores, nas direções x e y, em relação ao campo de visão (1/1000 do FOV, FOV = field of view = campo de visão). As câmeras usadas possuem lentes com distância focal de $6 \mathrm{~mm}$, e campo de visão horizontal de $45^{\circ}$. Os tamanhos relativos dos marcadores são monitorados através do computador hospedeiro. Experimentalmente foi observado que para a montagem descrita anteriormente a identificação dos marcadores apresentava melhor resultado quando o tamanho relativo para marcadores (sobre as hastes) mais próximos da câmera ficava em torno de 7 (tanto na direção x quanto na y). Desta forma, na montagem de cada exame, com as hastes ainda posicionadas nas extremidades do volume de mensuração, após a orientação das câmeras, suas aberturas foram ajustadas para que os tamanhos relativos dos marcadores próximos fossem de aproximadamente 7 .

Vários parâmetros das câmeras podem ser ajustados por software: iluminação, freqüência, taxa de comunicação entre as câmeras e o computador, tamanhos relativos máximo e mínimo dos marcadores, e quantidade máxima de marcadores.

A iluminação é definida pela combinação de um conjunto de 3 grupos de leds. O grupo mais próximo da lente, com 40 diodos, é ativado quando os marcadores estão no máximo a 2,5 m de distância da câmera. Para marcadores a uma distância de 2,5 m a $4 \mathrm{~m}$ é acrescido um conjunto de 80 leds ao grupo anterior. Finalmente, outro grupo de leds, com 130 diodos, é acrescido quando os marcadores estão além de $4 \mathrm{~m}$. Para a realização dos exames todas as câmeras foram configuradas para trabalharem com os dois grupos de leds mais próximos da lente $(40+80$ diodos $)$.

As câmeras podem capturar os dados numa frequência de $1 \mathrm{~Hz}$ a $240 \mathrm{~Hz}$. A freqüência selecionada nos exames foi de $60 \mathrm{~Hz}$. A taxa de transferência de bits das câmeras para o PC hospedeiro pode variar entre $9,6 \mathrm{kBit} / \mathrm{s}$ e $2.048 \mathrm{kBit} / \mathrm{s}$. Normalmente os exames foram realizados com uma taxa de $256 \mathrm{kBit} / \mathrm{s}$, no entanto quando havia problema de comunicação esta taxa era reduzida para $128 \mathrm{kBit} / \mathrm{s}$.

As câmeras podem filtrar os dados capturados especificando-se a quantidade máxima e os tamanhos relativos, máximo e mínimo, dos marcadores. As câmeras "varrem" o campo de visão de cima para baixo, então quando o número de marcadores da imagem excede o máximo estabelecido, os últimos marcadores serão rejeitados. O tamanho relativo máximo permitido é 100, e o mínimo 1. Neste trabalho, usamos um máximo de 30 marcadores, tamanho relativo máximo 15 e tamanho relativo mínimo 1. 
Como as câmeras iluminam a área com seus leds emissores de luz na faixa do infravermelho, dependendo da orientação das câmeras, surgem pontos de reflexo (normalmente no chão ou em quadros de parede presentes nas proximidades das câmeras). Estes pontos de reflexo devem ser eliminados para não prejudicar o processo de reconstrução dos marcadores. Os pontos de reflexo são eliminados colocando uma cobertura (neste trabalho foi usado papel toalha) sobre a superfície na qual aparecem.

O cálculo das coordenadas tridimensionais dos marcadores requer parâmetros externos das câmeras (suas localizações e orientações) que são obtidos através do procedimento de calibração. A calibração utiliza os arquivos de linearização individuais das câmeras (providos pelo fabricante), que contêm os parâmetros internos das câmeras, para correção de não-linearidades nas posições dos marcadores. E utiliza uma coleta das posições bidimensionais de 4 marcadores estáticos e de um par de marcadores em movimento no volume de calibração.

O marcador no vértice da estrutura em "L" (Fig 4.7(b)) , que contem os 4 marcadores estáticos, representa a origem do sistema de coordenadas global. O eixo Y, com dois marcadores, é perpendicular ao plano sagital, com variação positiva no sentido médiolateral. O eixo Y, em todos os exames, foi posicionado rente à borda anterior da plataforma de força (Fig 4.7(a)). O eixo X, com 3 marcadores, é perpendicular ao plano coronal, e possui variação positiva no sentido da progressão do movimento, postero-anetrior. O eixo $\mathrm{Z}$ é perpendicular ao plano transversal com varição positiva no sentido distal-proximal. O segmento Y da estrutura em "L" possui $550 \mathrm{~mm}$ (entre os centróides dos marcadores), e o segmento X possui $750 \mathrm{~mm}$, com um marcador intermediário distante $200 \mathrm{~mm}$ da origem.

Os dois marcadores usados para "varrer" o volume de calibração ficam fixos nas extremidades de um bastão de 750,3 mm. Durante a calibração este bastão deve ser movido ao longo do volume de calibração (Fig 4.7(a)) sendo orientado de acordo com os três eixos do sistema de coordenadas global. O tempo disponível para o deslocamento do bastão no volume de calibração foi de $26 \mathrm{~s}$, sendo que foi especificado o uso de 100 quadros ( selecionados de 15 em 15 quadros) para a calibração. 


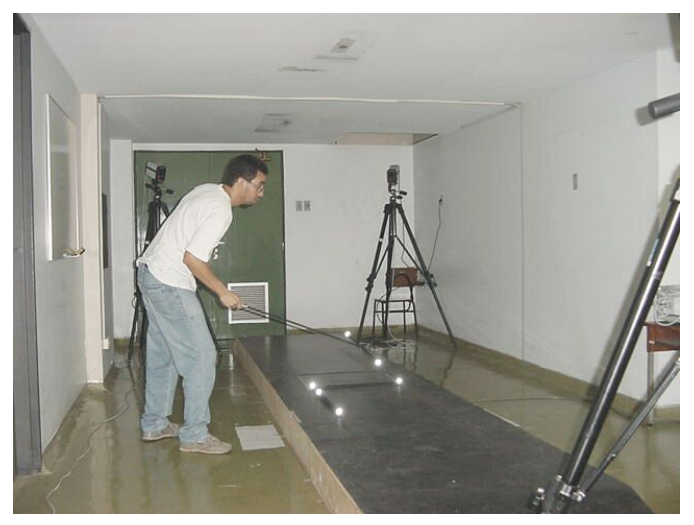

(a) Calibração

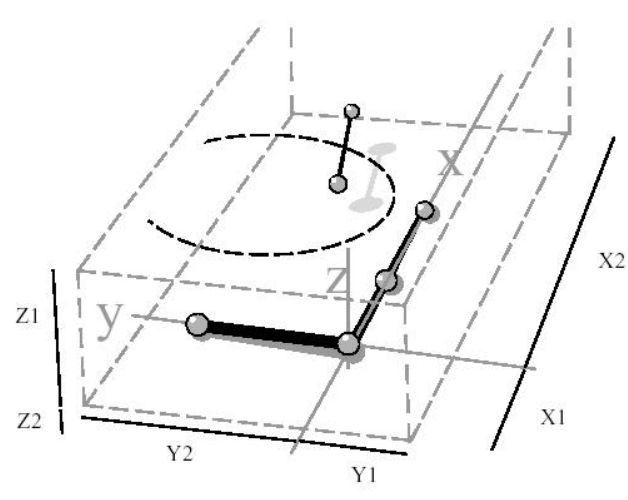

(b) Volume de calibração

Figura 4.7: Calibração do sistema de captura do movimento.

Tabela 4.4: Volume de calibração

\begin{tabular}{cccc}
\hline Limite & $\mathrm{X}$ & $\mathrm{Y}$ & $\mathrm{Z}$ \\
\hline \hline 1 & $-1200 \mathrm{~mm}$ & $-240 \mathrm{~mm}$ & $-30 \mathrm{~mm}$ \\
2 & $1200 \mathrm{~mm}$ & $780 \mathrm{~mm}$ & $1700 \mathrm{~mm}$ \\
\hline \hline
\end{tabular}

São necessárias várias câmeras porque o marcador precisa ser visto simultaneamente por diferentes ângulos para possibilitar o cálculo de suas coordenadas tridimensionais. Este cálculo envolve as coordenadas bidimensionais obtidas e os dados resultantes do processo de calibração. O software usado para realizar esta tarefa, o QTrac, requer a atribuição de valores para parâmetros que definirão o processo de reconstrução, dois deles são particularmente importantes: o erro de predição e resíduo máximo.

Durante o processo de reconstrução o QTrac constrói segmentos que são resultantes da identificação contínua de marcadores em uma seqüência de quadros de imagem. A formação destes segmentos requer a busca do marcador nos quadros consecutivos, baseando-se no movimento realizado nos quadros anteriores. A trajetória do marcador é calculada, no entanto como a posição avaliada matematicamente poderá não corresponder ao valor real, é estimada uma região, baseada em uma margem de erro, na qual o marcador poderá ser encontrado no quadro seguinte. Esta região é definida pelo erro de predição. O ideal é configurar o erro de predição para que o rastreador encontre o marcador correto, desta forma o seu valor dependerá da distância entre os marcadores. Se a distância entre os marcadores for grande e o movimento for irregular, o erro de predição deverá ser grande, caso contrário pequeno. O valor do erro de predição usado para o processamento dos dados dos exames foi de $30 \mathrm{~mm}$.

Resíduo é a distância que o valor calculado para uma câmera difere do valor tridimensional calculado, sendo este último o valor médio que melhor se ajusta a todas as câmeras. O valor do resíduo máximo normalmente fica entre 2 e 5 vezes o valor do 
resíduo médio, obtido durante a calibração. O valor do resíduo máximo é utilizado em conjunto com o valor do erro de predição no cálculo das trajetórias tridimensionais dos marcadores. O valor do resíduo máximo adotado para o processamento dos exames foi $10 \mathrm{~mm}$.

O resultado da reconstrução é um arquivo constituído por um conjunto de segmentos. O ideal seria que o número de segmentos fosse igual ao número de marcadores. No entanto, como há falhas (por exemplo, a ausência de marcadores em alguns quadros), cada vez que a trajetória de um dado marcador é interrompida, ocorre a formação de um novo segmento. Por isso, é necessário fazer a identificação (nomeação) dos diversos segmentos correspondentes à trajetória do mesmo marcador. Após esta identificação, é gerado um arquivo onde os dados foram filtrados e as trajetórias interpoladas. Neste arquivo final o número de segmentos corresponde ao número de marcadores utilizados no exame.

Para gerar este arquivo final é necessário selecionar um intervalo do arquivo inicial. Este intervalo deverá conter o ciclo da marcha para o qual as curvas de ângulos serão calculadas. O intervalo foi definido pelos eventos que determinam o ciclo, que são o primeiro e o segundo contatos iniciais direito. Os quadros (ou instantes de tempo) correspondentes a estes eventos foram selecionados através da verificação das projeções nos eixos X e Z dos marcadores dos calcanhares (direito e esquerdo), e das pontas dos pés (direito e esquerdo). Observando as curvas de tempo versus posição para estes marcadores, os eventos ficam claramente definidos.

Para o cálculo das curvas dos membros inferiores, por ser um requerimento do software utilizado (QGait), os intervalos iniciavam no primeiro contato inicial direito e terminavam no segundo desprendimento do pé esquerdo.

Foi usado um protocolo de posicionamento de marcadores sobre a pele desenvolvido inicialmente em Oxford e depois aprimorado no Laboratório de Lundberg. O QGait calculava, para esta configuração, as variações angulares, no espaço, das articulações dos membros inferiores (quadris, joelhos e tornozelos), da pélvis, e do tronco.

Os marcadores foram posicionados nos seguintes pontos anatômicos: décima segunda vértebra torácica e sacro; e bilateralmente, acrômio, espinha ilíaca ântero-superior, ponto médio da patela deslocado a $10 \mathrm{~mm}$ proximalmente de sua borda superior, lateralmente na linha articular do joelho, tuberosidade da tíbia, maléolo lateral, calcâneo, e o ponto médio entre o segundo e o terceiro metatarso distante proximalmente $10 \mathrm{~mm}$ da cabeça do metatarso.

As coordenadas dos marcadores são usadas para calcular os sistemas de coordenadas locais, embarcados nos segmentos. Estes sistemas de coordenadas locais são usados para calcular os ângulos entre os segmentos. A Fig. 4.8(a) mostra os sistemas de coordenadas locais calculados pelo QGait para a pélvis e para o tronco. Para o cálculo dos sistemas de coordenadas locais dos segmentos inferiores é necessário avaliar inicialmente a 
posição dos centros de suas articulações (quadris, joelhos e tornozelos), para isto o QGait calcula dois sistemas de coordenadas primários, um na pélvis e outro na canela, que são mostrados na Fig. 4.8(b). As posições dos centros das articulações são definidas por equações que envolvem os vetores dos sistemas de coordenadas primários, por parâmetros que descrevem a posição relativa dos centros das articulações em relação a estes sistemas, por parâmetros de ajuste de escala para corpos com proporções diferentes, e pela distância do centro do marcador para a superfície da pele.

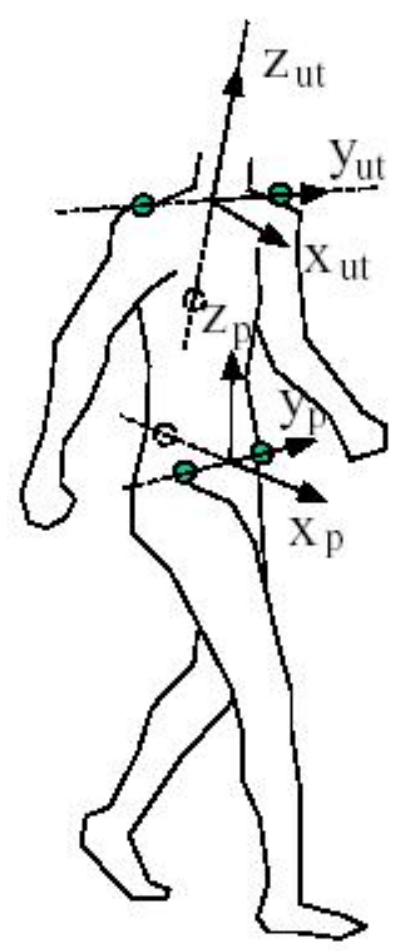

(a) Tronco

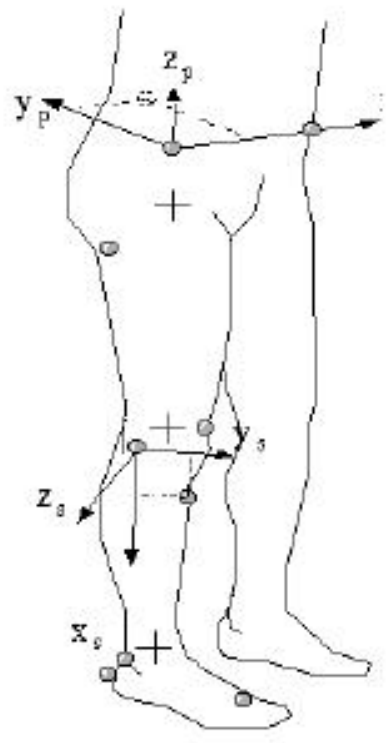

(b) Membros inferiores

Figura 4.8: Modelos biomecânicos da Qualisys.

O modelo biomecânico para os membros superiores foi baseado no trabalho de Barchschmidt, Harris \& Simoneau (2001) e implementado no Matlab. Os sistemas de coordenadas locais (Fig. 4.9) foram construídos a partir das coordenadas tridimensionais dos marcadores posicionados nos seguintes pontos anatômicos: sétima vértebra cervical, fúrcula esternal, acrômios direito e esquerdo, epicôndilos umerais lateral e medial, estilóides radial e ulnar, espinhas ilíacas ântero-superiores direita e esquerda.

Antes da construção dos sistemas de coordenadas locais foi necessário filtrar as coordenadas dos marcadores. Foi usado um filtro passa-baixa Butterworth de segunda ordem, com freqüência de corte de $6 \mathrm{~Hz}$, de acordo com o descrito por Winter (1990). Isto porque, para a marcha normal, a freqüência fundamental da marcha é a mesma da passada e esta fica em torno de $1 \mathrm{~Hz}$, e porque $99,7 \%$ da potência do sinal está contida 
nas 7 harmônicas inferiores. Este filtro foi implementado usando as funções BUTTER e FILTFILT do Matlab.

Os sistemas de coordenadas locais calculados estão esboçados na Fig. 4.9. Foram construídos sistemas de coordenadas locais para o tronco, os braços e os antebraços.

O sistema de coordenadas locais do tronco foi definido por marcadores posicionados nas espinhas ilíacas ântero-superiores direita e esquerda, na sétima vértebra cervical e na fúrcula esternal. O centro pélvico foi definido como o ponto médio entre as espinhas ilíacas ântero-superiores direita e esquerda. O eixo longitudinal do tronco $(\vec{z})$ foi definido passando através do centro pélvico para a sétima vértebra cervical. O eixo $\vec{x}$ foi definido perpendicular ao eixo $\vec{z}$ e no plano do marcador da fúrcula esternal. O eixo $\vec{y}$ foi normal aos eixos $\vec{x}$ e $\vec{z}$.

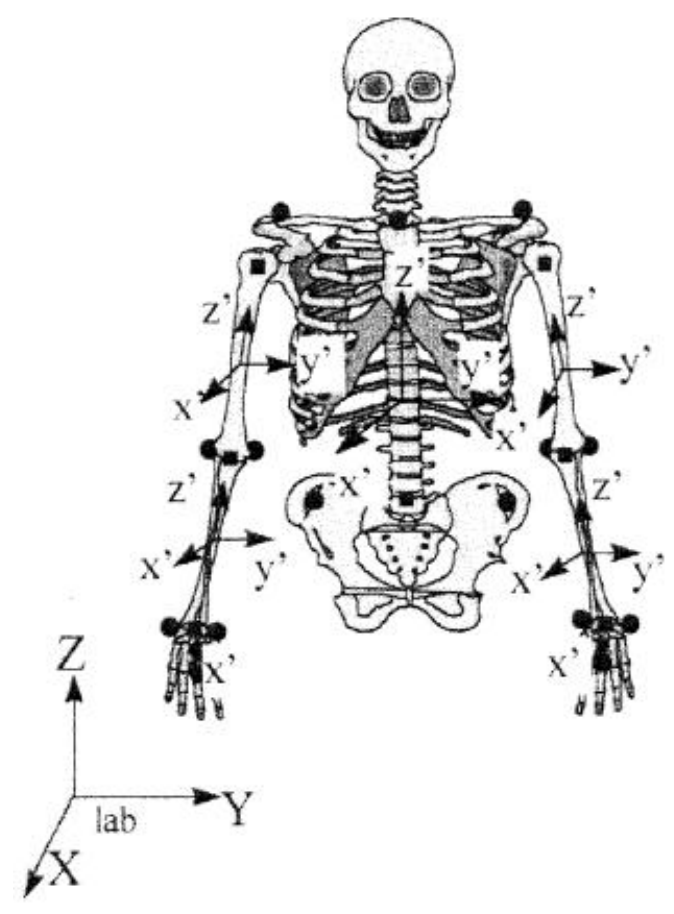

Figura 4.9: Modelo biomecânico dos membros superiores (Barchschmidt, Harris \& Simoneau 2001).

Os sistemas de coordenadas locais dos braços foram definidos por marcadores posicionados nos acrômios, e nos epicôndilos umerais. Barchschmidt et al. (2001) calcularam o centro de rotação da articulação glenoumeral usando equações descritas por VanDerHelm, Veeger, Pronk, Woude \& Rozendal (1992), no entanto no presente trabalho este cálculo não foi realizado. O centro da articulação do cotovelo foi calculado como o ponto médio entre os epicôndilos umerais lateral e medial. O eixo $\vec{x}$ foi obtido através do produto vetorial de um vetor temporário $\overrightarrow{y^{\prime}}$ pelo vetor do eixo longitudinal $\vec{z}$. O vetor temporário $\overrightarrow{y^{\prime}}$ foi calculado passando pelo centro da articulação do cotovelo para o marcador sobre o epicôndilo umeral medial (para o braço direito), e para o marcador sobre o 
epicôndilo umeral lateral (para o braço esquerdo). O eixo $\vec{y}$ foi obtido através do produto vetorial de $\vec{z}$ por $\vec{x}$.

Os sistemas de coordenadas locais dos antebraços foram definidos por marcadores posicionados nos epicôndilos umerias e nos estilóides radial e ulnar. O centro da articulação do punho foi calculado como o ponto médio entre os marcadores dos estilóides ulnar e radial. O eixo longitudinal $\vec{z}$ foi estabelecido passando através do centro da articulação do punho para o centro da articulação do cotovelo (cujo cálculo foi descrito no parágrafo anterior). O eixo $\vec{x}$ foi obtido através do produto vetorial de um vetor temporário $\overrightarrow{y^{\prime}}$ pelo vetor do eixo longitudinal $\vec{z}$. O vetor temporário $\overrightarrow{y^{\prime}}$ foi calculado passando pelo centro da articulação do punho para o marcador sobre o estilóide ulnar (para o braço direito), e para o marcador sobre o estilóide radial (para o braço esquerdo).

Os ângulos foram calculados de acordo com o procedimento descrito por Craig (1986). Inicialmente, os vetores unitários dos sistemas de coordenadas locais dos segmentos foram associados em matrizes que representavam a orientação de um dado segmento em relação à origem. Desta forma, o sistema de coordenadas local $(\{A\})$ anexado a um segmento foi expresso, em relação à origem, como uma matriz 3x3 de acordo com a equação abaixo (4.1):

$$
{ }_{A} R=\left[\begin{array}{lll}
\vec{X}_{A} & \vec{Y}_{A} & \vec{Z}_{A}
\end{array}\right]
$$

Onde $\vec{X}_{A}, \vec{Y}_{A}$ e $\vec{Z}_{A}$ são vetores unitários coluna $(3 \times 1)$ com as coordenadas dos eixos $(\vec{x}, \vec{y}$ e $\vec{z}$ respectivamente) do sistema de coordenadas local $(\{A\})$ do segmento em relação à origem.

Como o objetivo é obter a variação angular de um segmento distal, com o sistema de coordenadas $\{B\}$ anexado, em relação a um segmento proximal adjacente, com o sistema de coordenadas $\{A\}$ anexado, o passo seguinte foi calcular a matriz de rotação ${ }_{B}^{A} \mathrm{R}$ que descreve os vetores unitários do sistema de coordenadas locais $\{B\}$ do segmento distal em relação aos vetores unitários do sistema de coordenadas locais $\{A\}$ do segmento proximal. O cálculo da matriz de rotação ${ }_{B}^{A} \mathrm{R}$ foi realizado usando a equação abaixo (4.2):

$$
{ }_{B}^{A} \mathrm{R}=\left[{ }_{A} \mathrm{R}^{T} \cdot{ }_{B} \mathrm{R}\right]=\left[\begin{array}{cccc}
\vec{X}_{A} \cdot \vec{X}_{B} & \vec{X}_{A} \cdot \vec{Y}_{B} & \vec{X}_{A} \cdot \vec{Z}_{B} \\
\vec{Y}_{A} \cdot \vec{X}_{B} & \vec{Y}_{A} \cdot \vec{Y}_{B} & \vec{Y}_{A} \cdot \vec{Z}_{B} \\
\vec{Z}_{A} \cdot \vec{X}_{B} & \vec{Z}_{A} \cdot \vec{Y}_{B} & \vec{Z}_{A} \cdot \vec{Z}_{B}
\end{array}\right]=\left[\begin{array}{llll}
{ }^{A} \vec{X}_{B} & { }^{A} \vec{Y}_{B} & { }^{A} \vec{Z}_{B}
\end{array}\right]
$$

A matriz de rotação ${ }_{B}^{A} \mathrm{R}$ expressa a orientação do segmento distal, cujo sistema de coordenadas anexado é $\{B\}$, em relação ao segmento proximal, cujo sistema de coordenadas anexado é $\{A\}$. No entanto, uma forma mais compacta de representar esta orientação é obtida através de um conjunto de rotações denominadas ângulos de Euler.

Inicialmente o sistema em movimento $\{B\}$ é considerado alinhado ao sistema de referência $\{A\}$, então são realizadas três rotações sobre os eixos de $\{B\}$, que acontecem numa seqüência predefinida. A orientação resultante é representada por três ângulos, um 
para cada eixo, que são os ângulos de Euler: $\alpha$ representa a rotação no eixo $\vec{z}, \beta$ em $\vec{y}$ e $\gamma$ em $\vec{x}$.

A seqüência de rotações sobre o sistema distal $\{B\}$ resultará numa matriz de rotação, equivalente àquela obtida com os vetores dos sistemas de coordenadas locais, cujos termos são cosenos dos ângulos de Euler. Finalmente, relações trigonométricas são utilizadas para avaliar os ângulos de Euler a partir dos termos da matriz de rotação.

Este trabalho adotou a seqüência de rotações descrita por Kadaba, Ramakrishnan \& Wootten (1990): inicialmente o eixo $\vec{y}$ de referência foi rotacionado por um ângulo $\beta$; depois o eixo resultante $\overrightarrow{x_{1}}$ foi rotacionado por um ângulo $\gamma$; finalmente, rotacionando o eixo $\overrightarrow{z_{2}}$ por um ângulo $\alpha$ o sistema de coordenadas distal assume sua posição final.

Seguindo o procedimento descrito por Craig (1986) para o cálculo da matriz de rotação temos (4.3):

$$
\begin{aligned}
{ }_{B}^{A} \mathrm{R}_{y x z}(\beta \gamma \alpha) & =\operatorname{ROT}\left({ }^{B} \vec{Y}, \beta\right) \operatorname{ROT}\left({ }^{B} \vec{X}, \gamma\right) \operatorname{ROT}\left({ }^{B} \vec{Z}, \alpha\right) \\
& =\left[\begin{array}{ccc}
c \beta & 0 & s \beta \\
0 & 1 & 0 \\
-s \beta & 0 & c \beta
\end{array}\right]\left[\begin{array}{ccc}
1 & 0 & 0 \\
0 & c \gamma & -s \gamma \\
0 & s \gamma & c \gamma
\end{array}\right]\left[\begin{array}{ccc}
c \alpha & -s \alpha & 0 \\
s \alpha & c \alpha & 0 \\
0 & 0 & 1
\end{array}\right] \\
& =\left[\begin{array}{ccc}
c \beta c \alpha+s \beta s \gamma s \alpha & -c \beta s \alpha+s \beta s \gamma c \alpha & s \beta c \gamma \\
c \gamma s \alpha & c \gamma c \alpha & -s \gamma \\
-s \beta c \alpha+c \beta s \gamma s \alpha & s \beta s \alpha+c \beta s \gamma c \alpha & c \beta c \gamma
\end{array}\right]
\end{aligned}
$$

onde $c \alpha=\cos \alpha$ e $s \alpha=\operatorname{sen} \alpha$, etc.

É importante levar em consideração que o cálculo da matriz de rotação descrito por Craig (1986) tem como propósito mapear vetores do sistema $\{B\}$ no sistema de referência $\{\mathrm{A}\}$. Por isto a matriz de rotação resultante é a transposta daquela apresentada em Kadaba et al. (1990), onde a matriz de rotação foi aplicada no sistema de coordenadas $\{\mathrm{A}\}$ para a obtenção do sistema $\{\mathrm{B}\}$.

Os ângulos de Euler são obtidos através de relações trigonométricas entre os elementos da matriz de rotação. A função utilizada para o cálculo de todos os ângulos foi $\operatorname{Atan2}(y, x)$ que utiliza os sinais de $x$ e $y$ para determinar o quadrante no qual está o ângulo resultante da operação $\tan ^{-1}\left(\frac{x}{y}\right)$. As expressões usadas foram (4.4):

$$
\begin{aligned}
\beta & =\operatorname{Atan} 2(s \beta c \gamma, c \beta c \gamma) \\
\gamma & =\operatorname{Atan} 2\left(-(-s \gamma), \sqrt{(c \gamma s \alpha)^{2}+(c \gamma c \alpha)^{2}}\right) \\
\alpha & =\operatorname{Atan} 2(c \gamma s \alpha, c \gamma c \alpha)
\end{aligned}
$$

Como foi dito anteriormente, as matrizes 4.2 e 4.3 são equivalentes. Portanto, o cálculo dos ângulos de Euler usando os vetores unitários dos sistemas de coordenadas 
locais $\{\mathrm{A}\}$ e $\{\mathrm{B}\}$ pode ser feito usando as equações a seguir (4.5):

$$
\begin{aligned}
\beta & =\operatorname{Atan} 2\left(\vec{X}_{A} \cdot \vec{Z}_{B}, \vec{Z}_{A} \cdot \vec{Z}_{B}\right) \\
\gamma & =\operatorname{Atan} 2\left(-\left(\vec{Y}_{A} \cdot \vec{Z}_{B}\right), \sqrt{\left(\vec{Y}_{A} \cdot \vec{X}_{B}\right)^{2}+\left(\vec{Y}_{A} \cdot \vec{Y}_{B}\right)^{2}}\right) \\
\alpha & =\operatorname{Atan} 2\left(\vec{Y}_{A} \cdot \vec{X}_{B}, \vec{Y}_{A} \cdot \vec{Y}_{B}\right)
\end{aligned}
$$

A função Atand retorna valores entre $-\pi$ e $\pi$ radianos, portanto os resultados foram multiplicados por $\frac{180^{\circ}}{\pi}$ para serem apresentados em graus.

Quando os ângulos calculados são definidos usando termos clínicos (Fig. 3.11), eles são denominados ângulos ortopédicos (Kadaba et al. 1990). Portanto, em termos clínicos:

- Quando houver uma rotação de um ângulo $\beta$ no sentido anti-horário no eixo $\vec{y}$ ocorrerá extensão do ombro e do cotovelo. Quando a rotação for no sentido horário ocorrerá o movimento de flexão do ombro e do cotovelo. Para apresentar o movimento de flexão através de valores positivos e o movimento de extensão através de valores negativos, foi necessário inverter o sinal na expressão de $\beta$ (4.5).

- Quando houver uma rotação de um ângulo $\gamma$ no sentido anti-horário no eixo $\vec{x}$ ocorrerá adução do ombro e do cotovelo do membro direito e abdução do ombro e do cotovelo do membro esquerdo . Para apresentar o movimento de abdução através de valores positivos e o movimento de adução através de valores negativos, foi necessário inverter o sinal na expressão de $\gamma(4.5)$ nos cálculos relativos ao membro direito.

- Quando houver uma rotação de um ângulo $\alpha$ no sentido anti-horário no eixo $\vec{z}$ ocorrerá rotação interna do ombro e do cotovelo do membro direito e rotação externa do ombro e do cotovelo do membro esquerdo . Para apresentar o movimento de rotação interna através de valores positivos e o movimento de rotação externa através de valores negativos, foi necessário inverter o sinal na expressão de $\alpha$ (4.5) nos cálculos relativos ao membro esquerdo.

A normalização das amostras, como percentual do ciclo, foi feita através da média em intervalos de 0,5\% resultando em amostras normalizadas contendo 201 pontos.

\subsection{Eletromiografia}

A eletromiografia é o estudo do sinal elétrico (eletromiograma - EMG) associado à contração muscular (Winter 1990).

Na Sec. 3.4 foi dito que a fibra muscular esquelética realiza sua contração através da propagação de potenciais elétricos, denominados potenciais de ação. Eletrodos posicionados sobre a superfície de um músculo captarão a soma algébrica de todos os potenciais 
de ação das unidades motoras sendo transmitidos ao longo das fibras musculares em um dado instante de tempo.

Quando o sinal EMG de superfície é retificado e suavizado sua amplitude será qualitativamente relacionada à quantidade de torque (ou força) medido sobre a articulação (e/ou velocidade de contração), mas não haverá uma relação quantitativa precisa. Portanto, desde que o processo de fadiga não afete significativamente o sinal, poderá haver uma indicação de que o músculo está aumentando ou diminuindo sua força de saída em um dado período de tempo. Esta relação será mais significativa quando for considerado a raiz quadrática média (RMS - Root Mean Square), que é definida como a raiz quadrada da média dos quadrados dos valores instantâneos do sinal, e representa a potência do sinal (DeLuca 1993).

No entanto, é importante considerar que em contrações dinâmicas há um atraso entre a ativação do músculo observada pelo sinal EMG e a ativação do músculo observada pela detecção de força gerada pelo músculo (que aperece após o sinal EMG). Este atraso ocorre porque a contração ("twitch") alcança seu pico entre 40 e 100 ms após o disparo do potencial de ação da unidade motora correspondente (Winter 1990).

Além disso, quando a contração não for isométrica, várias modificações mecânicas, fisiológicas, anatômicas e elétricas ocorrem no decorrer da contração afetando significativamente a relação entre a amplitude do sinal e a força gerada pelo músculo. Desta forma, indica-se restringir a análise a épocas da amostra nas quais as contrações tenham sido aproximadamente isométricas (DeLuca 1993).

O trabalho negativo possui um custo metabólico menor que o trabalho positivo e a amplitude do sinal EMG indica o estado de ativação do elemento contrátil, que é diferente da tensão obtida no tendão, representando uma medida relativa do metabolismo muscular. Consequentemente, a amplitude do EMG associado ao trabalho negativo é consideravelmente menor que a associada com a mesma quantidade de trabalho positivo (Winter 1990).

É necessário normalizar o sinal EMG a ser estudado devido à variabilidade do sinal detectado em função das condições experimentais (eg, posição dos eletrodos, temperatura da pele), contrações repetitivas em um paciente, e entre diferentes pacientes (eg, tipo de fibra, espessura de gordura subcutânea, padrão de recrutamento). Yang \& Winter (1984) mostraram que a normalização pela média da família de amostras de um paciente é um dos melhores procedimentos para evitar a variabilidade entre pacientes. Além disto, este método utiliza um parâmetro resultante do exame realizado, portanto não requer procedimentos adicionais, como aqueles necessários quando se é considerada a contração voluntária máxima. No entanto, como o resultado é um percentual em relação à amplitude de referência (a média), este procedimento não provê informação sobre o grau de ativação muscular em relação à capacidade máxima do paciente. Portanto, é importante observar o valor médio de referência usado pela normalização durante a análise. Outro ponto 
importante para a comparação entre pacientes que deve ser considerado é a diferença na quantidade de tecido gordo subcutâneo presente em cada um (DeLuca 1993).

Barchschmidt et al. (2001) mostraram que na marcha assistida por andador o momento de extensão do cotovelo foi proeminente durante o período no qual o andador ficava em contato com o chão. Também foram significativos os momentos de flexão e adução do ombro. A Fig. 4.10 apresenta o efeito da força de reação do andador tendendo a flexionar o cotovelo e extender o ombro (Fig. 4.10(a)) e a força que causa a abdução do ombro (Fig. 4.10(b)), assim como os músculos usados para compensar o efeito de tais forças (Opila, Nicol \& Paul 1987).

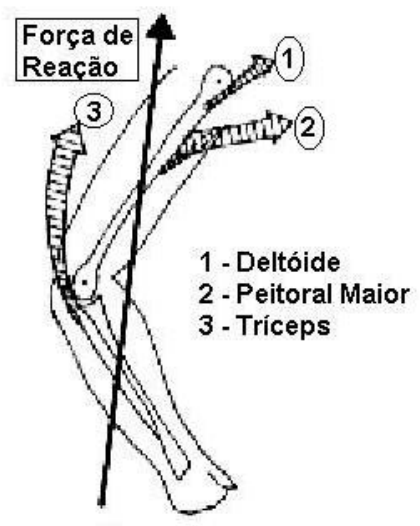

(a) Força de reação causando flexão do cotovelo e extensão do ombro.

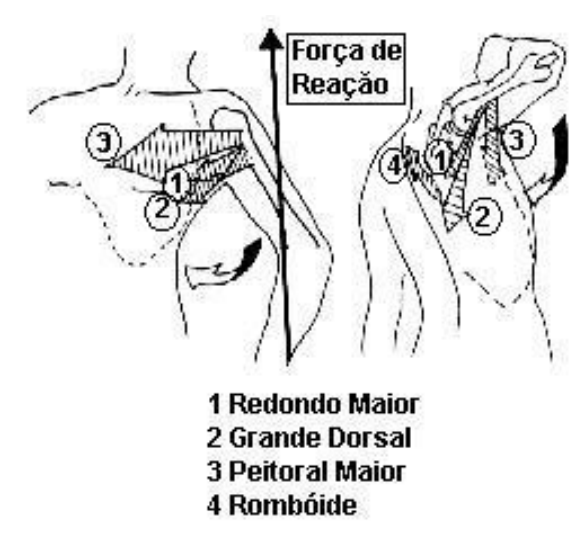

(b) Força de reação causando abdução.

Figura 4.10: Ação dos músculos para compensar o efeito da força de reação do andador (Opila, Nicol \& Paul 1987).

Foram selecionados 4 músculos para o estudo da eletromiografia: cabeça longa do tríceps, porção esternal do peitoral maior, deltóide médio, e extensor radial do carpo.

Como pode ser visto na Fig. 4.10(a) a cabeça longa do tríceps tem uma importante participação para evitar o colapso do corpo nos períodos onde há uma substancial sustentação do corpo pelos membros superiores. Isto porque embora este músculo participe na extensão e adução da articulação glenoumeral, sua principal função é a extensão da articulação do cotovelo (Halder, Itoi \& An 2000).

A porção esternal do peitoral maior contribui para a depressão do ombro e para a adução oblíqua do úmero em direção à crista ilíaca oposta (Kendall, McCreary \& Provance 1993). Como depressor do ombro ele possui um importante papel na sustentação do peso do corpo pelos membros superiores. Como adutor (o peitoral como um todo é um forte adutor) ele atuará para compensar a força de reação do andador que tende a abduzir o ombro, esboçada na Fig. 4.10(b).

O deltóide é o mais importante abdutor da articulação glenoumeral, e o deltóide 
médio é a porção que inicia o movimento, além de ser a mais forte (Halder et al. 2000). O monitoramento da atividade do deltóide médio foi realizado para verificar a atividade do ombro relacionado à transferência do peso do corpo que ocorre durante a marcha. Esta transferência depende da atividade dos membros superiores, e é presumido que a abdução seja importante neste processo.

As mãos apoiadas sobre o andador permanecem continuamente com punhos hiperestendidos permitindo a preensão das barras laterais do andador enquanto a base do antebraço aplica a força de apoio para a sustentação do corpo. O extensor radial do carpo gera uma posição (punho estendido com desvio radial) semelhante àquela presente no apoio sobre o andador. Especificamente: o extensor radial curto do carpo é muito mais ativo que o longo durante a extensão pura (exceto em uma extensão rápida, o longo é praticamente inativo); durante o desvio radial os dois participam ativamente; e na preensão ou cerramento do punho, o longo é muito ativo como sinergista (caso contrário, os flexores longos dos dedos produziriam flexão do punho além de flexão dos dedos), enquanto o curto é quase inativo (Rasch 1991, MacConaill \& Basmajian 1977). Portanto, este grupo foi escolhido para prover alguma informação sobre o contato com o andador. No entanto, é importante considerar que os resultados de Barchschmidt et al. (2001) apresentaram um momento de flexão do punho, o que é coerente, já que o punho está estendido durante o movimento. Ou seja, uma informação mais rica poderia ser obtida monitorando os grupos flexores do punho.

A eletromiografia foi realizada utilizando eletrodos bipolares de superfície (dual electrode-272) e eletromiógrafo (MyoSystem 2000) da Noraxon, adotando as recomendações da SENIAM (surface EMG for a non-invasive assessment of muscles) sobre o tipo de eletrodo (Fig. 4.11(a)) e procedimento de posicionamento(Fig. 4.11(b)) (Hermens, Freriks, Disselhorst-Klug \& Rau 2000).

Características do tipo de eletrodo usado:

- o tamanho da área condutiva de cada eletrodo foi de $10 \mathrm{~mm}$;

- a distância entre os centros das áreas condutivas dos eletrodos foi de 20mm;

- os eletrodos são tipo $\mathrm{Ag} / \mathrm{AgCl}$;

- os eletrodos são leves e usados em pares fixos.

Os cabos foram fixados, usando micropore, nas proximidades dos eletrodos para evitar sinais provenientes do puxar dos fios. Além disso, a fixação dos eletrodos (que são aderentes e descartáveis) foi reforçada com micropore.

Procedimento adotado para posicionamento dos eletrodos:

- a retirada de pêlos (tricotomia) não foi possível; 
- as áreas de aplicação dos eletrodos foram limpas usando gaze embebida em álcool. Após um pequeno período de espera para secar a área, os eletrodos foram posicionados;

- em relação à localização longitudinal do sensor sobre o músculo procurou-se colocar o sensor centralizado entre a zona da placa motora mais distal e o tendão distal;

- em relação à localização transversal do sensor sobre o músculo procurou-se colocar o sensor na superfície distante da fronteira com outras subdivisões ou músculos;

- após a definição desta posição, ela era marcada com caneta, e o centro do par de eletrodos era posto sobre ela;

- Os eletrodos foram posicionados de tal forma que sua orientação foi paralela às fibras musculares (a orientação dos eletrodos é definida como posição da linha entre os eletrodos em relação à direção das fibras musculares);

- o eletrodo de referência foi posto sobre o olécrano.

O posicionamento no extensor radial do carpo foi uma exceção, cujo ponto monitorado foi identificado através de estimulação elétrica, sendo o ponto no qual a estimulação gerava extensão e desvio radial do punho.

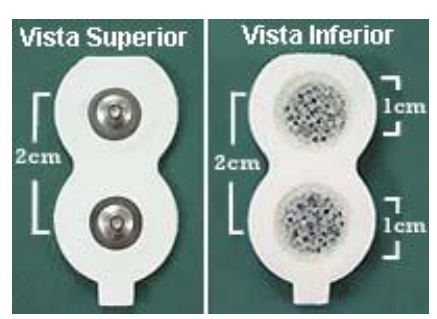

(a) Eletrodos usados.

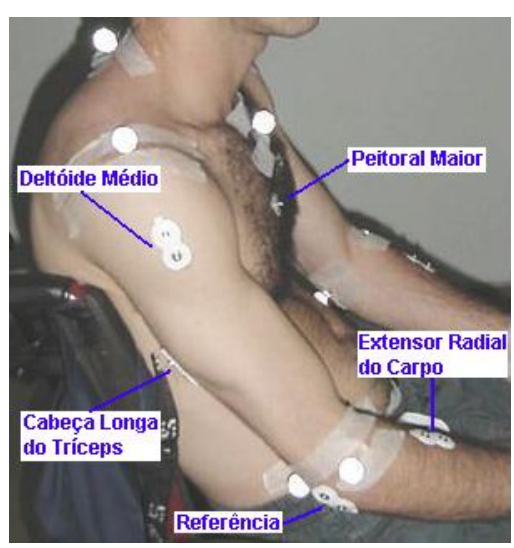

(b) Eletrodos posicionados no paciente.

Figura 4.11: Posicionamento dos eletrodos.

A aquisição dos sinais capturados pelo MyoSystem 2000 foi disparada por um sinal digital, proveniente do sistema de captura do movimento, que foi enviado para um dos canais do eletromiógrafo. O sinal digital foi especificado no software QTrac Capture que faz a interface entre o computador hospedeiro (um desktop), as câmeras, e a placa 
de aquisição de dados analógicos de 64 canais (uma placa PCI-DAS6402/16 da Measurement Computing Corp.). No QTrac Capture foi definida a porta digital da placa PCIDAS6402/16 que geraria um nível de tensão de aproximadamente 2,7 Volts no instante em que a captura do movimento iniciasse. A conexão entre a placa PCI-DAS6402/16 e o MyoSystem 2000 foi realizada com o auxilio de dois dispositivos. Uma placa CIO-MINI50 (Measurement Computing Corp.) foi utilizada para fazer a conexão com o pino, correspondente à porta de saída digital especificada, do conector de 100 pinos da PCI-DAS6402/16. Uma placa NorBNC (Noraxon) fez a interface entre o MyoSystem 2000, a conexão com o laptop (hospedeiro do eletromiógrafo) através do cartão PCMCIA-DAS16S/12 (Measurement Computing Corp.) de aquisição de dados analógicos, e com o fio conectado à placa CIO-MINI50.

O software MyoResearch 2.1 foi usado para a realizar a interface entre o computador hospedeiro do eletromiógrafo e o MyoSystem 2000. O MyoResearch 2.1 foi configurado para realizar a aquisição de dados com uma freqüência de amostragem de $1000 \mathrm{~Hz}$. Também foi configurado para realizar o disparo da gravação dos dados a partir da subida no nível de tensão presente no canal ao qual uma porta digital da placa PCI-DAS6402/16 foi conectada de acordo com o descrito no parágrafo anterior.

Após a aquisição, e a identificação dos intervalos das amostras, correspondentes aos ciclos, o MyoResearch 2.1 foi usado para calcular o valor RMS, usando uma janela de $40 \mathrm{~ms}$. Depois disto os intervalos correspondentes aos ciclos foram exportados no formato ASCII (American Standard Code for Information Innterchange), para serem processados usando o Matlab.

No Matlab, os dados foram processados por um filtro passa-baixa Butterworth de segunda ordem, com freqüência de corte de $4 \mathrm{~Hz}$ (Ferrarin, Bertelli, Frasson, Thorsen, Pavan \& Frigo 2001), implementado usando as funções BUTTER e FILTFILT. A etapa seguinte foi normalizar as amostras no tempo, como percentual do ciclo, foi feita através da média em intervalos de 0,05\% resultando em amostras normalizadas contendo 2001 pontos. Depois foi calculada a média das cinco amostras. Esta média foi normalizada em amplitude usando para isso o seu valor médio. Finalmente, o desvio padrão foi calculado usando a fórmula a seguir (4.6):

$$
s=\sqrt{\frac{\left(c_{1}-c_{m}\right)^{2}+\left(c_{2}-c_{m}\right)^{2}+\left(c_{3}-c_{m}\right)^{2}+\left(c_{4}-c_{m}\right)^{2}+\left(c_{5}-c_{m}\right)^{2}}{5}}
$$

onde $c_{m}$ é a média das cinco amostras normalizada em amplitude pelo seu valor médio, e $c_{i}(\mathrm{i}=1,2,3,4$ e 5$)$ são as amostras normalizadas em amplitude pelo valor médio da média das amostras. 


\subsection{Plataforma de força}

O suporte do peso do corpo pelas pernas implica na aplicação de forças sobre o solo durante a locomoção. Conseqüentemente, de acordo com a terceira lei de Newton, forças de reação do solo são aplicadas aos pés, que são os pontos de apoio.

Como o movimento do paraplégico é quase-estático, a componente vertical da força de reação do solo poderá indicar o percentual de peso do corpo sendo sustentado pelas pernas em um período particular do ciclo da marcha.

Foi usada uma plataforma de força da marca Advanced Mechanical Technology Inc (AMTI), modelo OR6-7-1000, para medir a componente vertical da força de reação do solo. Este equipamento também permite obter os momentos e as três componentes de força ao longo dos eixos $\vec{x}, \vec{y}$, e $\vec{z}$ (as dimensões da plataforma e as orientações dos eixos estão esboçadas na Fig. 4.12). As forças e momentos são medidos através de extensômetros ( "strain gages") arranjados em 6 pontes de Wheatstone sobre células de carga dispostas próximas dos quatro cantos da plataforma. A força aplicada a estas células de carga gera uma pequena deformação resultando num desbalanço em tensão elétrica proporcional à força aplicada. Desta forma, três dos sinais de saída são proporcionais às forças paralelas aos três eixos e as outras três saídas são proporcionais aos momentos sobre os três eixos.

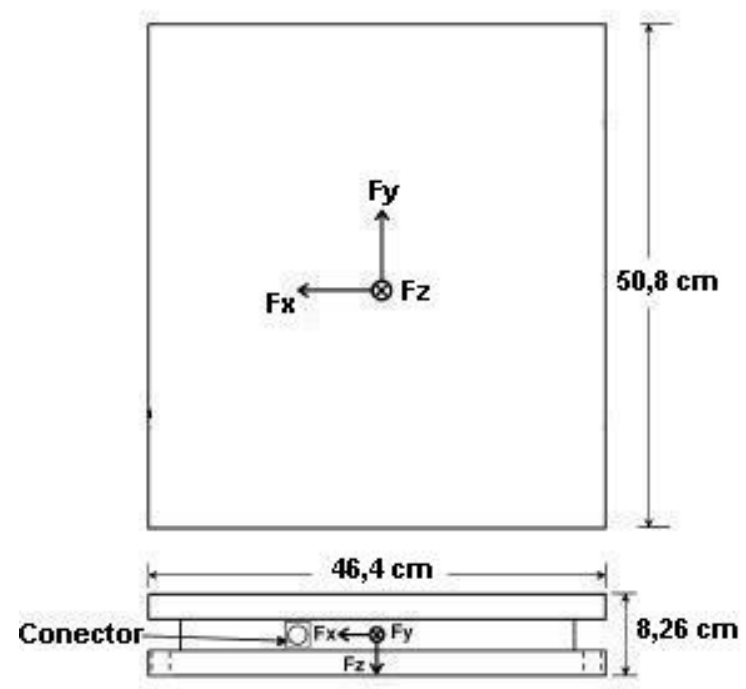

Figura 4.12: Dimensões da plataforma de força.

Os sinais de saída das 6 pontes de Wheatstone foram conduzidos através de um cabo para um amplificador modelo MCA-6 da AMTI. Os sinais resultantes filtrados e amplificados foram conectados a canais da placa PCI-DAS6402/16 através da placa CIO-MINI50. A aquisição dos dados da plataforma de força era disparada pelo sistema de captura do movimento através da comunicação da câmera mestre (usando a saída de sincronização externa de sua porta de controle) com a placa de aquisição de dados 
analógicos (porta de entrada para disparo externo), e ocorria na mesma freqüência de operação das câmeras $(60 \mathrm{~Hz})$.

Foram selecionadas duas amostras, correspondentes ao ciclo direito, para cada paciente. Em cada amostra o pé direito iniciava sobre a plataforma, como o passo do paraplégico era curto, após o balanço esquerdo o pé esquerdo normalmente era posicionado também sobre a plataforma.

Os valores de tensão $\left(V_{F_{Z}}\right)$ correspondentes à componente vertical $\left(F_{Z}\right)$ da força de reação do solo foram processados por um filtro passa-baixa Butterworth de segunda ordem, com freqüência de corte de $6 \mathrm{~Hz}$, implementado usando as funções BUTTER e FILTFILT do Matlab. A conversão dos valores $V_{F_{Z}}$, em volts $(V)$, para os valores $F_{Z}$, em newtons $(N)$, foi realizada usando a equação 4.7 (AMTI 1998):

$$
F_{Z}=\frac{\left(V_{F_{Z}} \times C_{33}\right)}{C F}
$$

onde $C_{33}$ é um elemento da matriz $(6 \times 6)$ de calibração provida pela AMTI. Para a plataforma de força usada $C_{33}=5,986 N \backslash \mu V \backslash V_{0}$. O fator de conversão $C F$ é obtido pela equação 4.8:

$$
C F=V_{\text {excita }} \times G_{a m p} \times 10^{-6}
$$

sendo que a tensão de excitação usada no amplificador $\left(V_{\text {exita }}\right)$ foi de $10 \mathrm{~V}$, e o ganho aplicado pelo mesmo $\left(G_{a m p}\right)$ foi igual a 4000. Portanto, $C F=0,04$. Conseqüentemente, substituindo os valores de $C_{33}$ e $C F$ na equação 4.7 , obtemos a equação final usada para converter $V_{F_{Z}}$ para $F_{Z}(4.9)$ :

$$
\begin{aligned}
F_{Z} & =\frac{\left(V_{F_{Z}} \times 5,986\right)}{0,04} \\
& =V_{F_{Z}} \times 149,65
\end{aligned}
$$

As amostras foram normalizadas no tempo, como percentual do ciclo, através da média em intervalos de 0,5\% resultando em amostras contendo 201 pontos. E foram normalizadas em amplitude como percentual do peso do paciente em newtons.

\subsection{Montagem do laboratório}

Os exames foram realizados nos meses de Maio e Junho de 2002. Nesta época o laboratório era montado em uma área provisória. Uma das conseqüências era a necessidade de posicionar os equipamentos nos dias dos exames, exigindo aproximadamente duas horas de trabalho, para cada dia, antes de cada exame. A Fig. 4.13 apresenta o laboratório em sua configuração final. 


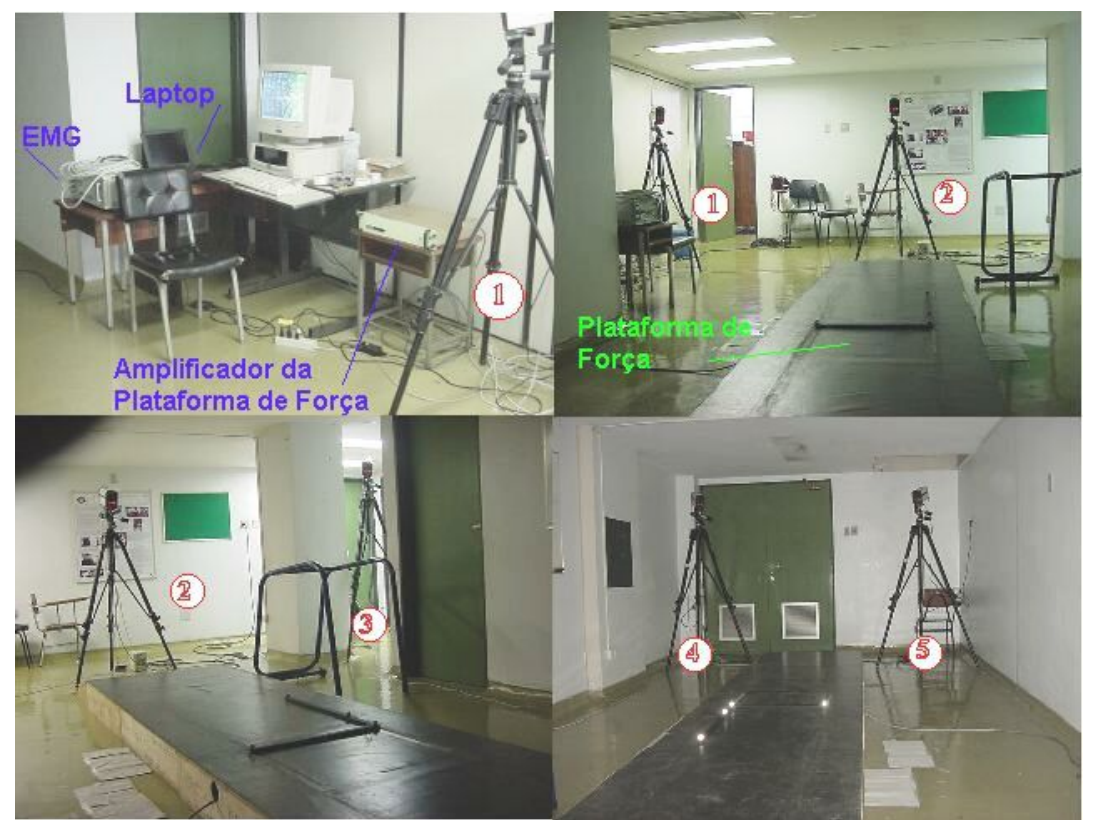

Figura 4.13: Arranjo final do laboratório.

\subsection{Preparação do paciente}

O posicionamento de marcadores e eletrodos, em cada paciente, era realizado em aproximadamente 01:30 hora. Os marcadores e eletrodos eram fixados, ou reforçados, usando micropore. A Fig. 4.14 apresenta uma visão geral do paciente com todos os marcadores, e eletrodos usados para eletromiografia e estimulação elétrica.

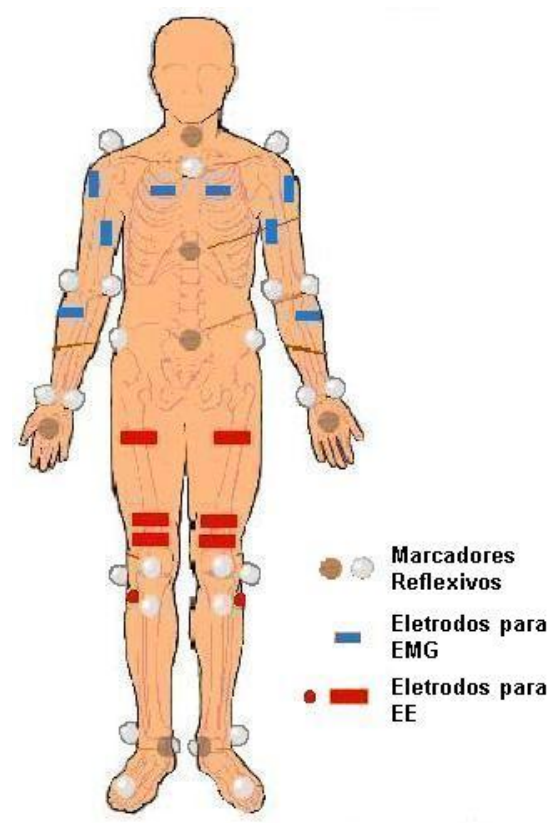

Figura 4.14: Configuração final do paciente. 


\section{Capítulo 5}

\section{Resultados}

Todos os resultados dos exames realizados nos cinco pacientes estão inseridos nos apêndices (sendo um apêndice para cada paciente: A, B, C, D, E).

Neste capítulo estes resultados serão apresentados de forma resumida, com o intuito de facilitar a discussão sobre os mesmos, ressaltando: as características temporais da marcha (Sec. 3.3); os percentuais associados aos eventos descritos na seção 4.1; e uma descrição subjetiva, através de tabelas, baseada na interpretação dos gráficos apresentados nos apêndices, das ações realizadas pelos pacientes nas fases da marcha (Tab. 4.1) definidas pelos eventos referidos acima.

\subsection{Características das passadas dos pacientes}

A tabela 5.1 contém os valores médios (das 5 amostras processadas para cada paciente) dos parâmetros temporais da marcha dos pacientes.

\begin{tabular}{ccccccc}
\hline Pacientes & $\begin{array}{c}\text { Cadência } \\
(\text { passos } / \mathrm{min})\end{array}$ & $\begin{array}{c}\text { Velocidade } \\
(\mathrm{cm} / \mathrm{s})\end{array}$ & $\begin{array}{c}\text { Passada } \\
(\mathrm{m})\end{array}$ & $\begin{array}{c}\text { Tempo do ciclo } \\
(\mathrm{s})\end{array}$ & $\begin{array}{c}\text { Apoio direito } \\
(\%)\end{array}$ & $\begin{array}{c}\text { Apoio esquerdo } \\
(\%)\end{array}$ \\
\hline \hline $\mathbf{A}$ & 21,40 & 10,08 & 0,56 & 5,76 & 84,38 & 84,90 \\
$\mathbf{B}$ & 15,00 & 4,73 & 0,38 & 8,08 & 93,32 & 94,10 \\
$\mathbf{C}$ & 21,20 & 8,60 & 0,50 & 5,88 & 83,80 & 85,28 \\
$\mathbf{D}$ & 16,20 & 6,55 & 0,48 & 7,54 & 90,32 & 89,76 \\
$\mathbf{E}$ & 18,00 & 7,58 & 0,50 & 6,64 & 90,48 & 86,72 \\
\hline \hline
\end{tabular}

Tabela 5.1: Parâmetros temporais

A tabela 5.2 apresenta os percentuais relativos aos eventos descritos na seção 4.1. 


\begin{tabular}{cccccccccccc}
\hline Pacientes & $\begin{array}{c}C I D_{1} \\
(\%)\end{array}$ & $\begin{array}{c}I A A_{1} \\
(\%)\end{array}$ & $\begin{array}{c}I B E \\
(\%)\end{array}$ & $\begin{array}{c}\text { DPE } \\
(\%)\end{array}$ & $\begin{array}{c}M B E \\
(\%)\end{array}$ & $\begin{array}{c}C I E \\
(\%)\end{array}$ & $\begin{array}{c}I A A_{2} \\
(\%)\end{array}$ & $\begin{array}{c}I B D \\
(\%)\end{array}$ & $\begin{array}{c}D P D \\
(\%)\end{array}$ & $\begin{array}{c}M B D \\
(\%)\end{array}$ & $\begin{array}{c}C I D_{2} \\
(\%)\end{array}$ \\
\hline \hline $\mathbf{A}$ & 0.0 & 5.4 & 25.1 & 35.6 & 41.7 & 50.6 & 56.8 & 75.4 & 84.4 & 91.9 & 100.0 \\
$\mathbf{B}$ & 0.0 & 18.9 & 28.7 & 41.8 & 45.3 & 48.2 & 70.7 & 80.2 & 93.3 & 96.8 & 100.0 \\
$\mathbf{C}$ & 0.0 & 8.7 & 28.0 & 37.3 & 44.3 & 51.4 & 62.8 & 75.1 & 83.8 & 87.3 & 100.0 \\
$\mathbf{D}$ & 0.0 & 5.5 & 19.7 & 34.0 & 39.5 & 44.8 & 53.5 & 75.4 & 90.3 & 95.7 & 100.0 \\
$\mathbf{E}$ & 0.0 & 8.5 & 28.4 & 37.1 & 42.1 & 49.9 & 58.7 & 77.1 & 90.5 & 94.3 & 100.0 \\
\hline \hline
\end{tabular}

Tabela 5.2: Percentuais das fases do ciclo de acordo com o descrito na sec. 4.1

\subsection{Descrição da locomoção do paciente $\mathrm{A}$}

A figura 5.1 apresenta a visualização das posições do corpo do paciente $\mathbf{A}$ nos eventos que definem a marcha, e a tabela 5.3 apresenta um resumo das variações que ocorrem nas diversas fases definidas por estes eventos.

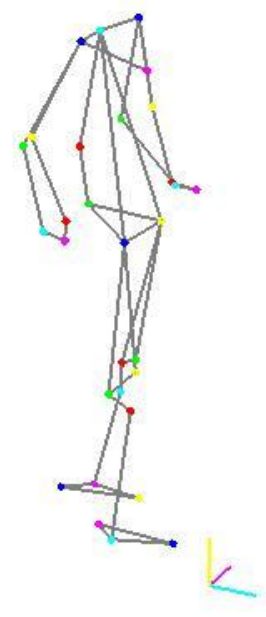

IAA_1 (5,4\%)

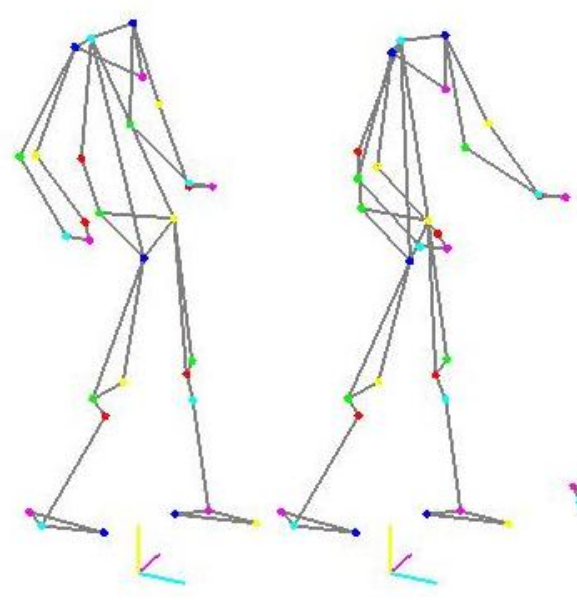

IAA_2 (56,8\%)

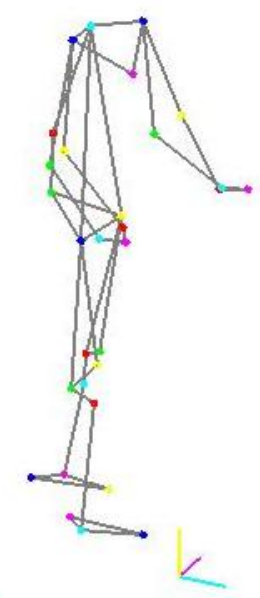

IBE $(25, \mathbf{1} \%)$

IBD $(75,4 \%)$

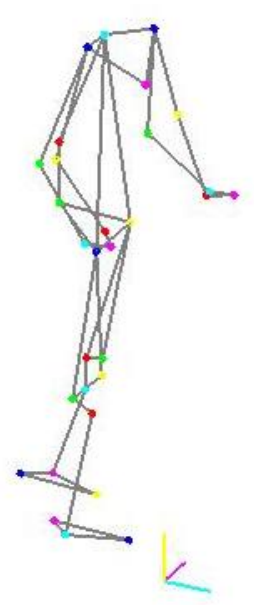

DPE $(35,6 \%)$

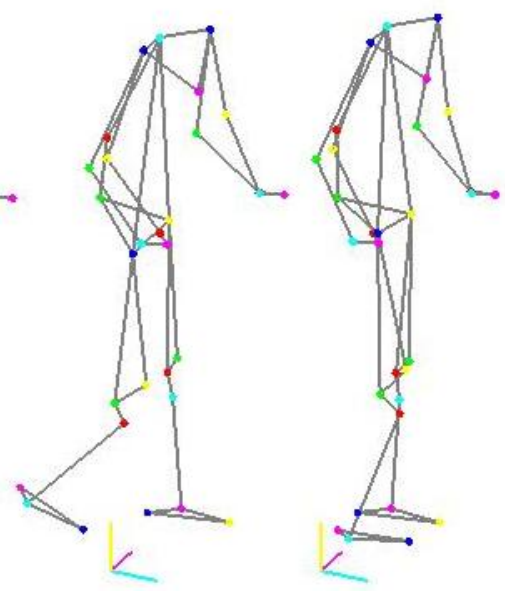

DPD $(84,4 \%)$

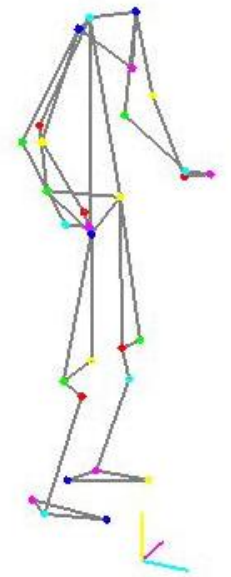

MBE $(41,7 \%)$

$\operatorname{MBD}(91,9 \%)$
CIE $(50,6 \%)$
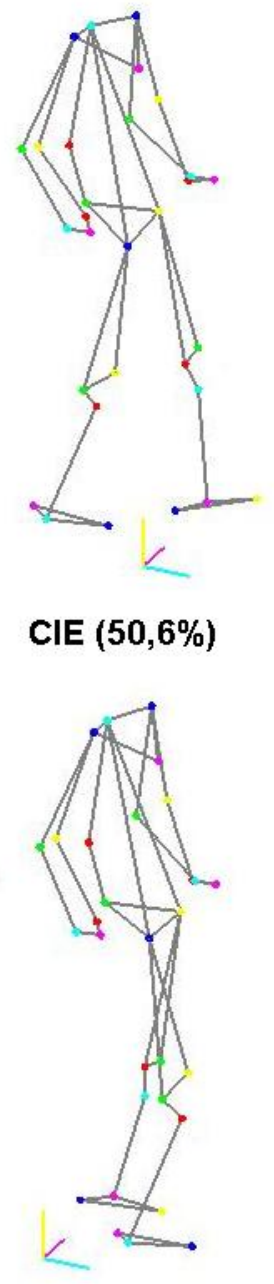

CID_2 $(100,0 \%)$

Figura 5.1: Posições do corpo do paciente A nos eventos da marcha. 


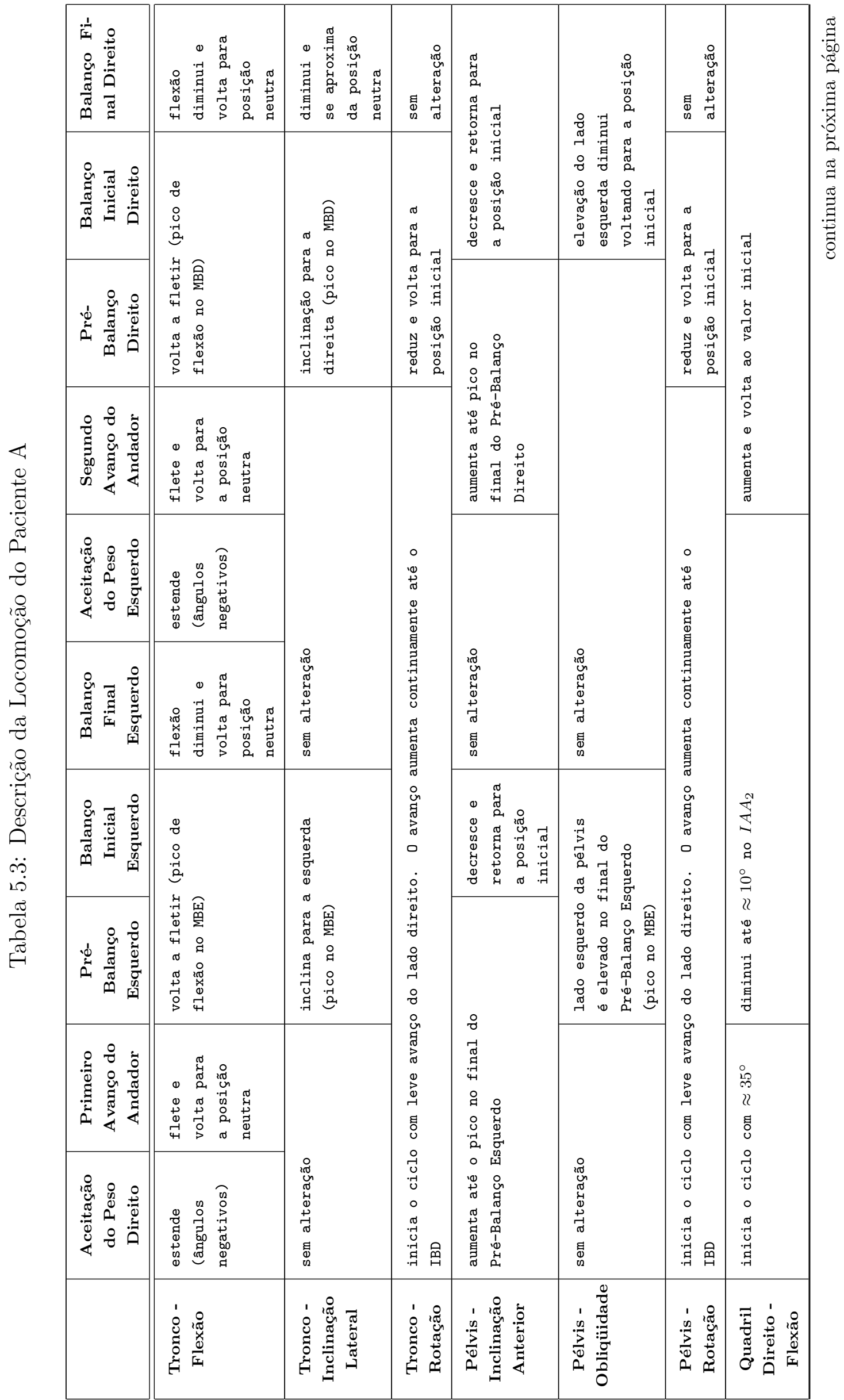




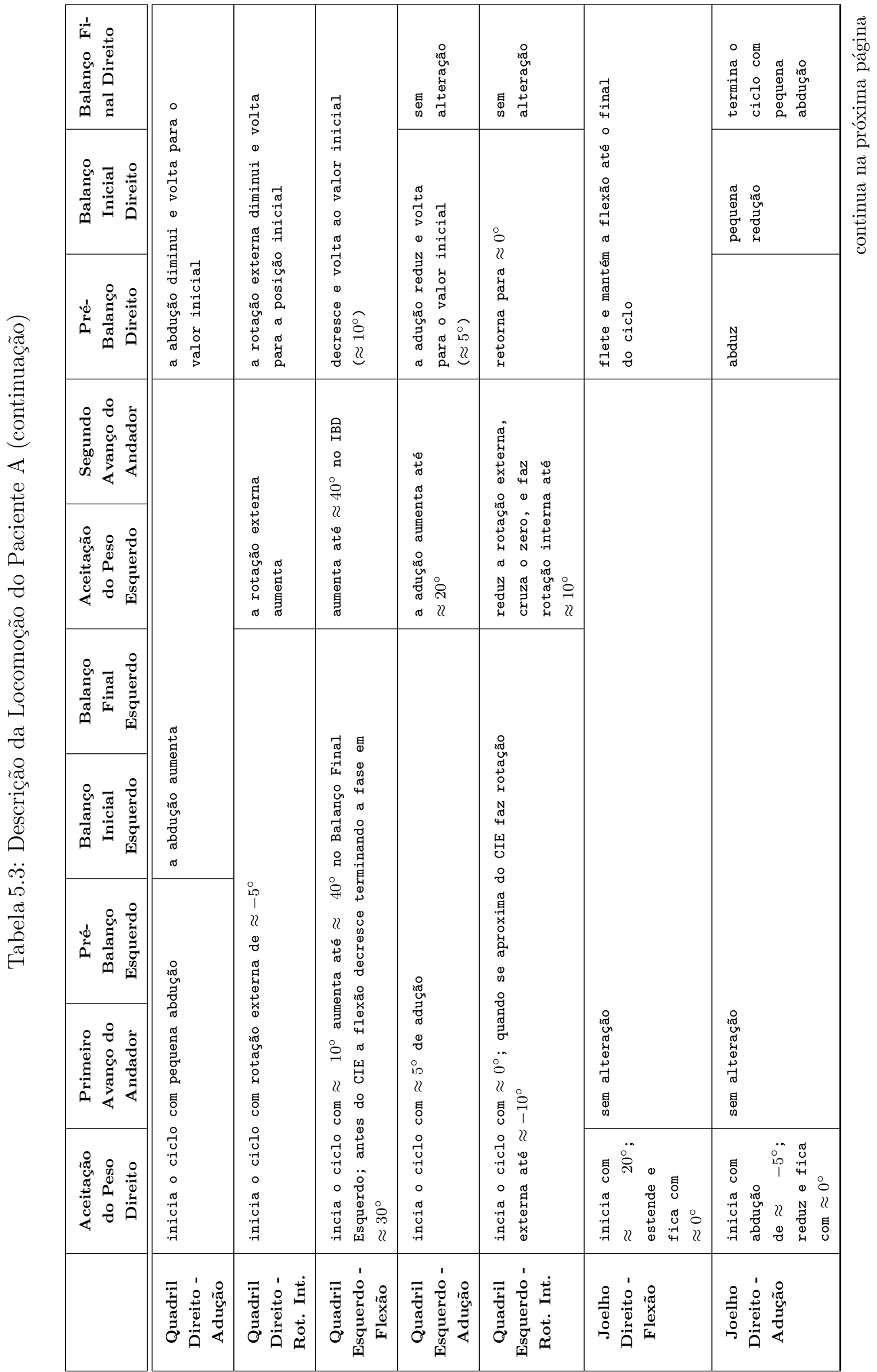




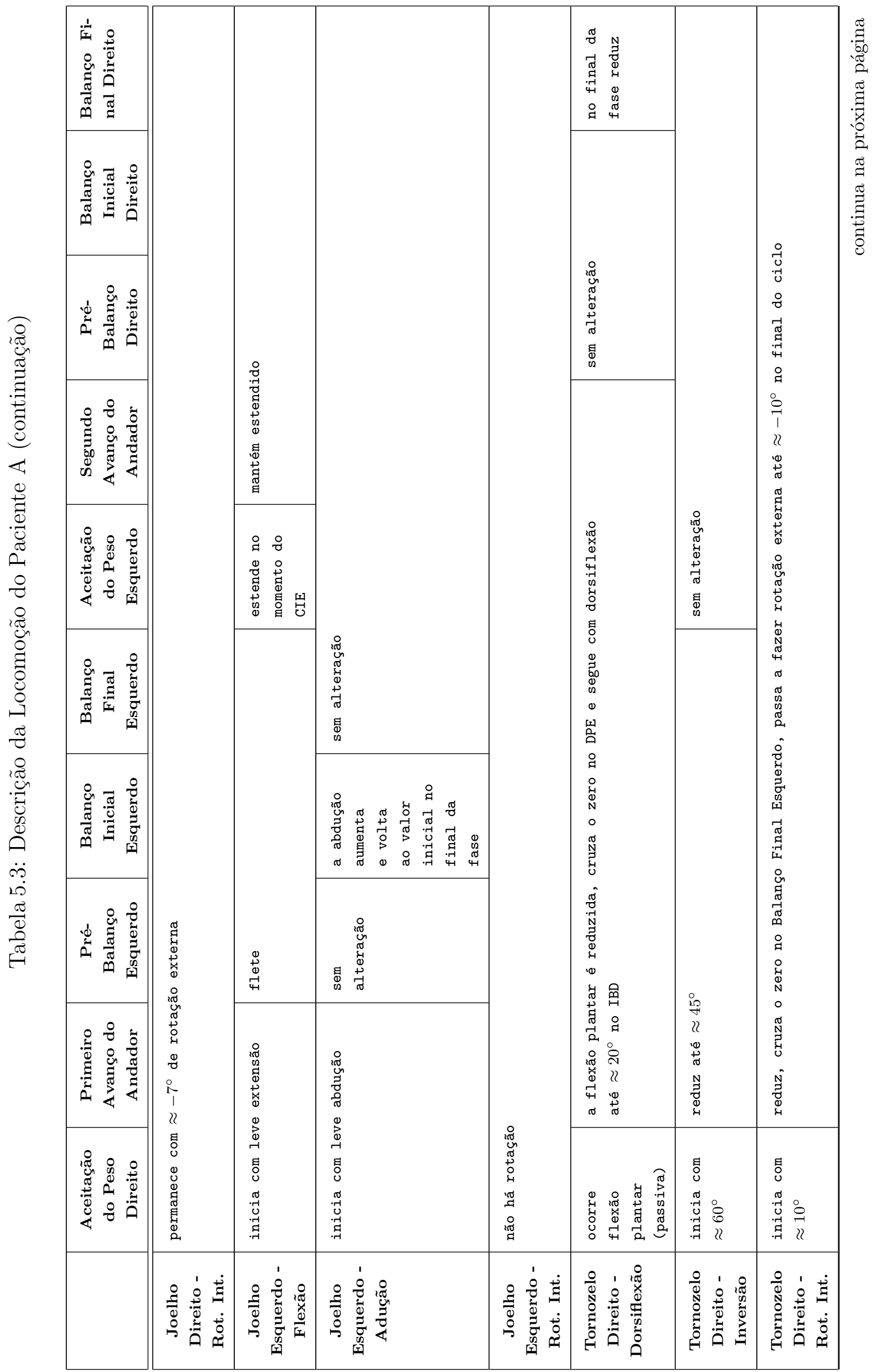




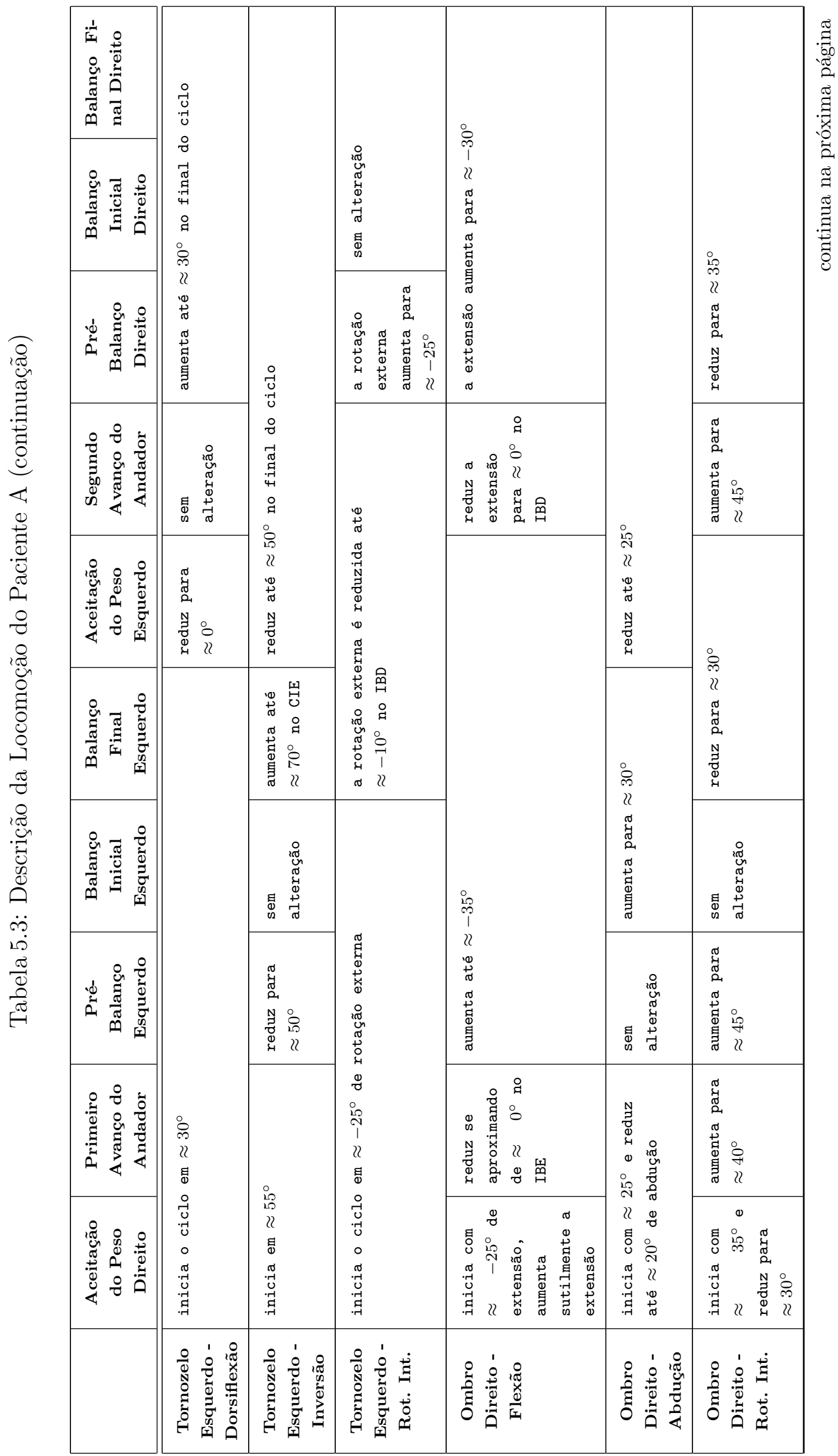




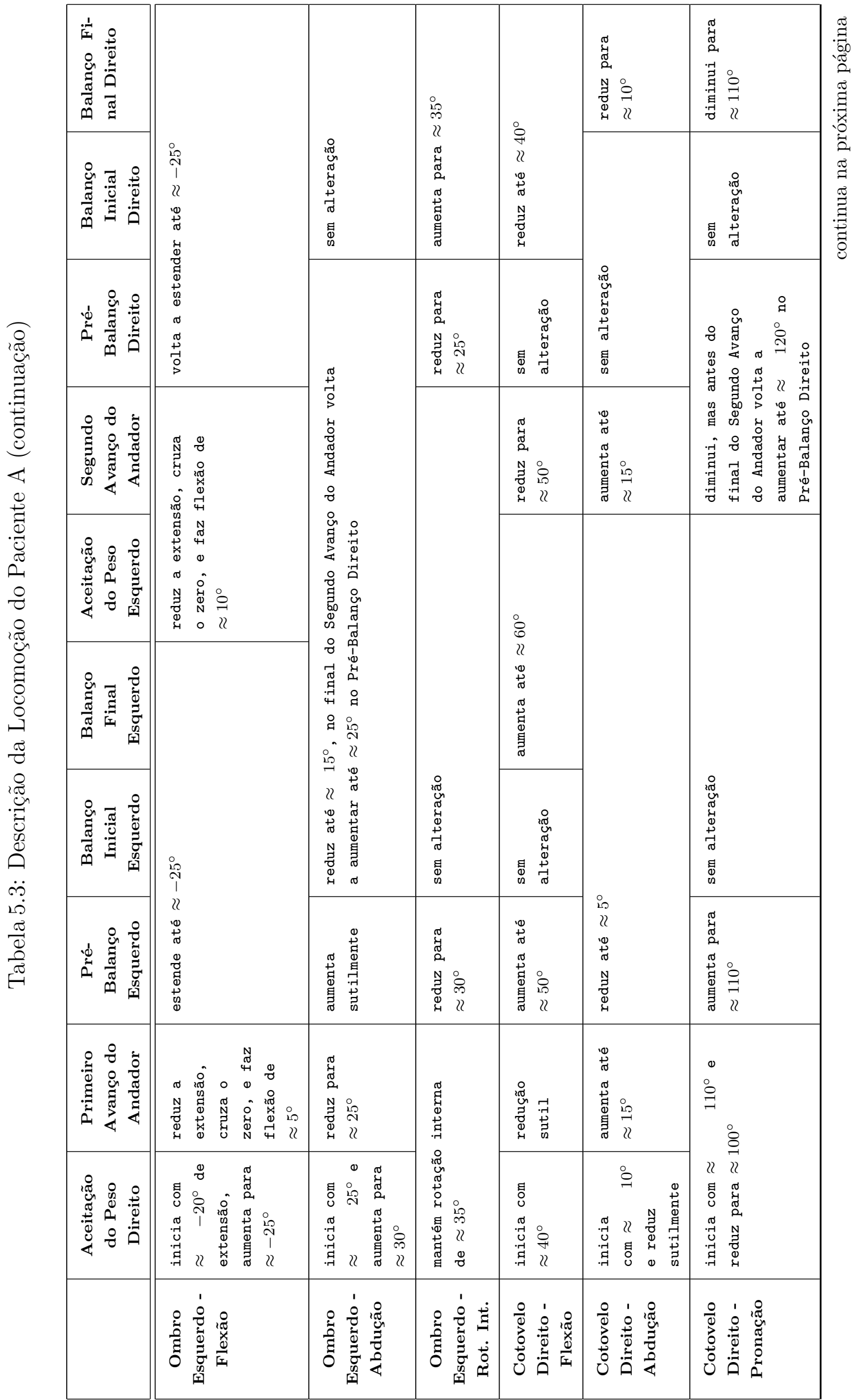




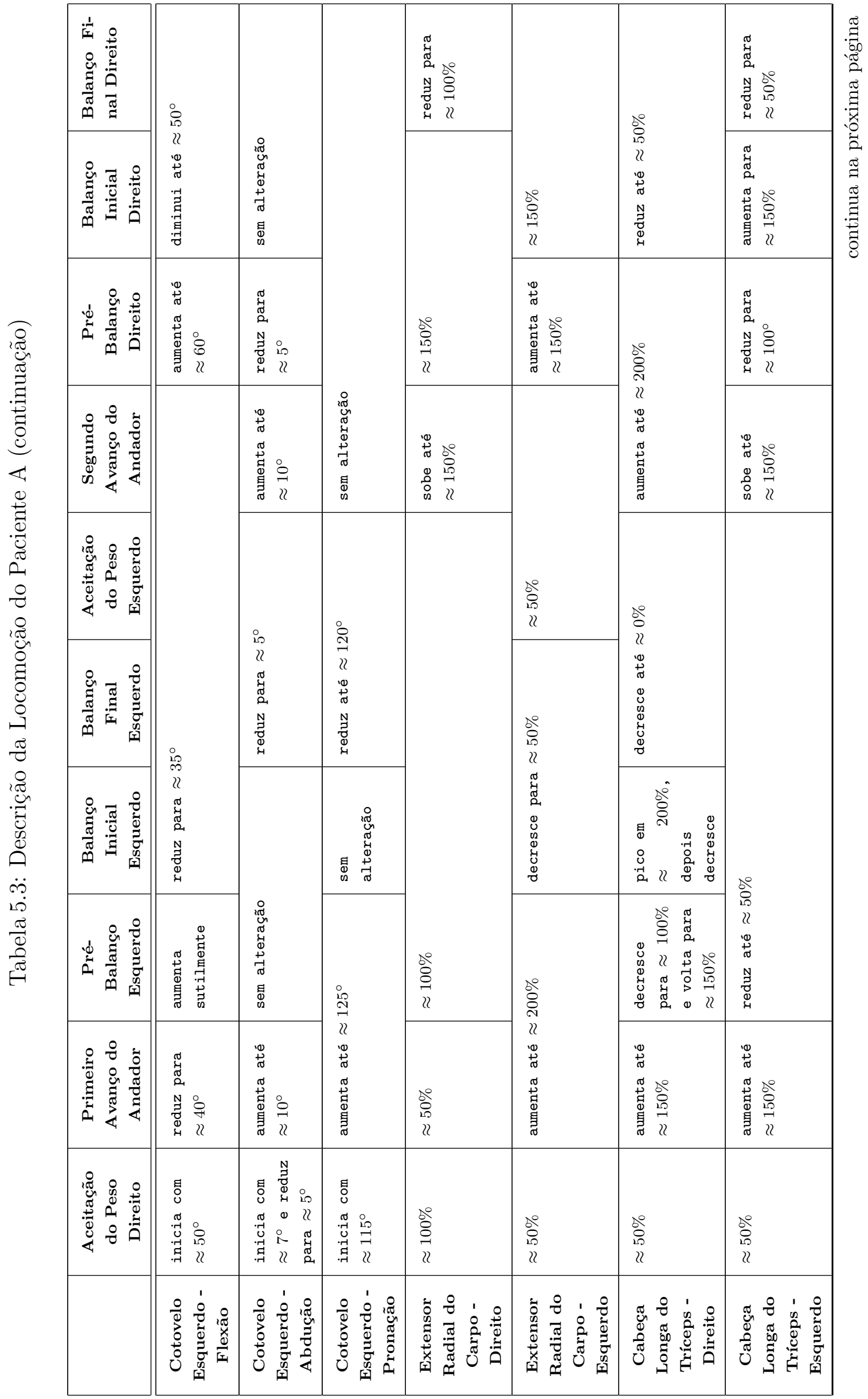


Tabela 5.3: Descrição da Locomoção do Paciente A (continuação)

\begin{tabular}{|c|c|c|c|c|c|c|c|c|c|c|}
\hline & $\begin{array}{c}\text { Aceitação } \\
\text { do Peso } \\
\text { Direito }\end{array}$ & $\begin{array}{c}\text { Primeiro } \\
\text { Avanço do } \\
\text { Andador }\end{array}$ & $\begin{array}{c}\text { Pré- } \\
\text { Balanço } \\
\text { Esquerdo }\end{array}$ & $\begin{array}{c}\text { Balanço } \\
\text { Inicial } \\
\text { Esquerdo }\end{array}$ & $\begin{array}{l}\text { Balanço } \\
\text { Final } \\
\text { Esquerdo }\end{array}$ & $\begin{array}{l}\text { Aceitação } \\
\text { do Peso } \\
\text { Esquerdo }\end{array}$ & $\begin{array}{l}\text { Segundo } \\
\text { Avanço do } \\
\text { Andador }\end{array}$ & $\begin{array}{c}\text { Pré- } \\
\text { Balanço } \\
\text { Direito }\end{array}$ & $\begin{array}{c}\text { Balanço } \\
\text { Inicial } \\
\text { Direito }\end{array}$ & $\begin{array}{l}\text { Balanço Fi- } \\
\text { nal Direito }\end{array}$ \\
\hline $\begin{array}{l}\text { Deltóide } \\
\text { Médio - } \\
\text { Direito }\end{array}$ & \multicolumn{2}{|l|}{$\approx 100 \%$} & \multicolumn{2}{|l|}{$\approx 150 \%$} & $\begin{array}{l}\text { decresce } \\
\text { para } \approx 50 \%\end{array}$ & $\begin{array}{l}\text { sobe até } \\
\approx 100 \%\end{array}$ & \multicolumn{4}{|l|}{$\approx 50 \%$} \\
\hline $\begin{array}{c}\text { Deltóide } \\
\text { Médio - } \\
\text { Esquerdo }\end{array}$ & \multicolumn{4}{|l|}{$\approx 100 \%$} & $\begin{array}{l}\text { aumenta até } \\
\approx 150 \%\end{array}$ & $\begin{array}{l}\text { decresce } \\
\text { para } \approx 50 \%\end{array}$ & \multicolumn{2}{|c|}{ aumenta até $\approx 150 \%$} & $\begin{array}{l}\text { reduz para } \\
\approx 100^{\circ}\end{array}$ & $\begin{array}{l}\text { aumenta até } \\
\approx 150 \%\end{array}$ \\
\hline $\begin{array}{c}\text { Porção } \\
\text { Esternal } \\
\text { do Peitoral } \\
\text { Maior - } \\
\text { Direito }\end{array}$ & $\begin{array}{l}\text { inicia com } \\
\approx \quad 50^{\circ} \mathrm{e} \\
\text { aumenta para } \\
\approx 100 \%\end{array}$ & $\begin{array}{l}\text { reduz para } \\
\approx 50 \%\end{array}$ & $\begin{array}{l}\text { aumenta } \\
\text { sutilmente }\end{array}$ & \multicolumn{2}{|c|}{ decresce para $\approx 50 \%$} & $\begin{array}{l}\text { sem } \\
\text { alteração }\end{array}$ & \multicolumn{2}{|c|}{ aumenta para $\approx 300 \%$} & \multicolumn{2}{|c|}{ decresce até $\approx 50 \%$} \\
\hline $\begin{array}{c}\text { Porção } \\
\text { Esternal } \\
\text { do Peitoral } \\
\text { Maior - } \\
\text { Esquerdo }\end{array}$ & $\begin{array}{l}\text { inicia com } \\
\approx \quad 50^{\circ} \mathrm{e} \\
\text { aumenta para } \\
\approx 100 \%\end{array}$ & $\begin{array}{l}\text { reduz para } \\
\approx 50 \%\end{array}$ & $\begin{array}{l}\text { aumenta para } \\
\approx 150 \%\end{array}$ & \multicolumn{2}{|c|}{ decresce para $\approx 50 \%$} & $\begin{array}{l}\text { aumenta até } \\
\approx 250 \%\end{array}$ & $\begin{array}{l}\text { reduz para } \\
\approx 50^{\circ}\end{array}$ & \multicolumn{3}{|l|}{ sem alteração } \\
\hline $\begin{array}{l}\text { Componente } \\
\text { Vertical da } \\
\text { Força de } \\
\text { Reação do } \\
\text { Solo }\end{array}$ & $\begin{array}{l}\text { sobe para } \\
\approx 20 \%\end{array}$ & $\begin{array}{l}\text { sem } \\
\text { alteração }\end{array}$ & $\begin{array}{l}\text { sobe para } \\
\approx 60 \%\end{array}$ & $\begin{array}{l}\text { reduz para } \\
\approx 40 \%\end{array}$ & $\begin{array}{l}\text { sobe para } \\
\approx 70 \%\end{array}$ & $\begin{array}{l}\text { sobe para } \\
\approx 90 \%\end{array}$ & $\begin{array}{l}\text { reduz para } \\
\approx 60 \%\end{array}$ & $\begin{array}{l}\text { sem } \\
\text { alteração }\end{array}$ & $\begin{array}{l}\text { reduz para } \\
\approx 40 \%\end{array}$ & $\begin{array}{l}\text { sem } \\
\text { alteração }\end{array}$ \\
\hline
\end{tabular}




\subsection{Descrição da locomoção do paciente B}

A figura 5.2 apresenta a visualização das posições do corpo do paciente $\mathbf{B}$ nos eventos que definem a marcha, e a tabela 5.4 apresenta um resumo das variações que ocorrem nas diversas fases definidas por estes eventos.
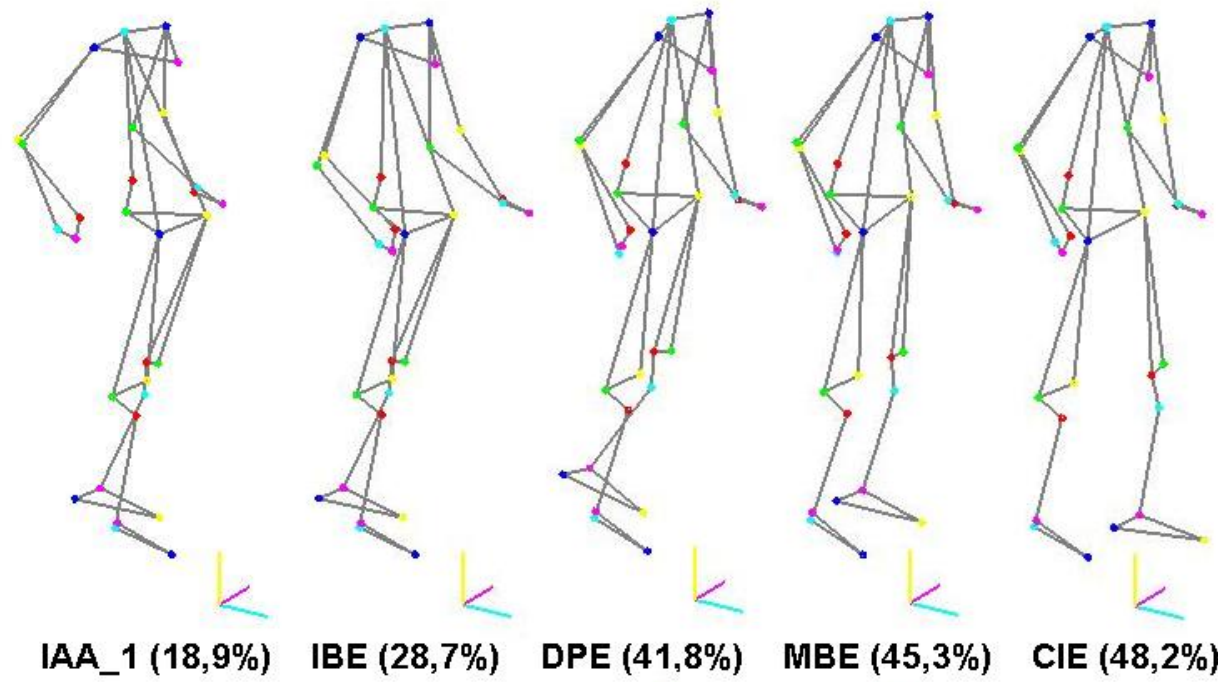

IBE $(28,7 \%)$

DPE $(41,8 \%)$

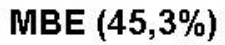

CIE $(48,2 \%)$
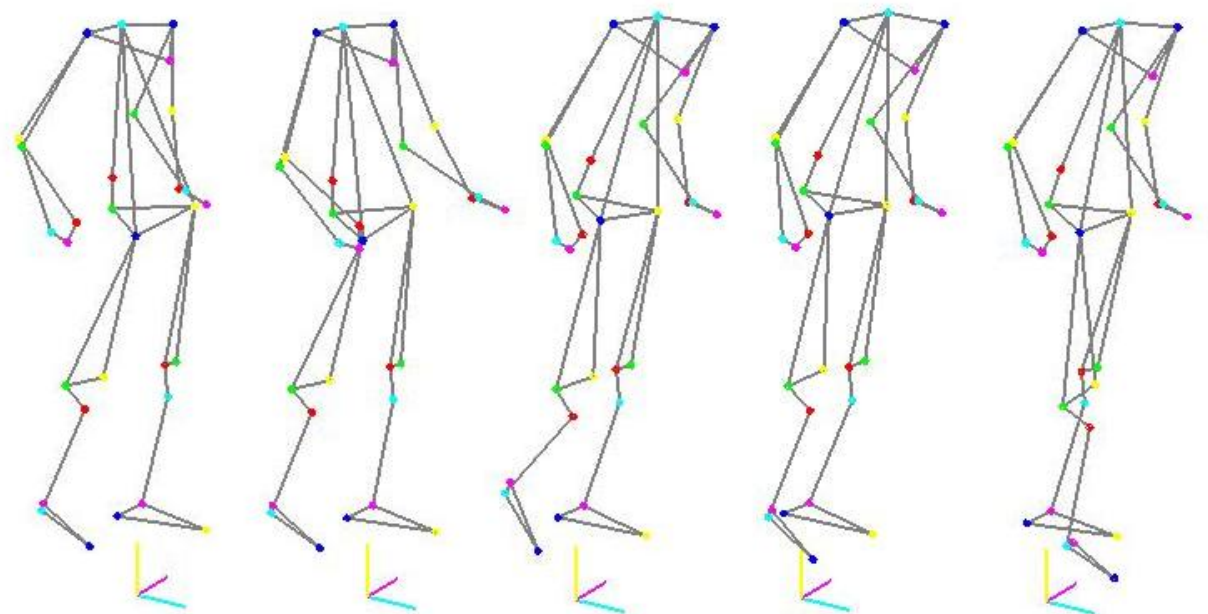

IAA_2 (70,7\%) IBD $(80,2 \%)$

DPD $(93,3 \%)$ MBD $(96,8 \%)$

CID_2 (100,0\%)

Figura 5.2: Posições do corpo do paciente $\mathbf{B}$ nos eventos da marcha. 


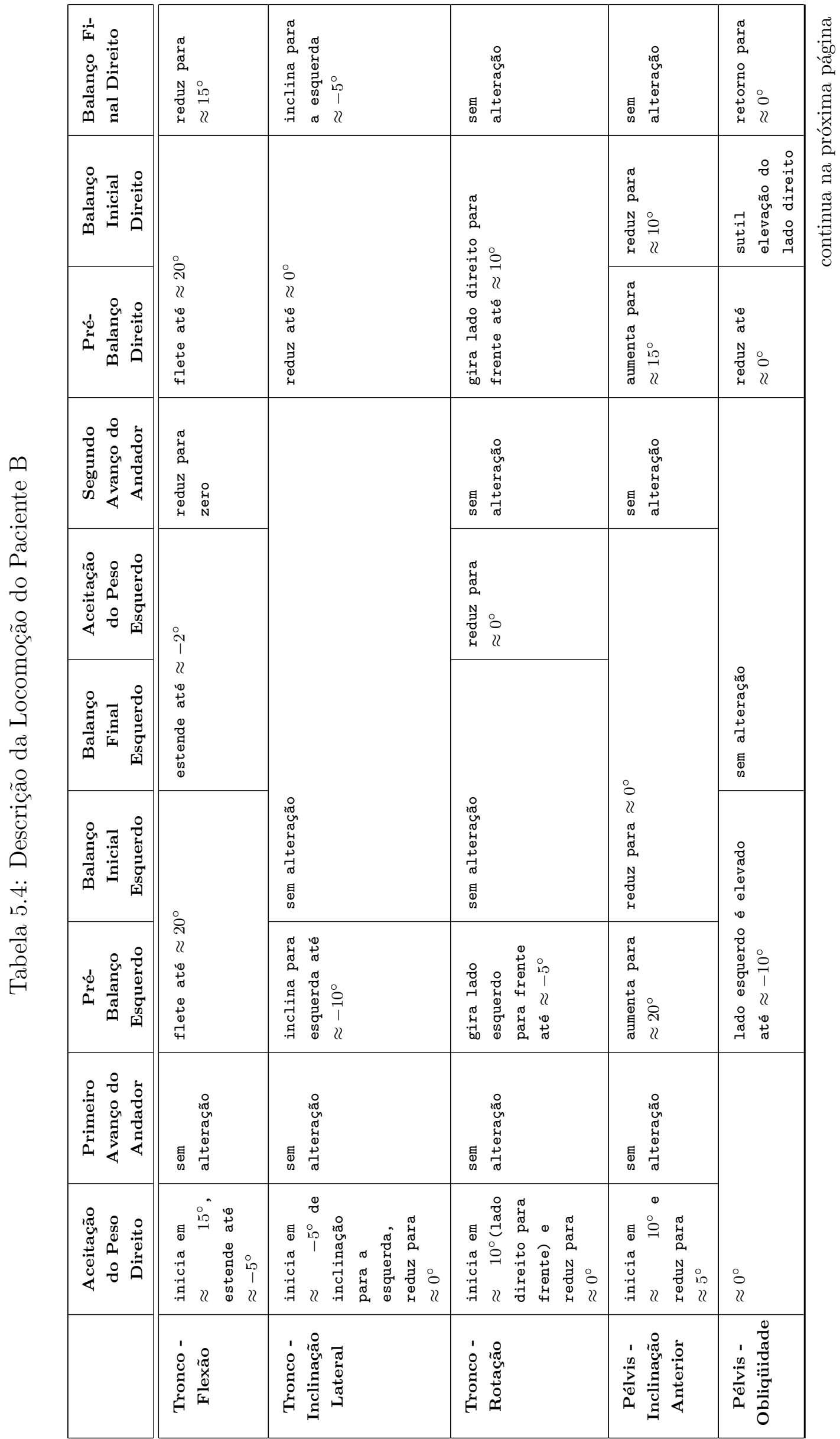




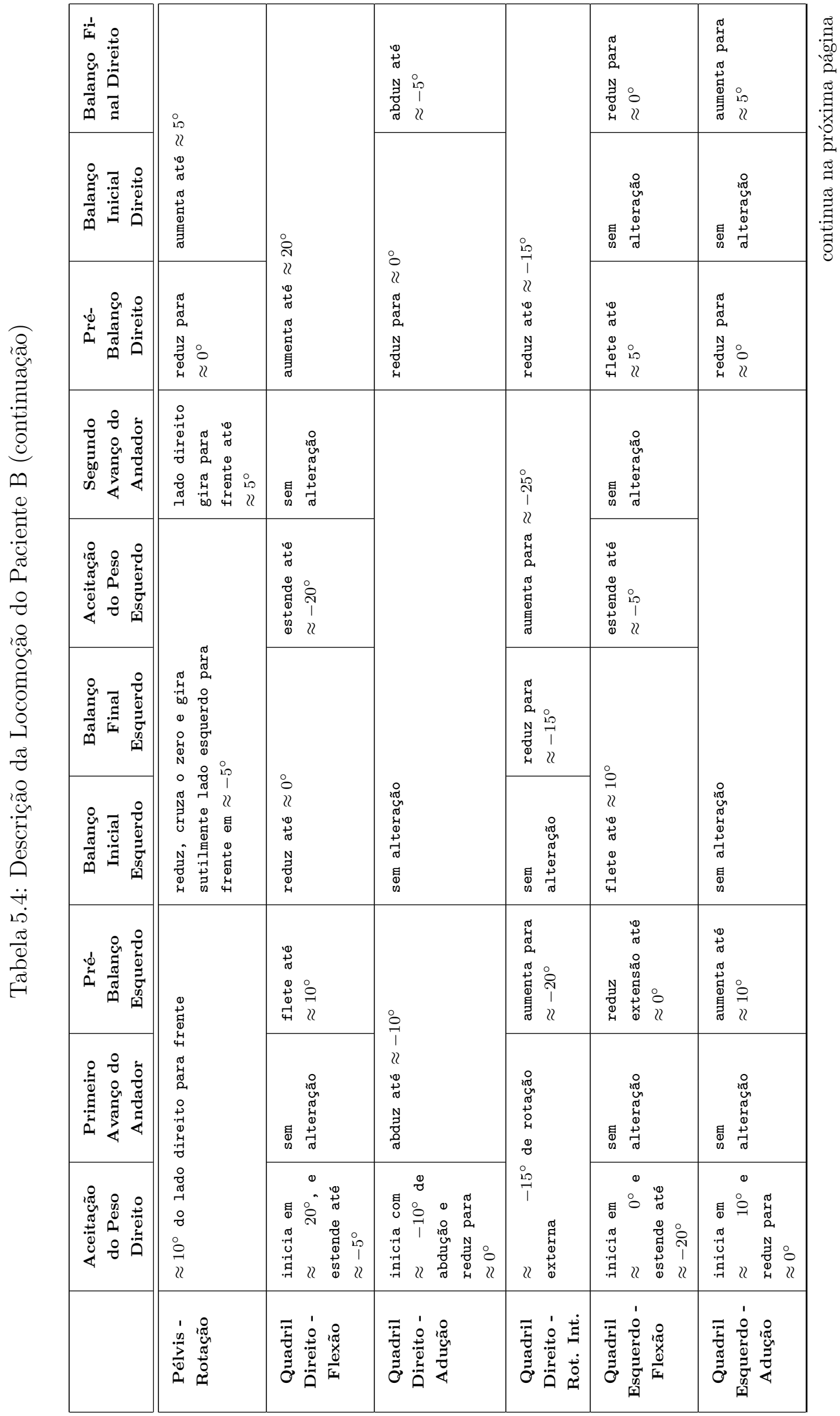




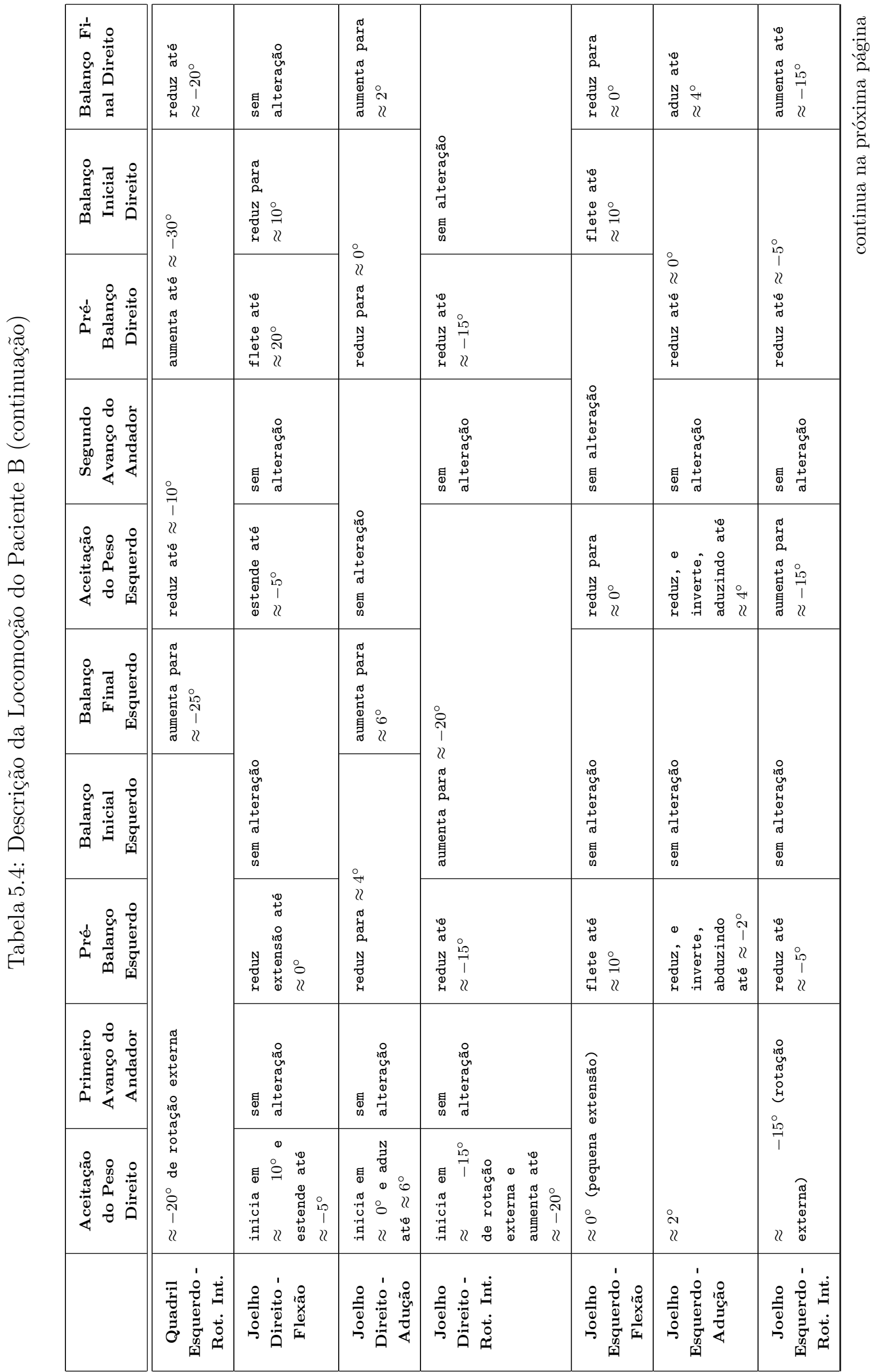




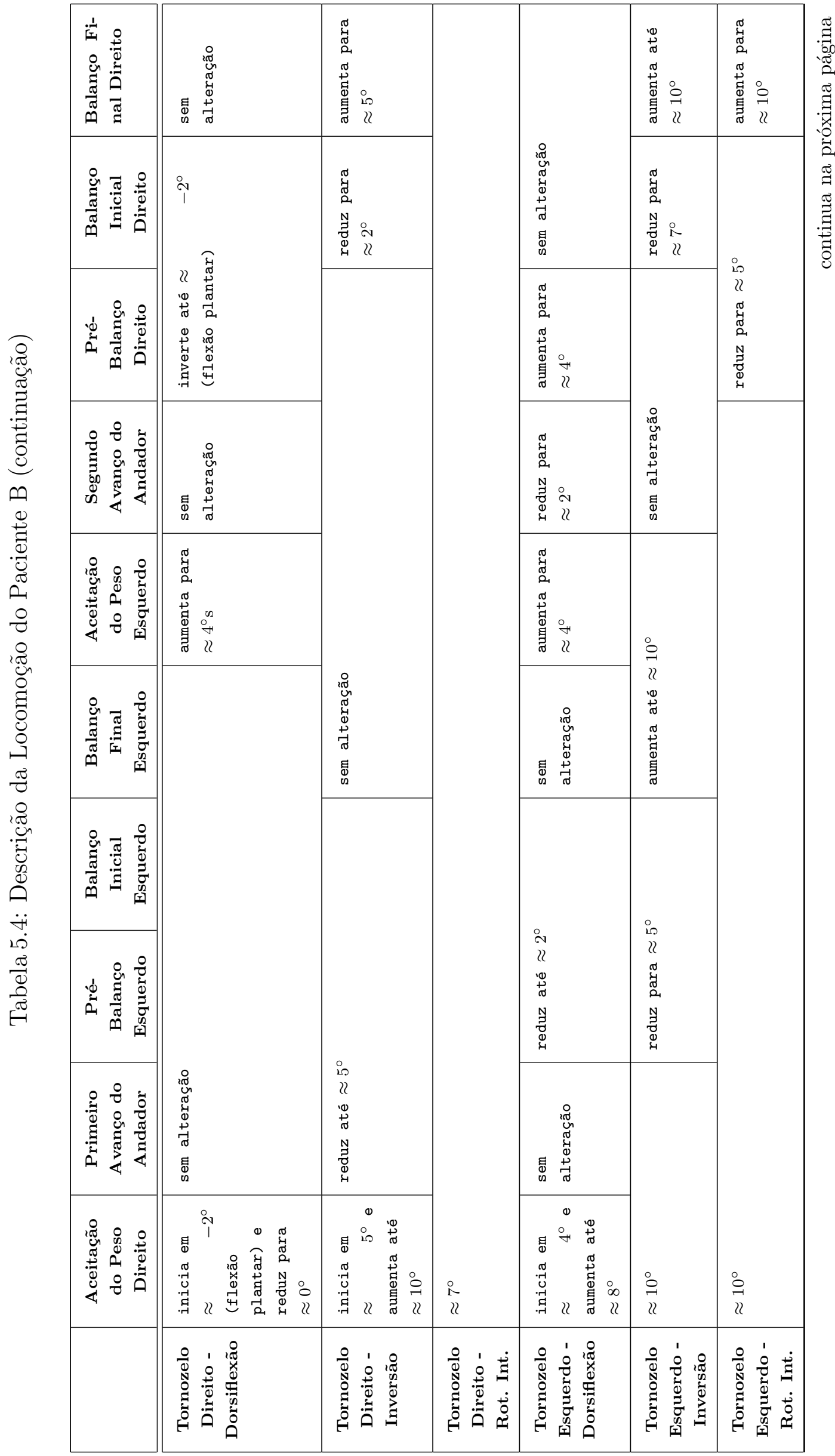




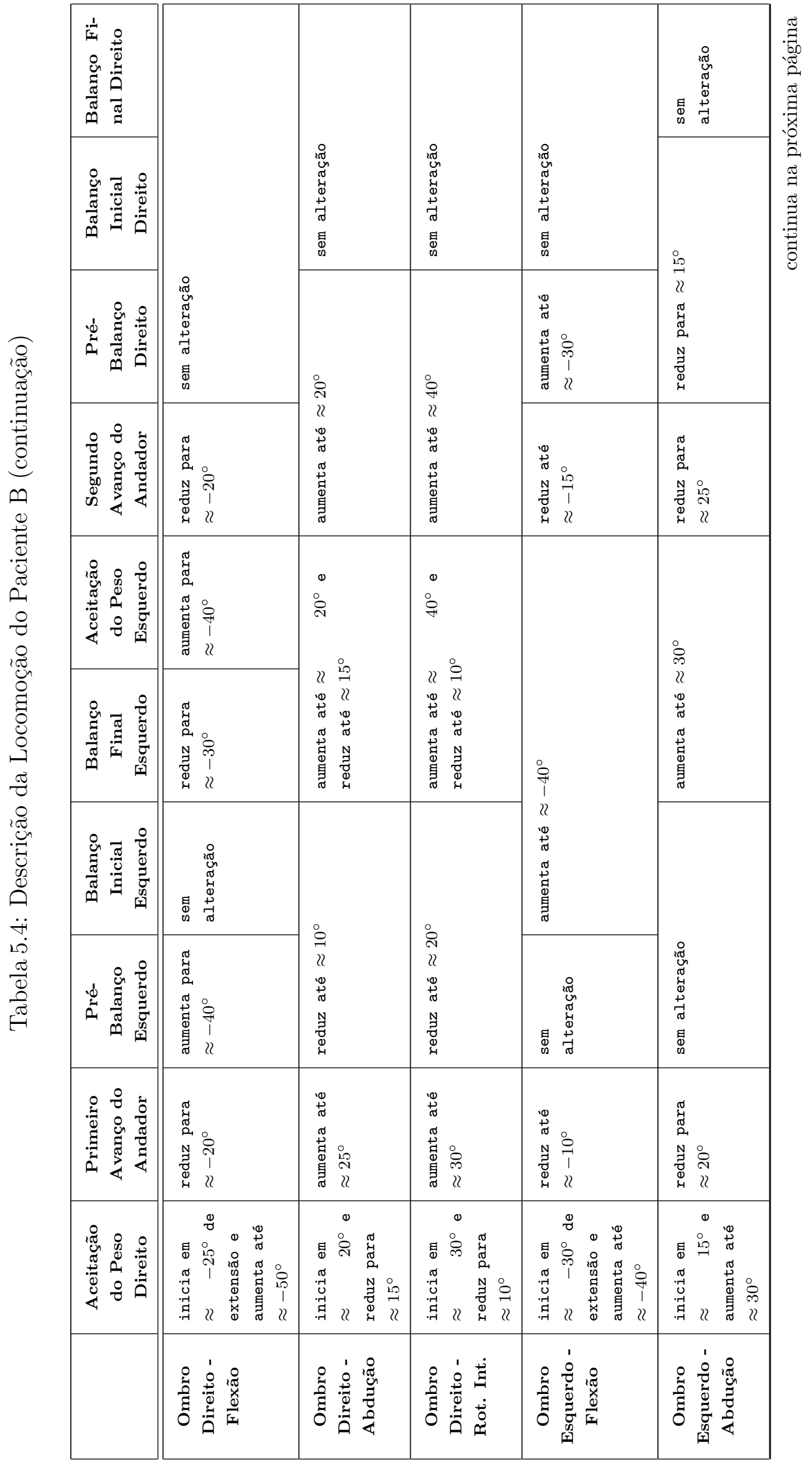




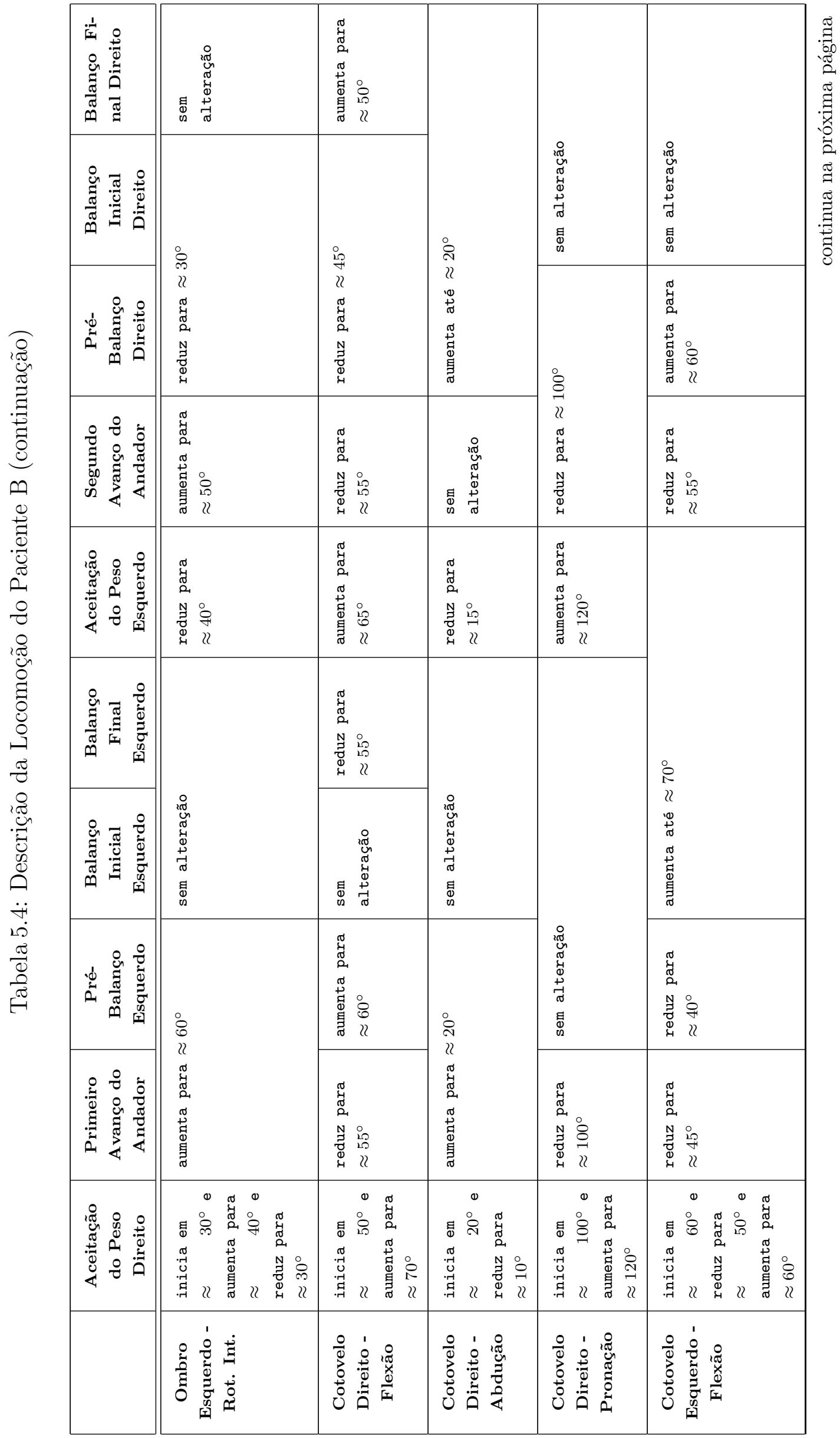




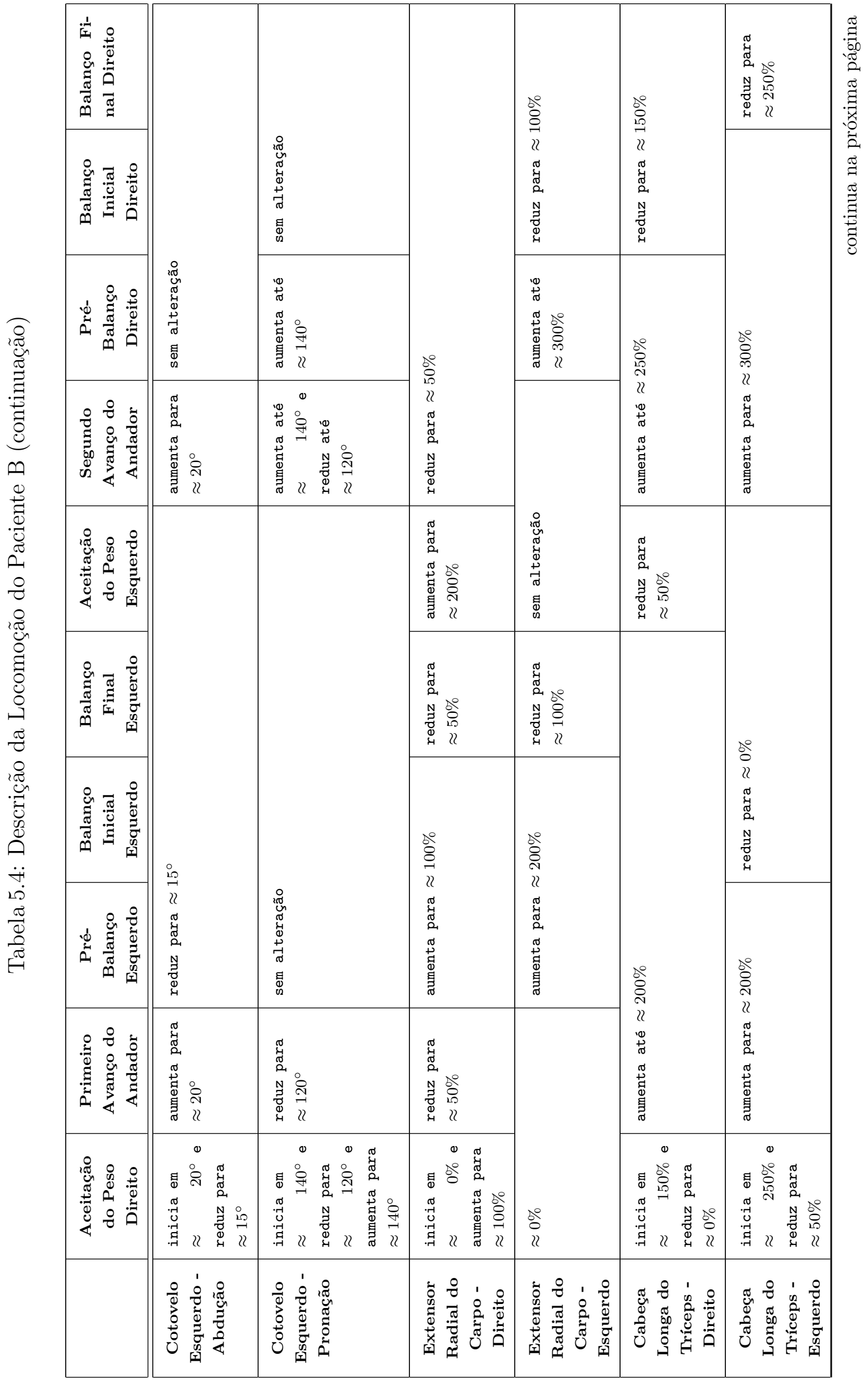


Tabela 5.4: Descrição da Locomoção do Paciente B (continuação)

\begin{tabular}{|c|c|c|c|c|c|c|c|c|c|c|}
\hline & $\begin{array}{c}\text { Aceitação } \\
\text { do Peso } \\
\text { Direito }\end{array}$ & $\begin{array}{c}\text { Primeiro } \\
\text { Avanço do } \\
\text { Andador }\end{array}$ & $\begin{array}{c}\text { Pré- } \\
\text { Balanço } \\
\text { Esquerdo }\end{array}$ & $\begin{array}{c}\text { Balanço } \\
\text { Inicial } \\
\text { Esquerdo }\end{array}$ & $\begin{array}{l}\text { Balanço } \\
\text { Final } \\
\text { Esquerdo }\end{array}$ & $\begin{array}{l}\text { Aceitação } \\
\text { do Peso } \\
\text { Esquerdo }\end{array}$ & $\begin{array}{c}\text { Segundo } \\
\text { Avanço do } \\
\text { Andador }\end{array}$ & $\begin{array}{c}\text { Pré- } \\
\text { Balanço } \\
\text { Direito }\end{array}$ & $\begin{array}{c}\text { Balanço } \\
\text { Inicial } \\
\text { Direito }\end{array}$ & $\begin{array}{l}\text { Balanço Fi- } \\
\text { nal Direito }\end{array}$ \\
\hline $\begin{array}{l}\text { Deltóide } \\
\text { Médio - } \\
\text { Direito }\end{array}$ & $\begin{array}{l}\text { inicia em } \\
\approx \quad 50 \% \text { e } \\
\text { aumenta para } \\
\approx 300 \%\end{array}$ & $\begin{array}{l}\text { reduz para } \\
\approx 50 \%\end{array}$ & $\begin{array}{l}\text { aumenta para } \\
\approx 100 \%\end{array}$ & \multicolumn{2}{|l|}{ sem alteração } & $\begin{array}{l}\text { aumenta até } \\
\approx 150 \%\end{array}$ & $\begin{array}{l}\text { reduz para } \\
\approx 50 \%\end{array}$ & \multicolumn{3}{|l|}{ sem alteração } \\
\hline $\begin{array}{l}\text { Deltóide } \\
\text { Médio - } \\
\text { Esquerdo }\end{array}$ & $\approx 150 \%$ & $\begin{array}{l}\text { reduz para } \\
\approx 50 \%\end{array}$ & \multicolumn{3}{|l|}{ sem alteração } & $\begin{array}{l}\text { aumenta para } \\
\approx 150 \%\end{array}$ & $\begin{array}{l}\text { reduz para } \\
\approx 50 \%\end{array}$ & \multicolumn{2}{|c|}{ aumenta para $\approx 150 \%$} & $\begin{array}{l}\text { reduz para } \\
\approx 100 \%\end{array}$ \\
\hline $\begin{array}{c}\text { Porção } \\
\text { Esternal } \\
\text { do Peitoral } \\
\text { Maior - } \\
\text { Direito }\end{array}$ & $\begin{array}{l}\text { inicia em } \\
\approx \quad 200^{\circ} \mathrm{e} \\
\text { reduz para } \\
\approx 50^{\circ}\end{array}$ & $\begin{array}{l}\text { sem } \\
\text { alteração }\end{array}$ & \multicolumn{2}{|c|}{ aumenta para $\approx 150 \%$} & \multicolumn{2}{|c|}{ reduz para $\approx 50 \%$} & $\begin{array}{l}\text { sem } \\
\text { alteração }\end{array}$ & \multicolumn{2}{|c|}{ aumenta para $\approx 350 \%$} & $\begin{array}{l}\text { reduz para } \\
\approx 250 \%\end{array}$ \\
\hline $\begin{array}{c}\text { Porção } \\
\text { Esternal } \\
\text { do Peitoral } \\
\text { Maior - } \\
\text { Esquerdo }\end{array}$ & \multicolumn{2}{|l|}{$\approx 50 \%$} & \multicolumn{3}{|c|}{ aumenta para $\approx 200^{\circ}$} & $\begin{array}{l}\text { reduz para } \\
\approx 50^{\circ}\end{array}$ & $\begin{array}{l}\text { sem } \\
\text { alteração }\end{array}$ & $\begin{array}{l}\text { aumenta para } \\
\approx 100 \%\end{array}$ & \multicolumn{2}{|l|}{ sem alteração } \\
\hline $\begin{array}{l}\text { Componente } \\
\text { Vertical da } \\
\text { Força de } \\
\text { Reação do } \\
\text { Solo }\end{array}$ & $\begin{array}{l}\text { inicia em } \\
\approx \quad 20 \% \text { e } \\
\text { aumenta para } \\
\approx 90 \%\end{array}$ & $\begin{array}{l}\text { sem } \\
\text { alteração }\end{array}$ & \multicolumn{2}{|c|}{ reduz para $\approx 40 \%$} & \multicolumn{3}{|c|}{ aumenta para $\approx 90 \%$} & $\begin{array}{l}\text { reduz para } \\
\approx 30 \%\end{array}$ & $\begin{array}{l}\text { sem } \\
\text { alteração }\end{array}$ & $\begin{array}{l}\text { aumenta para } \\
\approx 40 \%\end{array}$ \\
\hline
\end{tabular}




\subsection{Descrição da locomoção do paciente C}

A figura 5.3 apresenta a visualização das posições do corpo do paciente $\mathbf{C}$ nos eventos que definem a marcha, e a tabela 5.5 apresenta um resumo das variações que ocorrem nas diversas fases definidas por estes eventos.
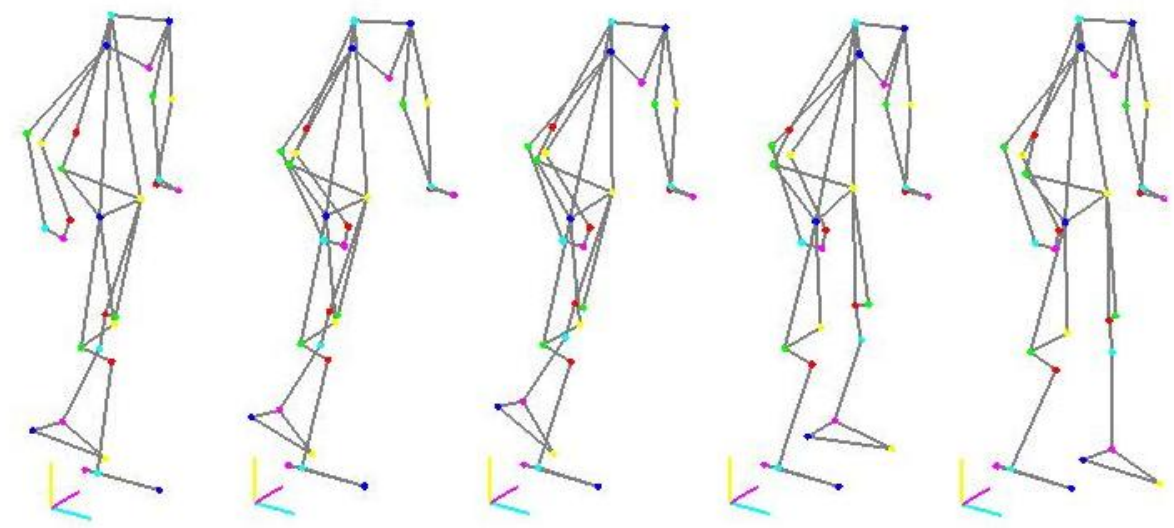

IAA_1 $(8,7 \%)$

IBE $(\mathbf{2 8 , 0 \% )}$

DPE $(37,3 \%)$

MBE $(44,3 \%)$

CIE $(51,4 \%)$
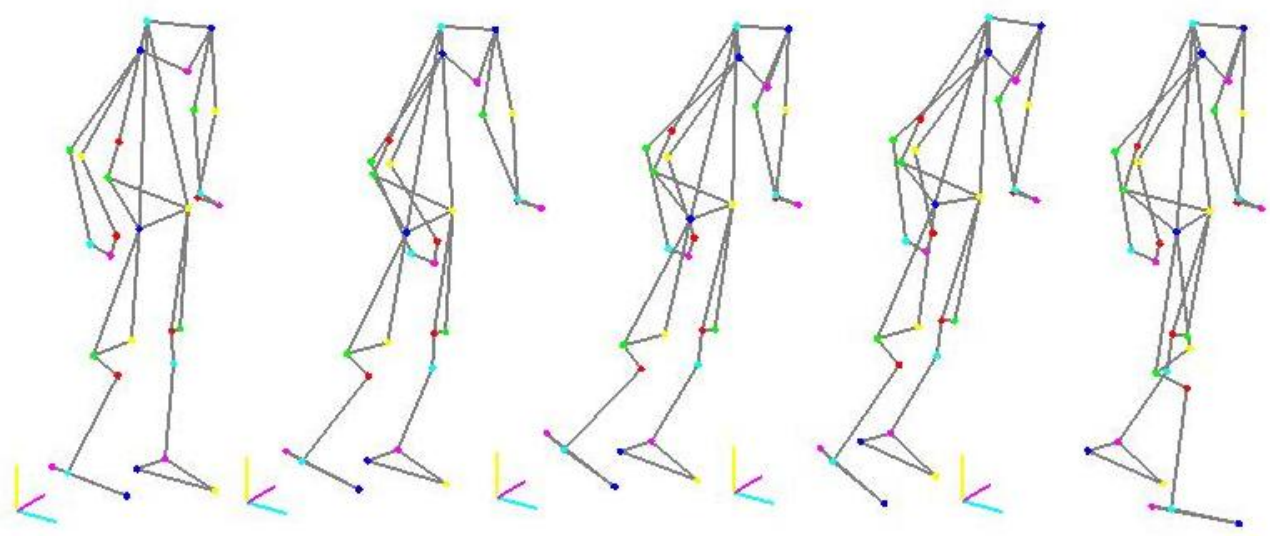

IAA_2 $(62,8 \%) \quad$ IBD $(75,1 \%) \quad$ DPD $(83,8 \%) \quad$ MBD $(87,3 \%) \quad$ CID_2 $(100,0 \%)$

Figura 5.3: Posições do corpo do paciente $\mathbf{C}$ nos eventos da marcha. 


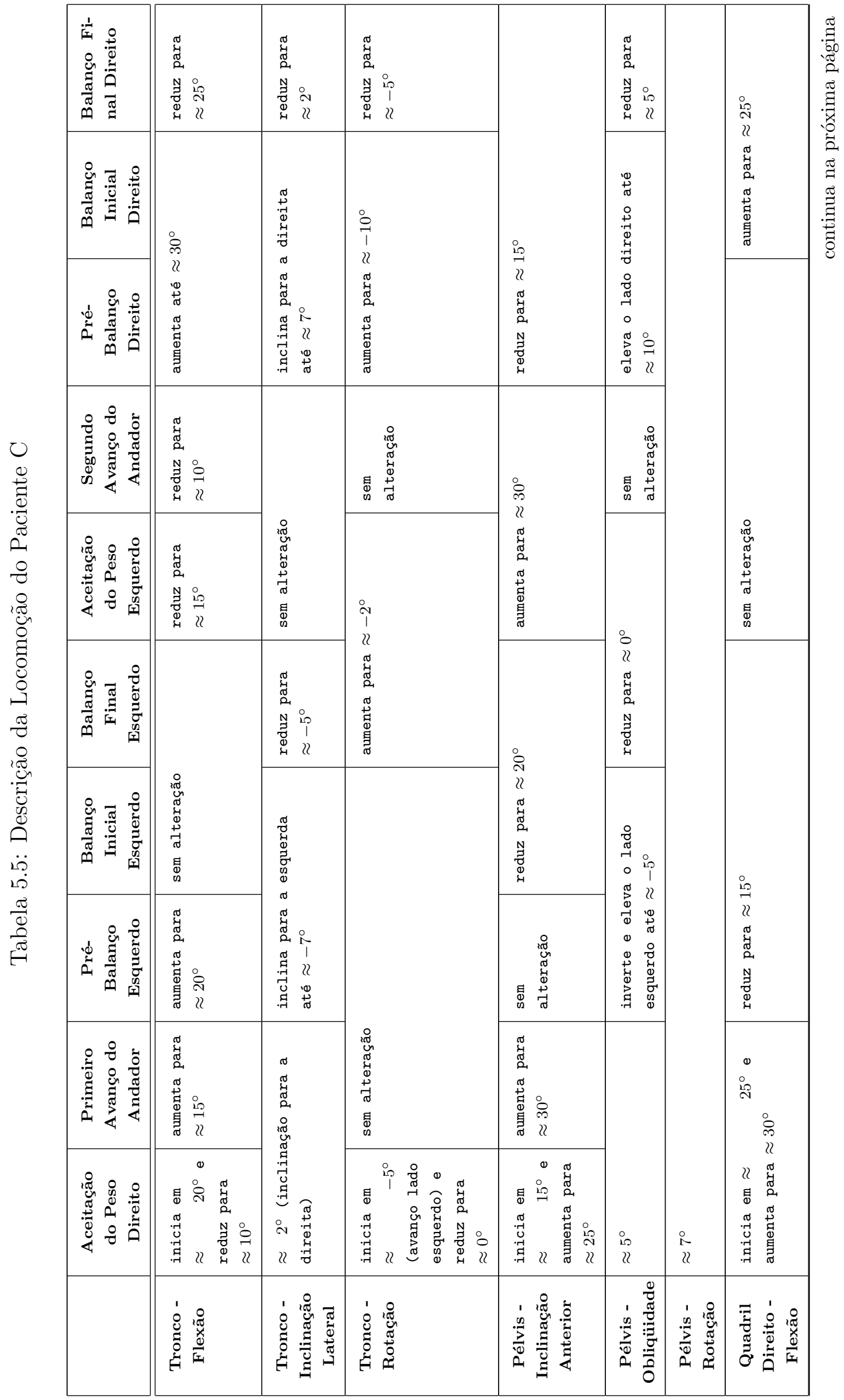




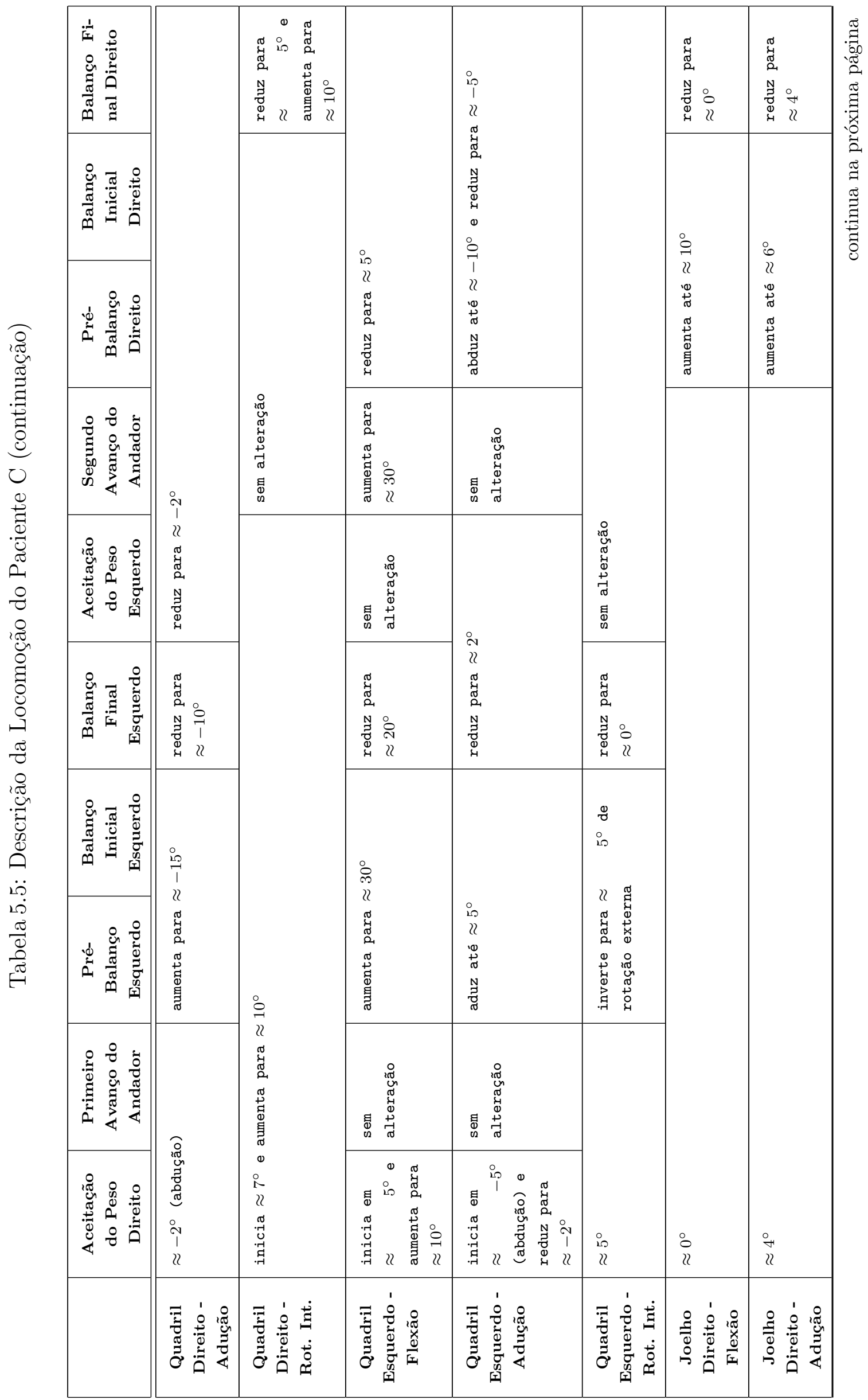




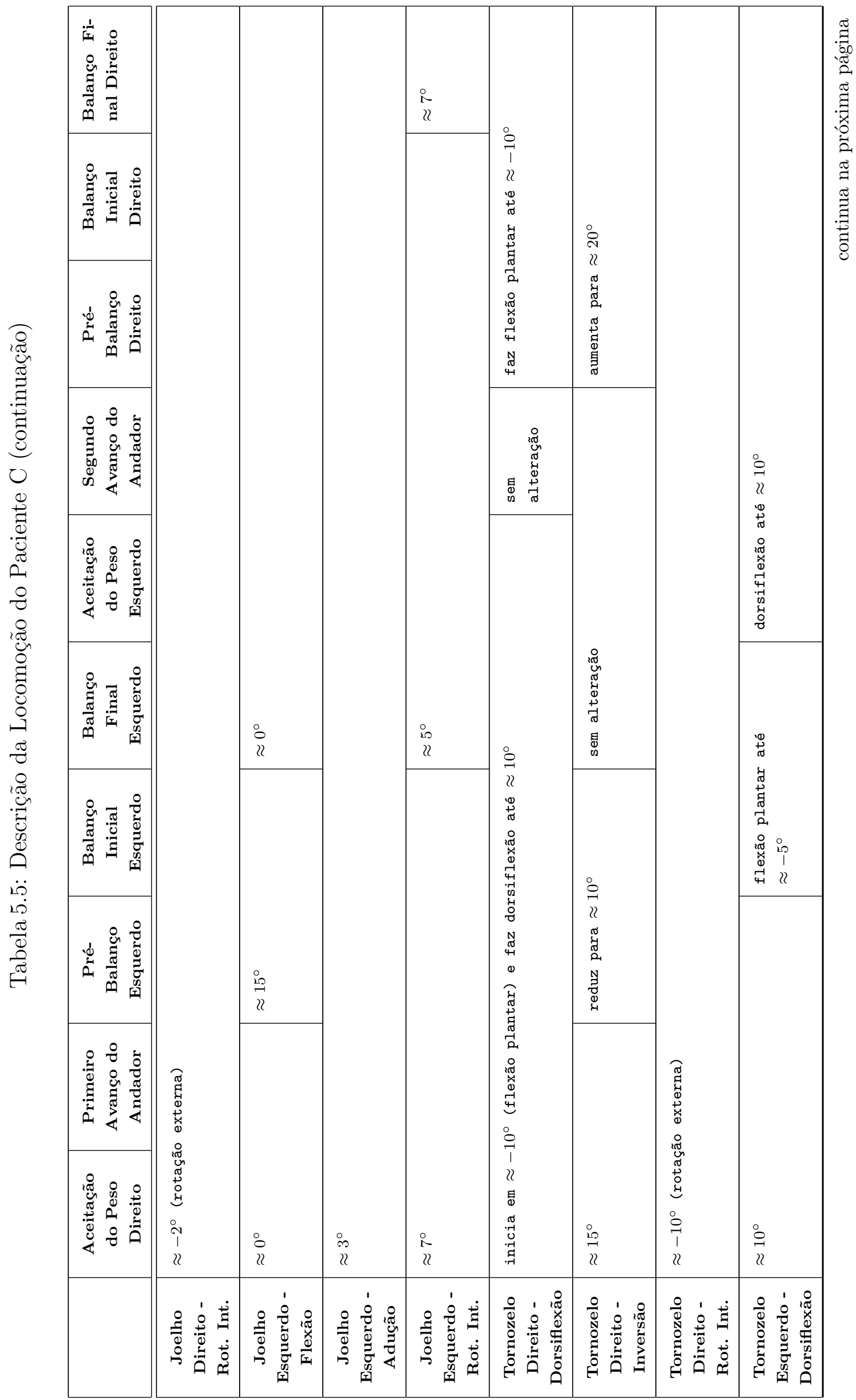




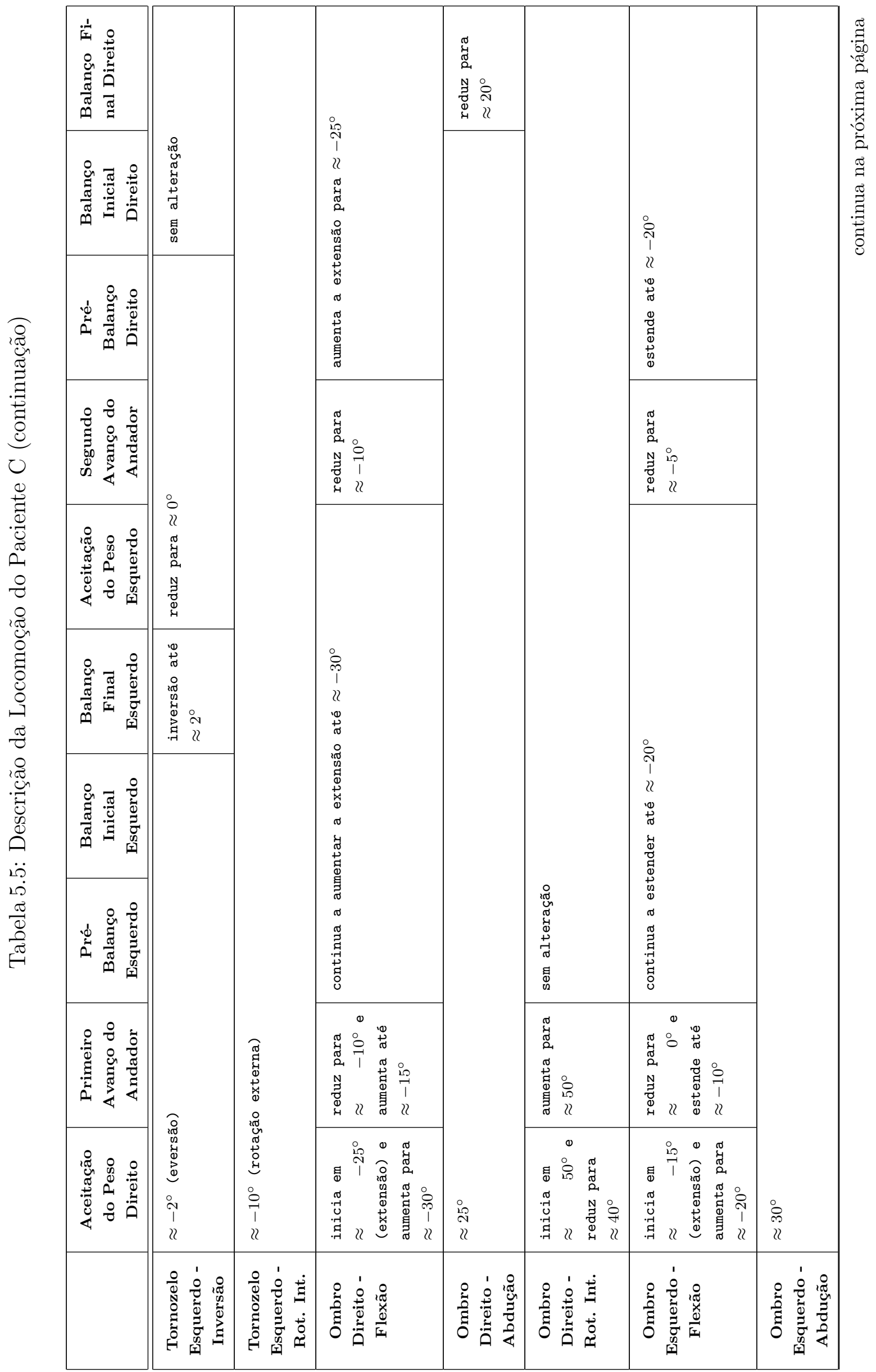




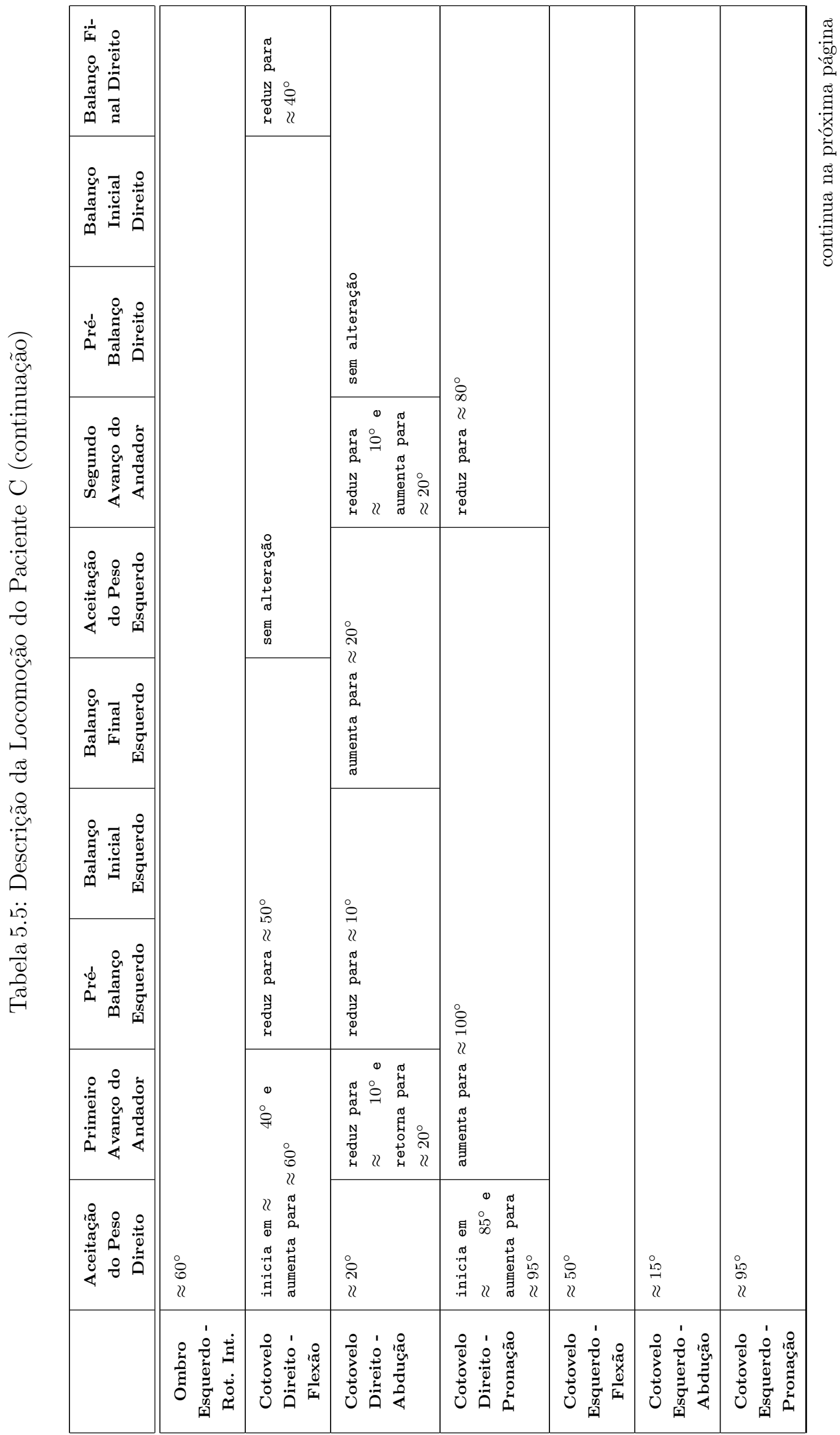




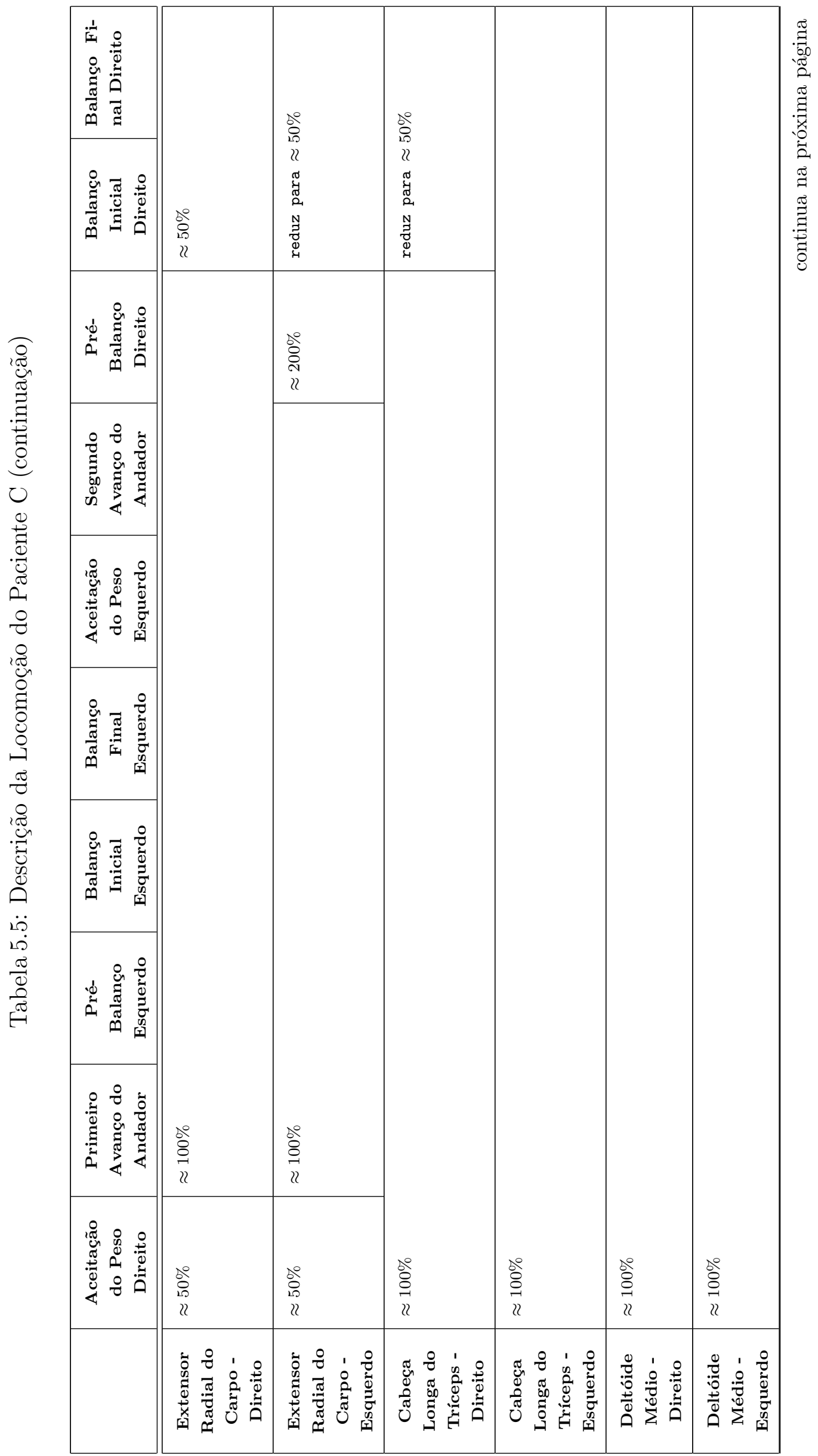


Tabela 5.5: Descrição da Locomoção do Paciente C (continuação)

\begin{tabular}{|c|c|c|c|c|c|c|c|c|c|c|}
\hline & $\begin{array}{c}\text { Aceitação } \\
\text { do Peso } \\
\text { Direito }\end{array}$ & $\begin{array}{l}\text { Primeiro } \\
\text { Avanço do } \\
\text { Andador }\end{array}$ & $\begin{array}{c}\text { Pré- } \\
\text { Balanço } \\
\text { Esquerdo }\end{array}$ & $\begin{array}{c}\text { Balanço } \\
\text { Inicial } \\
\text { Esquerdo }\end{array}$ & $\begin{array}{c}\text { Balanço } \\
\text { Final } \\
\text { Esquerdo }\end{array}$ & $\begin{array}{c}\text { Aceitação } \\
\text { do Peso } \\
\text { Esquerdo }\end{array}$ & $\begin{array}{l}\text { Segundo } \\
\text { Avanço do } \\
\text { Andador }\end{array}$ & $\begin{array}{c}\text { Pré- } \\
\text { Balanço } \\
\text { Direito }\end{array}$ & $\begin{array}{c}\text { Balanço } \\
\text { Inicial } \\
\text { Direito }\end{array}$ & $\begin{array}{l}\text { Balanço Fi- } \\
\text { nal Direito }\end{array}$ \\
\hline $\begin{array}{c}\text { Porção } \\
\text { Esternal } \\
\text { do Peitoral } \\
\text { Maior - } \\
\text { Direito }\end{array}$ & $\approx 50 \%$ & $\begin{array}{l}\text { inicia em } \\
\approx 100 \% \text { e } \\
\text { termina em } \\
\approx 50 \%\end{array}$ & \multicolumn{5}{|l|}{$\approx 50 \%$} & \multicolumn{2}{|c|}{ aumenta para $\approx 250 \%$} & $\begin{array}{l}\text { reduz para } \\
\approx 100 \%\end{array}$ \\
\hline $\begin{array}{c}\text { Porção } \\
\text { Esternal } \\
\text { do Peitoral } \\
\text { Maior - } \\
\text { Esquerdo }\end{array}$ & $\approx 50 \%$ & $\begin{array}{l}\text { inicia em } \\
\approx 100 \% \text { e } \\
\text { termina em } \\
\approx 50 \%\end{array}$ & $\begin{array}{l}\text { aumenta até } \\
\approx 200 \%\end{array}$ & reduz para & & & $\begin{array}{l}\text { inicia em } \\
\approx \quad 150 \% \text { e } \\
\text { termina em } \\
\approx 50 \%\end{array}$ & \multicolumn{3}{|l|}{ sem alteração } \\
\hline $\begin{array}{l}\text { Componente } \\
\text { Vertical da } \\
\text { Força de } \\
\text { Reação do } \\
\text { Solo }\end{array}$ & $\begin{array}{l}\text { aumenta até } \\
\approx 20 \%\end{array}$ & $\begin{array}{l}\text { aumenta até } \\
\approx 50 \%\end{array}$ & $\approx 60 \%$ & aumenta par & $80 \%$ & & $\begin{array}{l}\text { reduz para } \\
\approx \quad 60 \% \text { e } \\
\text { aumenta para } \\
\approx 80 \%\end{array}$ & $\begin{array}{l}\text { aumenta até } \\
\approx \quad 90 \% \text { e } \\
\text { reduz para } \\
\approx 80 \%\end{array}$ & \multicolumn{2}{|c|}{$\begin{array}{l}\text { continua a reduzir até } \\
\approx 70 \%\end{array}$} \\
\hline
\end{tabular}




\subsection{Descrição da locomoção do paciente $\mathrm{D}$}

A figura 5.4 apresenta a visualização das posições do corpo do paciente $\mathbf{D}$ nos eventos que definem a marcha, e a tabela 5.6 apresenta um resumo das variações que ocorrem nas diversas fases definidas por estes eventos.
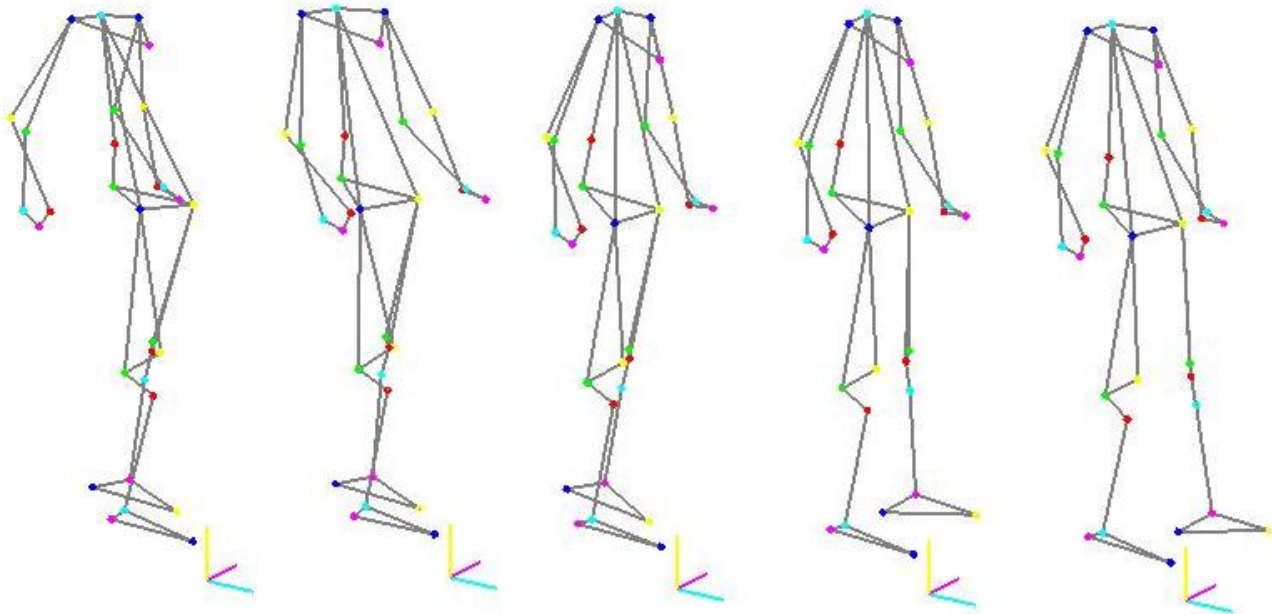

IAA_1 (5,5\%)

IBE $(\mathbf{1 9}, \mathbf{7} \%)$

DPE $(34,0 \%)$

MBE $(39,5 \%)$

CIE $(44,8 \%)$
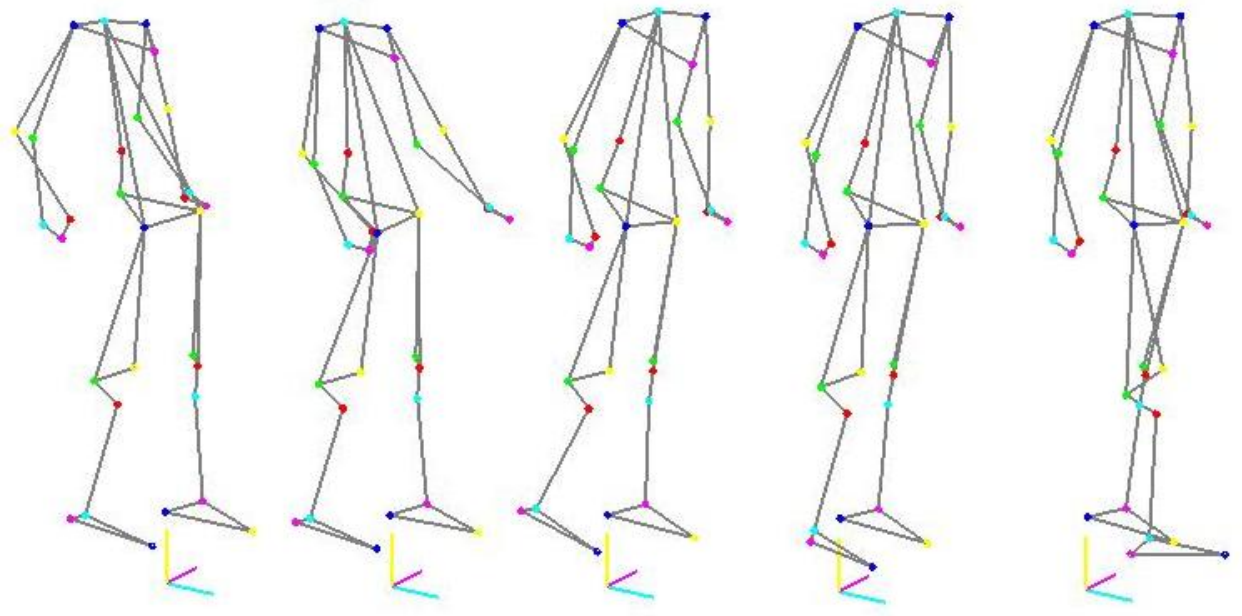

IAA_2 $(53,5 \%)$

IBD $(75,4 \%)$

DPD $(90,3 \%)$

MBD (95,7\%)

CID_2 (100,0\%)

Figura 5.4: Posições do corpo do paciente $\mathbf{D}$ nos eventos da marcha. 


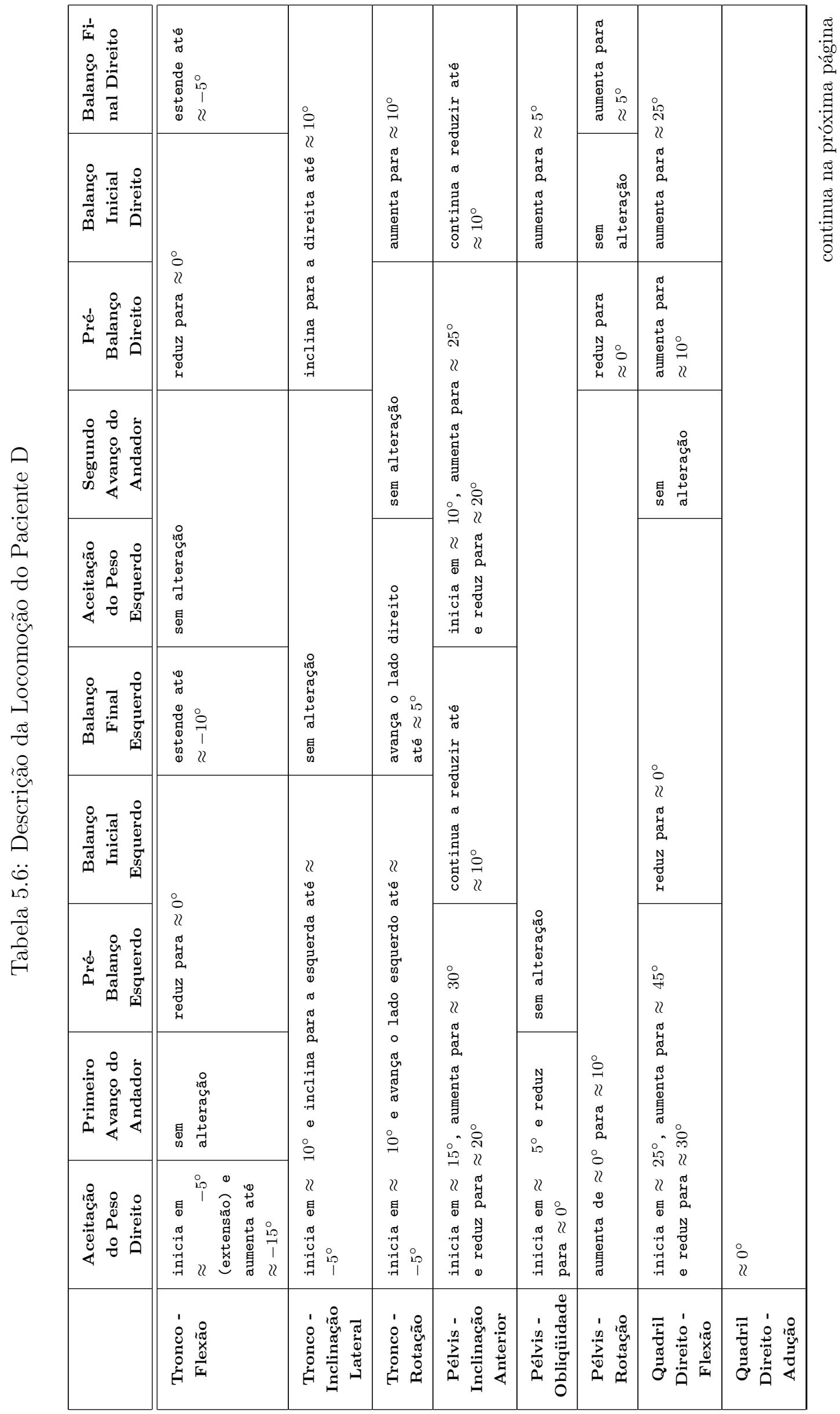




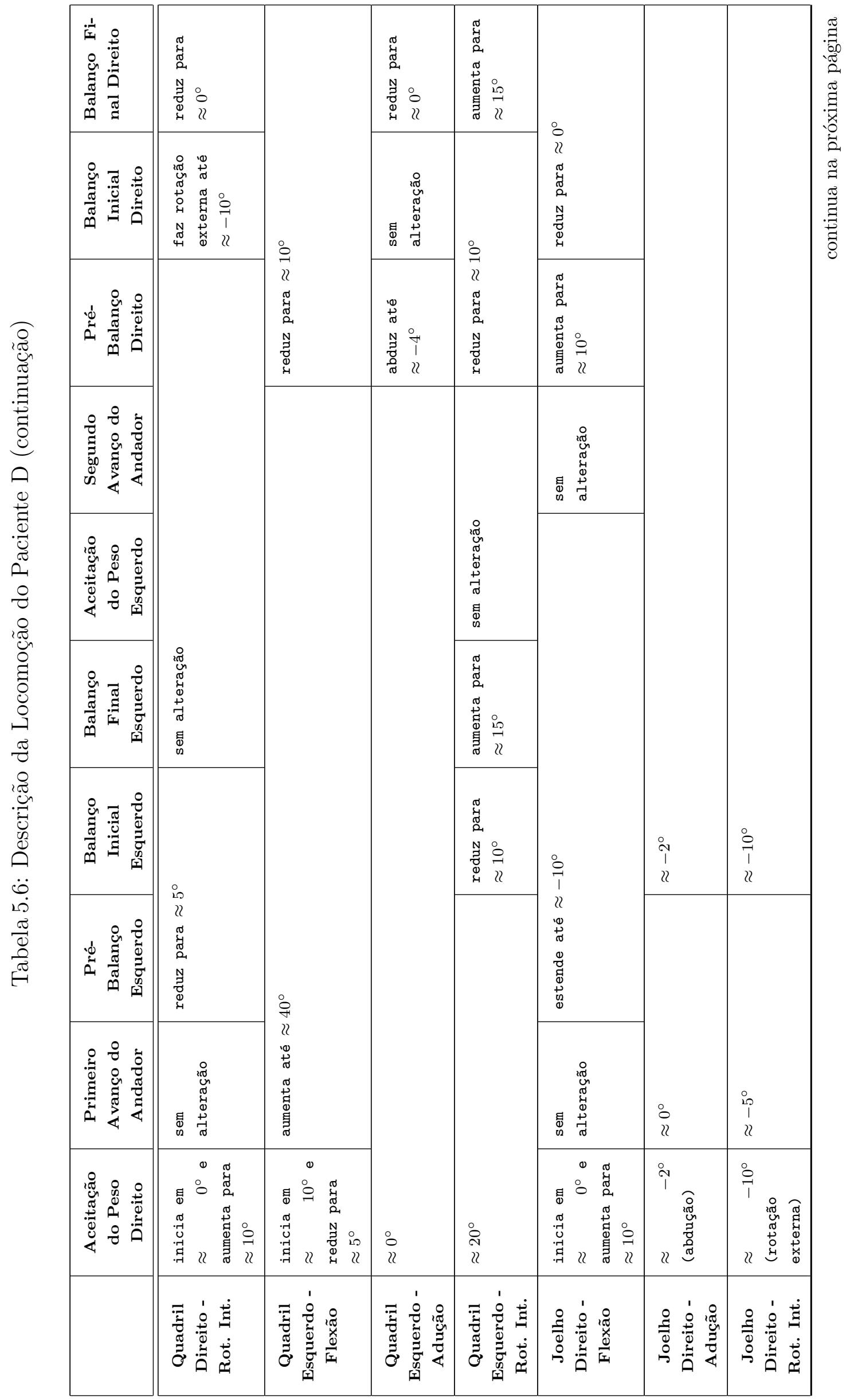




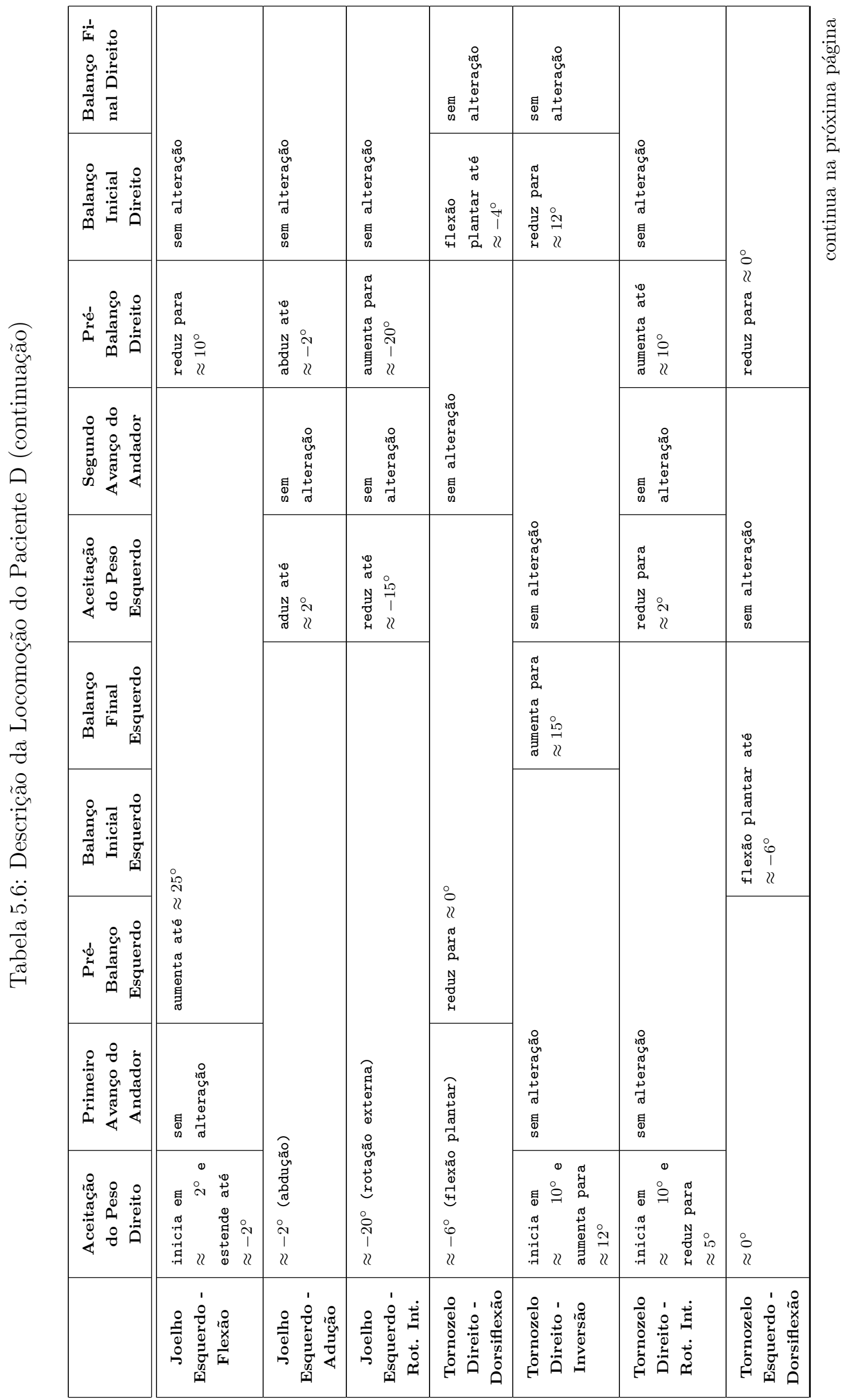




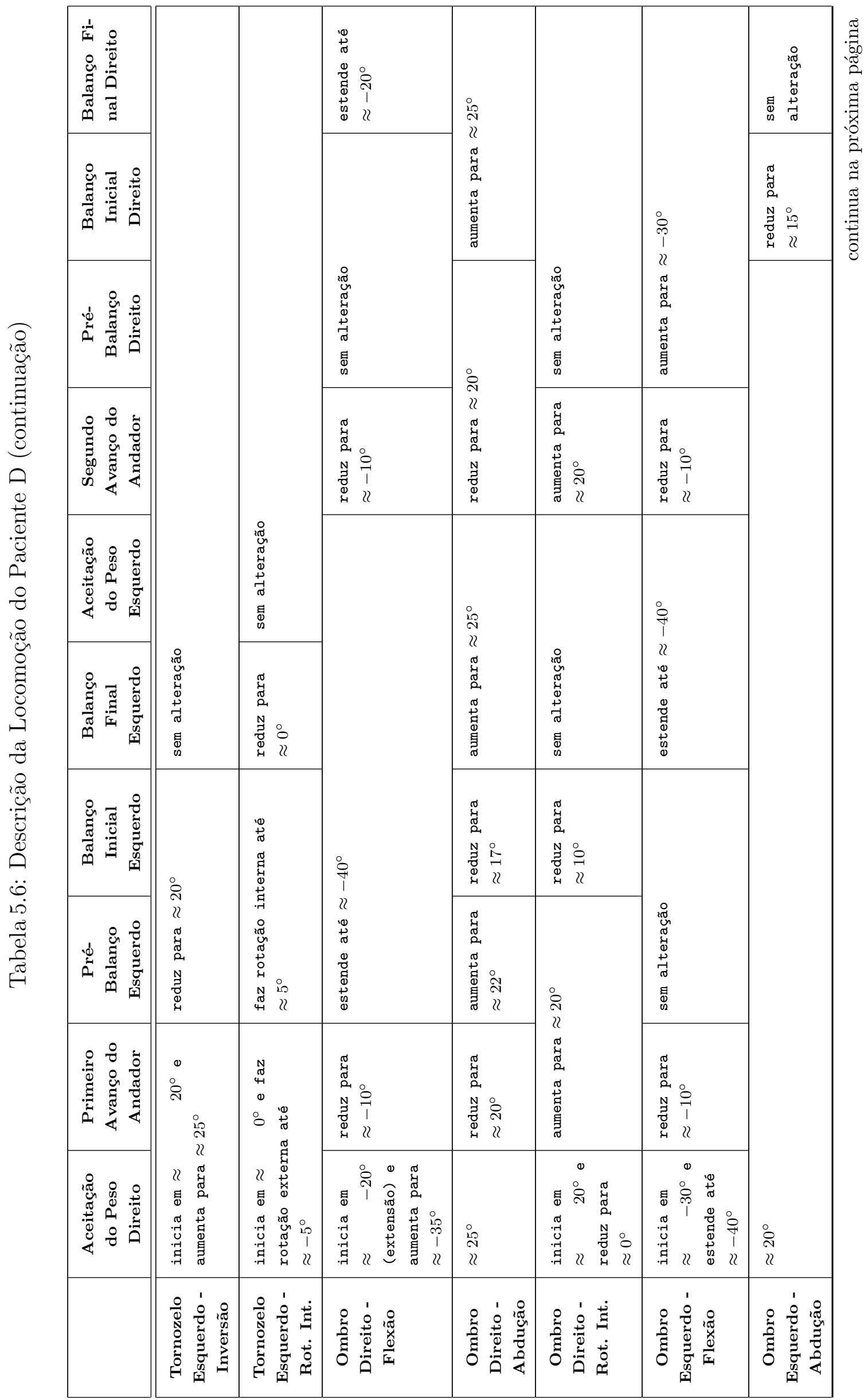




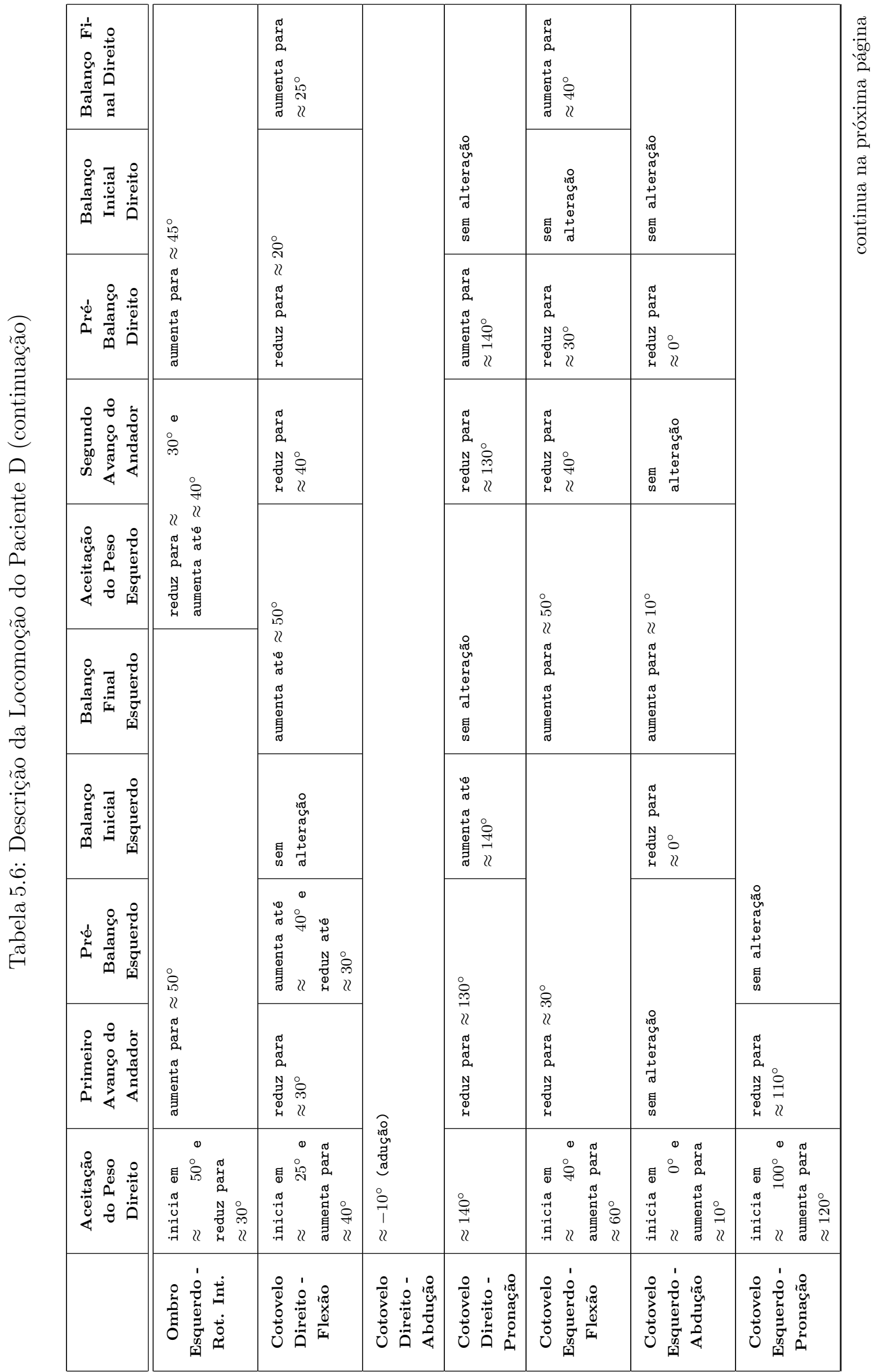




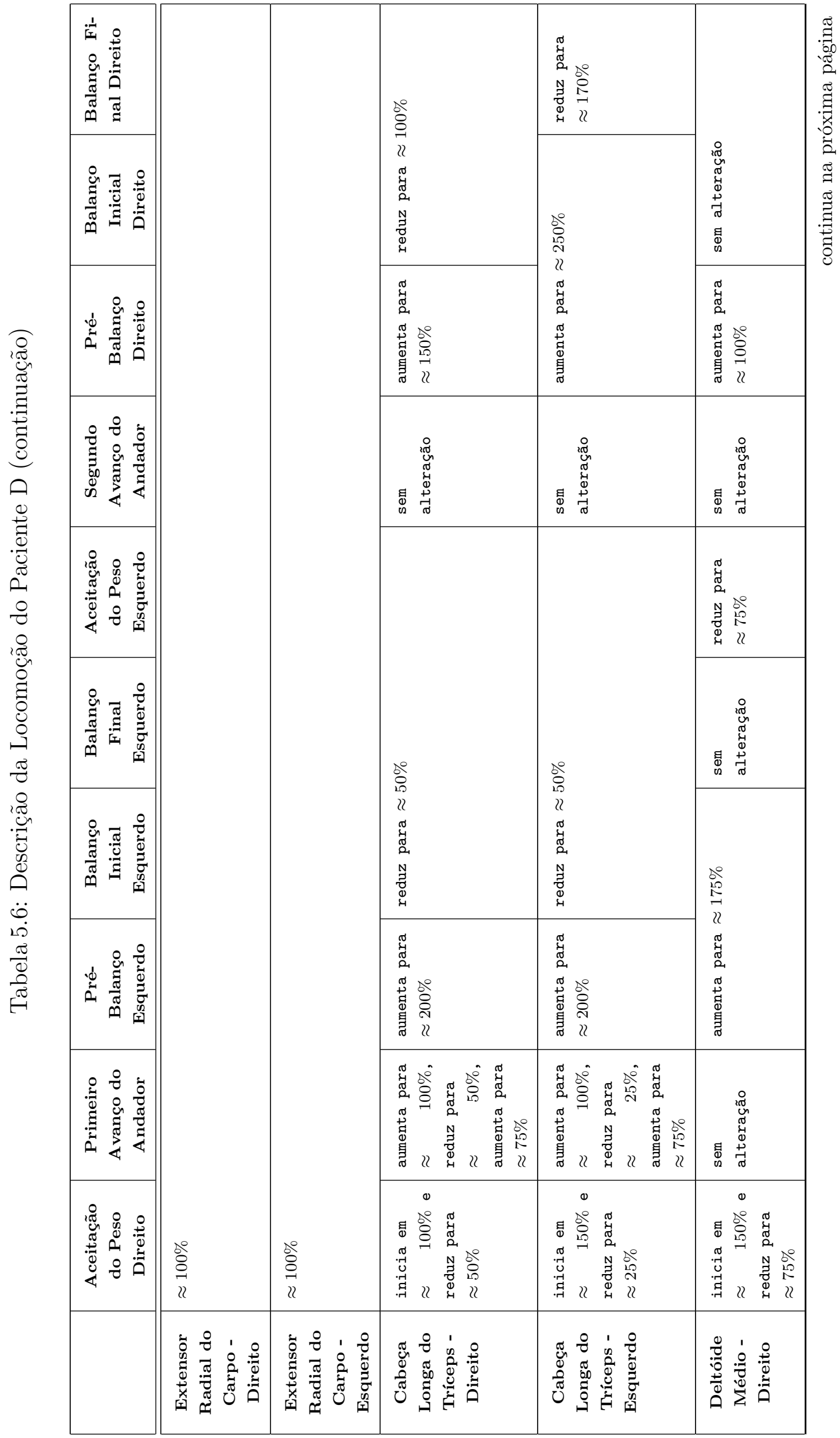


Tabela 5.6: Descrição da Locomoção do Paciente D (continuação)

\begin{tabular}{|c|c|c|c|c|c|c|c|c|c|c|}
\hline & $\begin{array}{c}\text { Aceitação } \\
\text { do Peso } \\
\text { Direito }\end{array}$ & $\begin{array}{l}\text { Primeiro } \\
\text { Avanço do } \\
\text { Andador }\end{array}$ & $\begin{array}{c}\text { Pré- } \\
\text { Balanço } \\
\text { Esquerdo }\end{array}$ & $\begin{array}{c}\text { Balanço } \\
\text { Inicial } \\
\text { Esquerdo }\end{array}$ & $\begin{array}{l}\text { Balanço } \\
\text { Final } \\
\text { Esquerdo }\end{array}$ & $\begin{array}{l}\text { Aceitação } \\
\text { do Peso } \\
\text { Esquerdo }\end{array}$ & $\begin{array}{l}\text { Segundo } \\
\text { Avanço do } \\
\text { Andador }\end{array}$ & $\begin{array}{c}\text { Pré- } \\
\text { Balanço } \\
\text { Direito }\end{array}$ & $\begin{array}{c}\text { Balanço } \\
\text { Inicial } \\
\text { Direito }\end{array}$ & $\begin{array}{l}\text { Balanço Fi- } \\
\text { nal Direito }\end{array}$ \\
\hline $\begin{array}{l}\text { Deltóide } \\
\text { Médio - } \\
\text { Esquerdo }\end{array}$ & $\begin{array}{l}\text { inicia em } \\
\approx \quad 150 \% \text { e } \\
\text { reduz para } \\
\approx 75 \%\end{array}$ & $\begin{array}{l}\text { aumenta para } \\
\approx \quad 100 \% \text { e } \\
\text { reduz para } \\
\approx 50 \%\end{array}$ & \multicolumn{3}{|c|}{ aumenta para $\approx 200 \%$} & $\begin{array}{l}\text { sem } \\
\text { alteração }\end{array}$ & $\begin{array}{l}\text { reduz para } \\
\approx 50 \%\end{array}$ & \multicolumn{3}{|c|}{ aumenta para $\approx 150 \%$} \\
\hline $\begin{array}{c}\text { Porção } \\
\text { Esternal } \\
\text { do Peitoral } \\
\text { Maior - } \\
\text { Direito }\end{array}$ & \multicolumn{7}{|l|}{$\approx 50 \%$} & $\begin{array}{l}\text { aumenta para } \\
\approx 400 \%\end{array}$ & \multicolumn{2}{|c|}{ reduz para $\approx 50 \%$} \\
\hline $\begin{array}{c}\text { Porção } \\
\text { Esternal } \\
\text { do Peitoral } \\
\text { Maior - } \\
\text { Esquerdo }\end{array}$ & \multicolumn{2}{|l|}{$\approx 60 \%$} & \multicolumn{2}{|c|}{ aumenta para $\approx 200 \%$} & $\begin{array}{l}\text { reduz para } \\
\approx 60 \%\end{array}$ & \multicolumn{2}{|l|}{ sem alteração } & $\begin{array}{l}\text { aumenta para } \\
\approx 200 \%\end{array}$ & \multicolumn{2}{|c|}{ reduz para $\approx 60 \%$} \\
\hline $\begin{array}{l}\text { Componente } \\
\text { Vertical da } \\
\text { Força de } \\
\text { Reação do } \\
\text { Solo }\end{array}$ & $\begin{array}{l}\text { inicia em } \\
\approx \quad 20 \% \text { e } \\
\text { aumenta para } \\
\approx 60 \%\end{array}$ & $\begin{array}{l}\text { reduz para } \\
\approx 40 \%\end{array}$ & reduz para $\curvearrowright$ & & aumenta para & $90 \%$ & $\begin{array}{l}\text { sem } \\
\text { alteração }\end{array}$ & $\begin{array}{l}\text { reduz para } \\
\approx 40 \%\end{array}$ & $\begin{array}{l}\text { sem } \\
\text { alteração }\end{array}$ & $\begin{array}{l}\text { reduz para } \\
\approx 30 \%\end{array}$ \\
\hline
\end{tabular}




\subsection{Descrição da locomoção do paciente E}

A figura 5.5 apresenta a visualização das posições do corpo do paciente $\mathbf{E}$ nos eventos que definem a marcha, e a tabela 5.7 apresenta um resumo das variações que ocorrem nas diversas fases definidas por estes eventos.

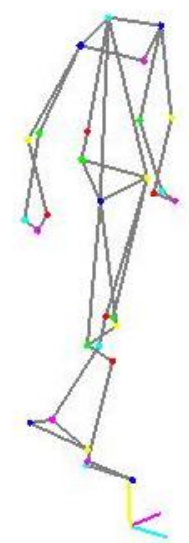

IAA_1 $(8,5 \%)$

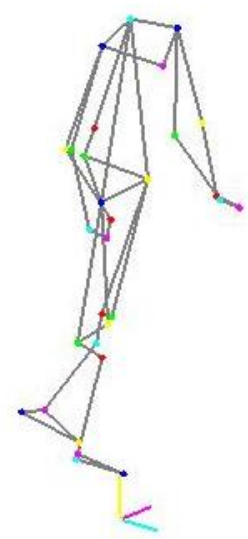

IBE $(\mathbf{2 8 , 4} \%)$

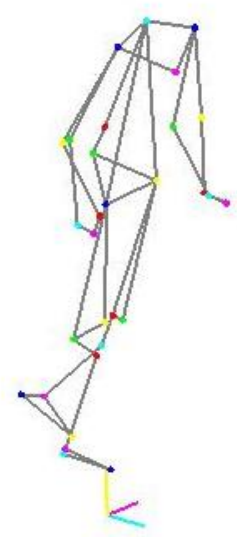

DPE $(37,1 \%)$

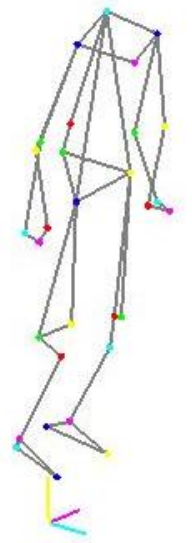

MBE $(42,1 \%)$

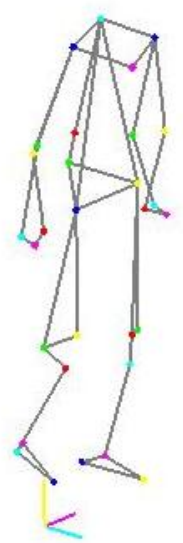

$\operatorname{CIE}(49,9 \%)$
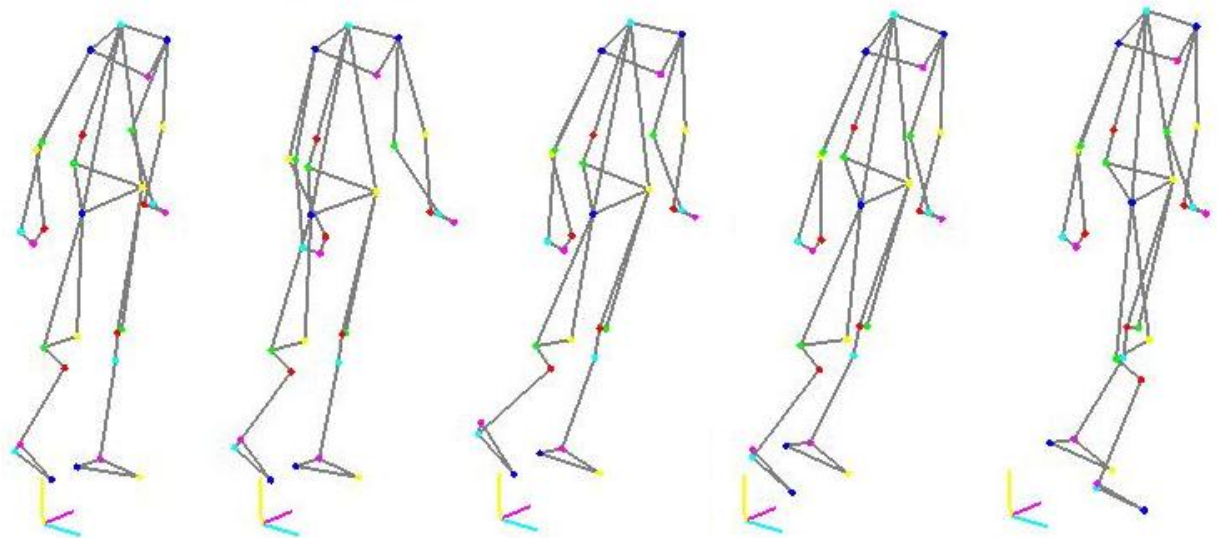

IAA_2 (58,7\%)

DPD $(90,5 \%)$

MBD $(94,3 \%) \quad$ CID_2 $(100,0 \%)$

Figura 5.5: Posições do corpo do paciente E nos eventos da marcha. 


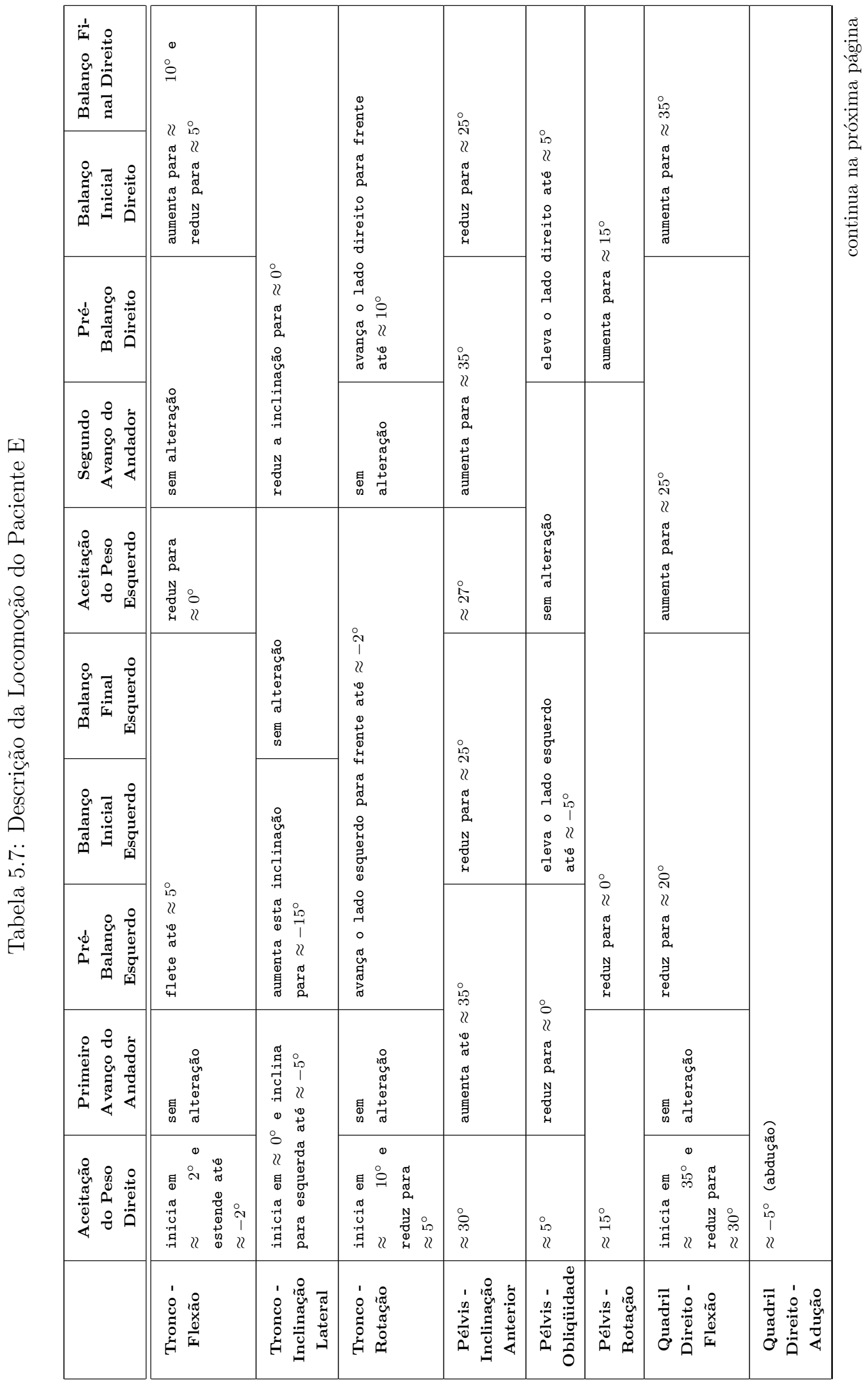




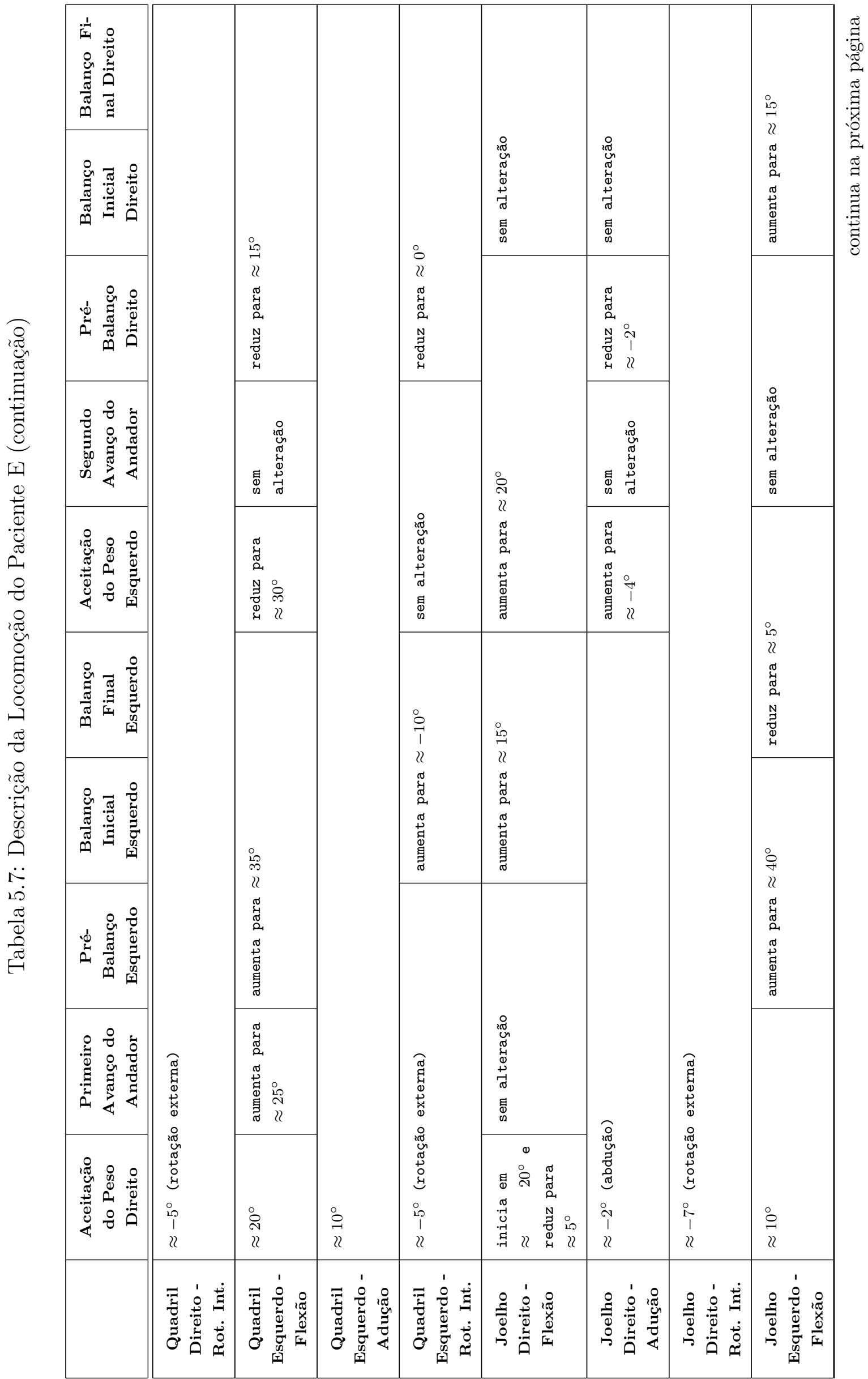




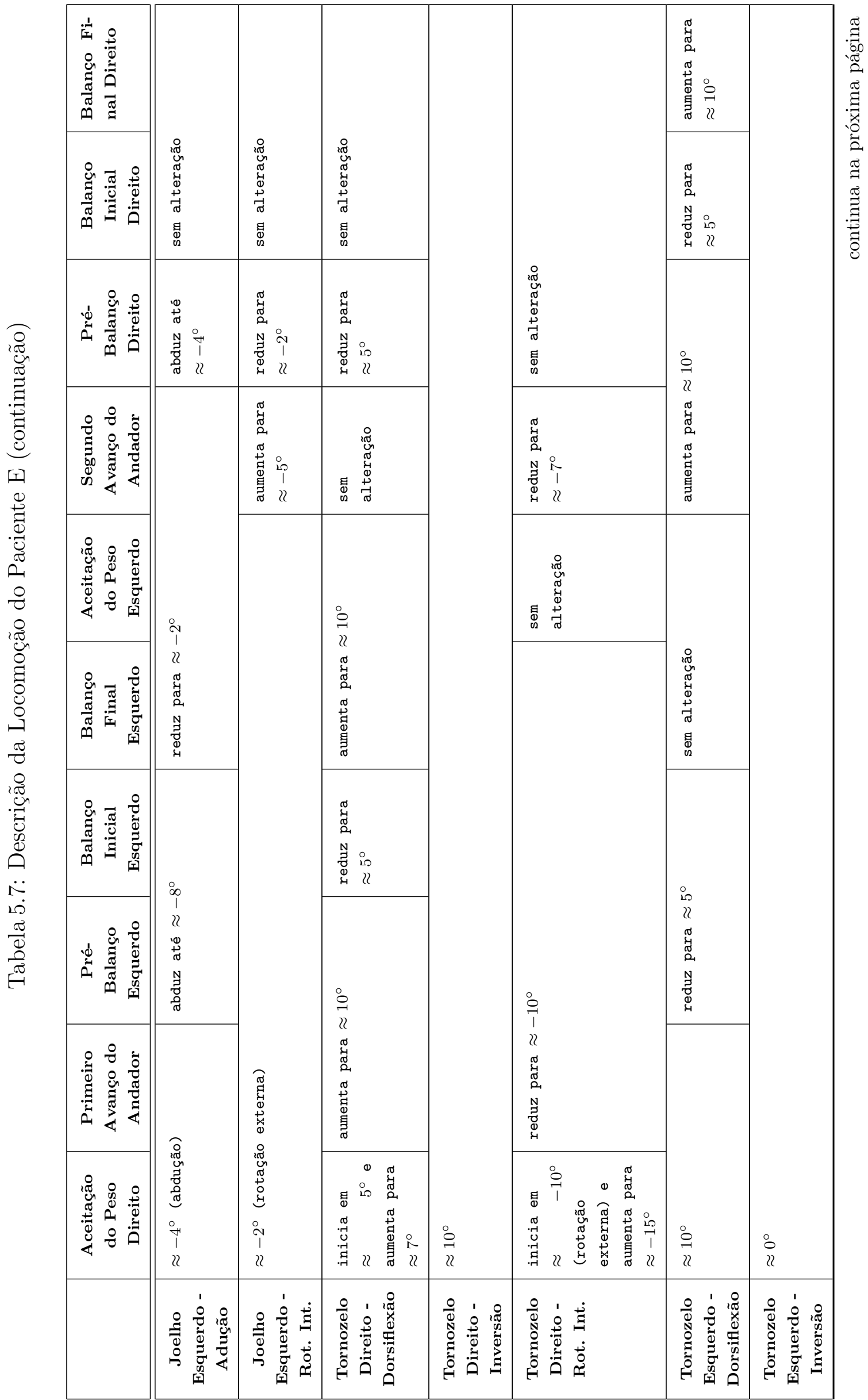




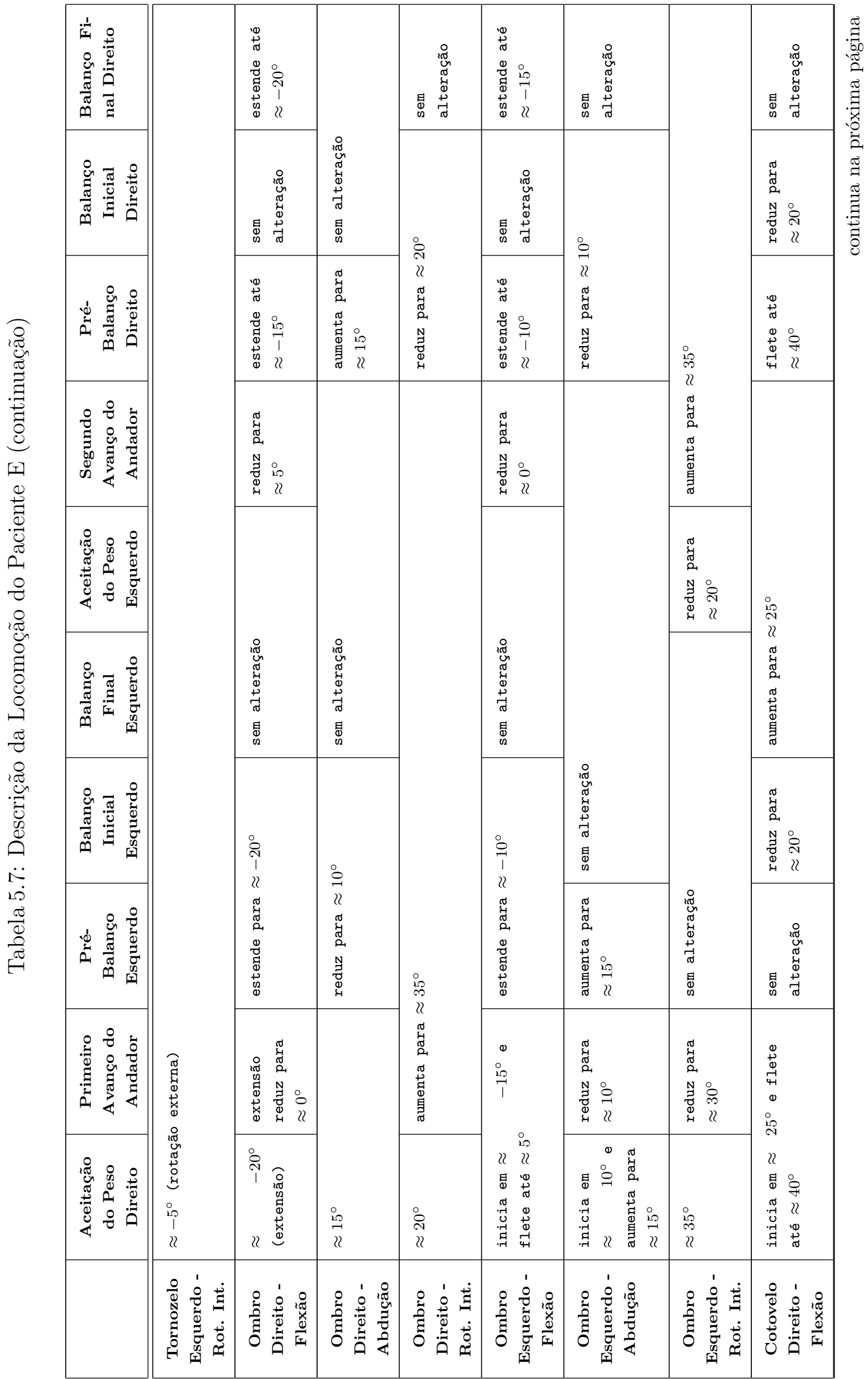




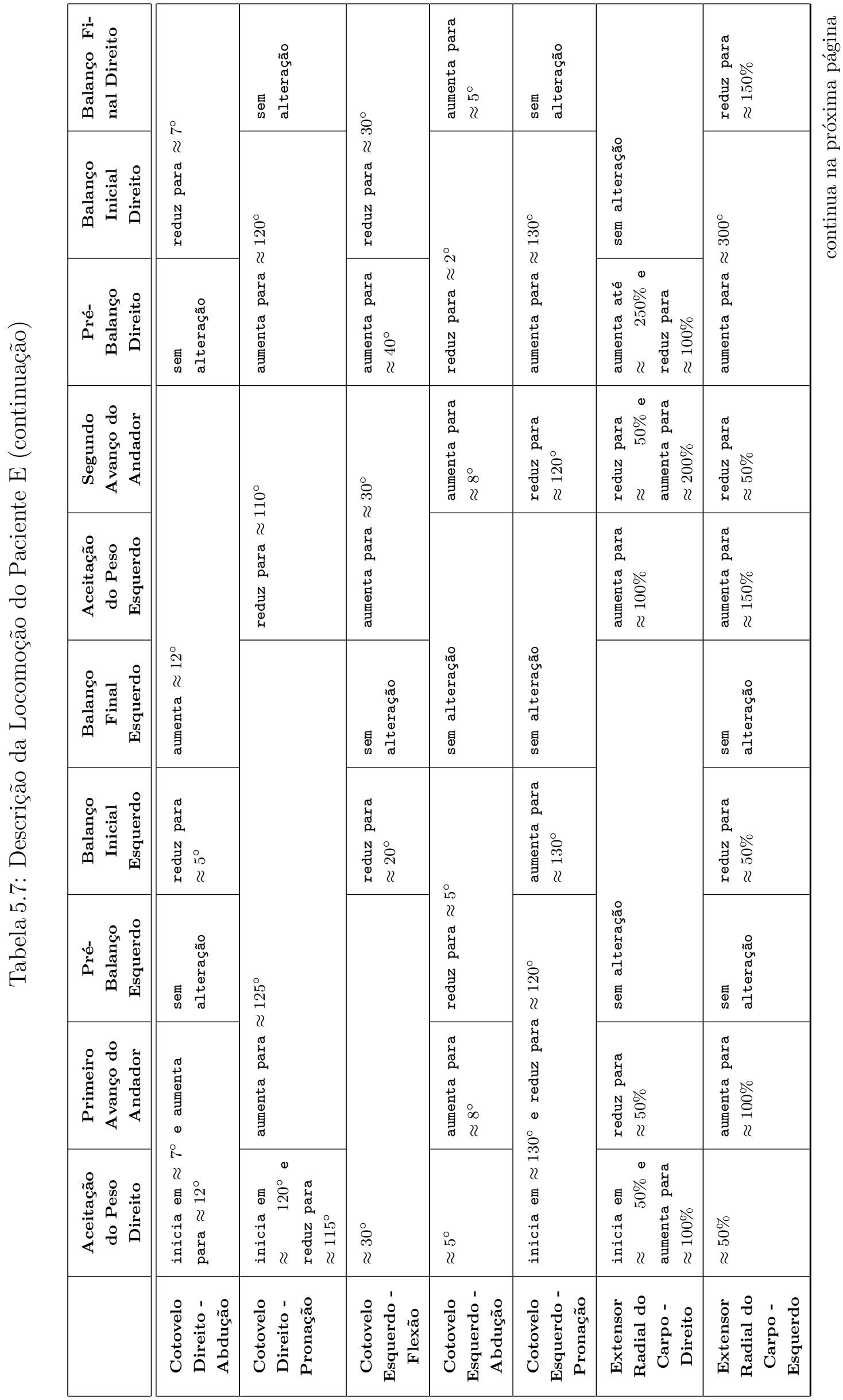




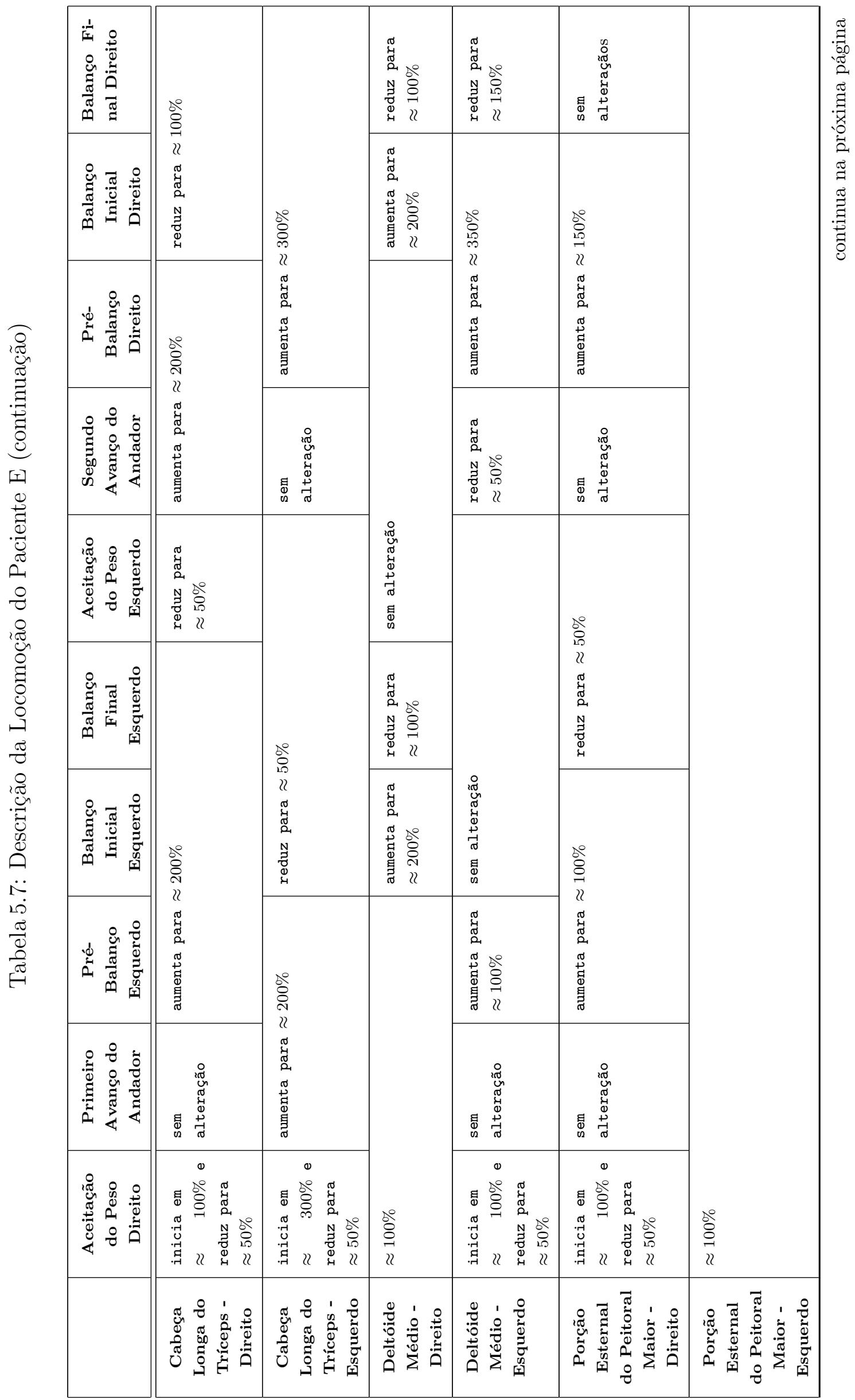


Tabela 5.7: Descrição da Locomoção do Paciente E (continuação)

\begin{tabular}{|c|c|c|c|c|c|c|c|c|c|c|}
\hline & $\begin{array}{c}\text { Aceitação } \\
\text { do Peso } \\
\text { Direito }\end{array}$ & $\begin{array}{l}\text { Primeiro } \\
\text { Avanço do } \\
\text { Andador }\end{array}$ & $\begin{array}{c}\text { Pré- } \\
\text { Balanço } \\
\text { Esquerdo }\end{array}$ & $\begin{array}{c}\text { Balanço } \\
\text { Inicial } \\
\text { Esquerdo }\end{array}$ & $\begin{array}{l}\text { Balanço } \\
\text { Final } \\
\text { Esquerdo }\end{array}$ & $\begin{array}{c}\text { Aceitação } \\
\text { do Peso } \\
\text { Esquerdo }\end{array}$ & $\begin{array}{l}\text { Segundo } \\
\text { Avanço do } \\
\text { Andador }\end{array}$ & $\begin{array}{c}\text { Pré- } \\
\text { Balanço } \\
\text { Direito }\end{array}$ & $\begin{array}{c}\text { Balanço } \\
\text { Inicial } \\
\text { Direito }\end{array}$ & $\begin{array}{l}\text { Balanço Fi- } \\
\text { nal Direito }\end{array}$ \\
\hline $\begin{array}{l}\text { Componente } \\
\text { Vertical da } \\
\text { Força de } \\
\text { Reação do } \\
\text { Solo }\end{array}$ & $\begin{array}{l}\text { inicia em } \\
\approx \quad 40 \% \text { e } \\
\text { aumenta para } \\
\approx 80 \%\end{array}$ & $\begin{array}{l}\text { aumenta para } \\
\approx \quad 100 \% \text { e } \\
\text { reduz para } \\
\approx 90 \%\end{array}$ & $\begin{array}{l}\text { sem } \\
\text { alteração }\end{array}$ & $\begin{array}{l}\text { reduz para } \\
\approx 30 \%\end{array}$ & $\begin{array}{l}\text { aumenta para } \\
\approx 50 \%\end{array}$ & $\begin{array}{l}\text { sem } \\
\text { alteração }\end{array}$ & $\begin{array}{l}\text { reduz para } \\
\approx 30 \%\end{array}$ & $\begin{array}{l}\text { reduz para } \\
\approx 0 \%\end{array}$ & $\approx 0 \%$ & \\
\hline
\end{tabular}




\section{Capítulo 6}

\section{Discussão}

Inicialmente será apresentada uma comparação dos resultados obtidos com referências similares. Finalmente serão apresentados comentários livres sobre os resultados obtidos.

\subsection{Comparação com referências}

Na Sec. 2.5 foram apresentados resumos de uma série de trabalhos que avaliaram o sistema de estimulação elétrica neuromuscular de 4 canais com eletrodos de superfície. Nesta seção ficou claro que este tipo de sistema apresenta benefícios para a saúde dos pacientes, mas que devido às suas limitações ele representa essencialmente uma ferramenta terapêutica.

Os exames realizados neste trabalho demonstram esta realidade, e confirmam informações publicadas anteriormente. Por exemplo, Mizrahi et al. (1985) avaliaram a marcha de 3 pacientes (o glúteo médio foi estimulado ao mesmo tempo que o quadríceps durante o apoio) e encontrou uma velocidade média de $10 \mathrm{~cm} / \mathrm{s}$. Neste artigo foram apresentados os dados de apenas um paciente cujos valores médios eram: velocidade = $7,7 \mathrm{~cm} / \mathrm{s}$; percentual do apoio direito $=77,3 \%$; percentual do balanço direito $=22,7 \%$; comprimento da passada $=42,5 \mathrm{~cm}$; duração da passada $=5,5 \mathrm{~s}$. Kralj \& Bajd (1989) apresentaram a duração do apoio como 82 \% do ciclo, e a duração da passada como 10,4 s.

No presente trabalho as médias dos dados dos cinco pacientes (Sec. 5.1) são: velocidade $=7,5 \mathrm{~cm} / \mathrm{s}$; percentual do apoio direito $=88,5 \%$; comprimento da passada $=$ $48,4 \mathrm{~cm}$; duração da passada $=6,8 \mathrm{~s}$.

Estes valores estão muito distantes da realidade do indivíduo normal, que possui as seguintes características (Sec. 3.3): velocidade $=143,3 \mathrm{~cm} / \mathrm{s}$; percentual do apoio direito $=60 \%$; percentual do balanço direito $=40 \%$; comprimento da passada $=146 \mathrm{~cm}$; duração da passada $=1 \mathrm{~s}$.

Triolo et al. (1996) mostraram que pacientes usando sistemas de estimulação elétrica neuromuscular multicanal, com eletrodos implantados (Sec. 2.6), alcançaram velocidades de $50 \mathrm{~cm} / \mathrm{s}$, e que com o disparo automático do balanço (através de palmilhas 
com chaves) esta velocidade aumentou para $73 \mathrm{~cm} / \mathrm{s}$. O percentual do ciclo dedicado ao balanço também se aproxima do normal, ou seja, fica em aproximadamente $40 \%$.

Mizrahi et al. (1985) fizeram o estudo dos parâmetros temporais com o propósito de obter uma avaliação objetiva do progresso do paciente durante seu período de treinamento. No entanto ele adverte que a marcha é resultante de intenso esforço de todo o corpo. Portanto, os parâmetros temporais representam uma medida do desempenho global de todo o corpo.

A importância da ação dos vários seguimentos do corpo durante a locomoção foi apresentada na Sec. 3.1. Por isso, neste trabalho foram avaliadas as diversas variações angulares que descrevem a postura do corpo durante a locomoção. Mizrahi et al. (1985) alertaram para o fato de que uma postura inadequada é um fator que contribui para a fadiga antecipada do paciente.

A Fig. 6.1(a) apresenta a variação angular, no plano sagital, das articulações do quadril, joelho e tornozelo de pessoas normais (Winter 1991).

Na passada normal ocorrem dois períodos distintos de variação angular do quadril: extensão durante o apoio (Sec. 3.2) e flexão durante o balanço (Perry 1992). A variação angular total do pico de flexão até o pico de extensão é de aproximadamente $40^{\circ}$. O ciclo inicia com o quadril fletido aproximadamente $30^{\circ}$, a partir do meio da fase de suporte o quadril estende progressivamente até alcançar $10^{\circ}$ de extensão no início da fase de prébalanço. Durante o pré-balanço o quadril reverte a direção de seu movimento e começa a fletir, alcançando a posição neutra do quadril $\left(0^{\circ}\right)$ no final do período de apoio $(60 \%)$. A flexão continua durante as fases de balanço inicial e meio da fase de balanço até $35^{\circ}$ no final do meio da fase de balanço.

Ocorre flexão e extensão do joelho normal de forma alternada em 4 etapas de movimento no ciclo da marcha (Perry 1992). No contato inicial o joelho está fletido em aproximadamente $5^{\circ}$, no entanto, esta postura poderá variar até uma leve hiperextensão $\left(-2^{\circ}\right)$. Logo após o início do apoio o joelho começa a fletir, até um pico de $18^{\circ}$ em $15 \%$ do ciclo da marcha, quando inicia o suporte simples. Durante o restante do meio do apoio o joelho estende até $3^{\circ}$ no meio do final da fase de suporte (40\% do ciclo da marcha). Após o final desta fase o joelho volta a fletir, principalmente após o início do suporte duplo, até alcançar $60^{\circ}$ no final balanço inicial. Após o início do meio do balanço começa a estender alcançando um pico de extensão em $97 \%$ do ciclo da marcha e fletindo sutilmente até $5^{\circ}$ antes do final do final do ciclo. 


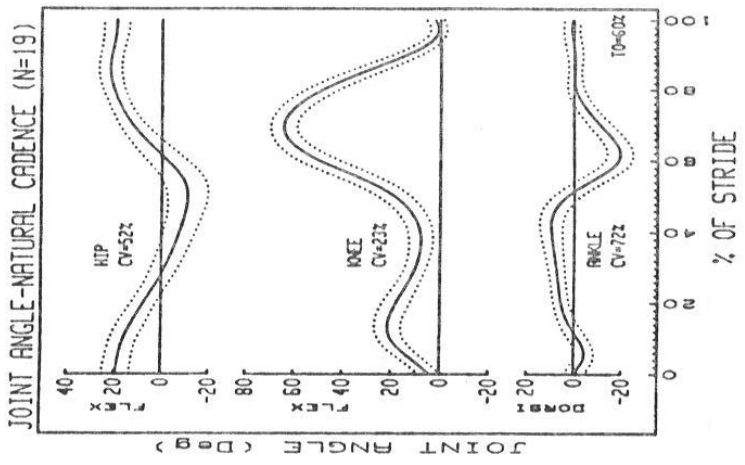

(a) Resultados obtidos para a marcha normal (Winter 1991).

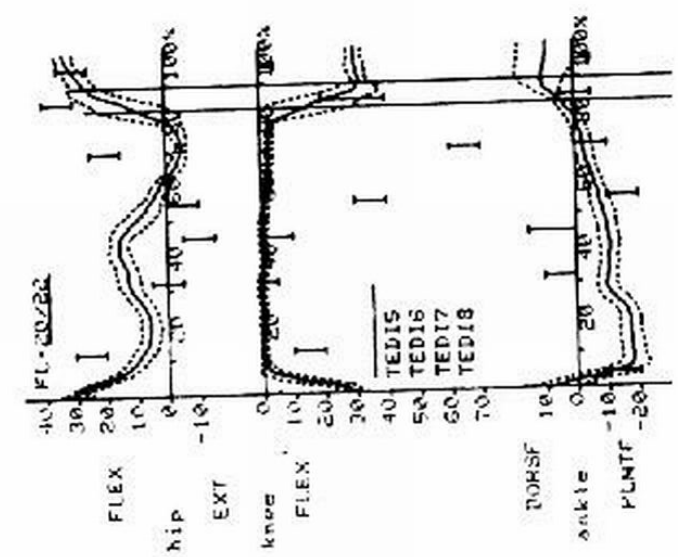

(b) Resultados do uso do estimulador de 4 canais (Kralj \& Bajd 1989).
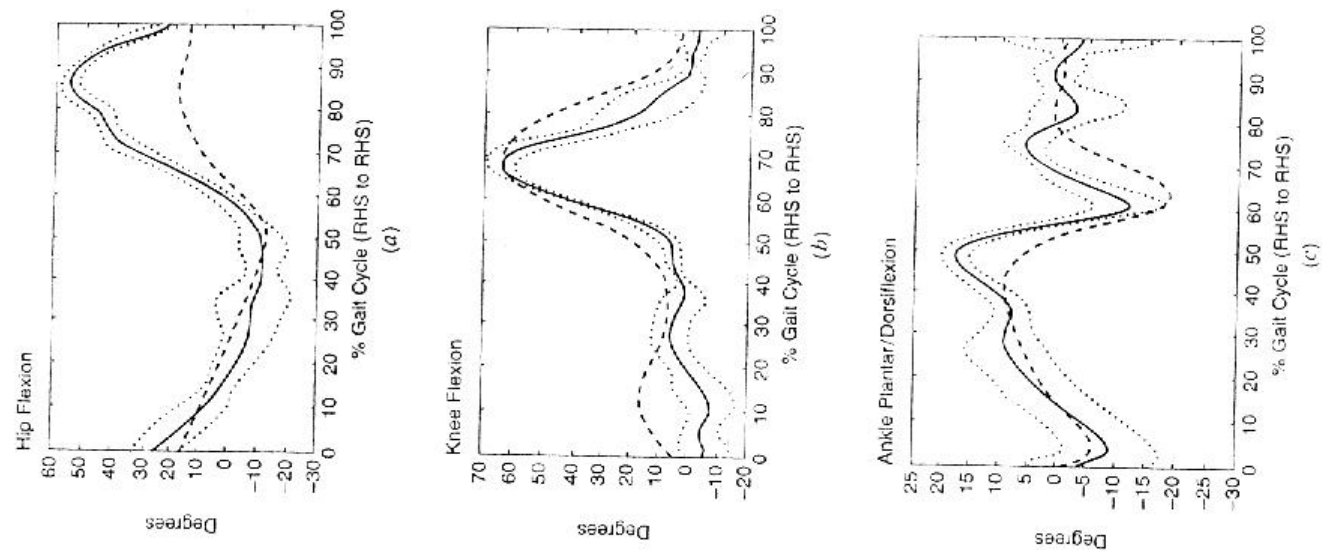

(c) Resultados do uso do sistema multicanal (Triolo et al. 1996).

Figura 6.1: Variação angular, no plano sagital, das articulações do quadril, joelho e tornozelo. 
O tornozelo realiza a flexão plantar e logo após a dorsiflexão, duas vezes durante o ciclo (Perry 1992). Durante o balanço o tornozelo faz apenas dorsiflexão, os outros três movimentos são realizados antes, no apoio. A variação angular total durante o ciclo fica em torno de $30^{\circ}$. O ciclo inicia com o tornozelo na posição neutra, ou em flexão plantar, e durante a resposta à carga faz flexão plantar até $7^{\circ}$. Durante o meio da fase de suporte começa a fazer dorsiflexão alcançando o máximo $\left(10^{\circ}\right)$ na primeira metade do final da fase de suporte (48\% do ciclo). Com o início do suporte duplo ocorre flexão plantar até alcançar $-20^{\circ}$ no final do apoio. A partir do balanço inicial ocorre dorsiflexão até voltar para a posição neutra $\left(0^{\circ}\right)$ no meio do balanço, terminando o ciclo nesta posição.

Kralj \& Bajd (1989) apresentaram as curvas dos ângulos no plano sagital das articulações do quadril, joelho e tornozelo, correspondentes à marcha de um paciente paraplégico utilizando os mesmos auxílios que fizeram parte deste trabalho (Fig. 6.1(b)). No entanto, não fizeram comentários sobre os resultados obtidos.

Triolo et al. (1996) apresentaram as curvas resultantes da marcha com o sistema multicanal implantado (Fig. 6.1(c)). Assim como nos dois casos anteriores o quadril inicia o ciclo fletido. Ocorre uma rápida extensão do quadril na fase de apoio, eles atribuíram à ação do paciente sobre o andador para propulsionar o corpo para frente. Observaram também que durante o balanço o quadril fletia muito mais que o normal, e que isto ocorria para facilitar o distanciamento do pé em relação ao solo. Também mostraram a ausência de flexão do joelho no inicio da fase de apoio indicando a falta da resposta à carga e a necessidade do corpo avançar sobre a perna estendida. O pré-balanço ocorria de forma inadequada, pois a flexão do joelho iniciava com atraso, e o durante o balanço o joelho estendia antecipadamente. Eles ressaltaram também uma flexão plantar levemente acelerada no início do ciclo possivelmente conseqüente da extensão do joelho no início do apoio , e uma dorsiflexão prematura durante o balanço para auxiliar o distanciamento do pé em relação ao solo.

Os resultados do exame do paciente B (Fig. B.4, Fig. B.6, Fig. B.8) foram muito parecidos com as curvas apresentadas por Kralj \& Bajd (1989) (Fig. 6.1(b)). Outro ponto em comum é que o paciente $\mathrm{B}$ possui a passada mais demorada (média $=8,08 \mathrm{~s}$ ), sendo o que mais se aproximou do tempo descrito por Kralj \& Bajd (1989) para a passada (10,4 s).

O quadril inicia o ciclo com $20^{\circ}$ de flexão e durante a resposta à carga estende até $-5^{\circ}$ (em $10 \%$ do ciclo aproximadamente). Possivelmente esta extensão no quadril está relacionada à extensão que ocorre no tronco (Fig. B.2) logo após o contato inicial e tem o propósito de manter a postura em "C" (Triolo et al. 1996), que auxilia a estabilidade do paciente por deslocar o centro de massa do mesmo para uma região central da sua área de suporte (Kralj \& Bajd 1989). Esta extensão do tronco pode estar relacionada também a ausência do controle da musculatura que possibilita o alinhamento do tronco.

A partir do pré-balanço esquerdo (Tab. 4.1) o quadril direito volta a fletir, até o final desta fase em $40 \%$ do ciclo. Durante esta fase, para auxiliar o avanço do corpo, 
o tronco começa a fletir, e a pélvis a inclinar anteriormente, provavelmente estas são as causas da flexão no quadril (Fig. B.2, Fig. B.3). Com o avanço da perna esquerda o quadril direito começa a estender novamente, alcançando a máxima extensão em aproximadamente $60 \%$ do ciclo, durante a aceitação do peso do lado esquerdo.

A partir do pré-balanço direito volta a fletir, assim como o tronco. Da mesma forma que foi dito anteriormente, este é o procedimento para auxiliar o avanço do corpo que depende primariamente da ação dos membros superiores. Nesta fase também há inclinação anterior da pélvis. Nesta fase, porém, com a ativação do reflexo de retirada para auxiliar o balanço direito, o quadril direito flete um pouco além da posição na qual estava no final da fase de pré-balanço direito.

O joelho inicia o ciclo com uma leve flexão, mas estende continuamente durante a aceitação do peso, enquanto o peso do corpo é continuamente deslocado para a perna direita. Ocorre uma flexão muito sutil durante o balanço esquerdo. Finalmente, durante o pré-balanço direito começa a fletir, devido ao disparo do reflexo de retirada, e continua fletido até o final do ciclo.

A variação no tornozelo foi muito pequena, pois o paciente usou AFO para auxiliar sua estabilidade.

Como pode ser visto há uma grande diferença entre a marcha normal e a marcha realizada com o sistema de estimulação de 4 canais. Pode ser visto também que o sistema multicanal possibilita uma aproximação maior da aparência da marcha normal, mas mesmo assim, aquele descrito aqui, ainda não corresponde a esta meta. Kralj \& Bajd (1989) alertaram no entanto, que o sujeito normal não é uma referência adequada para a restauração da marcha do paciente lesado medular, porque o gasto mínimo de energia deverá estar acima do propósito relacionado a aparência.

\subsection{Comentários gerais sobre os resultados obtidos}

Os pacientes com lesões mais baixas (A, C e E) tiveram melhor desempenho, expresso pelos parâmetros temporais (Tab. 5.1), que os pacientes com lesões mais elevadas (B e D). Pode-se observar que as médias da cadência, velocidade e comprimento da passada foram maiores, e que o tempo do ciclo e o percentual do apoio foram menores para os pacientes com lesões baixas. O paciente $\mathrm{E}$ apresentou resultados inferiores ao dos pacientes $\mathrm{A}$ e $\mathrm{C}$, no entanto ele possuía um tempo menor de uso do sistema de estimulação elétrica.

Mas, é importante salientar que embora os parâmetros indiquem o quão rápido o paciente possa estar se deslocando, isto não implica em informar o quanto ele poderá andar. Os pacientes B e D possuíam boa resistência e aptidão para andar por um longo período. Isto pode estar relacionado à economia de energia durante a marcha, permitida justamente por realizar uma marcha mais lenta, onde há uma preocupação maior com a 
postura necessária para garantir a estabilidade necessária para evitar um período prolongado de esforço com os membros superiores. No entanto, não foi realizado um experimento para avaliar esta hipótese.

A componente vertical da força de reação do solo, obtida para os pacientes B, D e E, decaía a partir do início do balanço e alcançava um mínimo no meio do balanço, tanto para o lado esquerdo quanto para o direito (Fig. B.18, Fig. D.18 e Fig. E.18). Enquanto ocorria este decréscimo no peso sustentado pelos membros inferiores, os sinais de eletromiografia dos tríceps dos referidos pacientes mostravam um aumento contínuo alcançando o pico no meio do balanço (Fig. B.15, Fig. D.15 e Fig. E.15). O pico de flexão do tronco também ocorria no meio do balanço (Fig. B.2, Fig. D.2 e Fig. E.2). E o pico de inclinação anterior da pélvis ocorria no desprendimento do pé (Fig. B.3, Fig. D.3 e Fig. E.3).

Estas ações em conjunto ocorrem para realizar o balanço. A flexão do tronco, e a conseqüente inclinação anterior da pélvis, são necessárias para permitir o avanço do membro, mas para isso ocorrer os tríceps são usados intensamente sustentando boa parte do peso do corpo. Além dos tríceps, o peitoral maior do lado em que ocorre o balanço participa ativamente, provavelmente para auxiliar o avanço do membro de balanço, e do próprio corpo para a nova posição à frente.

Para o paciente $\mathrm{C}$ a componente vertical da força de reação do solo aumenta à medida que os pés são posicionados sobre a plataforma de força e sua amplitude não é reduzida no momento do balanço (Fig. C.18). O tronco deste paciente é mantido continuamente fletido por todo o ciclo, implicando que o corpo está debruçado sobre o andador (Fig. C.2). Os níveis de atividade mioelétrica foram todos altos, implicando no esforço contínuo dos membros superiores durante a locomoção (Fig. C.15, Fig. C.16, e Fig. C.17). É possível que esta postura seja conseqüente da obesidade do paciente, pois este fator dificulta a estabilidade extrínseca (Kralj \& Bajd 1989).

O paciente A descarrega continuamente o peso sobre a plataforma de força no decorrer do ciclo, mas durante o balanço sustenta parte do peso do corpo com os membros superiores. A atividade dos tríceps aumenta continuamente durante as fases de avanço do andador, até picos nos inícios dos balanços, depois decresce continuamente até o mínimo no final da fase de aceitação do peso. O tríceps direito apresenta um pico extra no momento do meio do balanço esquerdo, o mesmo ocorre no lado esquerdo. Aparentemente, logo no início do balanço esses músculos atuam com o propósito de propulsionar o corpo para frente, além de auxiliarem a sustentação de parte de seu peso durante a transferência do membro de balanço. 


\section{Capítulo 7}

\section{Conclusão}

Os resultados corresponderam aos dados publicados anteriormente, e acrescentaram inúmeras informações relevantes para a avaliação dos pacientes com o fim de melhorar o desempenho de sua locomoção seja por treinamento, ou através do desenvolvimento de novos sistemas de estimulação elétrica. Em particular, poderão ser úteis para a definição dos grupos musculares a serem estimulados e do tipo de estratégia de controle adequada para o paciente.

A principal contribuição deste trabalho foi fazer a descrição detalhada da locomoção dos cinco pacientes. Inicialmente, pode-se perceber algumas distinções nos resultados associadas a diferenças entre níveis de lesão, como por exemplo: o desempenho global passado através dos parâmetros temporais, e os mecanismos associados à realização do balanço. Mas, o conjunto de descrições, além de servir de exemplo para avaliações futuras, constitui uma base de dados que contém as características específicas dos pacientes, o que permitirá o refinamento de sucessivas abordagens específicas para o aperfeiçoamento da locomoção dos mesmos.

A descrição da locomoção poderá ser enriquecida posteriormente através da avaliação dos momentos nas articulações dos membros superiores e inferiores e da avaliação do deslocamento do centro de massa do paciente. 


\title{
Referências Bibliográficas
}

\author{
AMTI (1998), Model OR6-5 Biomechanics Platform Instruction Manual.
}

Barchschmidt, R. A., Harris, G. F. \& Simoneau, G. G. (2001), 'Walker-assited gait in rehabilitation: A study of biomechanics and instrumentation', IEEE Trans. on Neural Systems and Rehabilitation Engineering 9(1), 96-105.

Bélanger, M., Stein, R. B., Wheeler, G. D., Gordon, T. \& Leduc, B. (2000), 'Electrical stimulation : can it increase muscle strength and reverse osteopenia in spinal cord injured individuals ?', Arch. Phys. Med. Rehabil. 81, 1090-1098.

Cliquet, A., Baxendale, R. H. \& Andrews, B. J. (1989), Paraplegic locomotion and its metabolic energy expenditure, in F. C. Rose, R. Jones \& G. Vrbová, eds, 'Neuromuscular Stimulation: Basic Concepts and Clinical Implications', Vol. 13 of Comprehensive Neurologic Rehabilitation, Demos, New York, pp. 139-146.

Cliquet, A., Nene, A. V., Barnett, R. \& Andrews, B. J. (1986), Fns augmentation of reciprocating hkafo and kafo braces, in 'Proceedings of 2nd Vienna International Workshop on Functional Electrical Stimulation', International Society for Artificial Organs, Vienna, pp. 83-86.

Craig, J. J. (1986), Introduction to Robotics Mechanics and Control, Addison-Wesley Publishing Company.

DeLuca, C. J. (1993), The use of surface electromyography in biomechanics, in 'The International Society for Biomechanics'. http://www.delsys.com/library/papers/ Biomechanics.pdf; verificado em 16 de outubro de 2003.

Douglas, R., Larson, P. F., D’Ambrosia, R. \& McCall, R. E. (1983), 'The lsu reciprocation gait orthosis', Orthopedics 6, 834-838.

Ferrarin, M., Bertelli, E., Frasson, W., Thorsen, R., Pavan, E. \& Frigo, C. (2001), On the correlation between upper body emg and knee moment during assisted sit to stand movement, in 'Proceedings of 6nd Annual International Functional Electrical Stimulation Society Meeting', Cleveland. 
Field-Fote, E. C. (2001), 'Combined use of body weight support, functional electric stimulation, and treadmill training to improve walking ability in individuals with chronic incomplete spinal cord injury', Arch. Phys. Med. Rehabil. 2(6), 818-824.

Garhammer, J. (1991), Biomecânica i, in P. J. Rasch, ed., 'Cinesiologia e Anatomia Aplicada', Guanabara Koogan S.A, Rio de Janeiro, pp. 54-69.

Gregor, R. J. (1991), A estrutura e função do músculo esquelético, in P. J. Rasch, ed., 'Cinesiologia e Anatomia Aplicada', Guanabara Koogan S.A, Rio de Janeiro, pp. 2232.

Guest, R. S., Klose, K. J., Needham-Shropshire, B. M. \& Jacobs, P. L. (1997), 'Evaluation of a training program for persons with sci paraplegia using the parastepâ1 ambulation system: Part 4. effect on physical self-concept and depression', Arch. Phys. Med. Rehabil. 78, 804-807.

Guyton, A. C. (1988), Fisiologia Humana, Editora Guanabara Koogan S.A, Rio de Janeiro.

Halder, A. M., Itoi, E. \& An, K. (2000), 'Anatomy and biomechanics of the shoulder', Orthopedic Clinics of North America 31(2), 159-176.

Hermens, H. J., Freriks, B., Disselhorst-Klug, C. \& Rau, G. (2000), 'Development of recommendations for semg sensors and sensor placement procedures', Journal of Electromyography and Kinesiology 10, 361-374.

Inman, V. T. (1993), 'The classic: Human locomotion', Clinical Orthopaedics and Related Research 288, 3-9.

Jacobs, P. L., Nash, M. S., Klose, K. J., Guest, R. S., Needham-Shropshire, B. M. \& Green, B. A. (1997), 'Evaluation of a training program for persons with sci paraplegia using the parastepâ1 ambulation system: Part 2. effects on physiological responses to peak arm ergometry', Arch. Phys. Med. Rehabil. 78, 794-798.

Jezernik, S., Colombo, G., Morari, M. \& Dietz, V. (2001), Relearning gait in spinal cord injured and stroke persons using robotic technology, in 'Proceedings of the Workshop on European Scientific and Industrial Collaboration (WESIC)', pp. 425-431.

Kadaba, M. P., Ramakrishnan, H. K. \& Wootten, M. E. (1990), 'Measurement of lower extremity kinematics during level walking', Journal of Orthopaedic Research 8, 383392.

Kantor, C., Andrews, B. J., Marsolais, E. B., Solomonow, M., Lew, R. D. \& Ragnarsson, K. T. (1993), 'Report on a conference on motor prostheses for workplace mobility of paraplegic patients in north america', Paraplegia 31, 430-438. 
Kendall, F. P., McCreary, E. K. \& Provance, P. G. (1993), Muscles, testing and function, 4th edn, Willians \& Wilkins, Maryland, USA.

Klose, K. J., Jacobs, P. L., Broton, J. G., Guest, R. S., Needham-Shropshire, B. M., Lebwohl, N., Nash, M. S. \& Green, B. A. (1997), 'Evaluation of a training program for persons with sci paraplegia using the parastepâ1 ambulation system: Part 1. ambulation performance and anthropometric measures', Arch. Phys. Med. Rehabil. 78, 789-793.

Kobetic, R., Triolo, R. J. \& Marsolais, E. B. (1997), 'Muscle selection and walking performance of multichannel fes systems for ambulation in paraplegia', IEEE Trans. Rehab. Eng. 5, 23-29.

Kobetic, R., Triolo, R. J., Uhlir, J. P., Bieri, C., Wibowo, M., Polando, G., Marsolais, E. B., Davis, J. A., Ferguson, K. A. \& Sharma, M. (1999), 'Implanted functional electrical stimulation system for mobility in paraplegia: A follow-up case report', IEEE Trans. Rehab. Eng. 7, 390-398.

Kralj, A. R. \& Bajd, T. (1989), Functional Electrical Stimulation: Standing and Walking after Spinal Cord Injury, CRC Press, Inc., Boca Raton, Florida.

Kralj, A. R., Bajd, T., Munih, M. \& Turk, R. (1993), Fes gait restoration and balance control in spinal cord-injured patients, in J. H. J. Allum, D. J. Allum-Mecklenburg, F. P. Harris \& R. Probst, eds, 'Progress in Brain Research', Vol. 97, Elsevier Science Publishers, pp. 387-396.

Kralj, A. R., Bajd, T. \& Turk, R. (1980), 'Electrical stimulation providing functional use of paraplegic patient muscles', Med. Prog. Technol. pp. 7-3.

Latash, M. L. (1998), Neurophysiological Basis of Movement, Human Kinetics.

Lundy-Ekman, L. (2000), Neurociência : Fundamentos para a Reabilitação, Editora Guanabara Koogan S.A., Rio de Janeiro.

MacConaill, M. A. \& Basmajian, J. V. (1977), Muscles and Movements a Basis for Human Kinesiology, Robert E. Krieger Publishing Company, New York.

Marsolais, E. B. \& Kobetic, R. (1987), 'Functional electrical stimulation for walking in paraplegia', The Journal of Bone and Joint Surgery 69-A, 728-733.

Marsolais, E. B. \& Kobetic, R. (1988), 'Development of a practical electrical stimulation system for restoring gait in the paralyzed patient', Clinical Orthopaedics and Related Research 233, 64-73. 
McClelland, M., Andrews, B. J., Patrick, J. H., Freeman, P. A. \& ElMasri, W. S. (1987), 'Augmentation of the oswestry parawalker orthosis by means of surface electrical stimulation: Gait analysis of three patients', Paraplegia 25, 32-38.

Mikelberg, R. \& Reid, S. (1981), 'Spinal cord lesions and lower extremity bracing : An overview and follow-up study', Paraplegia 19, 379-385.

Mizrahi, J., Braun, Z., Najenson, T. \& Graupe, D. (1985), 'Quantitative weightbearing and gait evaluation of paraplegics using functional electrical stimulation', Med. Biol. Eng. Comput. 23, 101.

Nash, M. S., Jacobs, P. L., Montalvo, B. M., Klose, K. J., Guest, R. S. \& NeedhamShropshire, B. M. (1997), 'Evaluation of a training program for persons with sci paraplegia using the parastepâ1 ambulation system: Part 5. lower extremity blood flow and hyperemic responses to occlusion are augmented by ambulation training', Arch. Phys. Med. Rehabil. 78, 808-814.

Needham-Shropshire, B. M., Broton, J. G., Klose, K. J., Lebwohl, N., Guest, R. S. \& Jacobs, P. L. (1997), 'Evaluation of a training program for persons with sci paraplegia using the parastepâ1 ambulation system: Part 3. lack of effect on bone mineral density', Arch. Phys. Med. Rehabil. 78, 799-803.

Nene, A. V. \& Andrews, B. J. (1986), An assessment of the parawalker hybrid orthosis, in 'Proceedings of 2nd Vienna International Workshop on Functional Electrical Stimulation', International Society for Artificial Organs, Vienna, pp. 79-82.

Nene, A. V., Hermens, H. J. \& Zilvold, G. (1996), 'Paraplegic locomotion : a review', Spinal Cord 34, 507-524.

Nester, C. J. (2000), 'Pragmatic approach to the effect of camera arrangement on the performance of a motion analysis system', Journal of Human Movement Studies 39, 265-276.

Opila, K. A., Nicol, A. C. \& Paul, J. P. (1987), 'Upper limb loadings of gait with crutches', Journal of Biomechanical Engineering 109, 285-290.

Peckham, P. H. (1988), Functional electrical stimulation, in J. G. Webster, ed., 'Encyclopedia of Medical Devices and Instrumentation', Vol. 1, John Wiley \& Sons, New York, pp. 1331-1352.

Pentland, W. E. \& Twomey, L. T. (1994a), 'Upper limb function in persons with long term paraplegia and implications for independence: Part i', Paraplegia 32, 211-218. 
Pentland, W. E. \& Twomey, L. T. (1994b), 'Upper limb function in persons with long term paraplegia and implications for independence: Part ii', Paraplegia 32, 219-224.

Perry, J. (1992), Gait Analysis : Normal and Pathological Function, SLACK Incorporated, New Jersey.

Phillips, C. A. (1989), 'Functional electrical stimulation and lower extremity bracing for ambulation exercise of the spinal cord injured individual: A medically prescribed system', Physical Therapy 69, 842-849.

Popovic, M. R., Curt, A., Keller, T. \& Dietz, V. (2001), 'Functional electrical stimulation for grasping and walking: indications and limitations', Spinal Cord 39, 403-412.

Rasch, P. J., ed. (1991), Cinesiologia e Anatomia Aplicada, Editora Guanabara Koogan S.A., Rio de Janeiro.

Rose, G. K. (1979), 'The principles and practice of hip guidance articulations', Prosthet. Orthot. Int. 3, 37-43.

Scruton, D. R. (1971), 'A reciprocating brace with poly-planar hip hinges used on spina bifida children', Physiotherapy 57, 61-66.

Sie, H. I., Waters, R. L., Adkins, R. H. \& Gellman, H. (1992), 'Upper extremity pain in the postrehabilitation spinal cord injured patient', Arch. Phys. Med. Rehabil. 73, 44-48.

SIGMEDICS (2003), http://www. sigmedics . com/FESQandA/fesqanda.html; verificado em 16 de outubro de 2003.

Solomonow, M., Baratta, R., Hirokawa, S., Rightor, N., Walker, W., Beaudette, P. \& (et al.) (1989), 'The rgo generation ii: muscle stimulation powered orthosis as a practical walking system for thoracic paraplegics', Orthopedics 12, 1309-1315.

Soutas-Little, R. W. (1998), Motion analysis and biomechanics, in J. A. DeLisa, ed., 'Gait Analysis in the Science of Rehabilitation'. http://www .vard.org/mono/gait/ soutas.htm; verificado em 16 de outubro de 2003.

Stallard, J., Major, R. E. \& Patrick, J. H. (1989), 'A review of the fundamental design problems of providing ambulation for paraplegic patients', Paraplegia 27, 70-75.

Tomovic, R., Vukobratovic, M. \& Vodovnik, L. (1973), Hybrid actuators for orthotic systems - hybrid assistive system, in 'Proc Int Symp External Control of Human Extremities', Dubrovnik, Yugoslavia, p. 73. 
Triolo, R. J., Kobetic, R. \& Betz, R. R. (1996), Standing and walking with functional neuromuscular stimulation : Technical and clinical challenges, in G. F. Harris \& P. A. S. and, eds, 'Human Motion Analysis : Current Applications and Future Directions', IEEE Press, pp. 318-350.

VanDerHelm, F. C. T., Veeger, H. E. J., Pronk, G. M., Woude, L. H. V. V. D. \& Rozendal, R. H. (1992), 'Geometry parameters for musculoskeletal modeling of the shoulder system', Journal of Biomechanics 25(2), 129-144.

Waters, R. L. (1992), Energy expenditure, in J. Perry, ed., 'Gait Analysis : Normal and Pathological Function', SLACK Incorporated, New Jersey, pp. 443-489.

Watkins, J. (1999), Structure and Function of the Musculoskeletal System, Human Kinetics.

Whittle, M. W. (1997), 'Three-dimensional motion of the center of gravity of the body during walking', Human Movement Science 16, 347-355.

Wickelgren, I. (1998a), 'Teaching the spinal cord to walk', Science 279, 319-321.

Wickelgren, I. (1998b), 'Watching “walking” nerves learn', Science 279, 320.

Wickelgren, I. (1999), 'Rat spinal cord function partially restored', Science 286, 18261827.

Winter, D. A. (1990), Biomechanics and motor control of human movement, John Wiley \& Sons Inc.

Winter, D. A. (1991), The Biomechanics and Motor Control of Human Gait: Normal, Elderly and Pathological., second edn, Waterloo Biomechanics.

Yang, J. F. \& Winter, D. A. (1984), 'Electromyographic amplitude normalization methods: Improving their sensitivity as diagnostic tools in gait analysis', Arch Phys Med Rehabil 65, 517-521. 


\section{Apêndice A}

\section{Paciente A}

Este apêndice apresentará os resultados do exame realizado no dia 15/05/2002. O conjunto de resultados é constituído por: as características da passada, variações angulares tridimensionais nos membros inferiores (pélvis, quadris, joelhos e tornozelos) e superiores (ombros, cotovelos, e tronco), eletromiografia de músculos dos membros superiores (peitoral maior, deltóide médio, cabeça longa do tríceps, extensor radial do carpo) e componente vertical da força de reação do solo.

\section{A.1 Características do paciente}

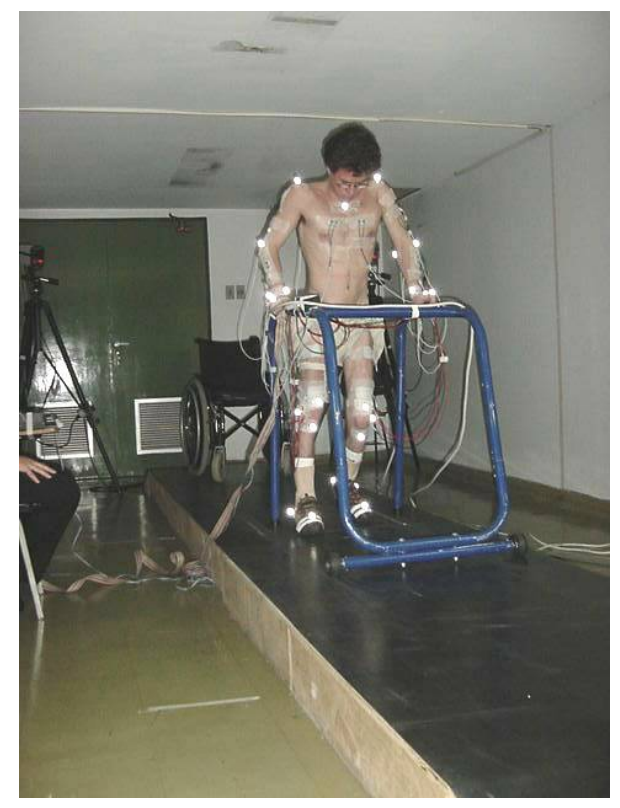

Figura A.1: Paciente A - Foto tirada durante um dos ensaios. O arquivo no formato PDF possui direcionamento para vídeo ao clicar na foto, desde que o QuickTime esteja instalado. Para abrir o vídeo fora do arquivo PDF, usando outro programa, clique aqui. 


\begin{tabular}{ccccccc}
\hline Nome & Idade & Nível da lesão & Causa & $\begin{array}{c}\text { Tempo da lesão } \\
(\operatorname{anos})\end{array}$ & $\begin{array}{c}\text { Peso } \\
(\mathrm{Kg})\end{array}$ & $\begin{array}{c}\text { Altura } \\
(\mathrm{m})\end{array}$ \\
\hline \hline $\mathrm{A}$ & 29 & $\mathrm{~T} 10$ & Acidente autom & 6 & 51 & 1,69 \\
\hline \hline
\end{tabular}

Tabela A.1: Dados dos pacientes

\section{A.2 Características da passada}

\begin{tabular}{ccccccc}
\hline Amostras & $\begin{array}{c}\text { Cadência } \\
(\text { passos } / \mathrm{min})\end{array}$ & $\begin{array}{c}\text { Velocidade } \\
(\mathrm{cm} / \mathrm{s})\end{array}$ & $\begin{array}{c}\text { Passada } \\
(\mathrm{m})\end{array}$ & $\begin{array}{c}\text { Tempo do ciclo } \\
(\mathrm{s})\end{array}$ & $\begin{array}{c}\text { Apoio direito } \\
(\%)\end{array}$ & $\begin{array}{c}\text { Apoio esquerdo } \\
(\%)\end{array}$ \\
\hline \hline 1 & 22,00 & 11,00 & 0,60 & 5,50 & 79,30 & 84,40 \\
2 & 22,00 & 9,17 & 0,50 & 5,40 & 83,00 & 85,40 \\
3 & 15,00 & 6,25 & 0,50 & 7,90 & 92,00 & 88,90 \\
5 & 25,00 & 12,50 & 0,60 & 4,80 & 86,40 & 82,10 \\
7 & 23,00 & 11,50 & 0,60 & 5,20 & 81,20 & 83,70 \\
& & & & & & \\
Média & 21,40 & 10,08 & 0,56 & 5,76 & 84,38 & 84,90 \\
Desvio & 3,78 & 2,46 & 0,05 & 1,23 & 5,00 & 2,54 \\
\hline \hline
\end{tabular}

Tabela A.2: Parâmetros temporais

\begin{tabular}{cccccccccccc}
\hline Amostras & $\begin{array}{c}C I D_{1} \\
(\%)\end{array}$ & $\begin{array}{c}I A A_{1} \\
(\%)\end{array}$ & $\begin{array}{c}I B E \\
(\%)\end{array}$ & $\begin{array}{c}D P E \\
(\%)\end{array}$ & $\begin{array}{c}M B E \\
(\%)\end{array}$ & $\begin{array}{c}C I E \\
(\%)\end{array}$ & $\begin{array}{c}I A A_{2} \\
(\%)\end{array}$ & $\begin{array}{c}I B D \\
(\%)\end{array}$ & $\begin{array}{c}D P D \\
(\%)\end{array}$ & $\begin{array}{c}M B D \\
(\%)\end{array}$ & $\begin{array}{c}C I D_{2} \\
(\%)\end{array}$ \\
\hline \hline 1 & 0.0 & 5.1 & 23.7 & 33.3 & 39.9 & 48.6 & 53.2 & 72.1 & 79.3 & 91.0 & 100.0 \\
2 & 0.0 & 4.6 & 23.8 & 33.4 & 36.2 & 48.6 & 50.8 & 68.7 & 83.0 & 90.4 & 100.0 \\
3 & 0.0 & 4.0 & 38.4 & 49.8 & 53.8 & 59.5 & 67.6 & 84.7 & 92.0 & 95.4 & 100.0 \\
5 & 0.0 & 5.9 & 19.5 & 30.3 & 38.3 & 48.1 & 58.9 & 76.7 & 86.4 & 91.3 & 100.0 \\
7 & 0.0 & 7.4 & 20.1 & 31.1 & 40.1 & 48.2 & 53.4 & 74.8 & 81.2 & 91.3 & 100.0 \\
& & & & & & & & & & & \\
Média & 0.0 & 5.4 & 25.1 & 35.6 & 41.7 & 50.6 & 56.8 & 75.4 & 84.4 & 91.9 & 100.0 \\
Desvio & 0.0 & 1.3 & 7.7 & 8.1 & 6.9 & 5.0 & 6.8 & 6.0 & 5.0 & 2.0 & 0.0 \\
\hline \hline
\end{tabular}

Tabela A.3: Percentuais das fases do ciclo de acordo com o descrito na sec.4.1 


\section{A.3 Variações angulares: tronco e membros inferiores}
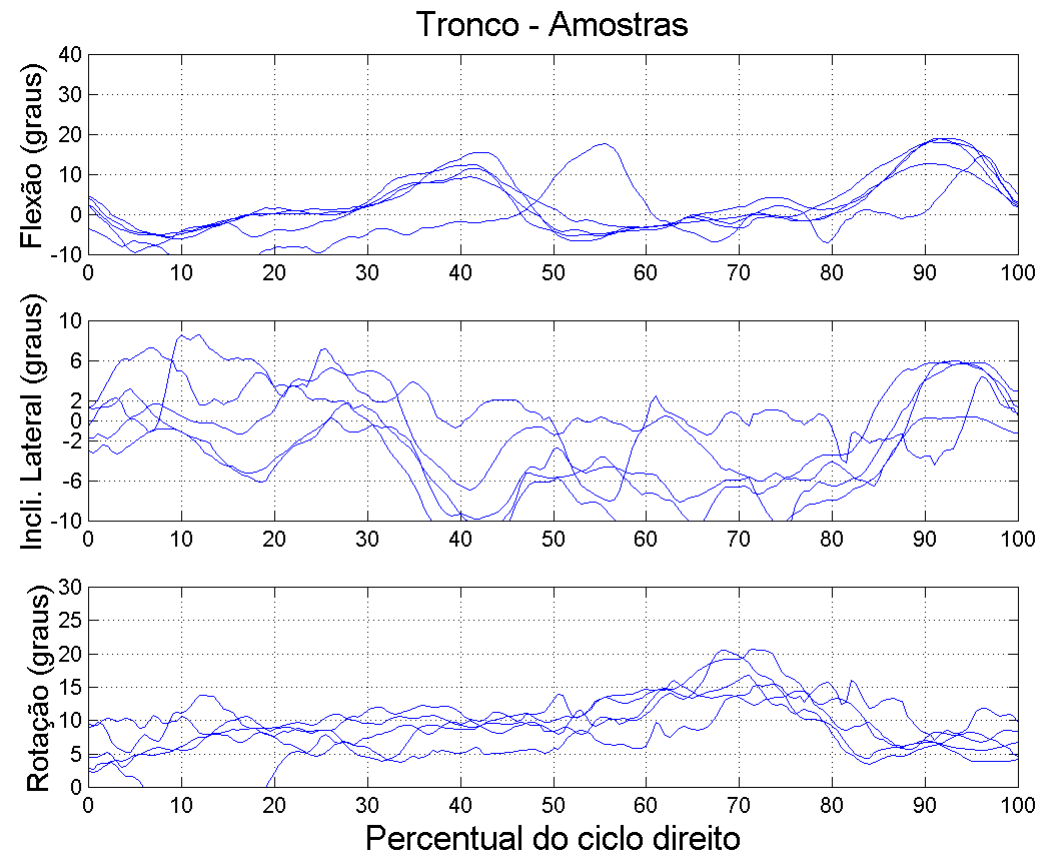

(a) Gráficos das variações angulares presentes nas cinco amostras.
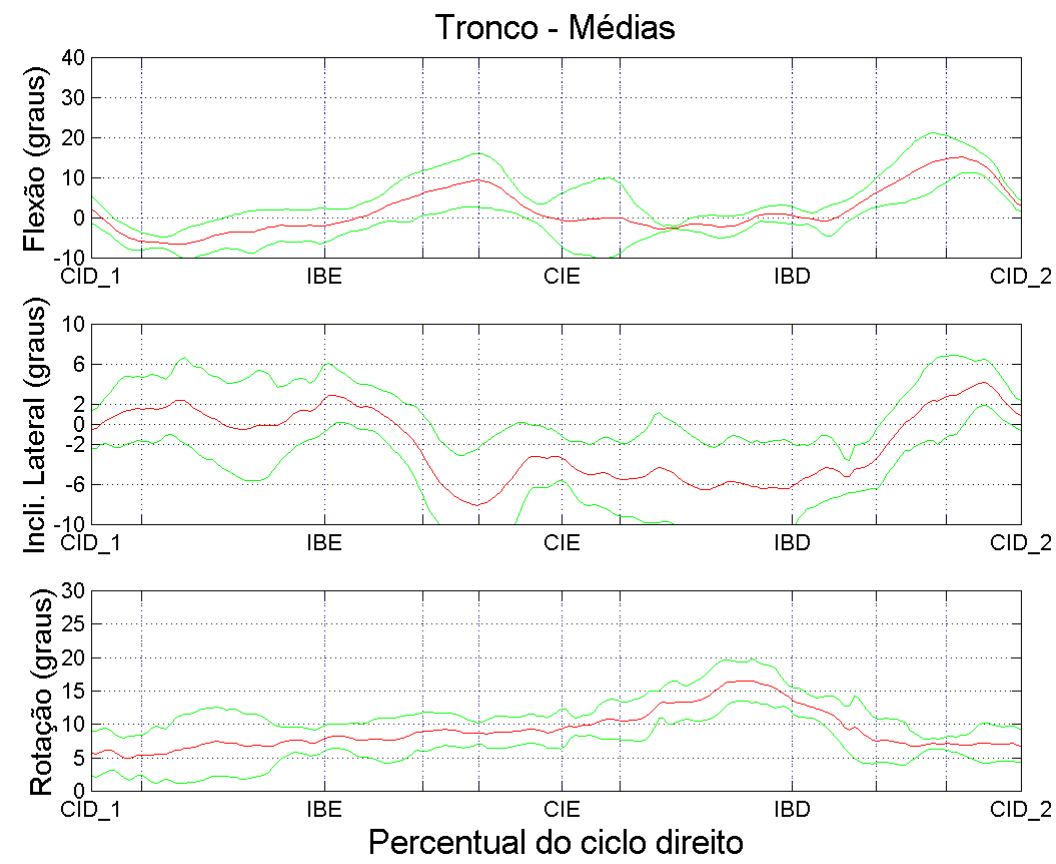

(b) Médias e desvios padrões dos dados apresentados em (a).

Figura A.2: Variações angulares do tronco. Os gráficos foram normalizados no tempo como percentual do ciclo direito da marcha. 

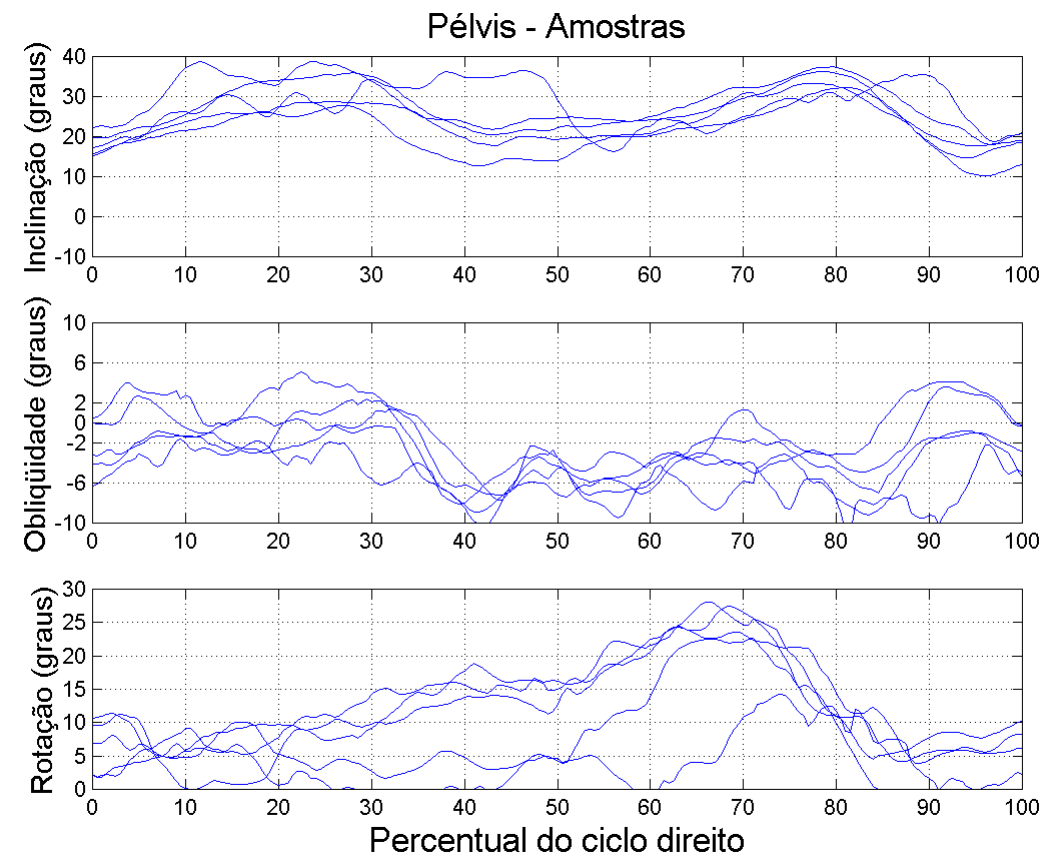

(a) Gráficos das variações angulares presentes nas cinco amostras.
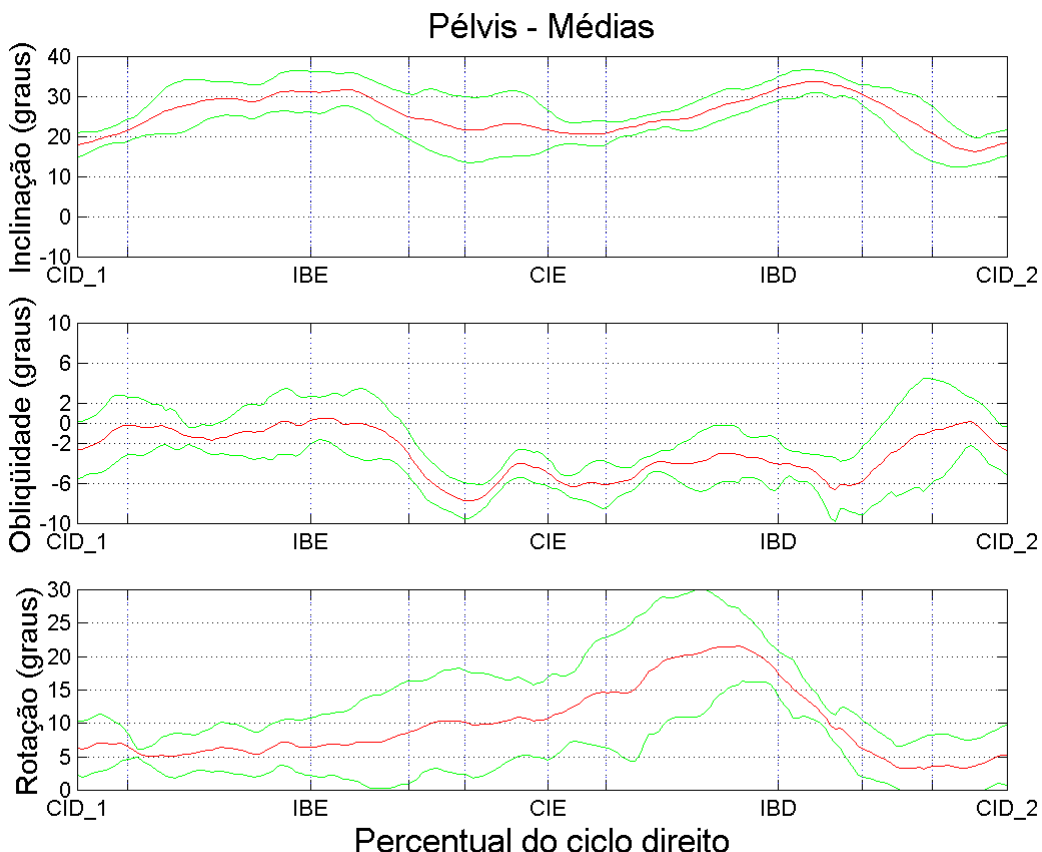

(b) Médias e desvios padrões dos dados apresentados em (a).

Figura A.3: Variações angulares do pélvis. Os gráficos foram normalizados no tempo como percentual do ciclo direito da marcha. 

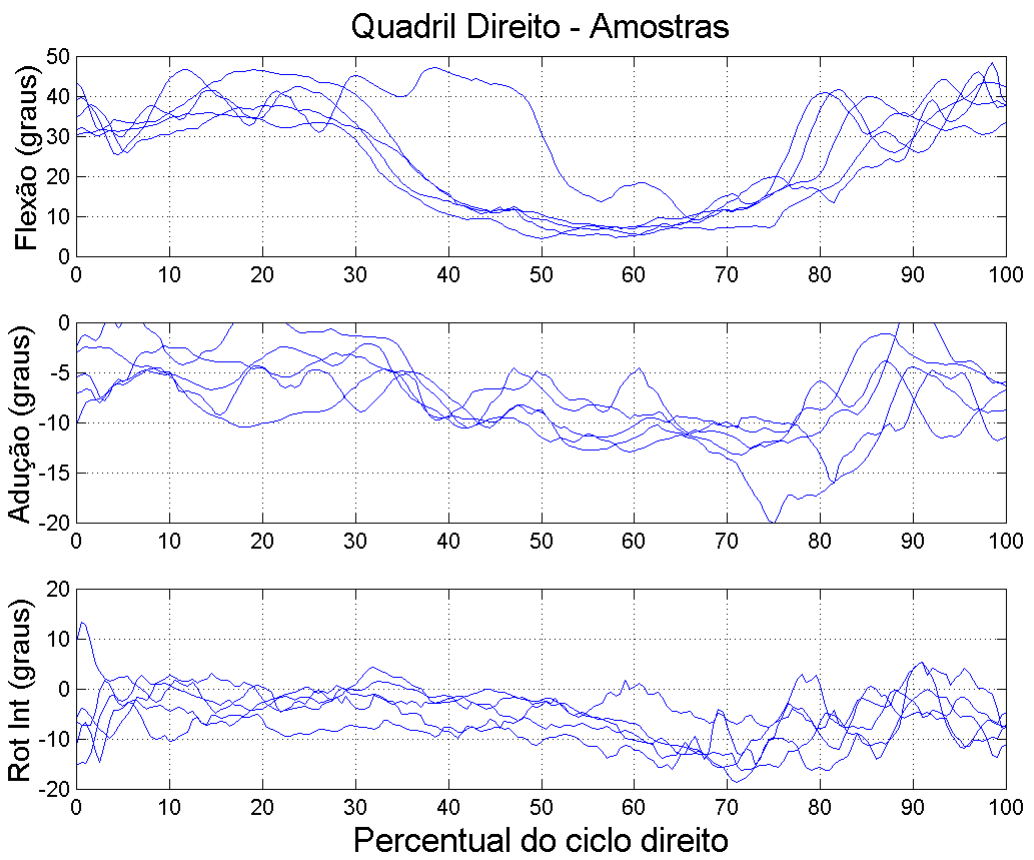

(a) Gráficos das variações angulares presentes nas cinco amostras.
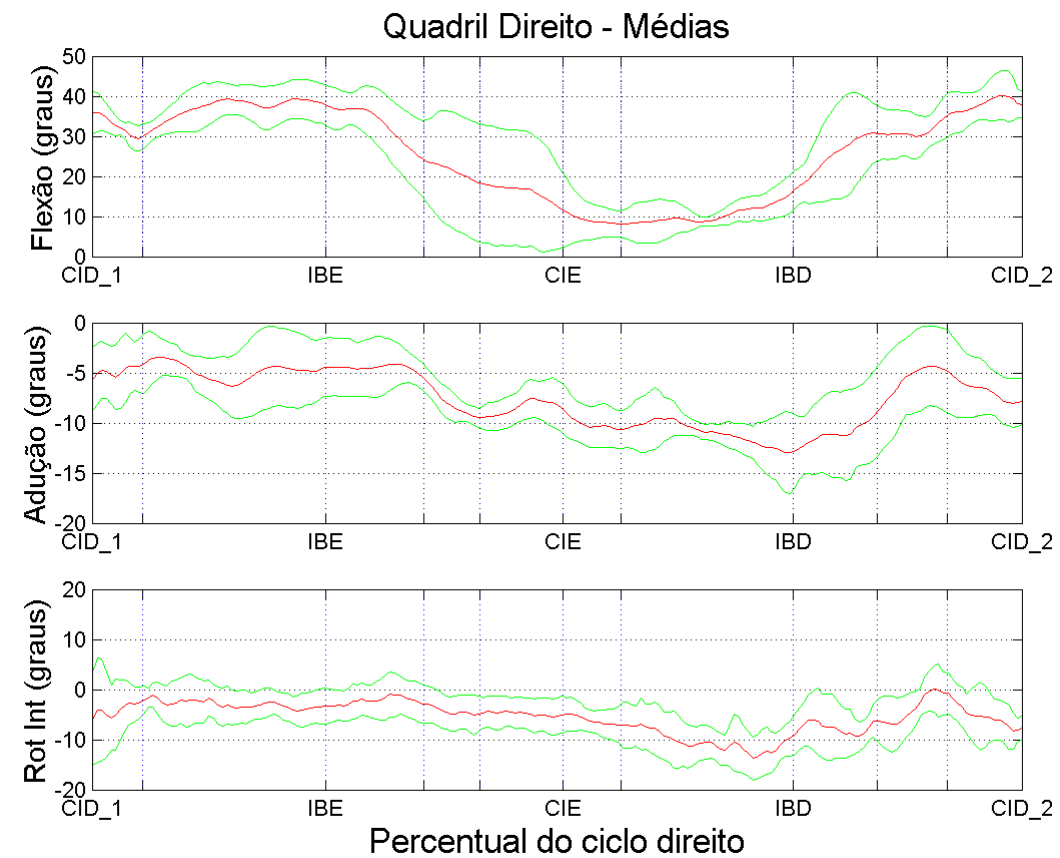

(b) Médias e desvios padrões dos dados apresentados em (a).

Figura A.4: Variações angulares no quadril direito. Os gráficos foram normalizados no tempo como percentual do ciclo direito da marcha. 

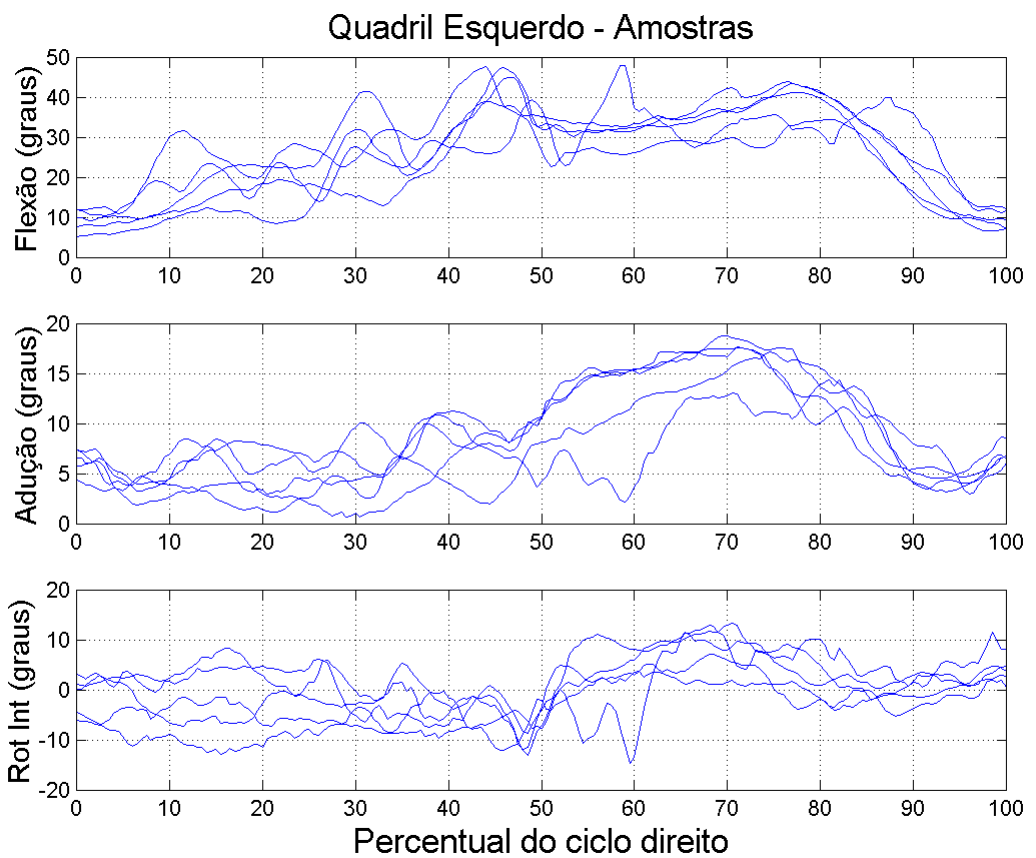

(a) Gráficos das variações angulares presentes nas cinco amostras.
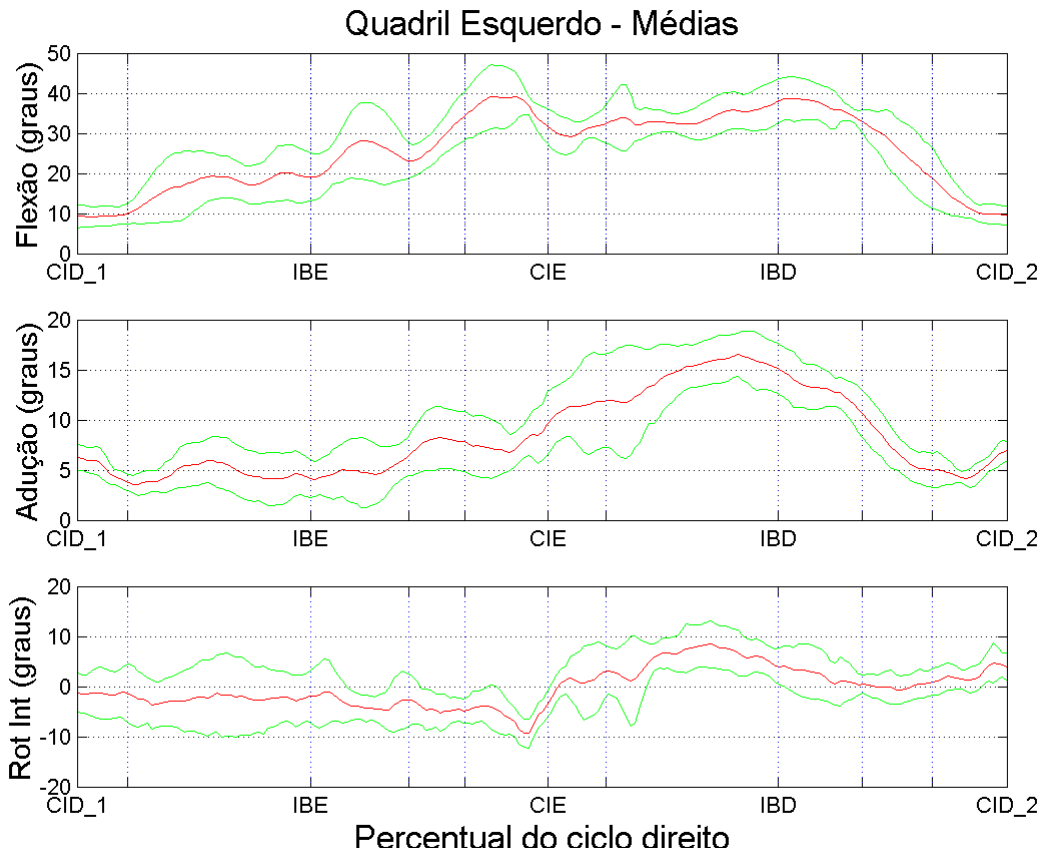

(b) Médias e desvios padrões dos dados apresentados em (a).

Figura A.5: Variações angulares no quadril esquerdo. Os gráficos foram normalizados no tempo como percentual do ciclo direito da marcha. 

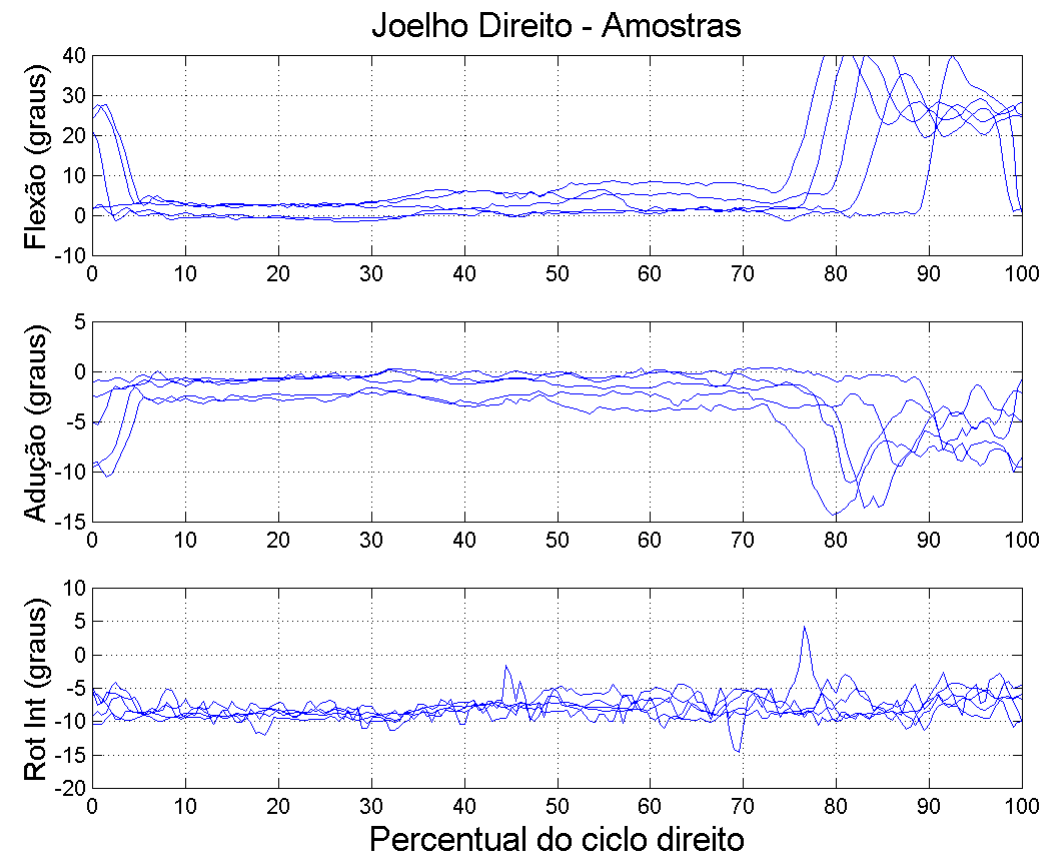

(a) Gráficos das variações angulares presentes nas cinco amostras.
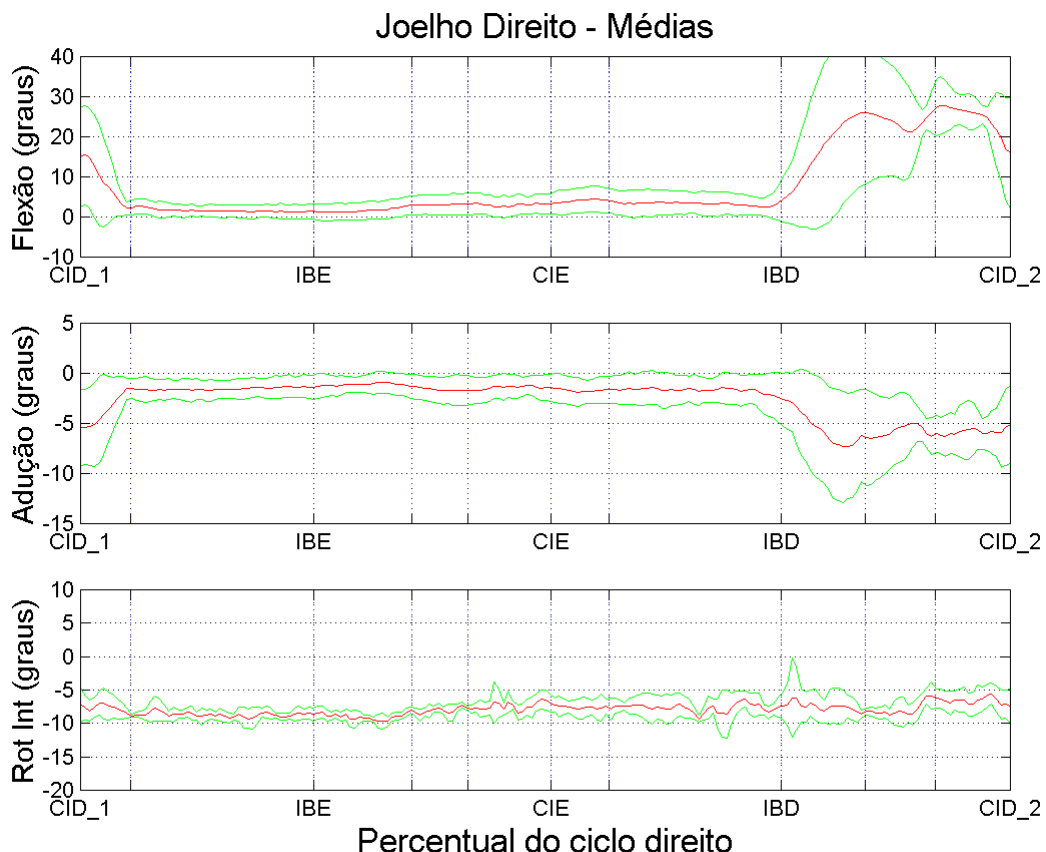

(b) Médias e desvios padrões dos dados apresentados em (a).

Figura A.6: Variações angulares no joelho direito. Os gráficos foram normalizados no tempo como percentual do ciclo direito da marcha. 

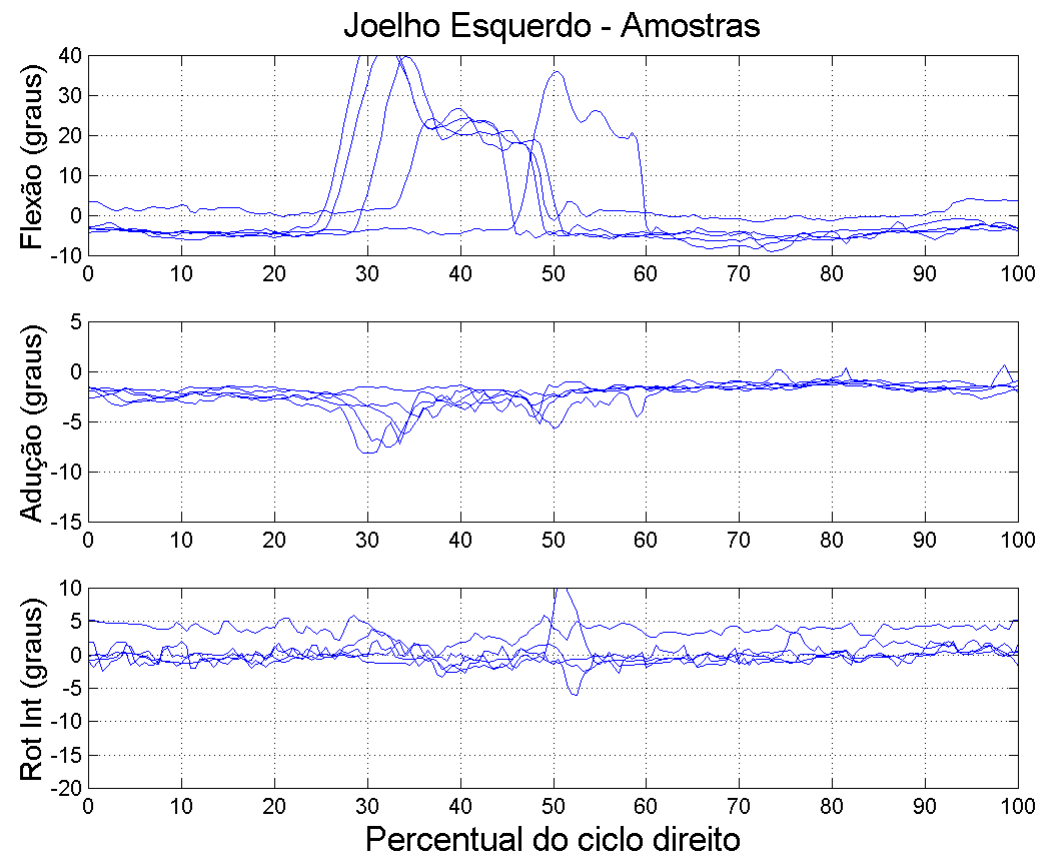

(a) Gráficos das variações angulares presentes nas cinco amostras.
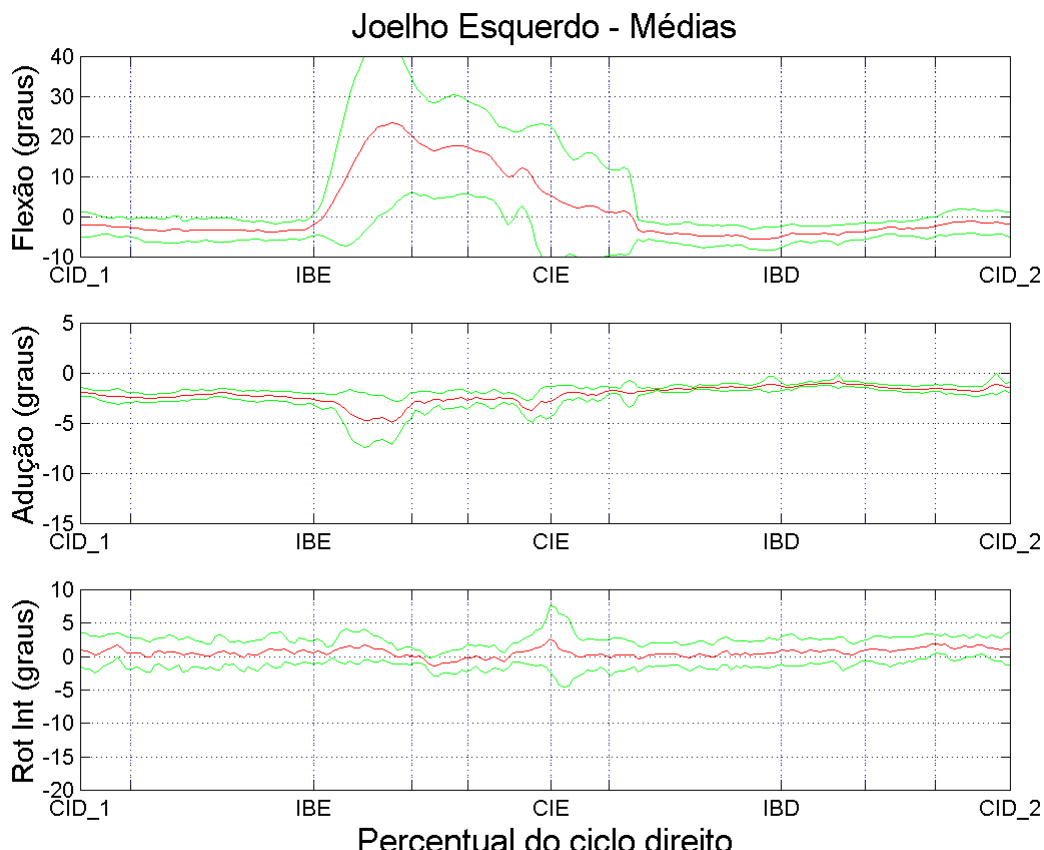

(b) Médias e desvios padrões dos dados apresentados em (a).

Figura A.7: Variações angulares no joelho esquerdo. Os gráficos foram normalizados no tempo como percentual do ciclo direito da marcha. 

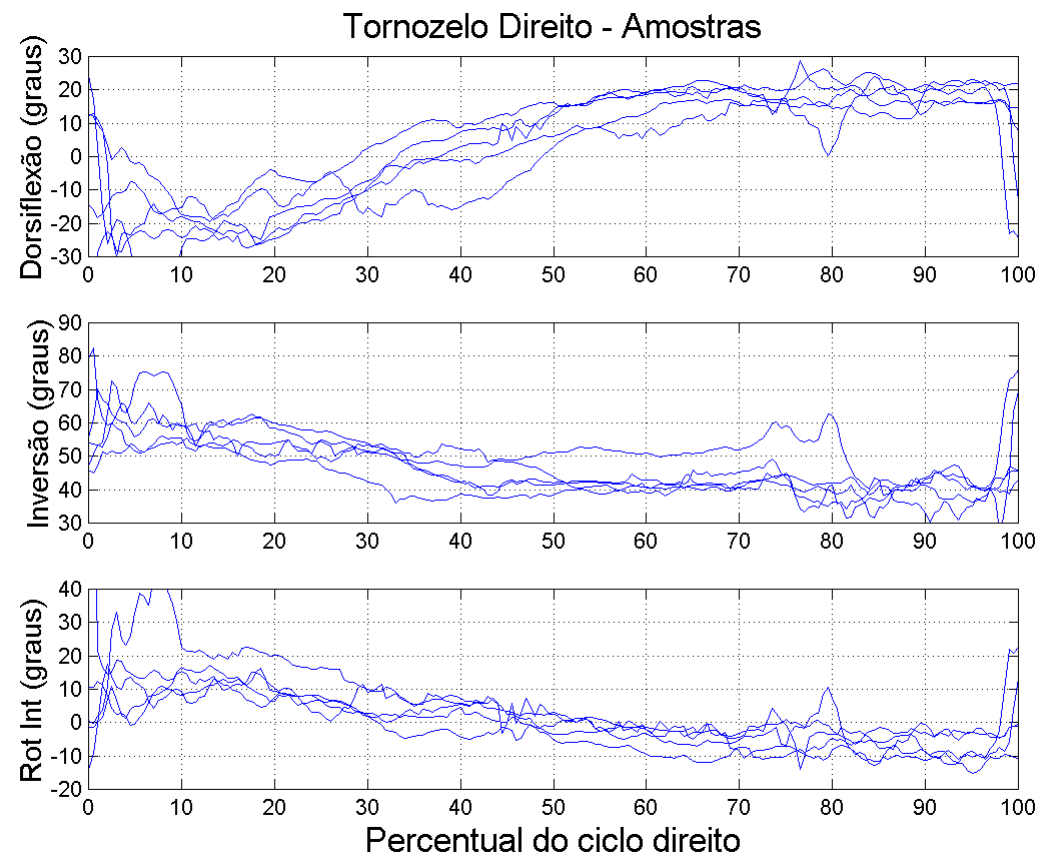

(a) Gráficos das variações angulares presentes nas cinco amostras.
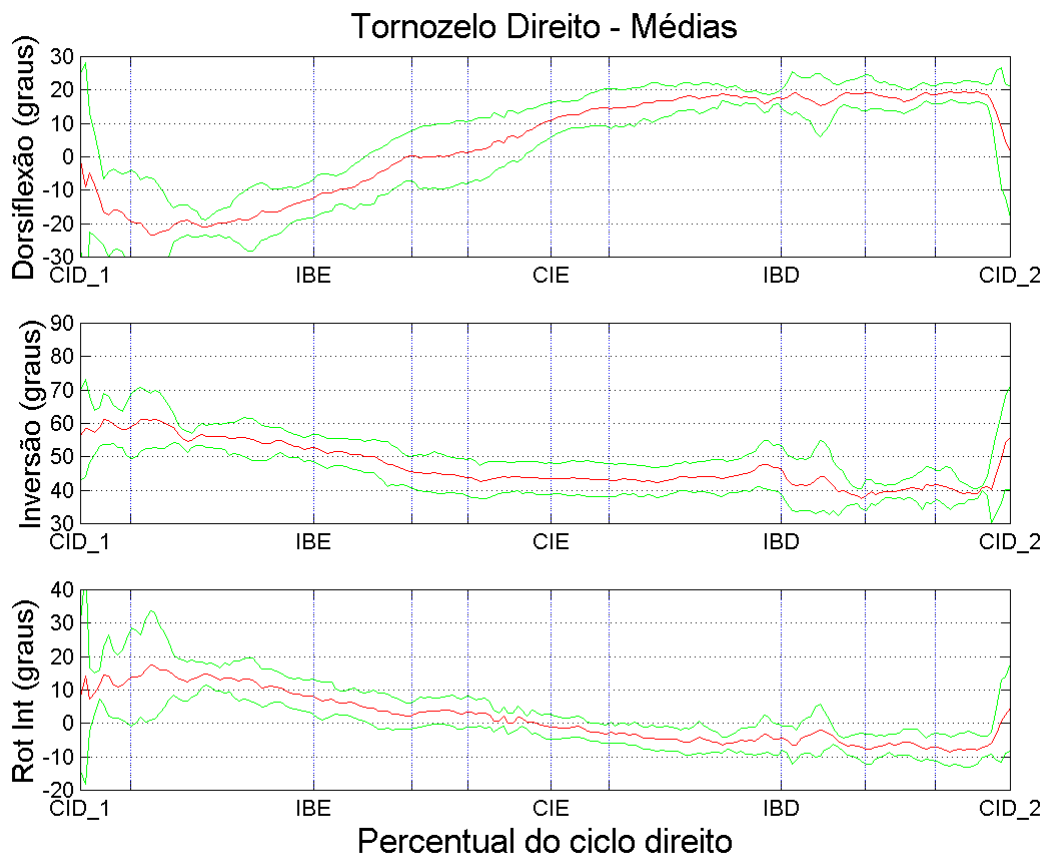

(b) Médias e desvios padrões dos dados apresentados em (a).

Figura A.8: Variações angulares no tornozelo direito. Os gráficos foram normalizados no tempo como percentual do ciclo direito da marcha. 

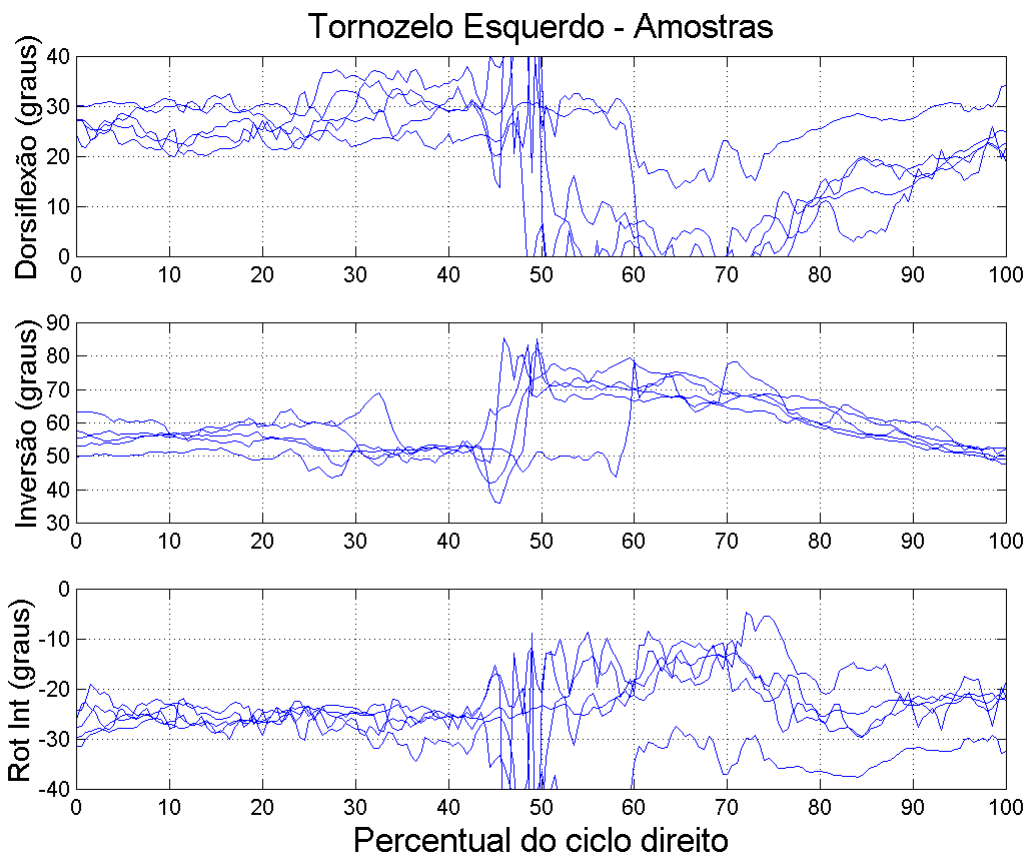

(a) Gráficos das variações angulares presentes nas cinco amostras.
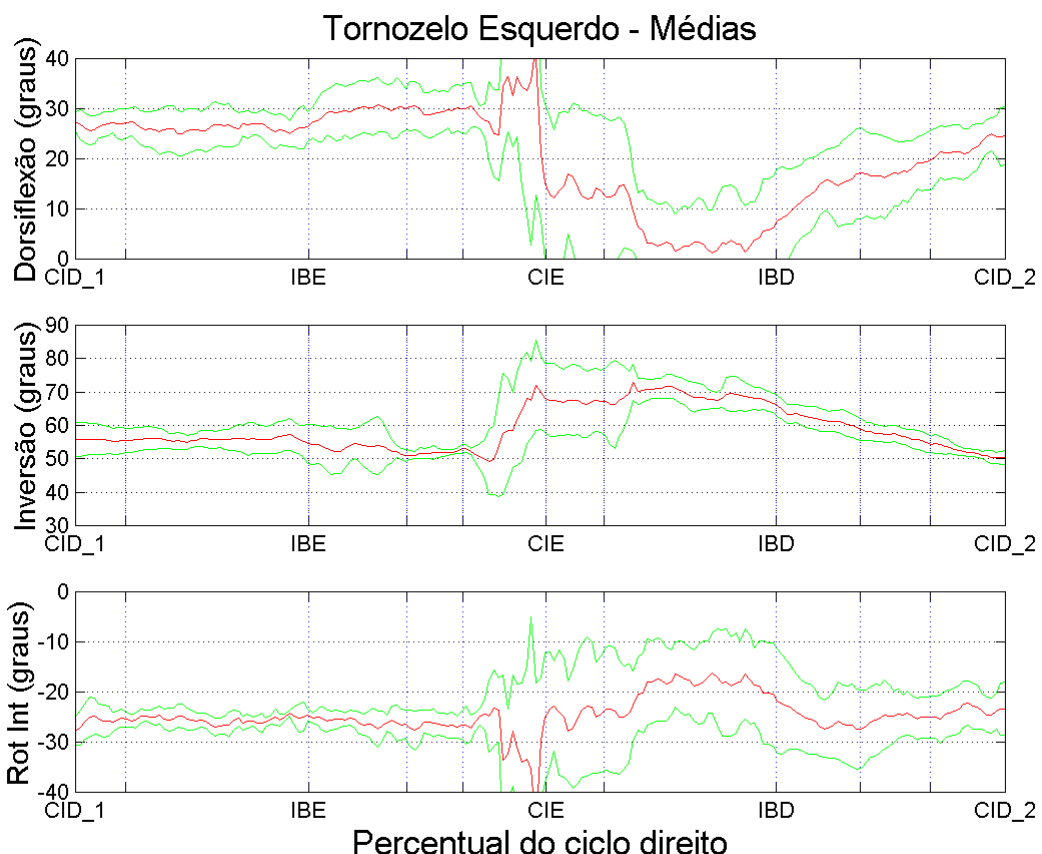

(b) Médias e desvios padrões dos dados apresentados em (a).

Figura A.9: Variações angulares no tornozelo esquerdo. Os gráficos foram normalizados no tempo como percentual do ciclo direito da marcha. 


\section{A.4 Variações angulares: ombros e cotovelos}
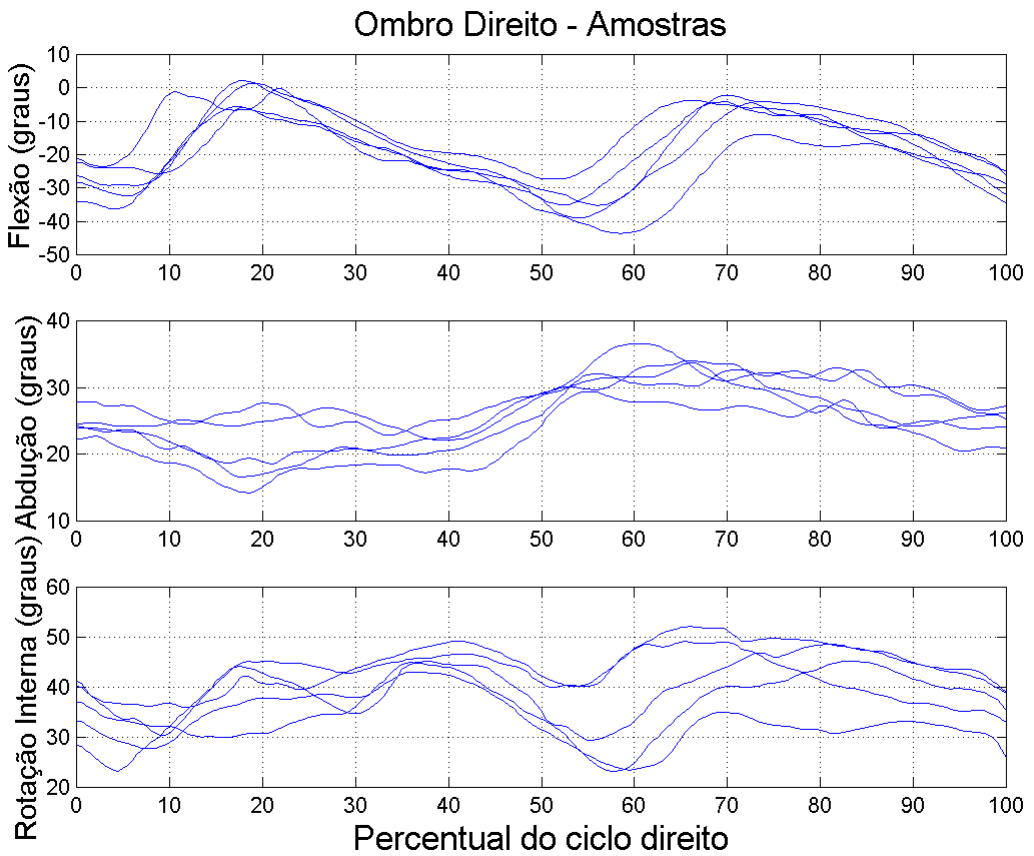

(a) Gráficos das variações angulares presentes nas cinco amostras.
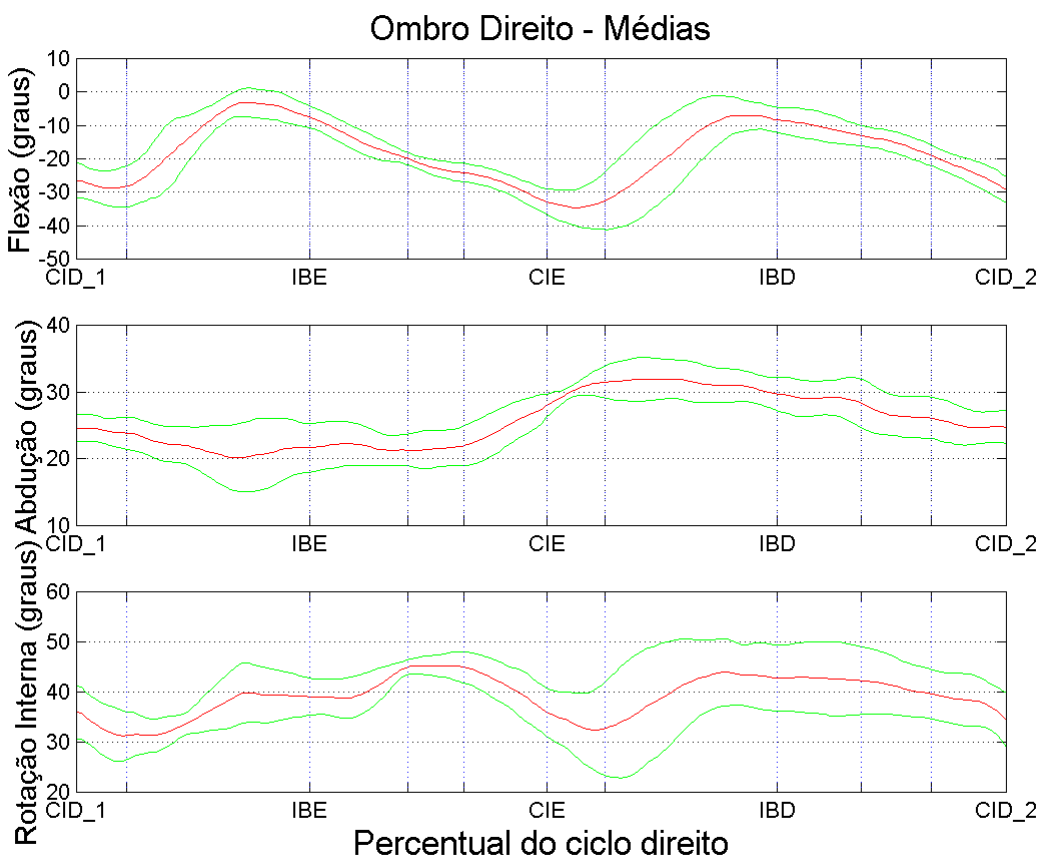

(b) Médias e desvios padrões dos dados apresentados em (a).

Figura A.10: Variações angulares no ombro direito. Os gráficos foram normalizados no tempo como percentual do ciclo direito da marcha. 

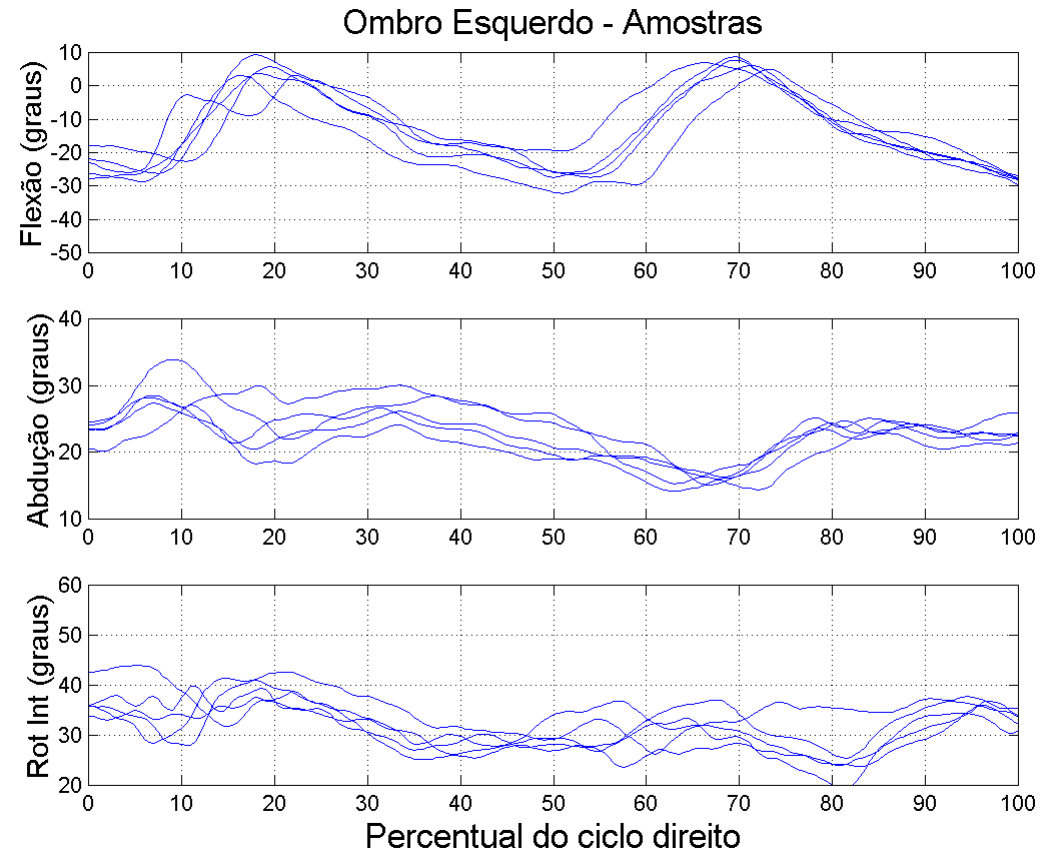

(a) Gráficos das variações angulares presentes nas cinco amostras.
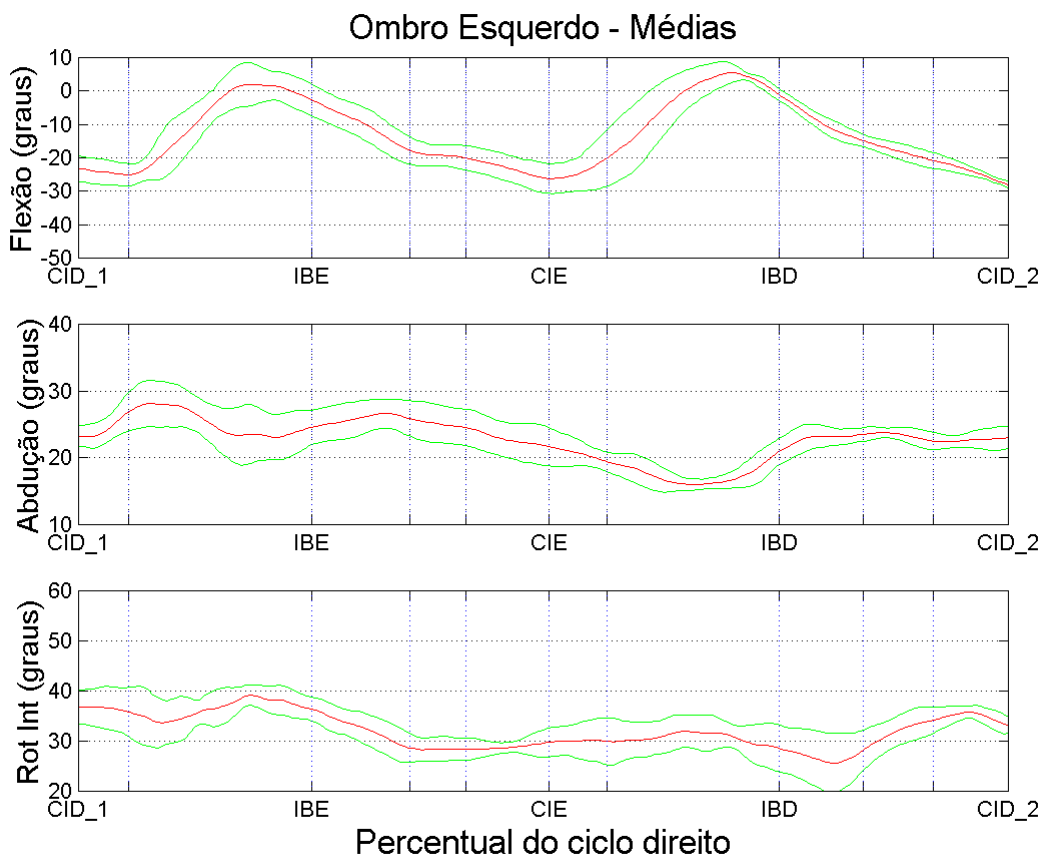

(b) Médias e desvios padrões dos dados apresentados em (a).

Figura A.11: Variações angulares no ombro esquerdo. Os gráficos foram normalizados no tempo como percentual do ciclo direito da marcha. 

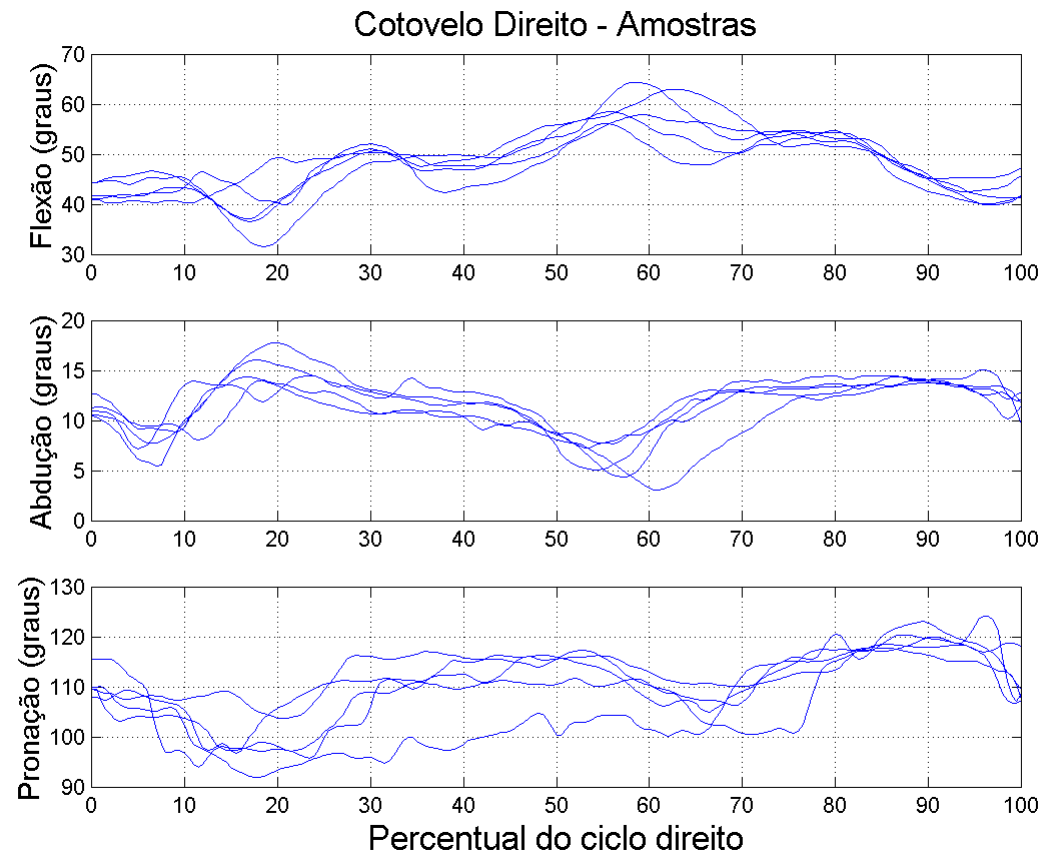

(a) Gráficos das variações angulares presentes nas cinco amostras.
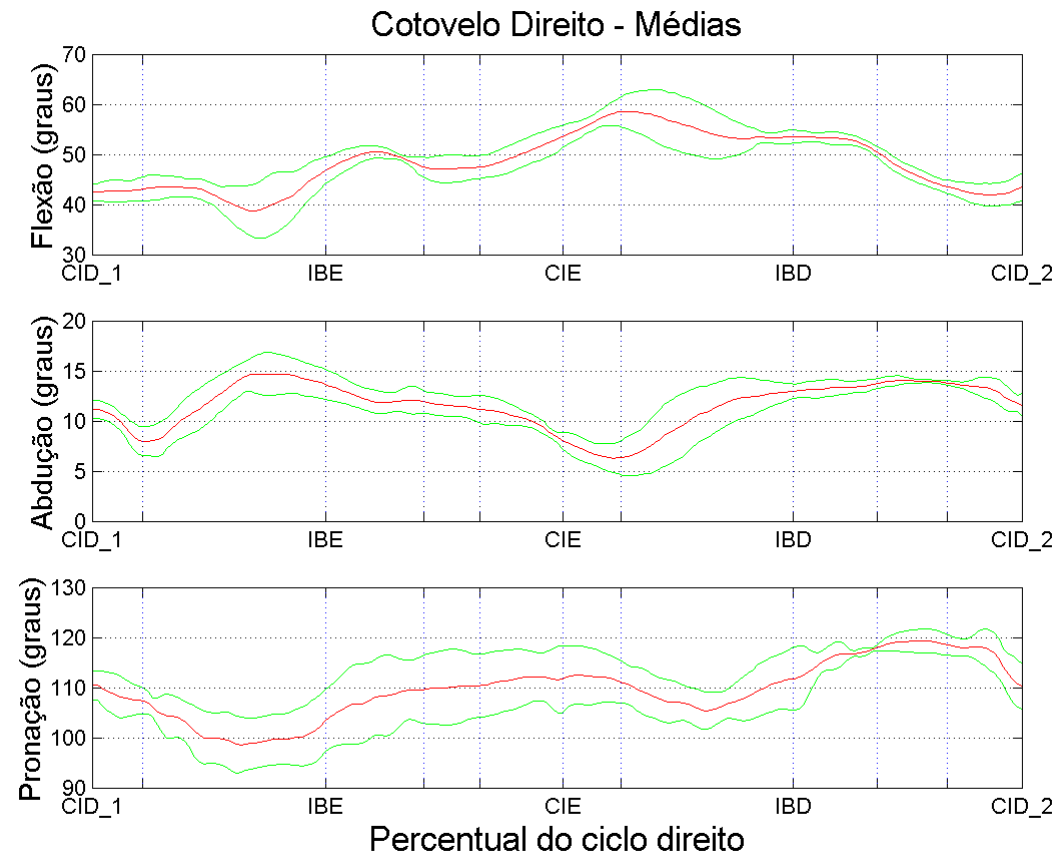

(b) Médias e desvios padrões dos dados apresentados em (a).

Figura A.12: Variações angulares no cotovelo direito. Os gráficos foram normalizados no tempo como percentual do ciclo direito da marcha. 

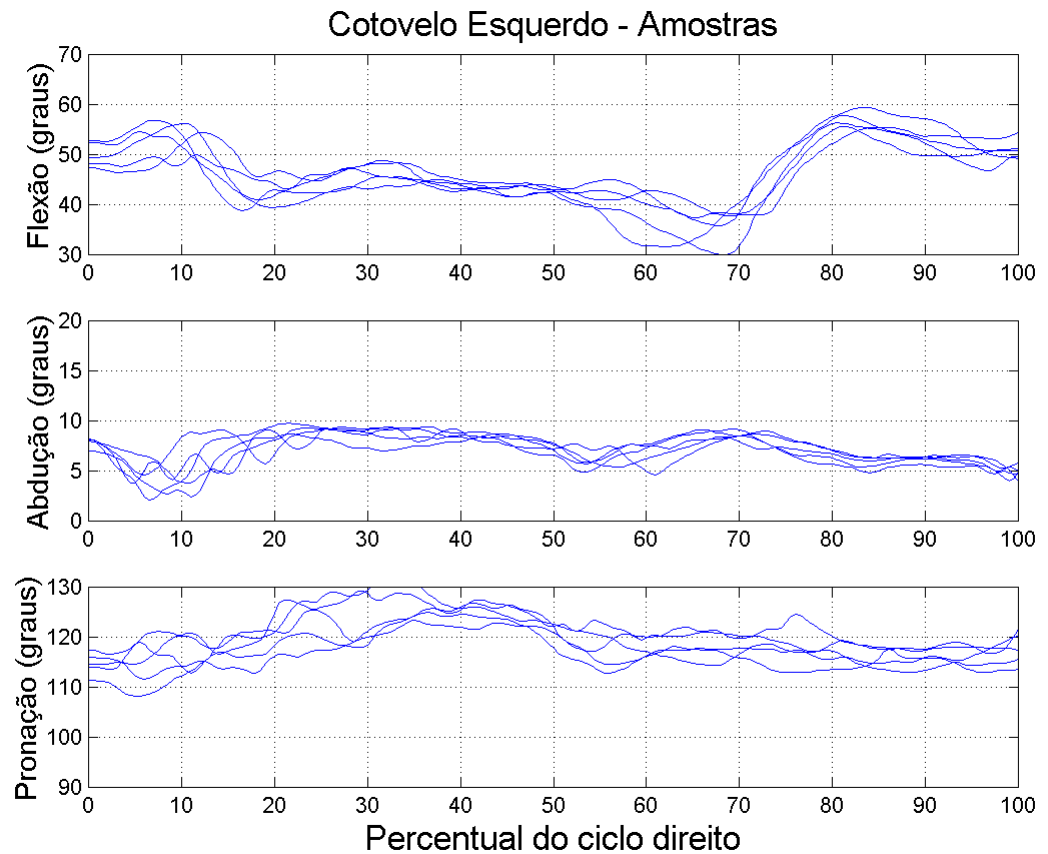

(a) Gráficos das variações angulares presentes nas cinco amostras.
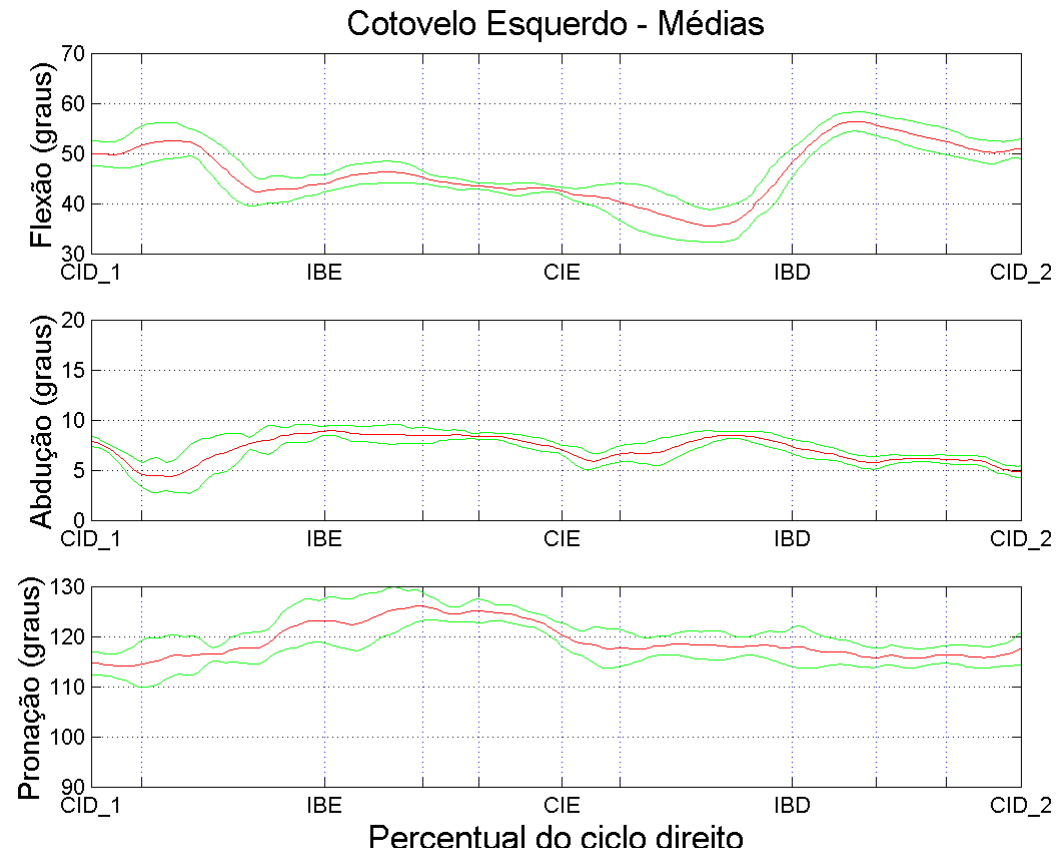

(b) Médias e desvios padrões dos dados apresentados em (a).

Figura A.13: Variações angulares no cotovelo esquerdo. Os gráficos foram normalizados no tempo como percentual do ciclo direito da marcha. 


\section{A.5 Eletromiografia}
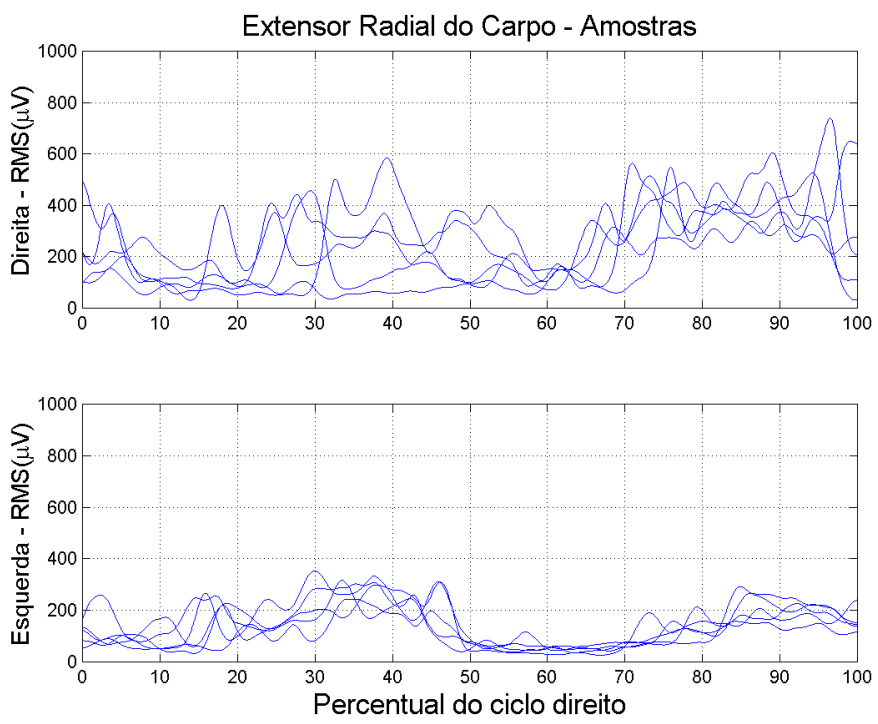

(a) Gráficos dos sinais presentes nas cinco amostras.
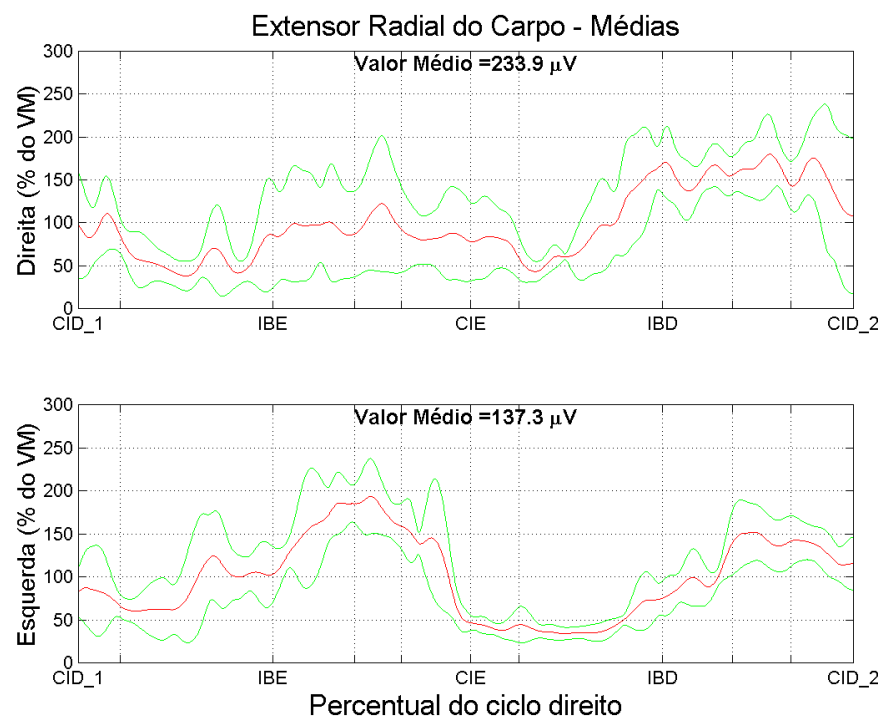

(b) Médias e desvios padrões dos dados apresentados em (a). Cada gráfico foi normalizado pelo valor médio ( $\boldsymbol{V} \boldsymbol{M})$ da média das cinco amostras.

Figura A.14: Eletromiografia do extensor radial do carpo (nos dois braços). Os gráficos foram normalizados no tempo como percentual do ciclo direito da marcha. 

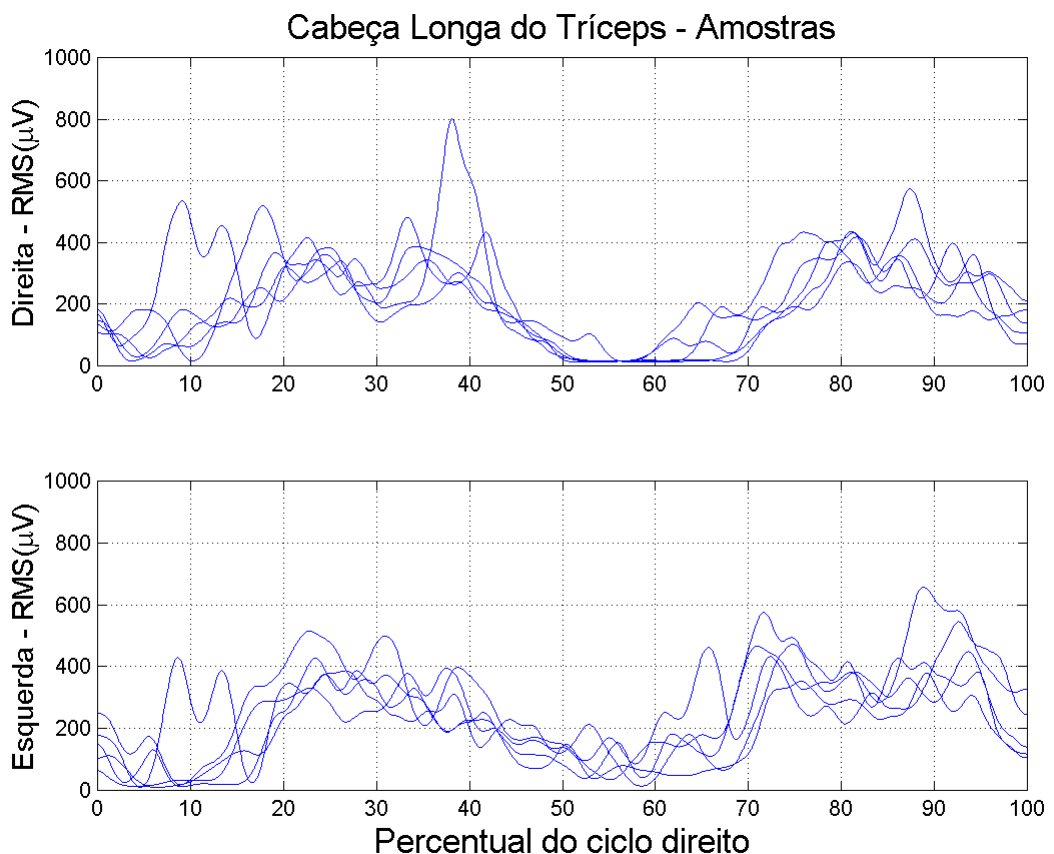

(a) Gráficos dos sinais presentes nas cinco amostras.
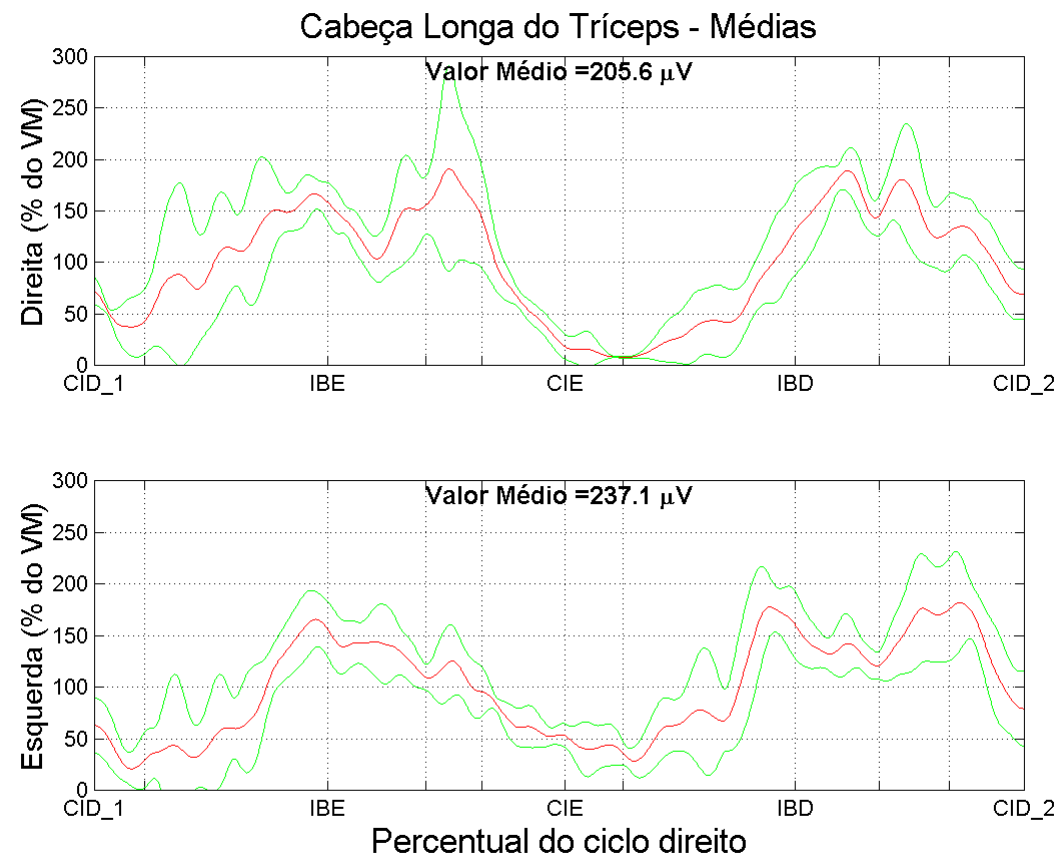

(b) Médias e desvios padrões dos dados apresentados em (a). Cada gráfico foi normalizado pelo valor médio ( $\boldsymbol{V M}$ ) da média das cinco amostras.

Figura A.15: Eletromiografia do cabeça longa do tríceps (nos dois braços). Os gráficos foram normalizados no tempo como percentual do ciclo direito da marcha. 

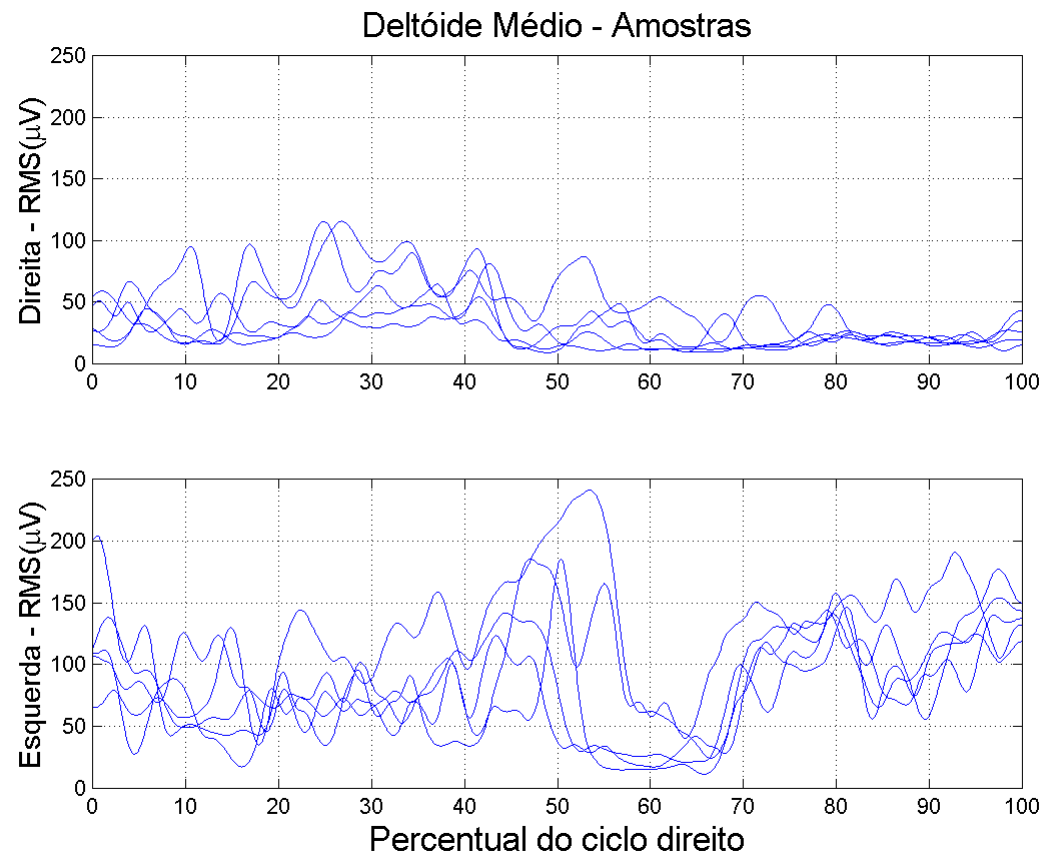

(a) Gráficos dos sinais presentes nas cinco amostras.
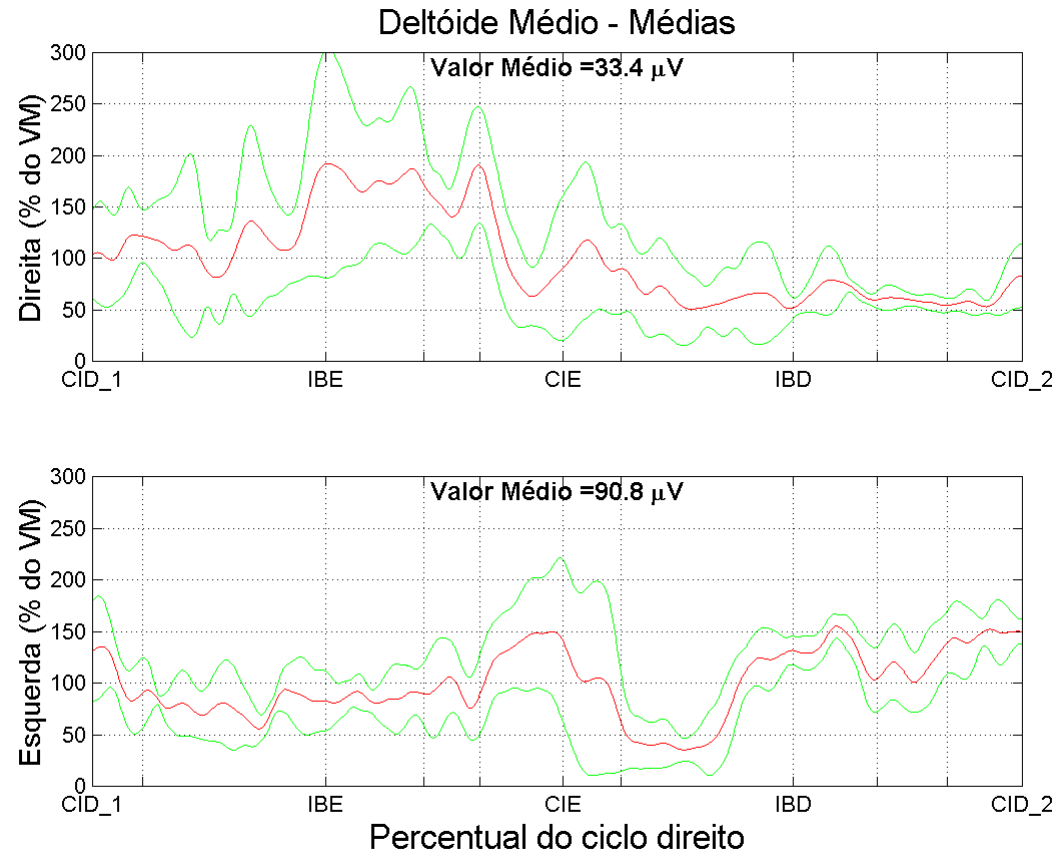

(b) Médias e desvios padrões dos dados apresentados em (a). Cada gráfico foi normalizado pelo valor médio ( $\boldsymbol{V M}$ ) da média das cinco amostras.

Figura A.16: Eletromiografia do deltóide médio (nos dois braços). Os gráficos foram normalizados no tempo como percentual do ciclo direito da marcha. 

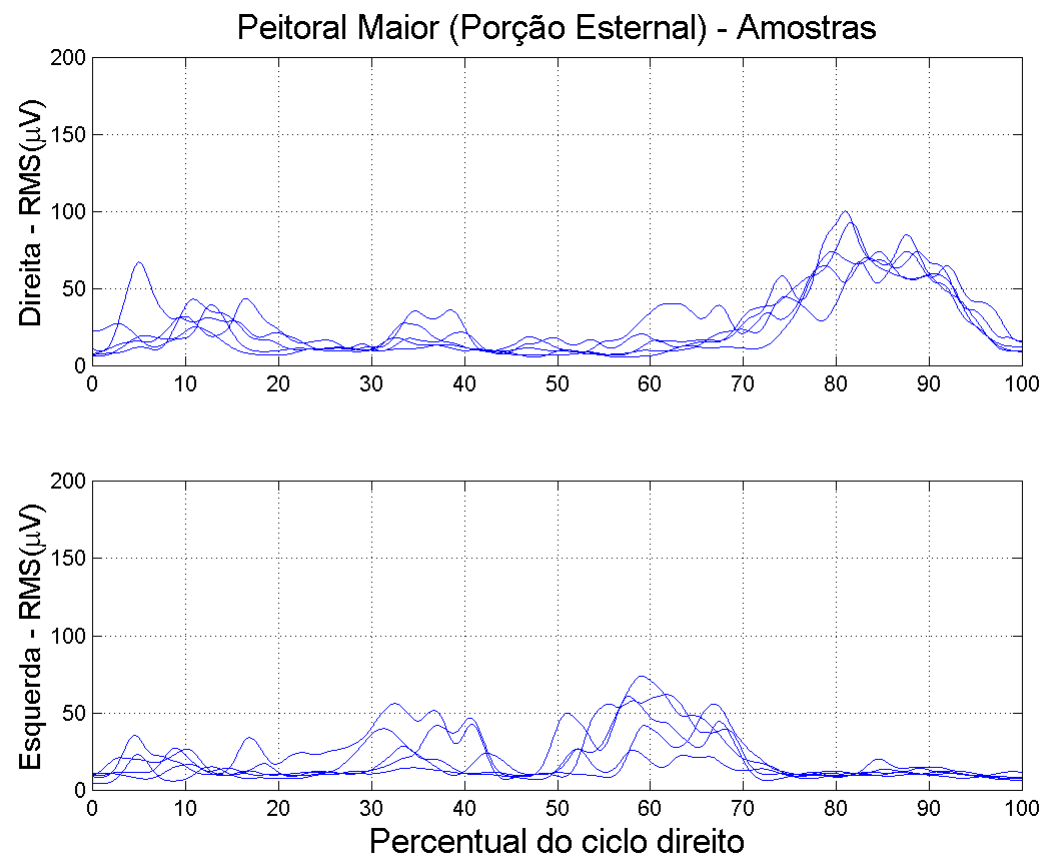

(a) Gráficos dos sinais presentes nas cinco amostras.
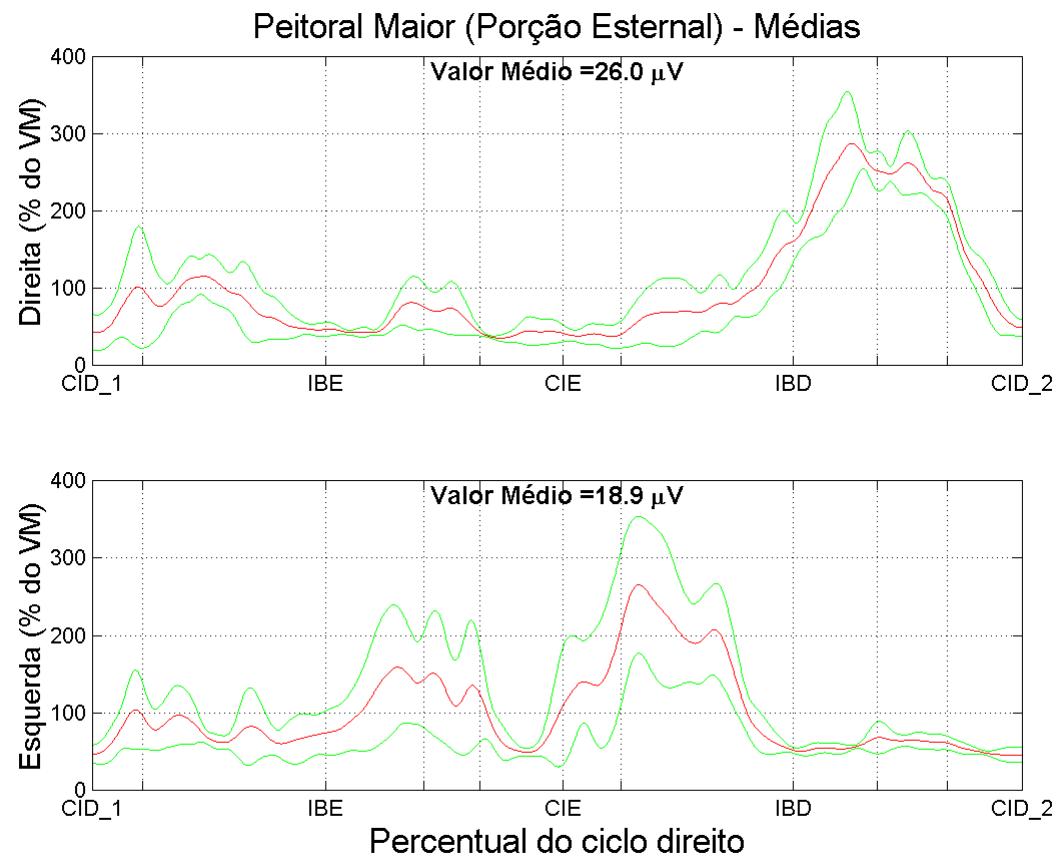

(b) Médias e desvios padrões dos dados apresentados em (a). Cada gráfico foi normalizado pelo valor médio ( $\boldsymbol{V M}$ ) da média das cinco amostras.

Figura A.17: Eletromiografia da porção esternal do peitoral maior. Os gráficos foram normalizados no tempo como percentual do ciclo direito da marcha. 


\section{A.6 Componente vertical da força de reação do solo}
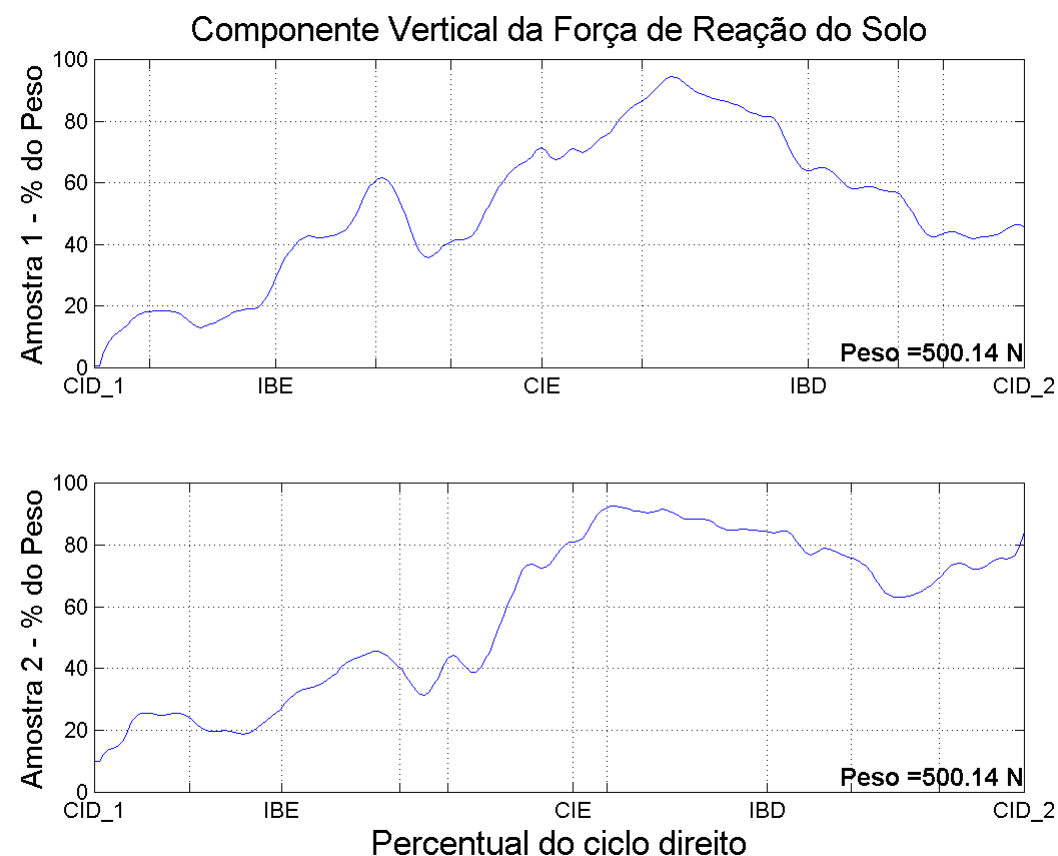

Figura A.18: Duas amostras da componente vertical da força de reação do solo conseqüente da ação dos pés do paciente sobre a plataforma de força durante a deambulação. Os gráficos foram normalizados no tempo como percentual do ciclo direito da marcha, e normalizados em amplitude como percentual do peso do paciente em Newtons.

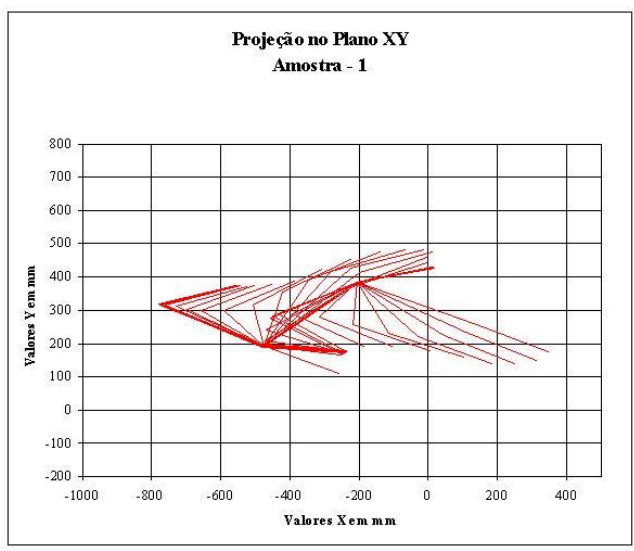

(a) Amostra 1

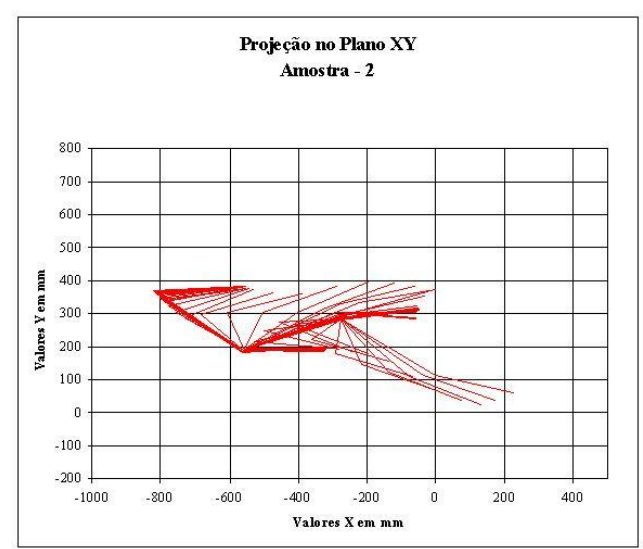

(b) Amostra 2

Figura A.19: Projeção do movimento dos pés do paciente sobre a plataforma de força no plano horizontal $(X Y)$. 


\section{Apêndice B}

\section{Paciente B}

Este apêndice apresentará os resultados do exame realizado no dia 17/05/2002. O conjunto de resultados é constituído por: as características da passada, variações angulares tridimensionais nos membros inferiores (pélvis, quadris, joelhos e tornozelos) e superiores (ombros, cotovelos, e tronco), eletromiografia de músculos dos membros superiores (peitoral maior, deltóide médio, cabeça longa do tríceps, extensor radial do carpo) e componente vertical da força de reação do solo.

\section{B.1 Características do paciente}

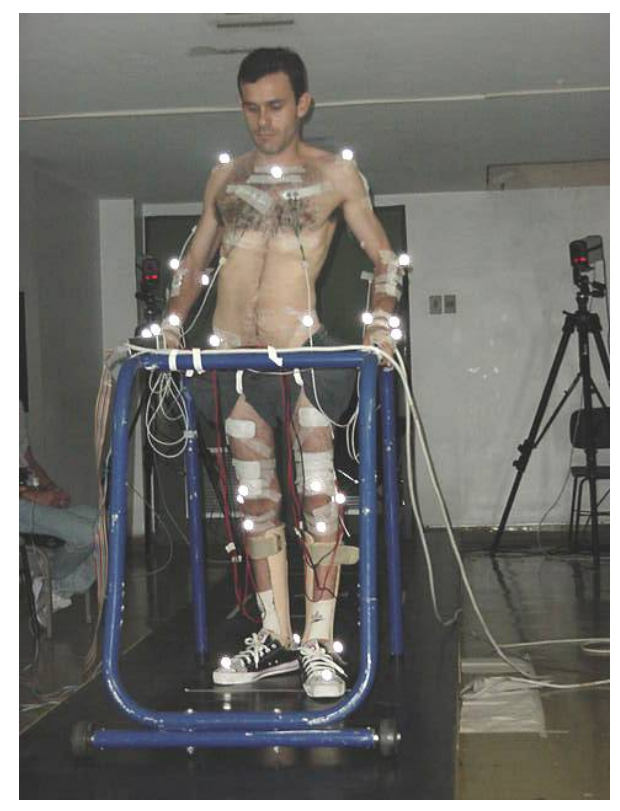

Figura B.1: Paciente B - Foto tirada durante um dos ensaios. O arquivo no formato PDF possui direcionamento para vídeo ao clicar na foto, desde que o QuickTime esteja instalado. Para abrir o vídeo fora do arquivo PDF, usando outro programa, clique aqui. 


\begin{tabular}{ccccccc}
\hline Nome & Idade & Nível da lesão & Causa & $\begin{array}{c}\text { Tempo da lesão } \\
(\text { anos })\end{array}$ & $\begin{array}{c}\text { Peso } \\
(\mathrm{Kg})\end{array}$ & $\begin{array}{c}\text { Altura } \\
(\mathrm{m})\end{array}$ \\
\hline \hline $\mathrm{B}$ & 28 & $\mathrm{~T} 4$ & Acidente autom & 5 & 55 & 1,69 \\
\hline \hline
\end{tabular}

Tabela B.1: Dados dos pacientes

\section{B.2 Características da passada}

\begin{tabular}{ccccccc}
\hline Amostras & $\begin{array}{c}\text { Cadência } \\
(\text { passos/min })\end{array}$ & $\begin{array}{c}\text { Velocidade } \\
(\mathrm{cm} / \mathrm{s})\end{array}$ & $\begin{array}{c}\text { Passada } \\
(\mathrm{m})\end{array}$ & $\begin{array}{c}\text { Tempo do ciclo } \\
(\mathrm{s})\end{array}$ & $\begin{array}{c}\text { Apoio direito } \\
(\%)\end{array}$ & $\begin{array}{c}\text { Apoio esquerdo } \\
(\%)\end{array}$ \\
\hline \hline 4 & 16,00 & 5,33 & 0,40 & 7,50 & 93,10 & 94,50 \\
5 & 13,00 & 4,33 & 0,40 & 9,30 & 92,30 & 92,90 \\
6 & 16,00 & 4,00 & 0,30 & 7,70 & 94,20 & 94,40 \\
1.2 & 16,00 & 5,33 & 0,40 & 7,60 & 93,20 & 94,20 \\
1.5 & 14,00 & 4,67 & 0,40 & 8,30 & 93,80 & 94,50 \\
& & & & & & \\
Média & 15,00 & 4,73 & 0,38 & 8,08 & 93,32 & 94,10 \\
Desvio & 1,41 & 0,60 & 0,04 & 0,75 & 0,73 & 0,68 \\
\hline \hline
\end{tabular}

Tabela B.2: Parâmetros temporais

\begin{tabular}{cccccccccccc}
\hline Amostras & $\begin{array}{c}C I D_{1} \\
(\%)\end{array}$ & $\begin{array}{c}I A A_{1} \\
(\%)\end{array}$ & $\begin{array}{c}I B E \\
(\%)\end{array}$ & $\begin{array}{c}D P E \\
(\%)\end{array}$ & $\begin{array}{c}M B E \\
(\%)\end{array}$ & $\begin{array}{c}C I E \\
(\%)\end{array}$ & $\begin{array}{c}I A A_{2} \\
(\%)\end{array}$ & $\begin{array}{c}I B D \\
(\%)\end{array}$ & $\begin{array}{c}D P D \\
(\%)\end{array}$ & $\begin{array}{c}M B D \\
(\%)\end{array}$ & $\begin{array}{c}C I D_{2} \\
(\%)\end{array}$ \\
\hline \hline 4 & 0.0 & 19.1 & 30.2 & 45.0 & 48.1 & 51.0 & 69.2 & 79.4 & 93.1 & 96.7 & 100.0 \\
5 & 0.0 & 21.1 & 29.9 & 38.2 & 43.0 & 45.3 & 73.8 & 82.4 & 92.3 & 97.7 & 100.0 \\
6 & 0.0 & 19.0 & 28.9 & 43.3 & 46.3 & 49.4 & 68.5 & 80.0 & 94.2 & 97.0 & 100.0 \\
1.2 & 0.0 & 18.1 & 28.2 & 42.5 & 46.0 & 49.3 & 70.5 & 78.9 & 93.2 & 96.3 & 100.0 \\
1.5 & 0.0 & 17.5 & 26.5 & 40.2 & 43.2 & 45.8 & 71.7 & 80.3 & 93.8 & 96.2 & 100.0 \\
& & & & & & & & & & & \\
Média & 0.0 & 18.9 & 28.7 & 41.8 & 45.3 & 48.2 & 70.7 & 80.2 & 93.3 & 96.8 & 100.0 \\
Desvio & 0.0 & 1.4 & 1.5 & 2.7 & 2.2 & 2.5 & 2.1 & 1.4 & 0.7 & 0.6 & 0.0 \\
\hline \hline
\end{tabular}

Tabela B.3: Percentuais das fases do ciclo de acordo com o descrito na sec.4.1 


\section{B.3 Variações angulares: tronco e membros inferiores}
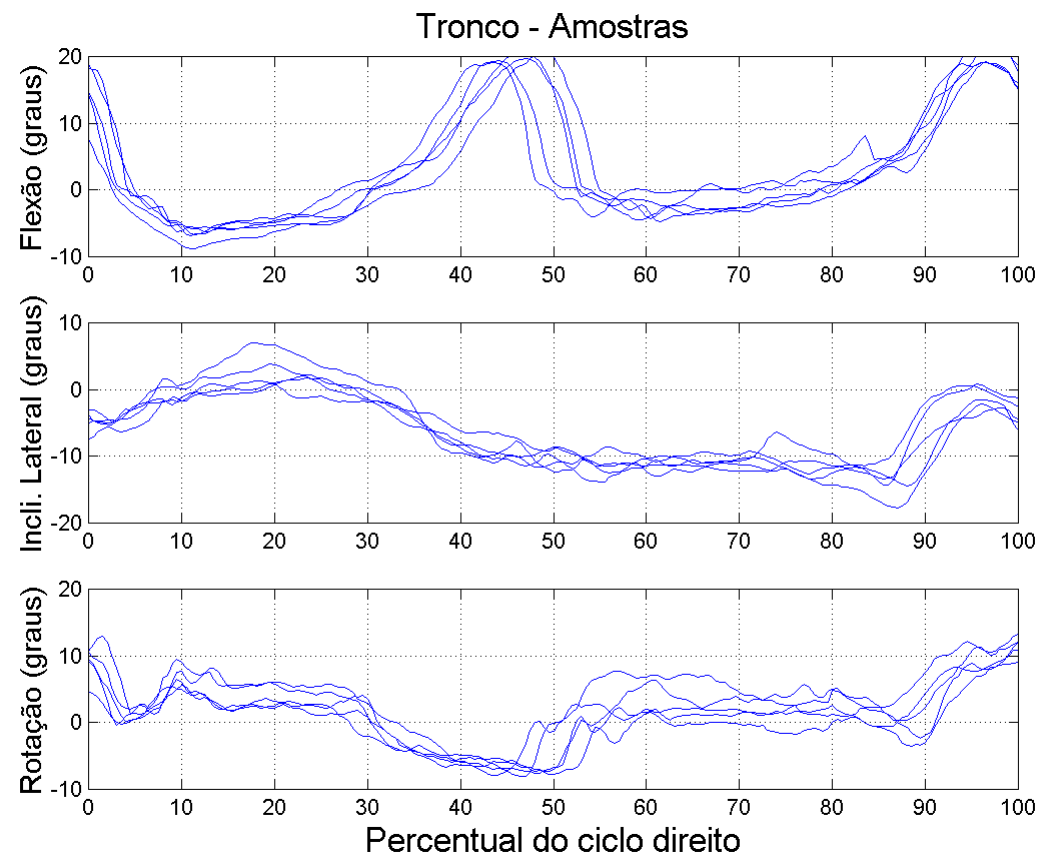

(a) Gráficos das variações angulares presentes nas cinco amostras.
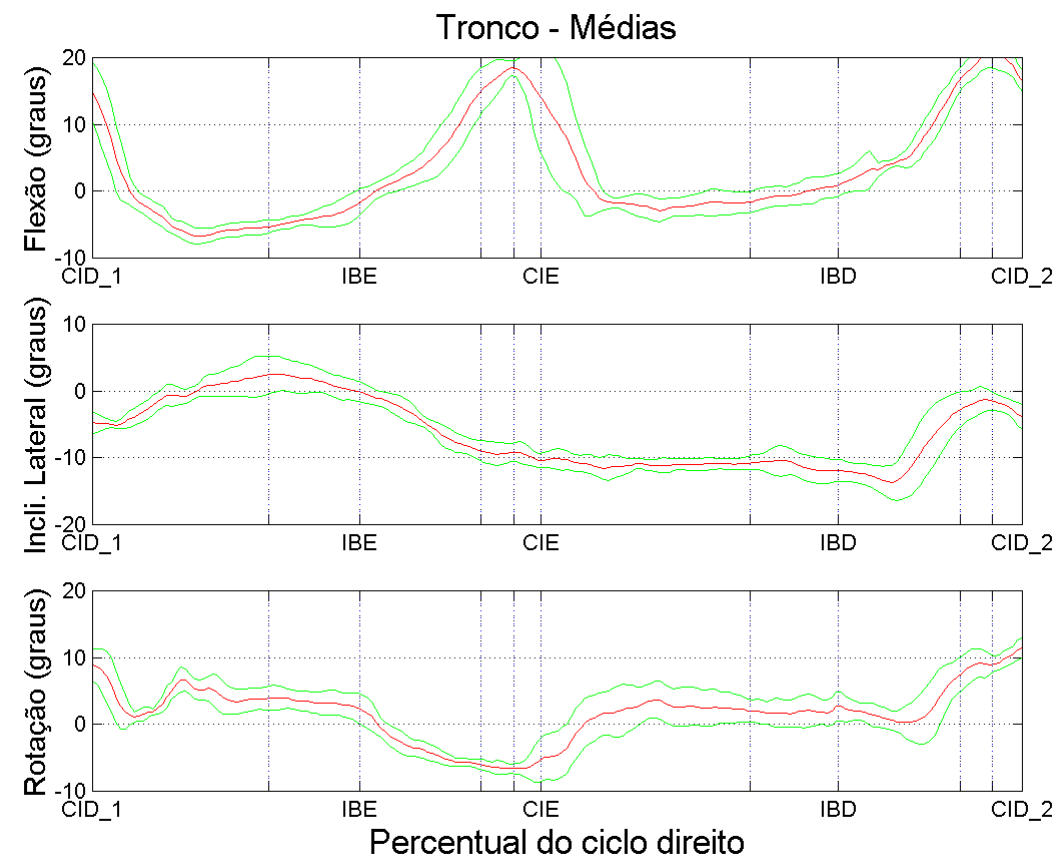

(b) Médias e desvios padrões dos dados apresentados em (a).

Figura B.2: Variações angulares do tronco. Os gráficos foram normalizados no tempo como percentual do ciclo direito da marcha. 

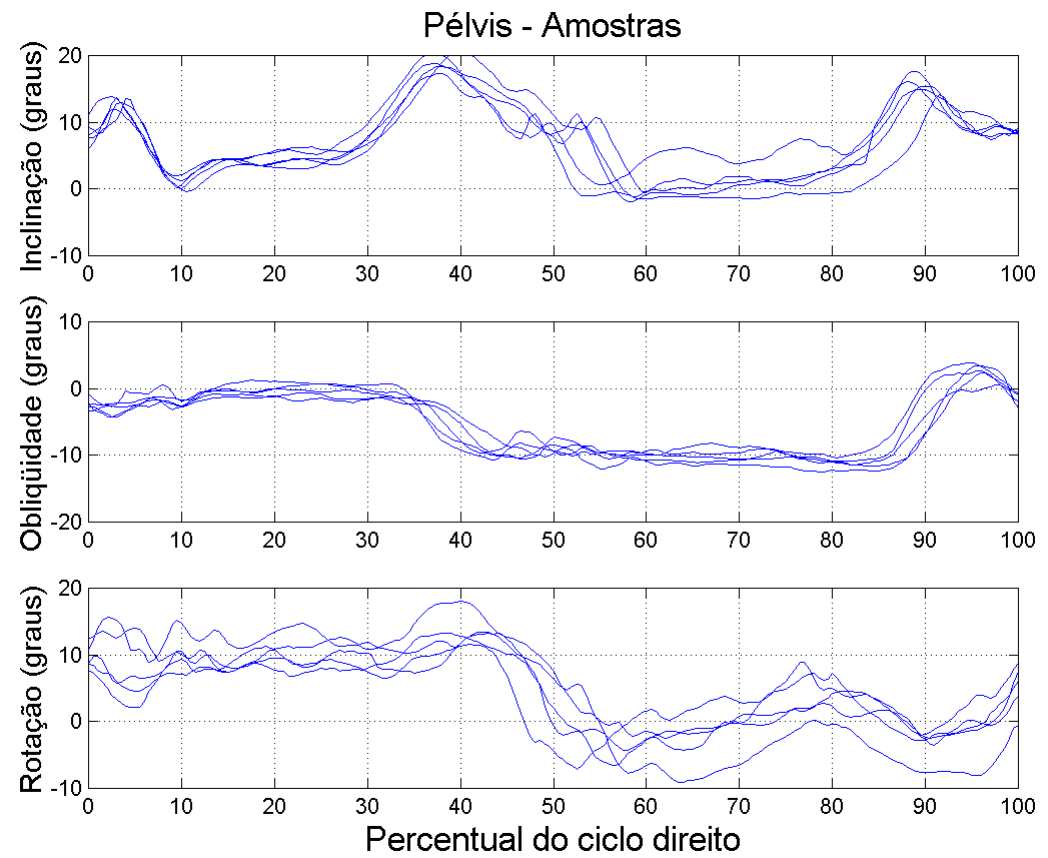

(a) Gráficos das variações angulares presentes nas cinco amostras.
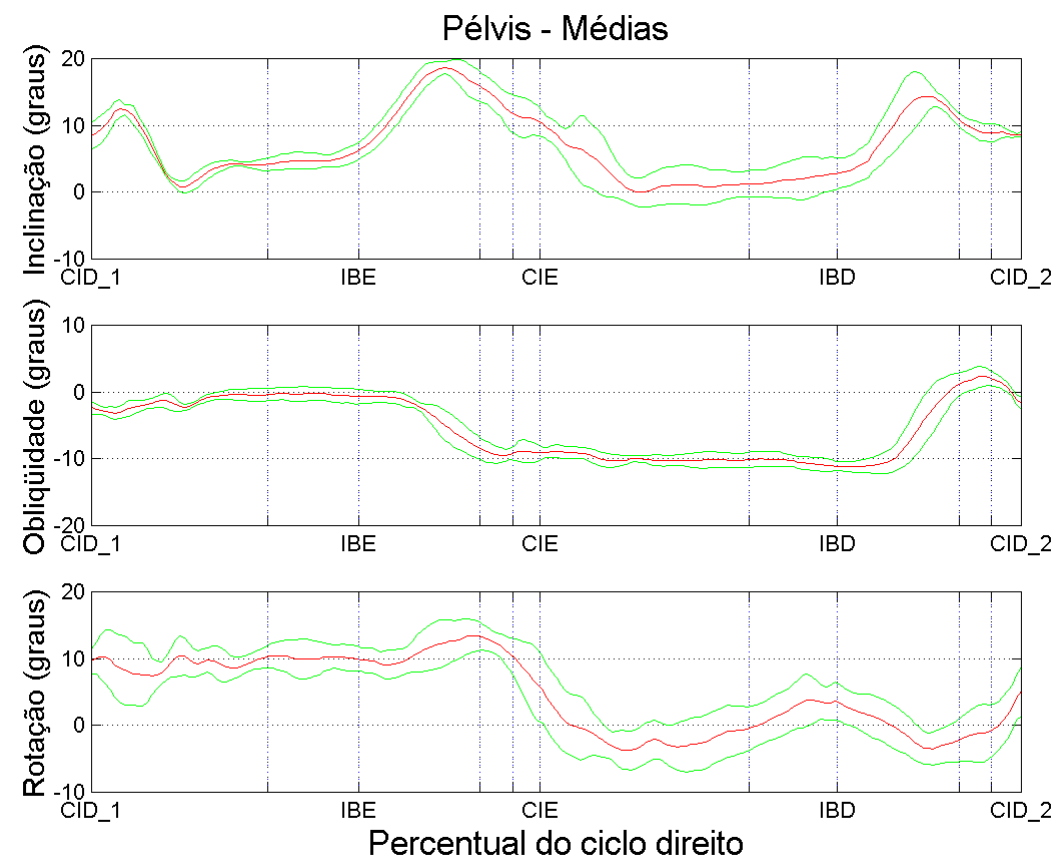

(b) Médias e desvios padrões dos dados apresentados em (a).

Figura B.3: Variações angulares do pélvis. Os gráficos foram normalizados no tempo como percentual do ciclo direito da marcha. 

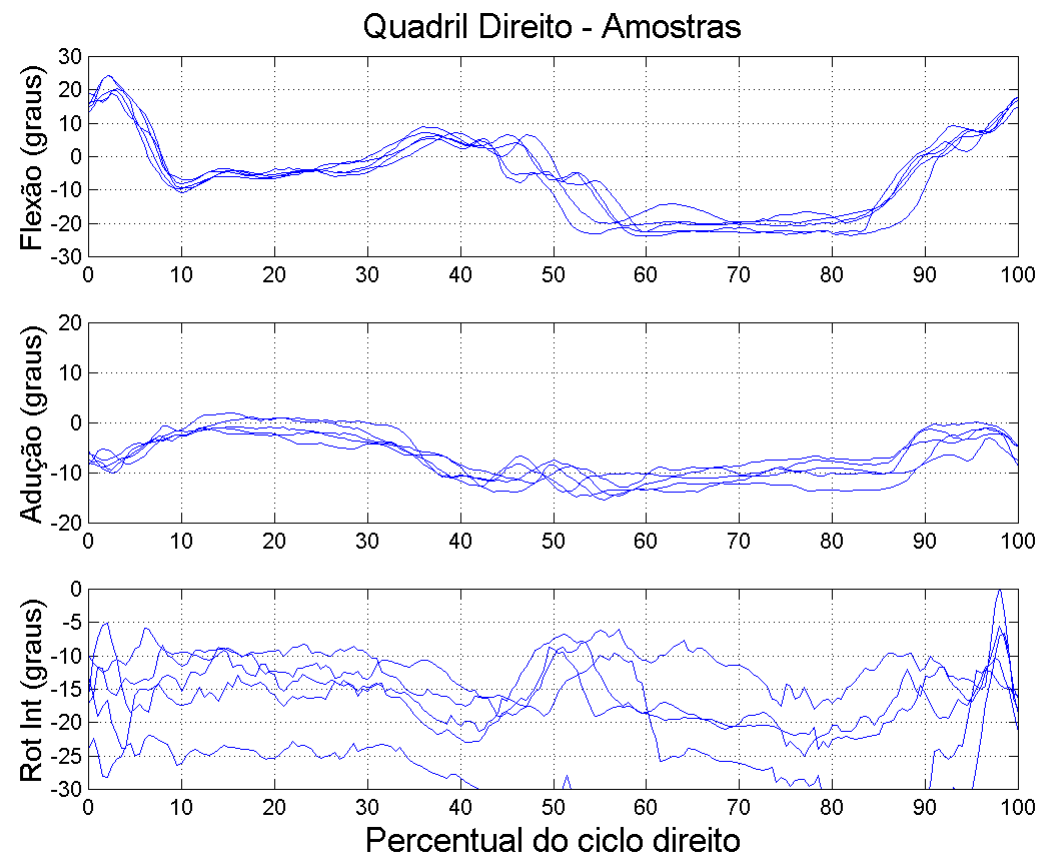

(a) Gráficos das variações angulares presentes nas cinco amostras.
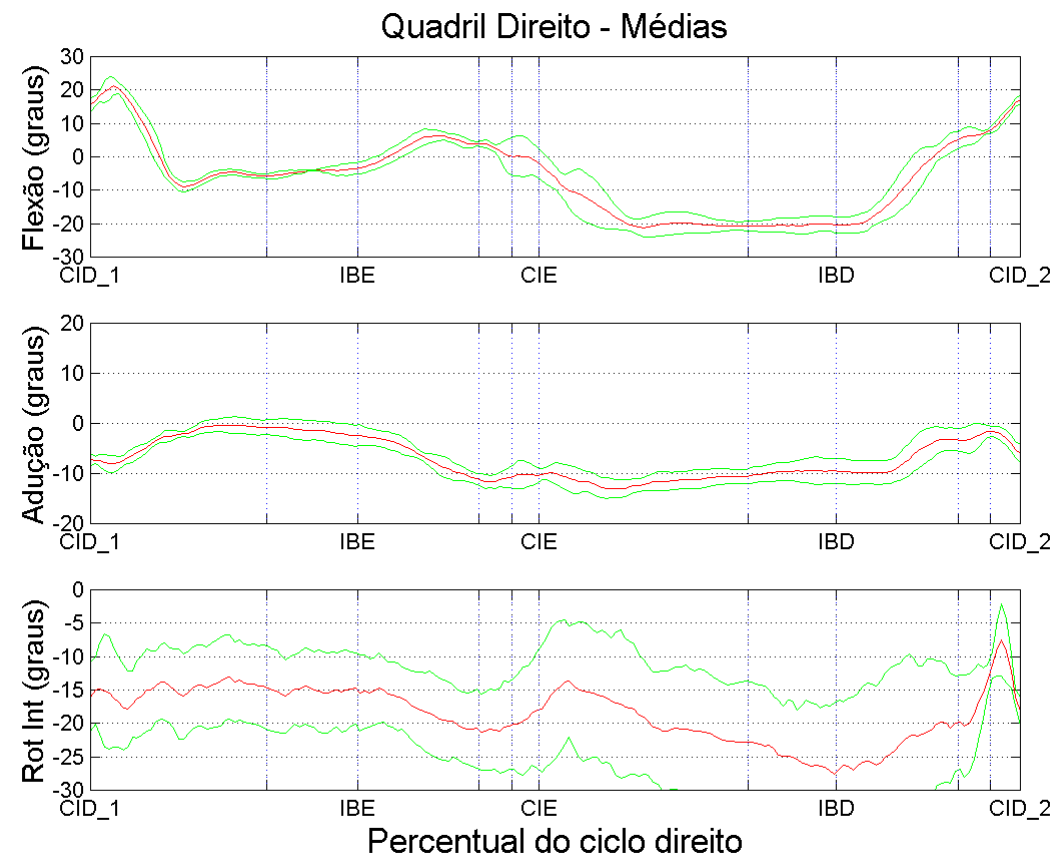

(b) Médias e desvios padrões dos dados apresentados em (a).

Figura B.4: Variações angulares no quadril direito. Os gráficos foram normalizados no tempo como percentual do ciclo direito da marcha. 

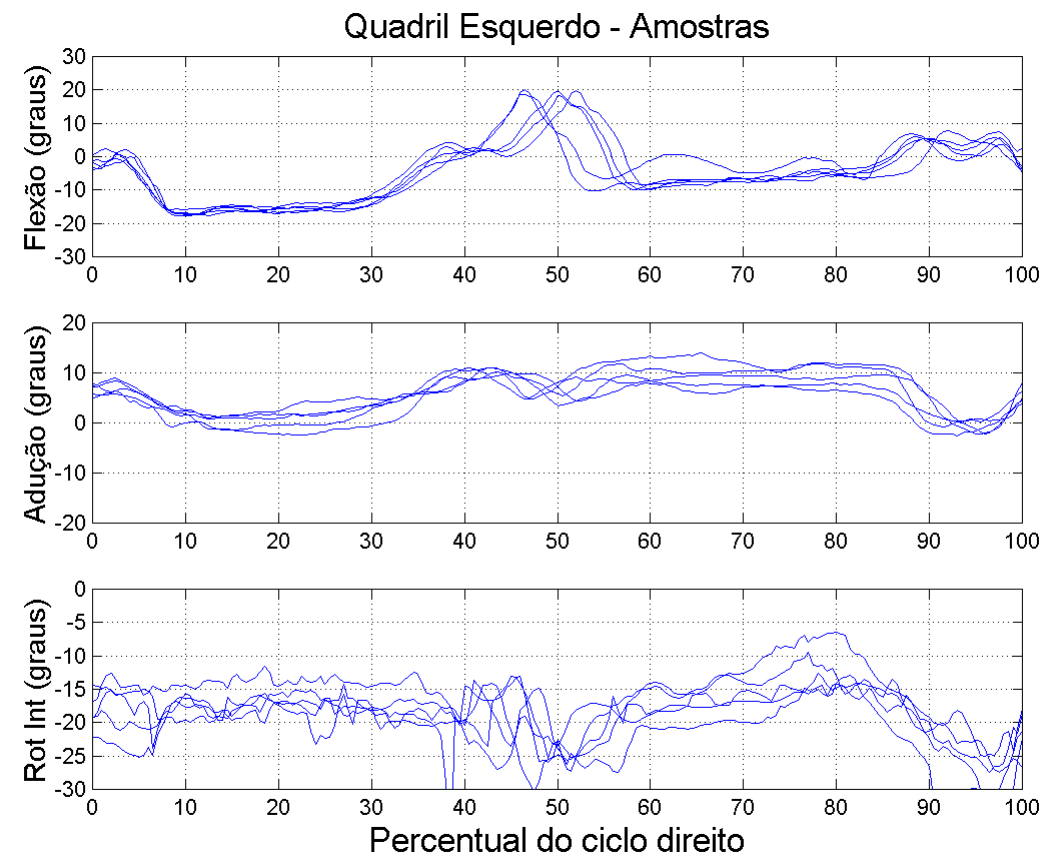

(a) Gráficos das variações angulares presentes nas cinco amostras.
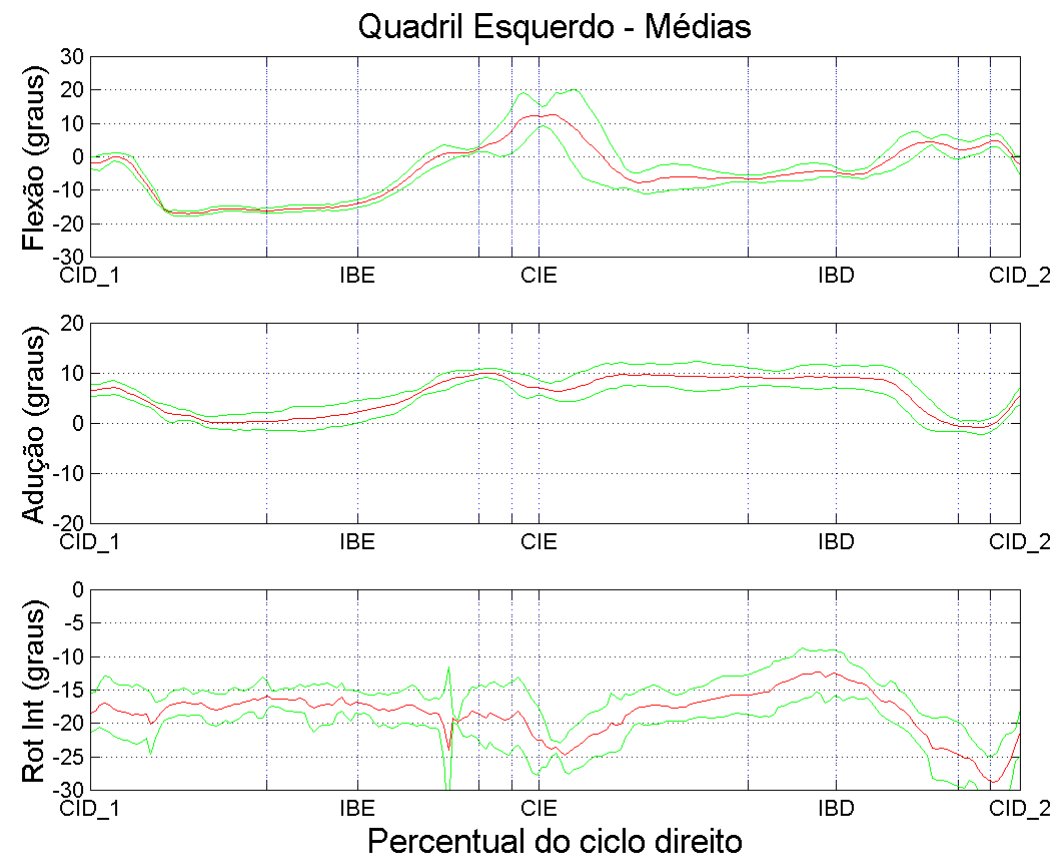

(b) Médias e desvios padrões dos dados apresentados em (a).

Figura B.5: Variações angulares no quadril esquerdo. Os gráficos foram normalizados no tempo como percentual do ciclo direito da marcha. 

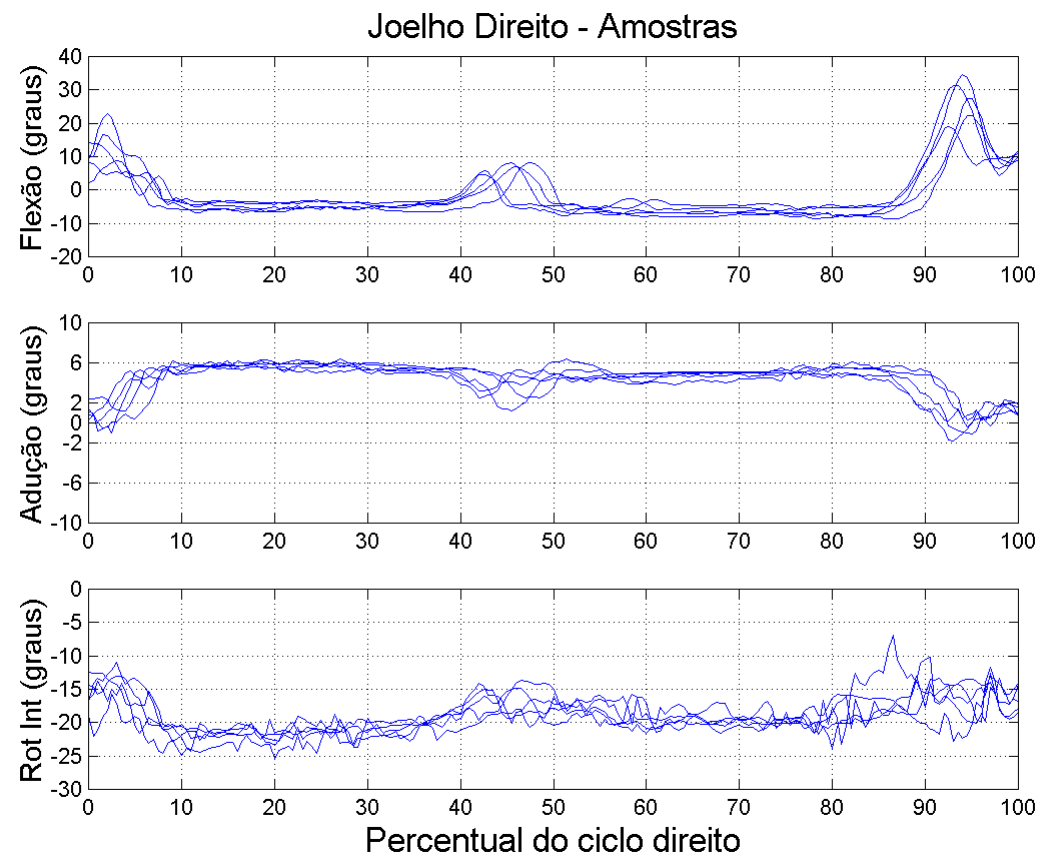

(a) Gráficos das variações angulares presentes nas cinco amostras.
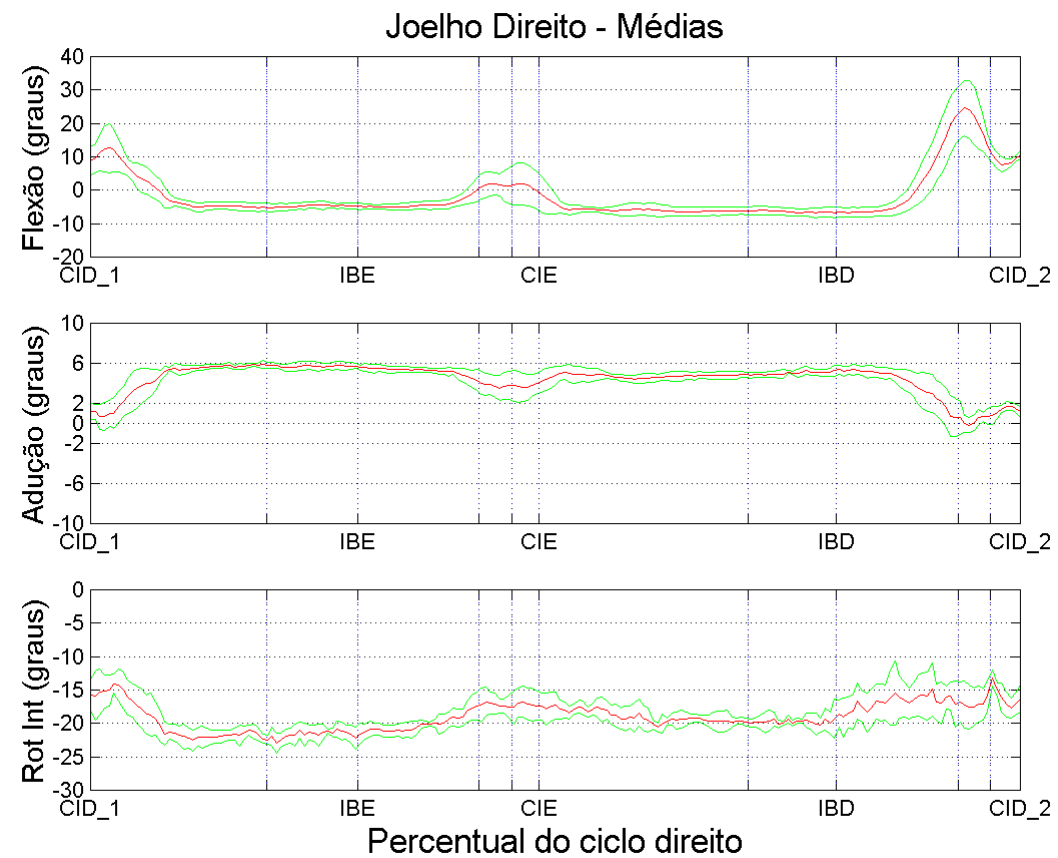

(b) Médias e desvios padrões dos dados apresentados em (a).

Figura B.6: Variações angulares no joelho direito. Os gráficos foram normalizados no tempo como percentual do ciclo direito da marcha. 

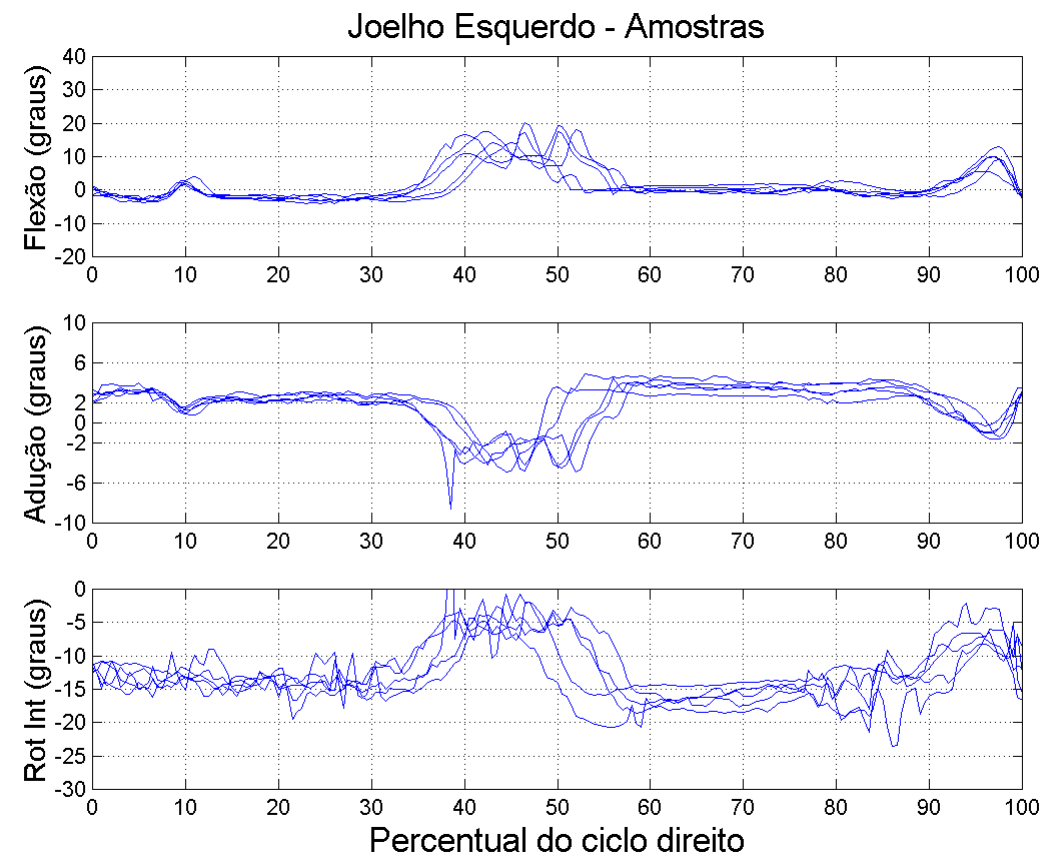

(a) Gráficos das variações angulares presentes nas cinco amostras.
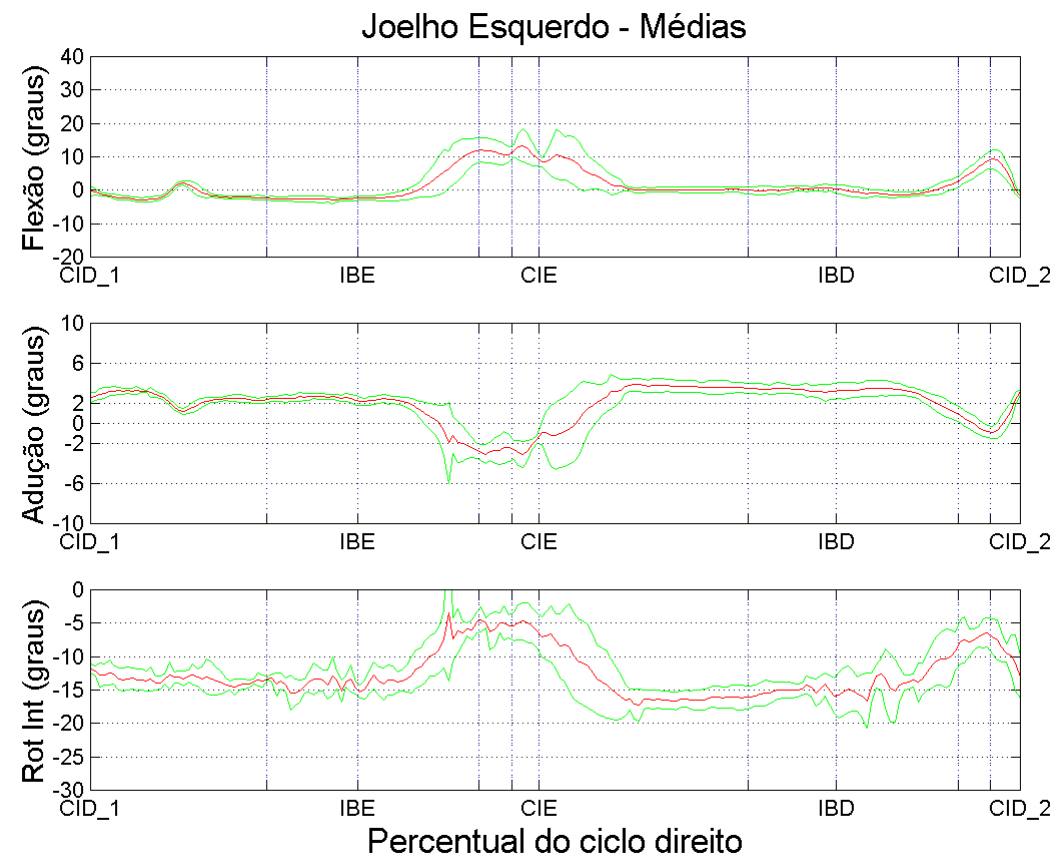

(b) Médias e desvios padrões dos dados apresentados em (a).

Figura B.7: Variações angulares no joelho esquerdo. Os gráficos foram normalizados no tempo como percentual do ciclo direito da marcha. 

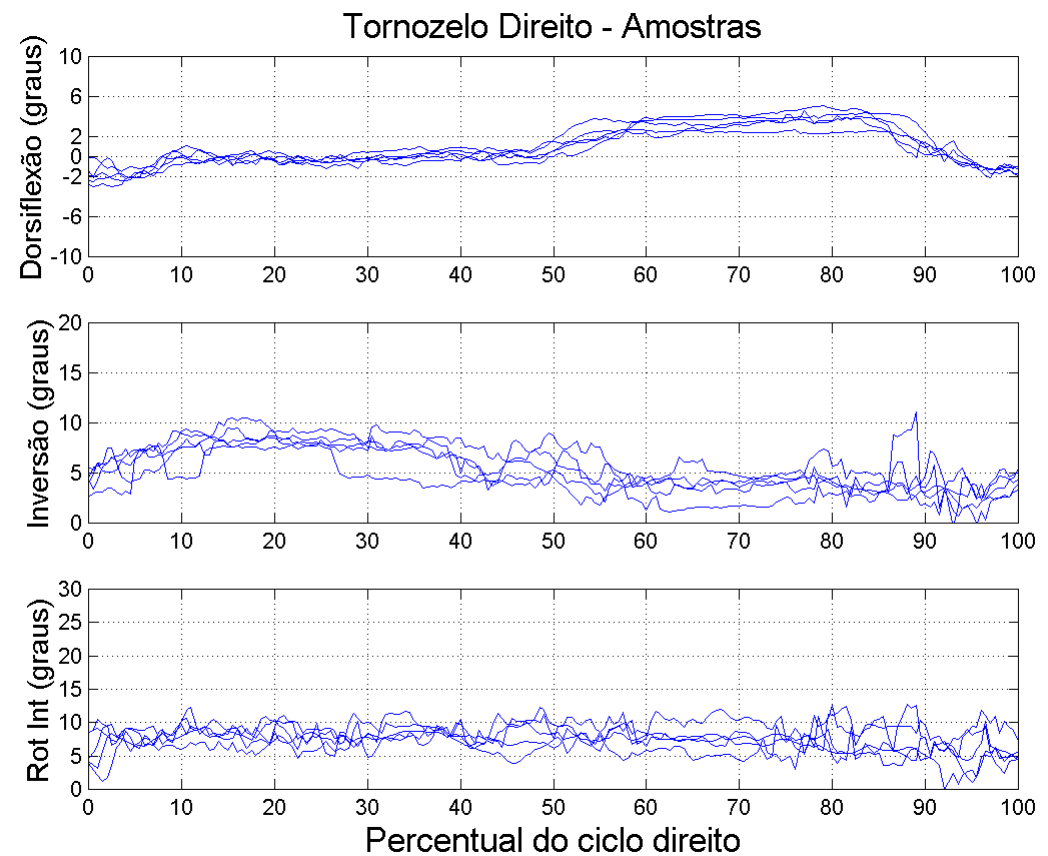

(a) Gráficos das variações angulares presentes nas cinco amostras.
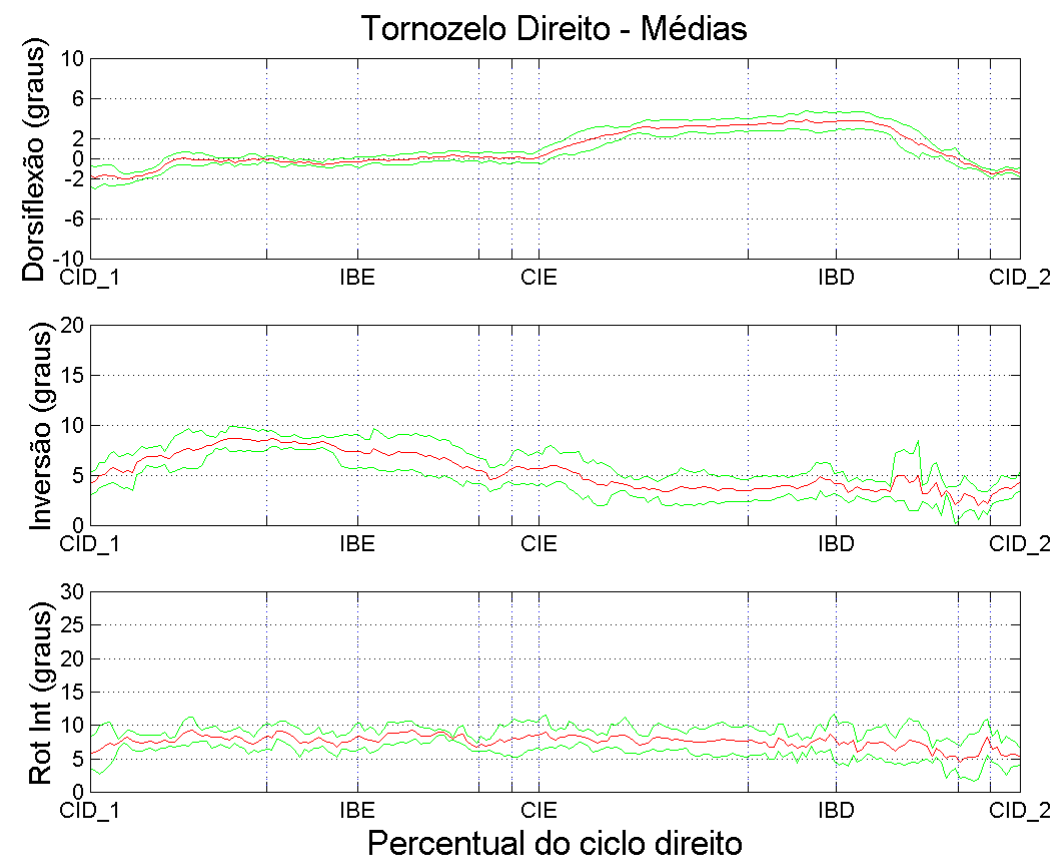

(b) Médias e desvios padrões dos dados apresentados em (a).

Figura B.8: Variações angulares no tornozelo direito. Os gráficos foram normalizados no tempo como percentual do ciclo direito da marcha. 

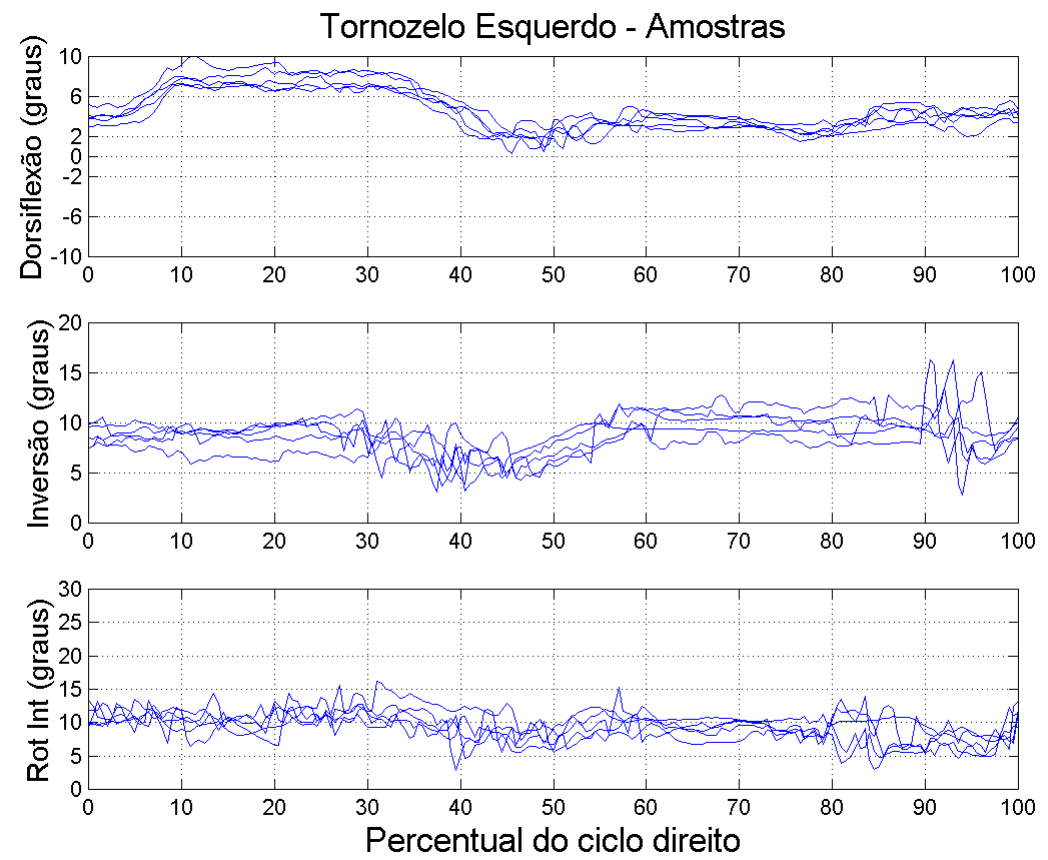

(a) Gráficos das variações angulares presentes nas cinco amostras.
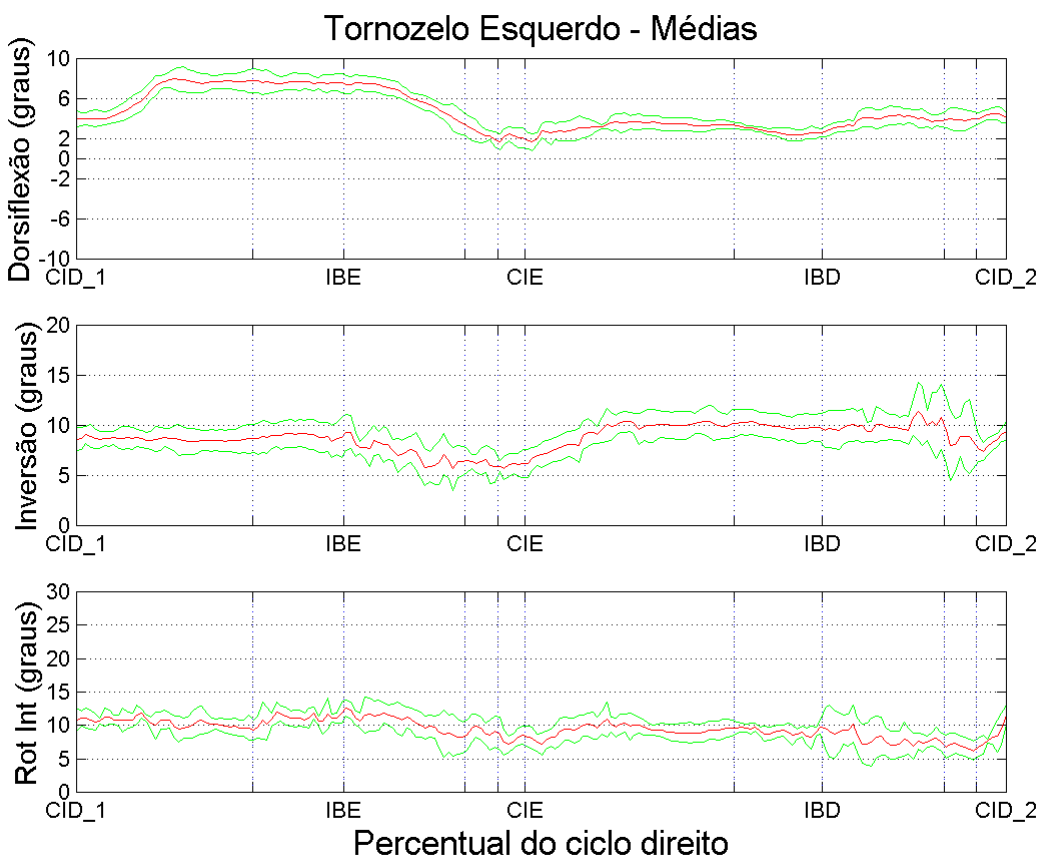

(b) Médias e desvios padrões dos dados apresentados em (a).

Figura B.9: Variações angulares no tornozelo esquerdo. Os gráficos foram normalizados no tempo como percentual do ciclo direito da marcha. 


\section{B.4 Variações angulares: ombros e cotovelos}
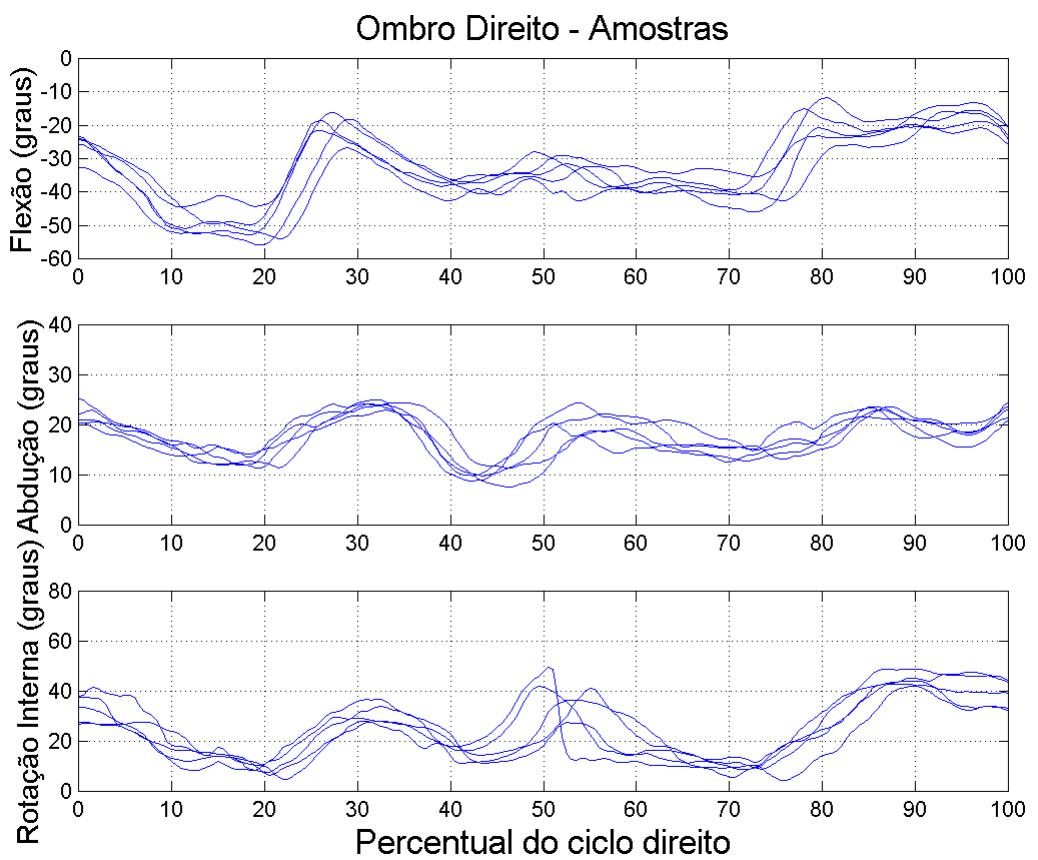

(a) Gráficos das variações angulares presentes nas cinco amostras.
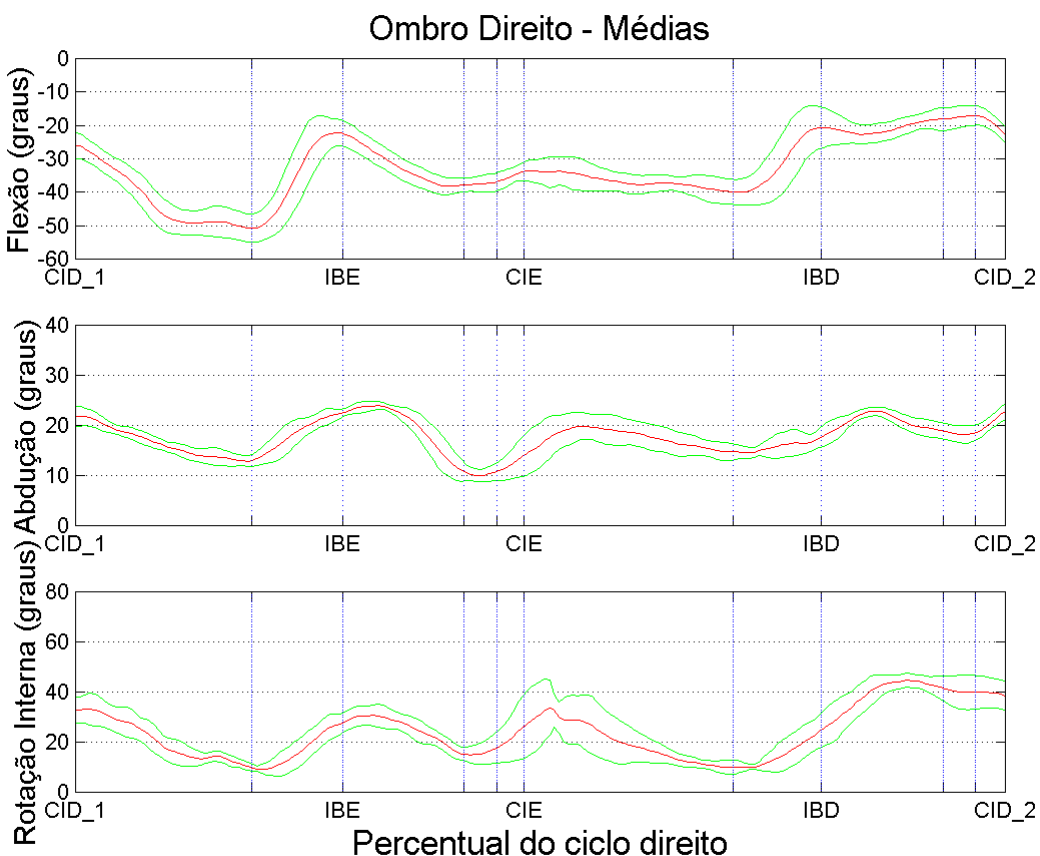

(b) Médias e desvios padrões dos dados apresentados em (a).

Figura B.10: Variações angulares no ombro direito. Os gráficos foram normalizados no tempo como percentual do ciclo direito da marcha. 

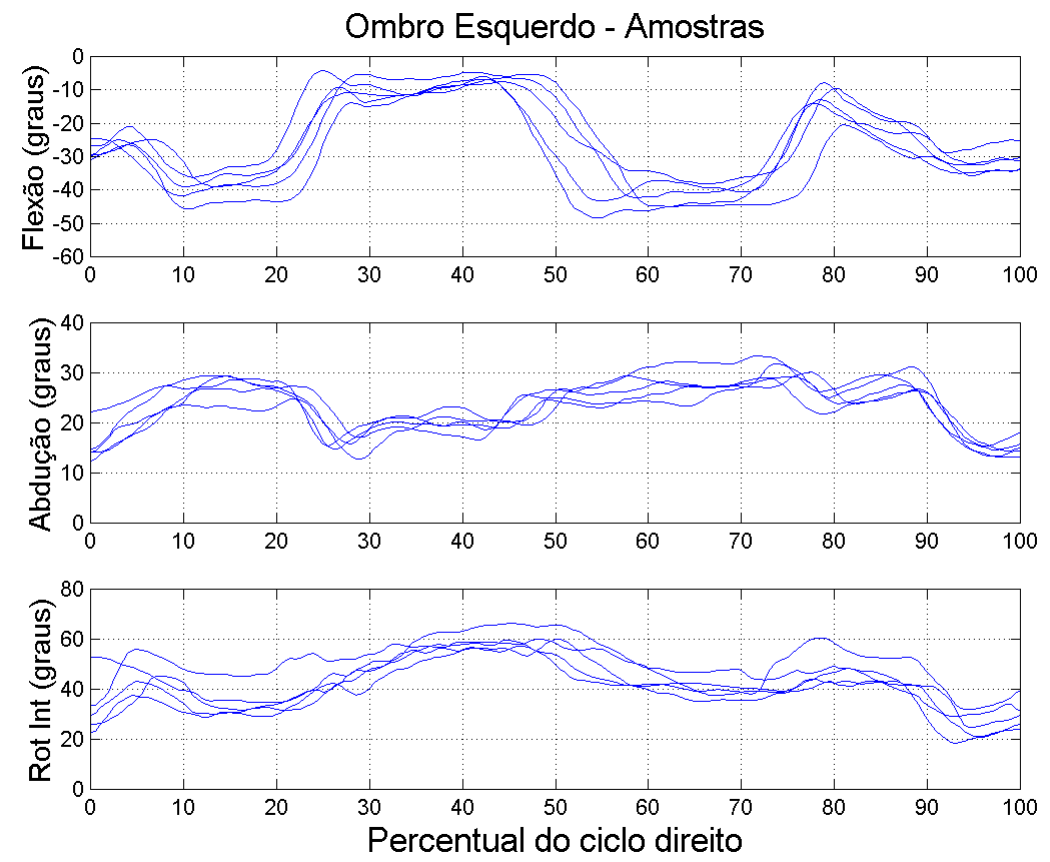

(a) Gráficos das variações angulares presentes nas cinco amostras.
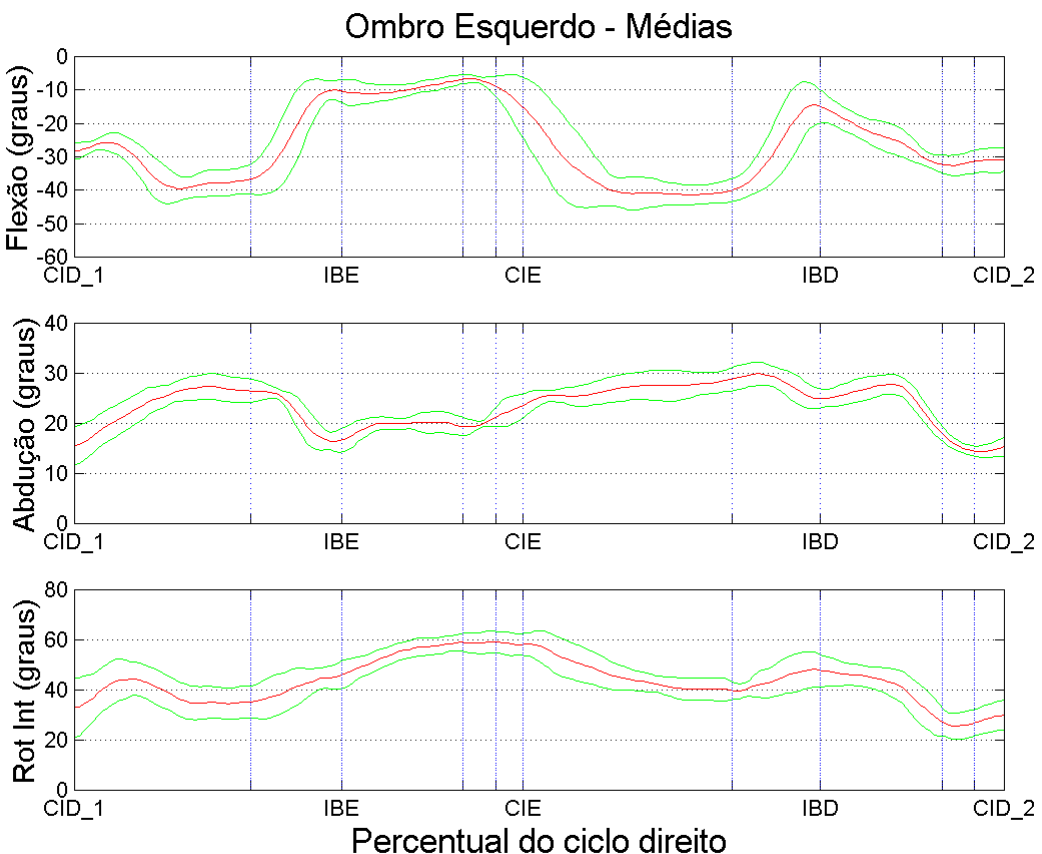

(b) Médias e desvios padrões dos dados apresentados em (a).

Figura B.11: Variações angulares no ombro esquerdo. Os gráficos foram normalizados no tempo como percentual do ciclo direito da marcha. 

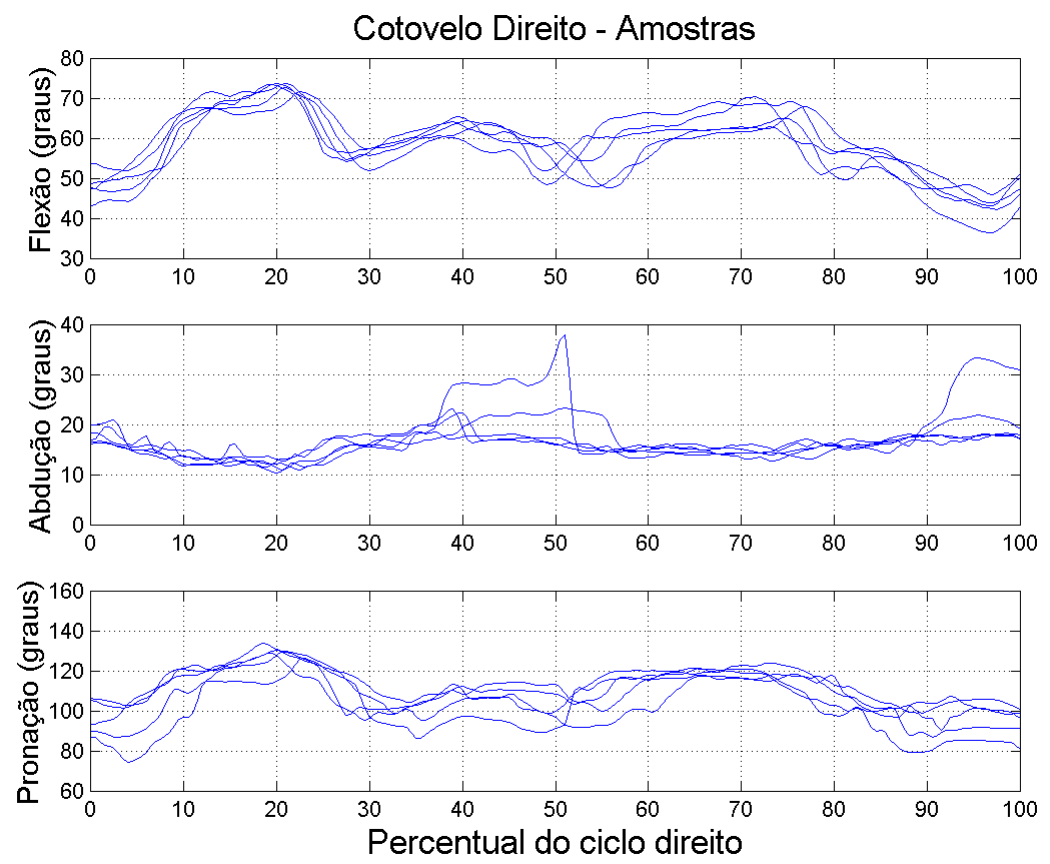

(a) Gráficos das variações angulares presentes nas cinco amostras.
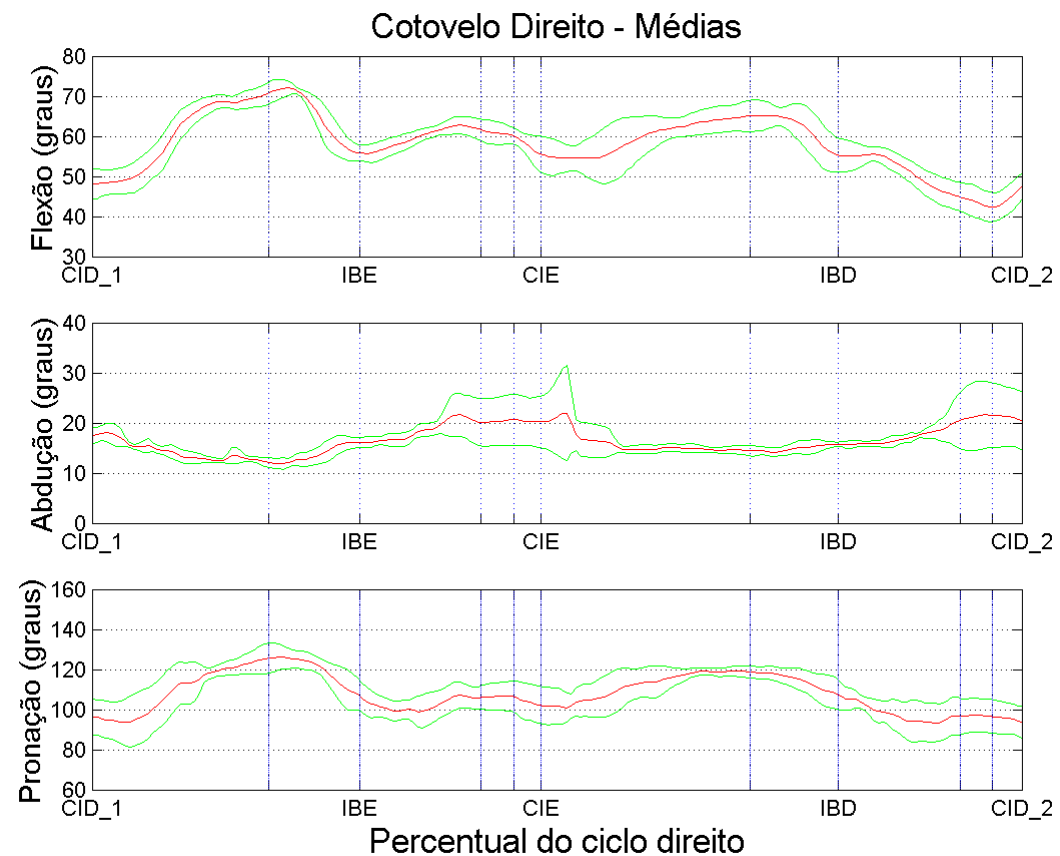

(b) Médias e desvios padrões dos dados apresentados em (a).

Figura B.12: Variações angulares no cotovelo direito. Os gráficos foram normalizados no tempo como percentual do ciclo direito da marcha. 

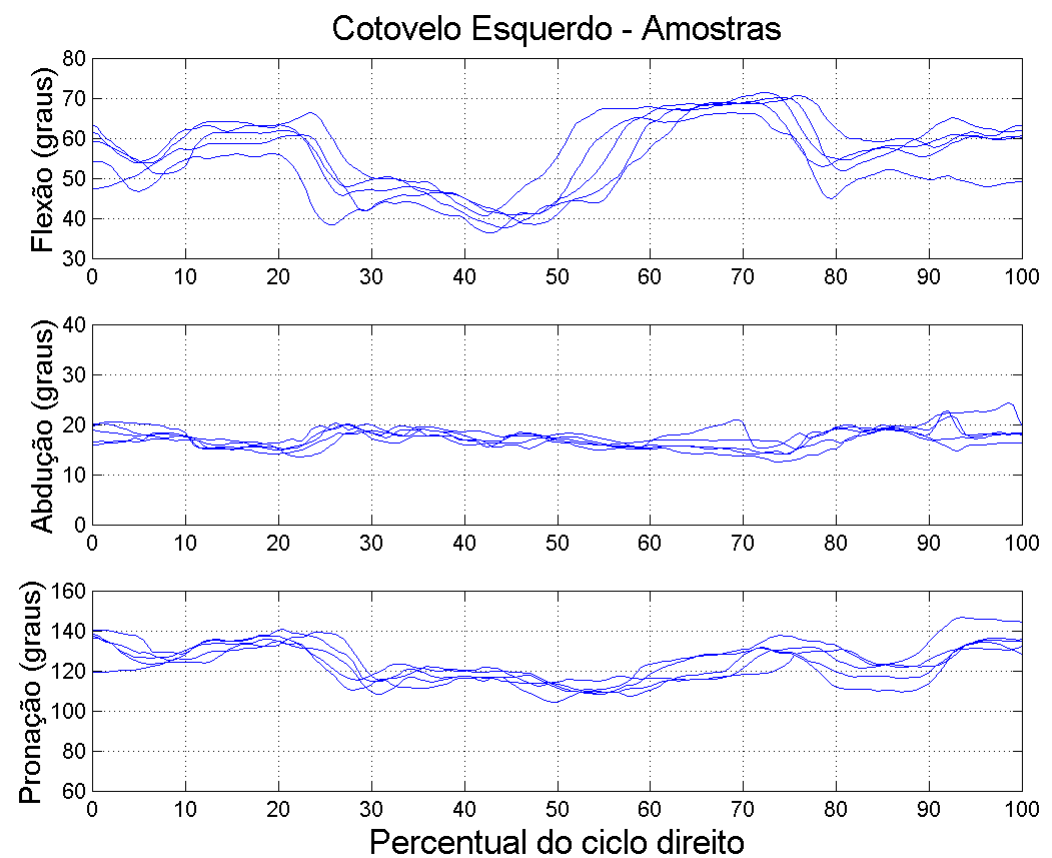

(a) Gráficos das variações angulares presentes nas cinco amostras.
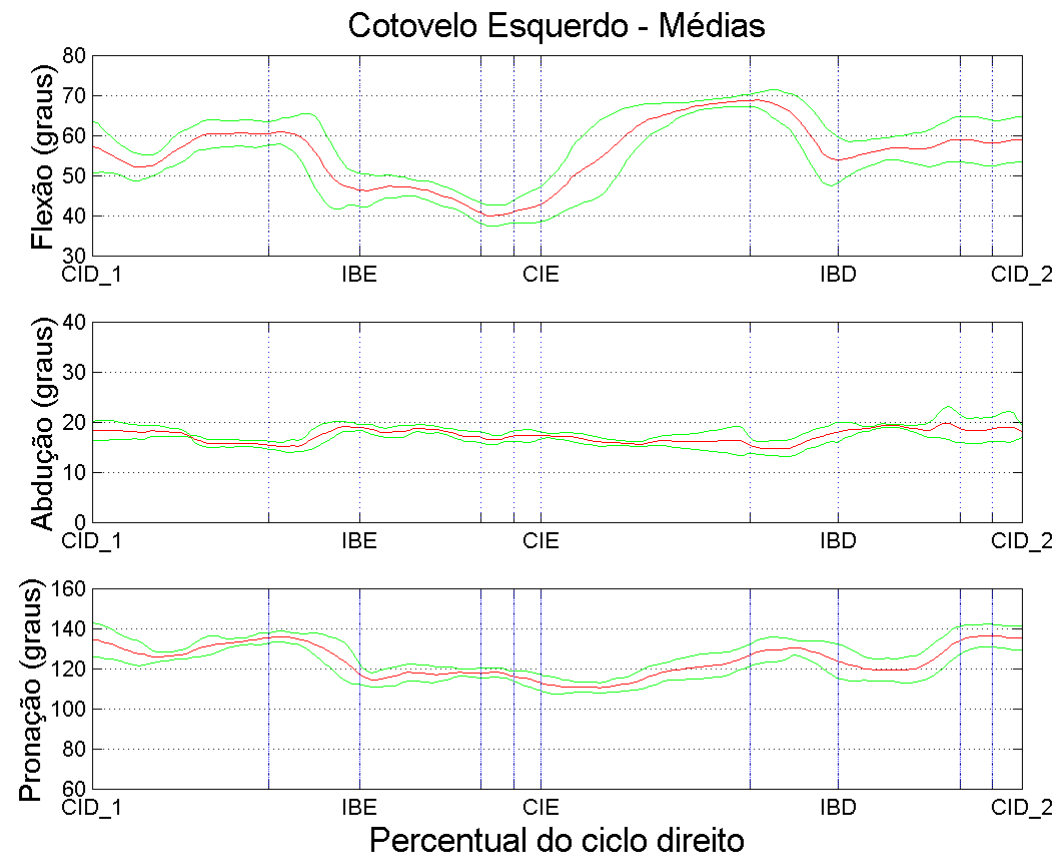

(b) Médias e desvios padrões dos dados apresentados em (a).

Figura B.13: Variações angulares no cotovelo esquerdo. Os gráficos foram normalizados no tempo como percentual do ciclo direito da marcha. 


\section{B.5 Eletromiografia}
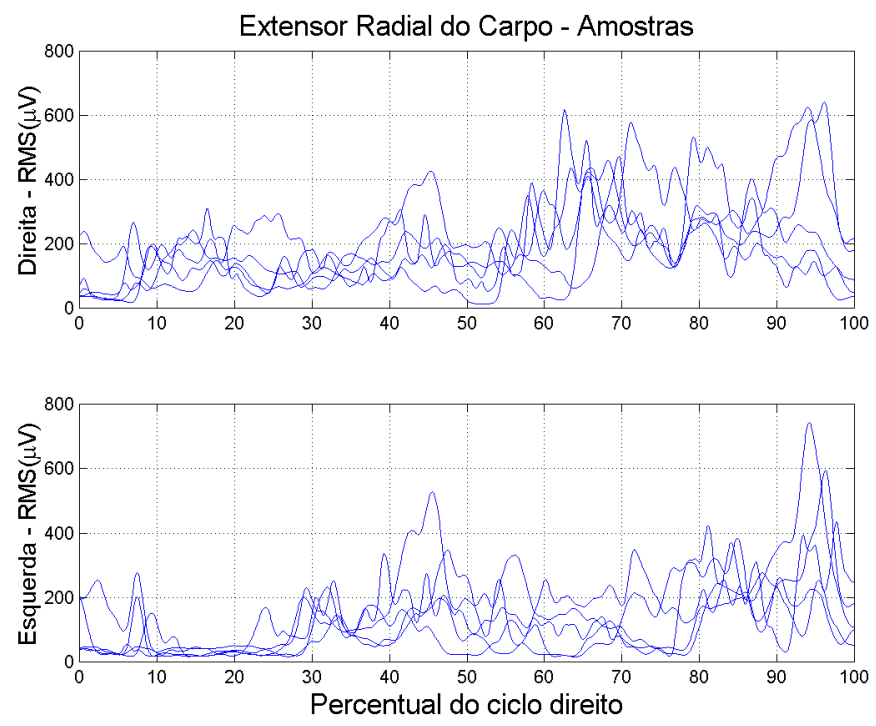

(a) Gráficos dos sinais presentes nas cinco amostras.
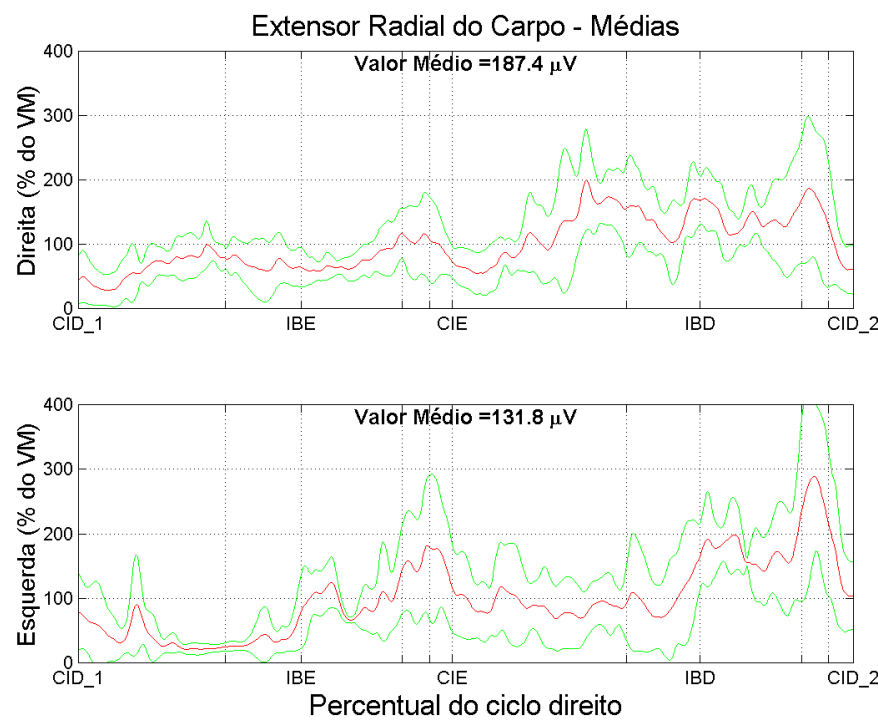

(b) Médias e desvios padrões dos dados apresentados em (a). Cada gráfico foi normalizado pelo valor médio ( $\boldsymbol{V} \boldsymbol{M})$ da média das cinco amostras.

Figura B.14: Eletromiografia do extensor radial do carpo (nos dois braços). Os gráficos foram normalizados no tempo como percentual do ciclo direito da marcha. 

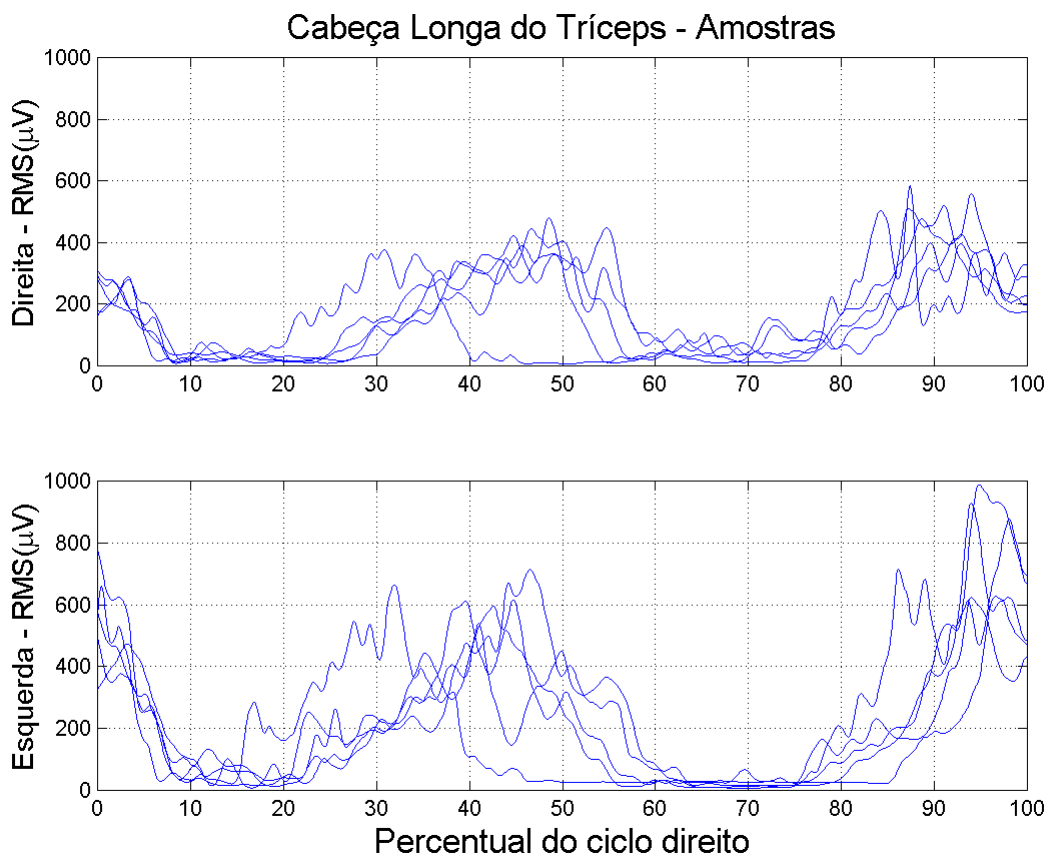

(a) Gráficos dos sinais presentes nas cinco amostras.
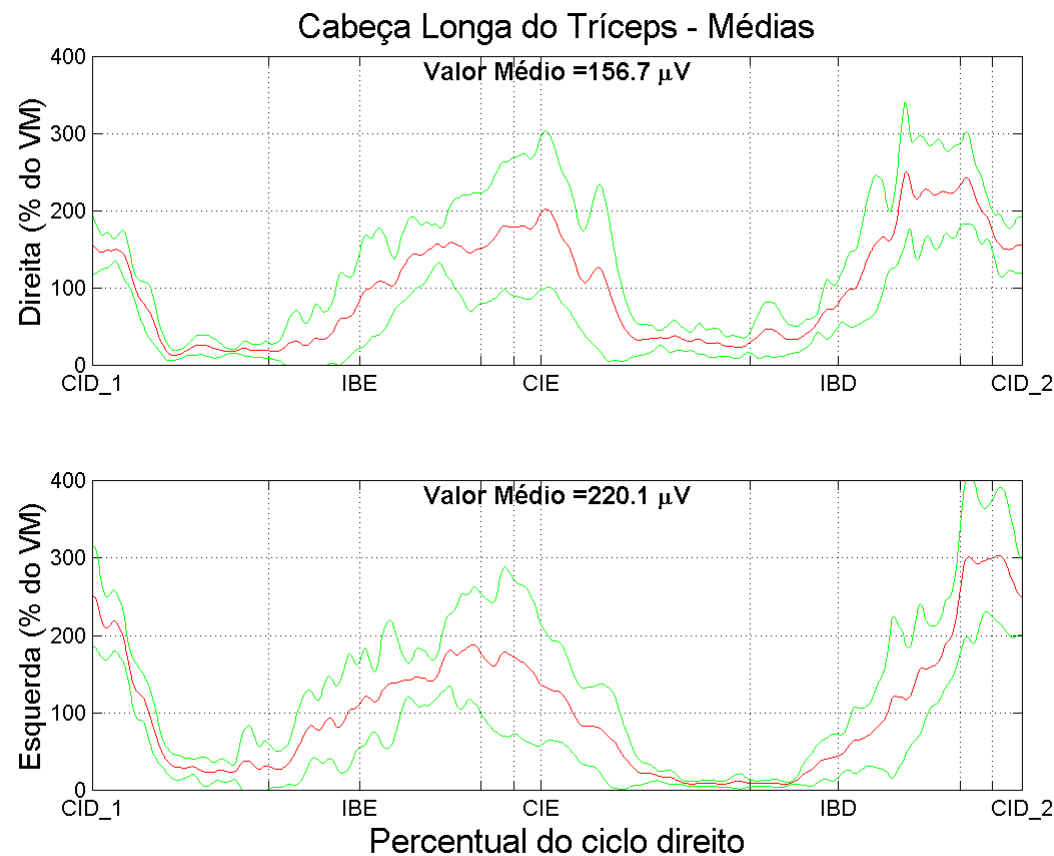

(b) Médias e desvios padrões dos dados apresentados em (a). Cada gráfico foi normalizado pelo valor médio ( $\boldsymbol{V M}$ ) da média das cinco amostras.

Figura B.15: Eletromiografia do cabeça longa do tríceps (nos dois braços). Os gráficos foram normalizados no tempo como percentual do ciclo direito da marcha. 

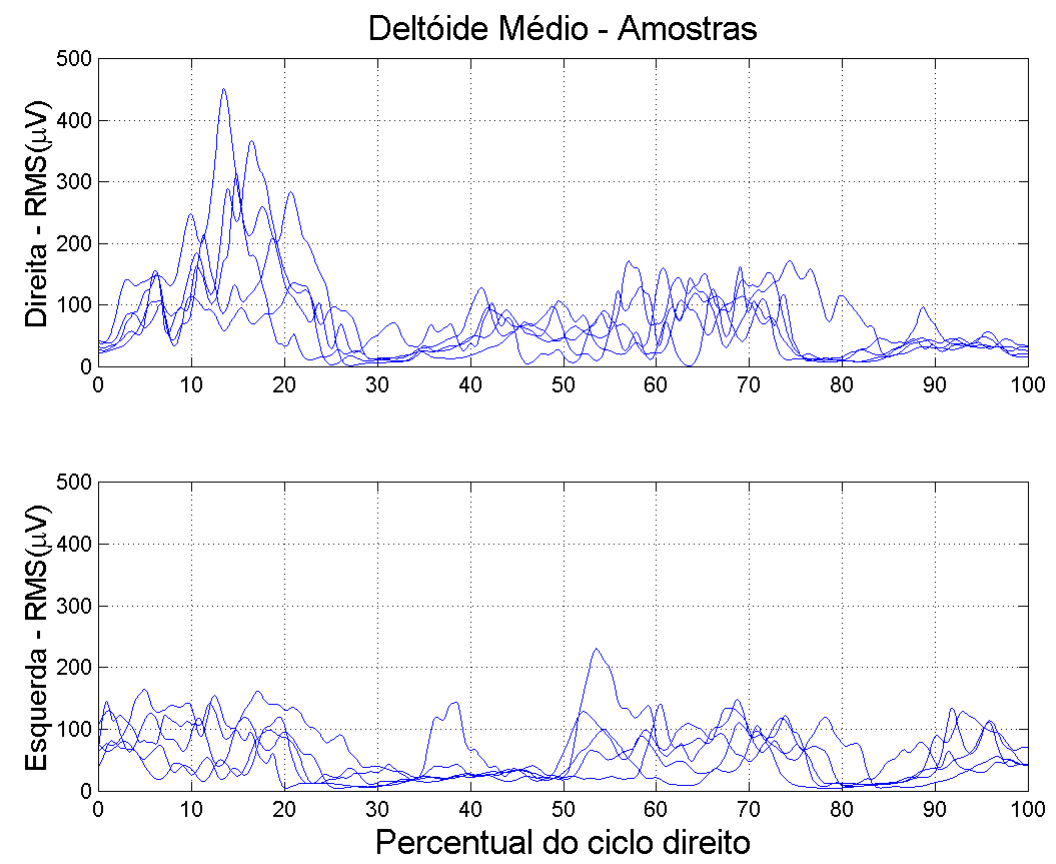

(a) Gráficos dos sinais presentes nas cinco amostras.
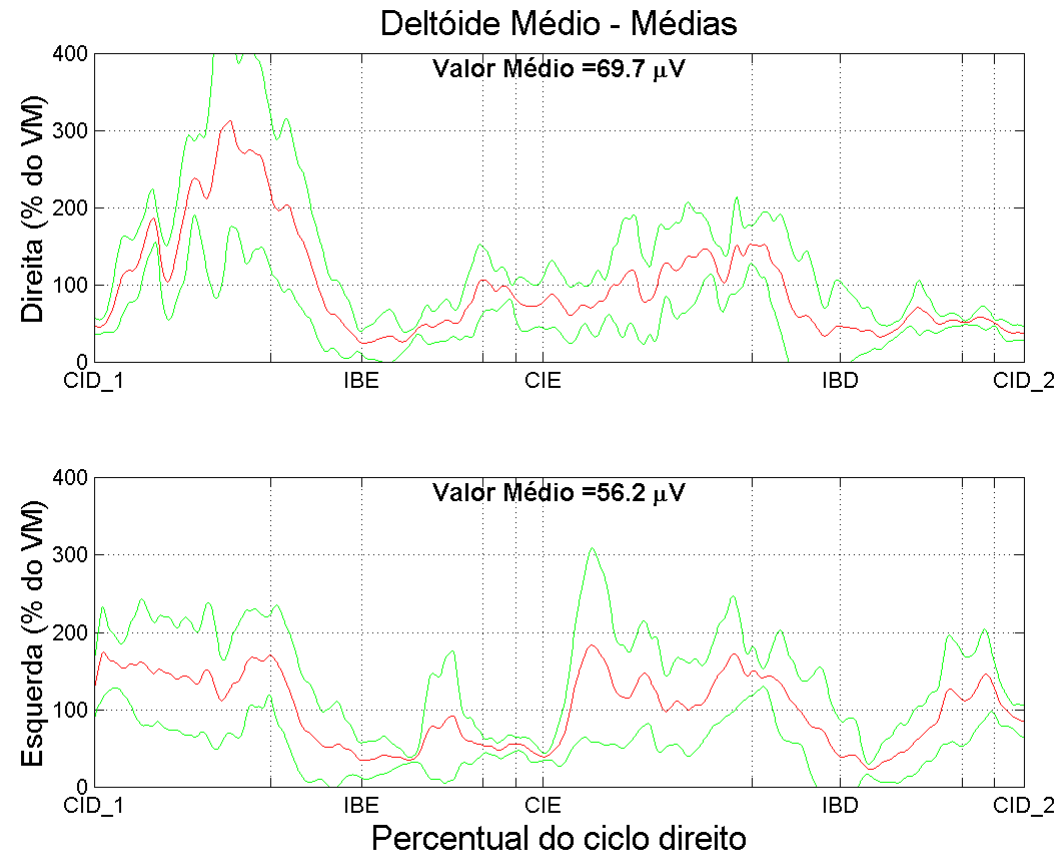

(b) Médias e desvios padrões dos dados apresentados em (a). Cada gráfico foi normalizado pelo valor médio ( $\boldsymbol{V} \boldsymbol{M})$ da média das cinco amostras.

Figura B.16: Eletromiografia do deltóide médio (nos dois braços). Os gráficos foram normalizados no tempo como percentual do ciclo direito da marcha. 

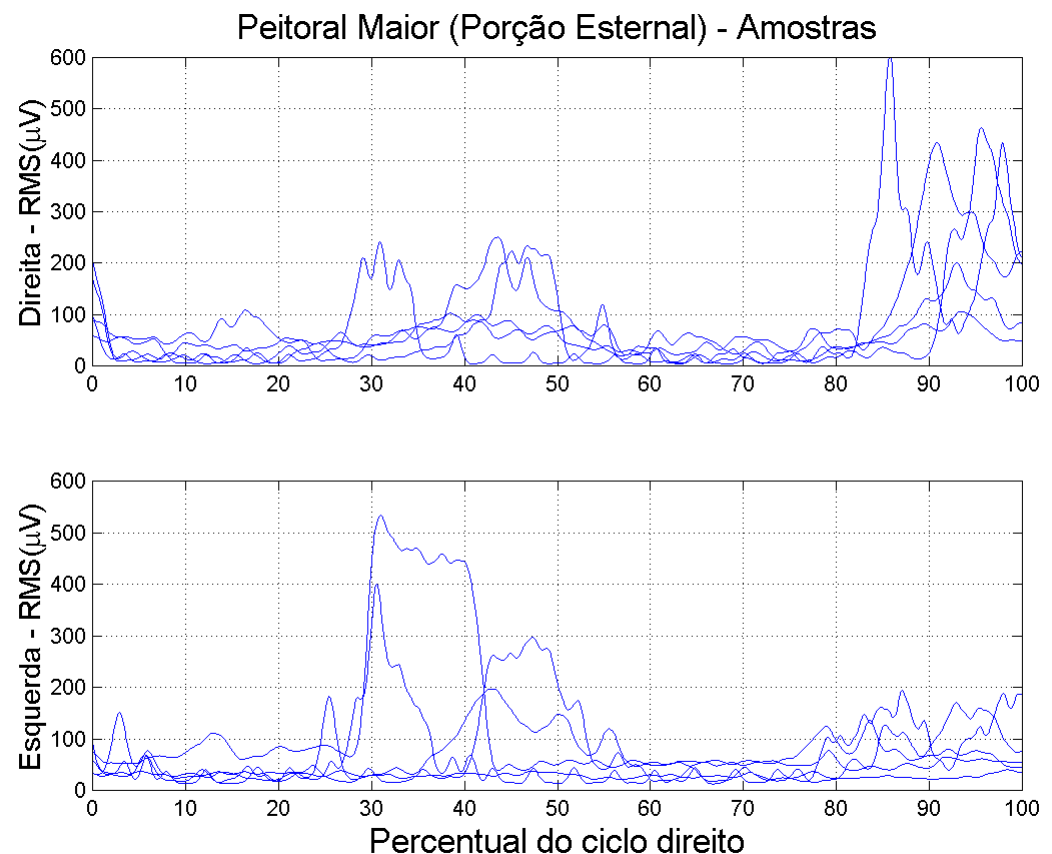

(a) Gráficos dos sinais presentes nas cinco amostras.
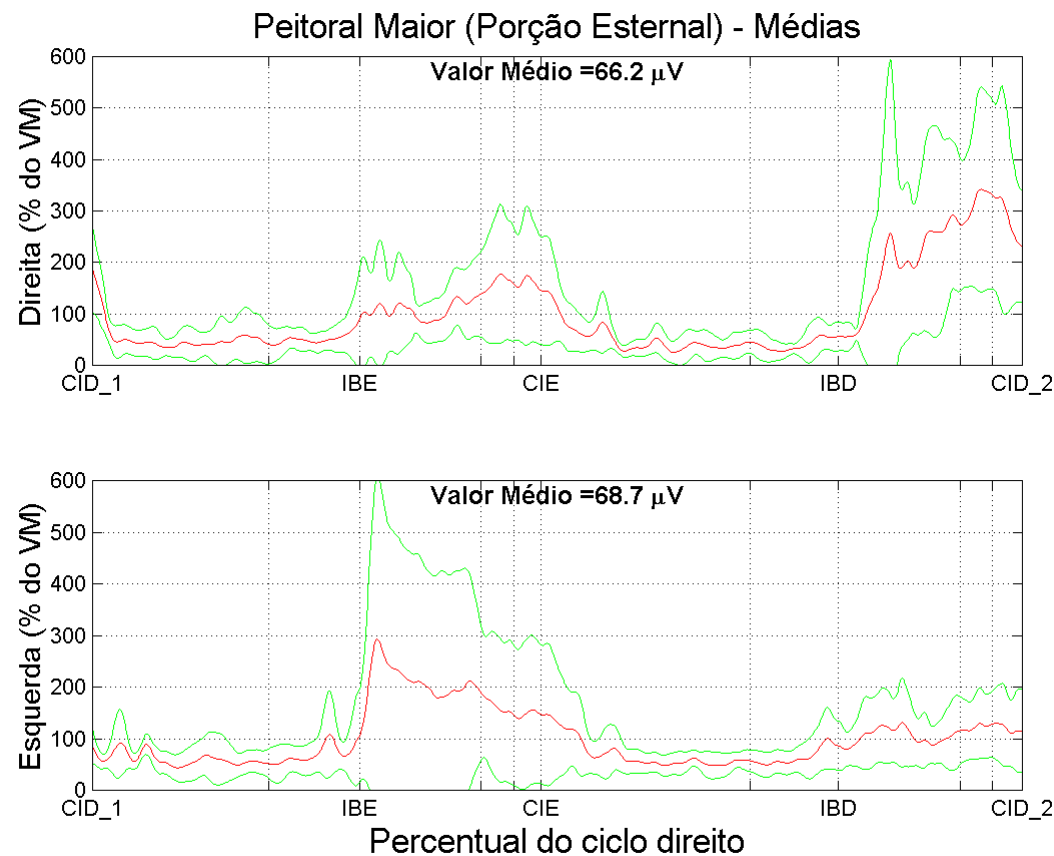

(b) Médias e desvios padrões dos dados apresentados em (a). Cada gráfico foi normalizado pelo valor médio ( $\boldsymbol{V M}$ ) da média das cinco amostras.

Figura B.17: Eletromiografia da porção esternal do peitoral maior. Os gráficos foram normalizados no tempo como percentual do ciclo direito da marcha. 


\section{B.6 Componente vertical da força de reação do solo}
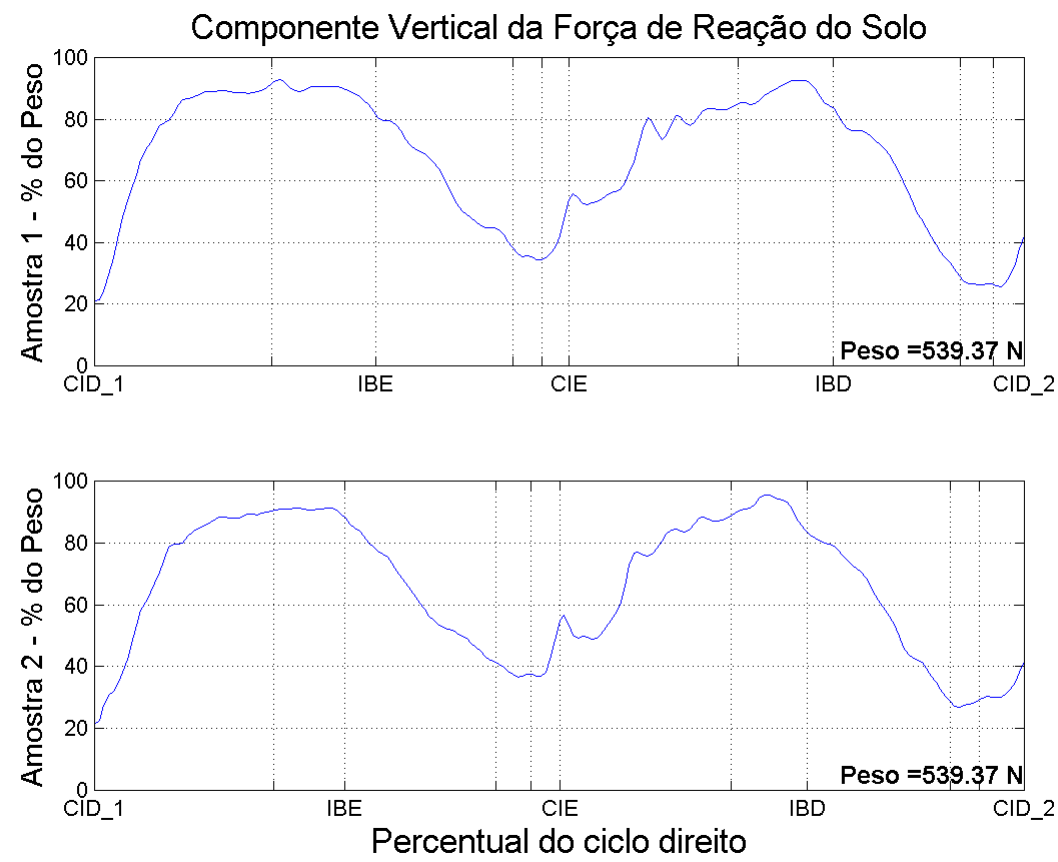

Figura B.18: Duas amostras da componente vertical da força de reação do solo conseqüente da ação dos pés do paciente sobre a plataforma de força durante a deambulação. Os gráficos foram normalizados no tempo como percentual do ciclo direito da marcha, e normalizados em amplitude como percentual do peso do paciente em Newtons.

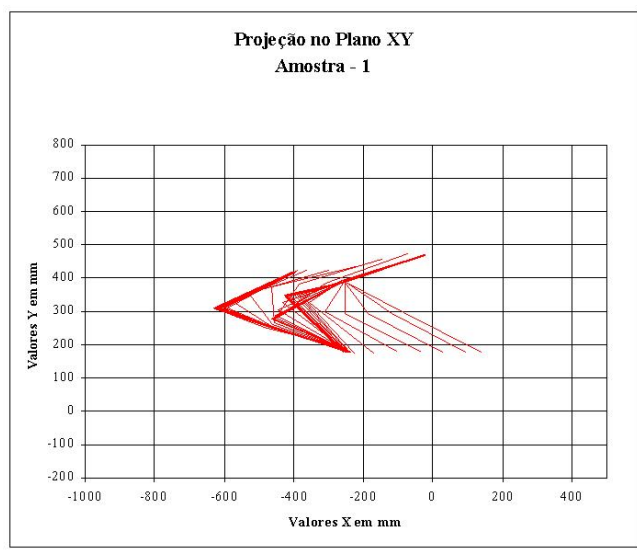

(a) Amostra 1

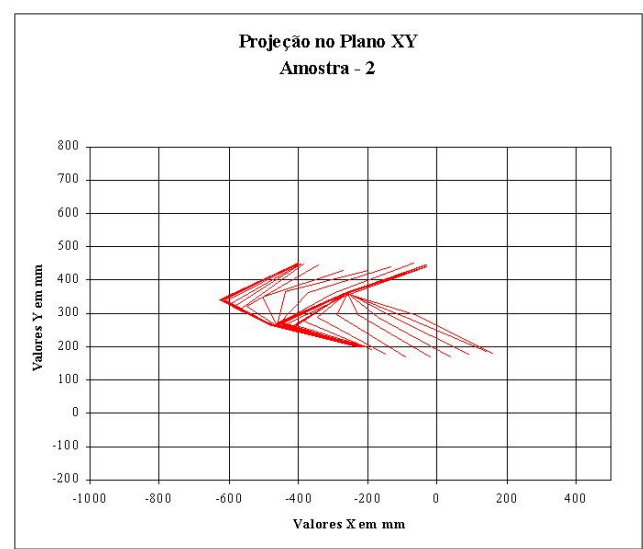

(b) Amostra 2

Figura B.19: Projeção do movimento dos pés do paciente sobre a plataforma de força no plano horizontal $(X Y)$. 


\section{Apêndice C}

\section{Paciente C}

Este apêndice apresentará os resultados do exame realizado no dia 22/05/2002. O conjunto de resultados é constituído por: as características da passada, variações angulares tridimensionais nos membros inferiores (pélvis, quadris, joelhos e tornozelos) e superiores (ombros, cotovelos, e tronco), eletromiografia de músculos dos membros superiores (peitoral maior, deltóide médio, cabeça longa do tríceps, extensor radial do carpo) e componente vertical da força de reação do solo.

\section{C.1 Características do paciente}

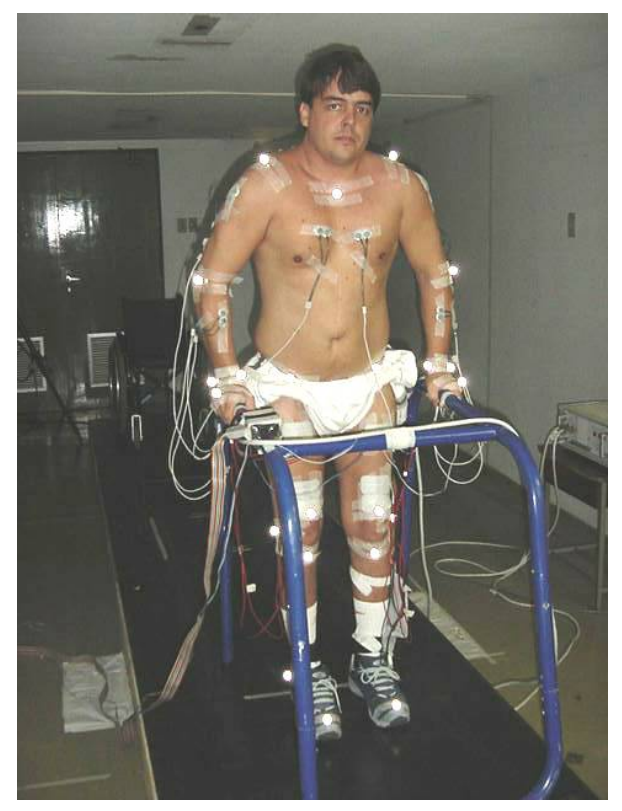

Figura C.1: Paciente C - Foto tirada durante um dos ensaios. O arquivo no formato PDF possui direcionamento para vídeo ao clicar na foto, desde que o QuickTime esteja instalado. Para abrir o vídeo fora do arquivo PDF, usando outro programa, clique aqui. 


\begin{tabular}{ccccccc}
\hline Nome & Idade & Nível da lesão & Causa & $\begin{array}{c}\text { Tempo da lesão } \\
(\text { anos })\end{array}$ & $\begin{array}{c}\text { Peso } \\
(\mathrm{Kg})\end{array}$ & $\begin{array}{c}\text { Altura } \\
(\mathrm{m})\end{array}$ \\
\hline \hline $\mathrm{C}$ & 33 & $\mathrm{~T} 11$ & Acidente autom & 14 & 83 & 1,76 \\
\hline \hline
\end{tabular}

Tabela C.1: Dados dos pacientes

\section{C.2 Características da passada}

\begin{tabular}{ccccccc}
\hline Amostras & $\begin{array}{c}\text { Cadência } \\
(\text { passos/min })\end{array}$ & $\begin{array}{c}\text { Velocidade } \\
(\mathrm{cm} / \mathrm{s})\end{array}$ & $\begin{array}{c}\text { Passada } \\
(\mathrm{m})\end{array}$ & $\begin{array}{c}\text { Tempo do ciclo } \\
(\mathrm{s})\end{array}$ & $\begin{array}{c}\text { Apoio direito } \\
(\%)\end{array}$ & $\begin{array}{c}\text { Apoio esquerdo } \\
(\%)\end{array}$ \\
\hline \hline 3 & 17,00 & 8,50 & 0,60 & 7,20 & 79,90 & 87,40 \\
5 & 20,00 & 8,33 & 0,50 & 6,20 & 88,90 & 81,20 \\
6 & 27,00 & 9,00 & 0,40 & 4,40 & 80,90 & 82,20 \\
7 & 23,00 & 7,67 & 0,40 & 5,20 & 84,90 & 87,50 \\
2 & 19,00 & 9,50 & 0,60 & 6,40 & 84,40 & 88,10 \\
& & & & & & \\
Média & 21,20 & 8,60 & 0,50 & 5,88 & 83,80 & 85,28 \\
Desvio & 3,90 & 0,69 & 0,10 & 1,09 & 3,58 & 3,30 \\
\hline \hline
\end{tabular}

Tabela C.2: Parâmetros temporais

\begin{tabular}{cccccccccccc}
\hline Amostras & $\begin{array}{c}C I D_{1} \\
(\%)\end{array}$ & $\begin{array}{c}I A A_{1} \\
(\%)\end{array}$ & $\begin{array}{c}I B E \\
(\%)\end{array}$ & $\begin{array}{c}D P E \\
(\%)\end{array}$ & $\begin{array}{c}M B E \\
(\%)\end{array}$ & $\begin{array}{c}C I E \\
(\%)\end{array}$ & $\begin{array}{c}I A A_{2} \\
(\%)\end{array}$ & $\begin{array}{c}I B D \\
(\%)\end{array}$ & $\begin{array}{c}\text { DPD } \\
(\%)\end{array}$ & $\begin{array}{c}M B D \\
(\%)\end{array}$ & $\begin{array}{c}C I D_{2} \\
(\%)\end{array}$ \\
\hline \hline 3 & 0.0 & 6.0 & 46.9 & 50.6 & 55.7 & 59.1 & 66.1 & 72.7 & 79.9 & 84.3 & 100.0 \\
5 & 0.0 & 8.4 & 17.1 & 32.0 & 38.8 & 49.1 & 68.8 & 77.5 & 88.9 & 88.9 & 100.0 \\
6 & 0.0 & 9.5 & 19.8 & 32.4 & 41.2 & 51.1 & 61.1 & 74.8 & 80.9 & 87.0 & 100.0 \\
7 & 0.0 & 12.5 & 24.4 & 33.0 & 41.7 & 47.8 & 60.3 & 73.1 & 84.9 & 88.8 & 100.0 \\
2 & 0.0 & 7.3 & 31.8 & 38.3 & 44.0 & 50.0 & 57.8 & 77.3 & 84.4 & 87.5 & 100.0 \\
& & & & & & & & & & & \\
Média & 0.0 & 8.7 & 28.0 & 37.3 & 44.3 & 51.4 & 62.8 & 75.1 & 83.8 & 87.3 & 100.0 \\
Desvio & 0.0 & 2.5 & 11.9 & 7.9 & 6.6 & 4.5 & 4.5 & 2.3 & 3.6 & 1.9 & 0.0 \\
\hline \hline
\end{tabular}

Tabela C.3: Percentuais das fases do ciclo de acordo com o descrito na sec. 4.1 


\section{C.3 Variações angulares: tronco e membros inferiores}
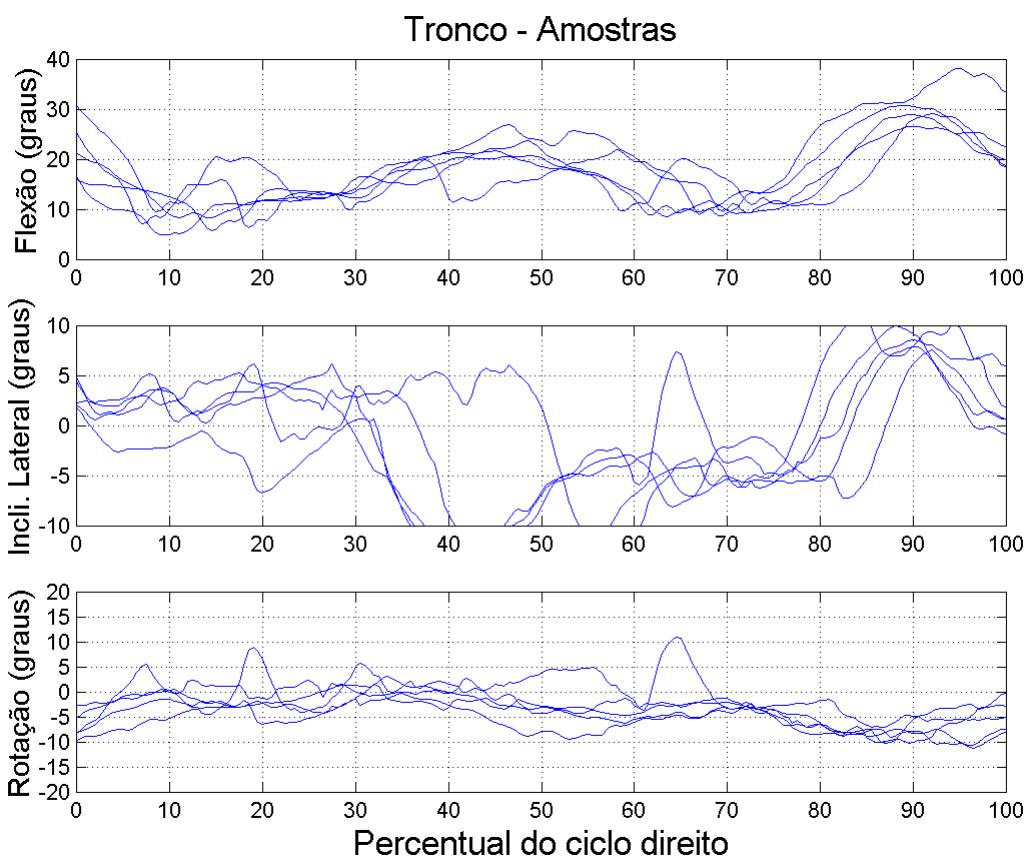

(a) Gráficos das variações angulares presentes nas cinco amostras.
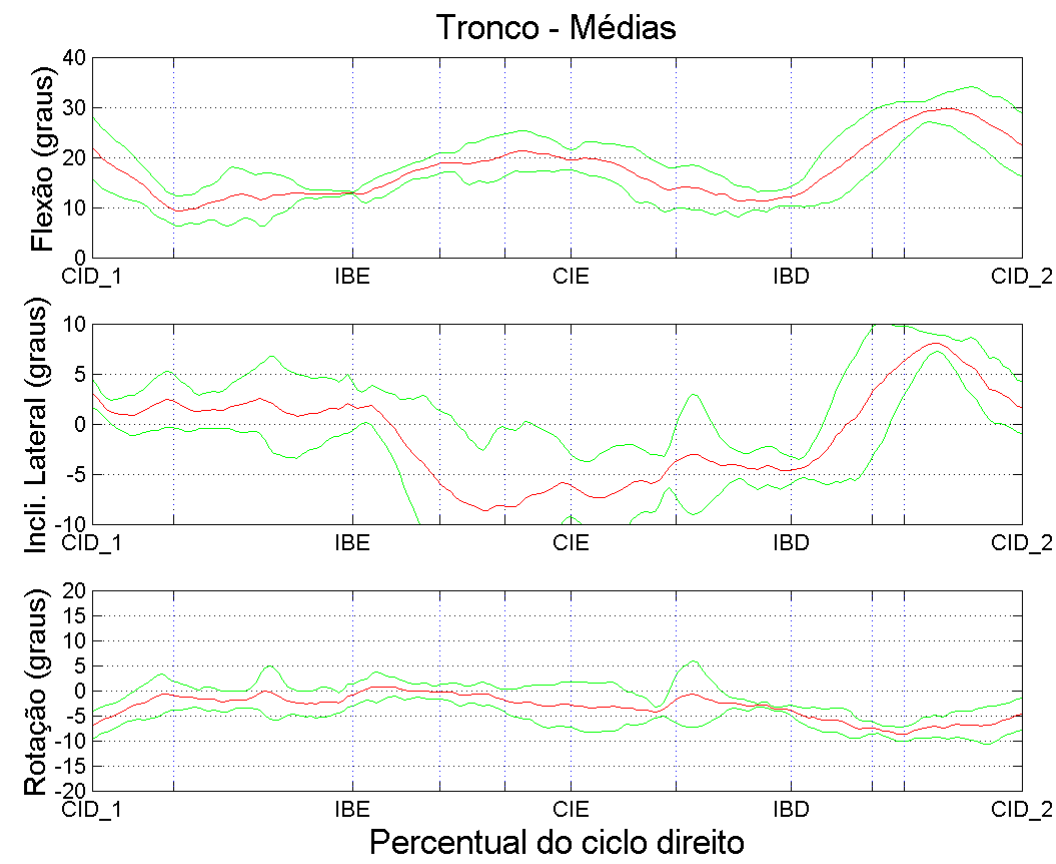

(b) Médias e desvios padrões dos dados apresentados em (a).

Figura C.2: Variações angulares no tronco. Os gráficos foram normalizados no tempo como percentual do ciclo direito da marcha. 

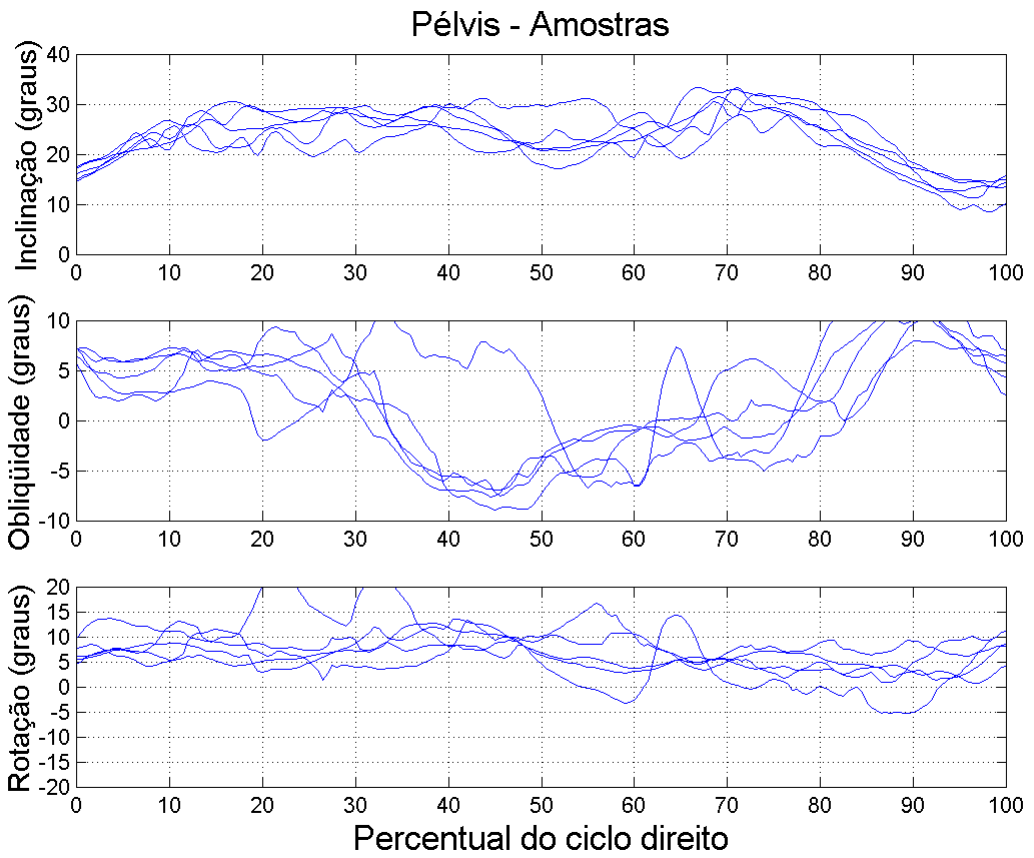

(a) Gráficos das variações angulares presentes nas cinco amostras.
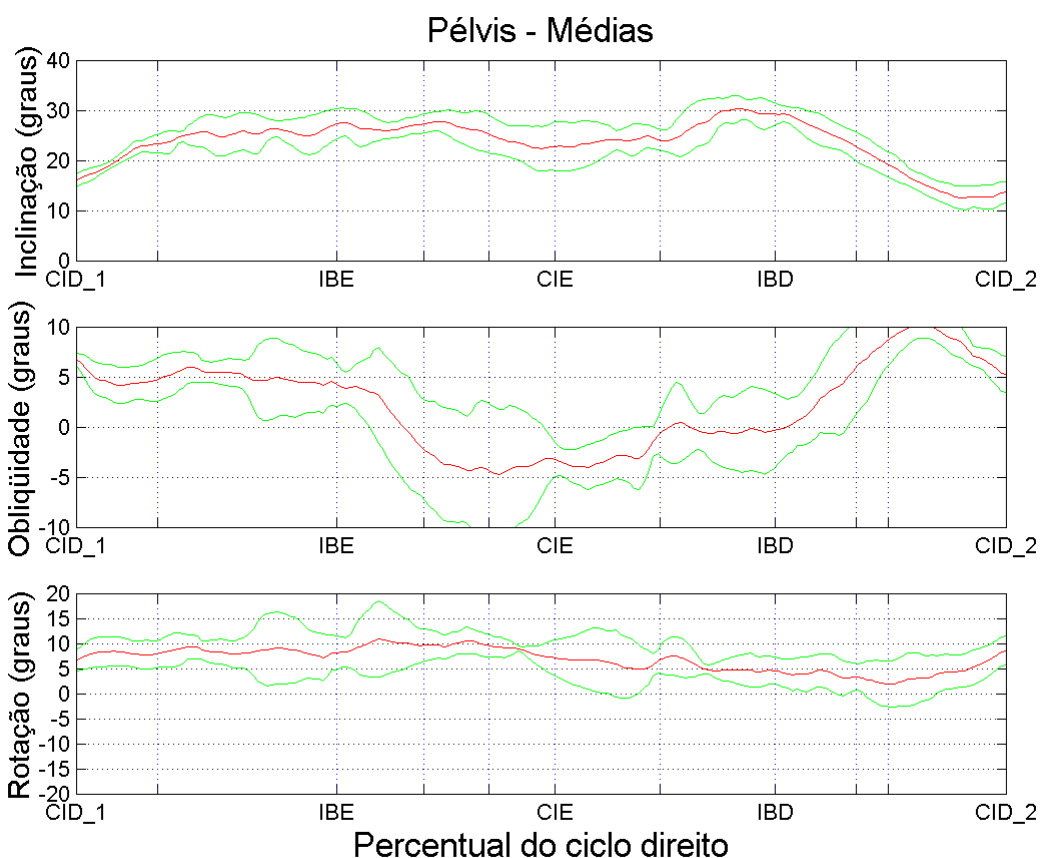

(b) Médias e desvios padrões dos dados apresentados em (a).

Figura C.3: Variações angulares no pélvis. Os gráficos foram normalizados no tempo como percentual do ciclo direito da marcha. 

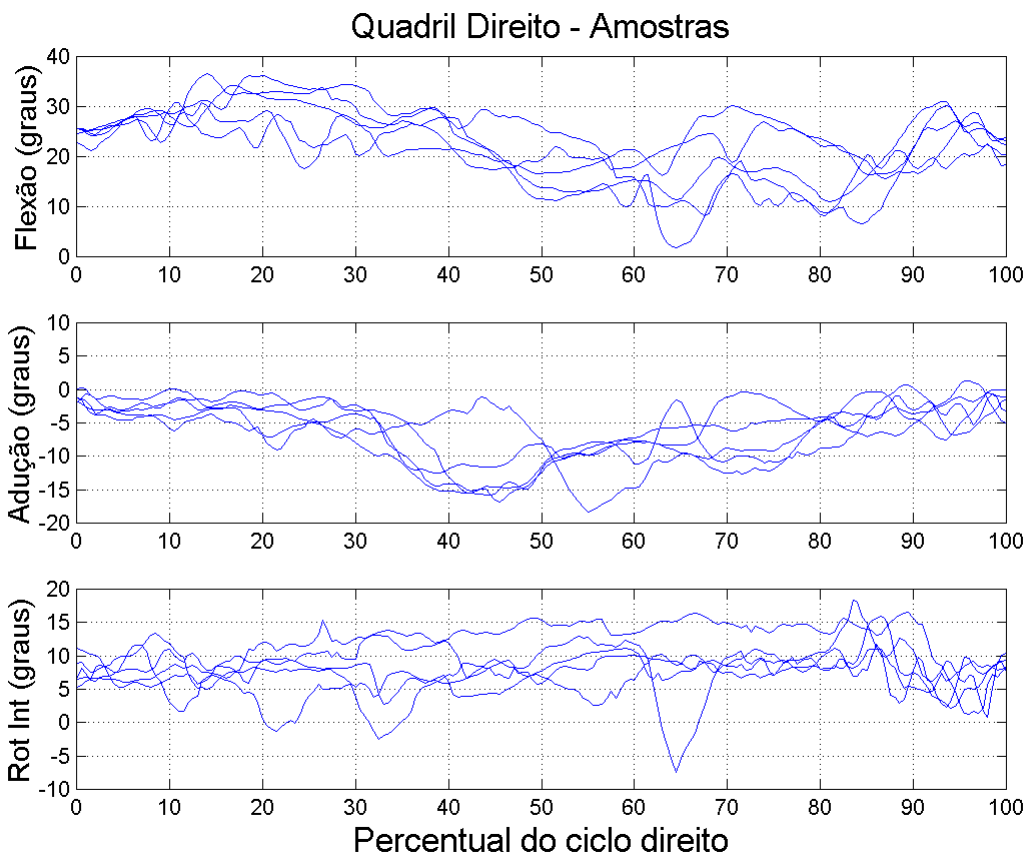

(a) Gráficos das variações angulares presentes nas cinco amostras.
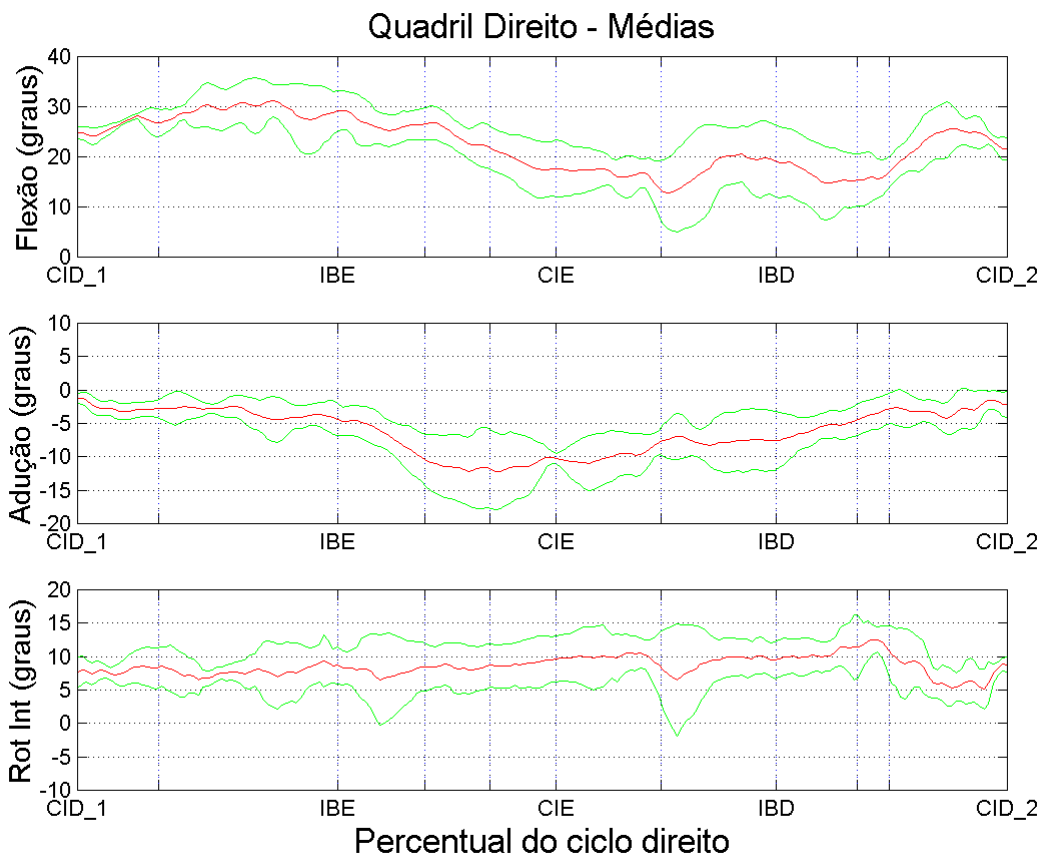

(b) Médias e desvios padrões dos dados apresentados em (a).

Figura C.4: Variações angulares no quadril direito. Os gráficos foram normalizados no tempo como percentual do ciclo direito da marcha. 

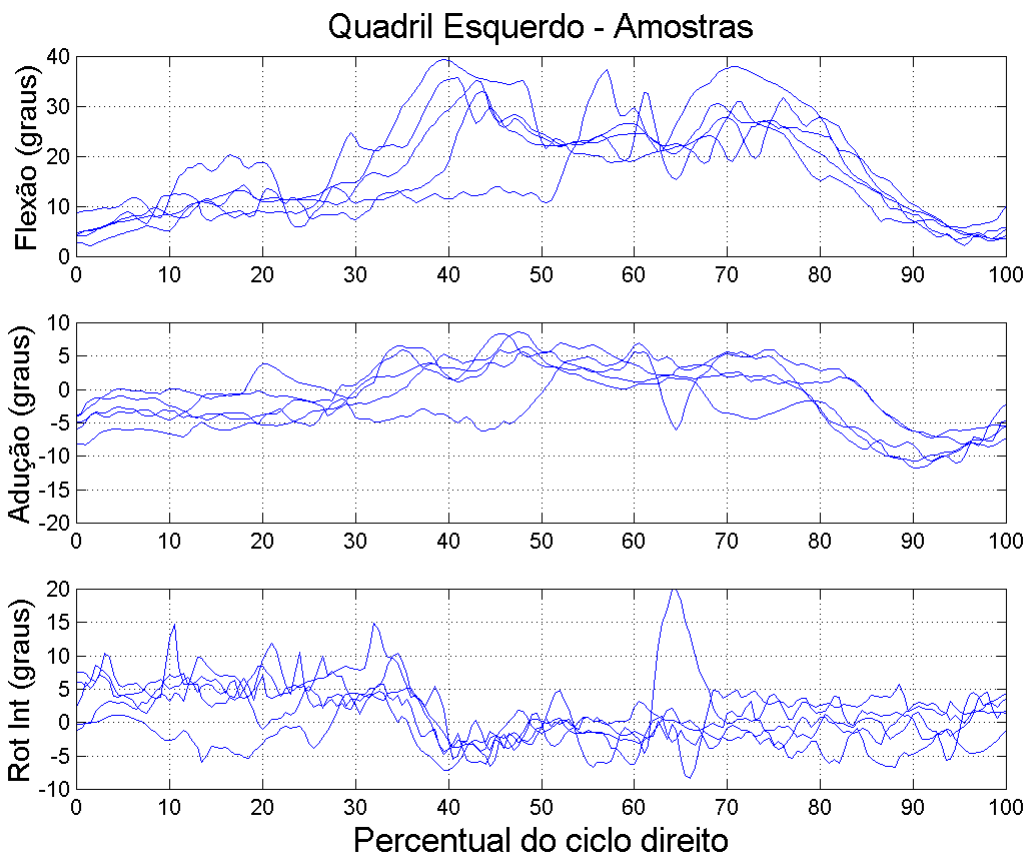

(a) Gráficos das variações angulares presentes nas cinco amostras.
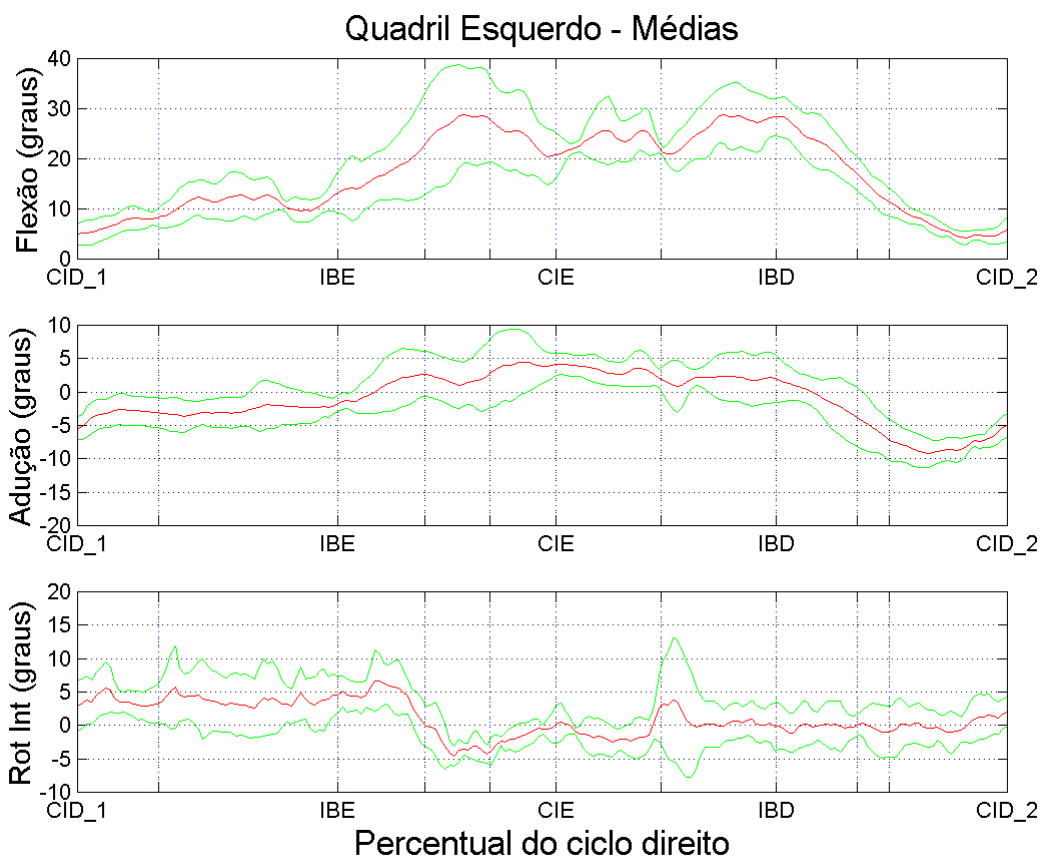

(b) Médias e desvios padrões dos dados apresentados em (a).

Figura C.5: Variações angulares no quadril esquerdo. Os gráficos foram normalizados no tempo como percentual do ciclo direito da marcha. 

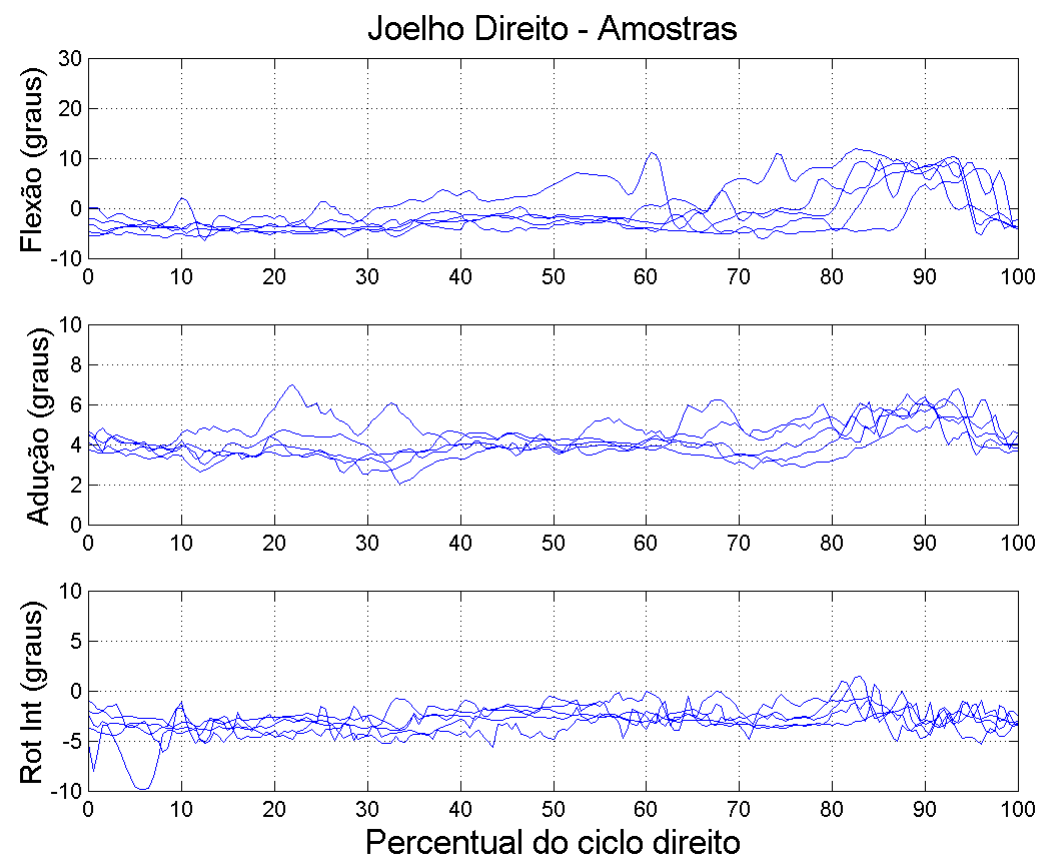

(a) Gráficos das variações angulares presentes nas cinco amostras.
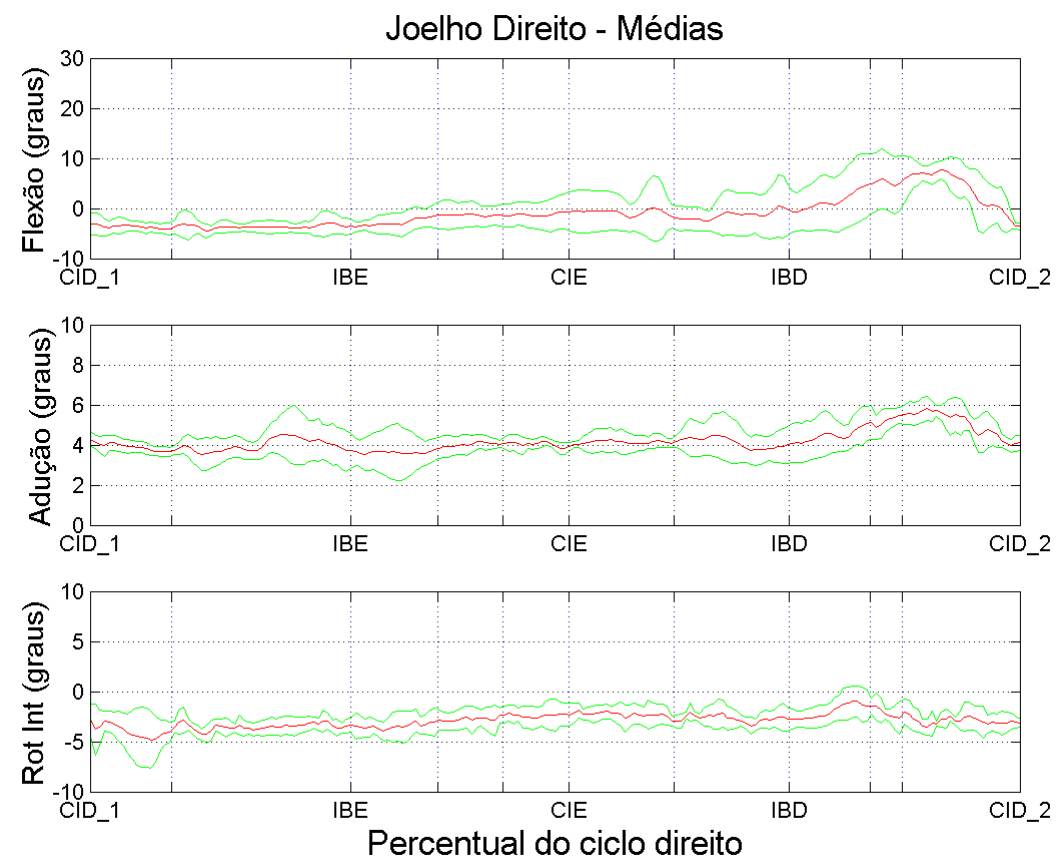

(b) Médias e desvios padrões dos dados apresentados em (a).

Figura C.6: Variações angulares no joelho direito. Os gráficos foram normalizados no tempo como percentual do ciclo direito da marcha. 

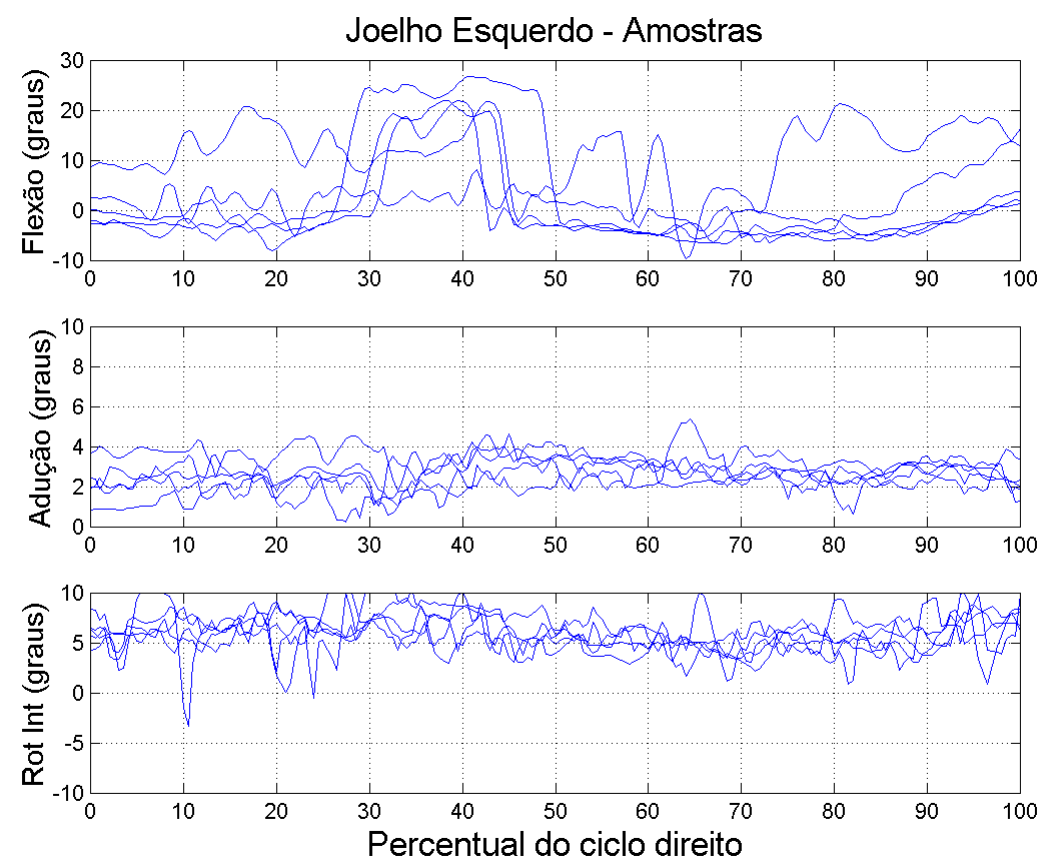

(a) Gráficos das variações angulares presentes nas cinco amostras.
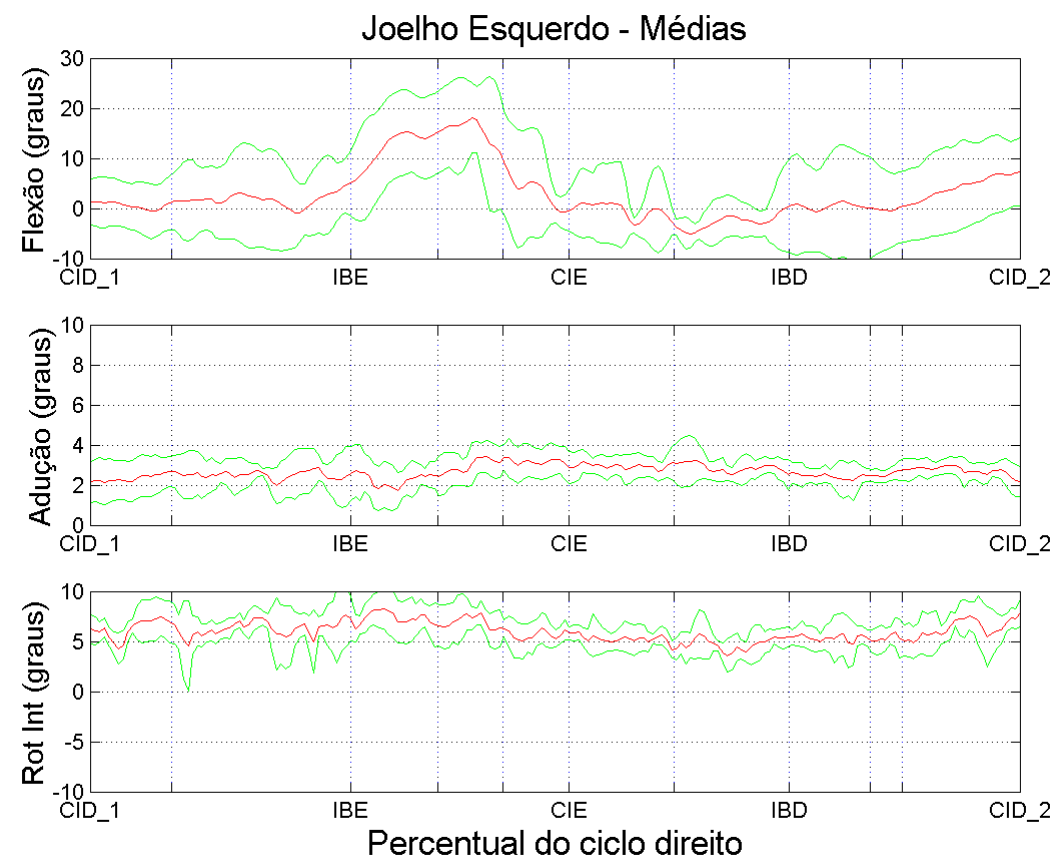

(b) Médias e desvios padrões dos dados apresentados em (a).

Figura C.7: Variações angulares no joelho esquerdo. Os gráficos foram normalizados no tempo como percentual do ciclo direito da marcha. 

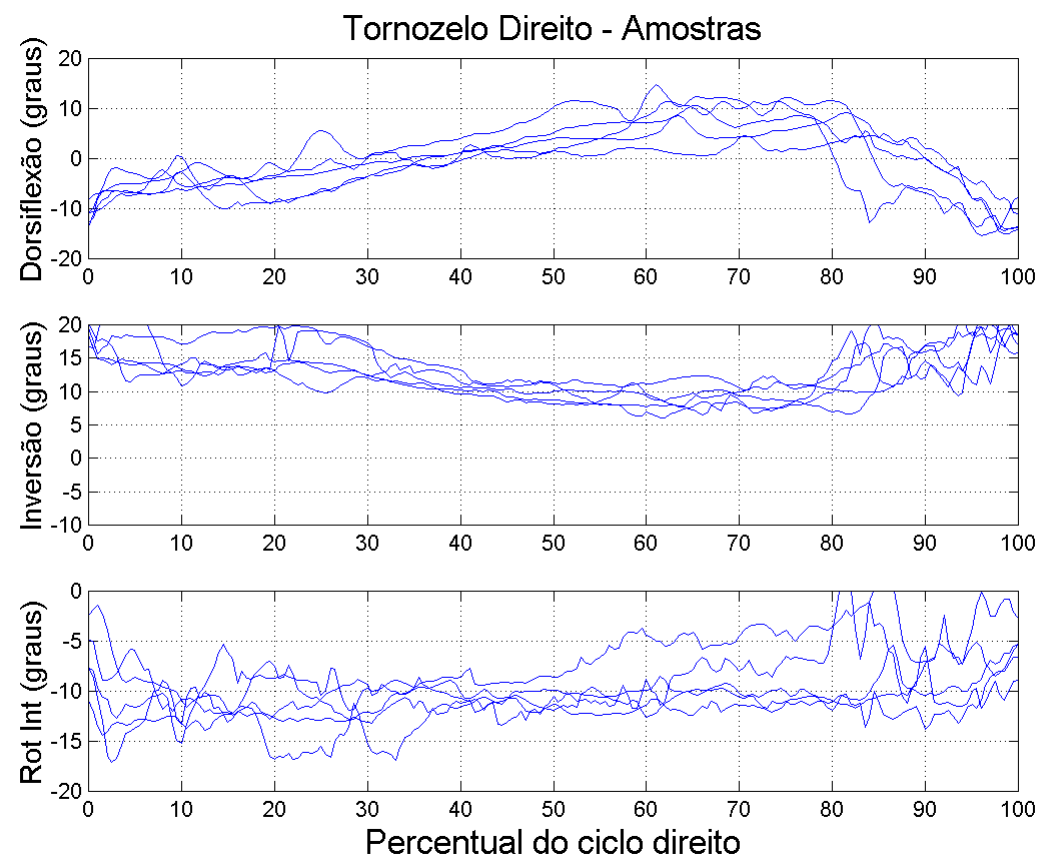

(a) Gráficos das variações angulares presentes nas cinco amostras.
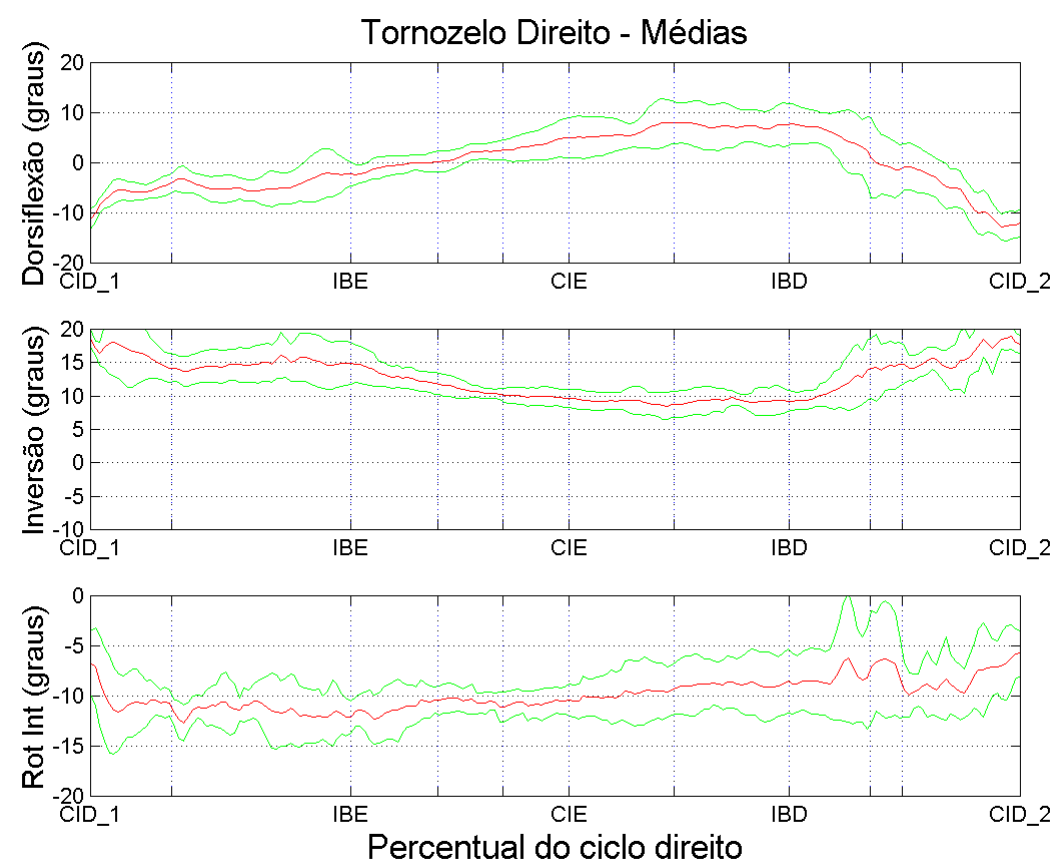

(b) Médias e desvios padrões dos dados apresentados em (a).

Figura C.8: Variações angulares no tornozelo direito. Os gráficos foram normalizados no tempo como percentual do ciclo direito da marcha. 

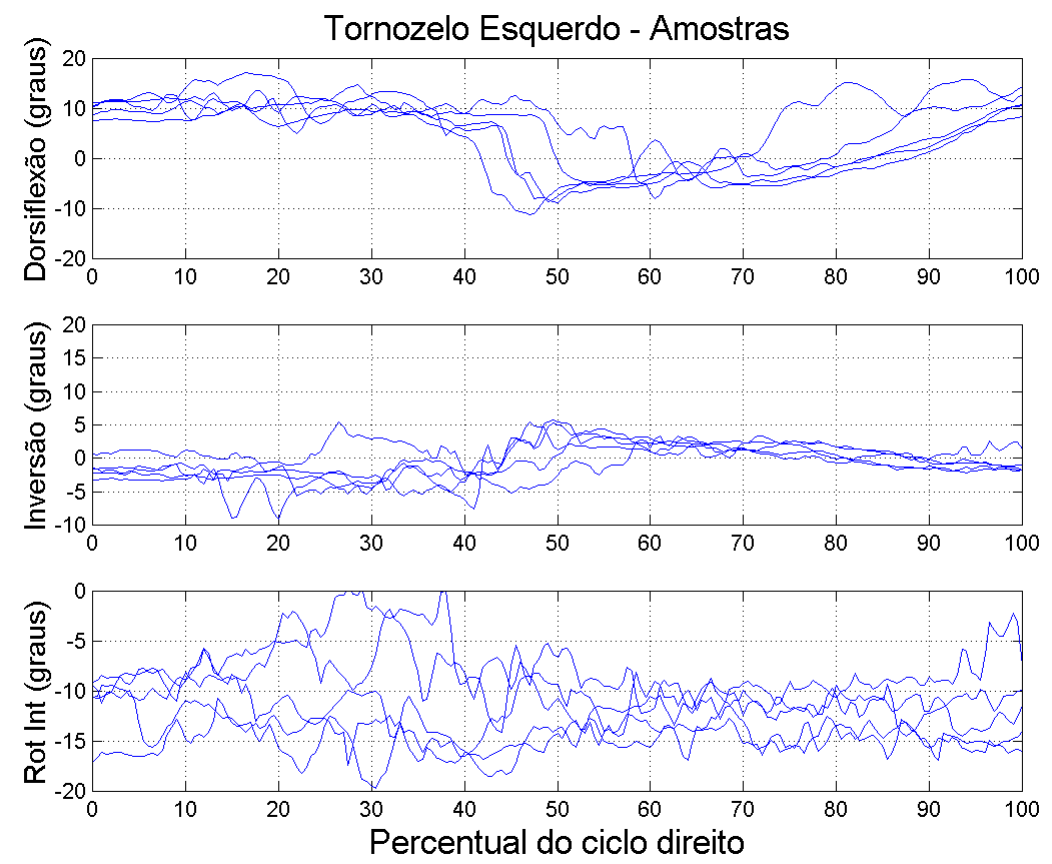

(a) Gráficos das variações angulares presentes nas cinco amostras.
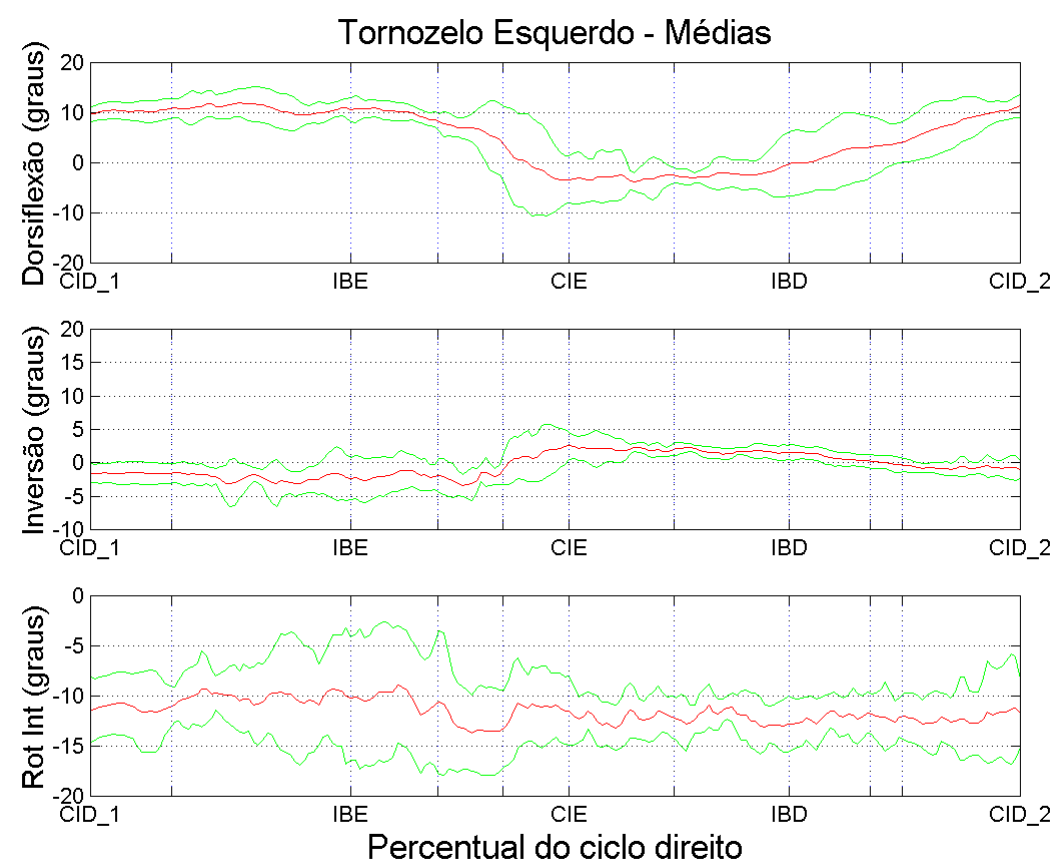

(b) Médias e desvios padrões dos dados apresentados em (a).

Figura C.9: Variações angulares no tornozelo esquerdo. Os gráficos foram normalizados no tempo como percentual do ciclo direito da marcha. 


\section{C.4 Variações angulares: ombros e cotovelos}
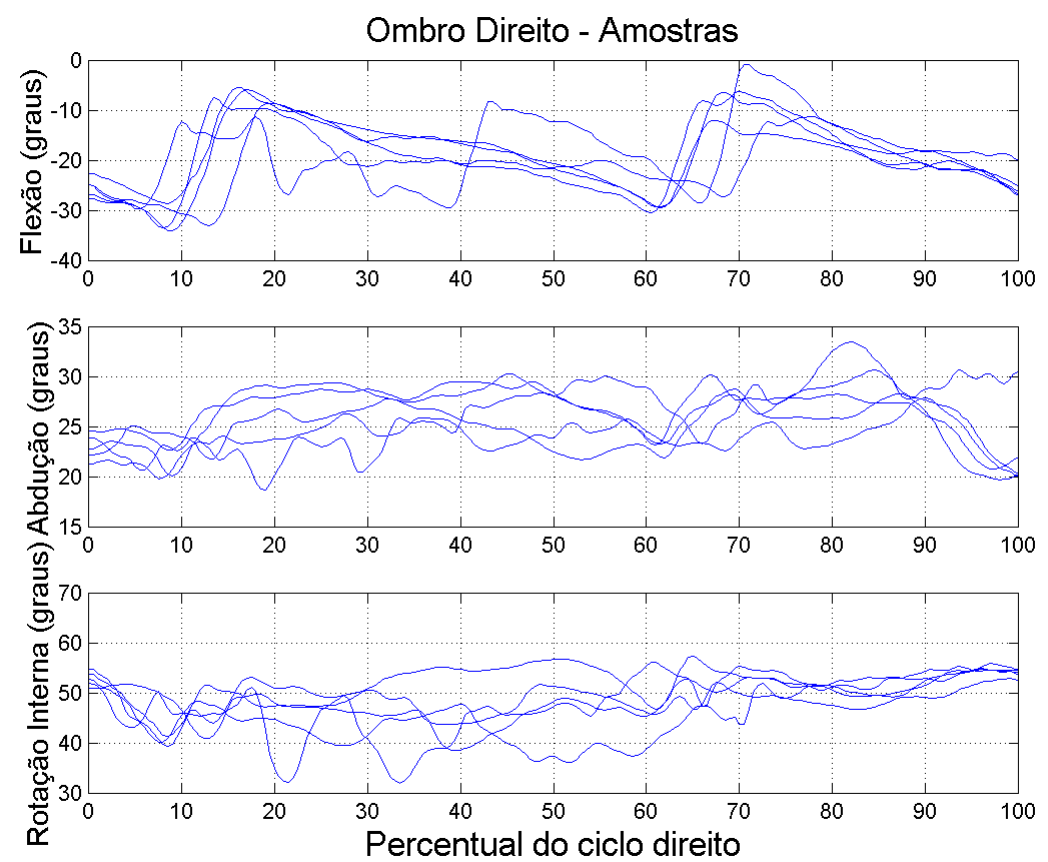

(a) Gráficos das variações angulares presentes nas cinco amostras.
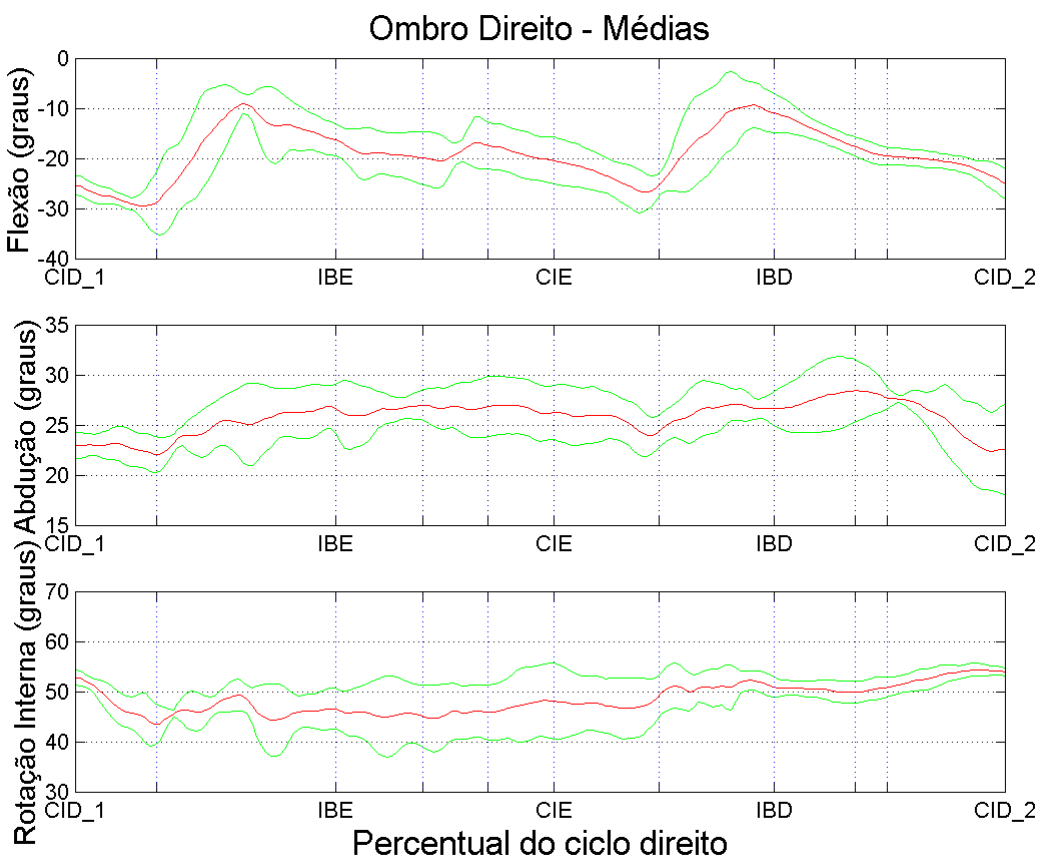

(b) Médias e desvios padrões dos dados apresentados em (a).

Figura C.10: Variações angulares no ombro direito. Os gráficos foram normalizados no tempo como percentual do ciclo direito da marcha. 

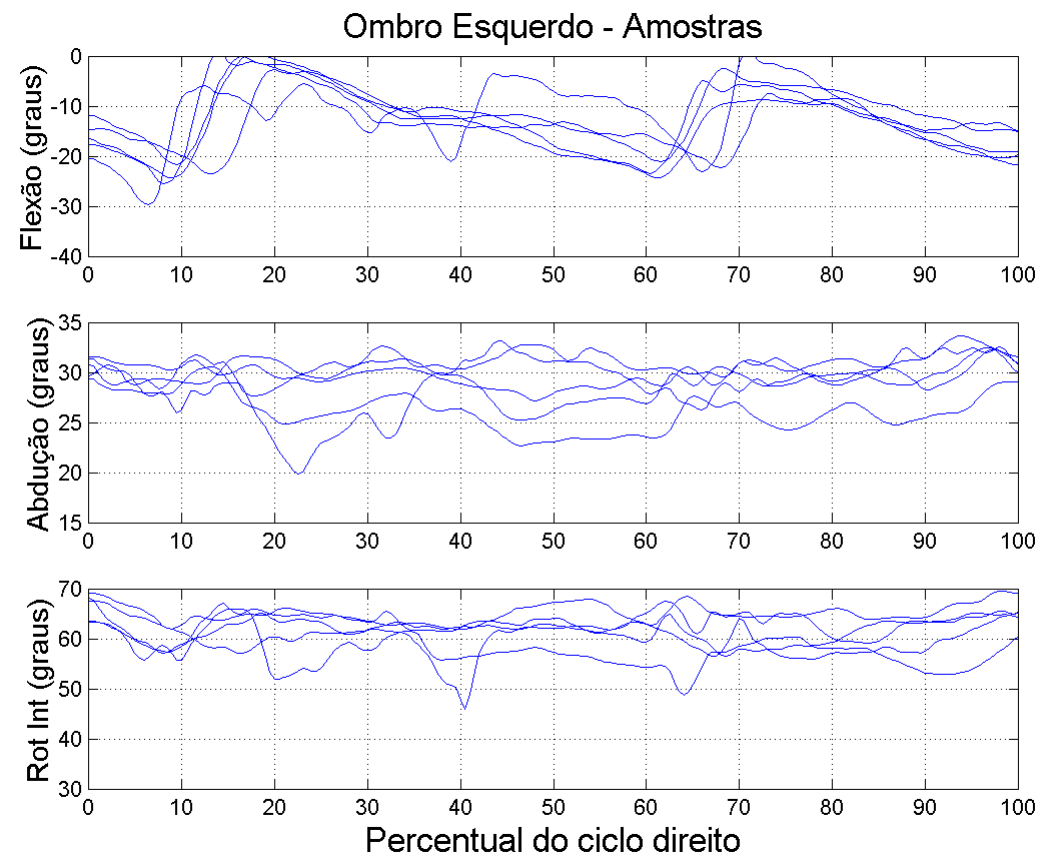

(a) Gráficos das variações angulares presentes nas cinco amostras.
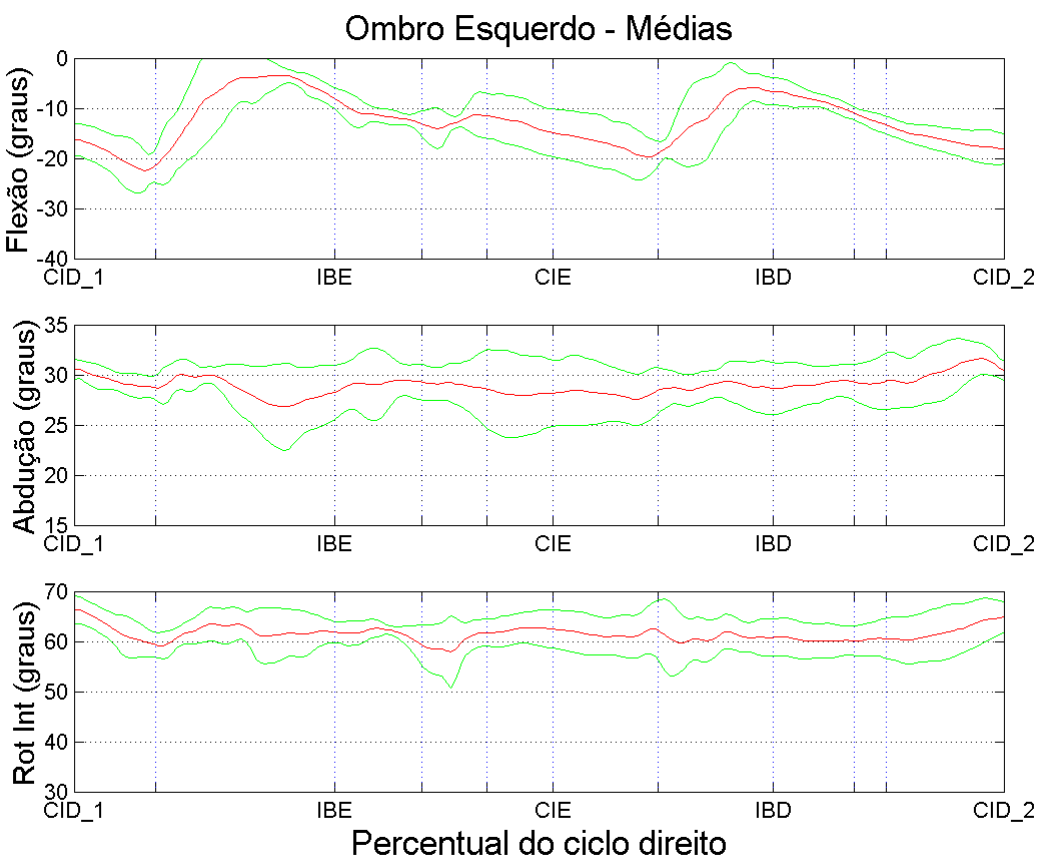

(b) Médias e desvios padrões dos dados apresentados em (a).

Figura C.11: Variações angulares no ombro esquerdo. Os gráficos foram normalizados no tempo como percentual do ciclo direito da marcha. 

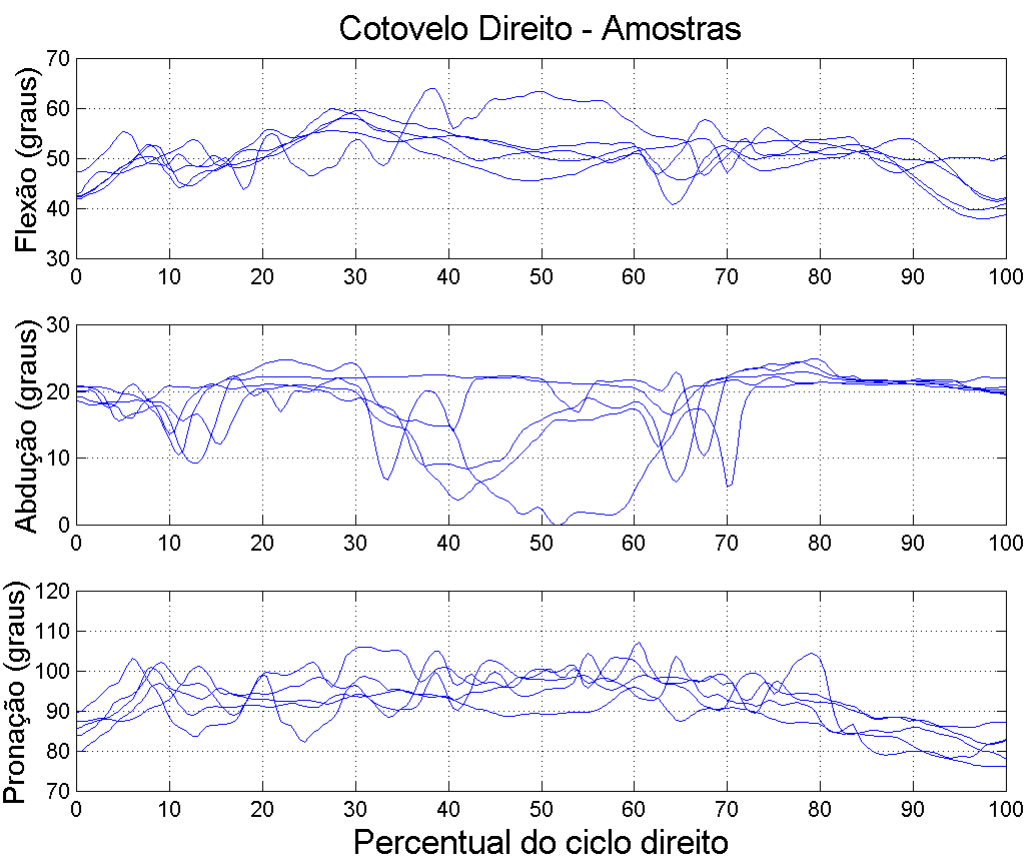

(a) Gráficos das variações angulares presentes nas cinco amostras.
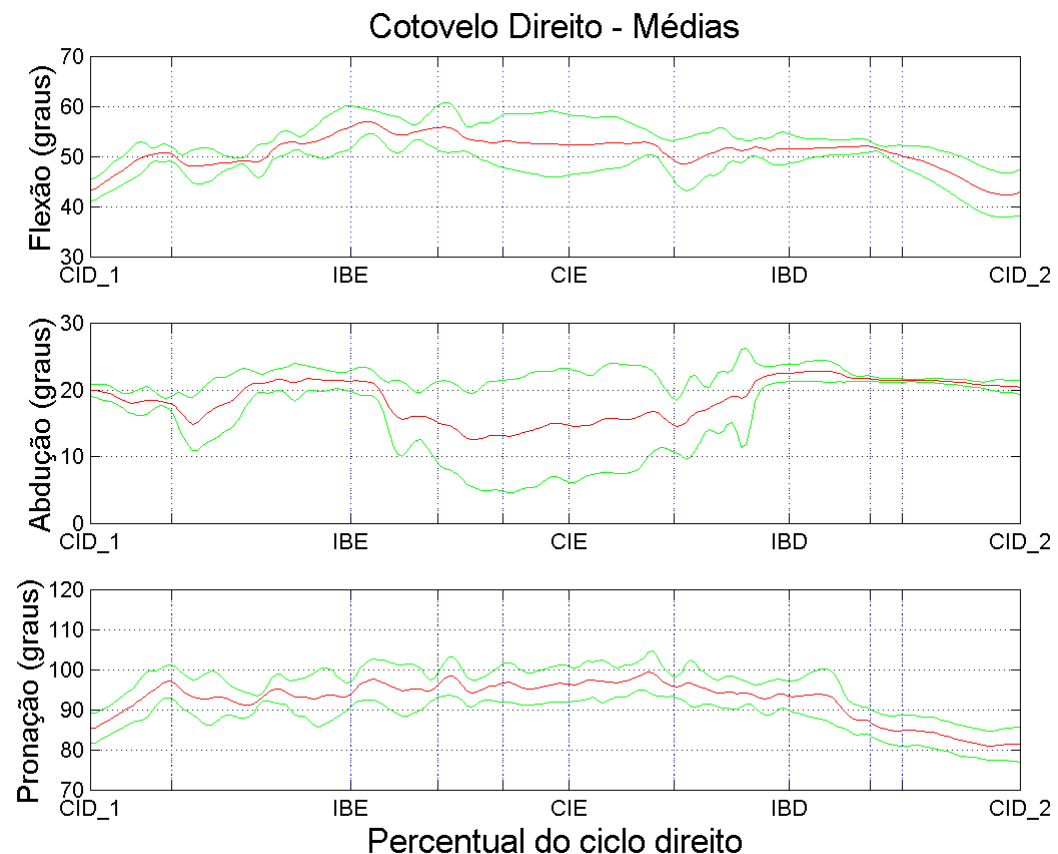

(b) Médias e desvios padrões dos dados apresentados em (a).

Figura C.12: Variações angulares no cotovelo direito. Os gráficos foram normalizados no tempo como percentual do ciclo direito da marcha. 

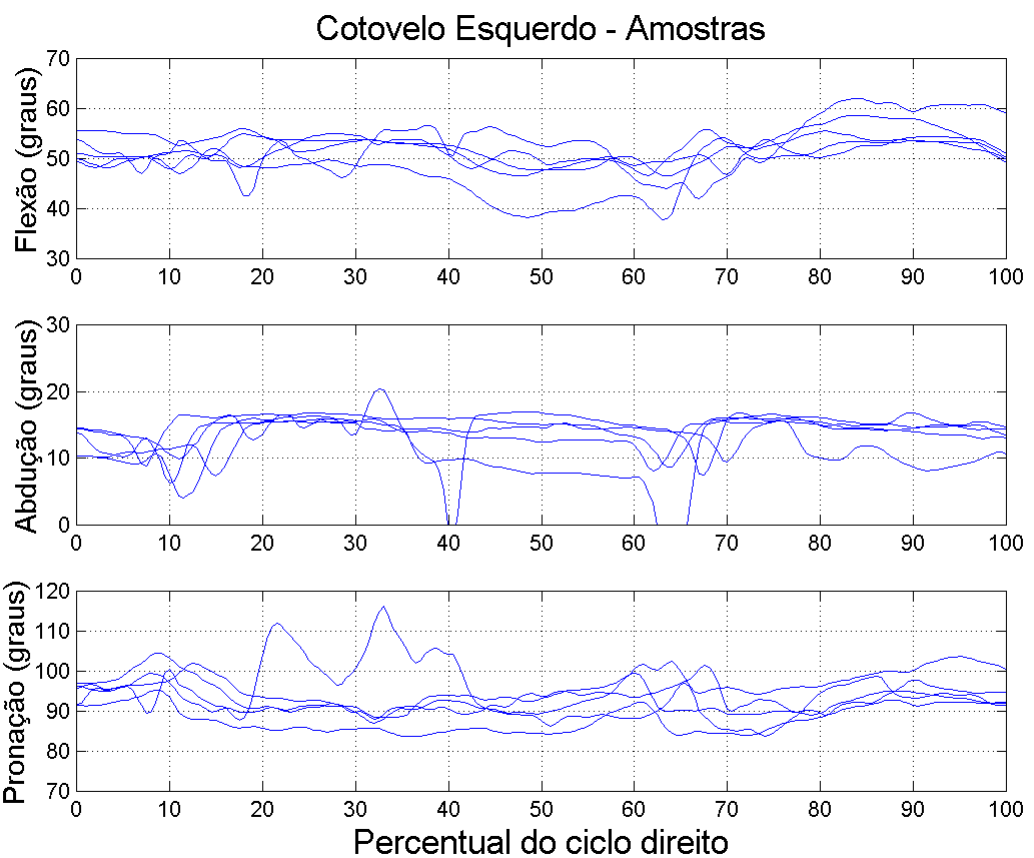

(a) Gráficos das variações angulares presentes nas cinco amostras.
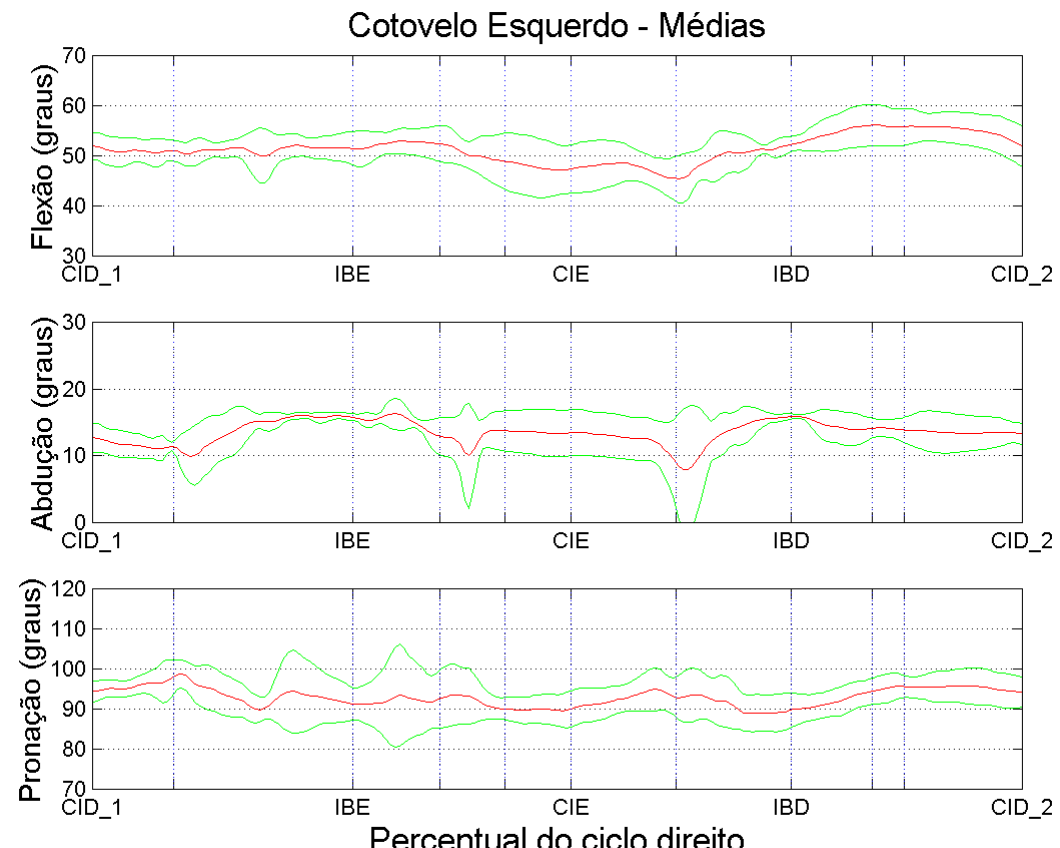

(b) Médias e desvios padrões dos dados apresentados em (a).

Figura C.13: Variações angulares no cotovelo esquerdo. Os gráficos foram normalizados no tempo como percentual do ciclo direito da marcha. 


\section{C.5 Eletromiografia}
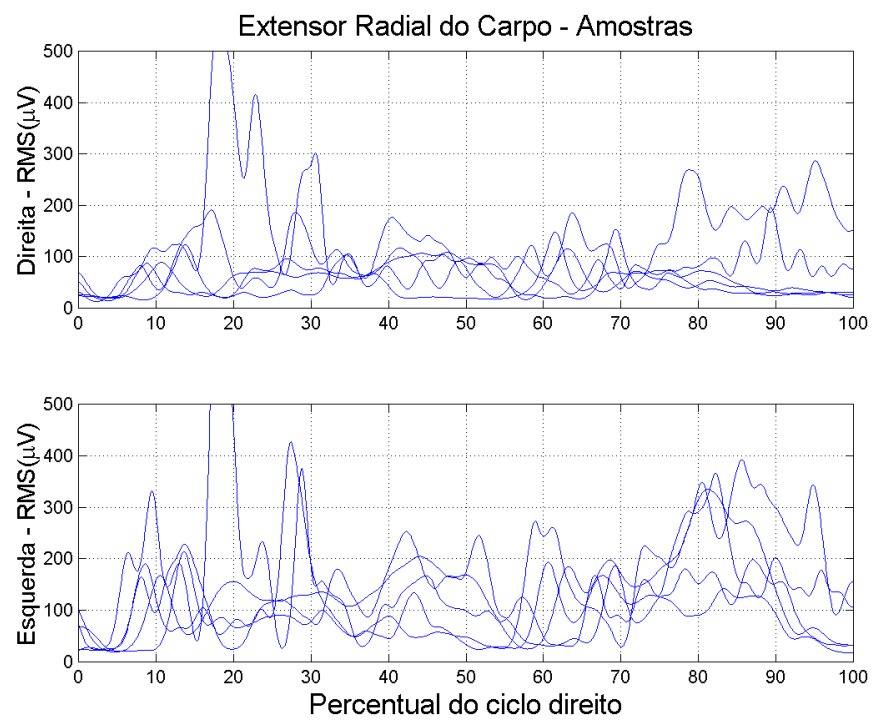

(a) Gráficos dos sinais presentes nas cinco amostras.
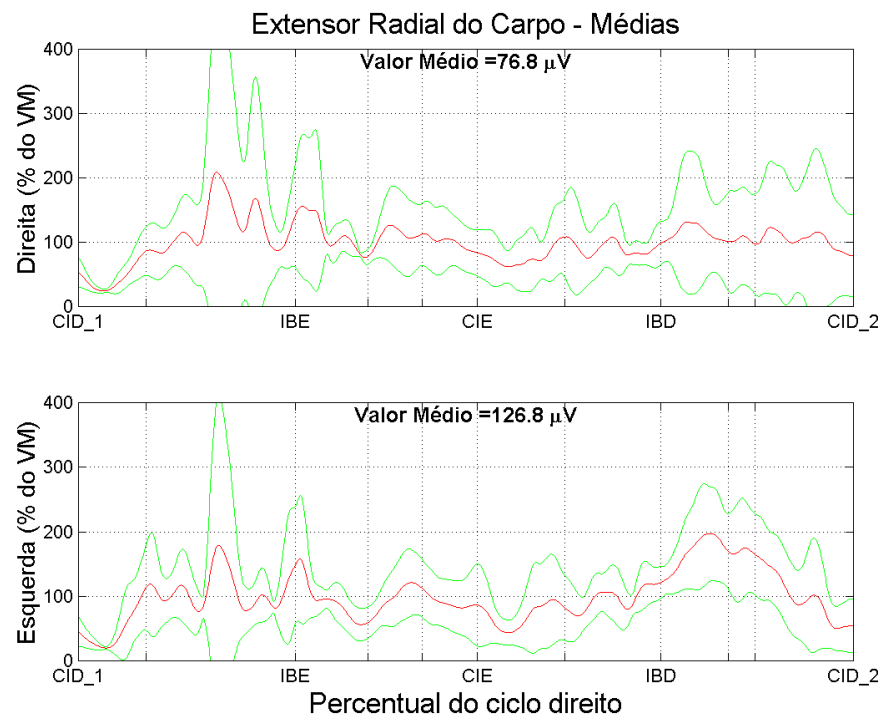

(b) Médias e desvios padrões dos dados apresentados em (a). Cada gráfico foi normalizado pelo valor médio ( $\boldsymbol{V} \boldsymbol{M})$ da média das cinco amostras.

Figura C.14: Eletromiografia do extensor radial do carpo (nos dois braços). Os gráficos foram normalizados no tempo como percentual do ciclo direito da marcha. 

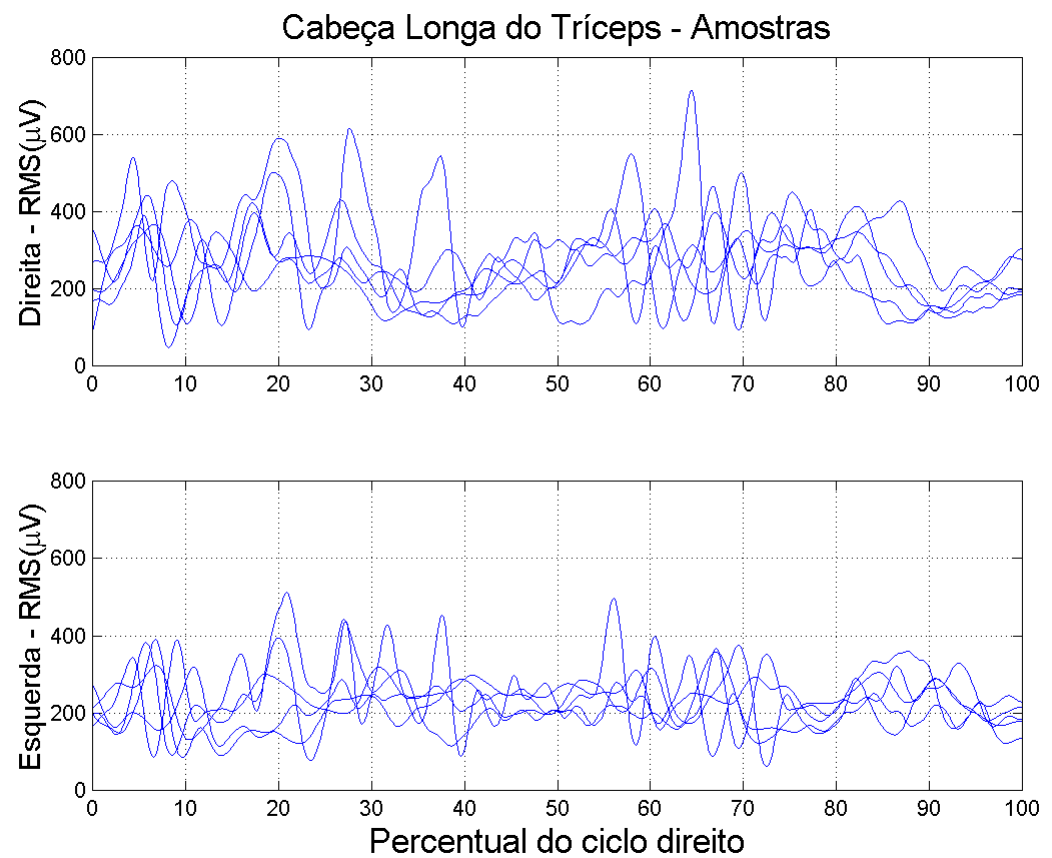

(a) Gráficos dos sinais presentes nas cinco amostras.
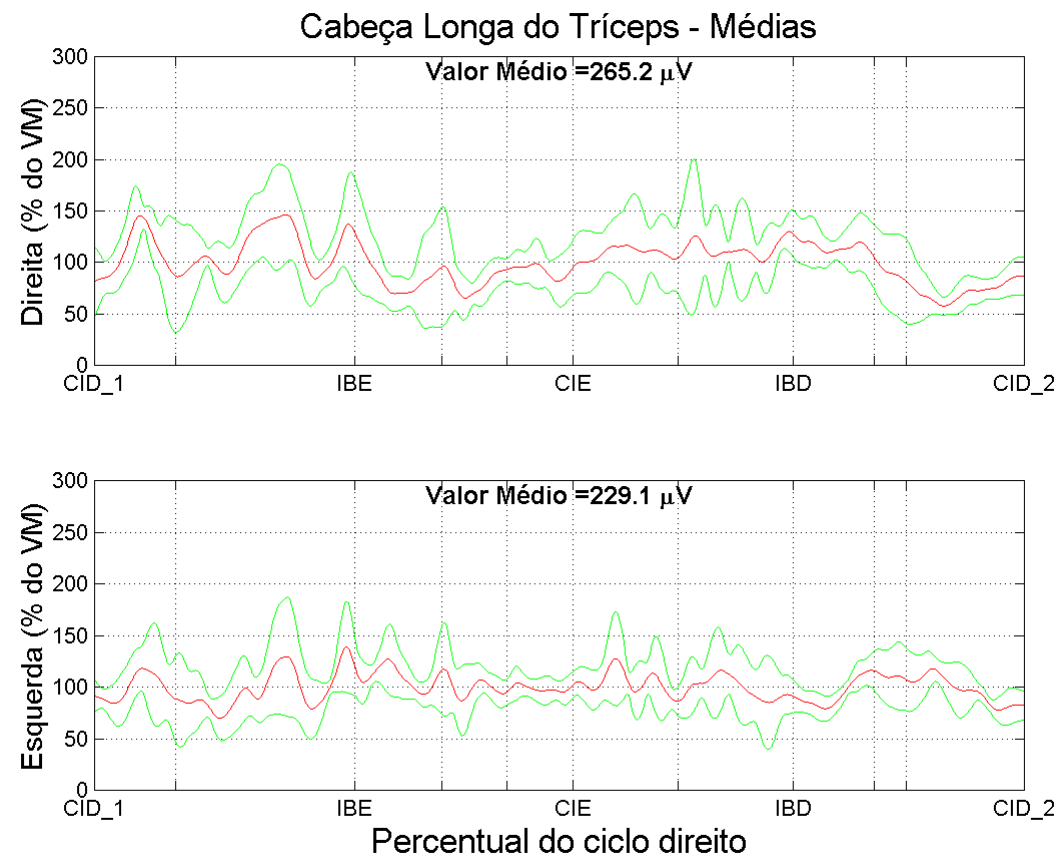

(b) Médias e desvios padrões dos dados apresentados em (a). Cada gráfico foi normalizado pelo valor médio $(\boldsymbol{V} \boldsymbol{M})$ da média das cinco amostras.

Figura C.15: Eletromiografia do cabeça longa do tríceps (nos dois braços). Os gráficos foram normalizados no tempo como percentual do ciclo direito da marcha. 

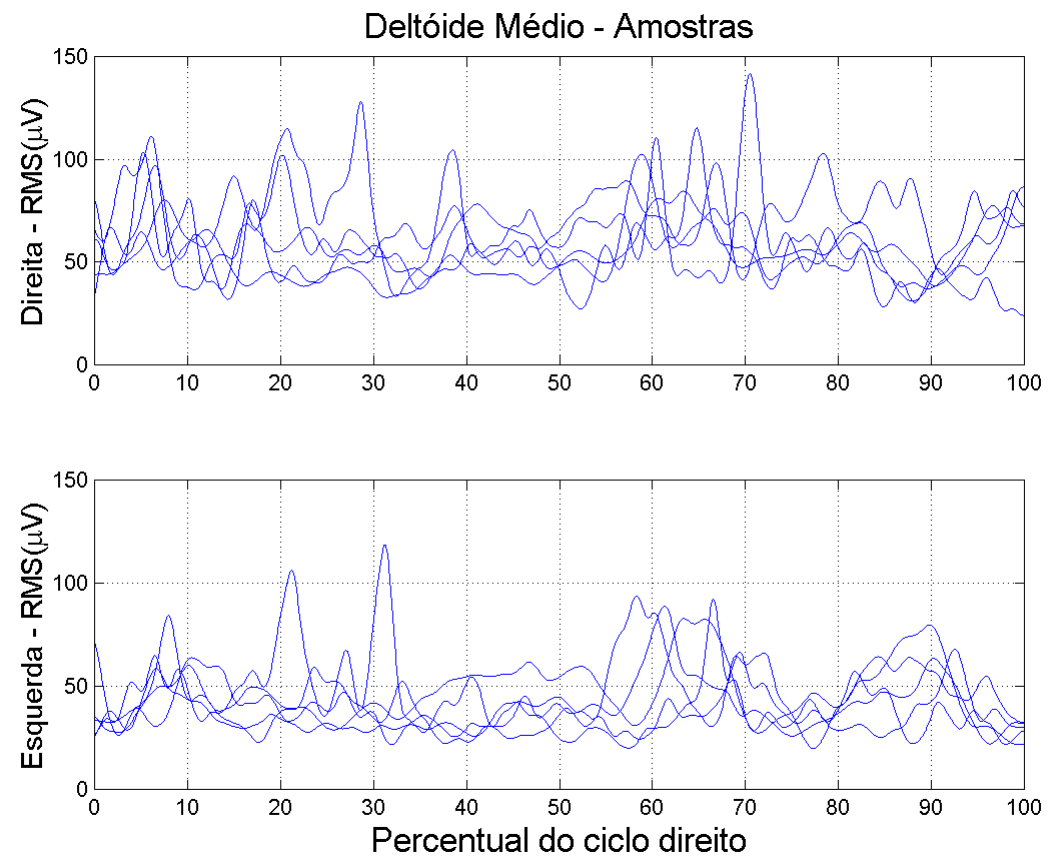

(a) Gráficos dos sinais presentes nas cinco amostras.
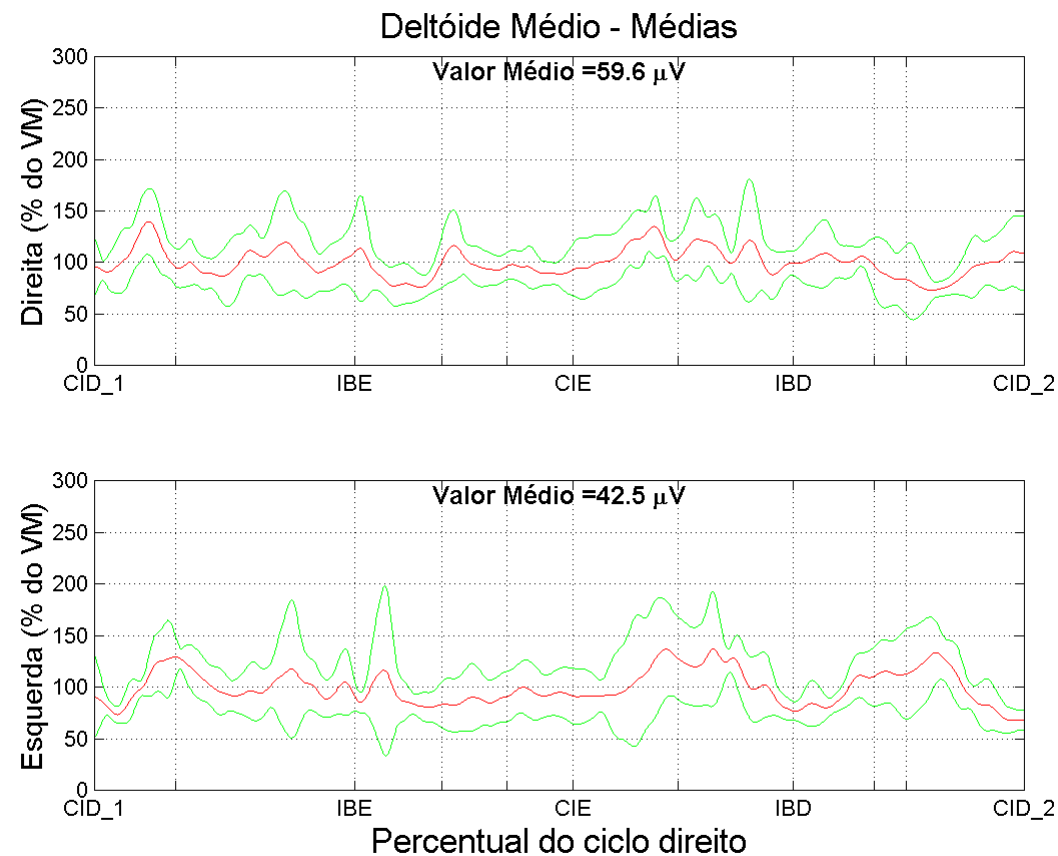

(b) Médias e desvios padrões dos dados apresentados em (a). Cada gráfico foi normalizado pelo valor médio $(\boldsymbol{V M})$ da média das cinco amostras.

Figura C.16: Eletromiografia do deltóide médio (nos dois braços). Os gráficos foram normalizados no tempo como percentual do ciclo direito da marcha. 

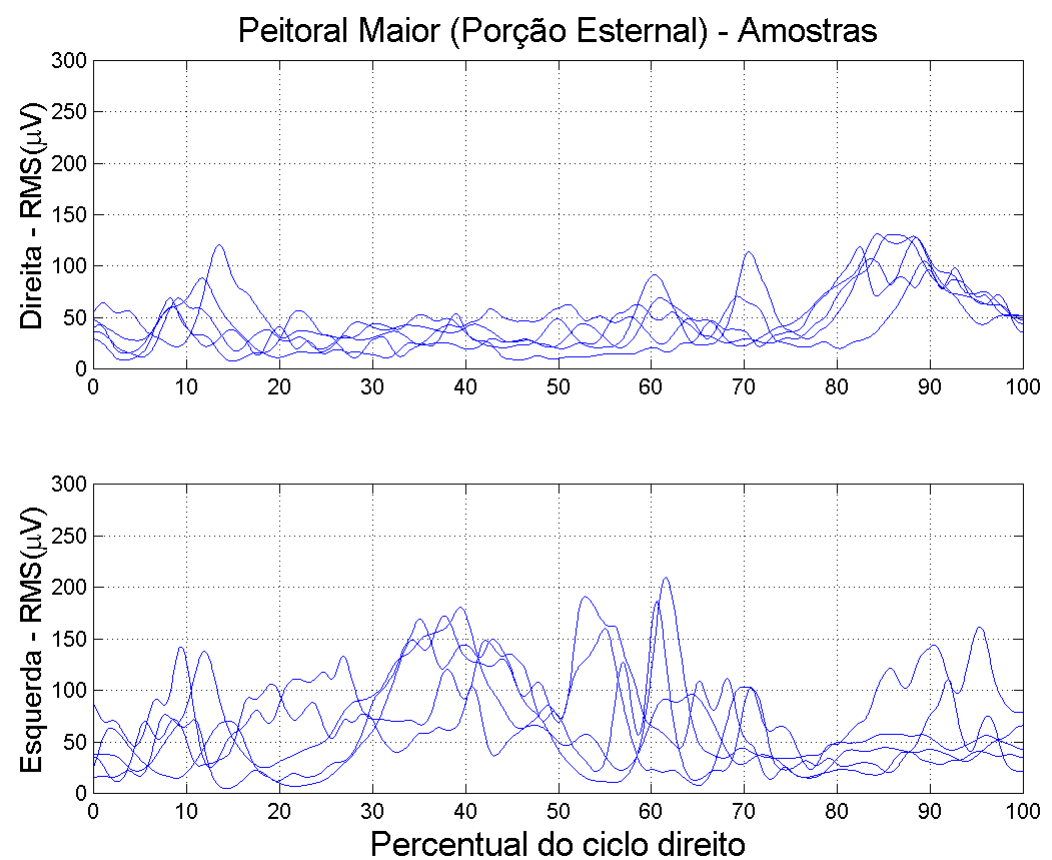

(a) Gráficos dos sinais presentes nas cinco amostras.
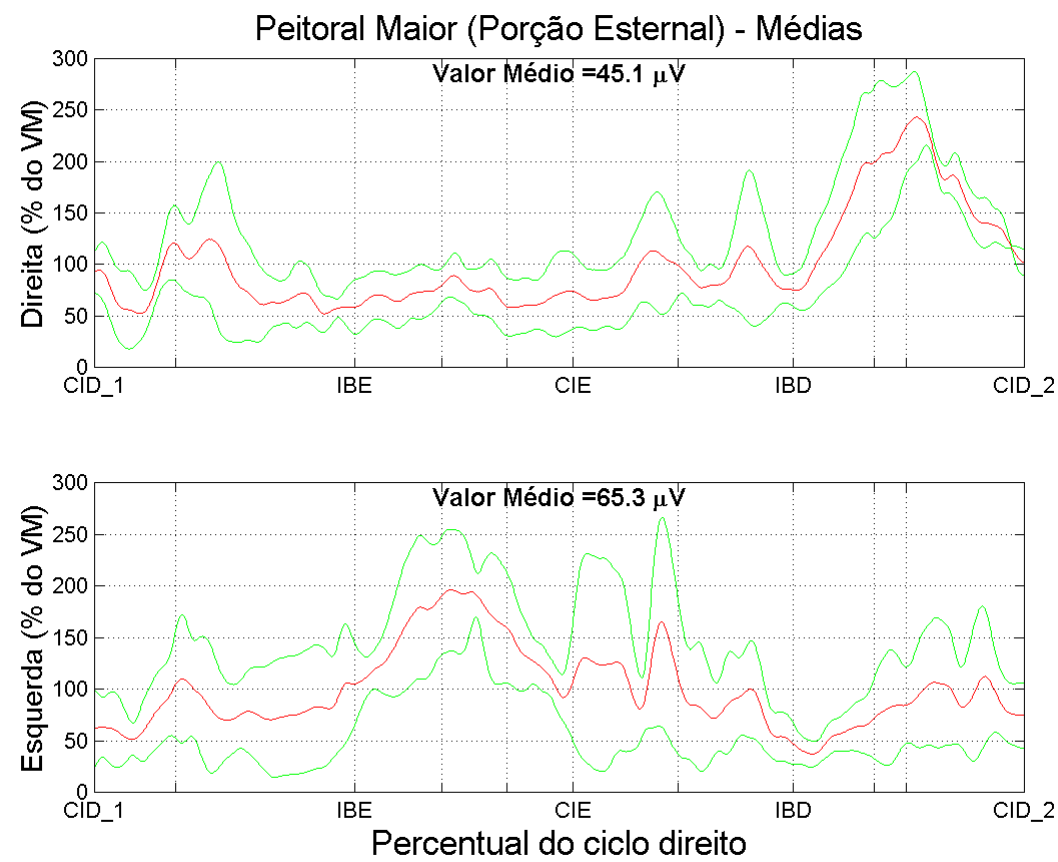

(b) Médias e desvios padrões dos dados apresentados em (a). Cada gráfico foi normalizado pelo valor médio $(\boldsymbol{V M})$ da média das cinco amostras.

Figura C.17: Eletromiografia da porção esternal do peitoral maior. Os gráficos foram normalizados no tempo como percentual do ciclo direito da marcha. 


\section{C.6 Componente vertical da força de reação do solo}
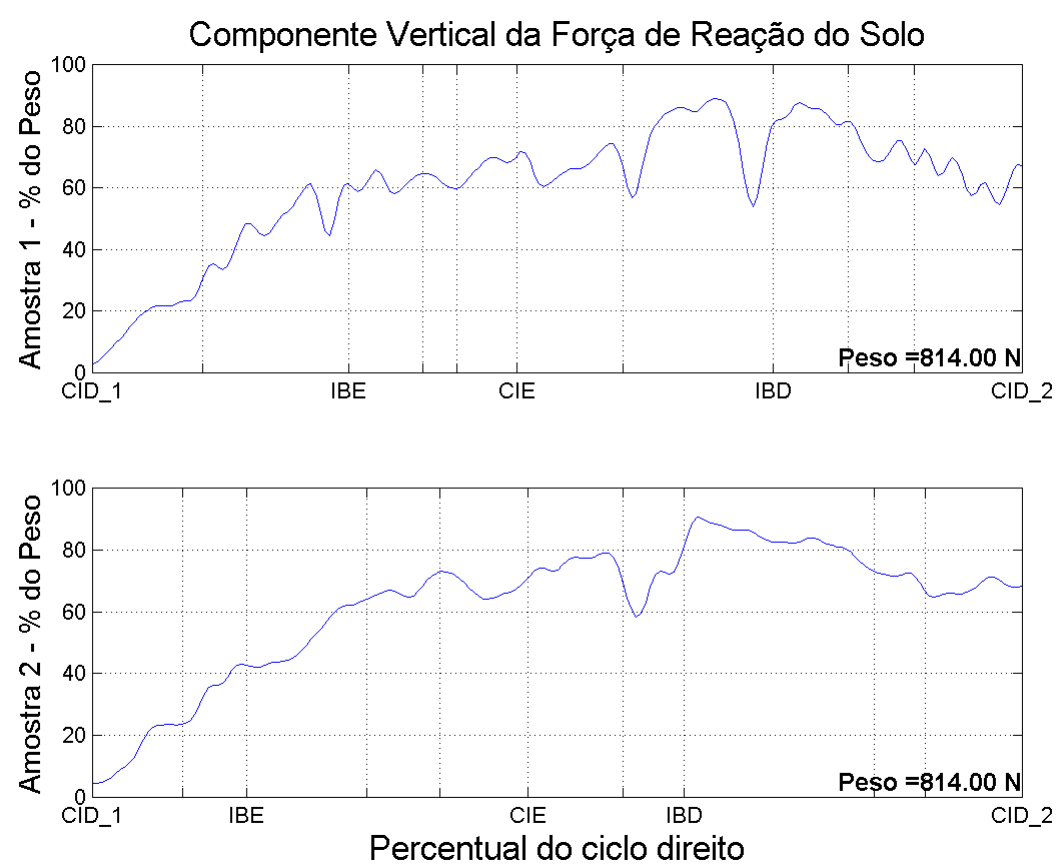

Figura C.18: Duas amostras da componente vertical da força de reação do solo conseqüente da ação dos pés do paciente sobre a plataforma de força durante a deambulação. Os gráficos foram normalizados no tempo como percentual do ciclo direito da marcha, e normalizados em amplitude como percentual do peso do paciente em Newtons.

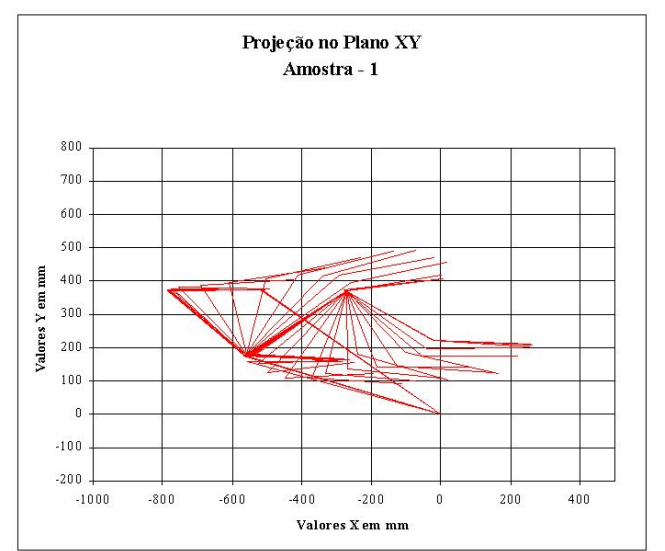

(a) Amostra 1

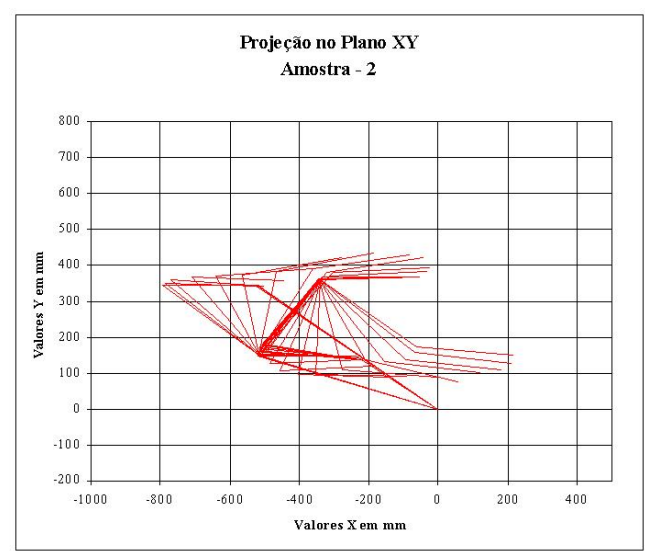

(b) Amostra 2

Figura C.19: Projeção do movimento dos pés do paciente sobre a plataforma de força no plano horizontal $(X Y)$. 


\section{Apêndice D}

\section{Paciente D}

Este apêndice apresentará os resultados do exame realizado no dia 23/05/2002. O conjunto de resultados é constituído por: as características da passada, variações angulares tridimensionais nos membros inferiores (pélvis, quadris, joelhos e tornozelos) e superiores (ombros, cotovelos, e tronco), eletromiografia de músculos dos membros superiores (peitoral maior, deltóide médio, cabeça longa do tríceps, extensor radial do carpo) e componente vertical da força de reação do solo.

\section{D.1 Características do paciente}

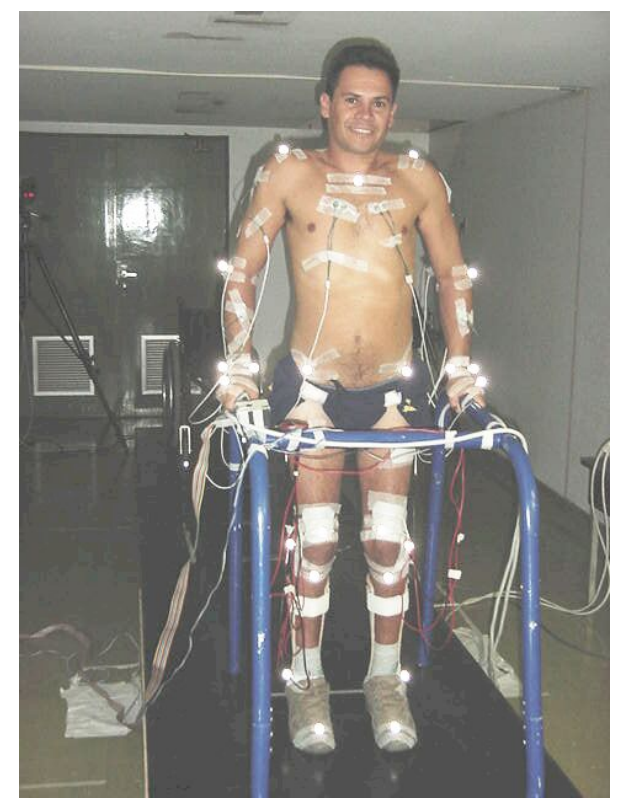

Figura D.1: Paciente D - Foto tirada durante um dos ensaios. O arquivo no formato PDF possui direcionamento para vídeo ao clicar na foto, desde que o QuickTime esteja instalado. Para abrir o vídeo fora do arquivo PDF, usando outro programa, clique aqui. 


\begin{tabular}{ccccccc}
\hline Nome & Idade & Nível da lesão & Causa & $\begin{array}{c}\text { Tempo da lesão } \\
(\text { anos })\end{array}$ & $\begin{array}{c}\text { Peso } \\
(\mathrm{Kg})\end{array}$ & $\begin{array}{c}\text { Altura } \\
(\mathrm{m})\end{array}$ \\
\hline \hline $\mathrm{D}$ & 32 & $\mathrm{~T} 2$ & Arma de fogo & 13 & 70 & 1,75 \\
\hline \hline
\end{tabular}

Tabela D.1: Dados dos pacientes

\section{D.2 Características da passada}

\begin{tabular}{ccccccc}
\hline Amostras & $\begin{array}{c}\text { Cadência } \\
(\text { passos } / \mathrm{min})\end{array}$ & $\begin{array}{c}\text { Velocidade } \\
(\mathrm{cm} / \mathrm{s})\end{array}$ & $\begin{array}{c}\text { Passada } \\
(\mathrm{m})\end{array}$ & $\begin{array}{c}\text { Tempo do ciclo } \\
(\mathrm{s})\end{array}$ & $\begin{array}{c}\text { Apoio direito } \\
(\%)\end{array}$ & $\begin{array}{c}\text { Apoio esquerdo } \\
(\%)\end{array}$ \\
\hline \hline 3 & 15,00 & 5,00 & 0,40 & 7,90 & 90,90 & 92,30 \\
4 & 16,00 & 5,33 & 0,40 & 7,70 & 89,70 & 88,90 \\
5 & 16,00 & 6,67 & 0,50 & 7,50 & 90,90 & 85,80 \\
9 & 19,00 & 9,50 & 0,60 & 6,40 & 89,30 & 89,60 \\
10 & 15,00 & 6,25 & 0,50 & 8,20 & 90,80 & 92,20 \\
& & & & & & \\
Média & 16,20 & 6,55 & 0,48 & 7,54 & 90,32 & 89,76 \\
Desvio & 1,64 & 1,78 & 0,08 & 0,69 & 0,76 & 2,69 \\
\hline \hline
\end{tabular}

Tabela D.2: Parâmetros temporais

\begin{tabular}{cccccccccccc}
\hline Amostras & $\begin{array}{c}C I D_{1} \\
(\%)\end{array}$ & $\begin{array}{c}I A A_{1} \\
(\%)\end{array}$ & $\begin{array}{c}I B E \\
(\%)\end{array}$ & $\begin{array}{c}D P E \\
(\%)\end{array}$ & $\begin{array}{c}M B E \\
(\%)\end{array}$ & $\begin{array}{c}C I E \\
(\%)\end{array}$ & $\begin{array}{c}I A A_{2} \\
(\%)\end{array}$ & $\begin{array}{c}I B D \\
(\%)\end{array}$ & $\begin{array}{c}D P D \\
(\%)\end{array}$ & $\begin{array}{c}M B D \\
(\%)\end{array}$ & $\begin{array}{c}C I D_{2} \\
(\%)\end{array}$ \\
\hline \hline 3 & 0.0 & 5.5 & 20.8 & 36.2 & 40.9 & 44.1 & 50.0 & 77.5 & 90.9 & 95.3 & 100.0 \\
4 & 0.0 & 7.5 & 21.6 & 33.8 & 37.9 & 45.3 & 62.1 & 76.7 & 89.7 & 96.6 & 100.0 \\
5 & 0.0 & 5.1 & 21.0 & 34.7 & 44.2 & 49.1 & 57.3 & 76.3 & 90.9 & 96.0 & 100.0 \\
9 & 0.0 & 5.5 & 14.9 & 30.6 & 36.4 & 42.4 & 49.0 & 72.8 & 89.3 & 95.0 & 100.0 \\
10 & 0.0 & 4.1 & 20.4 & 34.4 & 38.0 & 42.9 & 49.3 & 73.6 & 90.8 & 95.7 & 100.0 \\
& & & & & & & & & & & \\
Média & 0.0 & 5.5 & 19.7 & 34.0 & 39.5 & 44.8 & 53.5 & 75.4 & 90.3 & 95.7 & 100.0 \\
Desvio & 0.0 & 1.3 & 2.7 & 2.1 & 3.1 & 2.7 & 5.9 & 2.1 & 0.8 & 0.6 & 0.0 \\
\hline \hline
\end{tabular}

Tabela D.3: Percentuais das fases do ciclo de acordo com o descrito na sec. 4.1 


\section{D.3 Variações angulares: tronco e membros inferiores}
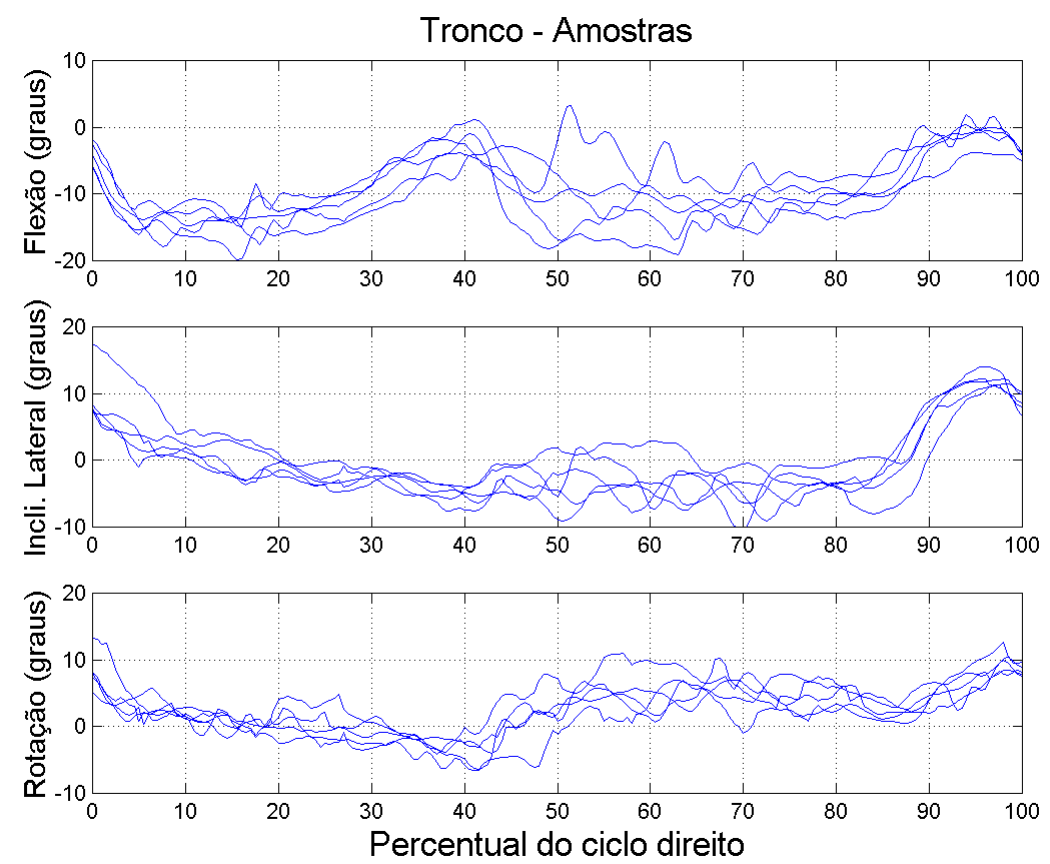

(a) Gráficos das variações angulares presentes nas cinco amostras.
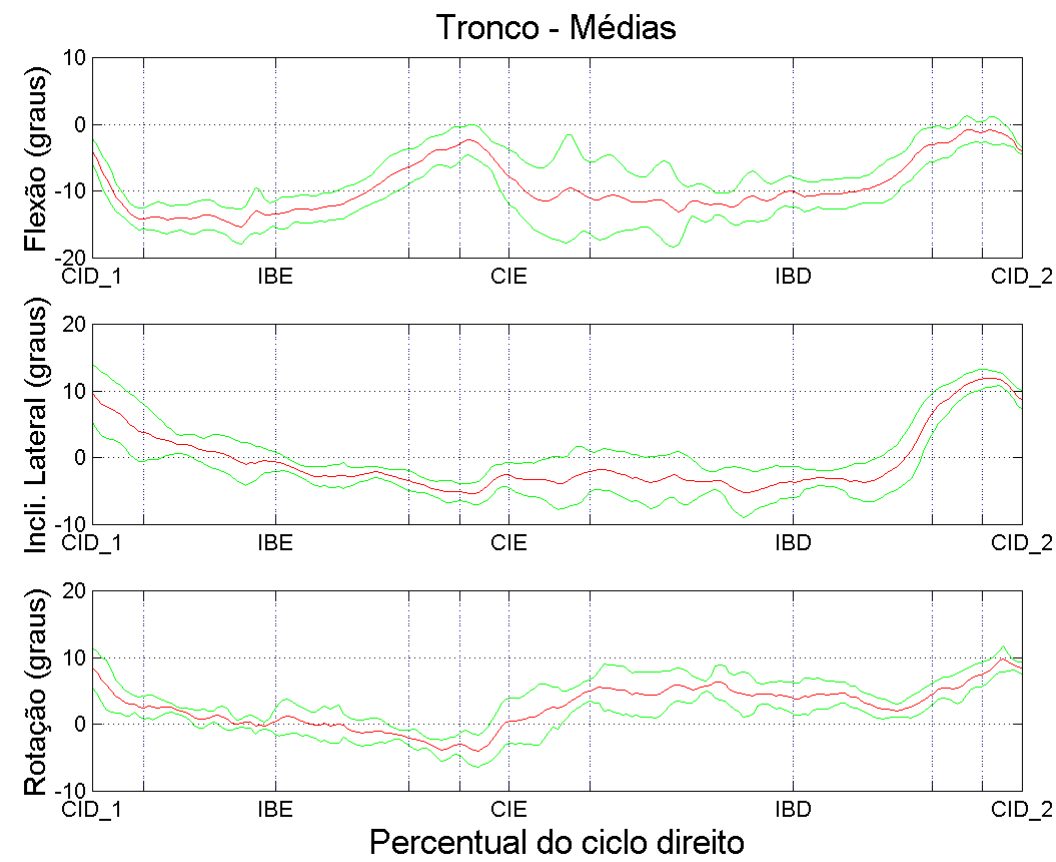

(b) Médias e desvios padrões dos dados apresentados em (a).

Figura D.2: Variações angulares do tronco. Os gráficos foram normalizados no tempo como percentual do ciclo direito da marcha. 

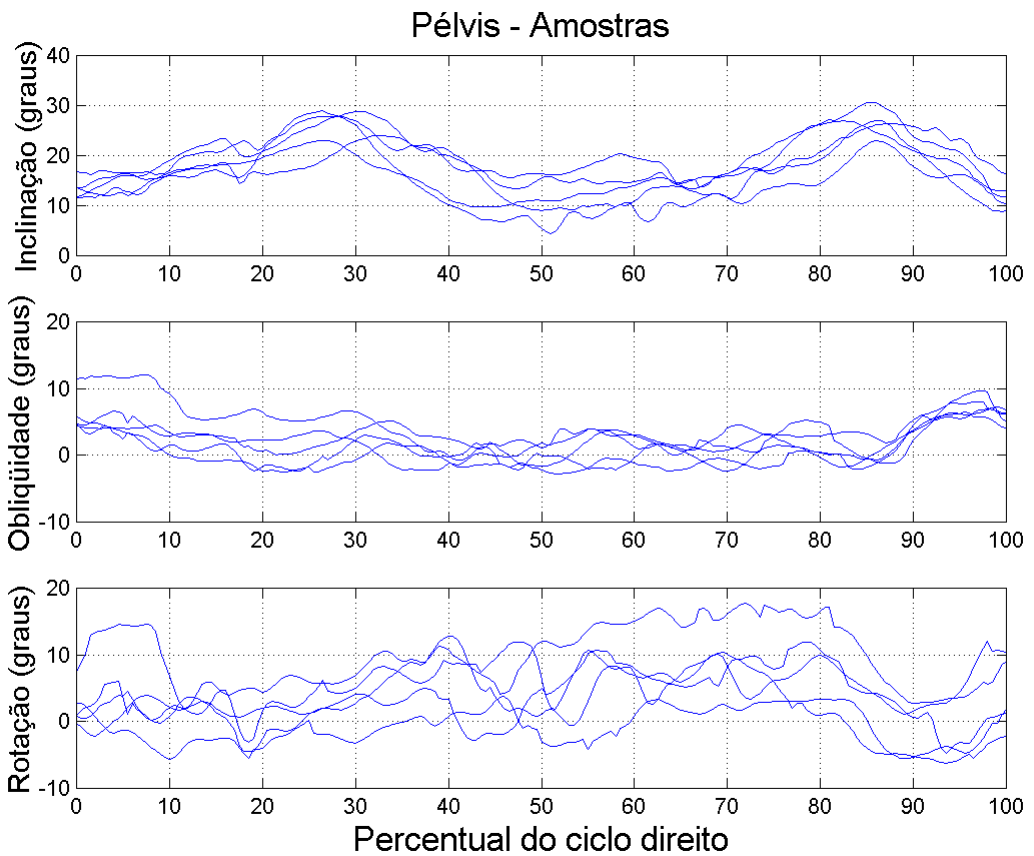

(a) Gráficos das variações angulares presentes nas cinco amostras.
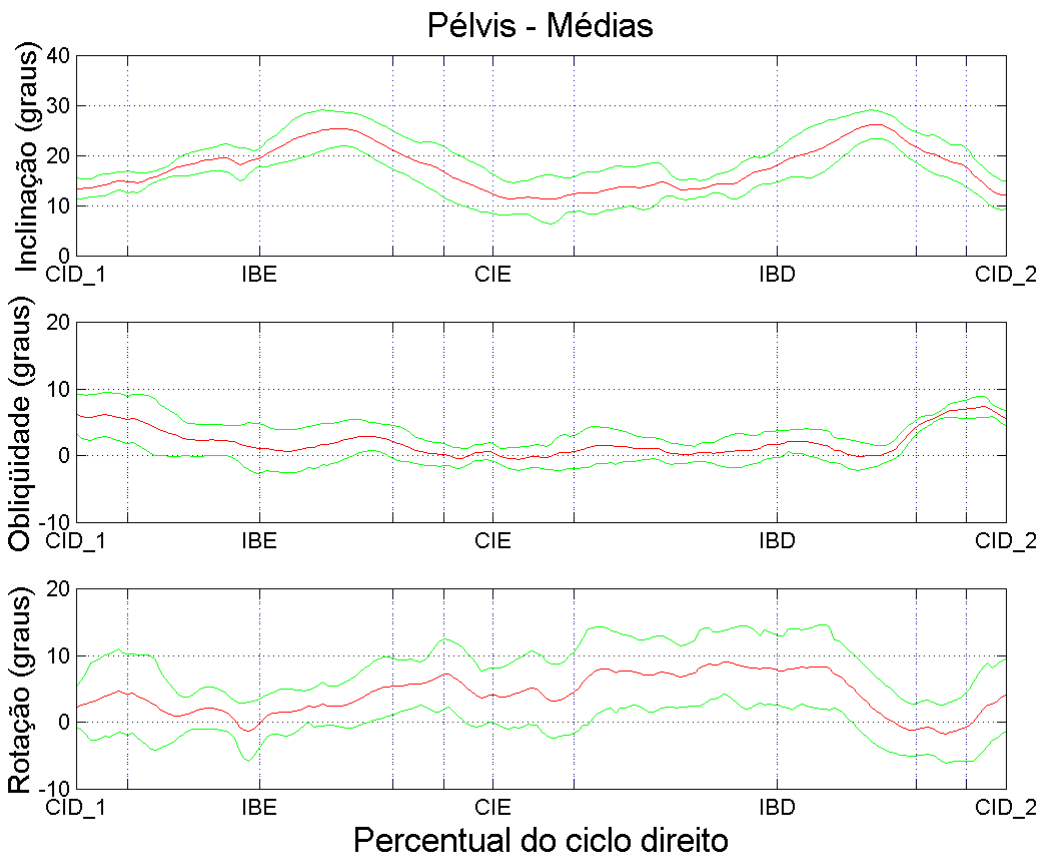

(b) Médias e desvios padrões dos dados apresentados em (a).

Figura D.3: Variações angulares do pélvis. Os gráficos foram normalizados no tempo como percentual do ciclo direito da marcha. 

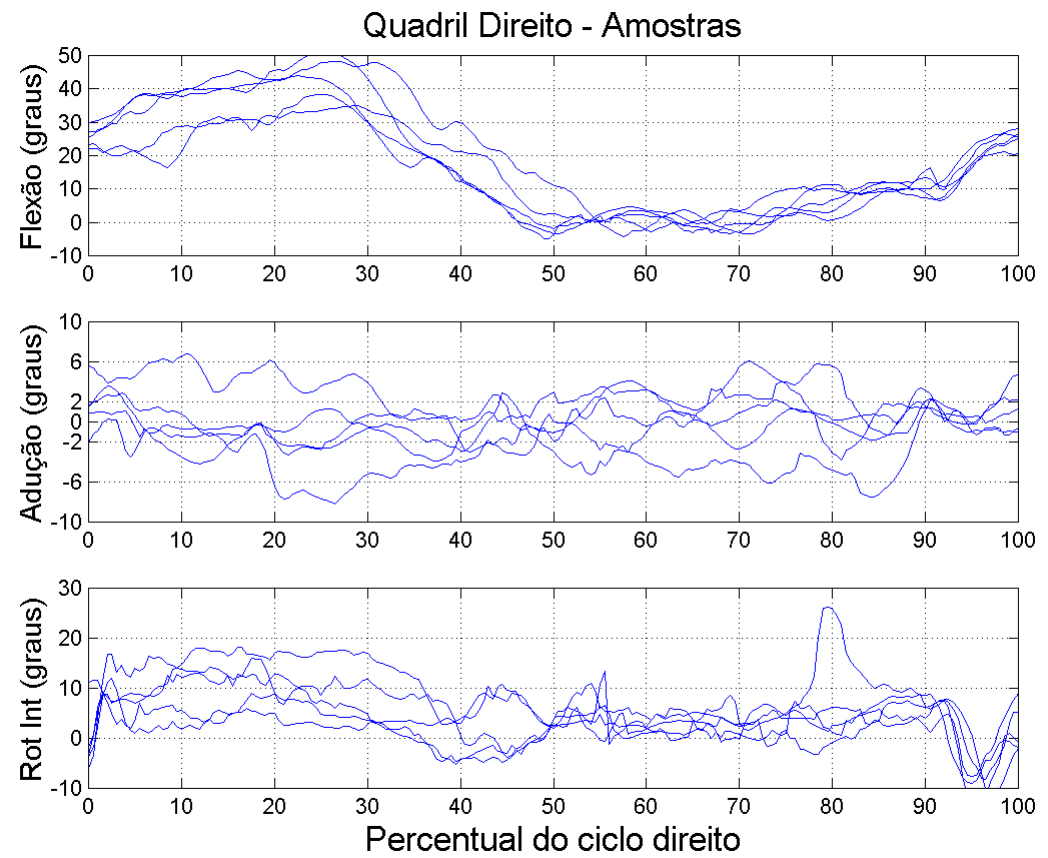

(a) Gráficos das variações angulares presentes nas cinco amostras.
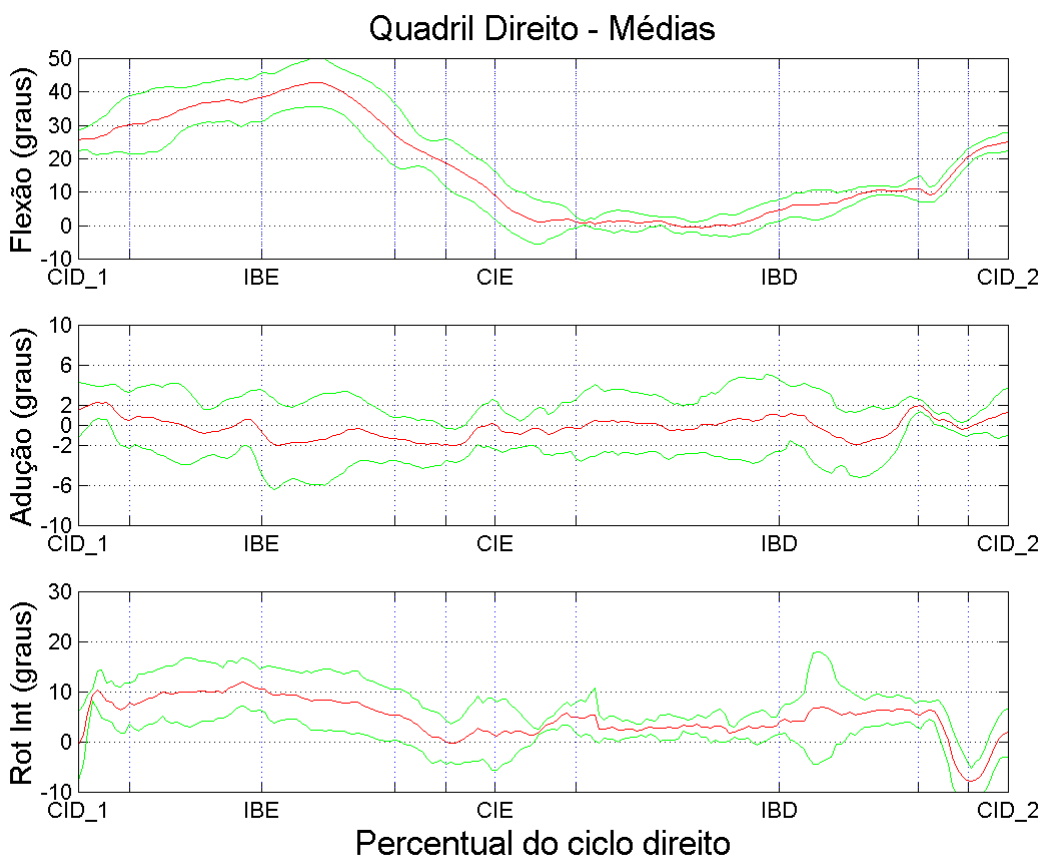

(b) Médias e desvios padrões dos dados apresentados em (a).

Figura D.4: Variações angulares no quadril direito. Os gráficos foram normalizados no tempo como percentual do ciclo direito da marcha. 

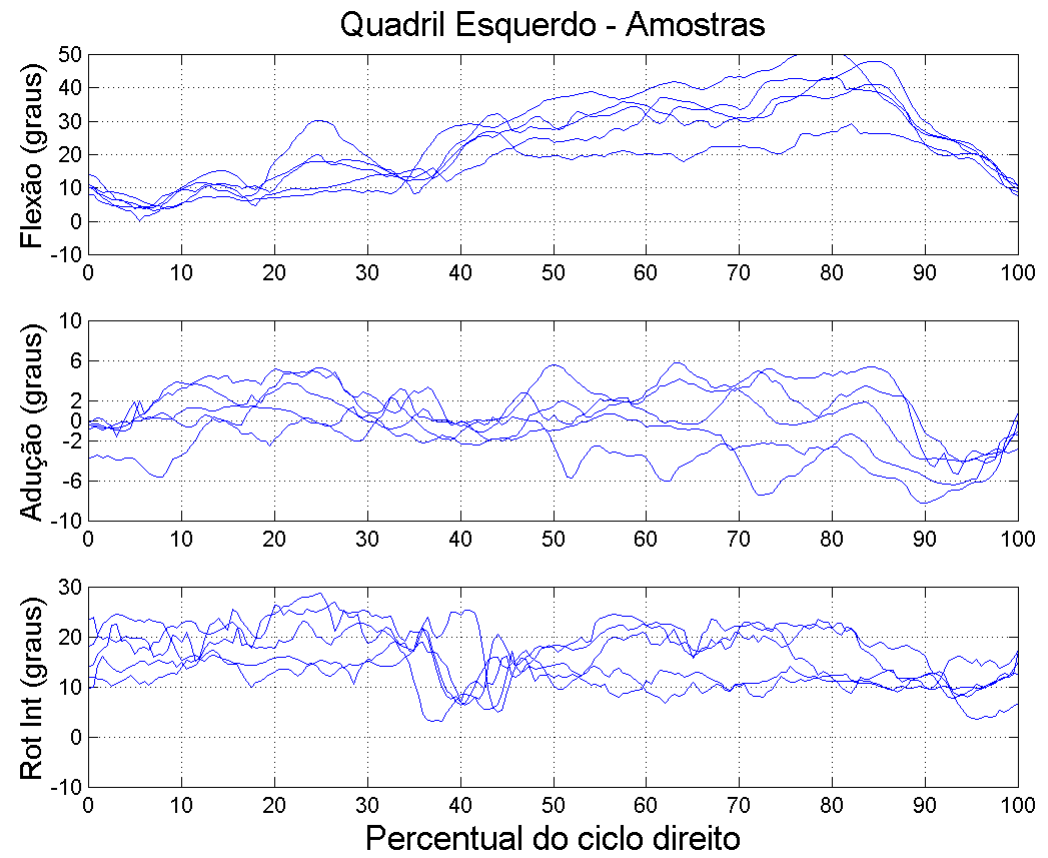

(a) Gráficos das variações angulares presentes nas cinco amostras.
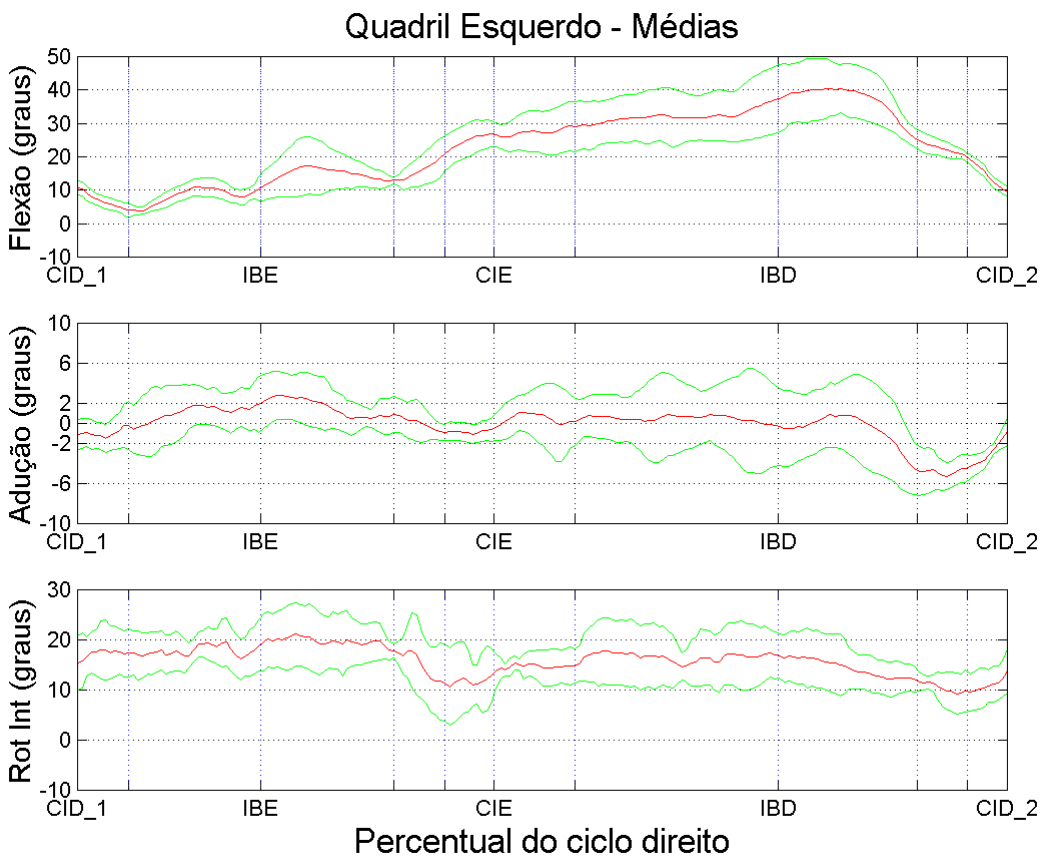

(b) Médias e desvios padrões dos dados apresentados em (a).

Figura D.5: Variações angulares no quadril esquerdo. Os gráficos foram normalizados no tempo como percentual do ciclo direito da marcha. 

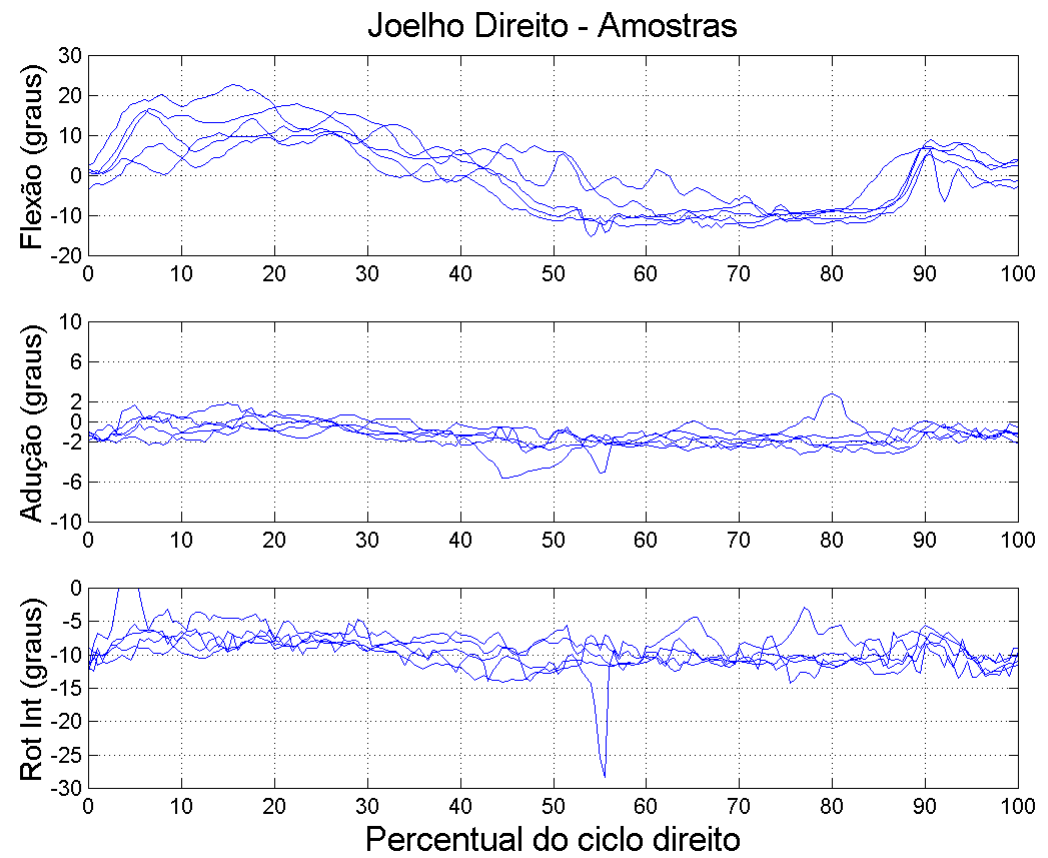

(a) Gráficos das variações angulares presentes nas cinco amostras.
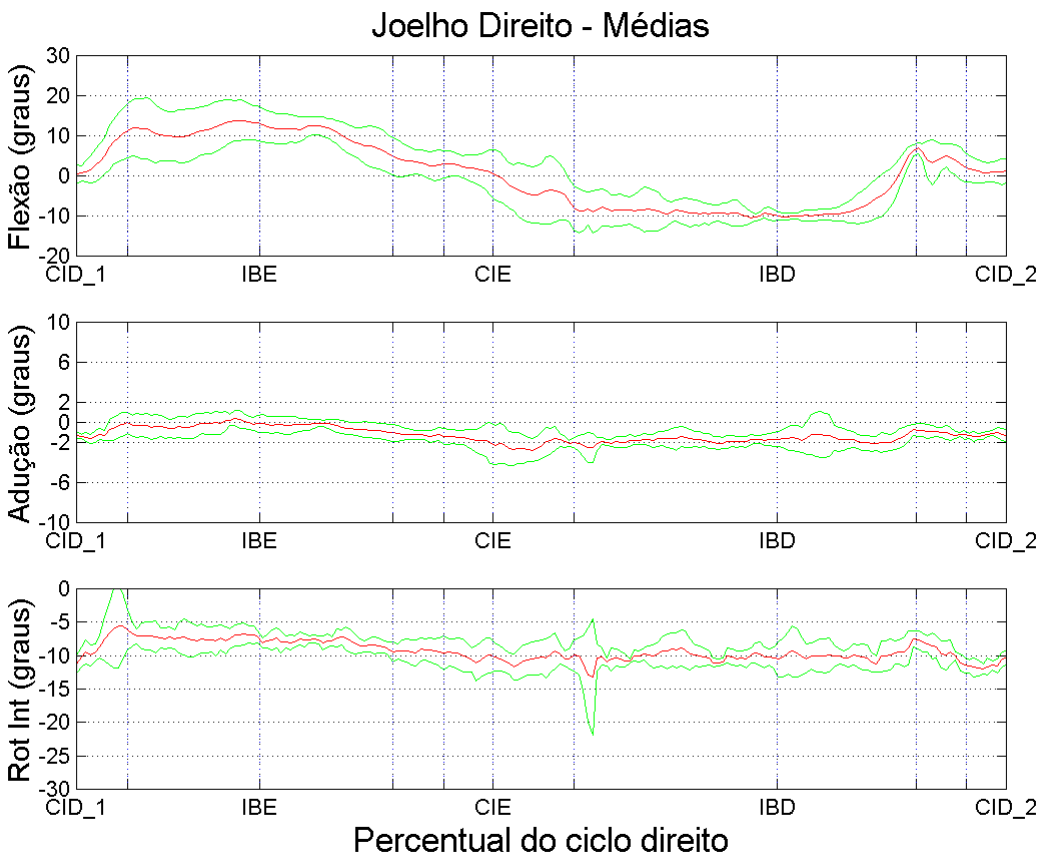

(b) Médias e desvios padrões dos dados apresentados em (a).

Figura D.6: Variações angulares no joelho direito. Os gráficos foram normalizados no tempo como percentual do ciclo direito da marcha. 

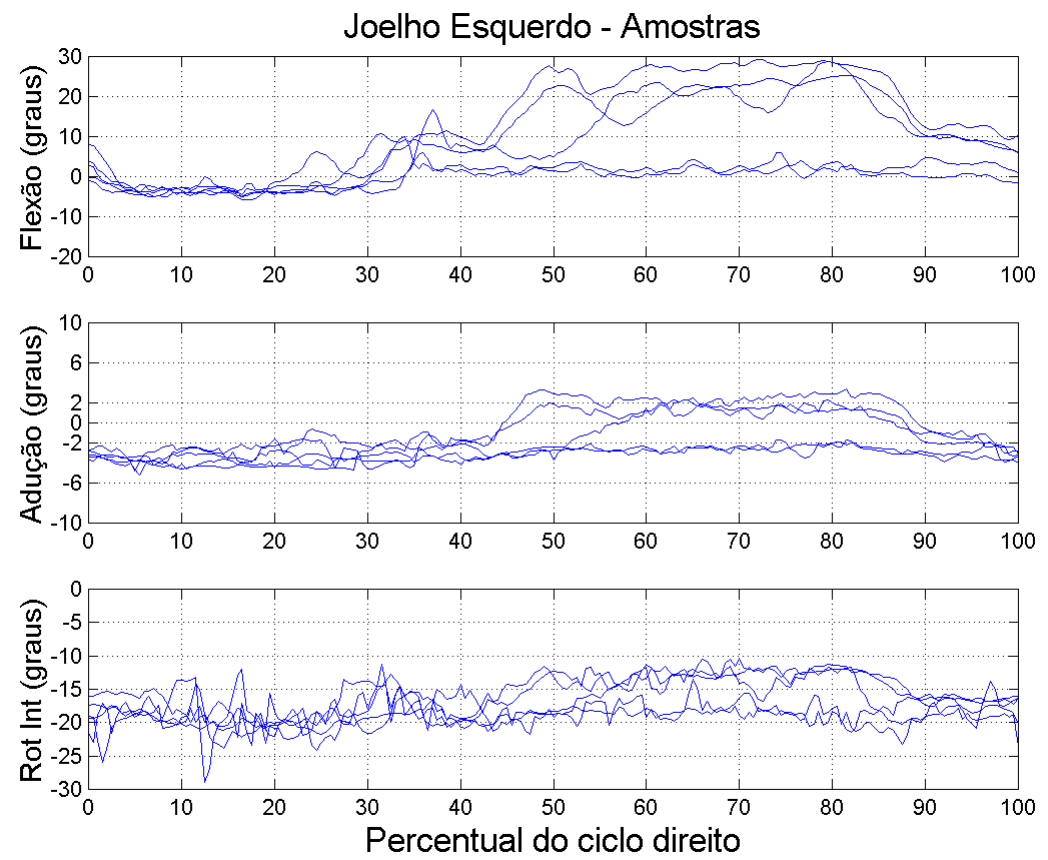

(a) Gráficos das variações angulares presentes nas cinco amostras.
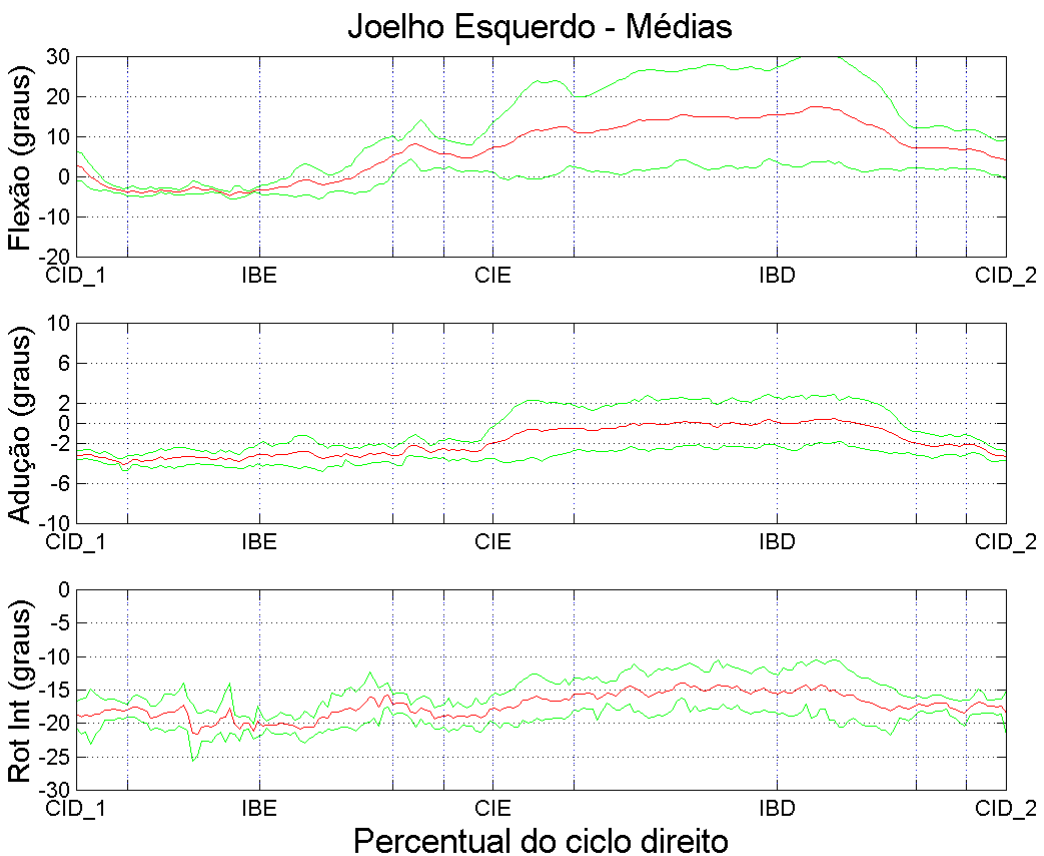

(b) Médias e desvios padrões dos dados apresentados em (a).

Figura D.7: Variações angulares no joelho esquerdo. Os gráficos foram normalizados no tempo como percentual do ciclo direito da marcha. 

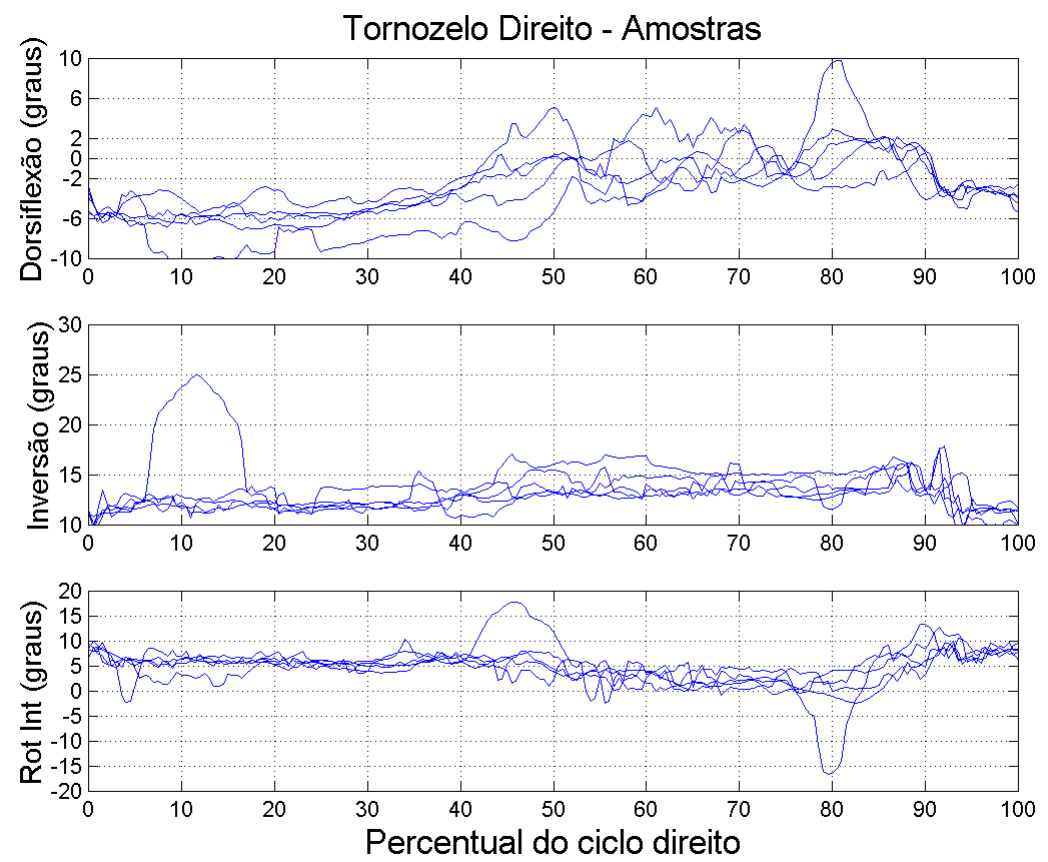

(a) Gráficos das variações angulares presentes nas cinco amostras.
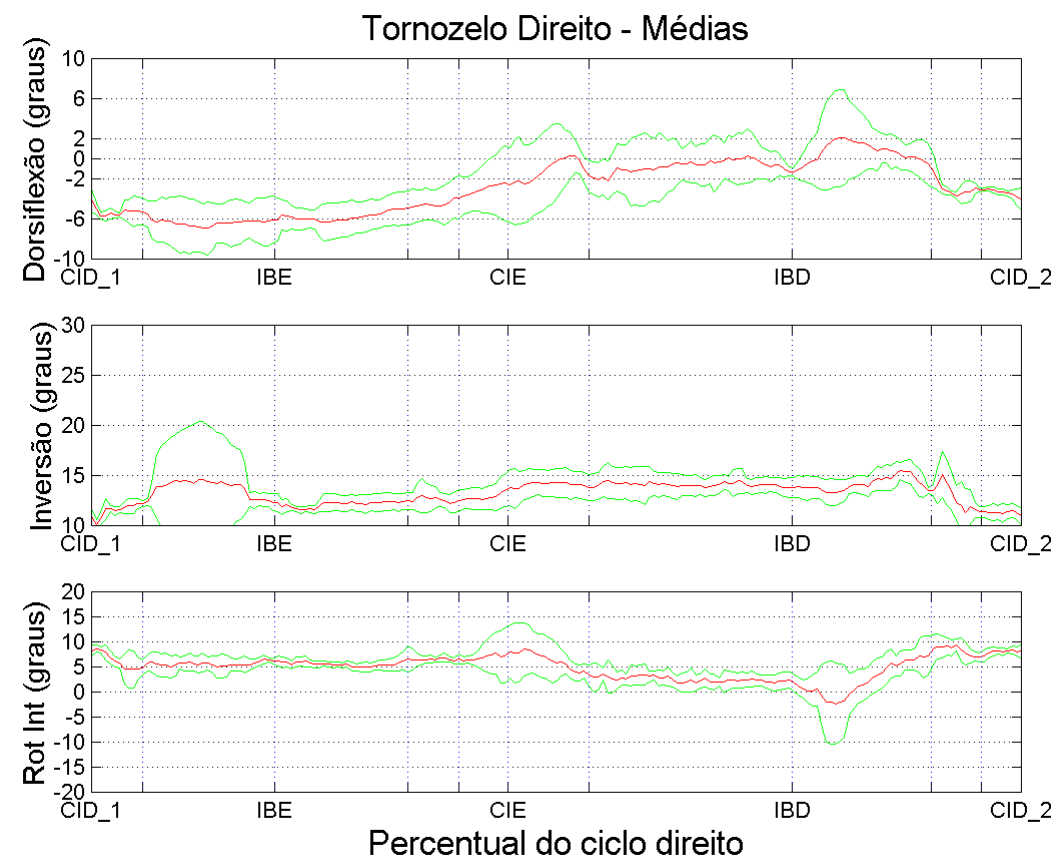

(b) Médias e desvios padrões dos dados apresentados em (a).

Figura D.8: Variações angulares no tornozelo direito. Os gráficos foram normalizados no tempo como percentual do ciclo direito da marcha. 

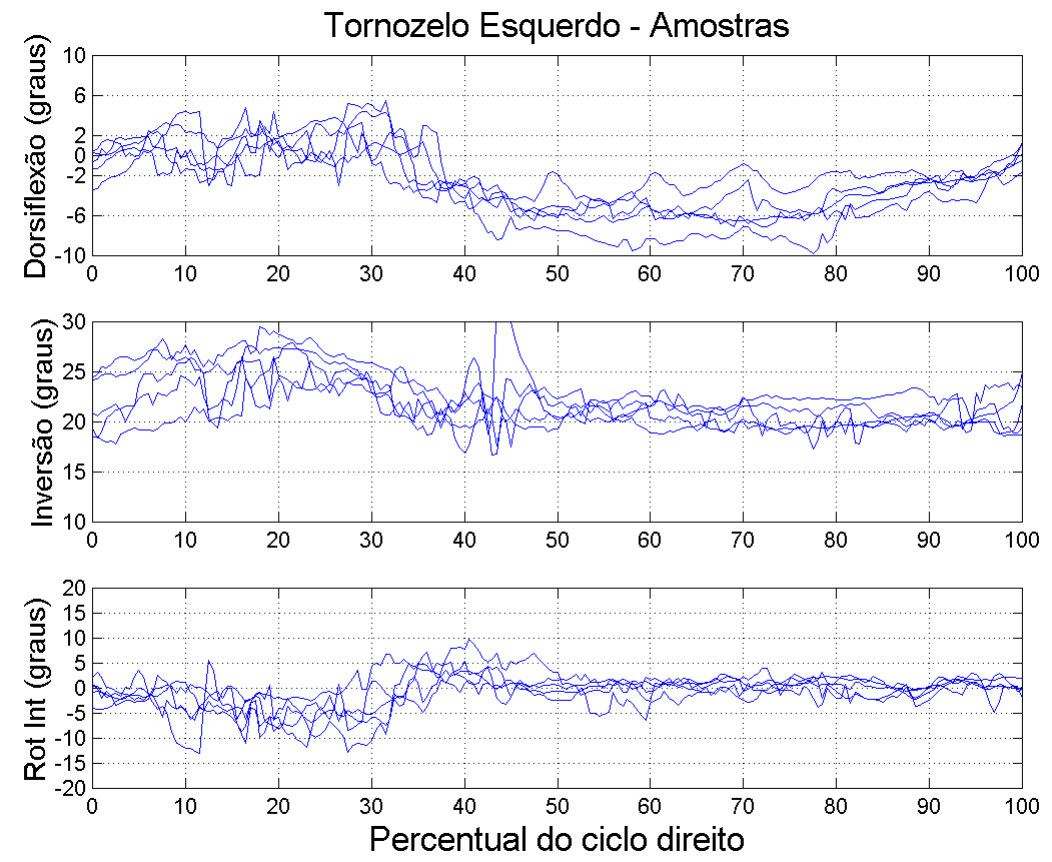

(a) Gráficos das variações angulares presentes nas cinco amostras.
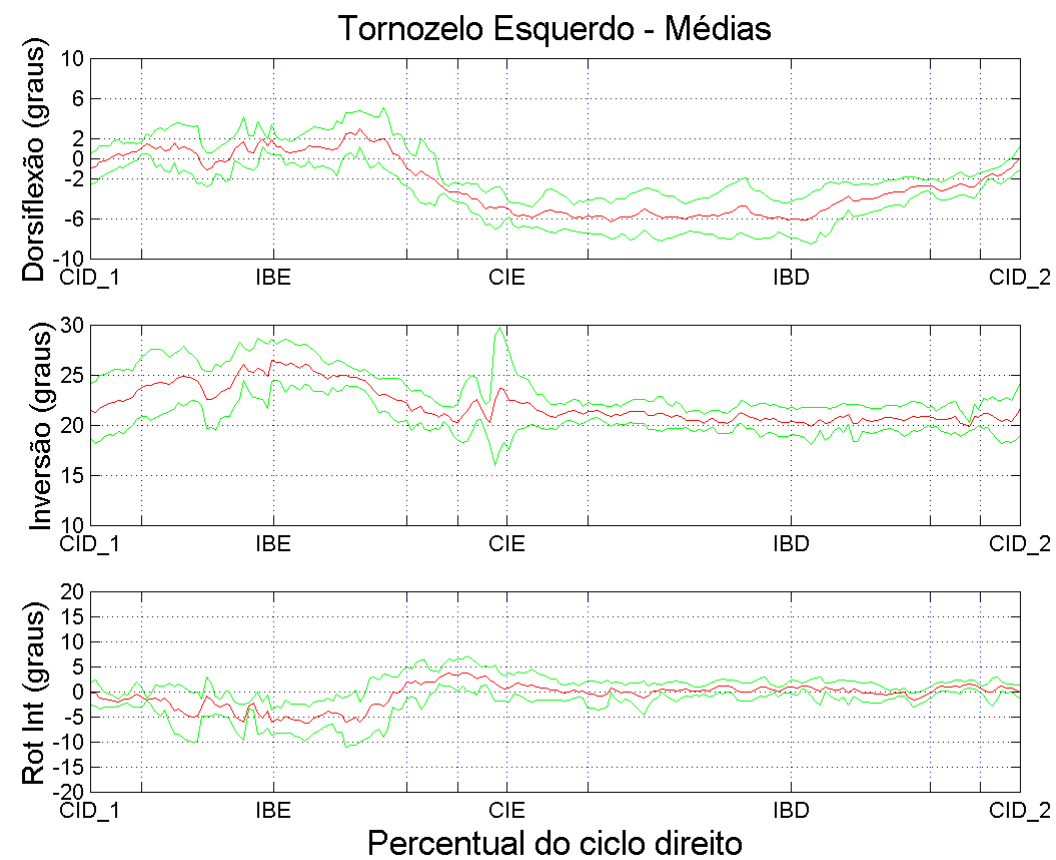

(b) Médias e desvios padrões dos dados apresentados em (a).

Figura D.9: Variações angulares no tornozelo esquerdo. Os gráficos foram normalizados no tempo como percentual do ciclo direito da marcha. 


\section{D.4 Variações angulares: ombros e cotovelos}
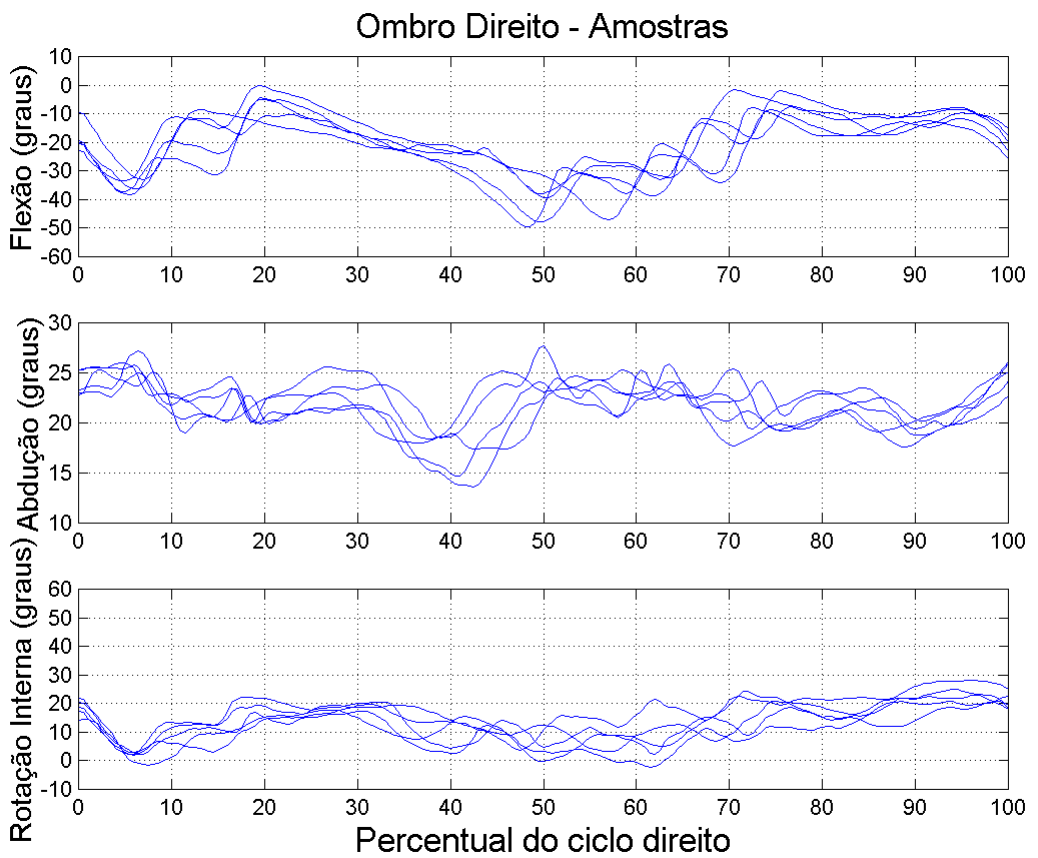

(a) Gráficos das variações angulares presentes nas cinco amostras.
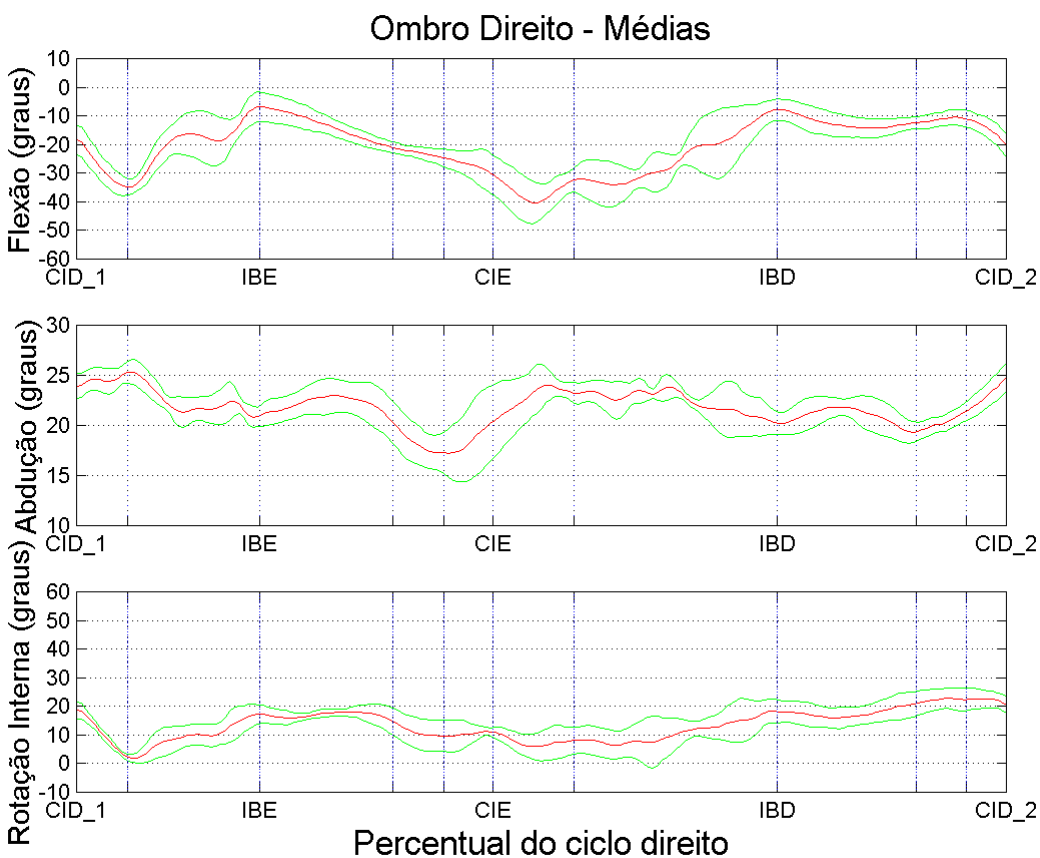

(b) Médias e desvios padrões dos dados apresentados em (a).

Figura D.10: Variações angulares no ombro direito. Os gráficos foram normalizados no tempo como percentual do ciclo direito da marcha. 

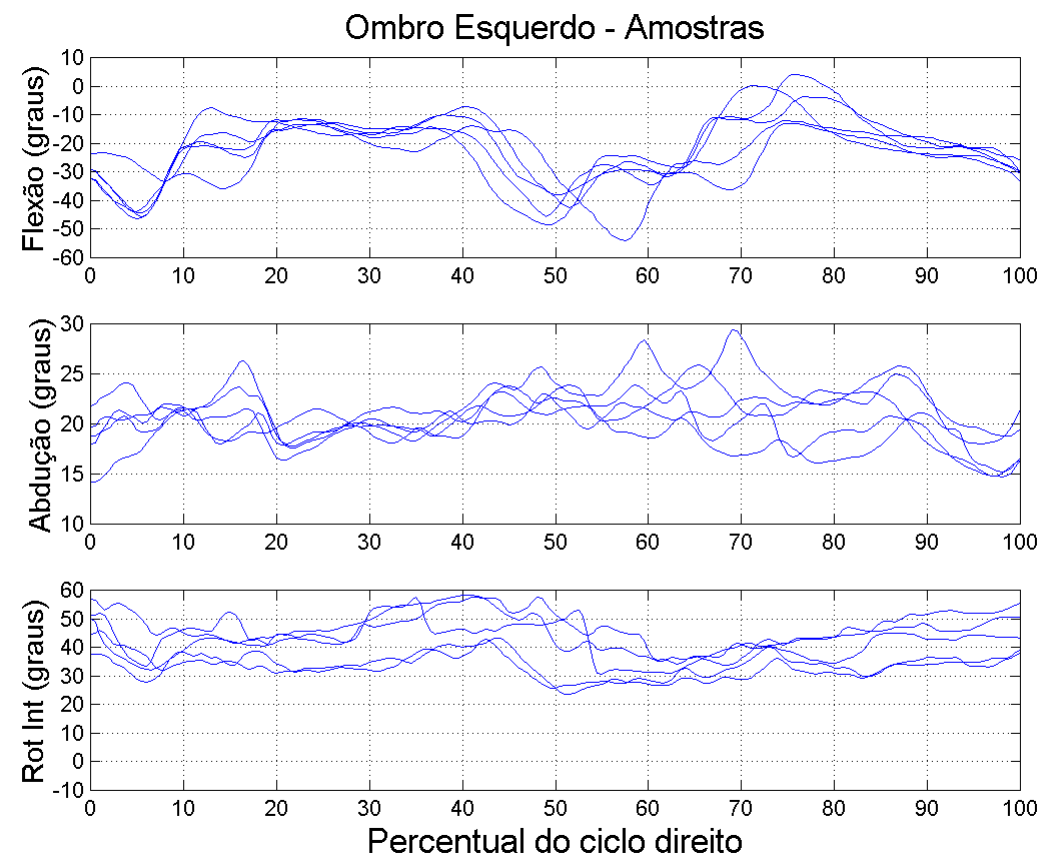

(a) Gráficos das variações angulares presentes nas cinco amostras.
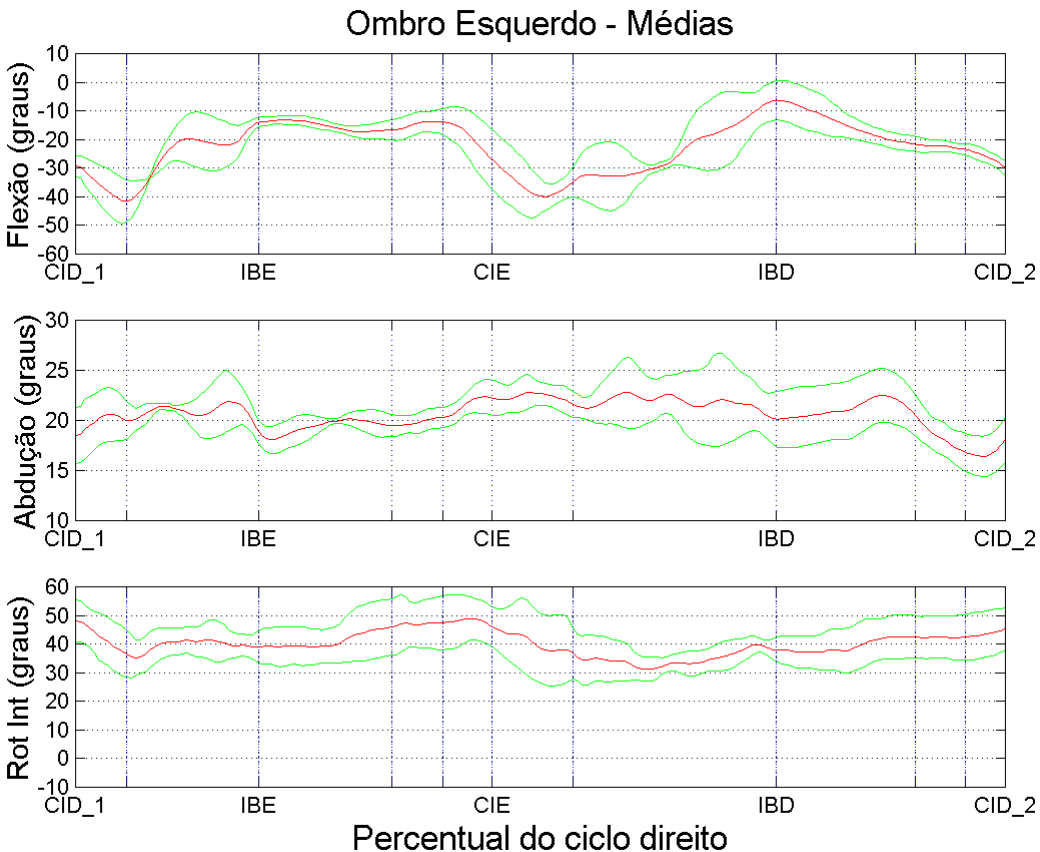

(b) Médias e desvios padrões dos dados apresentados em (a).

Figura D.11: Variações angulares no ombro esquerdo. Os gráficos foram normalizados no tempo como percentual do ciclo direito da marcha. 

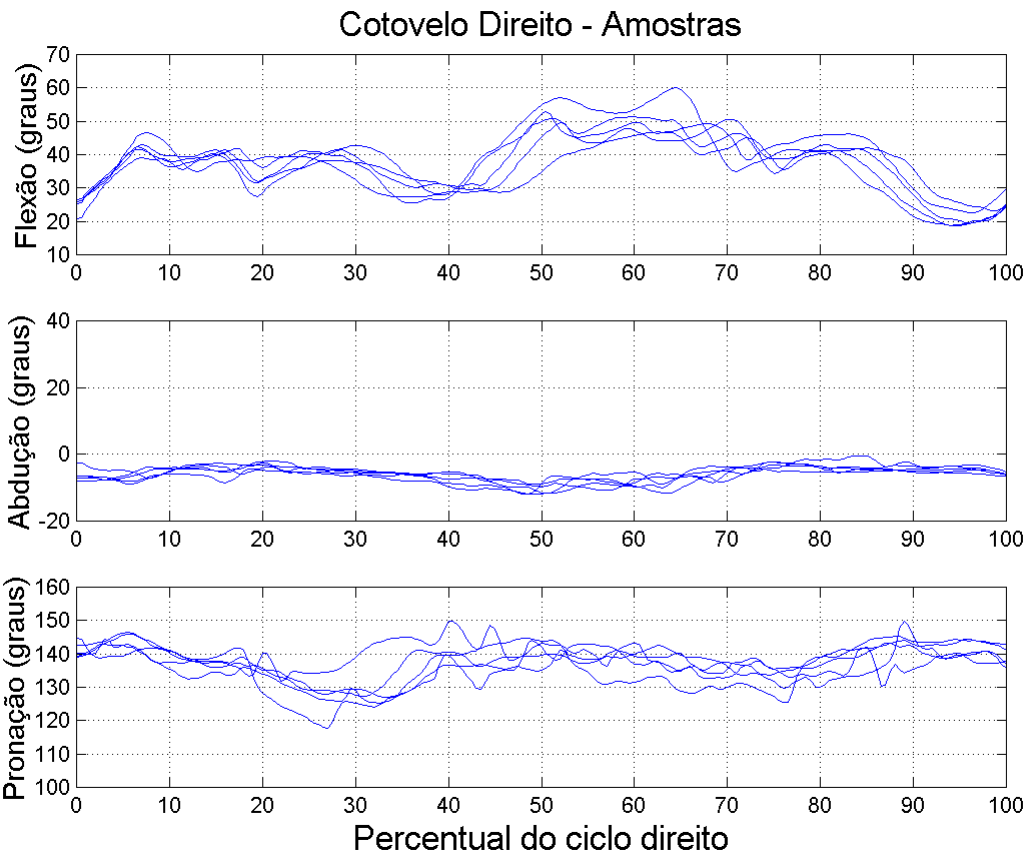

(a) Gráficos das variações angulares presentes nas cinco amostras.
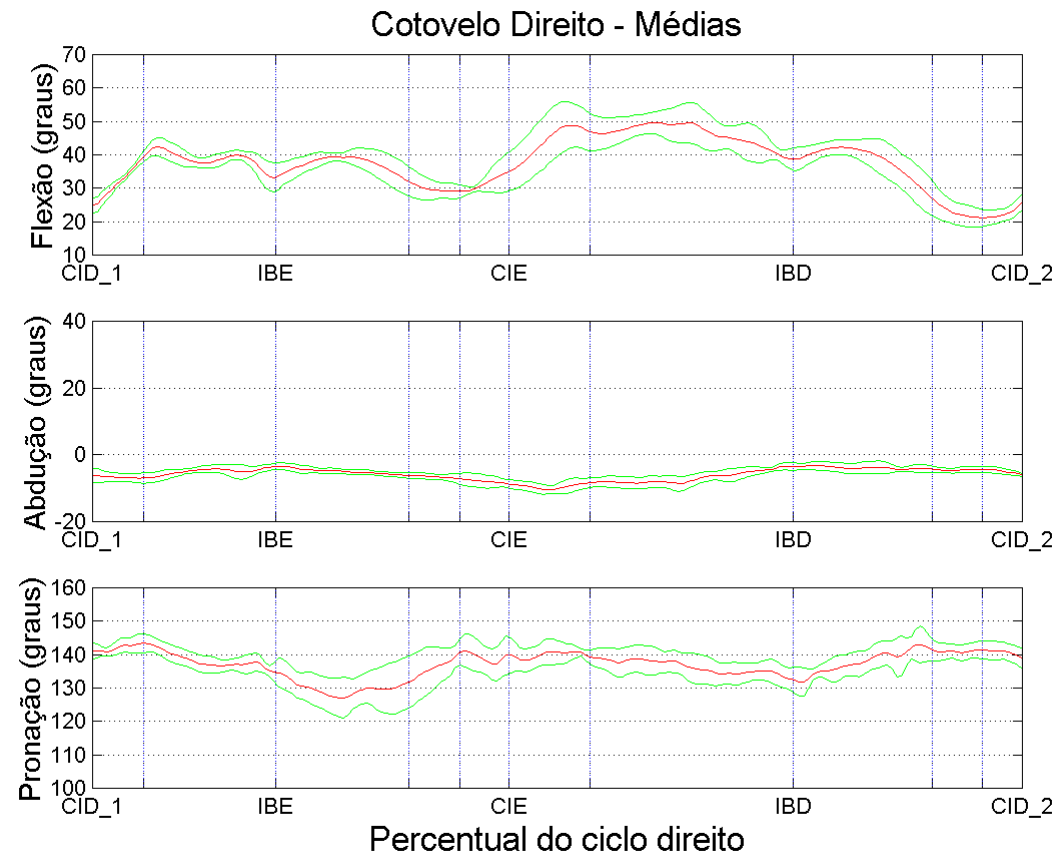

(b) Médias e desvios padrões dos dados apresentados em (a).

Figura D.12: Variações angulares no cotovelo direito. Os gráficos foram normalizados no tempo como percentual do ciclo direito da marcha. 

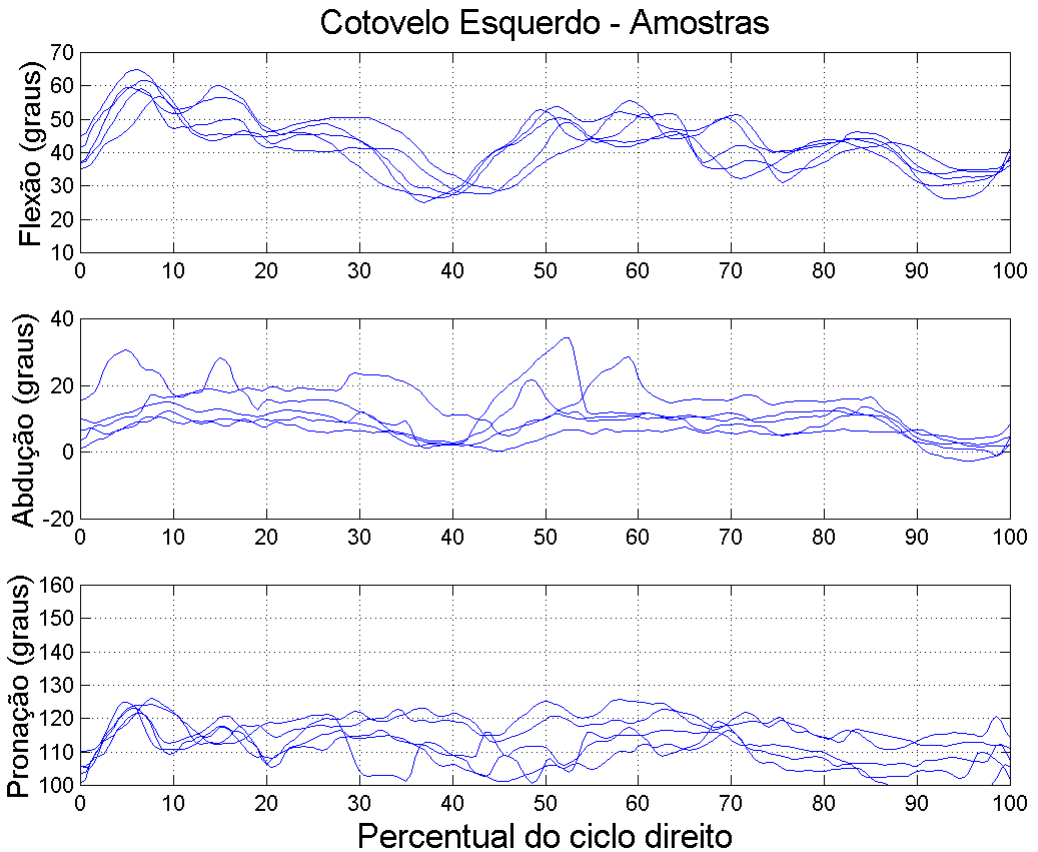

(a) Gráficos das variações angulares presentes nas cinco amostras.
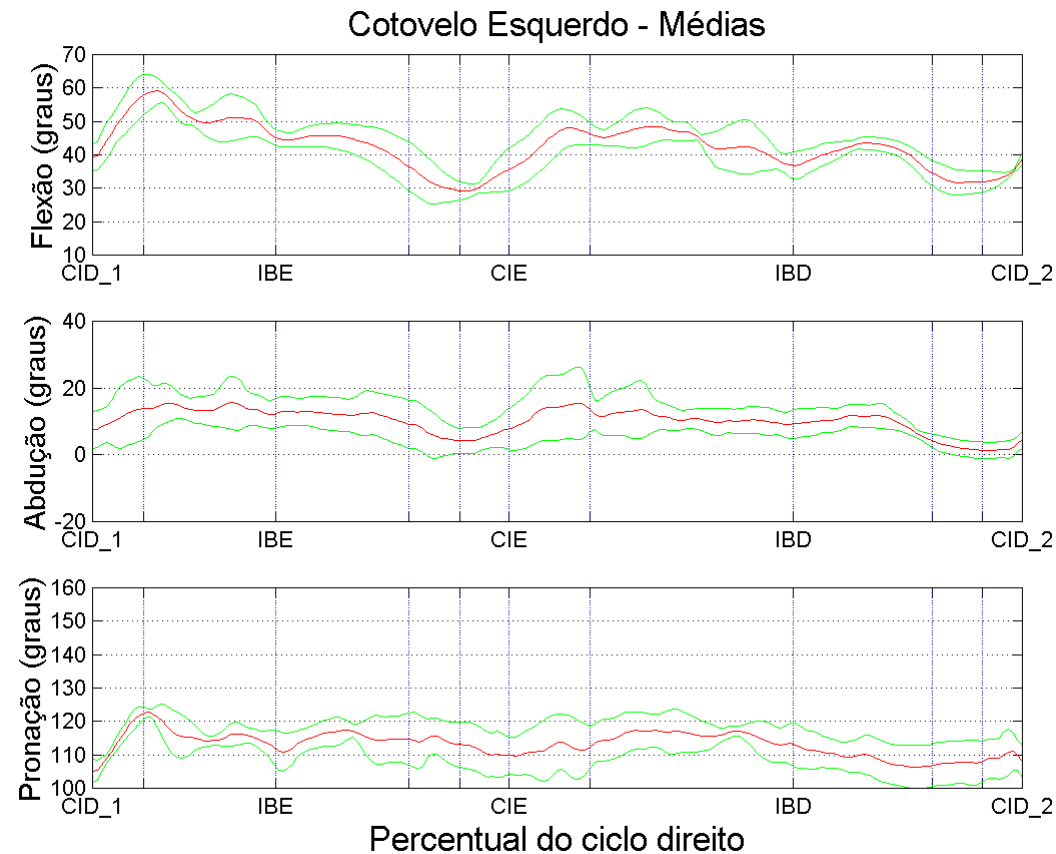

(b) Médias e desvios padrões dos dados apresentados em (a).

Figura D.13: Variações angulares no cotovelo esquerdo. Os gráficos foram normalizados no tempo como percentual do ciclo direito da marcha. 


\section{D.5 Eletromiografia}
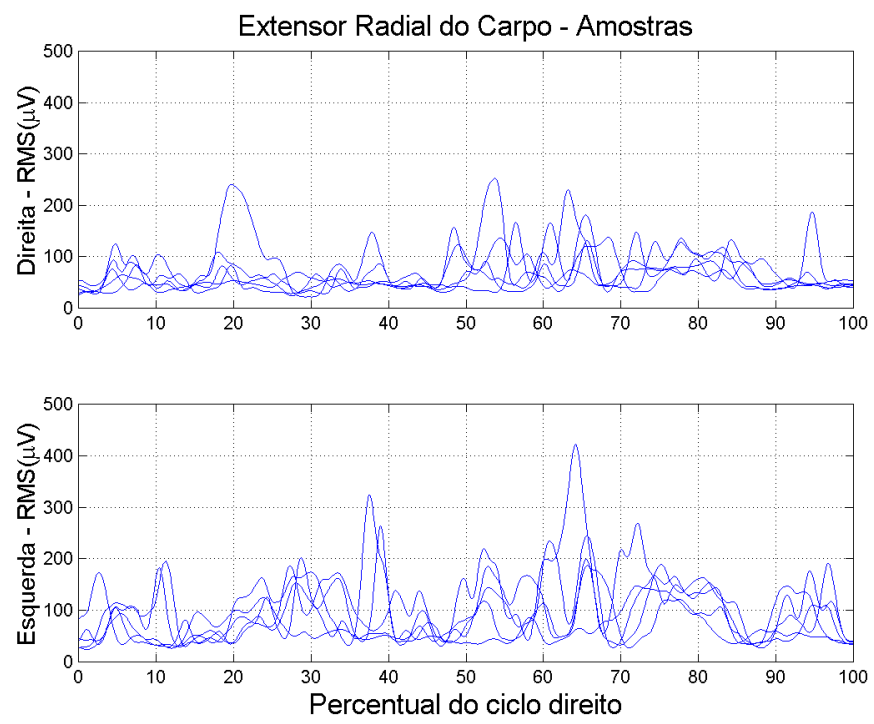

(a) Gráficos dos sinais presentes nas cinco amostras.
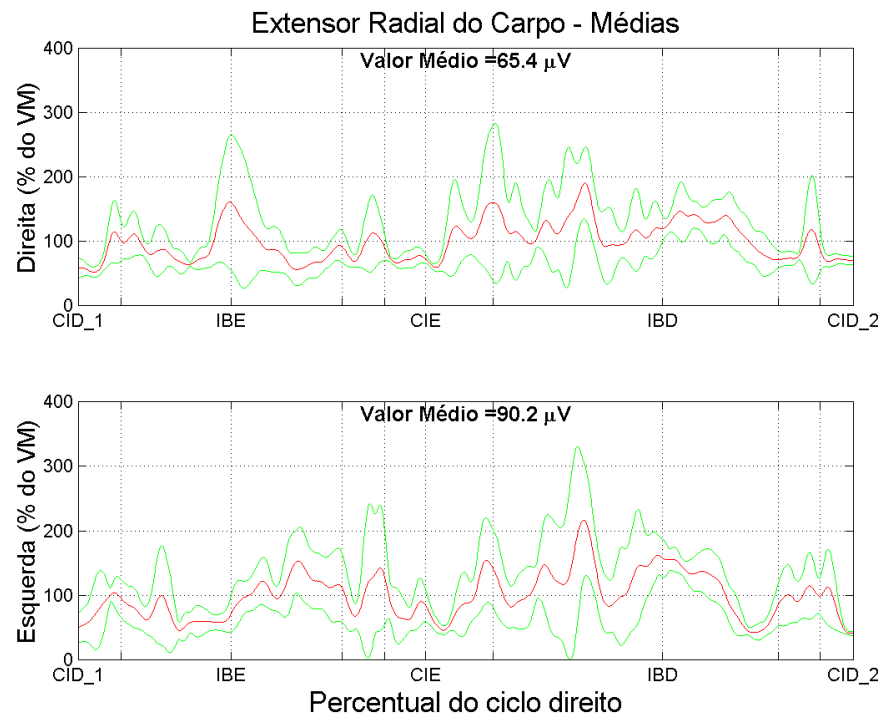

(b) Médias e desvios padrões dos dados apresentados em (a). Cada gráfico foi normalizado pelo valor médio ( $\boldsymbol{V} \boldsymbol{M})$ da média das cinco amostras.

Figura D.14: Eletromiografia do extensor radial do carpo (nos dois braços). Os gráficos foram normalizados no tempo como percentual do ciclo direito da marcha. 

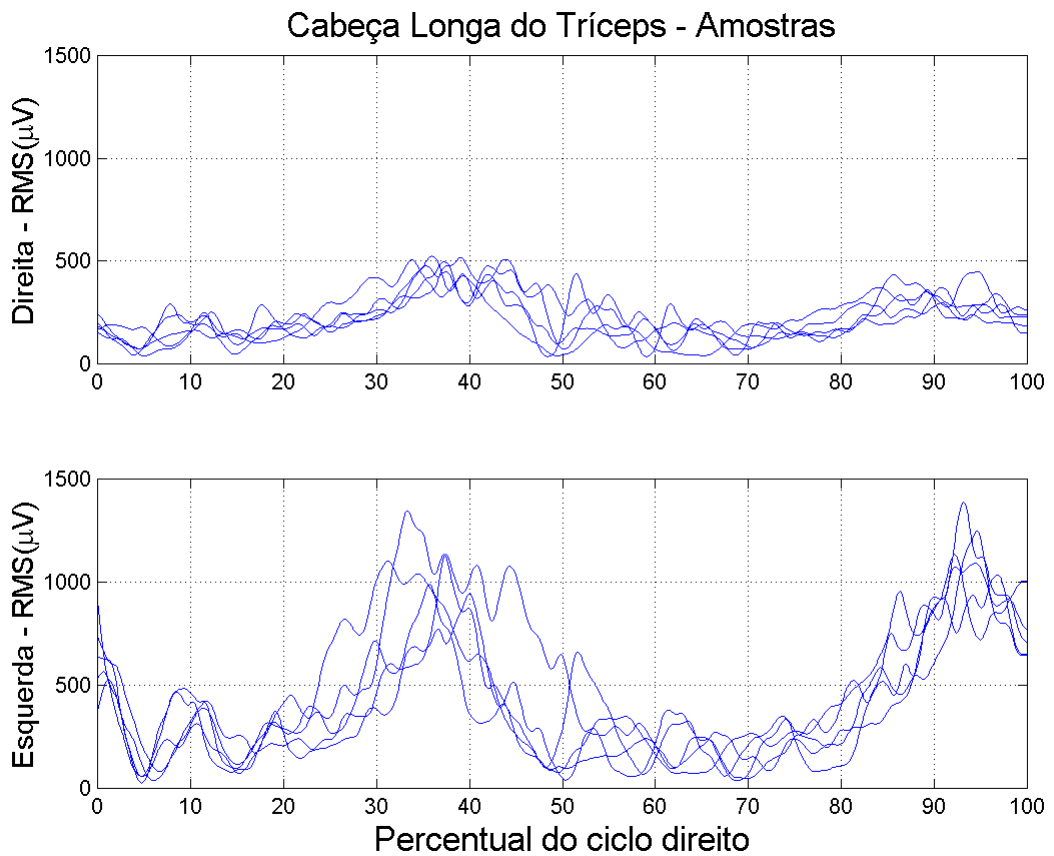

(a) Gráficos dos sinais presentes nas cinco amostras.
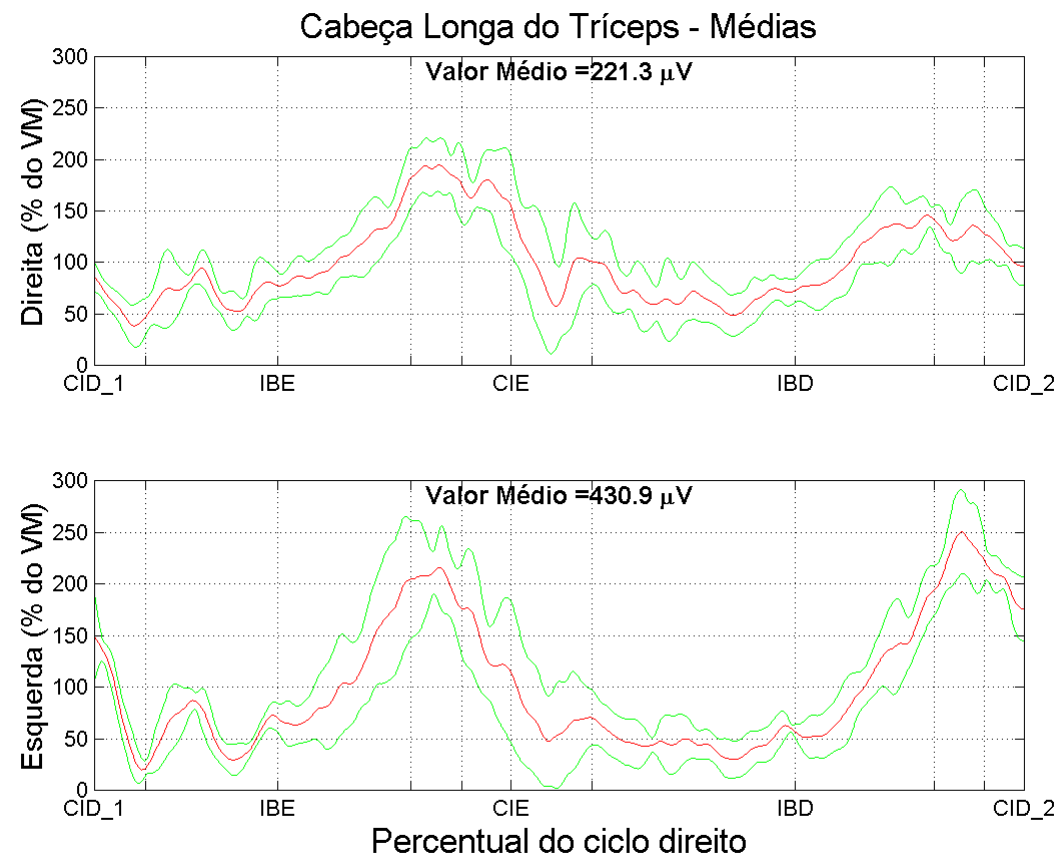

(b) Médias e desvios padrões dos dados apresentados em (a). Cada gráfico foi normalizado pelo valor médio ( $\boldsymbol{V M}$ ) da média das cinco amostras.

Figura D.15: Eletromiografia do cabeça longa do tríceps (nos dois braços). Os gráficos foram normalizados no tempo como percentual do ciclo direito da marcha. 

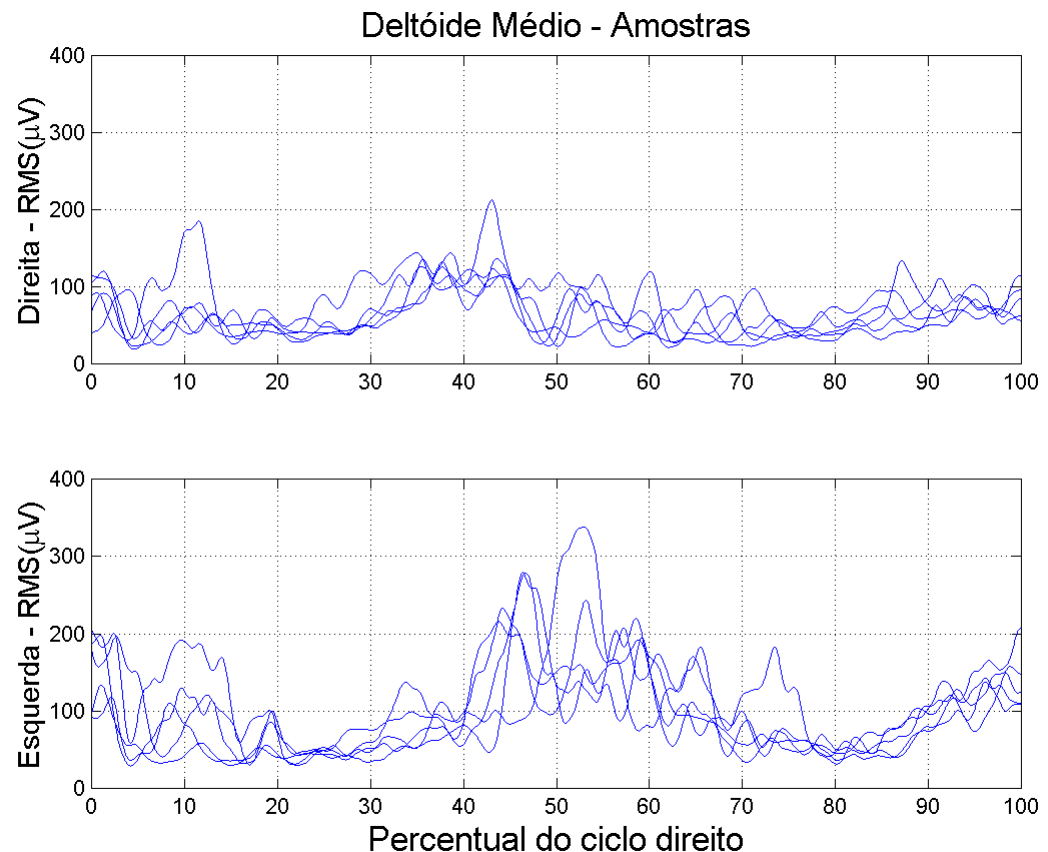

(a) Gráficos dos sinais presentes nas cinco amostras.
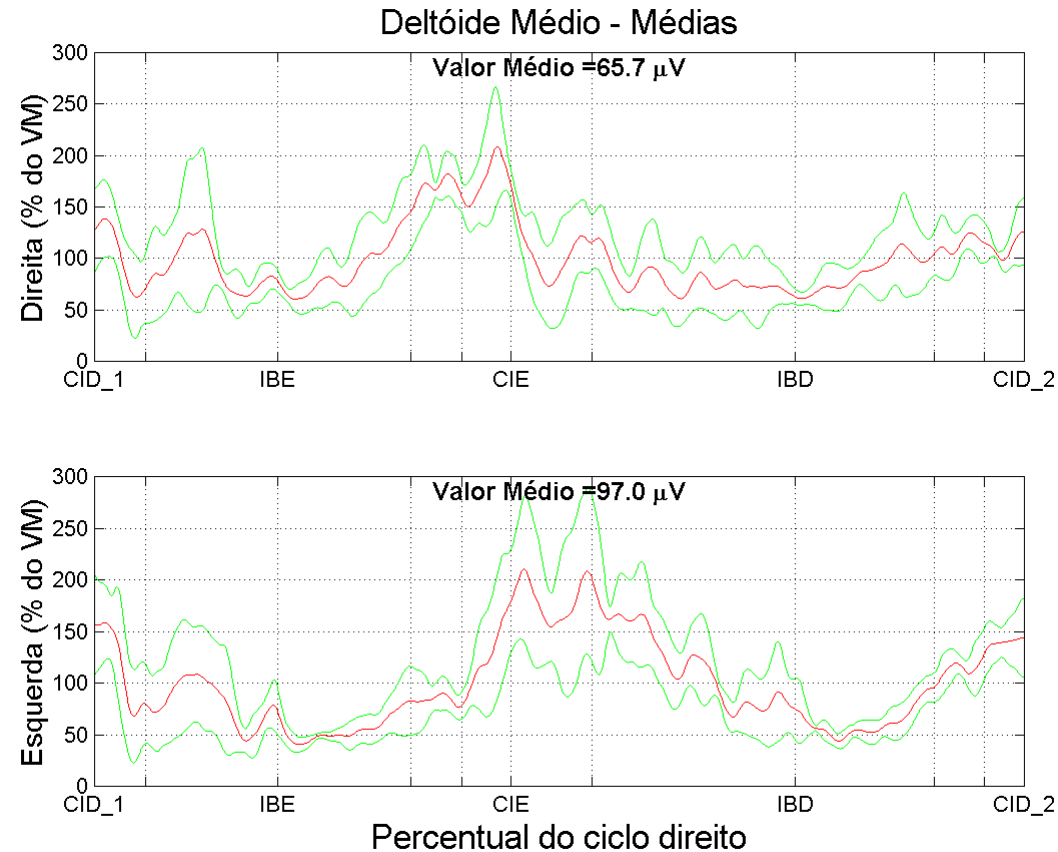

(b) Médias e desvios padrões dos dados apresentados em (a). Cada gráfico foi normalizado pelo valor médio $(\boldsymbol{V} \boldsymbol{M})$ da média das cinco amostras.

Figura D.16: Eletromiografia do deltóide médio (nos dois braços). Os gráficos foram normalizados no tempo como percentual do ciclo direito da marcha. 

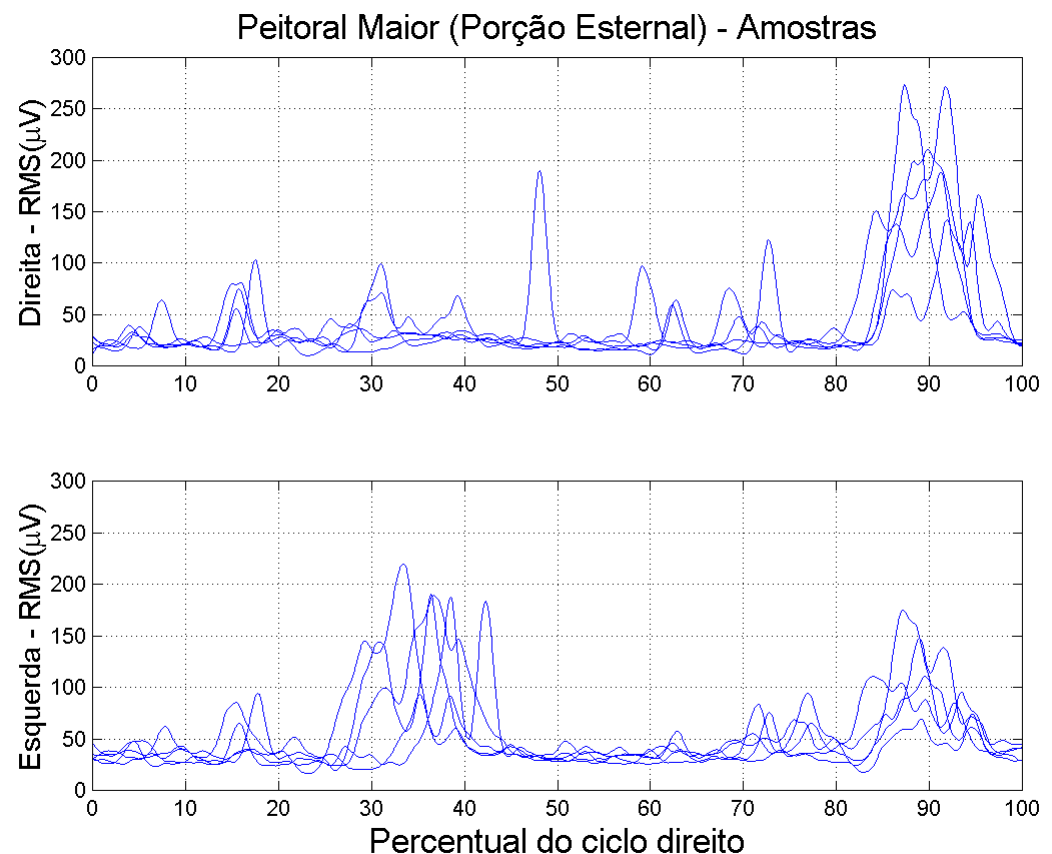

(a) Gráficos dos sinais presentes nas cinco amostras.
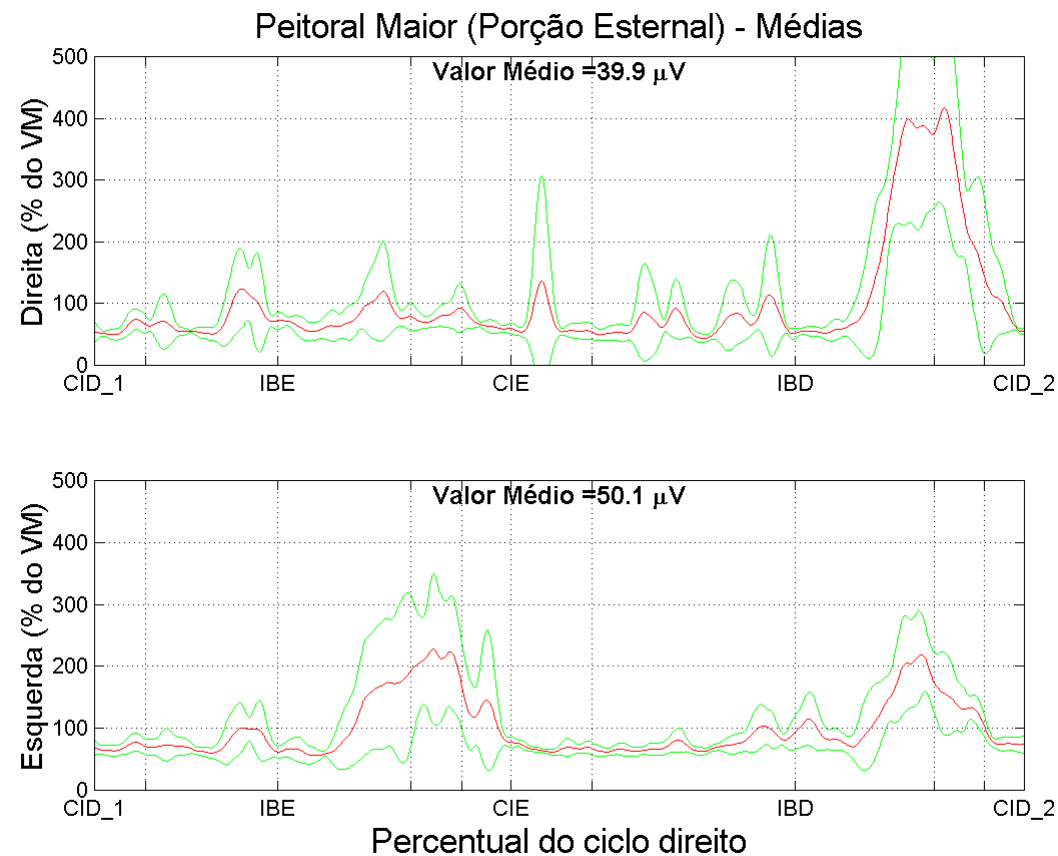

(b) Médias e desvios padrões dos dados apresentados em (a). Cada gráfico foi normalizado pelo valor médio ( $\boldsymbol{V M}$ ) da média das cinco amostras.

Figura D.17: Eletromiografia da porção esternal do peitoral maior. Os gráficos foram normalizados no tempo como percentual do ciclo direito da marcha. 


\section{D.6 Componente vertical da força de reação do solo}
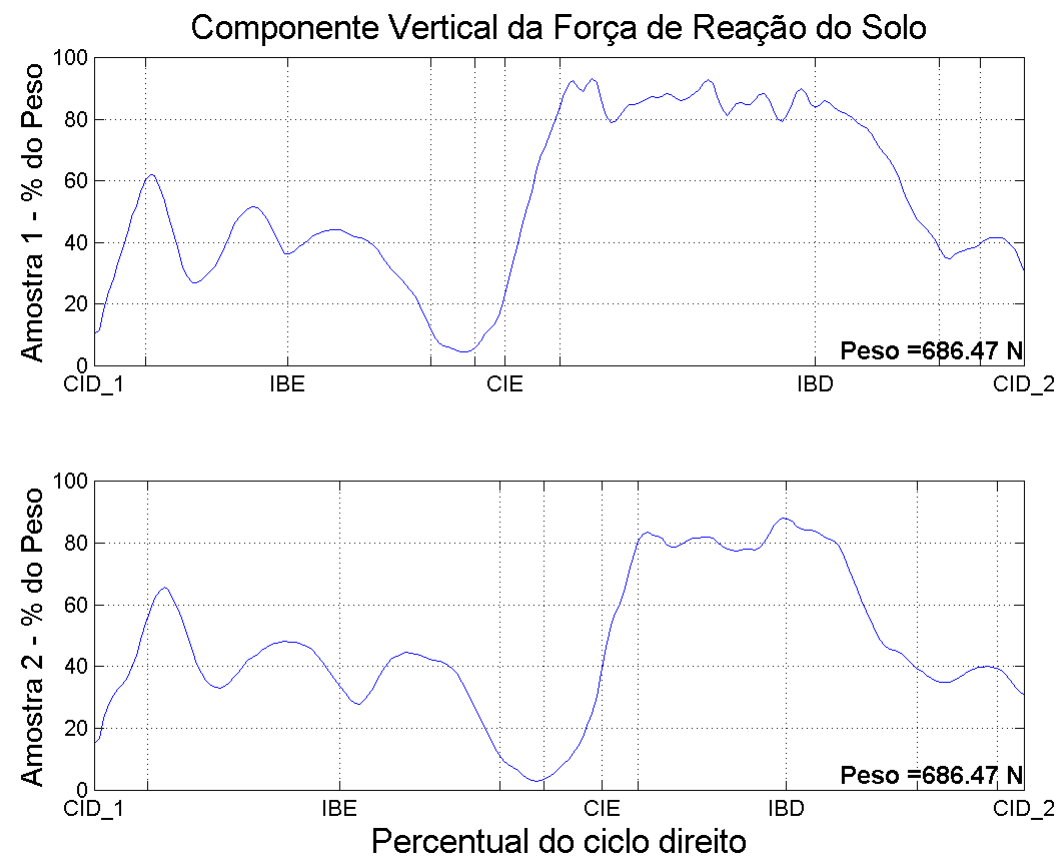

Figura D.18: Duas amostras da componente vertical da força de reação do solo conseqüente da ação dos pés do paciente sobre a plataforma de força durante a deambulação. Os gráficos foram normalizados no tempo como percentual do ciclo direito da marcha, e normalizados em amplitude como percentual do peso do paciente em Newtons.

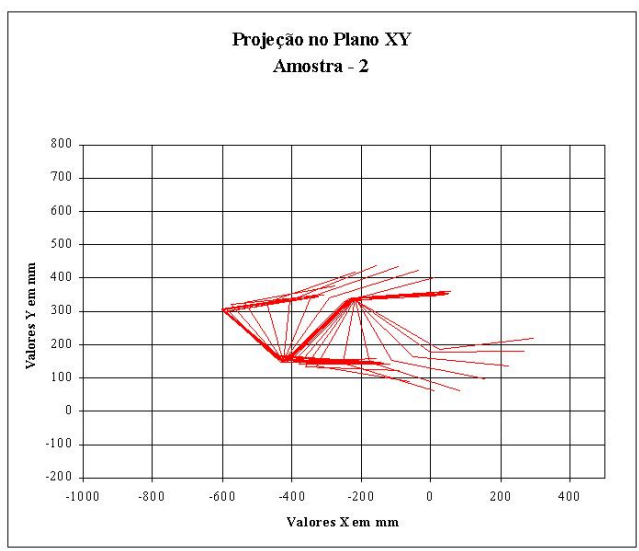

(a) Amostra 1

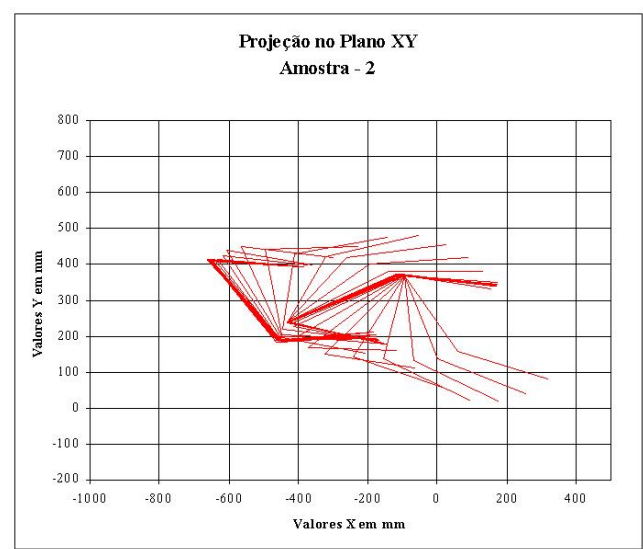

(b) Amostra 2

Figura D.19: Projeção do movimento dos pés do paciente sobre a plataforma de força no plano horizontal $(X Y)$. 


\section{Apêndice E}

\section{Paciente E}

Este apêndice apresentará os resultados do exame realizado no dia 27/06/2002. O conjunto de resultados é constituído por: as características da passada, variações angulares tridimensionais nos membros inferiores (pélvis, quadris, joelhos e tornozelos) e superiores (ombros, cotovelos, e tronco), eletromiografia de músculos dos membros superiores (peitoral maior, deltóide médio, cabeça longa do tríceps, extensor radial do carpo) e componente vertical da força de reação do solo.

\section{E.1 Características do paciente}

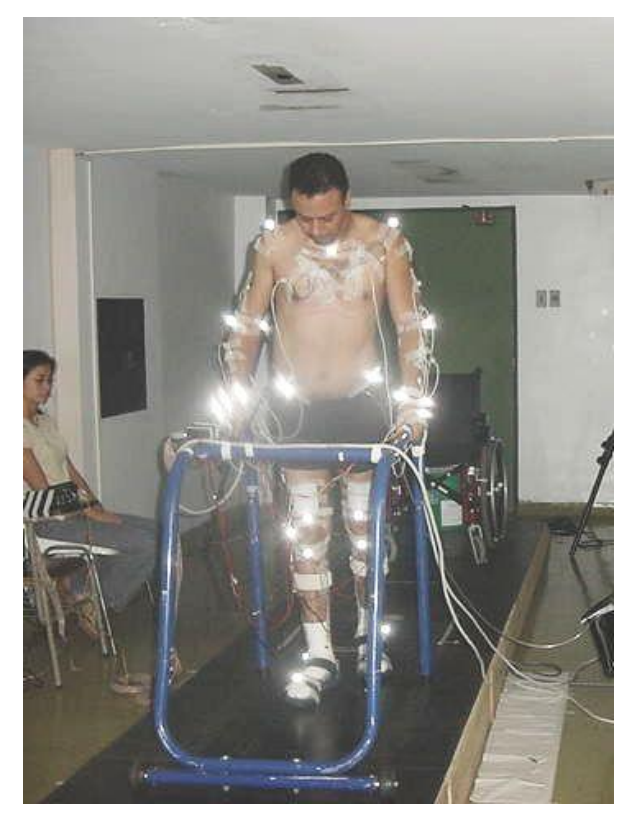

Figura E.1: Paciente E - Foto tirada durante um dos ensaios. O arquivo no formato PDF possui direcionamento para vídeo ao clicar na foto, desde que o QuickTime esteja instalado. Para abrir o vídeo fora do arquivo PDF, usando outro programa, clique aqui. 


\begin{tabular}{ccccccc}
\hline Nome & Idade & Nível da lesão & Causa & $\begin{array}{c}\text { Tempo da lesão } \\
(\text { anos })\end{array}$ & $\begin{array}{c}\text { Peso } \\
(\mathrm{Kg})\end{array}$ & $\begin{array}{c}\text { Altura } \\
(\mathrm{m})\end{array}$ \\
\hline \hline $\mathrm{E}$ & 35 & T11 & Cirurgia & 3 & 80 & 1,80 \\
\hline \hline
\end{tabular}

Tabela E.1: Dados dos pacientes

\section{E.2 Características da passada}

\begin{tabular}{ccccccc}
\hline Amostras & $\begin{array}{c}\text { Cadência } \\
(\text { passos/min })\end{array}$ & $\begin{array}{c}\text { Velocidade } \\
(\mathrm{cm} / \mathrm{s})\end{array}$ & $\begin{array}{c}\text { Passada } \\
(\mathrm{m})\end{array}$ & $\begin{array}{c}\text { Tempo do ciclo } \\
(\mathrm{s})\end{array}$ & $\begin{array}{c}\text { Apoio direito } \\
(\%)\end{array}$ & $\begin{array}{c}\text { Apoio esquerdo } \\
(\%)\end{array}$ \\
\hline \hline 1 & 18,00 & 7,50 & 0,50 & 6,70 & 90,50 & 86,50 \\
2 & 17,00 & 7,08 & 0,50 & 6,90 & 90,80 & 90,10 \\
3 & 16,00 & 5,33 & 0,40 & 7,30 & 91,60 & 84,40 \\
4 & 18,00 & 7,50 & 0,50 & 6,60 & 91,60 & 89,10 \\
7 & 21,00 & 10,50 & 0,60 & 5,70 & 87,90 & 83,50 \\
Média & 18,00 & 7,58 & 0,50 & 6,64 & & \\
Desvio & 1,87 & 1,86 & 0,07 & 0,59 & 1,52 & 86,72 \\
\hline \hline
\end{tabular}

Tabela E.2: Parâmetros temporais

\begin{tabular}{cccccccccccc}
\hline Amostras & $\begin{array}{c}C I D_{1} \\
(\%)\end{array}$ & $\begin{array}{c}I A A_{1} \\
(\%)\end{array}$ & $\begin{array}{c}I B E \\
(\%)\end{array}$ & $\begin{array}{c}D P E \\
(\%)\end{array}$ & $\begin{array}{c}M B E \\
(\%)\end{array}$ & $\begin{array}{c}C I E \\
(\%)\end{array}$ & $\begin{array}{c}I A A_{2} \\
(\%)\end{array}$ & $\begin{array}{c}I B D \\
(\%)\end{array}$ & $\begin{array}{c}D P D \\
(\%)\end{array}$ & $\begin{array}{c}M B D \\
(\%)\end{array}$ & $\begin{array}{c}C I D_{2} \\
(\%)\end{array}$ \\
\hline \hline 1 & 0.0 & 6.3 & 25.3 & 41.8 & 45.8 & 53.5 & 60.8 & 74.8 & 90.5 & 94.0 & 100.0 \\
2 & 0.0 & 10.4 & 24.8 & 40.5 & 43.9 & 50.1 & 60.5 & 78.6 & 90.8 & 94.2 & 100.0 \\
3 & 0.0 & 9.5 & 33.8 & 36.1 & 40.1 & 52.2 & 61.9 & 75.7 & 91.6 & 95.7 & 100.0 \\
4 & 0.0 & 7.6 & 29.7 & 32.2 & 38.3 & 42.6 & 49.7 & 78.2 & 91.6 & 94.2 & 100.0 \\
7 & 0.0 & 8.8 & 28.6 & 34.8 & 42.5 & 51.3 & 60.5 & 78.2 & 87.9 & 93.2 & 100.0 \\
& & & & & & & & & & & \\
Média & 0.0 & 8.5 & 28.4 & 37.1 & 42.1 & 49.9 & 58.7 & 77.1 & 90.5 & 94.3 & 100.0 \\
Desvio & 0.0 & 1.6 & 3.7 & 4.0 & 2.9 & 4.3 & 5.0 & 1.7 & 1.5 & 0.9 & 0.0 \\
\hline \hline
\end{tabular}

Tabela E.3: Percentuais das fases do ciclo de acordo com o descrito na sec. 4.1 


\section{E.3 Variações angulares: tronco e membros inferiores}
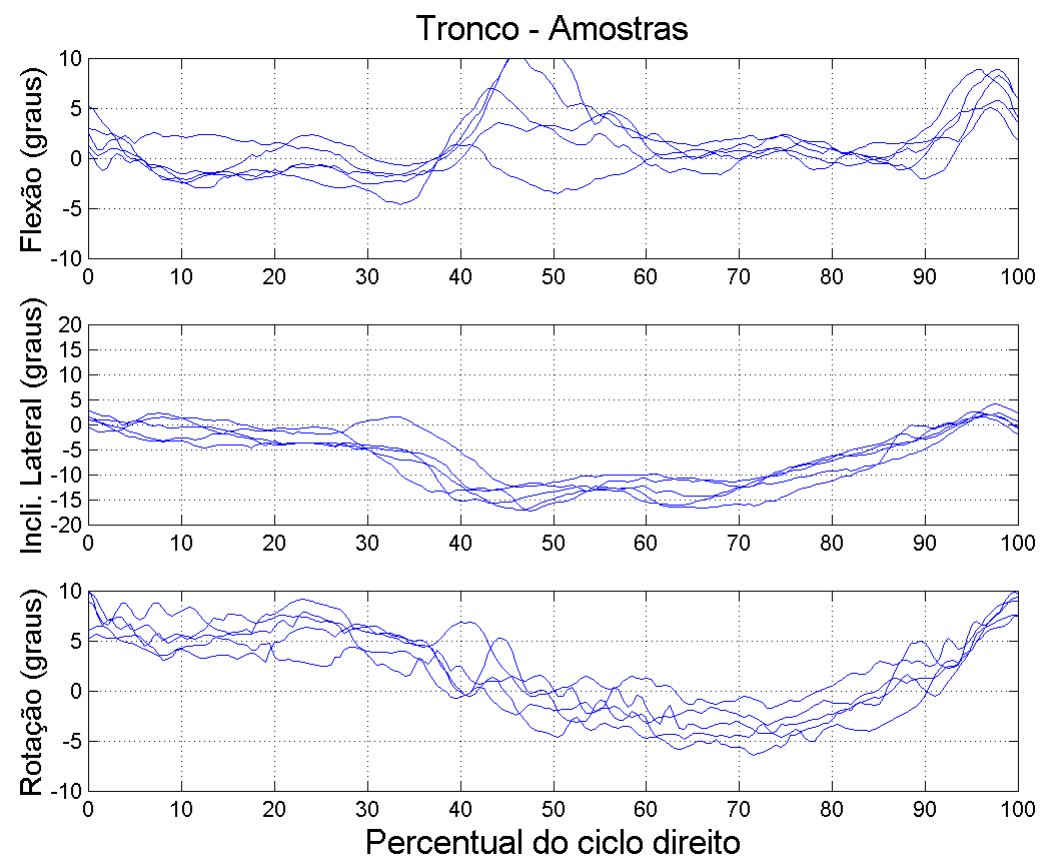

(a) Gráficos das variações angulares presentes nas cinco amostras.
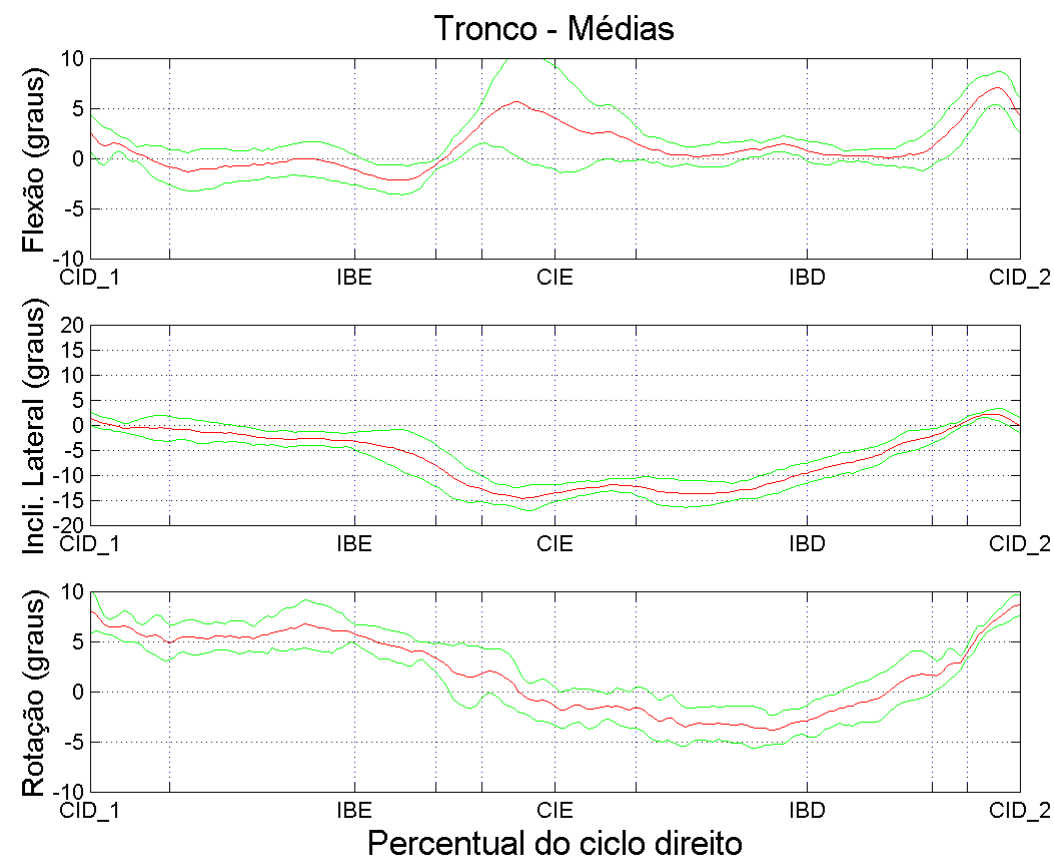

(b) Médias e desvios padrões dos dados apresentados em (a).

Figura E.2: Variações angulares do tronco. Os gráficos foram normalizados no tempo como percentual do ciclo direito da marcha. 

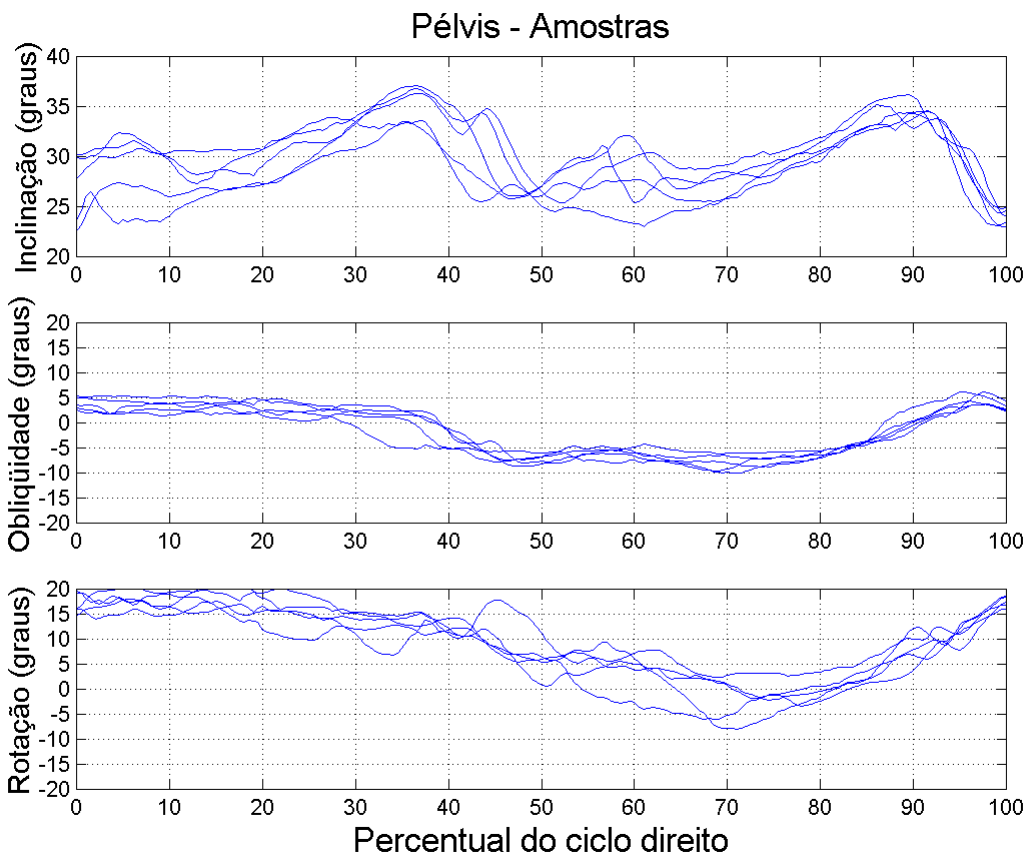

(a) Gráficos das variações angulares presentes nas cinco amostras.
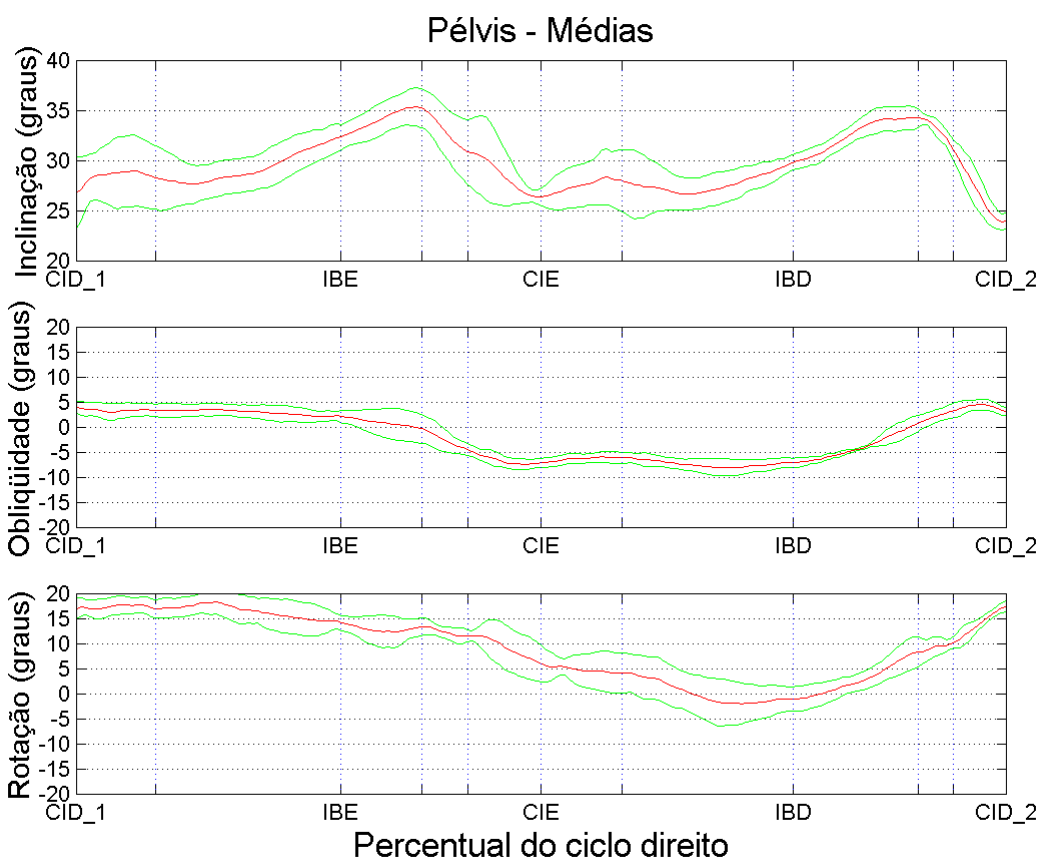

(b) Médias e desvios padrões dos dados apresentados em (a).

Figura E.3: Variações angulares do pélvis. Os gráficos foram normalizados no tempo como percentual do ciclo direito da marcha. 

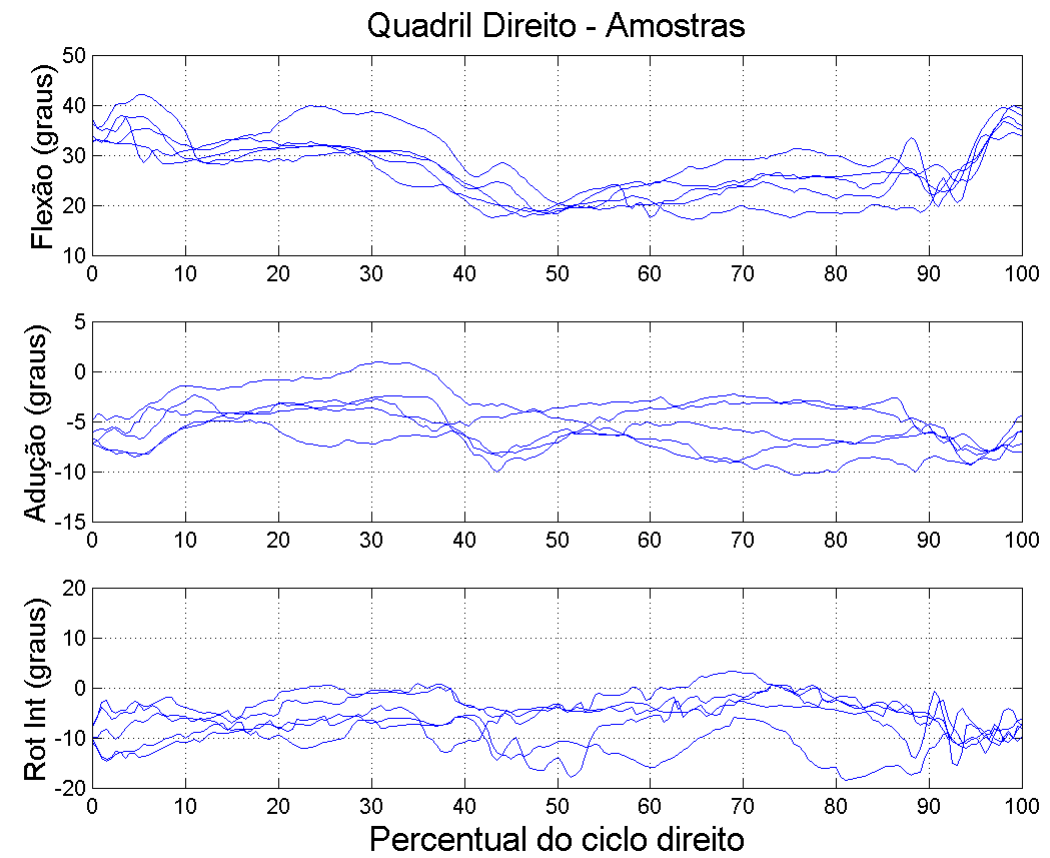

(a) Gráficos das variações angulares presentes nas cinco amostras.
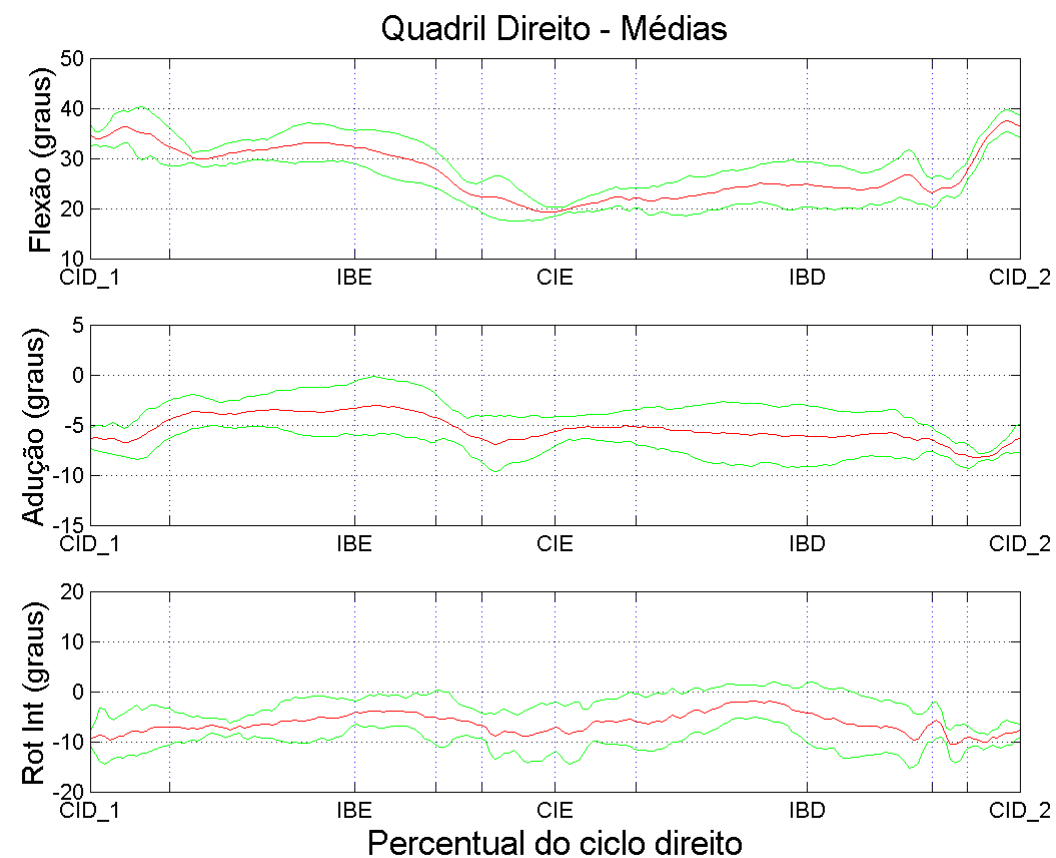

(b) Médias e desvios padrões dos dados apresentados em (a).

Figura E.4: Variações angulares no quadril direito. Os gráficos foram normalizados no tempo como percentual do ciclo direito da marcha. 

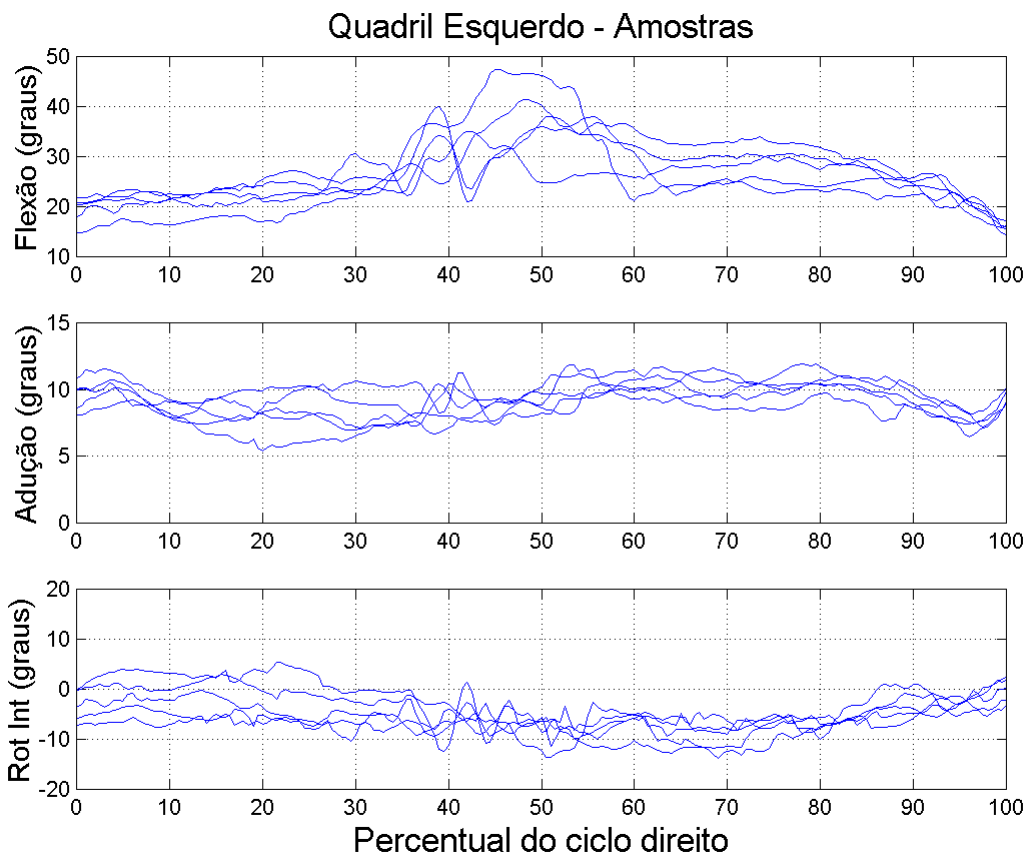

(a) Gráficos das variações angulares presentes nas cinco amostras.
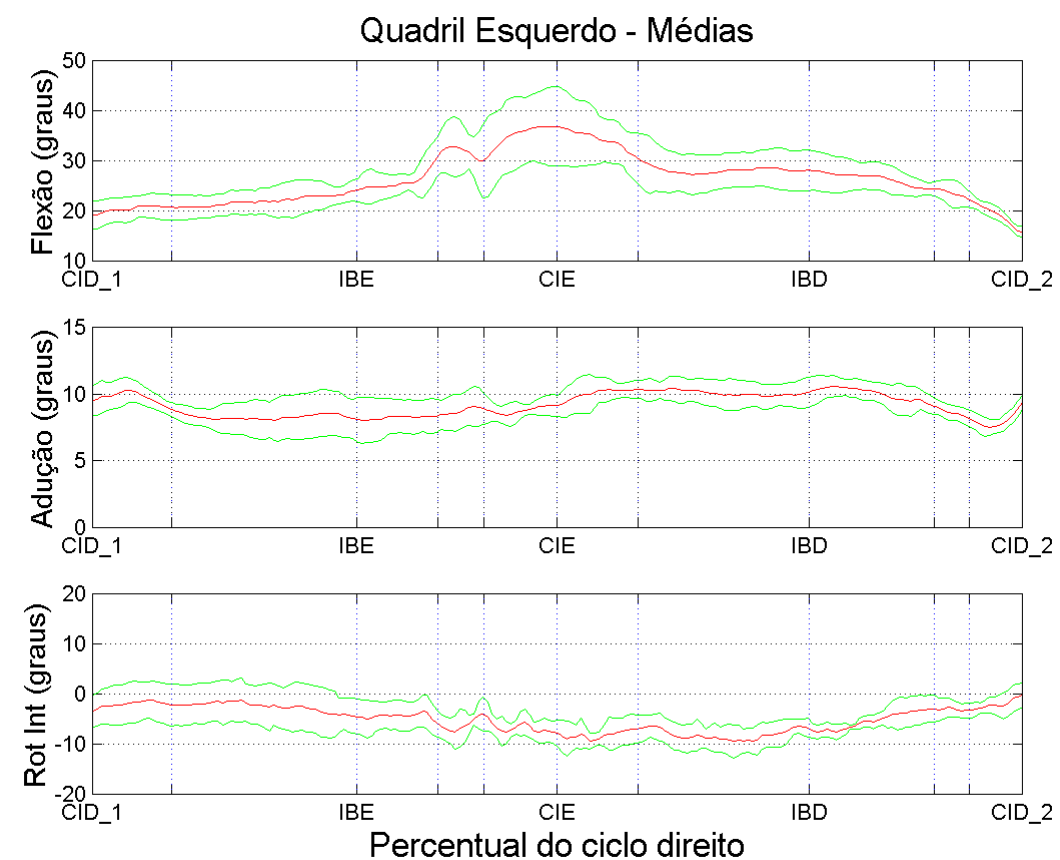

(b) Médias e desvios padrões dos dados apresentados em (a).

Figura E.5: Variações angulares no quadril esquerdo. Os gráficos foram normalizados no tempo como percentual do ciclo direito da marcha. 

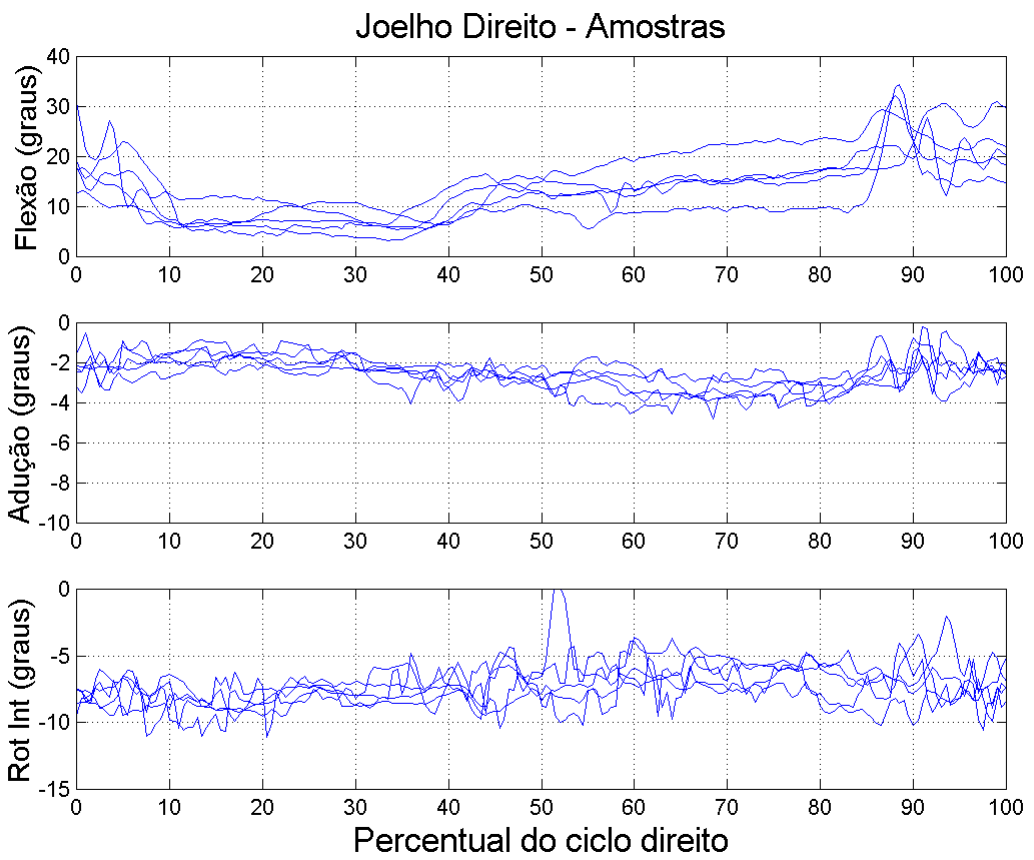

(a) Gráficos das variações angulares presentes nas cinco amostras.
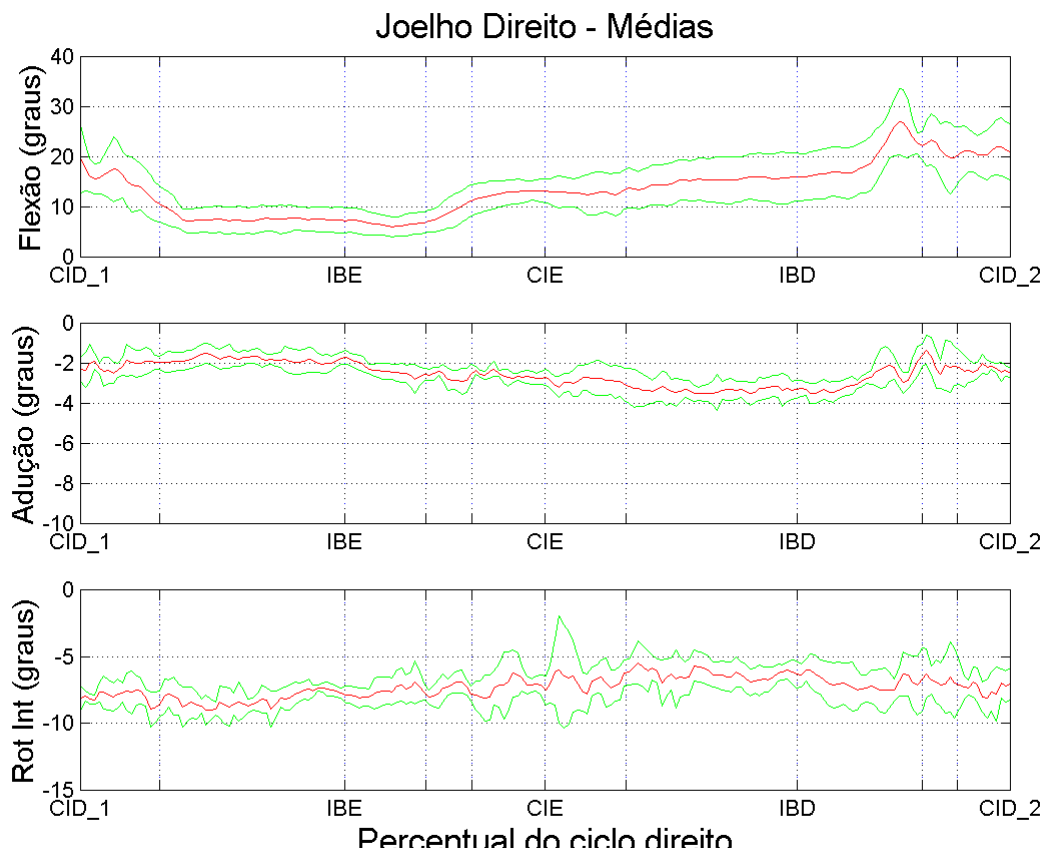

(b) Médias e desvios padrões dos dados apresentados em (a).

Figura E.6: Variações angulares no joelho direito. Os gráficos foram normalizados no tempo como percentual do ciclo direito da marcha. 

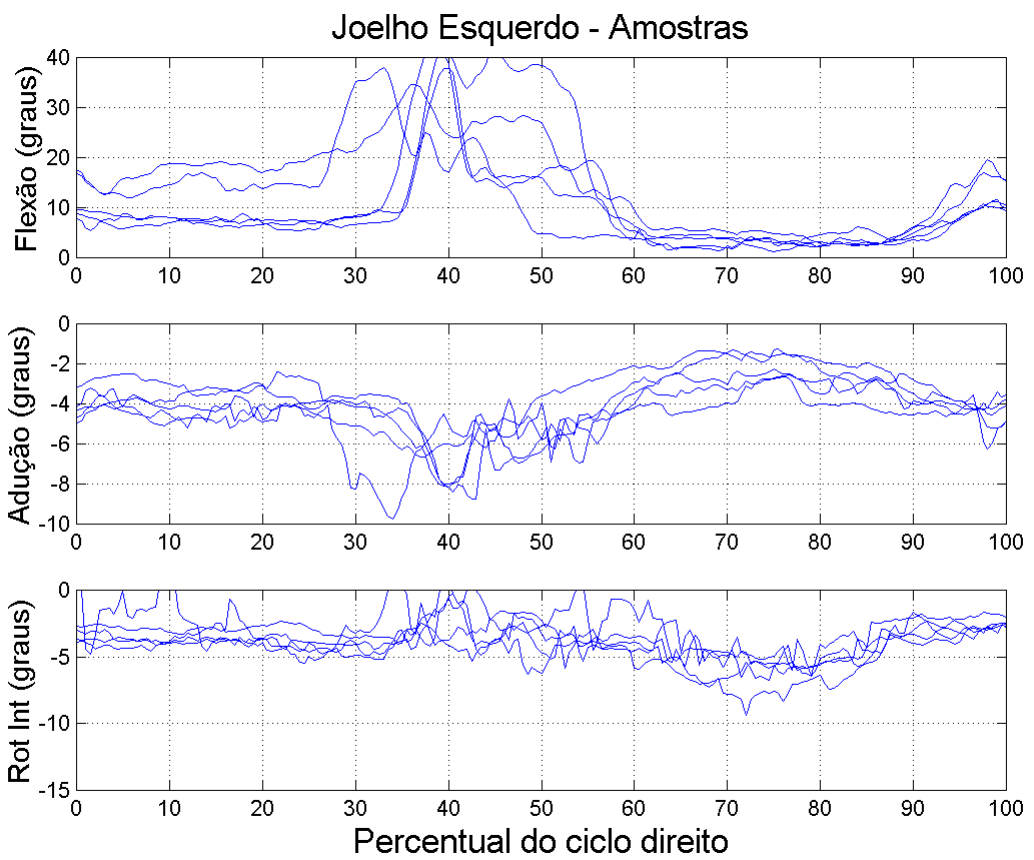

(a) Gráficos das variações angulares presentes nas cinco amostras.
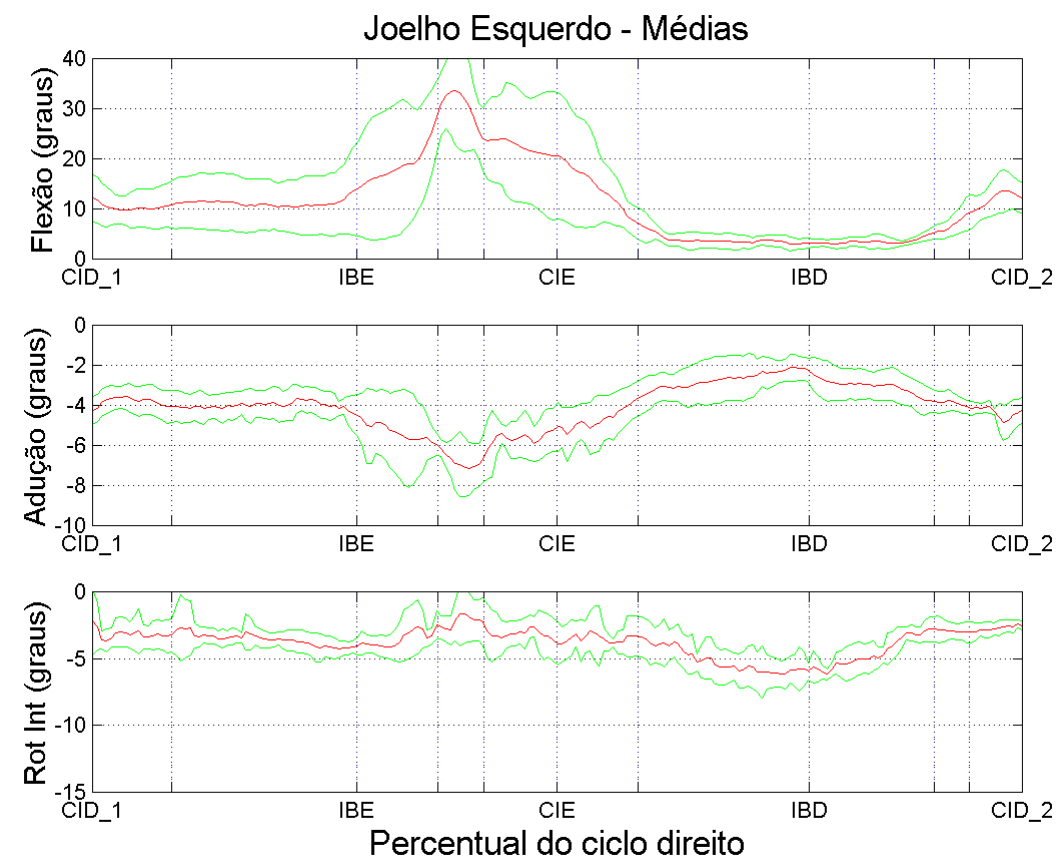

(b) Médias e desvios padrões dos dados apresentados em (a).

Figura E.7: Variações angulares no joelho esquerdo. Os gráficos foram normalizados no tempo como percentual do ciclo direito da marcha. 

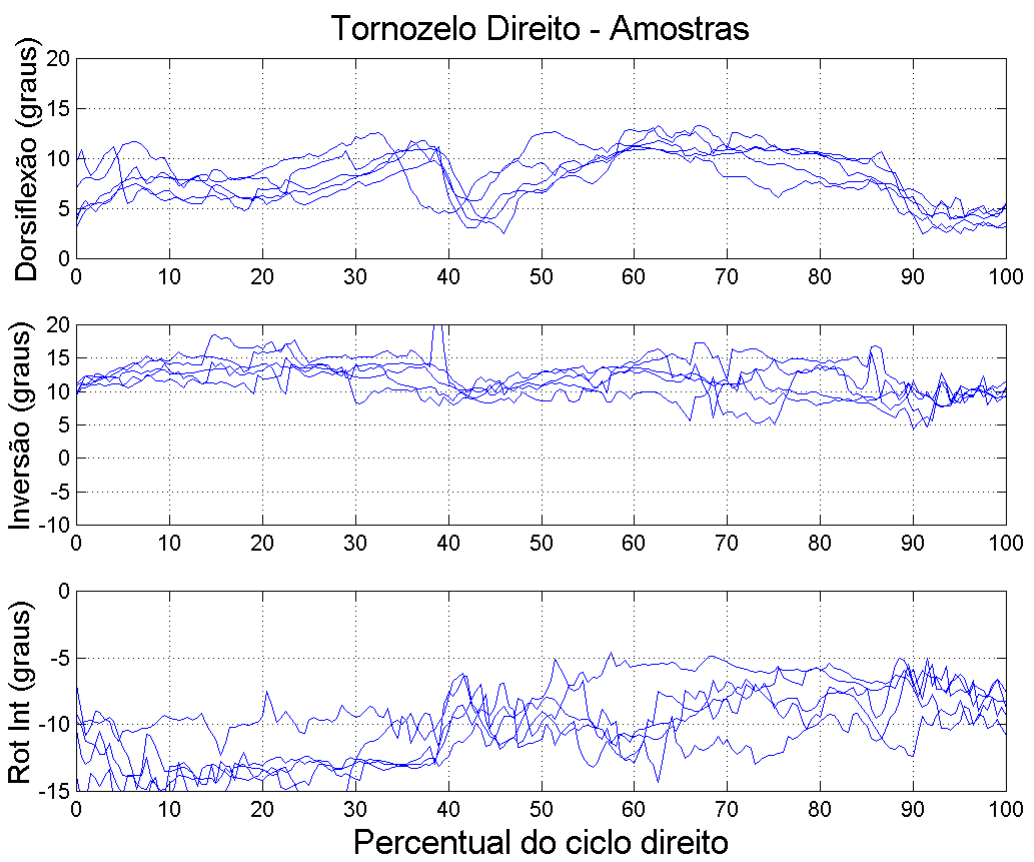

(a) Gráficos das variações angulares presentes nas cinco amostras.
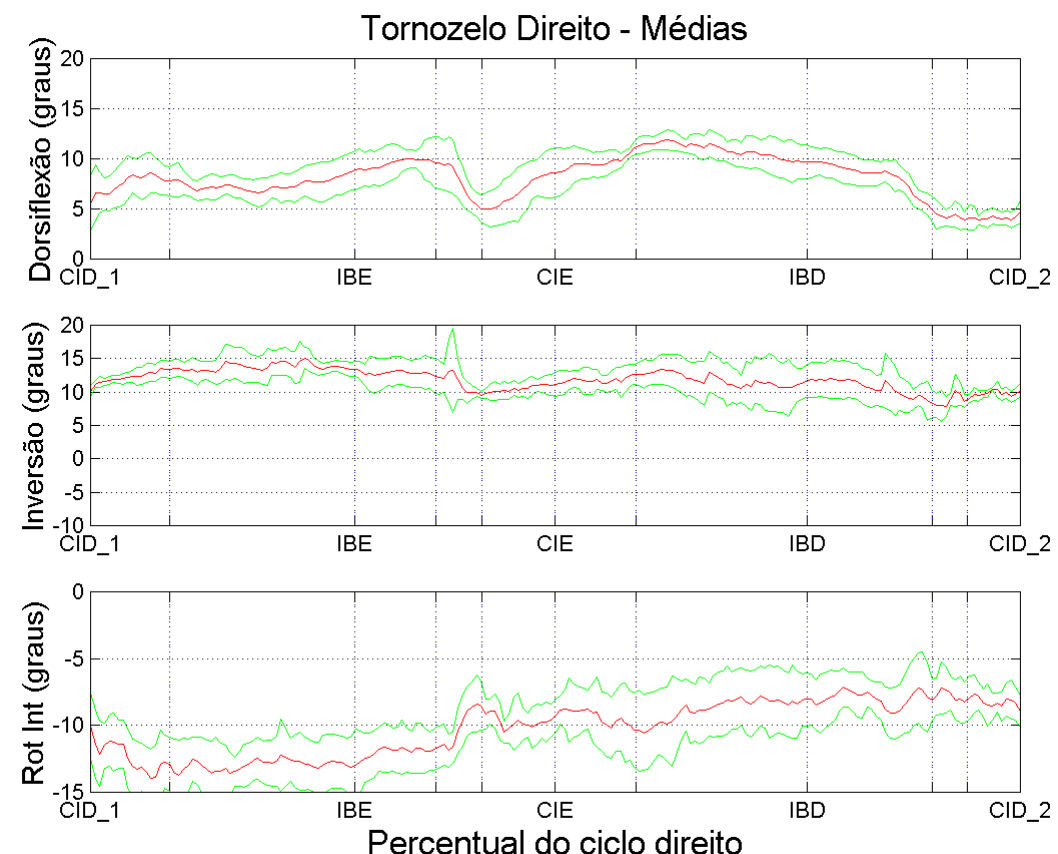

(b) Médias e desvios padrões dos dados apresentados em (a).

Figura E.8: Variações angulares no tornozelo direito. Os gráficos foram normalizados no tempo como percentual do ciclo direito da marcha. 

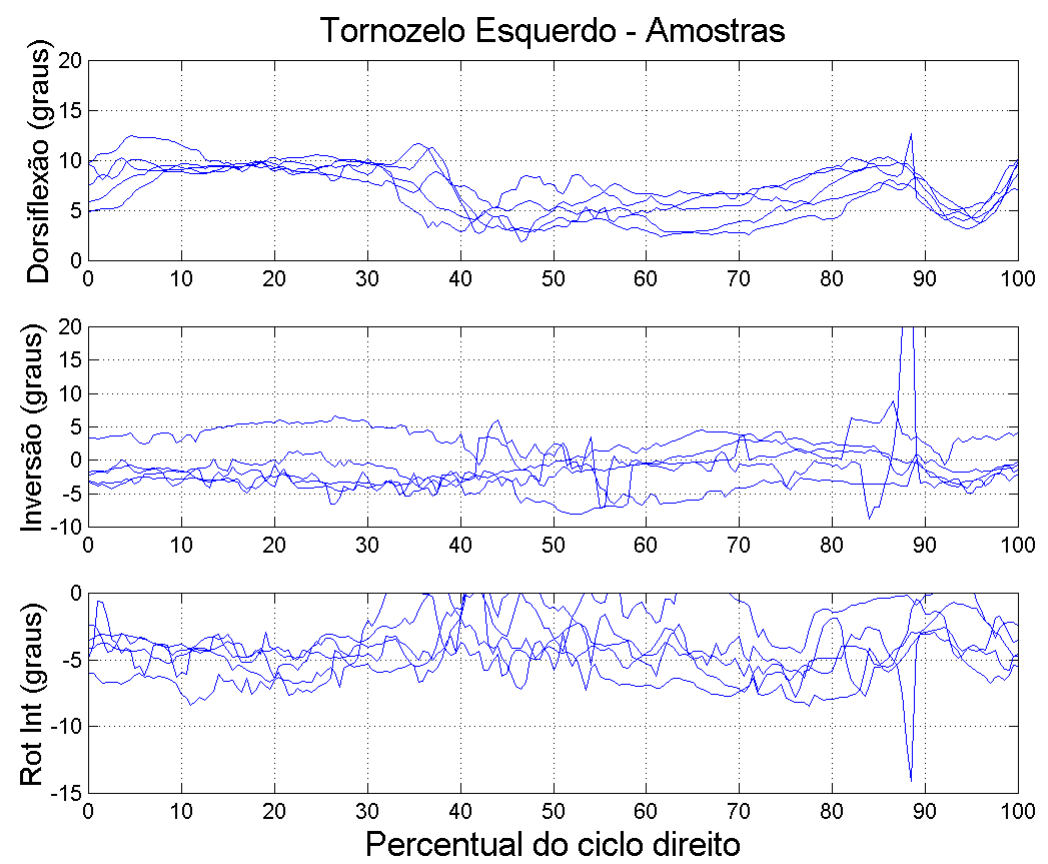

(a) Gráficos das variações angulares presentes nas cinco amostras.
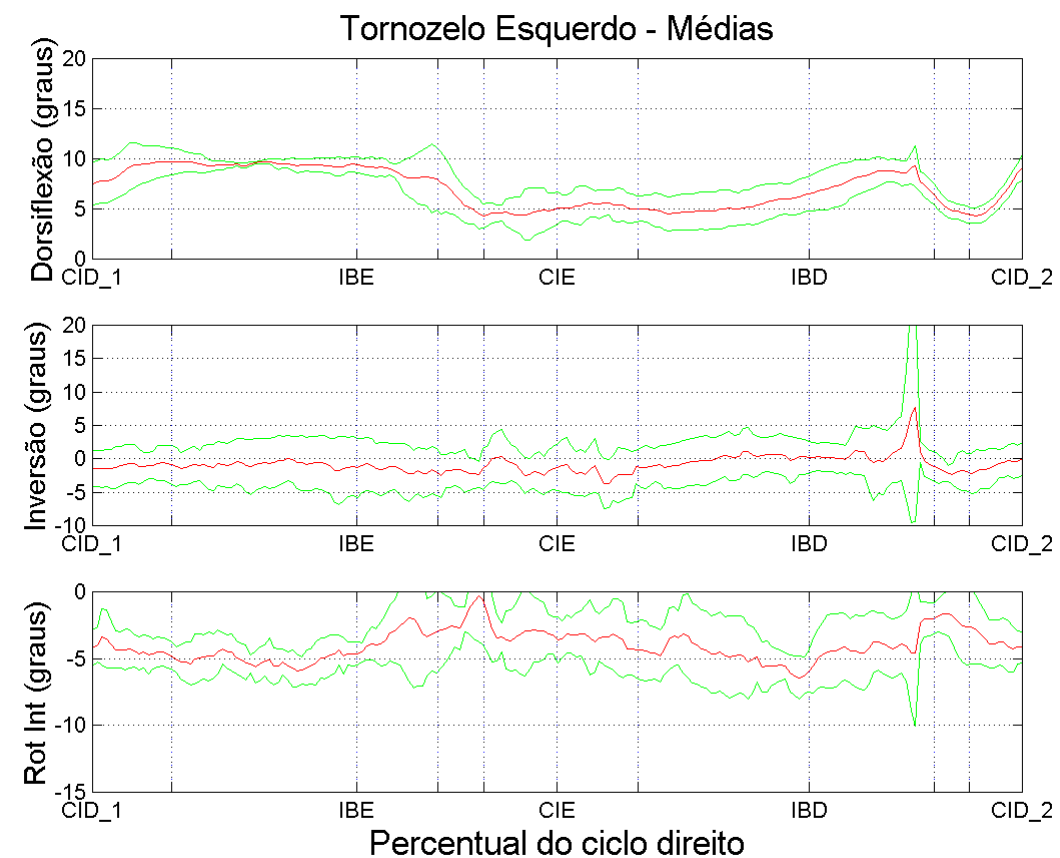

(b) Médias e desvios padrões dos dados apresentados em (a).

Figura E.9: Variações angulares no tornozelo esquerdo. Os gráficos foram normalizados no tempo como percentual do ciclo direito da marcha. 


\section{E.4 Variações angulares: ombros e cotovelos}
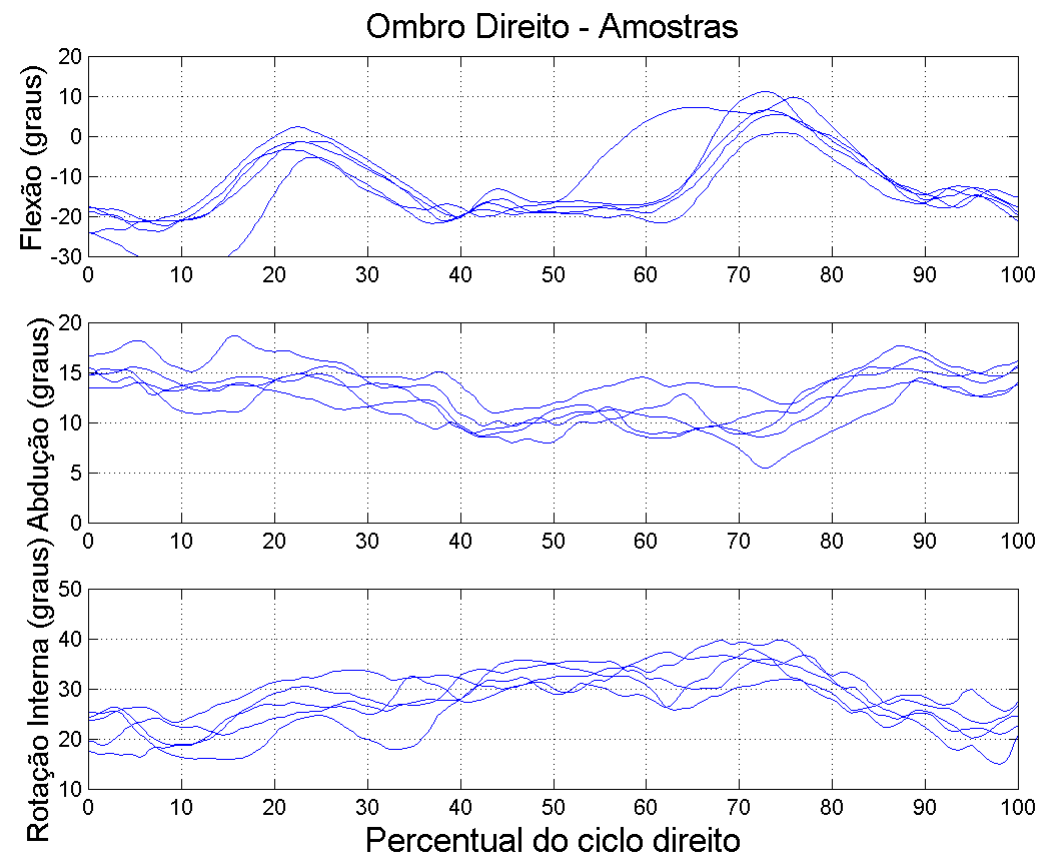

(a) Gráficos das variações angulares presentes nas cinco amostras.
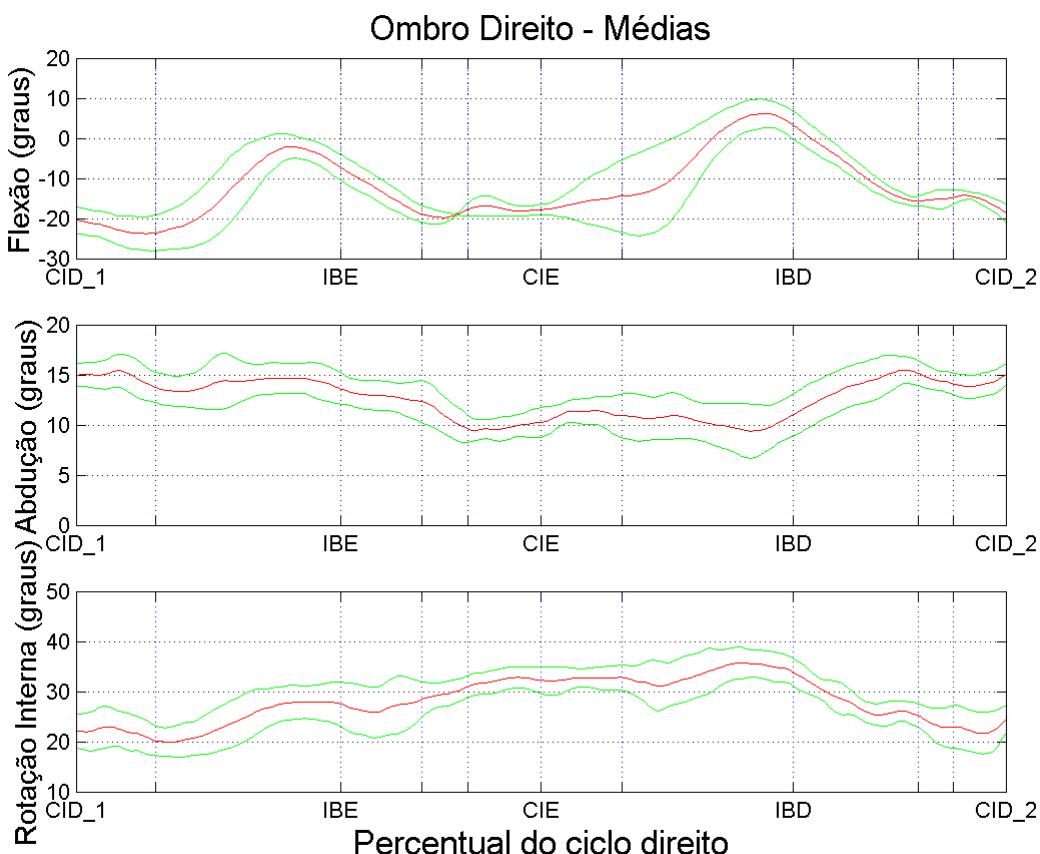

(b) Médias e desvios padrões dos dados apresentados em (a).

Figura E.10: Variações angulares no ombro direito. Os gráficos foram normalizados no tempo como percentual do ciclo direito da marcha. 

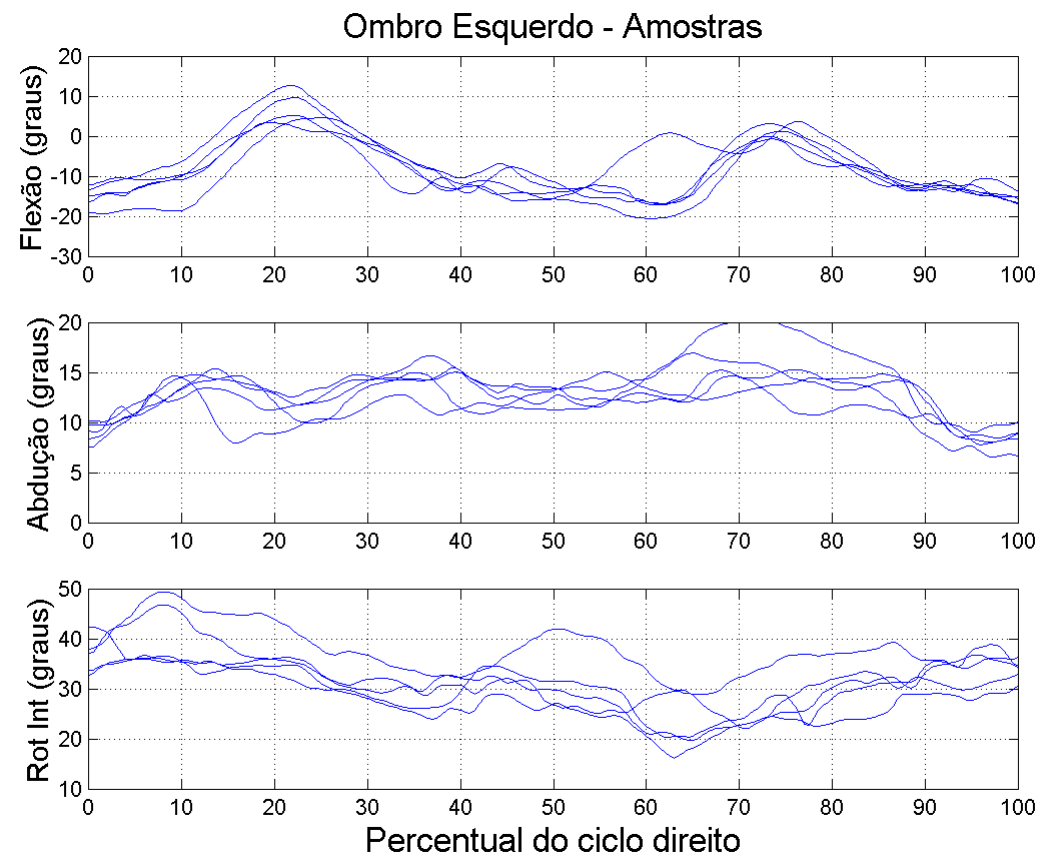

(a) Gráficos das variações angulares presentes nas cinco amostras.
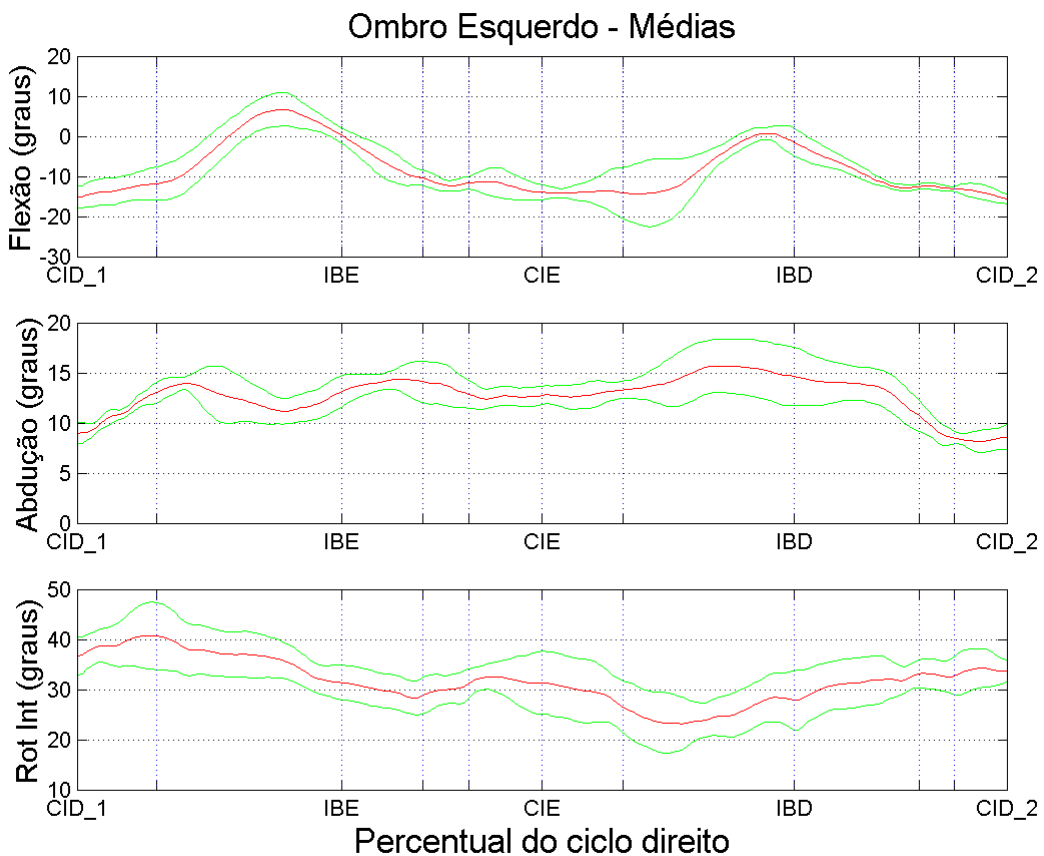

(b) Médias e desvios padrões dos dados apresentados em (a).

Figura E.11: Variações angulares no ombro esquerdo. Os gráficos foram normalizados no tempo como percentual do ciclo direito da marcha. 

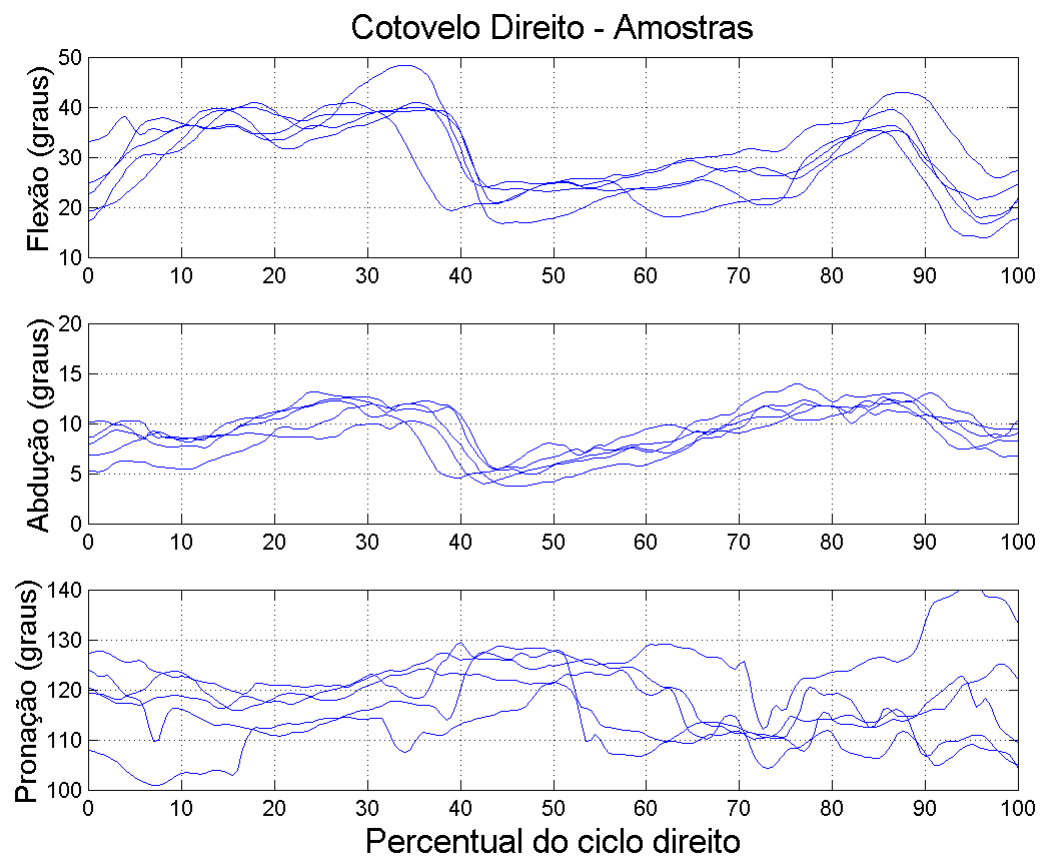

(a) Gráficos das variações angulares presentes nas cinco amostras.
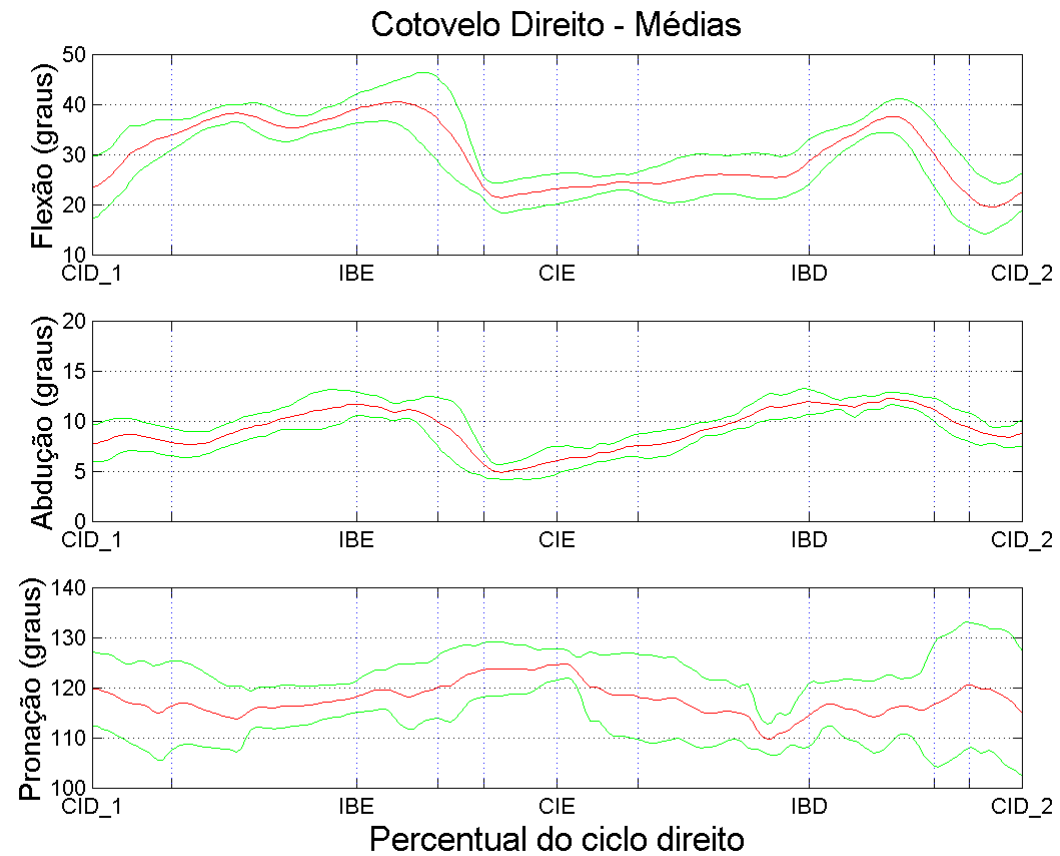

(b) Médias e desvios padrões dos dados apresentados em (a).

Figura E.12: Variações angulares no cotovelo direito. Os gráficos foram normalizados no tempo como percentual do ciclo direito da marcha. 

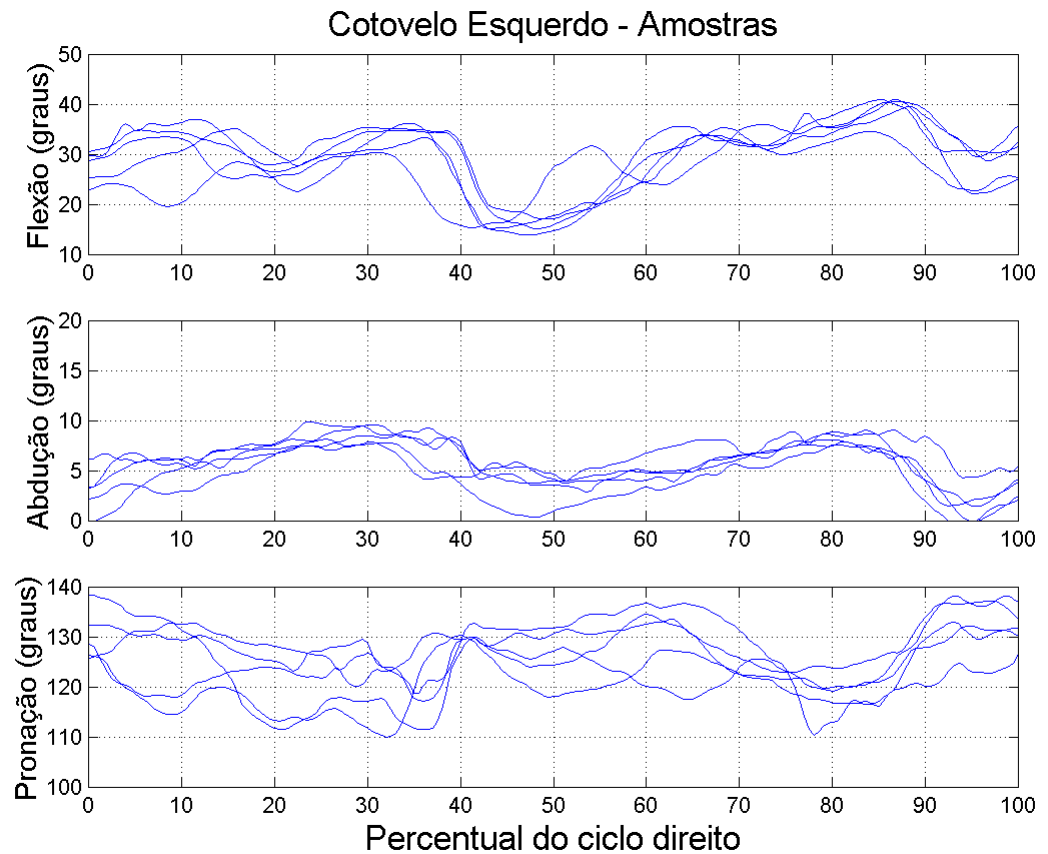

(a) Gráficos das variações angulares presentes nas cinco amostras.
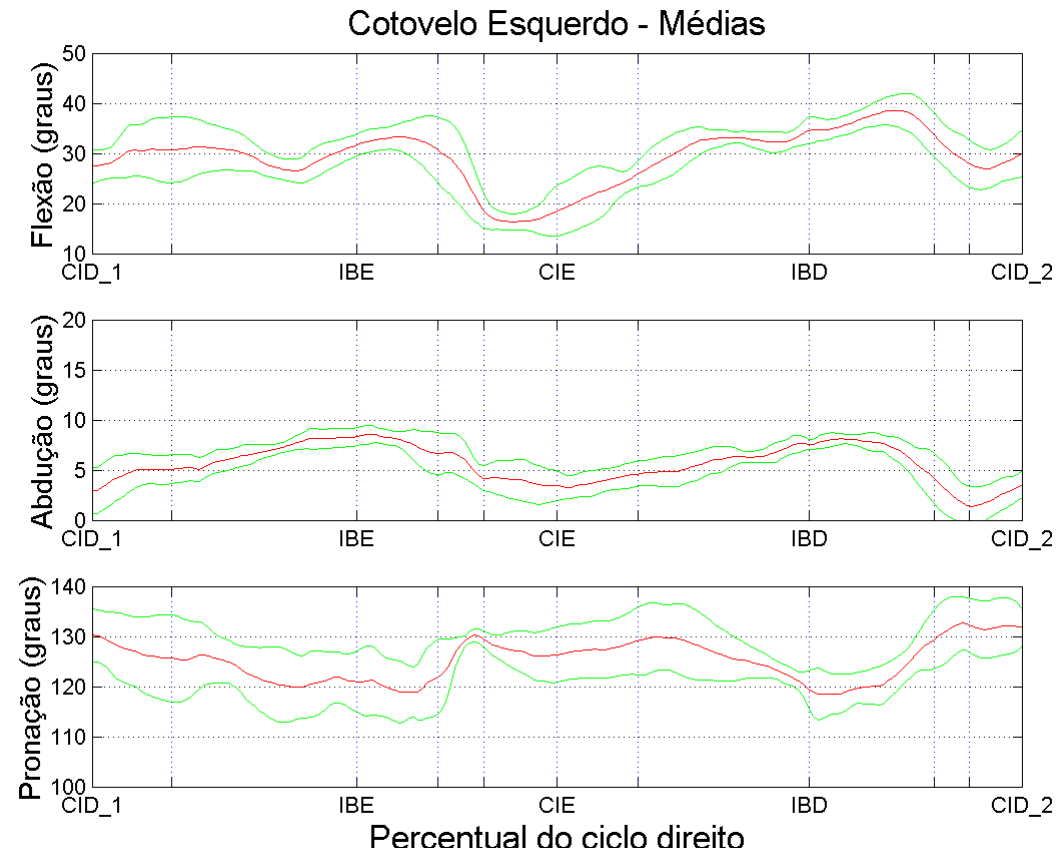

(b) Médias e desvios padrões dos dados apresentados em (a).

Figura E.13: Variações angulares no cotovelo esquerdo. Os gráficos foram normalizados no tempo como percentual do ciclo direito da marcha. 


\section{E.5 Eletromiografia}
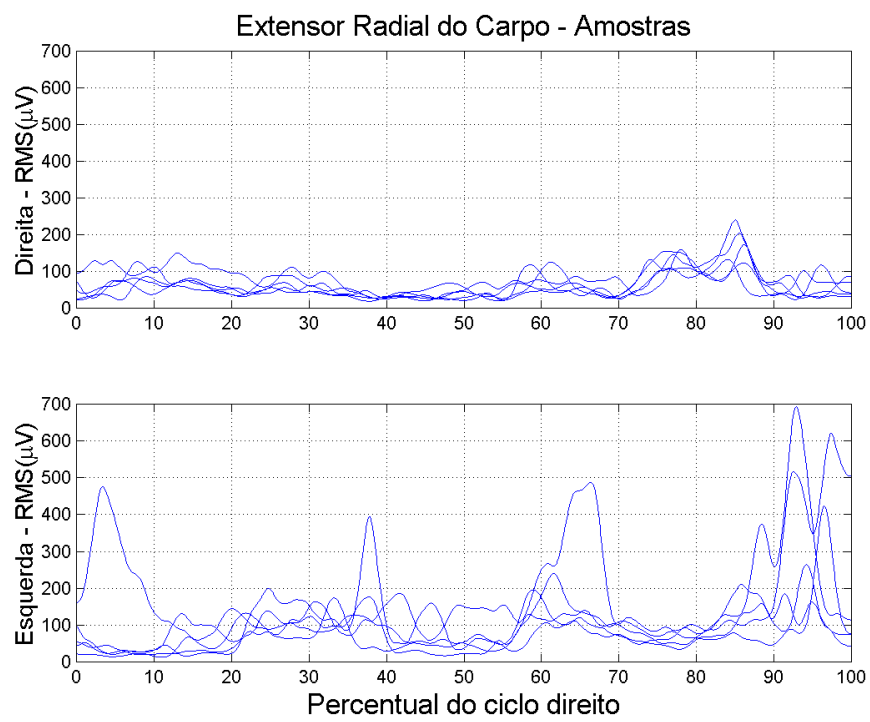

(a) Gráficos dos sinais presentes nas cinco amostras.
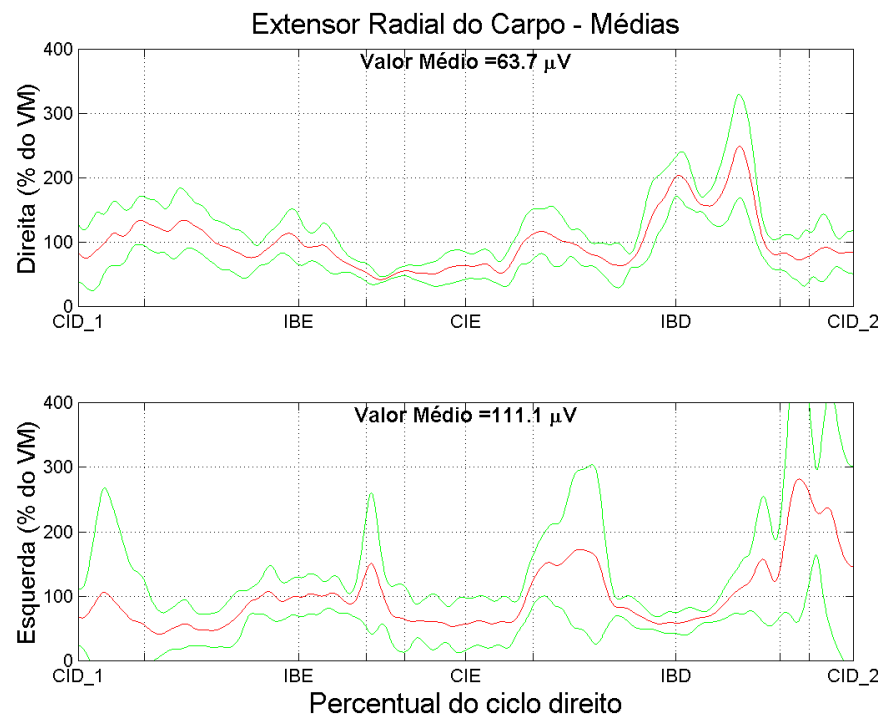

(b) Médias e desvios padrões dos dados apresentados em (a). Cada gráfico foi normalizado pelo valor médio ( $\boldsymbol{V} \boldsymbol{M})$ da média das cinco amostras.

Figura E.14: Eletromiografia do extensor radial do carpo (nos dois braços). Os gráficos foram normalizados no tempo como percentual do ciclo direito da marcha. 

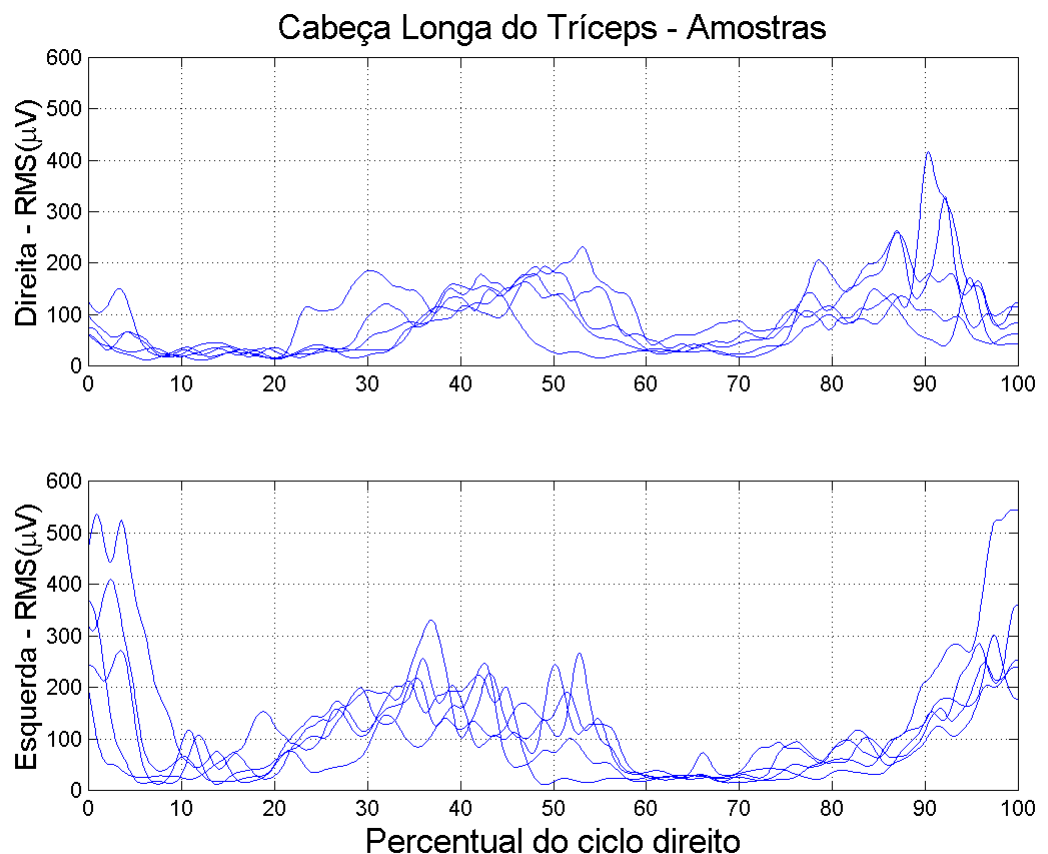

(a) Gráficos dos sinais presentes nas cinco amostras.
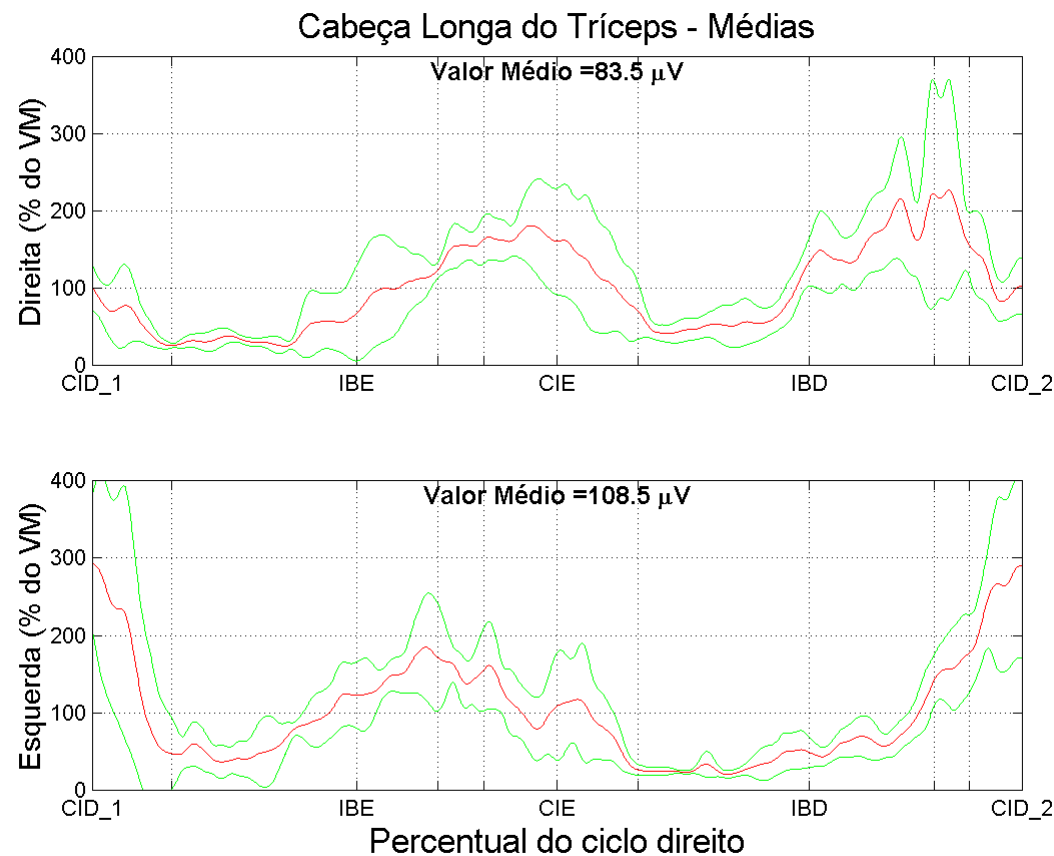

(b) Médias e desvios padrões dos dados apresentados em (a). Cada gráfico foi normalizado pelo valor médio ( $\boldsymbol{V M}$ ) da média das cinco amostras.

Figura E.15: Eletromiografia do cabeça longa do tríceps (nos dois braços). Os gráficos foram normalizados no tempo como percentual do ciclo direito da marcha. 

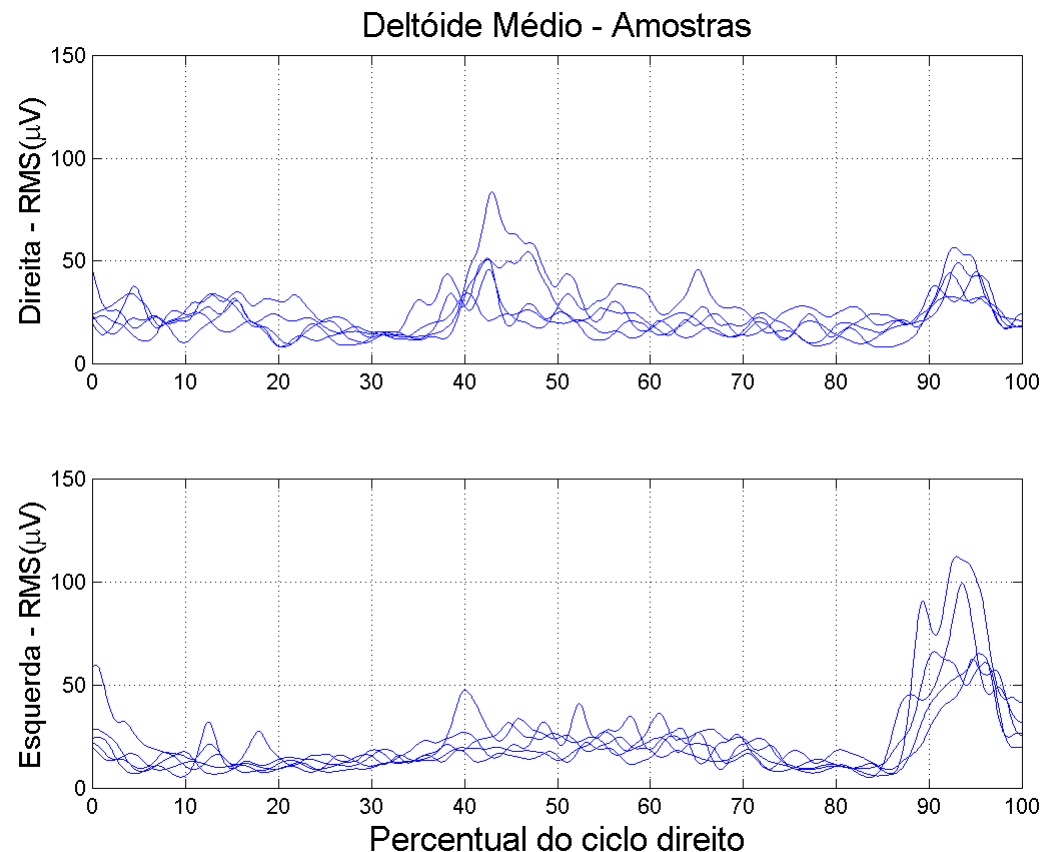

(a) Gráficos dos sinais presentes nas cinco amostras.
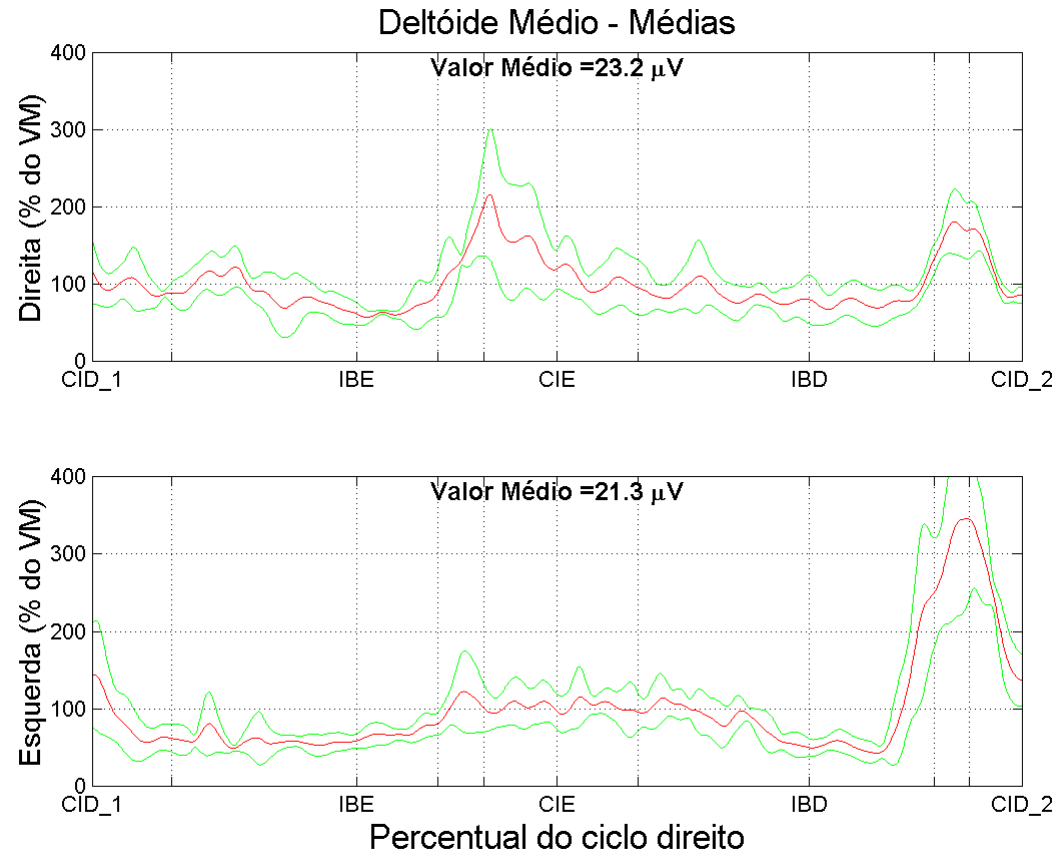

(b) Médias e desvios padrões dos dados apresentados em (a). Cada gráfico foi normalizado pelo valor médio ( $\boldsymbol{V M}$ ) da média das cinco amostras.

Figura E.16: Eletromiografia do deltóide médio (nos dois braços). Os gráficos foram normalizados no tempo como percentual do ciclo direito da marcha. 

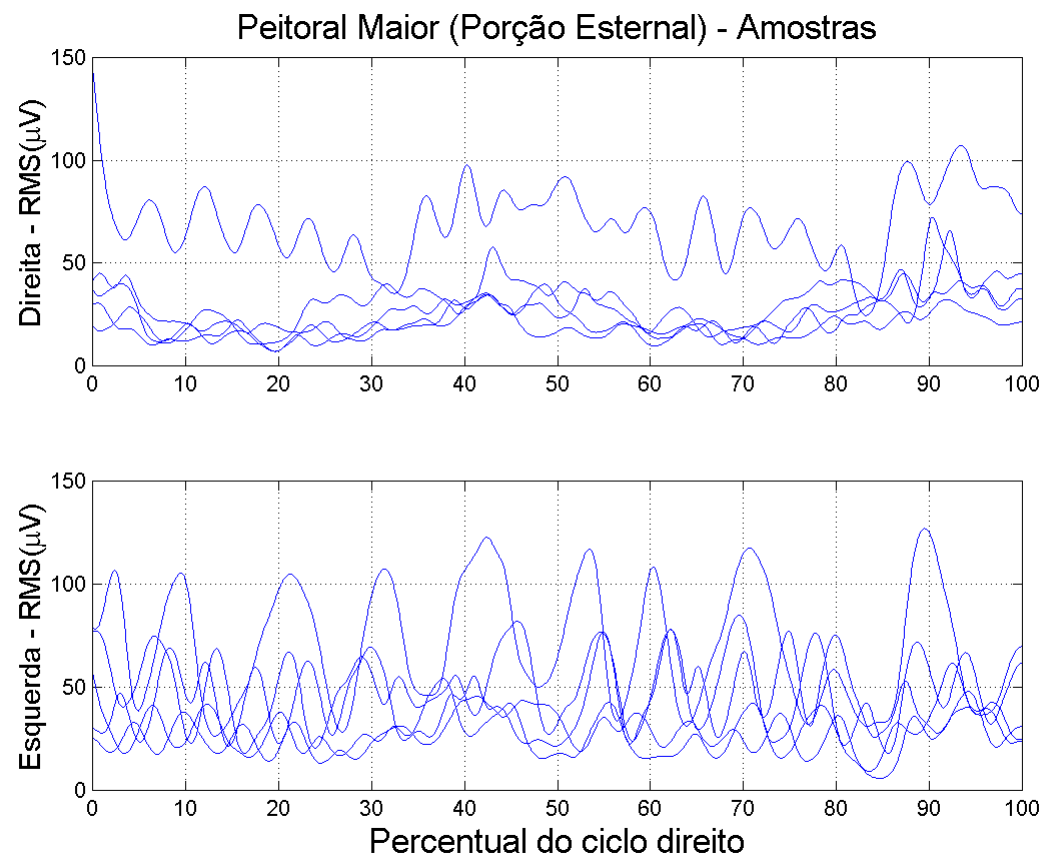

(a) Gráficos dos sinais presentes nas cinco amostras.
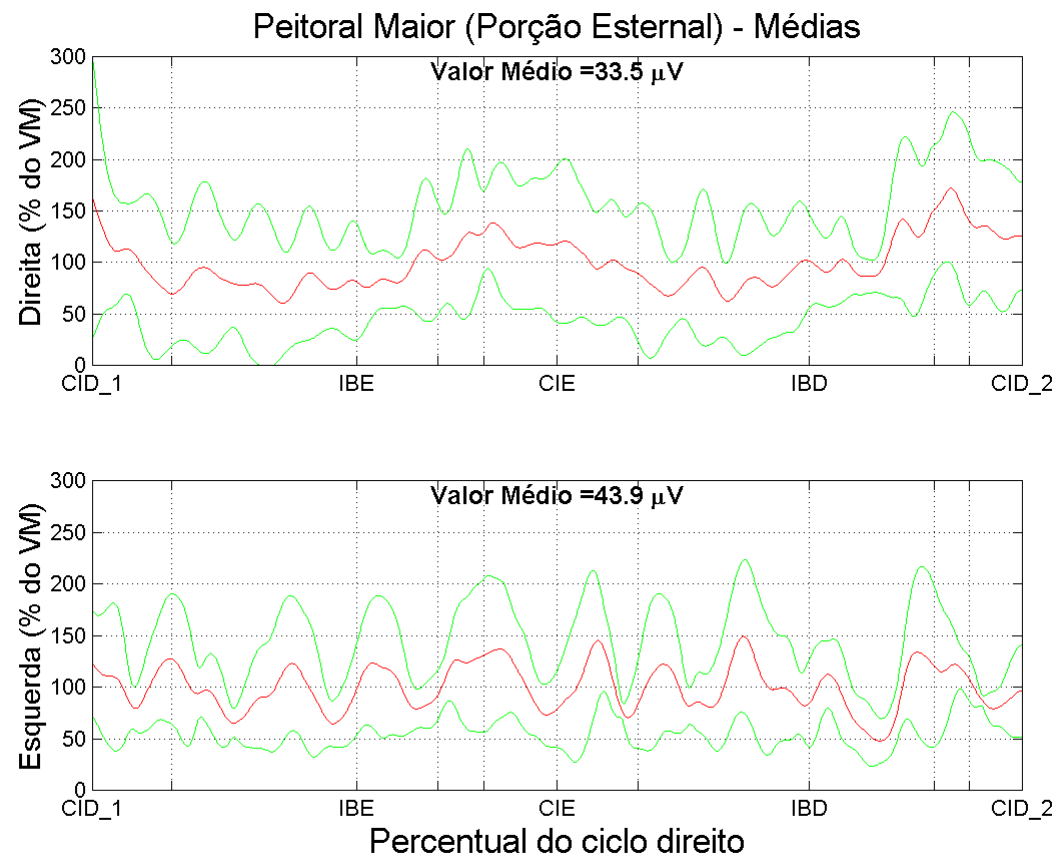

(b) Médias e desvios padrões dos dados apresentados em (a). Cada gráfico foi normalizado pelo valor médio ( $\boldsymbol{V M}$ ) da média das cinco amostras.

Figura E.17: Eletromiografia da porção esternal do peitoral maior. Os gráficos foram normalizados no tempo como percentual do ciclo direito da marcha. 


\section{E.6 Componente vertical da força de reação do solo}
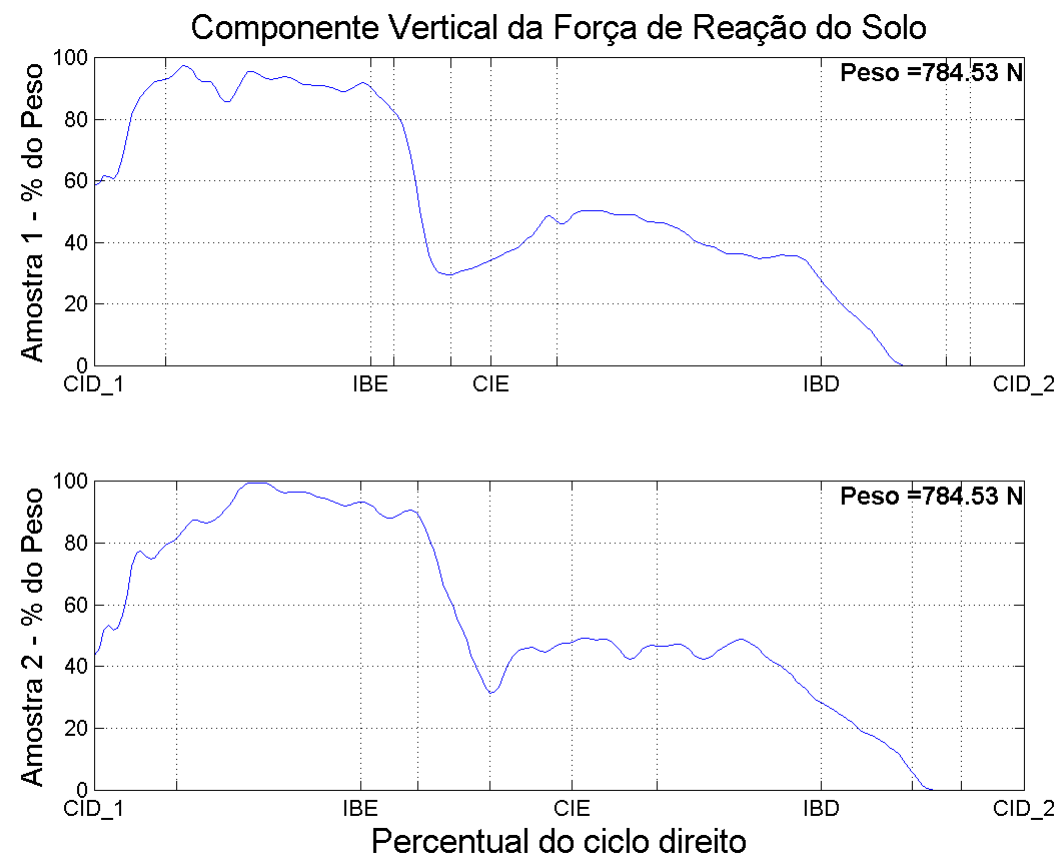

Figura E.18: Duas amostras da componente vertical da força de reação do solo conseqüente da ação dos pés do paciente sobre a plataforma de força durante a deambulação. Os gráficos foram normalizados no tempo como percentual do ciclo direito da marcha, e normalizados em amplitude como percentual do peso do paciente em Newtons.

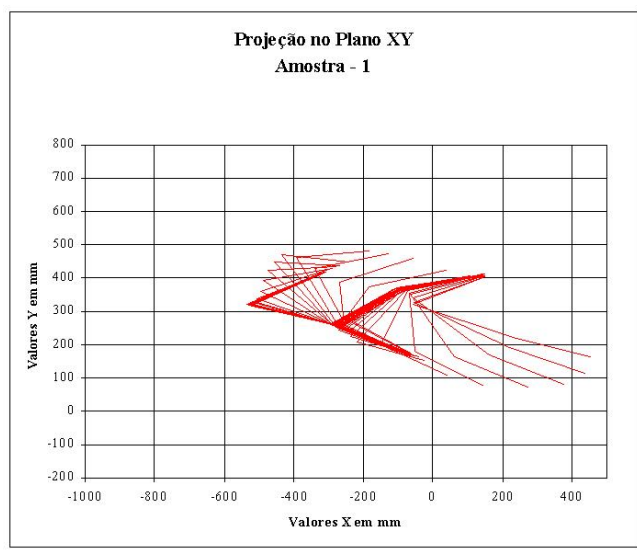

(a) Amostra 1

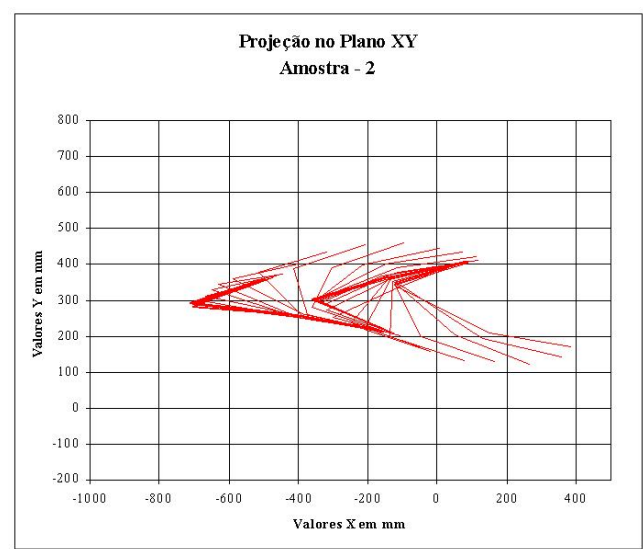

(b) Amostra 2

Figura E.19: Projeção do movimento dos pés do paciente sobre a plataforma de força no plano horizontal $(X Y)$. 


\section{Índice Remissivo}

\section{Paciente A, 108}

características da passada, 109

características do paciente, 109

componente vertical da força de reação

do solo, 126

eletromiografia

cabeça longa do tríceps, 123

deltóide médio, 124

extensor radial do carpo, 122

porção esternal do peitoral maior,

125

foto, 108

percentuais das fases do ciclo, 109

vídeo, 108

variações angulares

cotovelo direito, 120

cotovelo esquerdo, 121

joelho direito, 114

joelho esquerdo, 115

ombro direito, 119

ombro esquerdo, 119

pelvis, 111

quadril direito, 112

quadril esquerdo, 113

tornozelo direito, 116

tornozelo esquerdo, 117

tronco, 111

Paciente B, 127

características da passada, 128

características do paciente, 128

componente vertical da força de reação

do solo, 145 eletromiografia

cabeça longa do tríceps, 142

deltóide médio, 143

extensor radial do carpo, 141

porção esternal do peitoral maior, 144

foto, 127

percentuais das fases do ciclo, 128

vídeo, 127

variações angulares

cotovelo direito, 139

cotovelo esquerdo, 140

joelho direito, 133

joelho esquerdo, 134

ombro direito, 138

ombro esquerdo, 138

pelvis, 130

quadril direito, 131

quadril esquerdo, 132

tornozelo direito, 135

tornozelo esquerdo, 136

tronco, 130

Paciente C, 146

características da passada, 147

características do paciente, 147

componente vertical da força de reação do solo, 164

eletromiografia

cabeça longa do tríceps, 161

deltóide médio, 162

extensor radial do carpo, 160

porção esternal do peitoral maior, 
163

foto, 146

percentuais das fases do ciclo, 147

vídeo, 146

variações angulares

cotovelo direito, 158

cotovelo esquerdo, 159

joelho direito, 152

joelho esquerdo, 153

ombro direito, 157

ombro esquerdo, 157

pelvis, 149

quadril direito, 150

quadril esquerdo, 151

tornozelo direito, 154

tornozelo esquerdo, 155

tronco, 149

Paciente D, 165

características da passada, 166

características do paciente, 166

componente vertical da força de reação do solo, 183

eletromiografia

cabeça longa do tríceps, 180

deltóide médio, 181

extensor radial do carpo, 179

porção esternal do peitoral maior,

182

foto, 165

percentuais das fases do ciclo, 166

vídeo, 165

variações angulares

cotovelo direito, 177

cotovelo esquerdo, 178

joelho direito, 171

joelho esquerdo, 172

ombro direito, 176

ombro esquerdo, 176

pelvis, 168 quadril direito, 169

quadril esquerdo, 170

tornozelo direito, 173

tornozelo esquerdo, 174

tronco, 168

Paciente E, 184

características da passada, 185

características do paciente, 185

componente vertical da força de reação

do solo, 202

eletromiografia

cabeça longa do tríceps, 199

deltóide médio, 200

extensor radial do carpo, 198

porção esternal do peitoral maior, 201

foto, 184

percentuais das fases do ciclo, 185

vídeo, 184

variações angulares

cotovelo direito, 196

cotovelo esquerdo, 197

joelho direito, 190

joelho esquerdo, 191

ombro direito, 195

ombro esquerdo, 195

pelvis, 187

quadril direito, 188

quadril esquerdo, 189

tornozelo direito, 192

tornozelo esquerdo, 193

tronco, 187 